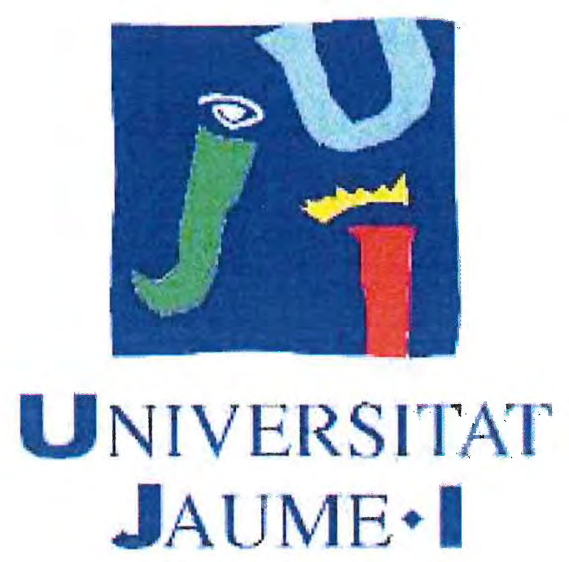

Programa de Doctorado en Tecnologías Industriales y Materiales Escuela de Doctorado de la Universitat Jaume I

\title{
Modelización de los Puntos Limpios y estudio de las variables que afectan a su diseño
}

Memoria presentada por Cristóbal Badenes Catalán para optar al grado de doctor por la Universitat Jaume I

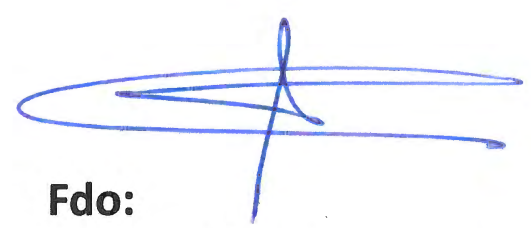

Cristóbal Badenes Catalán

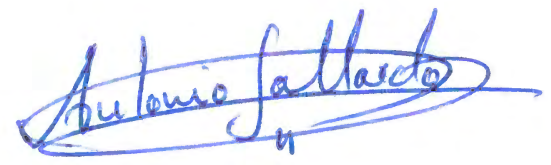

Fdo:

Antonio Gallardo Izquierdo

Castelló de la Plana, Julio 2021 
(C) (1) Esta obra está bajo una licencia de Creative Commons BY SA Reconocimiento-Compartir Igual 4.0 Internacional. 
A Pablo y Ana, con todo mi cariño. 



\section{AGRADECIMIENTOS}

En primer lugar, deseo agradecer a toda mi familia, empezando por mis padres, Cristóbal y Pilar, y hermanos, Javier y Jorge, y en especial a Teresa, por su cariño, comprensión y apoyo en el día a día y en concreto durante la realización del doctorado.

A mi director Antonio Gallardo Izquierdo, por su paciencia, colaboración e inestimable ayuda desde el inicio del doctorado y hasta la finalización de la tesis. Él ha sido quien me animó a emprender este camino y me ha guiado de forma eficiente durante todo el doctorado, y especialmente durante el desarrollo de la tesis.

También deseo agradecer a mis compañeros del grupo de Ingeniería de Residuos, por el apoyo recibido, así como a todo el Departamento de Ingeniería de Mecánica y Construcción de la Universitat Jaume I, por poner a mi disposición toda su experiencia y conocimiento en esta materia. Igualmente, estoy muy agradecido a Natalia Edo Alcón, como compañera doctorando que me ha orientado y facilitado muchísima información en cuanto a caracterización y tratamiento de residuos.

Reconocimiento especial para todos mis compañeros del Ayuntamiento de Castelló de la Plana, por la ayuda, el interés mostrado y sus valiosos consejos recibidos durante la elaboración de este documento, así como a todos mis amigos, por el apoyo y ánimo proporcionados en todo momento y a quienes debo una gran cantidad de tiempo.

A la empresa pública Reciplasa, que me ha facilitado muchísima información y conocimientos respecto a la gestión del Consorcio de Residuos C2, y a Reciclados Palancia Belcaire, S.L., por permitirme investigar durante varios meses en sus instalaciones.

A la UTE Saneamiento Urbano de Castellón, por permitir de forma desinteresada la realización de varias experiencias y por la información facilitada, en especial a Vicente Colás Ramos, Ángel Muñoz Nieto, Vicente Apolinar Roig y Pedro González Palazuelos, por todo el interés mostrado y su gran colaboración.

A los más de noventa ayuntamientos de toda España (Anexo A5.3) que han facilitado gran cantidad de información, colaborando de forma activa en esta investigación, y especialmente a los técnicos municipales responsables del control y seguimiento de la recogida de residuos en dichas ciudades, cuya participación ha sido indispensable.

A todos ellos quiero agradecer sinceramente su contribución, pues sin ella nunca hubiese podido finalizar este trabajo. 



\section{RESUMEN}

En la actualidad, el paquete de economía circular aprobado por el Parlamento Europeo y su Consejo el 30 de mayo de 2018 a través de sus Directivas 2018/849/CE, 2018/850/CE, 2018/851/CE y 2018/852/CE, establece la estrategia sobre la gestión de residuos, fundamentada en la transición hacia un nuevo modelo basado en la jerarquía de prioridades. De acuerdo con dicha jerarquía, el objetivo principal de todos los sectores implicados debe centrarse en la reducción de la producción y peligrosidad de los residuos (prevención y minimización). En segundo lugar, se debe enfocar hacia la reutilización y reciclaje de los materiales y la capacidad energética de los residuos mediante su valorización y, por último, se considerará la eliminación o vertido controlado.

En este sentido, la implementación de la recogida mediante puntos limpios es una alternativa con un alto grado de implantación a nivel europeo para aquellos residuos que, bien sea por su peligrosidad, tamaño u otras razones, no pueden ser gestionados a través de los sistemas de recogida tradicionales. Si bien, se trata de una solución adecuada en cuanto a la separación origen, presenta algunos inconvenientes, siendo el principal el transporte a cargo del propio ciudadano hasta dichas instalaciones.

El objetivo fundamental de esta tesis es el diseño de una metodología que permita modelizar un punto limpio a partir del análisis de determinadas variables, que se han ido recopilando a través de diferentes estudios. Dicha metodología permitirá localizar, dimensionar y establecer el régimen de funcionamiento, con el fin de obtener una instalación eficiente y con un elevado uso por parte de los ciudadanos.

Se han analizado investigaciones anteriores y normativas sectoriales y se ha realizado una encuesta a casi doscientos municipios de toda la geografía española. Una vez obtenida toda la información, se ha analizado y realizado un estudio estadístico con el objetivo de observar qué variables presentan mayor influencia en los dos factores que se han definido cómo claves para el funcionamiento eficiente de un punto limpio: tasa de visitas y la tasa de recogida por habitante y año.

La metodología propuesta agrupa las variables estudiadas en tres grandes grupos en función de las necesidades de diseño: localización, infraestructuras y funcionamiento, y recoge los casos de éxito de todas las variables estudiadas, así como la casuística particular que pueda tener cada municipio, principalmente en cuanto a las disponibilidades urbanísticas y la problemática de vertidos incontrolados en éstos.

La metodología supone una herramienta muy útil para los responsables municipales en gestión de residuos, tanto a nivel técnico como político, ya que a partir de los datos de cada municipio y, teniendo en cuenta la normativa sectorial aplicable, permitirá diseñar un punto limpio que maximice las aportaciones de residuos y reduzca los costes del servicio, mejorando la recogida selectiva y contribuyendo a alcanzar los nuevos objetivos de la Unión Europea sobre reducción de depósito en vertedero.

En el último apartado de la tesis se ha validado la metodología mediante su aplicación en el municipio de Castelló de la Plana, donde existe una diferencia suficientemente significativa entre la aportación de residuos por habitante en los ámbitos autonómico y municipal. De esta manera, se ha diseñado un segundo punto limpio para complementar las instalaciones actuales de la ciudad. 

En l'actualitat, el paquet d'economia circular aprovat pel Parlament Europeu i el seu Consell el 30 de maig de 2018 a través dels seus Directives 2018/849 / CE, 2018/850 / CE, 2018/851 / CE i 2018/852 / CE, estableix l'estratègia sobre la gestió de residus, fonamentada en la transició cap a un nou model basat en la jerarquia de prioritats. D'acord amb aquesta jerarquia, l'objectiu principal de tots els sectors implicats s'ha de centrar en la reducció de la producció i perillositat dels residus (prevenció i minimització). En segon lloc, s'ha d'enfocar cap a la reutilització i reciclatge dels materials i la capacitat energètica dels residus mitjançant la seva valorització i, finalment, es considerarà l'eliminació o abocament controlat.

En aquest sentit, la implementació de la recollida mitjançant punts nets és una alternativa amb un alt grau d'implantació a nivell europeu per a aquells residus que, bé sigui per la seva perillositat, mida o altres raons, no poden ser gestionats a través dels sistemes de recollida tradicionals. Si bé, es tracta d'una solució adequada pel que fa a la separació origen, presenta alguns inconvenients, sent el principal el transport a càrrec de el propi ciutadà fins aquestes instal·lacions.

L'objectiu fonamental d'aquesta tesi és el disseny d'una metodologia que permeta modelitzar un punt net a partir de l'anàlisi de determinades variables, que s'han anat recopilant a través de diferents estudis. Aquesta metodologia permetrà localitzar, dimensionar i establir el règim de funcionament, per tal d'obtenir una instal-lació eficient i amb un elevat ús per part dels ciutadans.

S'han analitzat investigacions anteriors i normatives sectorials i s'ha realitzat una enquesta a gairebé dos-cents municipis de tota la geografia espanyola. Un cop obtinguda tota la informació, s'ha analitzat i realitzat un estudi estadístic amb l'objectiu d'observar quines variables presenten major influència en els dos factors que s'han definit com claus per al funcionament eficient d'un punt net: taxa de visites i la taxa de recollida per habitant i any.

La metodologia proposada agrupa les variables estudiades en tres grans grups en funció de les necessitats de disseny: localització, infraestructures i funcionament, i recull els casos d'èxit de totes les variables estudiades, així com la casuística particular que pugui tenir cada municipi, principalment pel que fa a les disponibilitats urbanístiques i la problemàtica d'abocaments incontrolats en aquests.

La metodologia suposa una eina molt útil per als responsables municipals en gestió de residus, tant a nivell tècnic com polític, ja que a partir de les dades de cada municipi i, tenint en compte la normativa sectorial aplicable, permetrà dissenyar un punt net que maximitze les aportacions de residus i reduïsca els costos de el servei, millorant la recollida selectiva i contribuint a assolir els nous objectius de la Unió Europea sobre reducció de dipòsit en abocador.

En l'últim apartat de la tesi s'ha validat la metodologia mitjançant la seva aplicació en el municipi de Castelló de la Plana, on hi ha una diferència prou significativa entre l'aportació de residus per habitant en els àmbits autonòmic i municipal. D'aquesta manera, s'ha dissenyat un segon punt net per a complementar les instal-lacions actuals de la ciutat. 

Currently, the circular economy package approved by the European Parliament and its Council on May 30, 2018 through its Directives 2018/849 / EC, 2018/850 / EC, 2018/851 / EC and 2018/852 / $\mathrm{CE}$, establishes the strategy on waste management, based on the transition to a new model based on the hierarchy of priorities. In accordance with this hierarchy, the main objective of all the sectors involved should focus on reducing the production and dangerousness of waste (prevention and minimization). Secondly, it should focus on the reuse and recycling of materials and the energy capacity of waste through its recovery and, finally, it will be considered the elimination or controlled dumping.

In this sense, the implementation of collection through recycling centers is an alternative with a high degree of implementation at the European level for waste that, either due to its dangerousness, size or other reasons, cannot be managed through traditional waste management systems. Although it is an adequate solution in terms of separation of origin, it has some drawbacks, the main one being the transport by the citizen himself to said facilities.

The fundamental objective of this thesis is the design of a methodology that allows modeling a recycling center from the analysis of certain variables, which have been compiled through different studies. This methodology will allow locating, dimensioning and establishing the operating regime, in order to obtain an efficient installation with a high use by citizens.

Previous research and sector regulations have been analyzed, and a survey has been carried out in almost two hundred municipalities throughout the Spanish geography. Once all the information has been obtained, a statistical study has been analyzed and carried out in order to observe which variables have the greatest influence on the two factors that have been defined as keys to the efficient operation of a recycling center: visitor rate and collection rate per inhabitant and year.

The proposed methodology groups the variables studied into three large groups depending on the design needs: location, infrastructure and operation, and collects the success cases of all the variables studied, as well as the particular casuistry that each municipality may have, mainly in regarding urban availability and the problem of uncontrolled dumping in them.

The methodology is a very useful tool for municipal managers in waste management, both at a technical and political level, since based on the data of each municipality and, taking into account the applicable sectoral regulations, it will allow the design of a recycling center that maximizes the contributions of waste and reduce the costs of the service, improving selective collection and helping to achieve the new objectives of the European Union on reducing landfill deposits.

In the last section of the thesis, the methodology has been validated through its application in the municipality of Castelló de la Plana, where there is a sufficiently significant difference between the contribution of waste per inhabitant in the autonomous and municipal areas. In this way, a second recycling center has been designed to complement the current facilities of the city. 



\section{ÍNDICE DE LA MEMORIA}

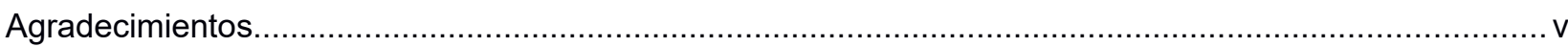

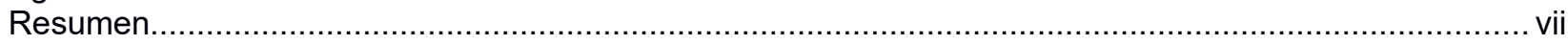

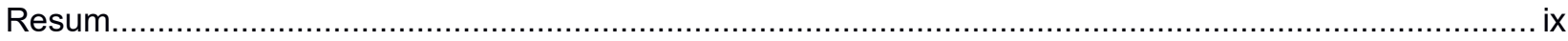

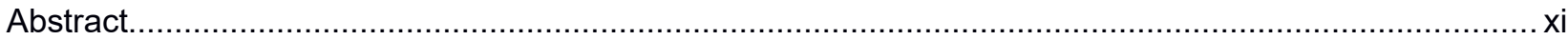

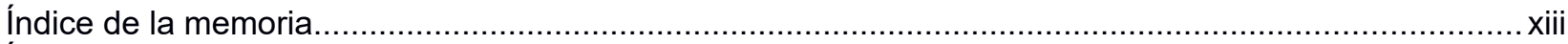

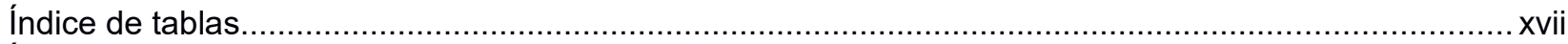

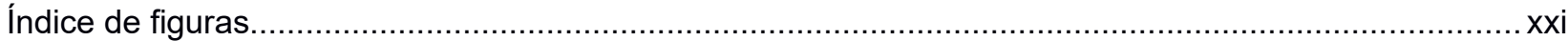

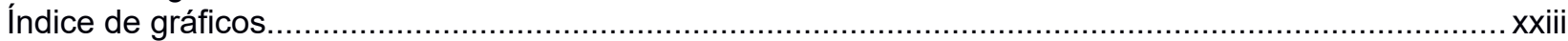

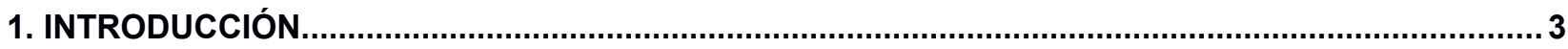

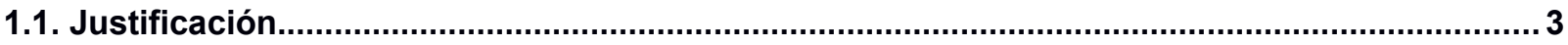

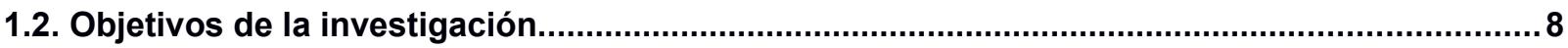

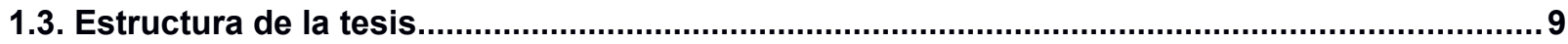

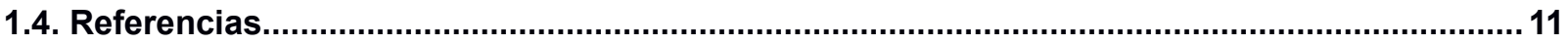

2. ESTADO DEL ARTE

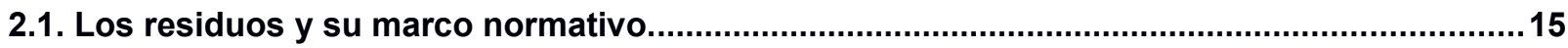

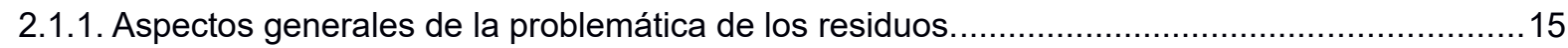

2.1.2. Estrategia de la Unión Europea sobre la gestión de residuos...........................................17

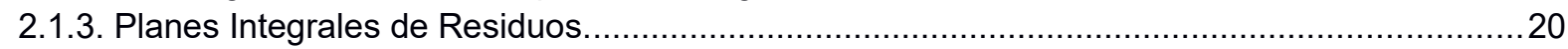

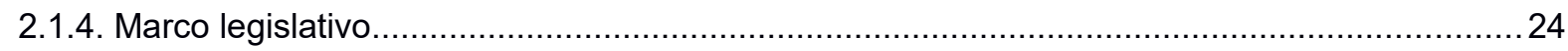

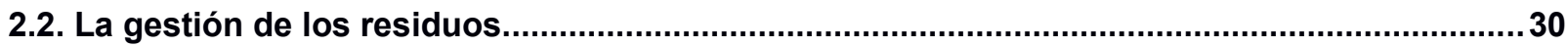

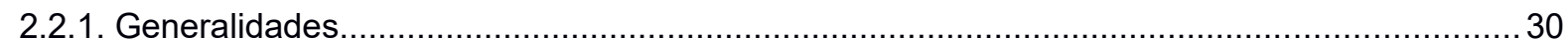

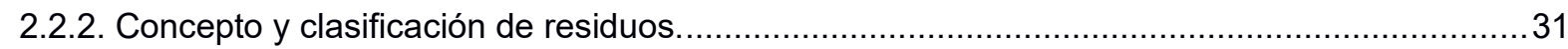

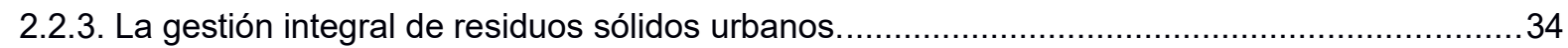

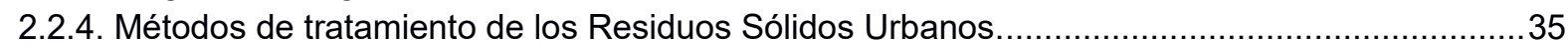

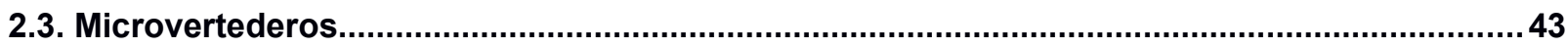

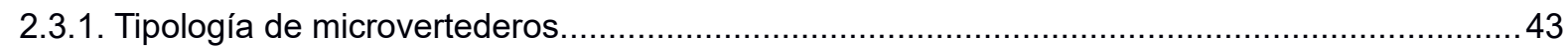

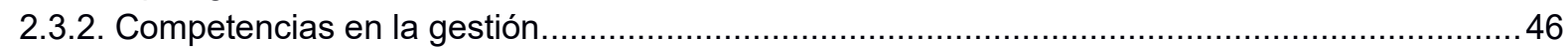

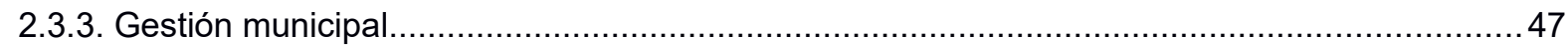

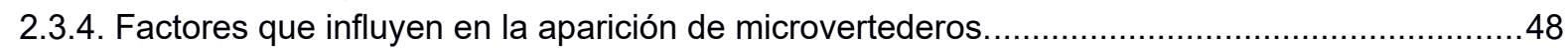

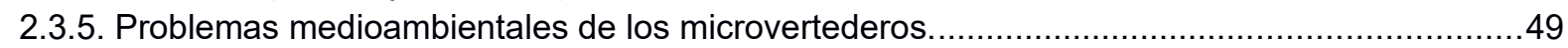

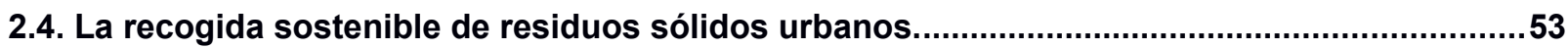

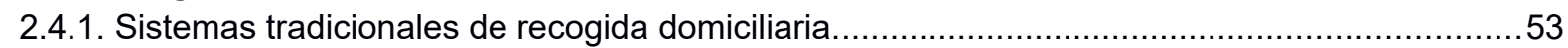

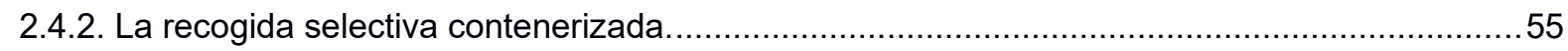

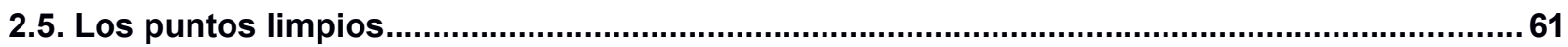

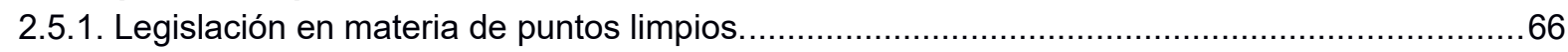

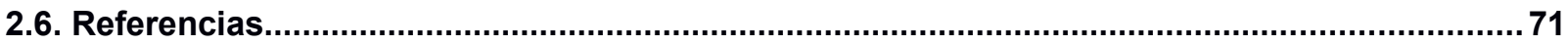

3. INFLUENCIA DE LOS PUNTOS LIMPIOS EN LA DISMINUCIÓN DE MICROVERTEDEROS INCONTROLADOS. ESTUDIO DEL CASO DE CASTELLÓ................................................................

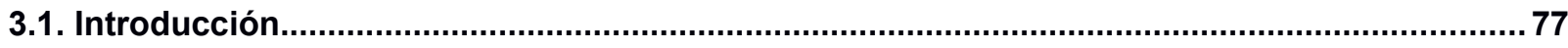

3.2. Estudio de la influencia del punto limpio en la disminución de microvertederos en Castelló

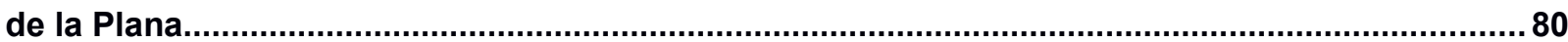

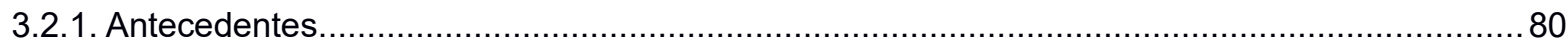

3.2.2. Descripción de los puntos limpios de la ciudad de Castelló de la Plana.................................82

3.2.3. Estudio de la influencia del punto limpio en la disminución de microvertederos en Castelló....93

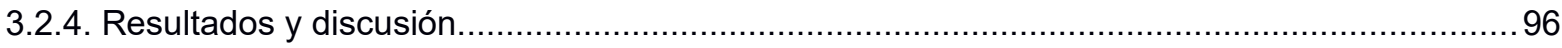

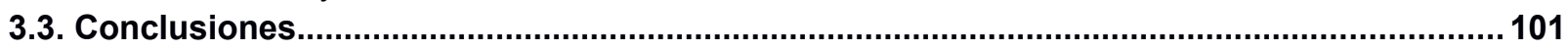

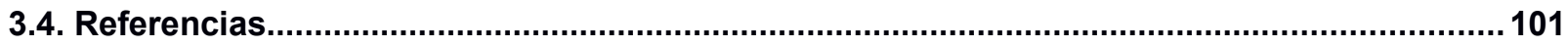




\section{IDENTIFICACIÓN DE VARIABLES QUE INFLUYEN EN LA UBICACIÓN Y DISEÑO DE UN PUNTO}

LIMPIO

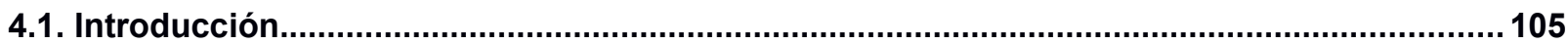

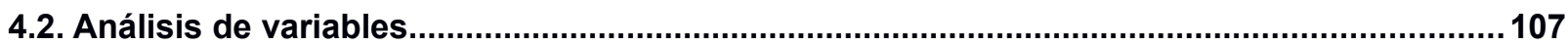

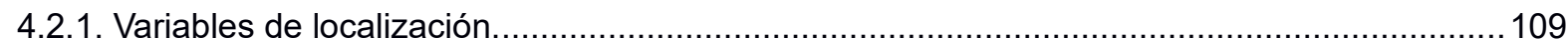

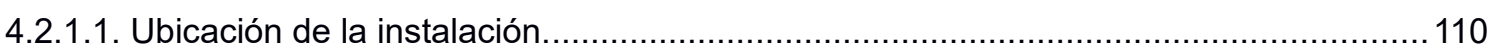

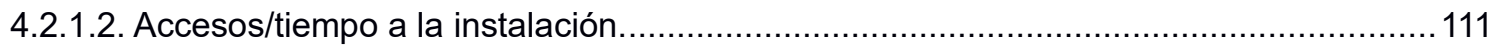

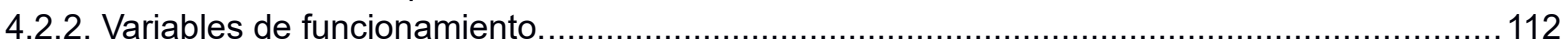

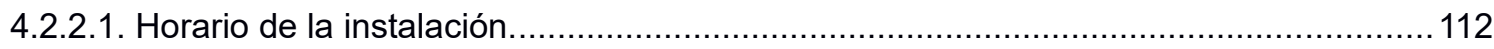

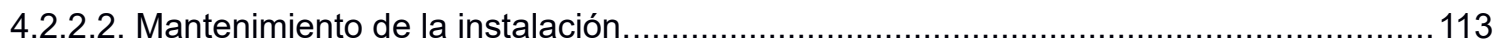

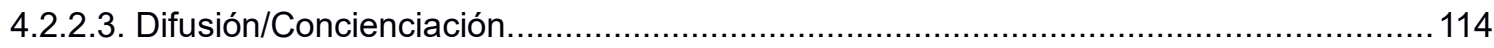

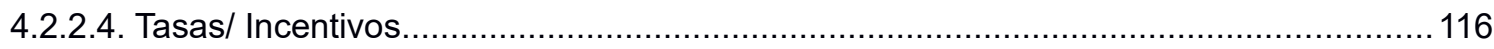

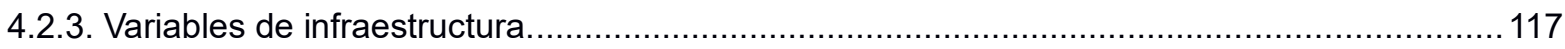

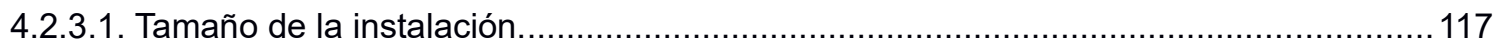

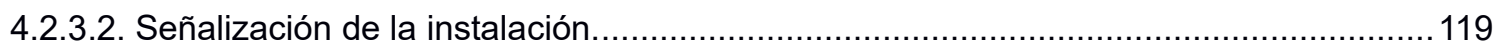

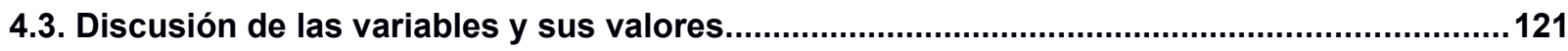

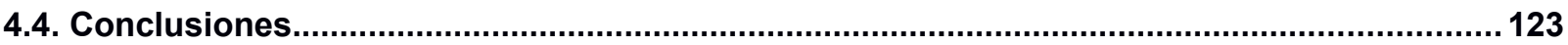

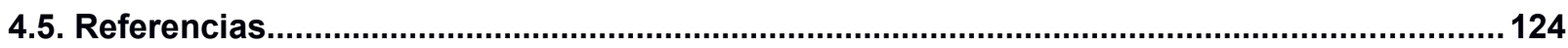

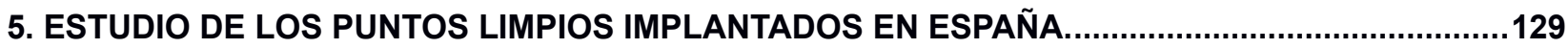

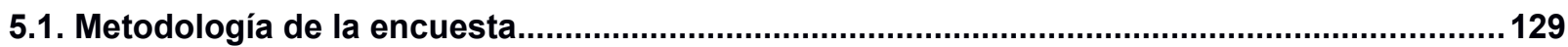

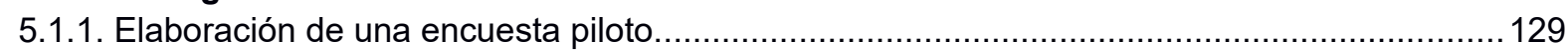

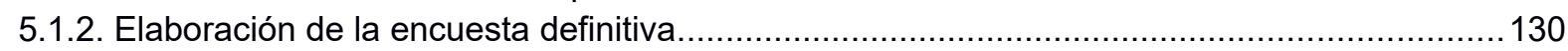

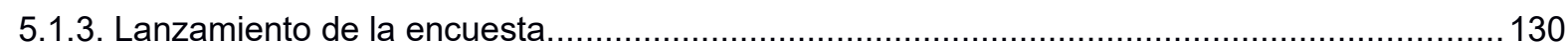

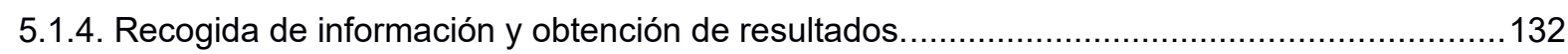

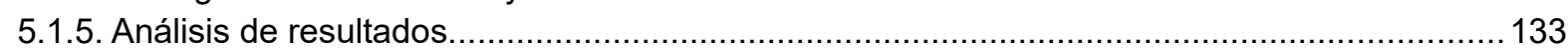

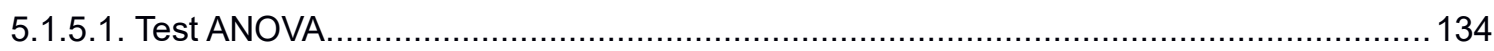

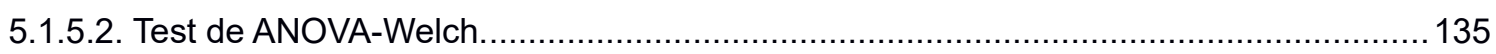

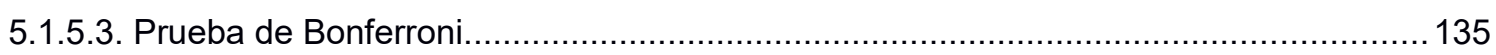

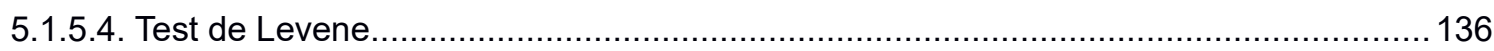

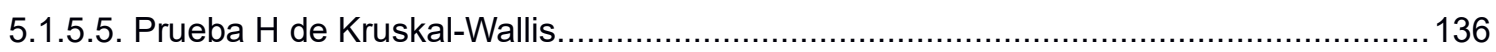

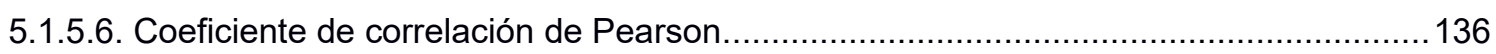

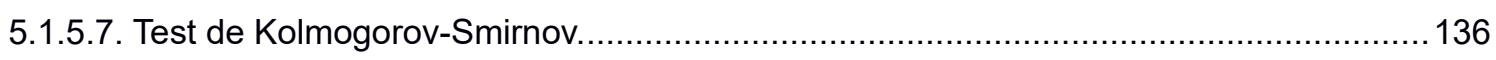

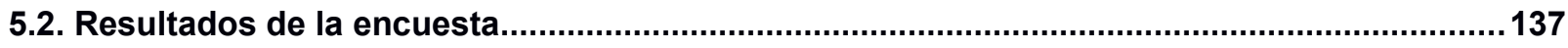

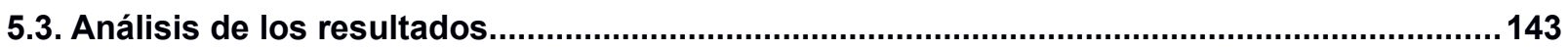

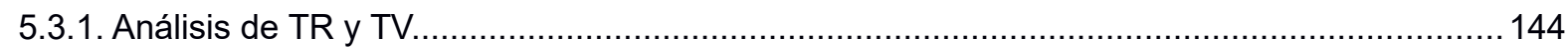

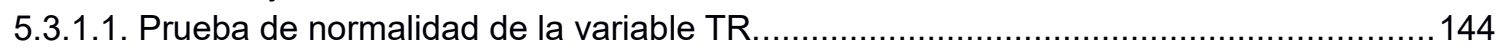

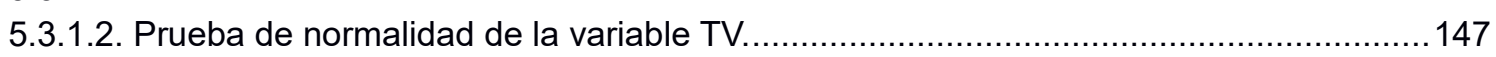

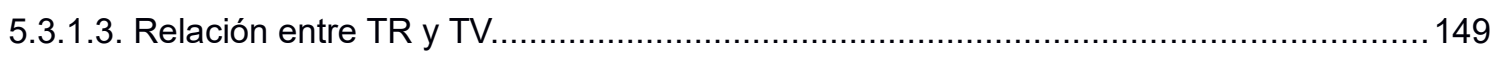

5.3.2. Análisis de TR y TV en función de los factores de localización de los puntos limpios............151

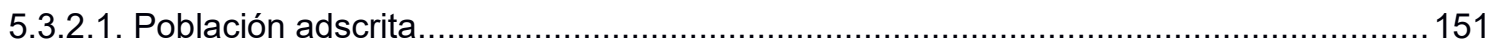

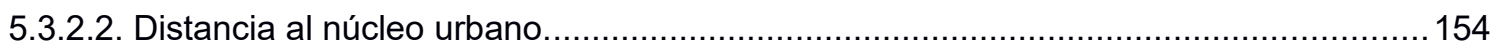

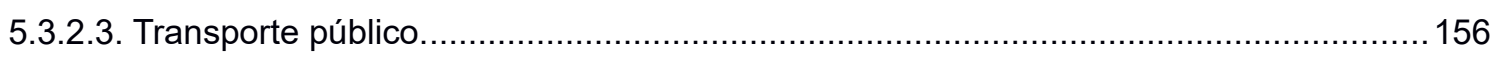

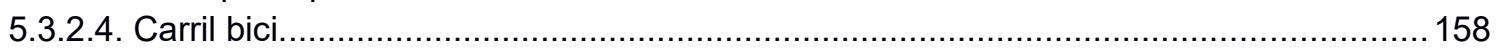

5.3.3. Análisis de TR y TV en función de los factores de infraestructuras de los puntos limpios......159

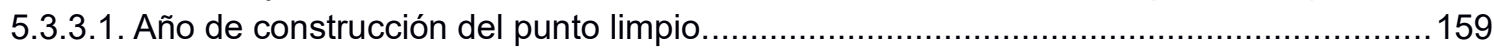

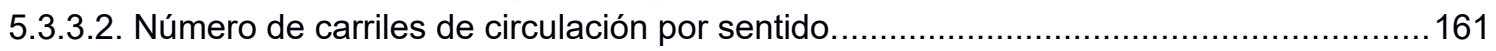

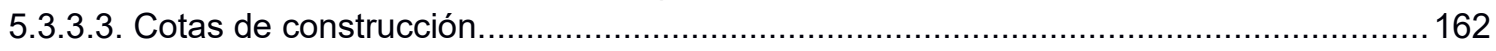

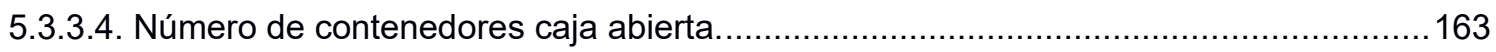

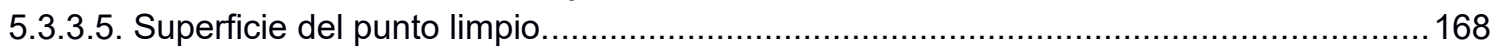

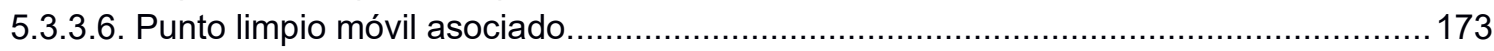

5.3.4. Análisis de TR y TV en función de los factores de funcionamiento de los puntos limpios......175

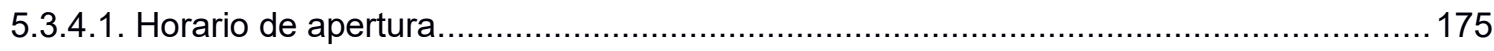

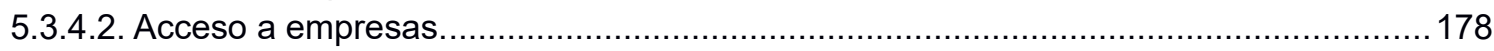




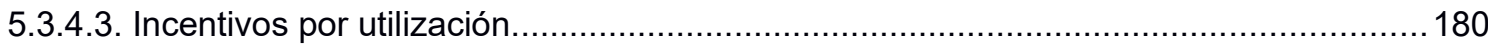

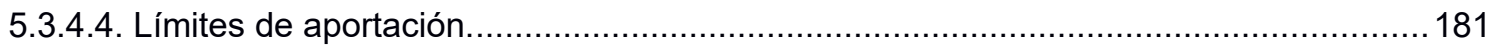

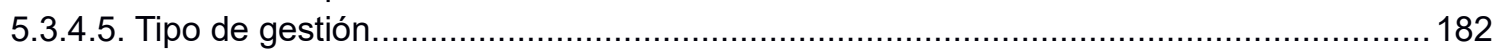

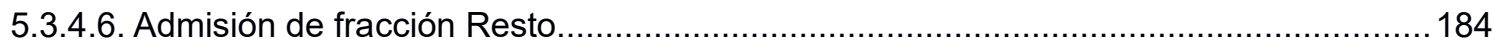

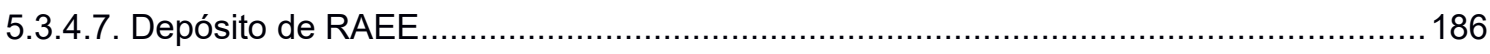

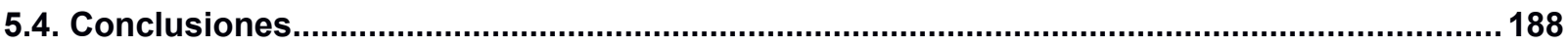

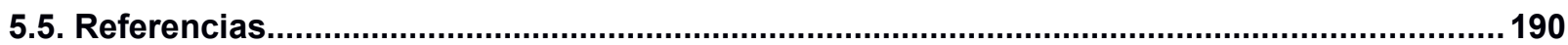

6. METODOLOGÍA PARA LA UBICACIÓN Y DISEÑO DE UN PUNTO LIMPIO..................................193

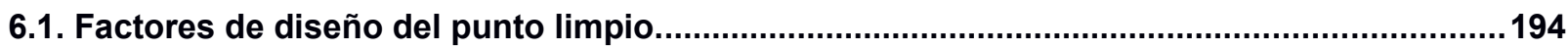

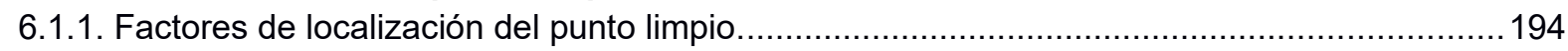

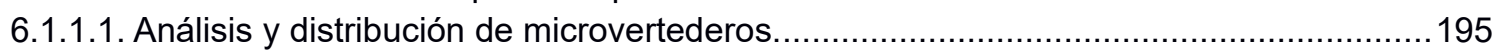

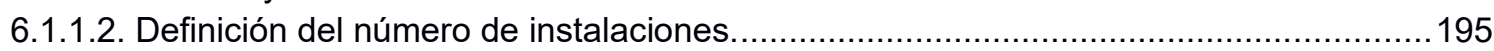

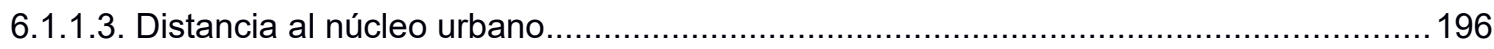

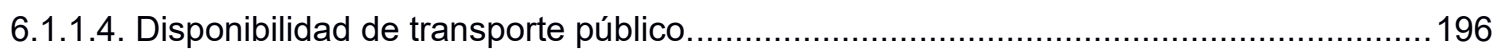

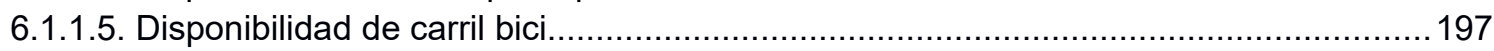

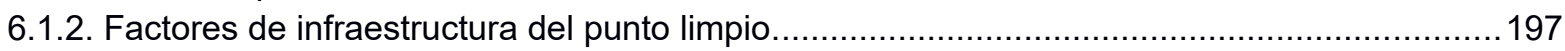

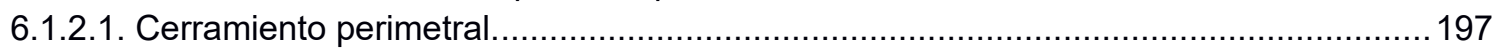

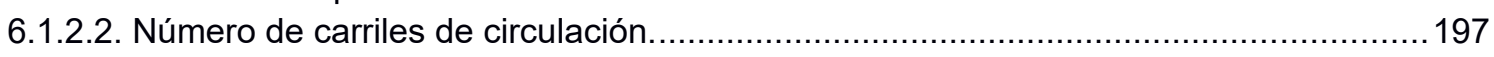

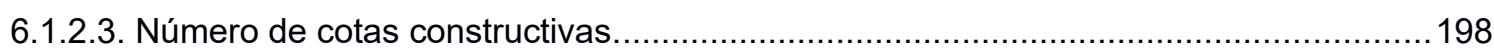

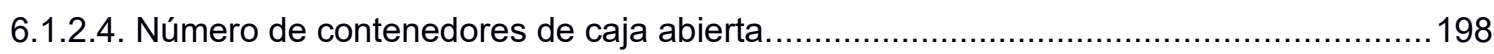

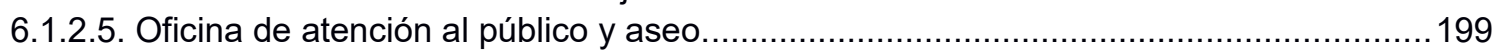

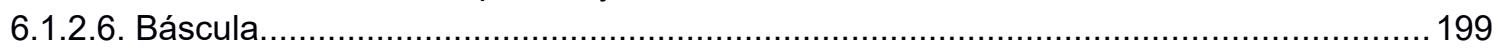

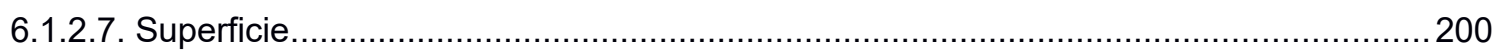

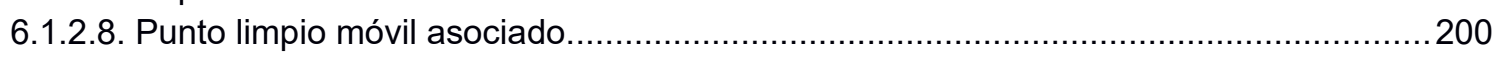

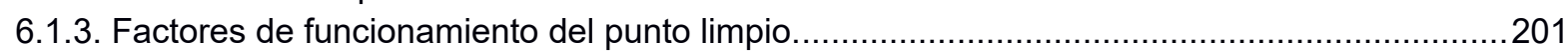

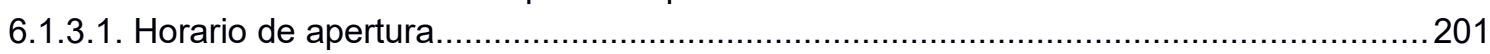

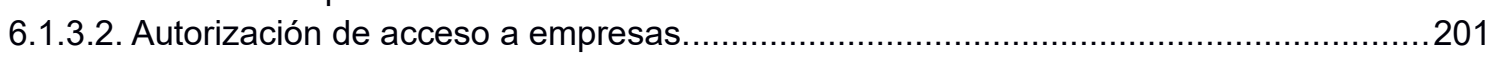

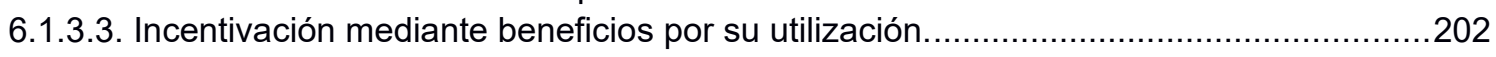

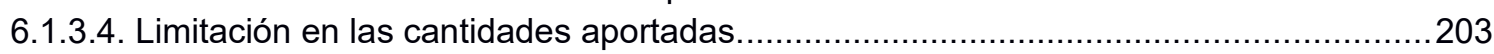

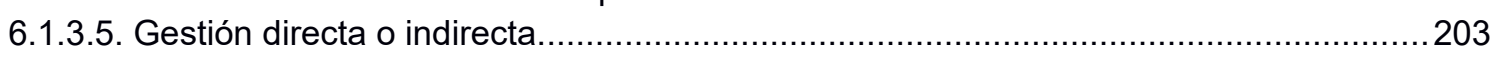

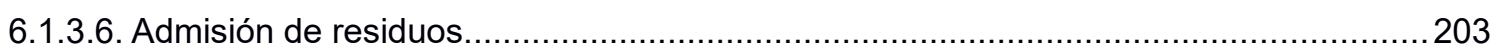

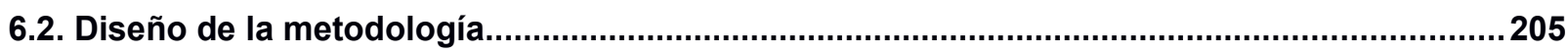

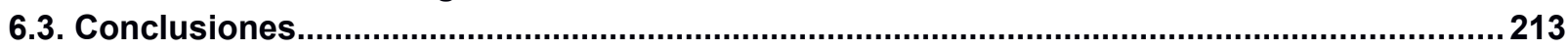

7. VALIDACIÓN DE LA METODOLOGÍA. DISEÑO DE UN SEGUNDO PUNTO LIMPIO EN LA CIUDAD

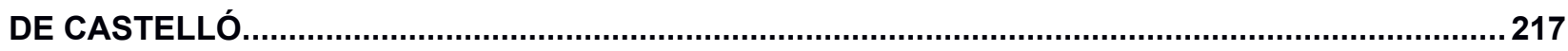

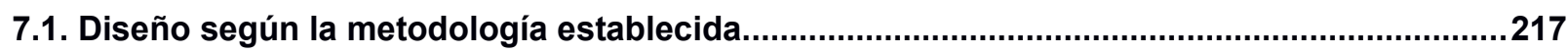

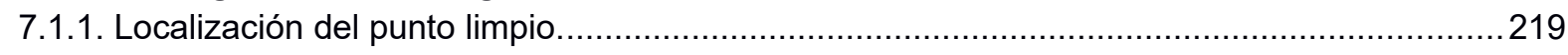

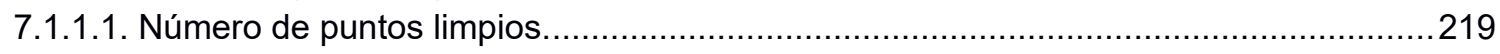

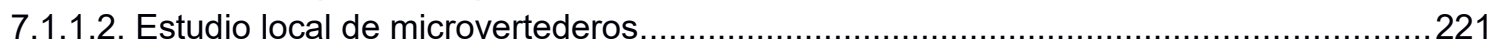

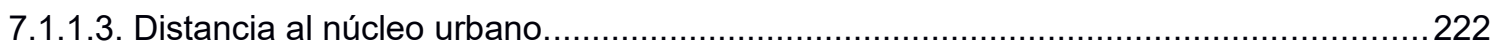

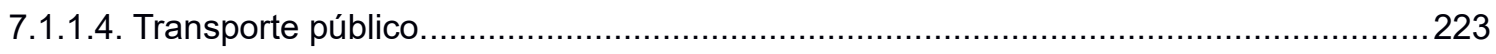

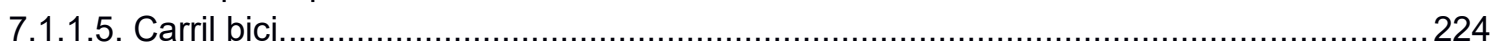

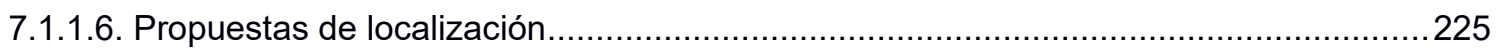

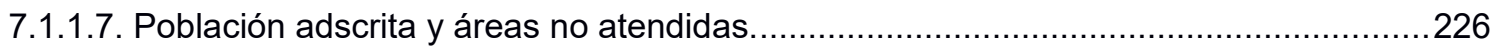

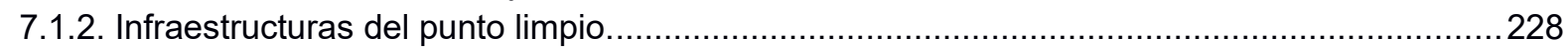

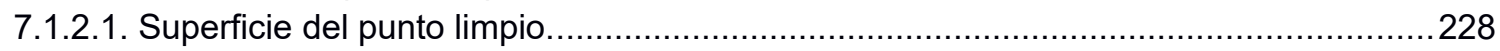

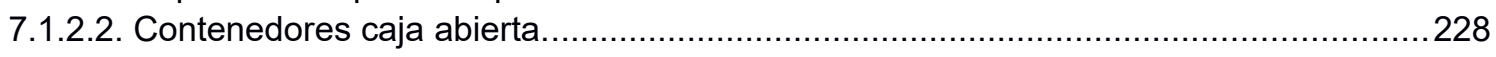

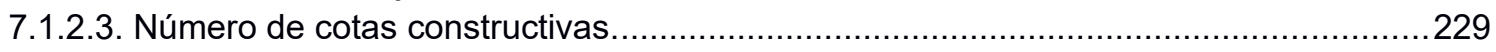

7.1.2.4. Báscula

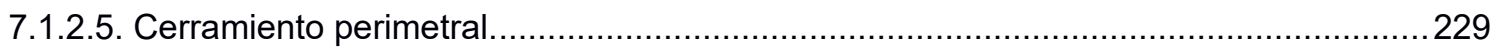

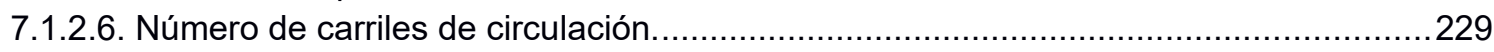

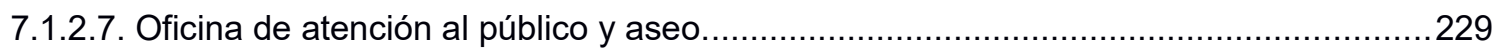

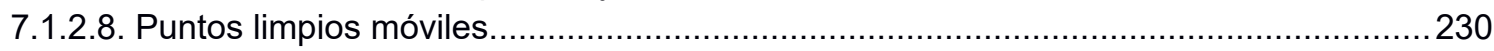




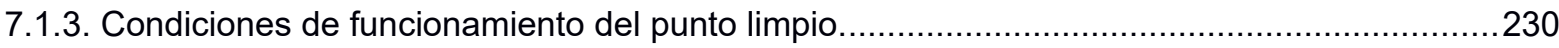

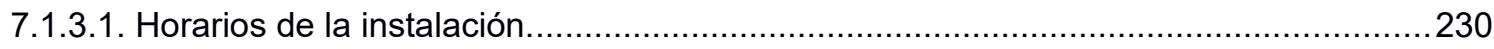

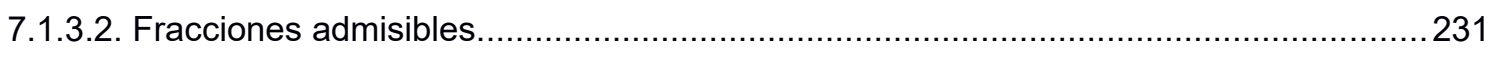

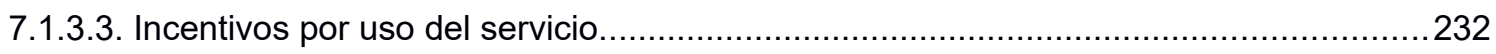

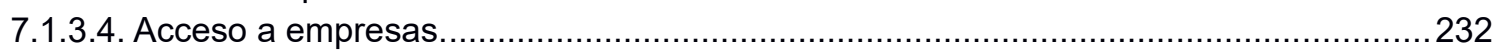

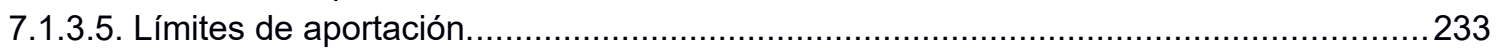

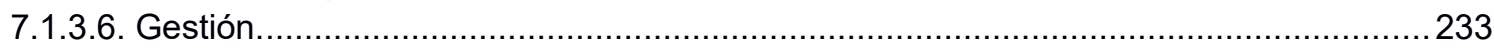

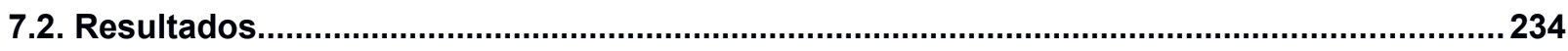

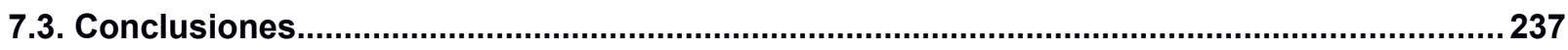

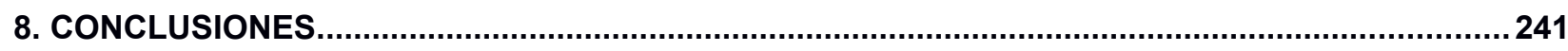

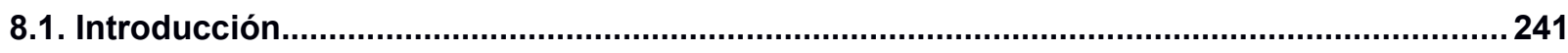

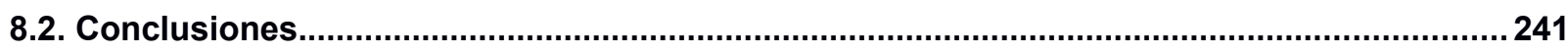

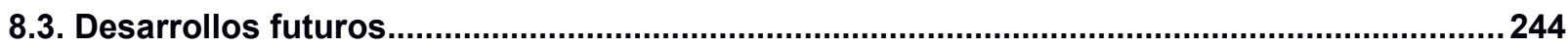




\section{ÍNDICE DE TABLAS}

Tabla 1.1: Cantidad de residuos de competencia municipal recogidos en España y su destino. 2017............................5

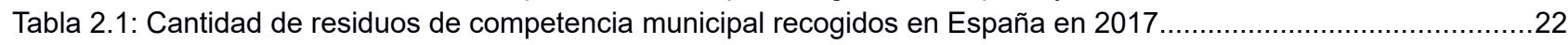

Tabla 2.2: Recogidas selectivas por Comunidad Autónoma (t). 2017 ................................................................23

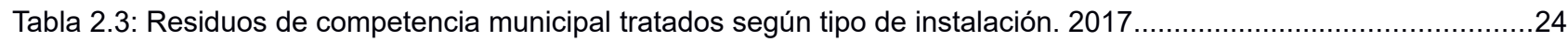

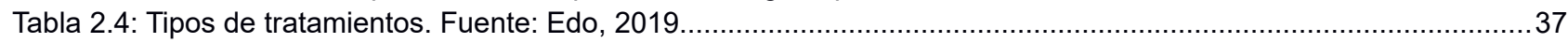

Tabla 2.5: Residuos admitidos en los ecoparques del EMTRE. Fuente: Normas de uso y gestión de los ecoparques integrantes de la red de ecoparques de gestión metropolitana. EMTRE..................................................................63

Tabla 2.6: Tipos de ecoparques. Fuente: Elaboración propia a partir del PIR-CVA 2019-2022 ....................................65

Tabla 2.7: Estimación del número de ecoparques es la Comunidad Valenciana. Fuente: Elaboración propia a partir del

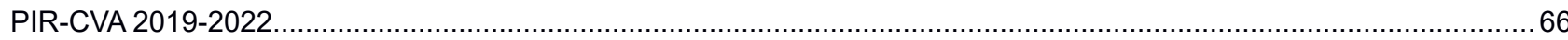

Tabla 3.1: Distribución de tamaños de los microvertederos y capacidad total en 1998 y en 2003. Martínez y Adsuara

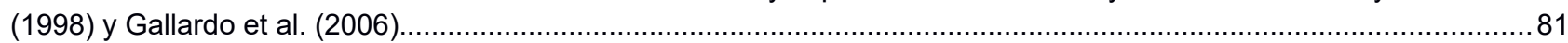

Tabla 3.2: Categorías y número de vertederos de cada tipo en 1998 y en 2003. Martínez y Adsuara (1998) y Gallardo et

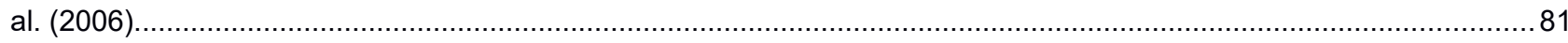

Tabla 3.3: Horario de apertura del punto limpio fijo de Castelló de la Plana. Fuente: Ayuntamiento de Castelló de la

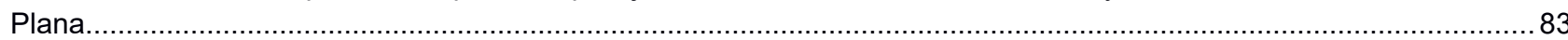

Tabla 3.4: Clasificación de los residuos según su admisibilidad en el punto limpio fijo de Castelló de la Plana. Fuente:

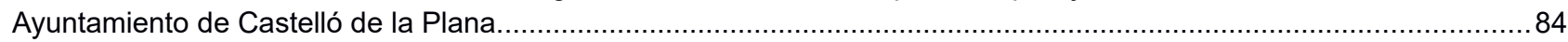

Tabla 3.5: Ubicaciones y horarios establecidos para el punto limpio sobre camión...................................................87 Tabla 3.6: Ubicaciones y horarios establecidos para el punto limpio caja móvil. Fuente: Ayuntamiento de Castelló de la

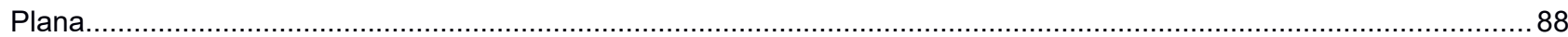

Tabla 3.7: Distribución de tamaños de los microvertederos, composición y capacidad total de cada categoría en $2014 . .99$

Tabla 4.1: Resumen de la normativa autonómica relativa a puntos limpios.......................................................... 108

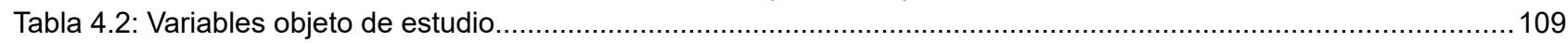

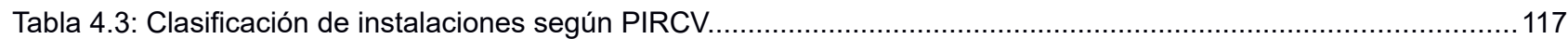

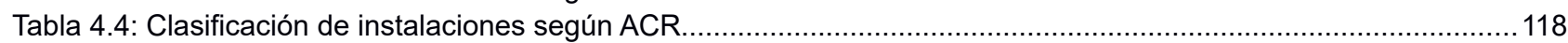

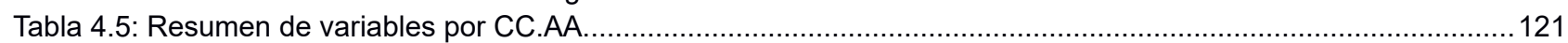

Tabla 5.1: Distribución de municipios y puntos limpios de la muestra por Comunidad Autónoma................................137

Tabla 5.2: Porcentaje de contestación a las preguntas de la encuesta..............................................................138

Tabla 5.3: Error de la muestra en poblaciones finitas para cada pregunta encuestada..........................................139

Tabla 5.4: Homogeneidad de respuestas a preguntas dicotómicas.................................................................... 140

Tabla 5.5: Valores de las variables en estudio para los puntos limpios de la muestra................................................141

Tabla 5.6: Resultados del test de Kolmogorov-Smirnov de normalidad de TR......................................................146

Tabla 5.7: Resultados del test de Kolmogorov-Smirnov de normalidad de TV....................................................148

Tabla 5.8: Resultados del test de correlación de Pearson para TR y TV................................................................150 Tabla 5.9: Media, desviación estándar, error estándar e intervalo de confianza de TR (kg/habitante/año) para los grupos

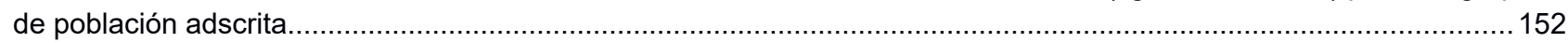

Tabla 5.10: Resultados del test $\mathrm{H}$ de Kruskal-Wallis de TR entre grupos de población adscrita..................................152

Tabla 5.11: Media, desviación estándar, error estándar e intervalo de confianza de TV para los grupos de población

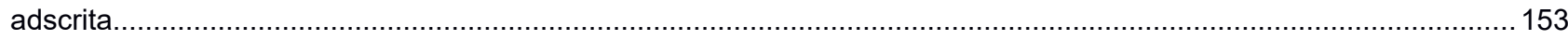

Tabla 5.12: Resultados de la prueba de significación sobre TV entre grupos de población adscrita.............................153

Tabla 5.13: Media, desviación estándar, error estándar e intervalo de confianza de TR (kg/habitante/año) para los grupos

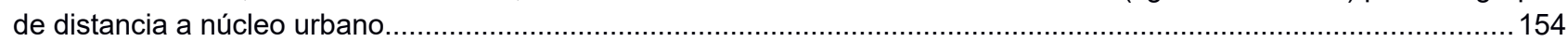

Tabla 5.14: Resultados del test de Kruskal-Wallis de TR entre grupos de distancia al núcleo urbano..........................155

Tabla 5.15: Media, desviación estándar, error estándar e intervalo de confianza de TV para los grupos de distancia a

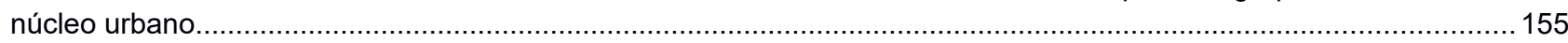

Tabla 5.16: Resultados de la prueba de significación sobre TV entre grupos de distancia al núcleo urbano..................156 Tabla 5.17: Media, desviación estándar, error estándar e intervalo de confianza de TR para los grupos de disponibilidad

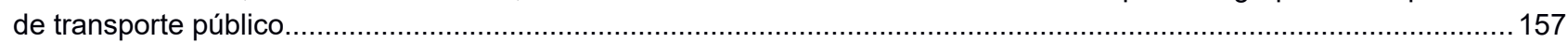
Tabla 5.18: Media, desviación estándar, error estándar e intervalo de confianza de TV para los grupos de disponibilidad

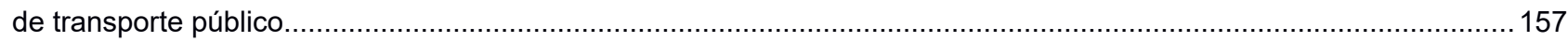
Tabla 5.19: Media, desviación estándar, error estándar e intervalo de confianza de TR para los grupos de disponibilidad

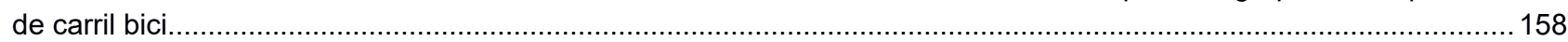


Tabla 5.20: Media, desviación estándar, error estándar e intervalo de confianza de TV para los grupos de disponibilidad

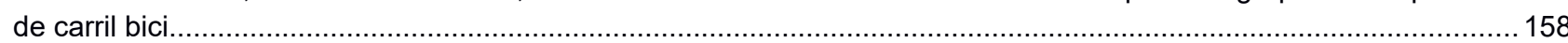

Tabla 5.21: Media, desviación estándar, error estándar e intervalo de confianza de TR para los grupos de antigüedad del

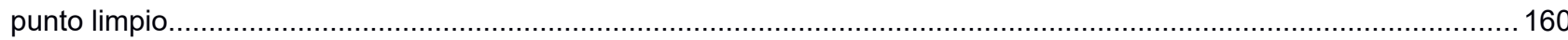
Tabla 5.22: Media, desviación estándar, error estándar e intervalo de confianza de TV para los grupos de antigüedad del

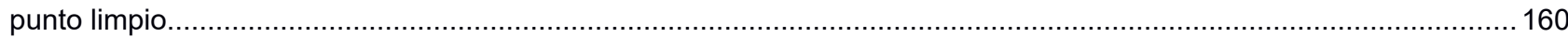

Tabla 5.23: Resultados de la prueba de significación sobre TV entre grupos de antigüedad del punto limpio................160 Tabla 5.24: Media, desviación estándar, error estándar e intervalo de confianza de TR para los grupos de $n^{\circ}$ de carriles de circulación...

Tabla 5.25: Media, desviación estándar, error estándar e intervalo de confianza de TV para los grupos de $n^{\circ}$ de carriles

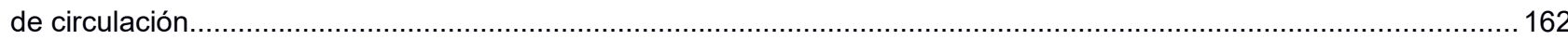
Tabla 5.26: Media, desviación estándar, error estándar e intervalo de confianza de TR para los grupos de $n^{\circ}$ de cotas de

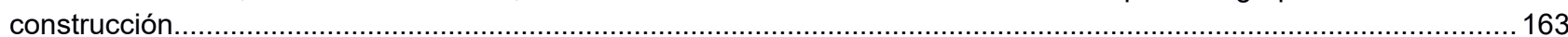
Tabla 5.27: Media, desviación estándar, error estándar e intervalo de confianza de TV para los grupos de $n^{\circ}$ de cotas de

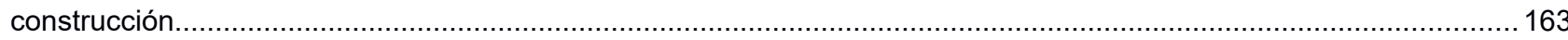
Tabla 5.28: Clasificación de puntos limpios por número de contenedores y tamaño de población adscrita...................165 Tabla 5.29: Media, desviación estándar, error estándar e intervalo de confianza de TR para los grupos de $n^{\circ}$ de

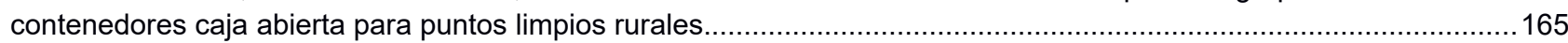
Tabla 5.30: Media, desviación estándar, error estándar e intervalo de confianza de TR para los grupos de $n^{\circ}$ de contenedores caja abierta para puntos limpios semiurbanos.........................................................................166 Tabla 5.31: Media, desviación estándar, error estándar e intervalo de confianza de TR para los grupos de $n^{\circ}$ de contenedores caja abierta para puntos limpios urbanos............................................................................ 166 Tabla 5.32: Media, desviación estándar, error estándar e intervalo de confianza de TV para los grupos de $n^{\circ}$ de

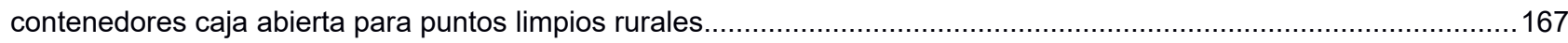
Tabla 5.33: Media, desviación estándar, error estándar e intervalo de confianza de TV para los grupos de $n^{\circ}$ de contenedores caja abierta para puntos limpios semiurbanos.......................................................................16 Tabla 5.34: Media, desviación estándar, error estándar e intervalo de confianza de TV para los grupos de $n^{\circ}$ de

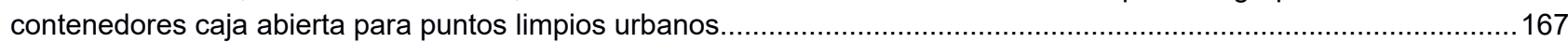

Tabla 5.35: Número de contenedores caja abierta adecuado por población adscrita...............................................168

Tabla 5.36: Clasificación de puntos limpios por superficie y tamaño de población adscrita..........................................169 Tabla 5.37: Media, desviación estándar, error estándar e intervalo de confianza de TR para los grupos de superficie para

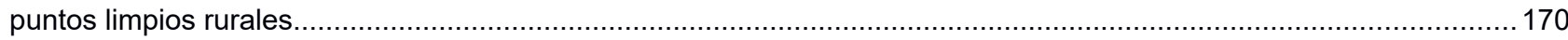
Tabla 5.38: Media, desviación estándar, error estándar e intervalo de confianza de TR para los grupos de superficie para

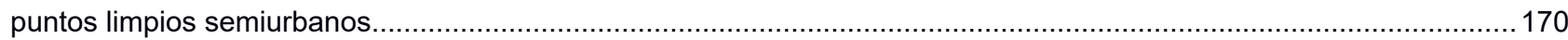
Tabla 5.39: Media, desviación estándar, error estándar e intervalo de confianza de TR para los grupos de superficie para

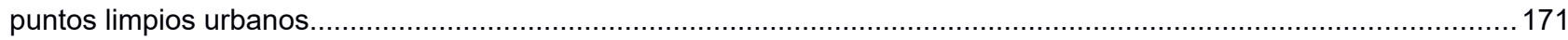
Tabla 5.40: Media, desviación estándar, error estándar e intervalo de confianza de TV para los grupos de superficie para

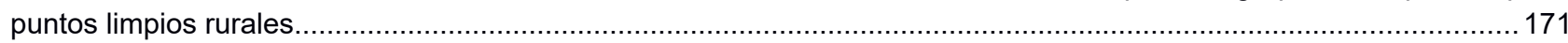
Tabla 5.41: Media, desviación estándar, error estándar e intervalo de confianza de TV para los grupos de superficie para

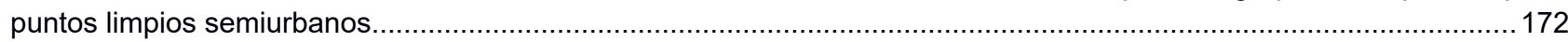
Tabla 5.42: Media, desviación estándar, error estándar e intervalo de confianza de TV para los grupos de superficie para

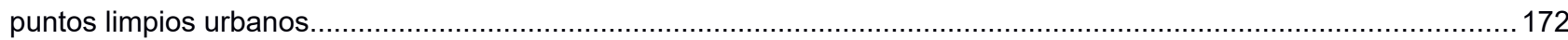
Tabla 5.43: Superficies adecuadas por población adscrita.................................................................................... 173 Tabla 5.44: Media, desviación estándar, error estándar e intervalo de confianza de TR para los grupos de disponibilidad

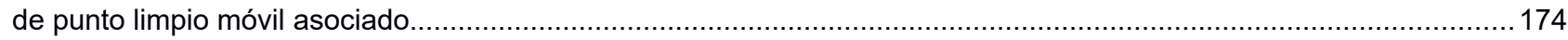
Tabla 5.45: Media, desviación estándar, error estándar e intervalo de confianza de TV para los grupos de disponibilidad

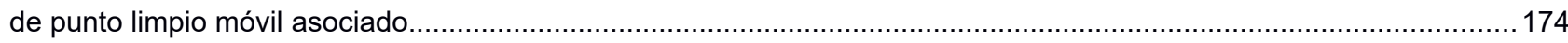
Tabla 5.46: TR. Número de puntos limpios abiertos y cerrados por día de la semana..............................................175 Tabla 5.47: Media, desviación estándar, error estándar e intervalo de confianza de TR para los grupos de apertura en

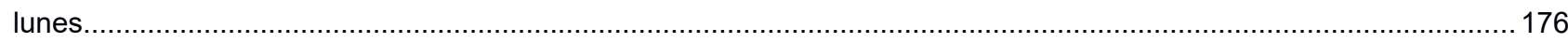
Tabla 5.48: Media, desviación estándar, error estándar e intervalo de confianza de TR para los grupos de apertura en

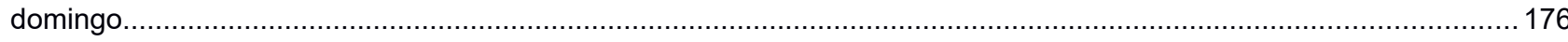
Tabla 5.49: TV. Número de puntos limpios abiertos y cerrados por día de la semana...........................................177 Tabla 5.50: Media, desviación estándar, error estándar e intervalo de confianza de TV para los grupos de apertura en

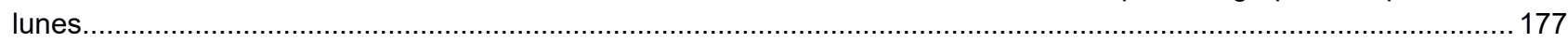
Tabla 5.51: Media, desviación estándar, error estándar e intervalo de confianza de TV para los grupos de apertura en domingo. 
Tabla 5.52: Media, desviación estándar, error estándar e intervalo de confianza de TR para los grupos de acceso a empresas.

Tabla 5.53: Media, desviación estándar, error estándar e intervalo de confianza de TV para los grupos de acceso a empresas.

Tabla 5.54: Media, desviación estándar, error estándar e intervalo de confianza de TR para los grupos de incentivos por

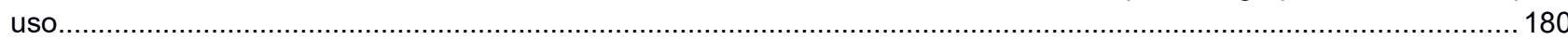
Tabla 5.55: Media, desviación estándar, error estándar e intervalo de confianza de TV para los grupos de incentivos por uso

Tabla 5.56: Media, desviación estándar, error estándar e intervalo de confianza de TR para los grupos de límites de

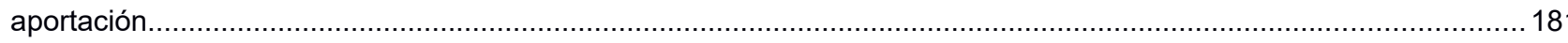

Tabla 5.57: Media, desviación estándar, error estándar e intervalo de confianza de TV para los grupos de límites de

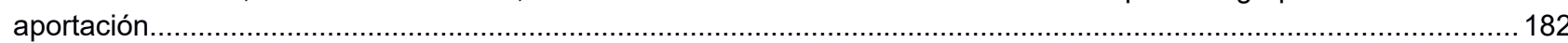

Tabla 5.58: Número de casos por tamaño de población adscrita y tipo de gestión.....................................................183

Tabla 5.59: Media, desviación estándar, error estándar e intervalo de confianza de TR para los grupos de tipo de gestión

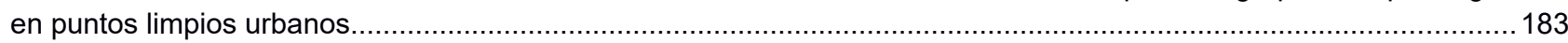
Tabla 5.60: Media, desviación estándar, error estándar e intervalo de confianza de TV para los grupos de tipo de gestión

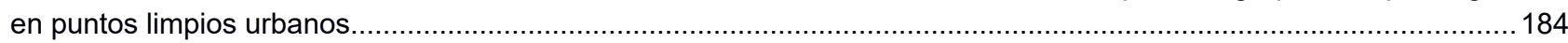
Tabla 5.61: Media, desviación estándar, error estándar e intervalo de confianza de TR para los grupos de admisión de fracción resto

Tabla 5.62: Media, desviación estándar, error estándar e intervalo de confianza de TR_noR para los grupos de admisión de fracción resto

Tabla 5.63: Media, desviación estándar, error estándar e intervalo de confianza de TV para los grupos de admisión de fracción resto.

Tabla 5.64: Media, desviación estándar, error estándar e intervalo de confianza de TR para los grupos de disponibilidad de zona para RAEE.

Tabla 5.65: Media, desviación estándar, error estándar e intervalo de confianza de TV para los grupos de disponibilidad

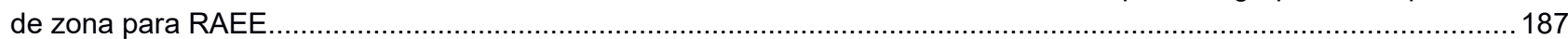

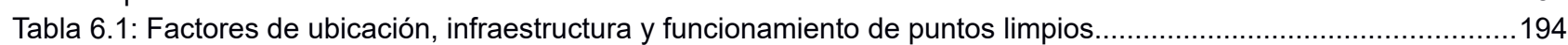

Tabla 6.2: Valores de TR y TV en función de la población adscrita ...................................................................... 195

Tabla 6.3: Valores de TR y TV en función de la distancia al núcleo urbano...........................................................196

Tabla 6.4: Número de contenedores de caja abierta en función de la población adscrita...........................................199

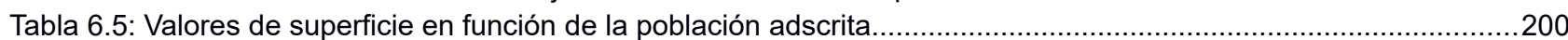

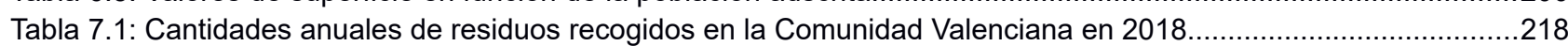

Tabla 7.2: Población de la ciudad de Castelló por núcleos urbanizados................................................................220 



\section{ÍNDICE DE FIGURAS}

Figura 2.1: Jerarquía o prioridades en la Gestión de Residuos. Fuente: Programa Estatal de Prevención de Residuos 2014-2020, MAGRAMA, 2012.

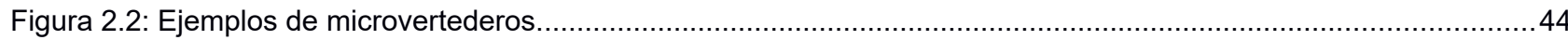

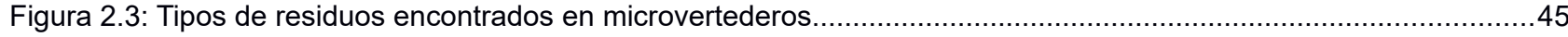

Figura 2.4: Servicios municipales de recogida de microvertederos y prohibiciones..................................................48

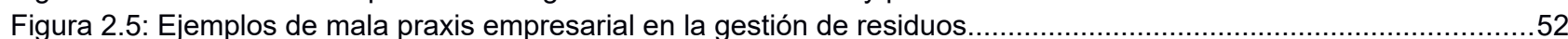

Figura 3.1: Ubicación del punto limpio de Castelló de la Plana...............................................................................83

Figura 3.2: Distribución del punto limpio Fijo de Castelló de la Plana. Fuente: Ayuntamiento de Castelló de la Plana.....85

Figura 3.3: Ecoparques móviles, camión y caja móvil, respectivamente, de Castelló de la Plana. Fuente: Ayuntamiento de Castelló de la Plana...

Figura 3.4: Localización de ubicaciones del Punto limpio sobre camión. Fuente: Ayuntamiento de Castelló de la Plana. 87 Figura 3.5: Localización de ubicaciones del Punto limpio caja móvil. Fuente: Ayuntamiento de Castelló. Fuente:

Ayuntamiento de Castelló de la Plana.

Figura 3.6: Localización de ubicaciones de los ecoparques móviles y su área de influencia (considerada de 200 m).

Fuente: Elaboración propia a partir de la información del Ayuntamiento de Castelló.

Figura 3.7: Ejemplo ruta inspección servicios municipales de limpieza de Castelló

Figura 3.8: Microvertederos en bordes de caminos, junto a contenedores y en solares en los que se abandonan principalmente Residuos de Construcción y Demolición y enseres voluminosos......................................................96

Figura 3.9: Evolución histórica de los microvertederos en diferentes años........................................................97

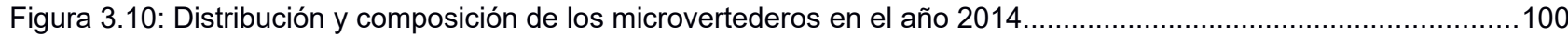

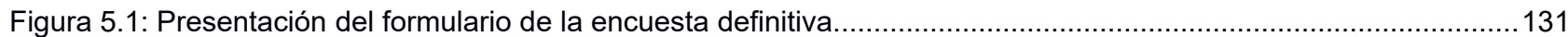

Figura 5.2: Formulario "1. Información general" de la encuesta definitiva...................................................................

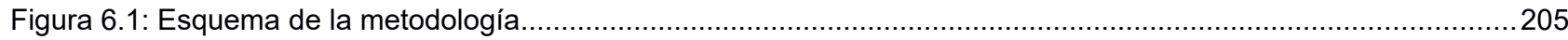

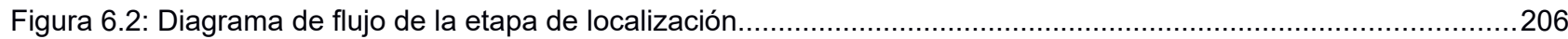

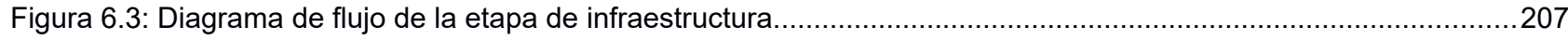

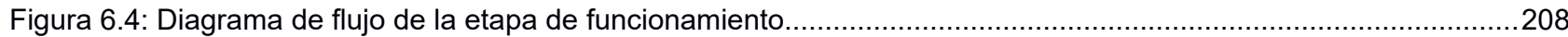

Figura 7.1: Término municipal de Castelló y área atendida por punto limpio actual................................................220

Figura 7.2: Microvertederos al Este de la ciudad de Castelló..........................................................................222

Figura 7.3: Núcleos urbanos no atendidos por punto limpio actual y distancia límite de la instalación..........................223

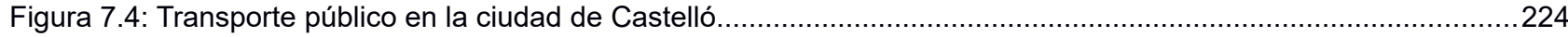

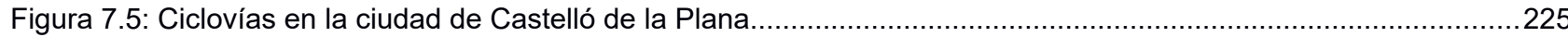

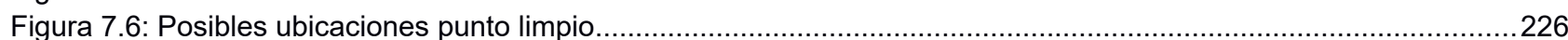

Figura 7.7: Áreas de influencia de los puntos limpios según su ubicación............................................................227

Figura 7.8: Propuestas iniciales y parcela disponible para instalación..............................................................234

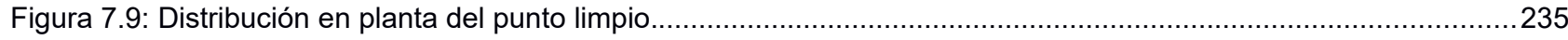





\section{ÍNDICE DE GRÁFICOS}

Gráfico 3.1: Toneladas de residuos aportadas en los ecoparques de Castelló de la Plana en el año 2019. Fuente: Ayuntamiento de Castelló de la Plana, informe anual de gestión de ecoparques (FCC).

Gráfico 3.2: Toneladas de residuos aportadas en los ecoparques de Castelló de la Plana en el año 2020. Fuente:

Ayuntamiento de Castelló de la Plana, informe anual de gestión de ecoparques (FCC) ..........................................91

Gráfico 3.3: Toneladas de residuos aportadas según su tipología en el punto limpio de Castelló de la Plana en el año 2019. Fuente: Ayuntamiento de Castelló de la Plana, informe anual de gestión de ecoparques (FCC).

Gráfico 3.4: Toneladas de residuos aportadas según su tipología en el punto limpio de Castelló de la Plana en el año 2020. Fuente: Ayuntamiento de Castelló de la Plana, informe anual de gestión de ecoparques (FCC)........................92

Gráfico 5.1: Cantidades anuales de residuos depositadas en los puntos limpios..................................................142

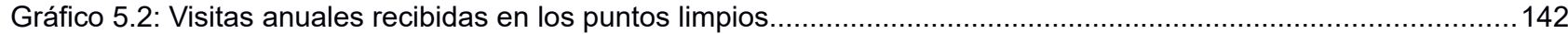

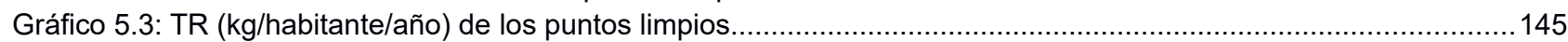

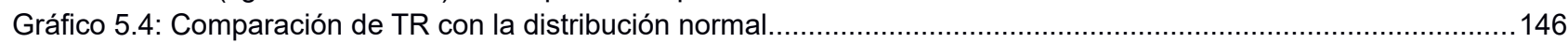

Gráfico 5.5: TV (visitas/100 habitantes/año) de los puntos limpios................................................................147

Gráfico 5.6: TV (visitas/100 habitantes/año) de los puntos limpios. Escala logarítmica...........................................148

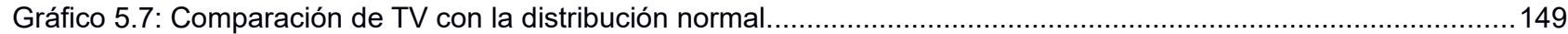

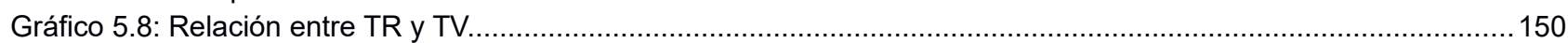

Gráfico 5.9: Número de puntos limpios por cantidad de contenedores caja abierta................................................ 164

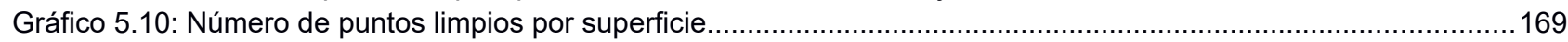



CAPÍTULO 1. INTRODUCCIÓN. 



\section{INTRODUCCIÓN.}

\subsection{Justificación.}

La población en el mundo ha experimentado un crecimiento notable en los últimos tiempos. En 1900 la población mundial rondaba los 1.600 millones de habitantes y en casi un siglo la población se ha cuadruplicado, dado que actualmente existen aproximadamente 7.500 millones de habitantes, con el correspondiente aumento en la generación de residuos por persona, que supone que en un día se generen en el mundo alrededor de 4 millones de toneladas de basura (Instituto Nacional Estadística, 2018).

Esta situación se ha visto agravada en los últimos años con las migraciones masivas del campo a la ciudad, concentrándose gran cantidad de población en áreas urbanas, lo que ha provocado el aumento indiscriminado de los residuos, muy por encima de las soluciones que se han puesto en práctica para su eliminación o recuperación. Los habitantes de las ciudades reciben bienes de consumo de distintos lugares de origen y una vez que han sido utilizados y se convierten en residuos, no vuelven a su origen, sino que se acumulan en las ciudades.

Se ha producido un gran incremento en la utilización de productos de un solo uso, así como en el envasado y empaquetado de los productos. Esto provoca un aumento en el volumen de los residuos a la vez que un despilfarro de materias primas y recursos no renovables.

El consumo compulsivo es otro factor que agrava la situación de los residuos, debido a la creación de nuevas necesidades que son saciadas por nuevos objetos de vida útil limitada y caducidad programada (tendencia a adquirir nuevas cosas y desechar otras). El $20 \%$ de la población mundial consume el $80 \%$ de los recursos. Según el informe del Fondo Mundial para la Naturaleza (WWF, Informe Plantea Vivo, 2019), si toda la población mundial consumiera como en los países desarrollados, se necesitarían entre tres y cuatro planetas para generar los recursos necesarios y asimilar los residuos y contaminación producidos.

Por otro lado, se nota una falta de conciencia y educación ciudadana sobre los problemas ambientales, para participar activamente en la solución de los mismos y frente a los sistemas que transmiten el concepto de un crecimiento ilimitado sin tener en cuenta el posible agotamiento de los recursos ni la contaminación ocasionada. Se hace necesaria una concepción ecológica del mundo, en la que los recursos sean considerados algo integrante de un todo limitado y gravemente alterado. 
El sistema económico en el que están inmersos los países desarrollados, basado en la fabricación, prestación y consumo de toda clase de productos y servicios, en el que la actividad se rige por criterios de crecimiento económicos, produce graves problemas ambientales tanto a escala local como global. No se tiene en cuenta que se vive en un mundo finito con límites físicos que cuestionan tal crecimiento ilimitado, debido tanto a la disponibilidad limitada de los recursos como a la capacidad limitada de absorción por parte de los sistemas naturales de los residuos y otras formas de contaminación.

Por tanto, hay que considerar a la economía dentro de un sistema ecológico y acomodarla a las limitaciones de éste, teniendo en cuenta el agotamiento de los recursos y su capacidad para absorber los contaminantes y residuos que generamos. De esta concepción surge el concepto de crecimiento económico sostenible, que vio la luz mediante el informe Bruntland, de 1987. Este crecimiento se basa en un uso racional de los recursos, para que las generaciones venideras puedan seguir disfrutando y haciendo uso de ellos. El desarrollo sostenible debe garantizar un nivel de bienestar mínimo que perdure en el futuro, por lo que no tiene una concepción solamente económica sino también social y ambiental.

La cantidad total de residuos sólidos urbanos (RSU) generados al año en España experimentó un incremento del $85 \%$ en el período comprendido entre el año 1990 y el 2018, situándose la cifra total de residuos producidos en este último año en 22.703 toneladas de residuos (INE, 2018). Por lo tanto, la generación de residuos urbanos contemplada desde todas las perspectivas está experimentando un crecimiento extremadamente alto en el país. En parte, esto se debe al no cumplimiento de determinados parámetros tratados en los planes nacionales de residuos (como ejemplo está la producción de ocho millones más de toneladas de las previstas en el Plan Nacional de Residuos Urbanos 2008 - 2015), al progresivo crecimiento de la población española en las últimas décadas y al hecho de que España es el primer destino turístico de la Unión Europea.

Únicamente, en el periodo comprendido entre 2013 y 2016, la producción de residuos sufrió un pequeño descenso con respecto a la tendencia anterior, aunque a partir de 2017 ha vuelto a situarse por encima de las 22 millones de toneladas anuales.

Desde hace cuatro años, la tendencia a la estabilización de la producción de residuos urbanos se ha generalizado en la mayoría de los países que forman parte del continente europeo, con algunas excepciones como es el caso de España, donde todavía existe una tendencia al crecimiento de la producción residual. De hecho, en 2018 la producción residual per cápita en España excedió ligeramente la del año anterior, situándose en 485,9kg/hab/año. 
Introducción.

Como ejemplo de lo expuesto anteriormente, en la Tabla 1.1 se muestran los datos respecto a la generación de residuos en España durante el año 2017.

\begin{tabular}{|c|c|c|c|c|c|c|}
\hline \multicolumn{2}{|r|}{ Código LER-Residuo } & \multirow{2}{*}{$\begin{array}{r}\text { Generación } \\
17.457 .709\end{array}$} & \multirow{2}{*}{\begin{tabular}{r|} 
Reciclado \\
660.153
\end{tabular}} & \multirow{2}{*}{$\begin{array}{r}\text { Compostaje } \\
3.307 .618 \\
\end{array}$} & \multirow{2}{*}{\begin{tabular}{l|} 
Vertido \\
10.840 .858
\end{tabular}} & \multirow{2}{*}{$\begin{array}{r}\text { Incineración } \\
2.649 .080\end{array}$} \\
\hline 20.03.01 & Mezclas de residuos municipales & & & & & \\
\hline 20.01 .01 & Papel y cartón & 1.061 .380 & 1.061 .380 & 0 & 0 & 0 \\
\hline 20.01 .02 & Vidrio & 13.176 & 13.176 & 0 & 0 & 0 \\
\hline 20.01.08 & $\begin{array}{l}\text { Residuos biodegradables de cocinas y } \\
\text { restaurantes }\end{array}$ & 610.043 & 0 & 443.046 & 105.115 & 61.882 \\
\hline 20.02.01 & Residuos biodegradables de parques y jardines & 266.779 & 0 & 167.371 & 87.883 & 11.525 \\
\hline 15.01.06 & Envases mezclados & 660.932 & 471.525 & & 148.591 & 40.816 \\
\hline 15.01.07 & Envases de vidrio & 802.706 & 802.706 & & & \\
\hline 20.01 .40 & Residuos metálicos & 20.940 & 20.925 & 0 & 15 & 0 \\
\hline 20.01.39 & Residuos de plástico & 24.571 & 17.337 & 0 & 6.573 & 661 \\
\hline 20.01.38 & Residuos de madera & 189.733 & 166.050 & 0 & 2.878 & 20.805 \\
\hline $\begin{array}{l}20.01 .10 \\
20.01 .11\end{array}$ & Residuos textiles & 39.235 & 24.047 & 0 & 14.395 & 793 \\
\hline $\begin{array}{l}20.01 .21 \\
20.01 .23 \\
20.01 .35 \\
20.01 .36\end{array}$ & Equipos desechados & 54.599 & 48.264 & 0 & 6.335 & 0 \\
\hline $\begin{array}{l}20.01 .33 \\
20.01 .34\end{array}$ & Residuos de pilas y acumuladores & 1.780 & 1.780 & 0 & 0 & 0 \\
\hline $\begin{array}{l}20.03 .02 \\
20.01 .34\end{array}$ & $\begin{array}{l}\text { Residuos de mercados } \\
\text { Residuos voluminosos }\end{array}$ & 814.281 & 745.594 & 0 & 50.774 & 17.913 \\
\hline 20.02 .02 & Tierras y piedras de parques y jardines & 0 & 0 & 0 & 0 & 0 \\
\hline \multicolumn{2}{|l|}{ TOTAL } & 22.017 .864 & 4.032 .938 & 3.918 .035 & 11.263.416 & 2.803.475 \\
\hline \multicolumn{3}{|l|}{$\%$} & 18,3 & 17,8 & 51,2 & 12,7 \\
\hline
\end{tabular}

Tabla 1.1: Cantidad de residuos de competencia municipal recogidos en España y su destino. 2017.

Como se observa en la Tabla 1.1, pese a los esfuerzos normativos y en materia de concienciación ciudadana por parte de las administraciones públicas, los residuos mezclados siguen suponiendo la mayor parte en la generación a nivel estatal. Respecto a la recogida selectiva, el vidrio y los envases suponen el porcentaje principal de las fracciones separadas en origen.

Respecto al tratamiento de residuos, se puede comprobar que el vertido controlado sigue siendo, con diferencia, el mayoritario con el $51 \%$ del total de residuos generados en España, seguido de lejos por el compostaje de la materia orgánica contenida en éstos.

Por todo lo expuesto anteriormente, los residuos deben controlarse de manera que el impacto medioambiental sea lo más bajo posible, se garantice de manera sostenible el bienestar y se preserven la salud de los seres humanos y de las especies que habitan el planeta. 
La gestión de los residuos urbanos en las sociedades avanzadas ha experimentado una gran evolución para adaptarse a los principios del desarrollo sostenible; en esta línea, la Unión Europea ha establecido una estrategia para esta gestión basada en el siguiente orden de prelación: prevención, reutilización, valorización y eliminación (Directiva 2088/98/CE).

La recuperación del material usado y la recuperación de energía son fundamentales para minimizar, en gran medida, el problema de la eliminación de los residuos urbanos y convertirlos en activos; así, en la última década, la variedad de métodos y tecnologías disponibles para llevar a cabo la recuperación de materia y energía ha originado muchas vías posibles para abordar estos dos aspectos, lo cual ha sido objeto de investigación en los últimos tiempos. Los resultados muestran que el incremento del nivel de separación en origen tiene un impacto positivo sobre la recuperación de materiales y sobre la eficiencia energética del proceso completo.

El problema de la gestión de los RSU se pone de manifiesto en los planes y programas más recientes, tanto en el ámbito Europeo como en el Nacional o Local. En el ámbito nacional existen diferentes planes y programas recientes donde se refleja que el mejor modelo de gestión para los denominados "Residuos Específicos", procedentes de los domicilios particulares, es la dotación de puntos limpios.

En las áreas urbanas, los problemas en la gestión son mayores en la medida en que se pretende darles una mejor gestión a todas y cada una de sus fracciones. Un esfuerzo más para mejorar la situación medioambiental y dar un mejor servicio a los ciudadanos, es la implantación de puntos limpios en las ciudades.

Los puntos limpios, como se desarrollará en los siguientes capítulos, son instalaciones que permiten a los ciudadanos deshacerse de forma adecuada de aquellos residuos que quedan fuera de los canales de recogida selectiva municipal, evitando la posible aparición de vertederos incontrolados y facilitando con ello las posteriores operaciones de reutilización, reciclaje y valorización. La característica fundamental de los puntos limpios, es que el ciudadano es el que se encarga del transporte de los residuos hasta la instalación. Estas instalaciones se caracterizan porque son centros vallados en todo su perímetro y por lo general con dos accesos, uno para usuarios y otro para los camiones que transportan los contenedores. Antes de entrar, se informa al usuario de cómo depositar los residuos y se anotan las características de éstos. A continuación, el usuario se desplaza en su vehículo hasta el contenedor apropiado. Normalmente, se pueden encontrar contenedores grandes para residuos voluminosos, y otros más pequeños específicos para residuos especiales. 
En Europa el concepto de Punto Limpio está muy extendido. No obstante, existen algunas diferencias a nivel de instalaciones y funcionamiento según el país o la región. En todos ellos, se trata también de una instalación cerrada donde los usuarios llevan residuos que no tienen cabida en otro sistema de recogida selectiva. En Francia toman el nombre de "déchettèrie", en Alemania de "recyclinghof", en Italia de "cicicleria" o "stazione ecologiche" y en Reino Unido de "recycling centre" o "civic ametitie".

Este tipo de centros cuenta ya con una experiencia notable en casi todos los municipios de tamaño medio-grande de España. Sus resultados son positivos, cumpliendo el objetivo de mejorar la calidad de la gestión de los residuos al aprovechar los materiales susceptibles de recuperación o reciclaje y evitar el vertido de aquellos residuos que no deben eliminarse a través de la recogida convencional, tratándose además, en ocasiones, de residuos peligrosos.

La recogida selectiva es la única manera de facilitar el reciclaje y/o la eliminación segura de los residuos. Llevando residuos al punto limpio, se evita su vertido incontrolado, se reduce el volumen de basura que termina en un vertedero, y se mejora el tratamiento adecuado de todos los residuos.

Una vez retirados los residuos de los puntos limpios, éstos son trasladados a otros centros donde:

- Los materiales aprovechables son reciclados y convertidos en nuevas materias primas, obteniendo un ahorro importante de recursos naturales y energía, además de evitar que acaben incinerados o en vertedero.

- Aquellos productos especialmente peligrosos son tratados previamente a su recuperación o eliminación, con el fin de evitar problemas medioambientales y de salud.

- Únicamente las fracciones que no son aprovechables se destinan a vertido controlado.

Los puntos limpios son una buena herramienta local para el cuidado del medio ambiente, puesto que son un recurso cercano al ciudadano, gratuito y de libre acceso. Por ello, son esenciales para reducir el abandono de residuos en vía pública, caminos, parcelas, etc. Como contrapartida, pueden presentar algunos problemas o retos futuros, tales como:

- Vigilancia reducida. Son instalaciones, que generalmente funcionan en horario diurno y presentan residuos que pueden tener valor comercial, especialmente metales, lo que genera robos.

- Aprovechar mejor los residuos. Las Directivas europeas están promoviendo cada vez más una mayor separación de los residuos (fundamentalmente en tipos de plásticos) que se entregan en los puntos limpios, lo que puede estar limitado por el espacio de la instalación. 
- Mejorar su información y divulgación. Numerosas fuentes apuntan a que deberían aprovecharse como centros de educación ambiental sobre el medio urbano, donde el ciudadano pueda concienciarse sobre la problemática de los residuos y ello ayude a prevenir y reciclar su basura.

- Aumentar su dotación. El uso de los puntos limpios suele ser gratuito, pero los consumidores tienen que ocuparse del transporte y generalmente se encuentran un tanto alejados de los centros urbanos.

Como se describirá a continuación, la presente tesis tiene como objetivo detectar, estudiar y analizar los factores que serán relevantes a la hora de diseñar y ubicar un punto limpio en una ciudad partiendo de los resultados de encuestas enviadas a municipios españoles.

\subsection{Objetivos de la investigación.}

Atendiendo al compromiso medioambiental de mejorar la recogida selectiva de los RSU y con ello optimizar su tratamiento en plantas especializadas, desde hace algún tiempo se han implantado en las ciudades los Puntos Limpios, que son centros especializados en la recogida, selección y recuperación de todos aquellos desechos que generamos en nuestros hogares, que no podemos reciclar en ninguno de los contenedores que encontramos en nuestras ciudades.

El objetivo principal de la Tesis ha sido establecer una metodología para ubicar y diseñar estas instalaciones en base a las áreas de aportación o ciudades que prestan su servicio y proponer diferentes modelos de gestión para estos puntos, para conseguir instalaciones y servicios más eficientes.

Para su cumplimiento se han definido los siguientes objetivos específicos:

- Conocer el estado de la gestión municipal de residuos sólidos urbanos, especialmente a la gestión de aquellas fracciones no contenerizadas que son las que se gestionan a través de los puntos limpios.

- Analizar la influencia que tiene la instalación de estos puntos en la mitigación de vertederos incontrolados. Con ello quedará demostrada la eficacia de estas instalaciones a la hora de mejorar el vertido incontrolado de residuos y con ello el medio ambiente que rodea a las poblaciones.

- Analizar los diferentes factores que pueden influir en el diseño y gestión de un punto limpio. Para ello, se realizará una encuesta que se enviará a varias poblaciones españolas. 
Sus resultados servirán para confeccionar una base de datos con aquellas variables que afectan al diseño de estas instalaciones y los valores más significativos de las mismas.

- Establecer una metodología específica para el diseño y gestión de los puntos limpios, en la que se tengan en cuenta las variables de diseño y los valores de las mismas determinados en esta tesis.

- Aplicar la metodología propuesta a la ciudad de Castelló de la Plana, con el objetivo de verificar su validez.

Dicha metodología será una herramienta muy útil para los técnicos de las entidades locales y mancomunidades encargados de la planificación de la recogida y gestión de los RSU.

\subsection{Estructura de la tesis.}

La presente tesis se estructura en ocho capítulos. A continuación, se procede a resumir cada uno de ellos, sin tener en cuenta este primero que sirve de introducción:

- Capítulo 2: En este capítulo se lleva a cabo una revisión del estado del arte de los diferentes aspectos relevantes para el desarrollo de la Tesis, partiendo de los modelos europeos de economía circular, hasta los planes y programas locales de residuos. En lo referente a los aspectos legales de aplicación, se han analizado las normativas europea, nacional y autonómica en materia de residuos, especialmente en lo que concierne a la instalación de puntos limpios como unidad de gestión, así como definido las políticas y estrategias comunitarias de economía circular.

Respecto a los RSU, tras estudiar su generación, problemática, composición y la legislación al respecto, también se describe la gestión sostenible de los diferentes tipos de residuos así como los sistemas de recogida existentes en la actualidad y los métodos de tratamiento. Posteriormente, se realiza una primera aproximación al concepto de microvertederos incontrolados, describiendo brevemente el problema ambiental que suponen a nivel municipal, para por último, relacionarlos con la existencia o no de puntos limpios y la distancia a los núcleos urbanos.

En cuanto a los puntos limpios, se desarrolla en profundidad el concepto de punto limpio como solución ideal para que la ciudadanía pueda desprenderse de manera selectiva de residuos peligrosos y de gran volumen, como muebles o restos de materiales de construcción por una reforma, así como analizado la normativa autonómica valenciana (PIRCV) en cuanto a la definición de tipología, tamaño, superficie y características de los 
puntos limpios. El capítulo concluye con una descripción de toda la normativa autonómica existente en España, en materia de puntos limpios.

- Capítulo 3: En este capítulo se analiza la influencia de los puntos limpios en la aparición de microvertederos incontrolados. En concreto, se pone el foco en la problemática de la ciudad de Castelló de la Plana; partiendo de los artículos publicados en esta materia se estudia la influencia de los puntos limpios sobre la evolución de los microvertederos incontrolados en su área de influencia, mediante la comparativa de tres estudios desarrollados en varios años. Así, se realiza un estudio en profundidad de la problemática de los microvertederos y de los residuos que los componen y de su relación con la evolución temporal de las instalaciones para su recogida en la ciudad.

- Capítulo 4: En este capítulo se identifican las variables y parámetros implicados en el diseño de la metodología para la modelización de un punto limpio. Para ello se realiza una revisión exhaustiva de diferentes estudios, investigaciones y normas técnicas autonómicas sobre la materia, partiendo de artículos publicados por esta Universidad y agrupando las variables en tres grandes grupos: localización, infraestructura y funcionamiento del punto limpio. Estos grupos de variables compondrán la base sobre la que posteriormente se desarrollará la metodología para el modelizado de puntos limpios.

- Capítulo 5: En este capítulo, de carácter marcadamente técnico, se realiza el análisis estadístico de las diferentes variables sobre las que se han encuestado a los casi doscientos municipios españoles que formaban parte de la muestra. Partiendo de la elaboración de la encuesta, la determinación de la muestra, el tipo de muestreo elegido, la justificación del tamaño, las preguntas realizadas y los resultados obtenidos en ella, se elabora un análisis estadístico de las medias y varianzas de diferentes variables, al objeto de recoger los casos de éxito que permitan diseñar una metodología que se desarrollará en el capítulo siguiente.

El análisis se fundamenta en observar cómo varían las dos variables que serán determinantes para el buen funcionamiento del punto limpio: Tasa de visitas y Tasa de recogida por habitante y año, en función de los diferentes parámetros encuestados.

- Capítulo 6: En este capítulo, partiendo de los datos analizados en el apartado anterior, se recogerán los casos de éxito que servirán para el diseño de la metodología para el posterior modelizado de un punto limpio. Es decir, de todos los parámetros que se han encuestado y analizado en el capítulo 5, aquí se detallarán de forma motivada aquéllos que han sido relevantes según los datos obtenidos. Serán estos parámetros los que permitirán diseñar una metodología para el diseño de un punto limpio. 
La metodología se describe con detalle en este capítulo y se ha resumido en un esquema gráfico para que pueda ser seguido por cualquier responsable técnico en materia de residuos como herramienta para el diseño de un punto limpio en cualquier municipio.

- Capítulo 7: En el capítulo 7 se valida la metodología del capítulo anterior, diseñando y ubicando de forma en que se maximice el rendimiento un punto limpio nuevo para la ciudad de Castelló de la Plana. En definitiva, se trata de la aplicación práctica de la metodología diseñada en el capítulo 6 , añadiendo los condicionantes particulares a nivel municipal de la ciudad de Castelló de la Plana, acompañado de una estimación económica de los costes de ejecución del nuevo punto limpio.

- Capítulo 8: En este capítulo se presentan las principales conclusiones de la Tesis y se propondrán varias líneas de investigación para futuros desarrollos y oportunidades de mejora de la metodología diseñada.

\subsection{Referencias.}

- Directiva 2008/98/CE del Parlamento Europeo y del Consejo, de 19 de noviembre de 2008 , sobre los residuos y por la que se derogan determinadas Directivas.

- Fondo mundial para la naturaleza, Informe https://www.wwf.es/informate/biblioteca_wwf/? 55320/Informe-Planeta-Vivo-2019.

- Instituto Nacional de Estadística, estadísticas sobre generación de residuos, https://www.ine.es/dyngs/INEbase/es/operacion.htmc=Estadistica_C\&cid=1254736176844 \&menu=ultiDatos\&idp $=1254735976612$.

- DECRETO 55/2019, de 5 de abril, del Consell, por el que se aprueba la revisión del Plan integral de residuos de la Comunitat Valenciana (PIRCV, 2019). 



\section{Capítulo 2. Estado del ARTE.}





\section{ESTADO DEL ARTE.}

\subsection{Los residuos y su marco normativo.}

\subsubsection{Aspectos generales de la problemática de los residuos.}

Por medio ambiente se entiende todo lo que rodea a un ser vivo, comprende el conjunto de valores naturales, sociales y culturales existentes en un lugar y en un momento determinado, que influyen en la vida del ser humano y en las generaciones venideras. Es decir, no se trata sólo del espacio en el que se desarrolla la vida, sino que también comprende seres vivos, objetos, agua, suelo, aire y las relaciones entre ellos, así como elementos tan intangibles como la cultura.

El punto de vista medioambiental, así como la preocupación universal acerca de la salud y la utilización sostenible del planeta y sus recursos, ha sido cada vez mayor, y la ONU, en 1972, convocó la Conferencia de las Naciones Unidas sobre el Medio Humano en Estocolmo. Aprovechando el impulso generado por esta Conferencia, la Asamblea General, en diciembre de 1972, estableció el Programa de las Naciones Unidas para el Medio Ambiente (PNUMA), encargado de coordinar los esfuerzos por parte de las Naciones Unidas en favor del medio ambiente.

EI PNUMA amplió su temática a raíz de la Conferencia de las Naciones Unidas sobre el Medio Ambiente y el Desarrollo celebrada en Río de Janeiro en 1992. Conocida con el nombre de «Cumbre para la Tierra», fue ahí donde se elaboró la Declaración de Río sobre el Medio Ambiente y el Desarrollo. En el denominado «Programa 21», la Declaración hizo célebre a escala mundial el concepto de desarrollo sostenible, convirtiéndolo así en el eje de todas las actividades de desarrollo del sistema de las Naciones Unidas.

EI PNUMA y la Organización Meteorológica Mundial (OMM) se reunieron en 1988 para crear el Grupo Intergubernamental de Expertos sobre el Cambio Climático (IPCC), fuente preeminente mundial para la información sobre el cambio climático. El principal instrumento internacional en esta materia, la Convención Marco de las Naciones Unidas sobre el Cambio Climático (UNFCCC) se aprobó en 1992. Del mismo modo, el Protocolo de Kyoto, que fija unos objetivos de obligado cumplimiento para 37 países industrializados y la Comunidad Europea con el fin de reducir las emisiones de los gases del efecto invernadero, se aprobó en 1997. De todo ello debía surgir un compromiso para la mejora medioambiental, sobretodo de aquellas actividades que tenían un mayor impacto ecológico en el planeta y por lo tanto de manera directa sobre la generación y gestión de los residuos que se generan. 
La relación entre medio ambiente y el almacenamiento, recogida y eliminación de residuos está muy clara. Fenómenos ecológicos tales como la contaminación del aire y del agua, han sido atribuidos en muchas ocasiones a la gestión inapropiada de los residuos (Tchobanoglous et al., 1994).

La problemática de los residuos ha evolucionado desde la inexistencia o la inadecuada gestión, hasta su tratamiento en condiciones controladas. En la actualidad, la posición cada vez más establecida es el empleo de medidas para prevenir la producción de éstos o en caso de imposibilidad, procurar su valorización máxima. Por ello, entre los retos actuales se encuentran tratar de controlar la generación de residuos, desviar hacia otros tratamientos los residuos destinados a vertedero, y separar las sustancias peligrosas que puedan contener.

Los residuos sólidos son todos los elementos que surgen de las actividades humanas y animales, que normalmente son sólidos y que se desechan como inútiles o no queridos (Tchobanoglous et al., 1994). A medida que las sociedades van avanzando, los residuos que éstas generan son cada vez mayores y más difíciles de gestionar por su composición. En las sociedades antiguas, los residuos estaban basados en materiales totalmente naturales (madera, barro, fibras, alimentos), pero en la actualidad el empleo de metales, productos químicos, derivados del petróleo, materiales compuestos, etc. hacen que su gestión sea mucho más complicada. Además, el desarrollo de la sociedad tecnológica ha traído consigo un gran incremento en la producción de residuos, así como cambios importantes en su composición; los vertederos se agotan y cada vez es más difícil encontrar lugares que sean capaces de recoger la gran masa de basuras sin producir problemas ambientales (Hontaria, Zamorano, 2000).

Como se ha dicho, los residuos son uno de los principales problemas ambientales de la sociedad, en concreto en las zonas económicamente más avanzadas. Se trata de un problema en auge, que se agrava debido al creciente consumo y a la estrecha relación entre el nivel de renta y el volumen de residuos. Esta circunstancia se ve incrementada por la falta de concienciación ciudadana en esta materia, que dificulta en ocasiones la gestión óptima de determinados residuos.

De la mala gestión de los residuos se pueden derivar efectos dañinos para el medio ambiente. Por ejemplo, de los residuos orgánicos biodegradables se puede generar amoniaco y metano; si se trata de sustancias tóxicas, éstas pueden contaminar los suelos, las aguas o la atmósfera; el vertido incontrolado de muchos otros residuos especiales conlleva daños tales como la contaminación de las aguas y el suelo por lixiviación, etc.

Si a esto añadimos el hecho de que en todos los países avanzados, el aumento en la generación de residuos sigue siendo una realidad año tras año, se llega a la conclusión de la necesidad de 
regular con rigor, planificar de manera realista y controlar mediante indicadores los resultados que se obtengan. Así, los indicadores ambientales son instrumentos indispensables para los responsables políticos y su utilidad persigue los tres objetivos siguientes (Bosch et al., 1999):

- Proporcionar información sobre los problemas ambientales, a fin de que los responsables de las políticas ambientales valoren la gravedad de los mismos.

- Identificar los factores clave que influyen sobre el medio ambiente y establecer prioridades en la toma de decisiones.

- Evaluar la efectividad y cumplimiento de las políticas ambientales.

En los últimos años, el principal objetivo en la gestión de los residuos sólidos se centra en la reducción en la generación y en la valorización máxima de los recursos que contienen, buscando con ello reducir las aportaciones a vertedero, ya que siempre existen materiales que no han podido ser separados o que no se pueden reciclar más y cuyo principal destino suele ser el vertedero. Por ello, a nivel europeo, la legislación persigue de manera constante dar tratamientos alternativos a los residuos antes de su vertido o incineración final.

\subsubsection{Estrategia de la Unión Europea sobre la gestión de residuos.}

En el ámbito de la lucha contra el Cambio Climático, las actuaciones de las ciudades se centran en los sectores difusos de emisiones de GEI, constituyendo entre sus principales objetivos de reducción la gestión de residuos urbanos. El paquete de economía circular aprobado por el Parlamento Europeo y su Consejo el 30 de mayo de 2018 a través de sus directivas, 2018/849/CE, 2018/850/CE, 2018/851/CE , 2018/852/CE, establece la estrategia sobre la gestión de residuos fundamentada en la transición hacia un nuevo modelo basado en la jerarquía de prioridades.

Esta estrategia obliga, entre otros aspectos, a plantear nuevos sistemas de recogida de residuos y a incrementar la separación de fracciones, gracias a la implantación de nuevos sistemas como el sistema puerta a puerta o los contenedores inteligentes. Entre las principales líneas de actuación se encuentran:

- Compostaje doméstico o comunitario.

- Recogida separada de biorresiduo con dos destinos: compostaje y biometanización.

- Reducción de desperdicios alimentarios.

- Promoción de la recogida selectiva. 
Estas líneas de actuación, contribuyen además a la implementación de los 17 Objetivos de Desarrollo Sostenible (ODS) y 169 metas que, en el año 2015, las Naciones Unidas y los Estados Miembros adoptaron en la Agenda 2030 para el Desarrollo Sostenible para erradicar la pobreza, proteger el planeta y garantizar el bienestar de todos los que habitamos en él. Entre ellos, el ODS 12 se centra en la Producción y consumo responsables que incluye, a su vez, la meta 12.5 que establece que se debe reducir de aquí a 2030 la generación de desechos mediante actividades de prevención, reducción, reutilización y reciclado.

La gestión clásica de los residuos ha sido un problema en los países de mayor desarrollo debido a la incapacidad del sistema para dar soluciones efectivas a los problemas que se han generado. Si a esto añadimos la tendencia de reducir los consumos de recursos que mayormente no son renovables (combustibles fósiles y agua), el futuro de los sistemas de gestión de residuos debe basarse en la prevención de su generación bajo la filosofía de que "el residuo mejor gestionado es aquél que no se ha llegado a producir". La prevención tiene ventajas tanto de tipo medioambiental y económico como de salud pública.

En base a la jerarquía de la gestión de residuos establecida por la Unión Europea, el objetivo principal de todos los sectores implicados debe centrarse en la reducción de la producción y peligrosidad de los residuos (prevención y minimización). En segundo lugar, se debe enfocar hacia la reutilización y reciclaje de los materiales y de la capacidad energética de los residuos mediante su valorización y por último, se considerará la eliminación o vertido controlado.

Los tres tipos de niveles de esta jerarquía, que aparecen en la Figura 2.1, son los siguientes:

- Prevención: Se basa en la disminución del volumen, toxicidad y peligrosidad de los residuos generados. Es la forma más eficaz de disminuir la cantidad de residuos, el coste de su manipulación posterior y el consecuente impacto ambiental. En el anexo IV de la Ley 22/2011 de 29 de julio de residuos, se presentan medidas en cuanto a la prevención, que afectan a las condiciones de generación, al diseño, producción y distribución y medidas que afectan en la fase de consumo y utilización.

- Valorización máxima: Se realiza tratando de conseguir que los residuos generados se conviertan en subproductos, reciclando los materiales o recuperando los materiales y energía que contienen. Permite una reducción en la demanda de recursos naturales y en el volumen de residuos que requieren ser eliminados. Implica las siguientes acciones:

- Separación y recogida selectiva de los residuos.

- La preparación de los residuos seleccionados para su recuperación, reciclado y transformación en nuevos productos consumibles. 
- En este tipo de valorización se incluyen algunas transformaciones físicas, químicas o biológicas de los residuos, como por ejemplo la producción de compost en plantas de compostaje, la producción de biogás o la incineración con recuperación energética.

- Eliminación: Debe ser la última alternativa para determinados residuos que no pueden ser reciclados, han sido rechazos en la valorización energética, o son materiales residuales que quedan después de los procesos de recuperación. Aún a día de hoy las técnicas más habituales de eliminación de los residuos sólidos urbanos son el vertido y la incineración sin recuperación energética.

\section{JERARQUIA EUROPEA EN LA GESTIÓN DE RESIDUOS}

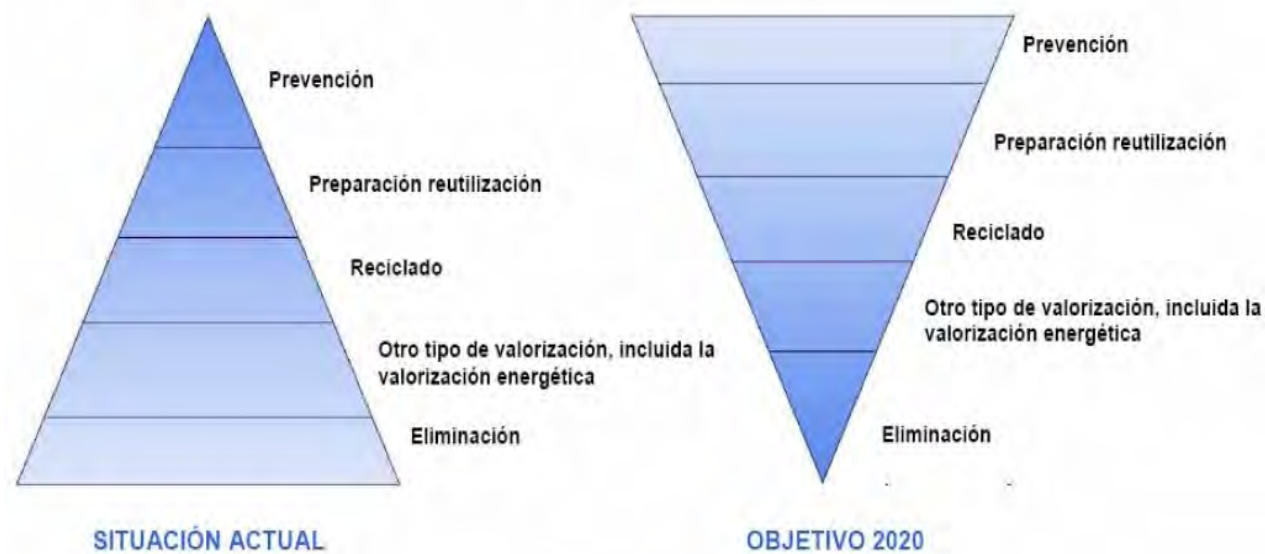

Figura 2.1: Jerarquía o prioridades en la Gestión de Residuos. Fuente: Programa Estatal de Prevención de Residuos 2014-2020, MAGRAMA, 2012.

Además, la estrategia plantea la cuestión de la responsabilidad de los productores. Si se tiene en cuenta el ciclo vital de un producto, desde su fabricación hasta el final de su vida útil, los fabricantes, distribuidores, los consumidores y administraciones públicas comparten responsabilidades en materia de gestión de residuos. Ahora bien, el papel principal se le otorga al fabricante, ya que le corresponde adoptar las decisiones fundamentales sobre el producto que determinan en gran parte su potencial en materia de gestión de residuos. Por consiguiente, este principio se integrará en las nuevas medidas, examinando cada caso concreto y teniendo en cuenta las responsabilidades específicas de los distintos agentes económicos.

La estrategia reconoce la necesidad de un control adecuado de los traslados de residuos con arreglo al marco jurídico definido en el Reglamento (CEE) $n^{\circ}$ 259/93. Hace hincapié en la 
consecución de garantizar un nivel elevado de protección del medio ambiente sin alterar el funcionamiento del mercado interior. En consecuencia, los residuos deberán eliminarse en una de las instalaciones adecuadas más próximas y los residuos producidos en la Comunidad Europea no deberán ser eliminados fuera de ésta. No obstante, estos principios no se aplican a los residuos destinados a la valorización, sino tan sólo a los que se destinen a la eliminación.

Según la Directiva 2018/851, por la que se modifica la Directiva 2008/98/ce sobre los residuos, se distinguen dos ramificaciones de la estrategia de gestión de éstos en función de las acciones que pretenden:

- Estrategias de prevención: Medidas orientadas a minimizar la producción y la peligrosidad de los residuos. "El mejor residuo es el que no se genera".

- Estrategias de tratamiento: Medidas tendentes a minimizar los efectos negativos de los residuos generados, y entre las que se incluyen las medidas de valorización (reciclaje de materiales y recuperación de materia y de contenidos energéticos de los residuos) y la eliminación segura de aquellos residuos no valorizables.

Ambas se deben desarrollar en los Planes de residuos Nacionales, Autonómicos y Locales, y son objeto de análisis en los siguientes apartados.

\subsubsection{Planes Integrales de Residuos.}

La finalidad de un Plan de Residuos es la de promover una política adecuada en la gestión de los residuos, disminuyendo su generación e impulsando un correcto tratamiento de los mismos. Así mismo, requiere de la implicación de administraciones públicas, consumidores y usuarios, con objeto de que todos ellos asuman responsabilidades, impulsando la creación de infraestructuras que garanticen este correcto tratamiento y gestión de los residuos en los lugares más próximos a su generación.

La Directiva 2008/98/CE incorpora la obligación de establecer planes de prevención y gestión de residuos, que deben integrar en su proceso de desarrollo o revisión la toma en consideración de los impactos medioambientales asociados a su generación y gestión. En esta línea, el 6 de noviembre de 2015 se aprobó el Plan Estatal Marco de Gestión de Residuos (PEMAR) 2016-2022 que sustituye al Plan Nacional Integrado de Residuos (PNIR) 2008-2015. Este nuevo Plan, introduce algunas modificaciones para mejorar y actualizar la información relativa a la producción y gestión de residuos. Además, incluye las previsiones sobre la evaluación de la generación de residuos y su tratamiento y trata de asegurar que se cumplan los objetivos en los plazos establecidos (MITECO, 2016). 
EI PEMAR se enmarca en la Directiva Marco de Residuos de la Unión Europea, con la que comparte el objetivo de cambiar el enfoque de la gestión de residuos, dejando atrás el modelo actual basado en producir, consumir y tirar, para sustituirlo por una economía circular. De este modo se tratan de reincorporar al proceso productivo una y otra vez los materiales que contienen los residuos, para la producción de nuevos productos o materias primas, creando con ello una sociedad eficiente en el uso de los recursos.

Por su parte, La Ley 22/2011, de 28 de julio, de residuos y suelos contaminados, establece que corresponde a las comunidades autónomas la elaboración de los programas de prevención de residuos, y de los planes autonómicos de gestión de residuos. Los primeros son un instrumento novedoso introducido por la Directiva marco de residuos, incidiendo así en la trascendencia de las políticas de prevención. Además, en el artículo 14, establece que "los planes autonómicos de gestión contendrán un análisis actualizado de la situación de la gestión de residuos en el ámbito territorial de la Comunidad Autónoma, así como una exposición de las medidas para facilitar la reutilización, el reciclado, la valorización y la eliminación de los residuos, estableciendo objetivos de prevención, preparación para la reutilización, reciclado, valorización y eliminación y la estimación de su contribución a la consecución de los objetivos establecidos en esta Ley, en las demás normas en materia de residuos y en otras normas ambientales".

En definitiva, los planes de gestión de residuos nacionales y autonómicos tienen que desempeñar un papel clave en la gestión sostenible de los residuos y encontrarse en línea con la legislación comunitaria sobre residuos. Su principal objetivo es dar una visión general de todos los residuos generados y las opciones de tratamiento para estos residuos. Así, los planes que se desarrollen proporcionarán un marco para:

- El cumplimiento de la política de residuos y de los objetivos propuestos.

- Inventario de la situación de los residuos y de la capacidad de su gestión.

- Detección de las necesidades futuras.

- Establecer las líneas generales para la gestión de residuos de envases.

- Desarrollar las líneas generales para la gestión de los residuos biodegradables.

- Información sobre las políticas de gestión de residuos en general y medidas tecnológicas.

Por último, a continuación se detallan las cantidades de residuos en España del año 2017, por generación y tratamiento (último dato disponible del Instituto Nacional de Estadística), que son una muestra de la necesidad de continuar implementando planes y programas en aras a minimizar la generación y mejorar la separación de las diferentes fracciones existentes. 


\begin{tabular}{|c|c|c|c|c|}
\hline Modalidad recogida & & Código LER-RESIDUO & t/año & $\%$ \\
\hline Residuos mezclados & 20.03 .01 & Mezclas de residuos municipales & 17.457.709 & 84 \\
\hline \multirow{6}{*}{$\begin{array}{l}\text { Residuos recogidos } \\
\text { selectivamente }\end{array}$} & 20.01 .01 & Papel y cartón & 1.061 .380 & \multirow[b]{7}{*}{100} \\
\hline & 20.01 .02 & Vidrio & 13.176 & \\
\hline & 20.01 .08 & Residuos biodegradables de cocinas y restaurantes & 610.043 & \\
\hline & 20.02 .01 & Residuos biodegradables de parques y jardines & 266.779 & \\
\hline & 15.01 .06 & Envases mezclados & 660.932 & \\
\hline & 15.01 .07 & Envases de vidrio & 802.706 & \\
\hline \multicolumn{3}{|l|}{ TOTAL } & 20.872 .724 & \\
\hline
\end{tabular}

Tabla 2.1: Cantidad de residuos de competencia municipal recogidos en España en 2017.

Como se puede observar en la Tabla 2.1, pese a los esfuerzos de las administraciones en materia de concienciación y dotación de contenedores de selectiva, la fracción resto (residuos mezclados) continúa siendo la que representa el mayor porcentaje en cuanto a residuos generados. 
Estado del arte.

\begin{tabular}{|c|c|c|c|c|c|c|c|}
\hline \multirow[b]{2}{*}{ CCAA } & $220101 / 150101$ & 200102 & 200108 & 200201 & 150106 & 150107 & \multirow[b]{2}{*}{ TOTAL } \\
\hline & Papel/cartón & Vidrio & $\begin{array}{l}\text { Residuos } \\
\text { biodegrad. } \\
\text { de cocinas y } \\
\text { restaurantes }\end{array}$ & $\begin{array}{c}\text { Residuos } \\
\text { biodegrad. } \\
\text { de parques y } \\
\text { jardines }\end{array}$ & $\begin{array}{c}\text { Envases } \\
\text { mezcla }\end{array}$ & $\begin{array}{l}\text { Envases } \\
\text { de Vidrio }\end{array}$ & \\
\hline Andalucía & 102.877 & 0 & 78.360 & 13.685 & 85.646 & 91.570 & 372.138 \\
\hline Aragón & 26.725 & 167 & 107 & 1.431 & 16.236 & 18.030 & 62.697 \\
\hline Asturias & 53.924 & 42 & 2.515 & 15.711 & 11.443 & 32.089 & 115.723 \\
\hline Baleares & 45.630 & 11 & 18.825 & 24.004 & 31.911 & 38.629 & 159.009 \\
\hline Canarias & 31.954 & 42 & 514 & 21.298 & 20.067 & 38.845 & 112.722 \\
\hline Cantabria & 4.053 & 196 & 0 & 3.035 & 5.748 & 10.784 & 23.816 \\
\hline Castilla La Mancha & 31.374 & 0 & 0 & 3.131 & 19.696 & 21.371 & 75.573 \\
\hline Castilla y León & 45.179 & 0 & 0 & 4.204 & 23.634 & 48.353 & 121.370 \\
\hline Cataluña & 296.067 & 10.406 & 405.183 & 60.047 & 141.409 & 172.354 & 1.085 .466 \\
\hline Ceuta & 3.896 & 0 & 0 & 0 & 0 & 0 & 326 \\
\hline C. de Madrid & 99.641 & 1.582 & 2.089 & 52.437 & 140.324 & 87.602 & 383.676 \\
\hline C. Foral Navarra & 26.211 & 9 & 23.656 & 10.534 & 21.217 & 16.170 & 97.798 \\
\hline C. Valenciana & 60.081 & 484 & 24.978 & 39.105 & 44.216 & 82.286 & 251.150 \\
\hline Extremadura & 31.576 & 0 & 0 & 0 & 11.776 & 7.943 & 51.295 \\
\hline Galicia & 33.262 & 0 & 44.162 & 3.115 & 23.194 & 43.307 & 147.039 \\
\hline La Rioja & 7.971 & 0 & 0 & 0 & 4.989 & 8.570 & 21.530 \\
\hline Melilla & 2.810 & 0 & 0 & 0 & 0 & 0 & 2.810 \\
\hline País Vasco & 139.386 & 212 & 9.654 & 10.228 & 43.283 & 59.691 & 262.454 \\
\hline Región de Murcia & 18.764 & 25 & 0 & 4.812 & 16.144 & 24.785 & 64.529 \\
\hline TOTAL & 1.061 .380 & 13.176 & 610.043 & 266.779 & 660.932 & 802.706 & 3.415 .016 \\
\hline
\end{tabular}

Tabla 2.2: Recogidas selectivas por Comunidad Autónoma (t). 2017.

A la vista de los datos de la Tabla 2.2, es muy destacable la posición de la Comunidad Autónoma de Cataluña como líder en cuanto a separación en origen. Esto se debe a que desde hace años es la comunidad en la que se está haciendo un mayor esfuerzo político y normativo en materia de sostenibilidad. 


\begin{tabular}{|l|r|r|}
\hline \multicolumn{1}{|c|}{ Instalaciones de tratamiento de residuos } & N. ${ }^{\circ}$ de instalaciones & Entrada (t/año) \\
\hline Instalaciones de clasificación de envases & 660.932 \\
\hline Instalaciones de triaje & 63 & 1.052 .138 \\
\hline $\begin{array}{l}\text { Instalaciones de compostaje de fracción orgánica recogida } \\
\text { separadamente }\end{array}$ & 417.863 \\
\hline Instalaciones de triaje y compostaje & 66 & 8 \\
\hline $\begin{array}{l}\text { Instalaciones de triaje, biometanización y compostaje de } \\
\text { fracción orgánica recogida separadamente }\end{array}$ & 8.617 .873 \\
\hline Instalaciones de triaje, biometanización y compostaje & 260.761 \\
\hline Instalaciones de incineración & 21 & 10 \\
\hline Vertederos & 3.184 .152 \\
\hline
\end{tabular}

Tabla 2.3: Residuos de competencia municipal tratados según tipo de instalación. 2017.

Como se puede observar en la Tabla 2.3, las aportaciones a vertedero son las mayores de todas, seguidas de las que se realizan a plantas de triaje y compostaje. Las de menor aportación son las de instalaciones de triaje, biometanización y compostaje de fracción orgánica, ya que este sistema está todavía por desarrollar en el ámbito de los RSU. Por otro lado, se observa un número elevado de plantas de clasificación de envases, aunque con una baja aportación, y de instalaciones de triaje y compostaje. Este elevado número de instalaciones no se corresponde con la gran cantidad de toneladas que terminan en vertedero, debido al bajo rendimiento de las mismas que oscila entre el $30 \%$ y el $70 \%$ en función del tipo de planta (Edo, 2019).

\subsubsection{Marco legislativo.}

La normativa comunitaria, estatal y autonómica es extensa. A modo de resumen, a continuación se presenta un listado con la más relevante de los últimos años en esta materia según su origen:

\section{DIRECTIVAS U.E.}

- Directiva 75/439/CEE del Consejo, de 6 de junio de 1975, relativa a la gestión de aceites usados.

- Directiva 87/101/CEE del Consejo, de 22 de diciembre de 1986, por la que se modifica la Directiva 75/439/CEE del Consejo, de 6 de junio de 1975, relativa a la gestión de aceites usados.

- Directiva 94/62/CE, del Parlamento Europeo y del Consejo, de 20 de diciembre de 1994, relativa a los envases y residuos de envases. 
- Directiva 99/31/CE del Consejo, de 26 de abril de 1999, relativa al vertido de residuos sólidos urbanos.

- Directiva 2000/76/CE del Parlamento y del Consejo de 4 de diciembre de 2000, relativa a la incineración de residuos.

- Directiva 2002/95/CE del Parlamento Europeo y del Consejo, de de 27 de enero de 2003, sobre restricción a la utilización de determinadas sustancias peligrosas en determinados aparatos eléctricos y electrónicos (RAEE).

- Directiva 2002/96/CE del Parlamento Europeo y del Consejo, de 27 de enero de 2003, sobre residuos de aparatos eléctricos y electrónicos (RAEE).

- Directiva 2003/108/CE, del Parlamento Europeo y del Consejo, de 8 de diciembre de 2003, por la que se modifica la Directiva 2002/96/CE, sobre residuos de aparatos eléctricos y electrónicos (RAEE).

- Directiva 2004/12/CE del Parlamento Europeo y del Consejo, de 11 de febrero de 2004, por la que se modifica la Directiva 94/62/CE, del Parlamento Europeo y del Consejo, de 20 de diciembre de 1994, relativa a los envases y residuos de envases.

- Directiva 2005/20/CE del Parlamento Europeo y del Consejo de 9 de marzo de 2005, por la que se modifica la Directiva 94/62/CE, del Parlamento Europeo y del Consejo, de 20 de diciembre de 1994, relativa a los envases y residuos de envases.

- Directiva 2006/12/CE del Parlamento Europeo y del Consejo de 5 de abril de 2006 relativa a los residuos.

- Directiva 2006/66/CE del Parlamento Europeo y del Consejo de 6 de septiembre de 2006, relativa a las pilas y acumuladores y a los residuos de pilas y acumuladores y por la que se deroga la Directiva 91/157/CEE.

- Directiva 2008/1/CE del Parlamento Europeo y del Consejo, de 15 de enero de 2008, relativa a la prevención y al control integrados de la contaminación.

- Directiva 2008/12/CE del Parlamento Europeo y del Consejo de 11 de marzo de 2008, por la que se modifica la Directiva 2006/66/CE del Parlamento Europeo y del Consejo de 6 de septiembre de 2006, relativa a las pilas y acumuladores y a los residuos de pilas y acumuladores.

- Directiva 2008/34/CE del Parlamento Europeo y del Consejo de 11 de marzo de 2008, por la que se modifica la Directiva 2006/96/CE sobre residuos de aparatos eléctricos y electrónicos.

- Directiva 2008/35/CE del Parlamento Europeo y del Consejo de 11 de marzo de 2008, por la que se modifica la Directiva 2002/95/CE sobre restricciones a la utilización de determinadas sustancias peligrosas en aparatos eléctricos y electrónicos. 
- Directiva 2008/98/CE del Parlamento Europeo y del Consejo, de 19 de noviembre de 2008, sobre los residuos y por la que se derogan determinadas directivas.

- Directiva 2008/103/CE del Parlamento Europeo y del Consejo, de 19 de noviembre de 2008, por la que se modifica la Directiva 2006/66/CE del Parlamento Europeo y del Consejo de 6 de septiembre de 2006, relativa a las pilas y acumuladores y a los residuos de pilas y acumuladores.

- Directiva 2009/1/CE, de la Comisión del 7 de enero de 2009, por la que se modifica para su adaptación al progreso técnico la Directiva 2005/64/CE del Parlamento Europeo y del Consejo, relativa a la homologación de tipo de los vehículos de motor en lo que concierne a su aptitud para la reutilización, el reciclado y la valoración.

- Directiva 2012/19/UE del Parlamento y del Consejo de 4 de julio de 2012, sobre residuos de aparatos eléctricos y electrónicos.

- Directiva 2013/2/UE de la Comisión de 7 de febrero de 2013, por la que se modifica el Anexo I de la Directiva 94/62/CE del Parlamento Europeo y del Consejo relativa a los envases y residuos de envases.

- Directiva 2013/56/UE del Parlamento y del Consejo de 20 de noviembre de 2013, por la que se modifica la Directiva 2006/66/CE del Parlamento Europeo y del Consejo de 6 de septiembre de 2006, relativa a las pilas y acumuladores y a los residuos de pilas y acumuladores.

- Directiva 2018/849/UE del Parlamento Europeo y del Consejo de 30 de mayo de 2018 por la que se modifica la Directiva 2000/53/CE, la Directiva 2006/66/CE y la Directiva 2012/19/UE.

- Directiva 2018/850/UE del Parlamento Europeo y del Consejo de 30 de mayo de 2018, por la que se modifica la Directiva 1999/31/CE relativa al vertido de residuos.

- Directiva 2018/851/UE del Parlamento Europeo y del Consejo de 30 de mayo de 2018, por la que se modifica la Directiva 2008/98/CE sobre residuos.

- Directiva 2018/852/UE del Parlamento Europeo y del Consejo de 30 de mayo de 2018, por la que se modifica la Directiva 94/92/CE relativa a los envases y residuos de envases.

\section{REGLAMENTOS U.E.}

- Reglamento (CE) n. ${ }^{\circ} 1192 / 2006$ de la Comisión de 4 de agosto de 2006, por el que se aplica el Reglamento de la CE n. ${ }^{\circ} 1774 / 2002$ del Parlamento Europeo y del Consejo, en lo que se refiere a las listas de plantas autorizadas en los Estados Miembros. 
- Reglamento (UE) $n^{\circ}$ 849/2010 de la Comisión, de 27 de septiembre de 2010 , por el que se modifica el Reglamento (CE) $n^{\circ}$ 2150/2002 del Parlamento Europeo y del Consejo, relativo a las estadísticas sobre residuos.

- Reglamento (UE) No 493/2012 de la comisión de 11 de junio de 2012 por el que se establecen, de conformidad con la Directiva 2006/66/CE del Parlamento Europeo y del Consejo, normas detalladas para el cálculo de los niveles de eficiencia de los procesos de reciclado de los residuos de pilas y acumuladores.

\section{DECISIONES U.E.}

- Decisión 2001/118/CE de la Comisión de 16 de enero de 2001, por la que se modifica la Decisión 2000/532/CE en lo que se refiere a la lista de residuos.

- Decisión 2001/119/CE de la Comisión de 22 de enero de 2001, que modifica la Decisión 2000/532/CEE.

- Decisión 1600/2002/CE del Parlamento y del Consejo, de 22 de julio de 2002, por el que se establece el Sexto Programa en Materia Comunitaria de Medio Ambiente.

- Decisión 2003/33/CE del Consejo de 19 de diciembre de 2002, por el que se establecen los criterios y procedimiento de admisión de residuos en los vertederos de acuerdo con el artículo 16 y el Anexo II de la Directiva 1999/31/CEE.

- Decisión 2014/955/UE de la Comisión de 18 de diciembre de 2014, por el que se modifica la Decisión 2000/532/CEE, sobre la lista de residuos, de conformidad con la Directiva 2008/98/CE.

\section{LEGISLACIÓN NACIONAL.}

- Ley 11/1997, de 24 de abril, de envases y residuos de envases.

- Ley 22/2011, de 28 de julio, de residuos y suelos contaminados.

- Ley 11/2012, de 19 de diciembre, de medidas urgentes en materia de medio ambiente.

- Ley 5/2013, de 11 de junio, por la que se modifican la Ley 16/2002 de 1 de julio, de prevención y control integrados de la contaminación, y la Ley 22/2011, de 28 de julio, de residuos y suelos contaminados.

- REAL DECRETO 782/1998, de 30 de abril, por el que se aprueba el Reglamento para el desarrollo y ejecución de la Ley 11/1997, de 24 de abril, de Envases y Residuos de Envases. 
- Real Decreto 782/1998, de 30 de abril, por el que se aprueba el Reglamento para el desarrollo y ejecución de la Ley 11/1997, de 24 de abril, de Envases y Residuos de Envases.

- Real Decreto 646/2020, de 7 de julio, por el que se regula la eliminación de residuos en vertedero.

- Real Decreto 1619/2005, de 30 de diciembre, sobre la gestión de neumáticos fuera de uso.

- Real Decreto 252/2006, de 3 de marzo, por el que se revisan los objetivos de reciclado y valorización establecidos en la Ley 11/1997, de 24 de abril, de Envases y Residuos de Envases y por el que se modifica el Reglamento para su ejecución aprobado por Real Decreto 782/1998, de 30 de abril.

- Real Decreto 105/2008, de 1 de febrero, por el que se regula la producción y gestión de los residuos de construcción y demolición.

- Real Decreto 106/2008, de 1 de febrero, sobre pilas y acumuladores y la gestión ambiental de sus residuos.

- Real Decreto 943/2010, de 23 de julio, por el que se modifica el Real Decreto 106/2008, de 1 de febrero, sobre pilas y acumuladores y la gestión ambiental sobre sus residuos.

- Real Decreto $1436 / 2010$, de 5 de noviembre, por el que se modifican diversos reales decretos para su adaptación a la Directiva 2008/112/CE, del Parlamento Europeo y del Consejo, que modifica varias directivas para adaptarlas al Reglamento (CEE) n. ${ }^{\circ}$ $1272 / 2008$, sobre clasificación, etiquetado y envasado de sustancias y mezclas.

- Real Decreto 110/2015, de 20 de febrero, sobre residuos de aparatos eléctricos y electrónicos

- Real Decreto 180/2015, de 13 de marzo, por el que se regula el traslado de residuos en el interior del territorio del Estado.

- Real Decreto 710/2015, de 24 de julio, por el que se modifica el Real Decreto 106/2008, de 1 de febrero sobre pilas y acumuladores y la gestión ambiental de sus residuos

- Real Decreto 27/2021, de 19 de enero, por el que se modifican el Real Decreto 106/2008, de 1 de febrero, sobre pilas y acumuladores y la gestión ambiental de sus residuos, y el Real Decreto 110/2015, de 20 de febrero, sobre residuos de aparatos eléctricos y electrónicos.

- Orden 27 de abril de 1998, por la que se establecen las cantidades individualizadas a cobrar en concepto de depósito y el símbolo identificativo de los envases que se pongan en el mercado a través de un sistema de depósito, devolución y retorno regulado por la Ley 11/1997, de 24 de abril, de Envases y Residuos de Envases. 
- ORDEN de 12 junio de 2001 por la que se establecen las condiciones para la no aplicación a los envases de vidrio de los niveles de concentración de metales pesados establecidos en el artículo 13 de la Ley 11/1997, de 24 de abril de Envases y Residuos de Envases.

- Orden MAM/304/2002, de 8 de febrero, por la que se publican las operaciones de valorización y eliminación de residuos y la lista europea de residuos.

- Orden AAA/1783/2013, de 1 de octubre, por la que se modifica el Anejo I del Reglamento para el desarrollo y ejecución de la Ley 11/1997, de 24 de abril de Envases y Residuos de Envases aprobado por Real Decreto 782/1998, de 30 de abril.

- Orden AAA/699/2016 de 9 de mayo por la que se modifica la operación R1 del Anexo II de la Ley 22/2011, de 28 de julio de residuos y suelos contaminados.

- RESOLUCIÓN de 20 de enero de 2009, de la Secretaría de Estado de Cambio Climático, por la que se publica el Acuerdo del Consejo de Ministros por el que se aprueba el Plan Nacional Integrado de Residuos para el período 2008-2015.

- Resolución de 16 noviembre de 2015, de la Dirección General de la Calidad Ambiental y Evaluación Ambiental y Medio Natural, por la que se publica el Acuerdo del Consejo de Ministros de 6 de noviembre de 2015, por el que se aprueba el Plan Estatal Marco de Gestión de Residuos (PEMAR) 2016-2022.

\section{NORMATIVA AUTONÓMICA.}

- Ley 10/2000 de 12 de diciembre, de Residuos de la Comunidad Valenciana.

- Decreto 240/1994, de 22 de noviembre, del Gobierno Valenciano, por el que se aprueba el Reglamento Regulador de la Gestión de Residuos Sanitarios.

- Decreto 218/1996, de 26 de noviembre, del Gobierno Valenciano, por el que se designa en el ámbito de la CV el organismo competente para efectuar las funciones a que se refiere el Reglamento CEE 259/93, de 1 de febrero relativo a la vigilancia y control de los traslados de residuos en el interior, a la entrada y a la salida de la Comunidad Europea.

- Decreto 81/2013, de 21 de junio, del Consell, de aprobación definitiva del Plan Integral de Residuos de la Comunitat Valenciana.

- Decreto 22/2015, de 13 de febrero, del Consell, por el que se regulan las funciones y el Registro de Entidades Colaboradoras en materia de calidad ambiental de la Comunitat Valenciana.

- Decreto-Ley 4/2016, de 10 de junio, del Consell, por el que se establecen las medidas urgentes para garantizar la gestión de residuos municipales. 
- Decreto 55/2019, de 5 de abril, del Consell, por el que se aprueba la Revisión del Plan Integral de Residuos de la Comunitat Valenciana.

\subsection{La gestión de los residuos.}

\subsubsection{Generalidades.}

En la antigüedad, la evacuación de residuos no planteaba grandes problemas debido al tamaño reducido de la población y la disponibilidad de terreno. Por otra parte, los productos empleados eran de origen natural, con lo que podían ser directamente devueltos al medio ambiente mediante el ciclo natural de los mismos. Es decir, el volumen generado podía ser absorbido gracias a la capacidad autodepurativa del medio así como para la agricultura y ganadería.

La sociedad actual genera cientos de toneladas de residuos en todas las actividades. A cualquier nivel, la necesidad de almacenar y eliminar ciertas sustancias $u$ objetos se convierte en un problema. Es por esto que las sociedades realizan grandes esfuerzos en materia de gestión de residuos, para preservar la calidad de vida, la salud humana y las condiciones medio ambientales. Además, la evolución cambia los comportamientos en cuanto al tipo de actividades o al tipo de recursos que se utilizan y como consecuencia, surgen nuevos residuos que precisan de ser desprendidos al final de su vida útil y podrían requerir un nuevo tratamiento distinto.

No hay duda que los recursos naturales requieren un tiempo de regeneración para volver a su estado inicial. Algunos de los recursos son renovables pero otros están disponibles de manera limitada, ya que la capacidad de regeneración de dicho recurso es mucho menor a la velocidad de extracción. Desde un punto de vista sostenible, independientemente de que un recurso consumido sea renovable o no, se debe aprovechar mejor los recursos mediante la recuperación o reutilización de materiales o sustancias para otros usos.

Por ello, los residuos deben controlarse de manera que el impacto medioambiental sea lo menor posible, se garantice de manera sostenible el bienestar y se asegure la salud de los seres vivos. 


\subsubsection{Concepto y clasificación de residuos.}

Cualquier producto, material, sustancia o elemento, después de abandonar su proceso de fabricación, manipulación o que haya llegado al fin de su vida útil y ya no posea el valor para el cual ha sido empleado, puede considerarse residuo. La Ley 22/2011 de 28 de julio de residuos y suelos contaminados define el concepto de residuo como "cualquier sustancia u objeto que su poseedor deseche o tenga la intención o la obligación de desechar".

El concepto de residuos sólidos incluye todos los materiales sólidos que el poseedor ya no considera de valor lo suficientemente útil como para retenerlo. El diseño de los elementos necesarios para la gestión de residuos está condicionado por el conocimiento sobre los tipos de residuos que pueden tener diferentes orígenes, así como su cantidad y composición. Para ello, es vital realizar una clasificación de los residuos basada en dos criterios, origen y peligrosidad. La clasificación según su origen es la considerada tradicional y la clasificación según su peligrosidad se determina según los criterios marcados por la Unión Europea. No obstante, la evolución de la sociedad y los hábitos de consumo pueden generar cambios en los tipos de residuos y esta clasificación podría requerir modificaciones, así como cambios en la normativa.

Según su origen, la Ley 22/2011 de Residuos y Suelos contaminados establece las siguientes categorías:

- Residuos domésticos: son los "residuos generados en los hogares como consecuencia de las actividades domésticas. Se consideran también residuos domésticos los similares a los anteriores generados en servicios e industrias. Se incluyen también en esta categoría los residuos que se generan en los hogares de aparatos eléctricos y electrónicos, ropa, pilas, acumuladores, muebles y enseres así como los residuos y escombros procedentes de obras menores de construcción y reparación domiciliaria".

"Tendrán la consideración de residuos domésticos los residuos procedentes de limpieza de vías públicas, zonas verdes, áreas recreativas y playas, los animales domésticos muertos y los vehículos abandonados".

- Residuos comerciales: Según la definición de la propia Ley son los "Residuos generados por la actividad propia del comercio, al por mayor y al por menor, de los servicios de restauración y bares, de las oficinas y de los mercados, así como del resto del sector servicios".

- Sanitarios: Obviamente, son los que proceden de los hospitales, ambulatorios, centros de asistencia, etc. Normalmente, consisten en restos de comida, vidrio, envases, yesos, 
textiles y otro tipo de residuos peligrosos como restos anatómicos, sangre, fármacos, residuos líquidos, etc. La normativa a nivel del Estado Español es heterogénea, ya que poseen normativa específica en varias comunidades, entre ellas la Valenciana.

Dentro de esta tipología de residuos, se establecen cuatro grupos:

- Grupo I: asimilables a urbanos.

- Grupo II: incluye a residuos asimilables a urbanos, pero propios de la actividad sanitaria y que podrían ser peligrosos para personas enfermas o con pocas defensas: vendas, ropa, guantes o material desechable impregnado de sangre o secreciones.

- Grupo III: formado por residuos punzantes o cortantes y por residuos infecciosos capaces de transmitir determinadas enfermedades como cólera, meningitis, brucelosis, difteria, hepatitis vírica, etc.

- Grupo IV: residuos peligrosos excepto los incluidos en el grupo III, incluidos los de medicamentos citotóxicos y citostáticos.

La gestión de los Grupos I, II y IV se rige por la normativa genérica de residuos, mientras que los del Grupo III son sometidos a tratamientos de esterilización mediante presión y temperatura, para a continuación ser triturados y gestionados como residuos municipales.

- Construcción: Generalmente son restos minerales procedentes de construcciones, obras, derribos, etc.

Los residuos de la construcción y demolición (RCD) han de gestionarse en el marco del Real Decreto 105/2008, de 1 de febrero, por el que se regula la producción y gestión de los residuos de construcción y demolición y de la Orden APM/1007/2017, de 10 de octubre, sobre normas generales de valorización de materiales naturales excavados para su utilización en operaciones de relleno y obras distintas a aquéllas en las que se generaron. La mayor parte de los producidos en este sector son residuos inertes: ladrillo y otros componentes cerámicos, hormigón y tierra. El resto se completa con los residuos de envases (plástico, vidrio, cartón y papel, madera), metal y yeso. Pero también pueden contener residuos peligrosos, generados en mucho menor volumen, entre los que encontramos aditivos para el hormigón, sellantes, adhesivos, estructuras que contienen amianto (fibrocemento), aparatos o equipos con PCB's, disolventes, pinturas o los envases que han contenido los productos antes mencionados.

Respecto a la gestión de estos residuos, la responsabilidad del productor finaliza cuando le hace entrega a una empresa o entidad autorizada para el almacenamiento o tratamiento por la administración competente, que en este caso son las comunidades autónomas. 
- Agropecuarios: Proceden de la agricultura, actividades de ganadería, granjas, etc. Consisten en restos vegetales, materias fecales, animales muertos, plásticos de envases e invernaderos, etc. Mayoritariamente los sectores hortofrutícola, el de fabricación de zumos, de conservas o industria cervecera, se destinan a la alimentación animal, principalmente rumiantes, donde el aumento del precio de los cereales de los últimos años ha provocado una substitución de éstos por subproductos vegetales (Cerisuelo y Piquer, 2009).

- Mineros: Según el Real Decreto 975/2009, de 12 de junio, sobre gestión de los residuos de las industrias extractivas y de protección y rehabilitación del espacio afectado por actividades mineras, son los residuos que proceden de las explotaciones de canteras y minas. Consisten mayoritariamente en lodos, tierras y rocas.

- Radiactivos: Proceden de las centrales nucleares, laboratorios, clínicas, hospitales, industria e investigación. Existen dos grandes grupos dentro de esta categoría, los de baja/media actividad (periodo de semidesintegración inferior a 30 años) y los de alta actividad (periodo de semidesintegración superior a 30 años).

En función de la peligrosidad, se establece la siguiente clasificación de residuos:

- Residuos peligrosos: según la Ley 22/2011 de 28 de Julio de residuos y suelos contaminados, "residuo que presenta una o varias de las características peligrosas enumeradas en el anexo III, y aquél que pueda aprobar el Gobierno de conformidad con lo establecido en la normativa europea o en los convenios internacionales de los que España sea parte, así como los recipientes y envases que los hayan contenido".

- Residuos no peligrosos: Son aquellos que no tienen calificación de peligrosos de acuerdo con la definición anterior. Dentro de este grupo se encontrarán los residuos inertes que se definen como aquellos que por su naturaleza o composición no experimentan transformaciones físicas, químicas o biológicas significativamente importantes. Los inertes no son solubles, no son biodegradables, no afectan negativamente a otras materias con las que puedan entrar en contacto de forma que pueden dar lugar a contaminación del medio o perjudicar a la salud humana.

Según el Anexo III de la Ley 22/2011, de 28 de julio sobre residuos y suelos contaminados, modificado por el Reglamento 1357/2014 de 18 de diciembre de 2014, un residuo no peligroso deberá cumplir las siguientes condiciones:

- Punto de inflamación mayor a $55^{\circ} \mathrm{C}$.

- Un pH entre 2 y 12,5 . 
- No ser corrosivo, no causar daño a los tejidos humanos, no ser reactivo, no contener sustancias que generen gases tóxicos, no ser explosivo, no contener productos cancerígenos o sustancias mutagénicas o teratogénicas.

- Baja toxicidad.

- Lixiviados de baja toxicidad.

- Residuos inertes: Provienen normalmente de la extracción, procesamiento o utilización de los recursos minerales, como los de la construcción, demolición, etc. Son no biodegradables e incombustibles (Hontaria, Zamorano, 2000).

\subsubsection{La gestión integral de residuos sólidos urbanos.}

Los residuos sólidos urbanos (RSU) son aquellas sustancias y objetos de los cuales su poseedor se desprenda o tenga la obligación de desprenderse dentro el ámbito urbano. Incluyen los residuos domésticos, comerciales, sanitarios y residuos de obras menores. La gestión de los RSU, se puede definir como el camino recorrido por los residuos desde su generación hasta su disposición final, incluyendo en los últimos tiempos el aprovechamiento de algunos de sus constituyentes (Hontoria, Zamorano, 2000). Esta gestión comprende diferentes etapas, desde su generación hasta el tratamiento final.

Las actividades que son propias de la gestión de RSU son las siguientes: generación, manipulación y separación en origen, recolección, transporte, transferencia, valorización y eliminación. Cuando todos estos aspectos han sido evaluados para su uso, la gestión integral de RSU (GIRSU) puede ser definida como la selección y aplicación de técnicas, tecnologías y programas de gestión idóneos para lograr metas y objetivos específicos de gestión de residuos (Tchobanoglous et al., 1994).

La GIRSU comprende todas las funciones administrativas, económicas y técnico-legales relacionadas con los residuos. Las soluciones pueden conllevar relaciones complejas entre la política, el urbanismo, los servicios públicos o las redes de infraestructuras.

Debe destacarse, respecto a la generación, la importancia de la reducción en el origen, ya que se encuentra en el primer lugar en la jerarquía, porque es la forma más eficaz de reducir la cantidad y toxicidad de residuos, el coste asociado a su manipulación y los impactos ambientales (Rodríguez, H., 2012). Respecto a la separación y recogida de materiales en origen, facilitará la preparación de estos materiales para la reutilización y transformación en nuevos productos. 
Como se verá más adelante, la valorización es un factor importante para ayudar a conservar y reducir la demanda de recursos naturales, así como el consumo de energía, reduciendo las aportaciones a vertido final y por tanto la contaminación asociada. Con el fin de obtener a partir de los RSU productos que puedan tener un interés económico, al mismo tiempo que se minimiza su vertido, éstos pueden someterse a distintos procesos de tratamiento. La alternativa de tratamiento más adecuada se elegirá en función del objetivo establecido en los planes integrales de gestión de RSU. No obstante, ésta también puede variar de unas regiones a otras en función de factores socio-económicos y culturales (Montejo Méndez, 2015). Siempre existirá un rechazo final en la gestión integral y son aquellos residuos que no tienen ningún uso adicional, en este caso se debe garantizar el vertido controlado o la incineración.

La gestión adecuada por parte de las administraciones públicas en la recogida y tratamiento de los RSU y su incidencia en el medioambiente, es un factor clave en los momentos actuales en los que se pretende avanzar hacia un nuevo modelo de economía circular, que genera interés y preocupación en los ciudadanos (Rodríguez-Martín et al., 2020). En la Unión Europea (UE), la gestión sostenible de los RSU es una de las principales preocupaciones medioambientales, por lo que la regulación en materia de gestión de residuos desempeña un papel fundamental (Sastre et al., 2018). En esta línea, la Directiva 2008/98/CE sobre residuos (Parlamento Europeo y Consejo de la Unión Europea, 2008), modificada por la Directiva 2018/851/UE (Parlamento Europeo y Consejo de la Unión Europea, 2018), son las leyes fundamentales en este contexto. En ellas se establece la obligatoriedad para los estados miembros de fomentar el desarrollo de tecnologías sostenibles, la prevención de la generación de residuos y la valorización de los residuos mediante políticas de reutilización, reciclaje y recuperación de energía.

\subsubsection{Métodos de tratamiento de los Residuos Sólidos Urbanos.}

Llegados a este punto, es conveniente tomar una visión general de la evolución en la gestión de los RSU, estableciendo como punto de partida el momento en el que se generan los residuos a causa de la ejecución de alguna actividad. Todos los ciudadanos necesitan almacenar temporalmente los residuos hasta acumular un pequeño volumen que posteriormente depositan en los contenedores de la vía pública o si son residuos concretos, peligrosos o voluminosos, que pueden recurrir a otras vías más directas como el punto limpio, como se detallará más adelante.

Mediante el servicio de recogida, se obtienen la totalidad de los residuos y se trasladan generalmente a plantas de transferencia. En ellas se une el volumen de residuos procedente de diferentes áreas de recogida para que después se lleven a un centro de tratamiento. 
En la actualidad, el proceso de recogida es mayormente selectivo, es decir, existen diferentes flujos de residuos que seguirán una trayectoria u otra, y por ello dicho servicio se realizará por separado para los restos orgánicos, papel/cartón, envases y otros residuos. En definitiva, aquellos residuos que pueden recuperarse, reciclarse o transformarse, son capaces de generar productos y servicios aptos para un nuevo consumo. De esta manera, existen en el mercado bienes y servicios que reducen el consumo de recursos naturales, y por ello más respetuosos con el medio ambiente.

Por otra parte, son muchas las ventajas que ofrece el reaprovechamiento de los materiales componentes de los residuos desde el punto de vista económico y medioambiental. En función de las actividades, los beneficios potenciales pueden ofrecer grandes retornos de inversiones a las empresas gestoras de residuos.

La fase de tratamiento de residuos comprende todas las operaciones de selección, tratamiento, valorización, recuperación y reciclaje para obtener productos que pueden emplearse directamente en el consumo o en otros procesos de fabricación como si se tratara de materias primas, reduciendo así el consumo de recursos naturales. Desde una idea general, las entradas de este proceso son los residuos recogidos y los elementos de salida resultantes los productos y rechazos obtenidos. La elección del método de tratamiento adecuado a cada caso requiere conocer las características del problema global a resolver, incluyendo la situación de los centros de generación de RSU, los posibles centros de tratamiento y las características de los residuos.

El tratamiento de los RSU es diferente en función del modelo de recogida y la separación en origen de los distintos materiales. En la Tabla 2.4 se presentan los tratamientos más habituales para cada fracción. 


\begin{tabular}{|l|l|l|}
\hline \multirow{2}{*}{ TIPOLOGÍA R.S.U } & \multicolumn{1}{|c|}{ TIPO DE TRATAMIENTO } & \\
\hline \multirow{3}{*}{ FORSU } & $\begin{array}{l}\text { BIOLÓGICO: COMPOSTAJE } \\
\text { Y/O BIOMETANIZACIÓN }\end{array}$ & PLANTAS DE DE BIOMETANIZACIÓN Y COMPOSTAJE DE LA FORSU \\
\cline { 2 - 3 } & MECÁNICO & PLANTAS COMPOSTAJE DE LA FORSU \\
\cline { 2 - 3 } \multirow{3}{*}{ RSU MEZCLADOS } & \multirow{3}{*}{ MECÁNICO-BIOLÓGICO } & PLANTAS DE TRIAJE \\
\cline { 2 - 3 } & & PLANTAS DE RECUPERACIÓN Y COMPOSTAJE \\
\cline { 2 - 3 } & TÉRMICO: INCINERACIÓN & PLANTASTAS DE DE INCINERACIÓN Y RECUPERACIÓN ENERGÉTICA \\
\cline { 2 - 3 } & DISPOSICIÓN FINAL & VERTEDERO CONTROLADO \\
\hline ENVASES LIGEROS & MECÁNICO & PLANTAS DE SELECCIÓN DE ENVASES \\
\hline VIDRIO & MECÁNICO & INSTALACIÓN DE PREPARACIÓN DEL VIDRIO \\
\hline PAPEL/CARTÓN & MECÁNICO & INSTALACIÓN DE PREPARACIÓN DE PAPEL/CARTÓN \\
\hline
\end{tabular}

Tabla 2.4: Tipos de tratamientos. Fuente: Edo, 2019.

Como se puede observar, los residuos que se separan en origen, requieren de unos tratamientos más sencillos. De ahí, la importancia de la concienciación ciudadana en esta materia, ya que resulta vital para alcanzar los objetivos de reducción de rechazo a vertedero.

A continuación se describen de forma breve cada uno de los tratamientos:

\section{Tratamiento mecánico.}

Este tratamiento tiene como objetivo seleccionar y recuperar los diferentes materiales valorizables contenidos en los RSU para su preparación y entrega a empresas recicladoras. Para ello se utiliza una serie de operaciones y procesos mecánicos automatizados (plantas automáticas) o mano de obra directa (plantas manuales). Finalmente, los materiales que no se han podido separar para su recuperación componen el rechazo de estas instalaciones que se envía a vertedero o a valorización energética.

Las plantas de preparación del vidrio y del papel/cartón tienen rendimientos cercanos al $100 \%$, puesto que la cantidad de impropios en los contenedores de recogida selectiva de estos materiales es pequeña, del 1,7\% para el vidrio y de 3,8\% para el papel/cartón (MAGRAMA, 2015). Las plantas de selección de envases tienen un rendimiento algo inferior, con una media del $78,28 \%$ en 2016 respecto a los residuos entrantes (MITECO, 2019). Ello es debido, por un lado, a que los residuos de entrada son una mezcla de envases de metal, plástico y brik, lo que dificulta su separación, por otro, a que el porcentaje de impropios en el contenedor para esta fracción es mayor, un 28\% (MAGRAMA, 2015). 
Por último, en las plantas de triaje se realiza la separación mecánica de los distintos materiales que se encuentran en los RSU mezclados, las distintas fracciones separadas pueden destinarse a fines distintos: reciclaje de materiales recuperados (papel/cartón, plásticos, vidrio, metales, briks, etc.), compostaje/biometanización de la fracción orgánica de los residuos sólidos urbanos o la recuperación energética.

\section{Tratamiento biológico.}

Estos tratamientos comprenden una serie de procesos para la descomposición biológica de la materia orgánica presente en los RSU, tanto de la que proviene de la recogida selectiva como de los RSU mezclados. El objetivo de esta biodegradación es la valorización de la materia orgánica de los RSU, transformándola en compost y/o biogás, así como su estabilización y reducción de volumen. Principalmente, se pueden distinguir dos tipos de tratamiento en función de si la degradación llevada a cabo por los microorganismos se realiza en presencia de oxígeno o no: compostaje y biometanización, respectivamente:

- La biometanización o digestión anaerobia es un proceso de degradación y descomposición de la materia orgánica presente en los RSU, llevado a cabo por la acción de microorganismos en ausencia de oxígeno. Tras este tratamiento se obtiene biogás, que es un gas compuesto por una mezcla de metano y dióxido de carbono principalmente, que se utiliza como combustible. Además, se obtiene también un producto semisólido que contiene la materia difícil de degradar y que se denomina digestato, el cual se puede someter a un proceso de compostaje para su estabilización de forma que se obtiene compost. Este tratamiento es mucho más costoso que el compostaje $y$, por lo tanto, tiene una menor implantación. Para conseguir la transformación de la fracción orgánica en biogás se precisa una gran cantidad de reacciones bioquímicas que se producen en varias etapas, siendo las fundamentales: hidrólisis, fermentación ácida y fermentación metánica.

Las instalaciones de plantas de biometanización de la FORSU aparecen cuando el sistema de gestión incluye la recogida separada de la fracción orgánica. El rendimiento medio de estas plantas en España en el año 2016 fue de 69,36\% (MITECO, 2019).

- El compostaje es un proceso biológico aerobio que para realizarse necesita: materia orgánica, microorganismos y las condiciones óptimas para que éstos se desarrollen. Para ello deben mantenerse una serie de proporciones: aire/agua, biopolímeros y nutrientes y, en el caso de aplicarse a elevadas cantidades de residuos orgánicos, un control estricto para conseguir eficiencia, reducción mínima de emisiones y pérdida de nutrientes al objeto de conseguir un producto final con calidad para su uso. El producto 
resultante de las plantas de compostaje puede emplearse en agricultura y jardinería como abono.

El proceso de compostaje ocurre en diferentes etapas (Colomer and Gallardo, 2007; FUCOVASA et al.,2015): la primera se caracteriza por una elevada actividad microbiana llevada a cabo principalmente por bacterias que utilizan parte del carbono como fuente de energía generando $\mathrm{CO}_{2}$ y calor. Tras el aumento de la temperatura, se pasa a la segunda etapa, donde la materia orgánica alcanza su bioestabilización por medio de la microflora termofílica. En esta etapa se alcanzan temperaturas elevadas $\left(40-70^{\circ} \mathrm{C}\right)$ que aseguran la eliminación de patógenos, hongos, esporas, semillas y otros elementos biológicos no deseados, permitiendo la higienización del material. En la última etapa la temperatura disminuye y la actividad microbiana es más baja, actuando hongos y actinomicetos que contribuyen a la estabilidad de la materia. Esta etapa es la denominada etapa de maduración y, cuando la temperatura desciende hasta valores cercanos a la temperatura ambiente, se da por finalizado el proceso.

Las plantas de compostaje de la FORSU aparecen cuando el sistema de gestión de RSU del municipio ha implementado la separación en origen y recogida diferenciada de la fracción orgánica de los RSU. El rendimiento medio de estas plantas específicas en España en el año 2016 fue del 71,91\% respecto a los residuos entrantes (MITECO, 2019).

\section{Tratamiento mecánico-biológico.}

El tratamiento mecánico-biológico (TMB) consiste en la combinación de procedimientos mecánicos y biológicos para tratar los RSU mezclados o fracción "todo en uno", puesto que estos residuos presentan un contenido importante de fracción orgánica mezclada con otros materiales.

Este tipo de tratamiento está muy generalizado y permite realizar un tratamiento diferenciado de la fracción orgánica y de los materiales reciclables contenidos en los RSU mezclados.

En las plantas de recuperación y compostaje se realiza una clasificación mecánica de los RSU mezclados, junto con la estabilización de la fracción orgánica contenida en los mismos mediante compostaje. El rendimiento global de estas plantas en el año 2016 en España fue de 32,34\% respecto al material entrante (MITECO, 2019).

En las plantas de recuperación, biometanización y compostaje, además de la clasificación mecánica y recuperación de materiales, la fracción orgánica se trata mediante biometanización. Posteriormente, el digestato obtenido se composta y bioestabiliza. Para este tipo de plantas el rendimiento global medio en España para 2016 fue de 26,36\% (MITECO, 2019). 
Como se observa, los rendimientos de las plantas de TMB son menores que los anteriores, consecuencia de la gran heterogeneidad del material que reciben debido a que no se recoge de manera selectiva.

\section{Tratamiento térmico.}

El tratamiento térmico de los residuos comprende todos los procesos destinados a la trasformación de los RSU mediante la aplicación de energía calorífica (incineración, gasificación, pirólisis, etc.). El objetivo de estos tratamientos es la recuperación energética de los residuos y la reducción del peso (70-80\%) y volumen (80-90\%) de los mismos, minimizando la cantidad enviada a vertedero. Además, los tratamientos térmicos tienen otra serie de ventajas como: la destrucción de contaminantes orgánicos (McKay, 2002; Buekens and Cen, 2011); la concentración e inmovilización de contaminantes inorgánicos (Astrup, 2008; Samaras et al., 2010); el reciclado de los metales de las cenizas y escorias (Crillesen and Skaarup, 2006), y la reducción de las emisiones de gases de efecto invernadero en comparación a los que se emitirían con la descomposición de los RSU en los vertederos (Psomopoulos et al., 2009).

Actualmente, existen diferentes tecnologías para este tratamiento. De todas ellas, la incineración es la que está más ampliamente instalada y es la más utilizada internacionalmente. En España, el control de la contaminación de los gases procedentes de la incineración es una preocupación importante para la mayor parte de la población, por lo que la incineración tiene una baja aceptación en la ciudadanía y no se ha llegado a imponer frente al vertido controlado.

A continuación, se resume brevemente en qué consisten las diferentes tecnologías de tratamiento térmico:

- La incineración o combustión controlada consiste en un proceso de combustión en medio oxidante a una temperatura de $850-1100^{\circ} \mathrm{C}$ y con un exceso de oxígeno que garantice su completa oxidación $(6 \%$ respecto al estequiométrico (Colomer and Gallardo, 2007). El objetivo es reducir el volumen y peso de los residuos y recuperar parte de la energía calorífica contenida en los RSU para la producción de electricidad o calefacción. Posteriormente a la incineración, los efluentes (emisiones atmosféricas, cenizas y escorias), deben ser tratados adecuadamente (Gallardo et al., 2019).

Existen tecnologías de combustión que se han desarrollado para diferentes tipos y formas físicas de residuos, los más importantes son los diseños de inyección líquida, hornos rotatorios, hornos fijos y lechos fluidizados (Kisuk CPE, 1998; Oppelt, 1986). La opción de horno de parrilla es la más extendida para el tratamiento de RSU, puesto que no se requiere una trituración previa y tolera variaciones en composición y poder 
calorífico de los RSU. El lecho fluidizado proporciona mayor eficiencia, pero requiere un control en el tamaño y composición de los residuos, los cuales generalmente necesitan un pretratamiento (Arena et al., 2011).

La incineración genera mucha polémica desde el punto de vista ambiental, generándose una fuerte oposición social, debido a la emisión de compuestos tóxicos durante el proceso. No obstante, el desarrollo normativo es cada vez más estricto en relación a los límites de emisión de las incineradoras. Ello junto con la evolución de las tecnologías hace que cada vez más estos procedimientos sean más eficaces en la eliminación de contaminantes.

- La pirólisis es un proceso de valorización energética que consiste en el calentamiento de un material combustible en un rango de temperatura de $500-900^{\circ} \mathrm{C}$ en ausencia total de oxígeno. Es un proceso endotérmico que hace que la parte volátil de los residuos se vaporice debido a la rotura de las cadenas de hidrocarburos. La reacción da lugar a tres productos (FUCOVASA 2015; Gallardo et al., 2019):

- Un vapor que puede ser condensado a líquido en forma de aceites ligeros (mezclas de benceno, tolueno, xileno y otros), fenoles, metanol, ceras, acetona o ácido acético. Con esta fracción líquida puede obtenerse un bioaceite que se refina para producir fuel o gasolina. Si no se refina se obtienen otros productos como aditivos para combustibles tradicionales, resinas sintéticas, etc.

- Un gas de síntesis compuesto por monóxido y dióxido de carbono, hidrógeno, metano, etano, propano, butano, pentano, amoniaco, oxígeno y nitrógeno, con un poder calorífico elevado. Tras su lavado y filtrado es utilizado para generar electricidad.

- Un residuo sólido carbonoso llamado coque y formado por carbón, alquitrán, cenizas, sales y metales reducidos. Éste puede utilizarse como combustible o para fabricar carbón activo.

- La gasificación consiste en la descomposición térmica a través de una oxidación parcial de los residuos usando una cantidad de oxígeno inferior a la requerida estequiométricamente (un 25-30\%) y a una temperatura de trabajo por encima de los $750^{\circ} \mathrm{C}$. Como resultado, se obtiene un gas de síntesis combustible (syngas) que contiene dióxido de carbono, hidrógeno, metano, nitrógeno y otros hidrocarburos ligeros. El syngas tiene un poder calorífico elevado y puede utilizarse como combustible en turbinas, motores de combustión interna o calderas para producir 
energía eléctrica o térmica (Gallardo et al., 2019). Como agente oxidante se puede usar aire, oxígeno o vapor de agua. En función del uso de uno u otro el syngas tendrá un poder calorífico diferente: un $25 \%$ de poder calorífico del gas natural cuando se usa aire y entre un $25-40 \%$ cuando se usa oxígeno o aire enriquecido (Colomer and Gallardo, 2007). Además, en el proceso también se genera un residuo sólido parecido a las escorias que se debe gestionar de forma adecuada.

Existen diferentes tipos de reactores de gasificación, los más comercializados son: lecho descendente (fijo), lecho fluidizado, lecho de arrastre y reactor rotativo (Gallardo et al., 2019).

- La gasificación por plasma es un tipo de gasificación con la que se alcanza una reducción en peso y volumen de los residuos superior al 90\%. El plasma es la ionización de un flujo gaseoso, eléctricamente neutro, por medio de un campo electromagnético para crear un gas ionizado que contiene partículas eléctricamente cargadas, neutras y átomos excitados. Las antorchas de plasma consiguen concentrar una gran cantidad de energía en una zona reducida por medio de la ionización con arco eléctrico de un gas (generalmente aire). La temperatura que se alcanza es de 2.000 a $4.000^{\circ} \mathrm{C}$. En un reactor de gasificación con antorcha de plasma, la altísima temperatura alcanzada permite romper los enlaces moleculares de los residuos, formando un gas de síntesis y una lava fundida que al enfriar se transforma en un producto vítreo inerte. Tras el tratamiento se obtienen un material vitrificado y un gas combustible compuesto principalmente de hidrógeno, monóxido de carbono, nitrógeno, cloro y azufre. El gas de síntesis, una vez sometido a un proceso de limpieza, puede ser utilizado como combustible (Gallardo et al., 2019).

La eliminación es la última etapa de la jerarquía de gestión de RSU e implica el depósito de los residuos de forma permanente en un vertedero controlado. El Real Decreto 646/2020, de 7 de julio, por el que se regula la eliminación de residuos mediante depósito en vertedero, define vertedero como "la instalación para la eliminación de residuos mediante depósito en superficie o subterráneo". Por su parte, la Ley 22/2011 establece que todos los RSU deben ser sometidos a algún tipo de tratamiento antes de su vertido, salvo que el tratamiento previo de los mismos no sea viable desde una perspectiva técnica o económica, como puede ocurrir en las islas o en zonas rurales y aisladas.

La eliminación de los RSU en vertedero controlado consiste en depositar los residuos en una excavación sobre el terreno. Una vez han sido vertidos, se compactan hasta alcanzar el menor volumen posible y se recubren con tierra u otro material inerte. Para su construcción, se deben 
realizar unos trabajos y estudios previos muy importantes en cuanto a composición del suelo, proximidad a viviendas, acuíferos, etc., así como una evaluación de impacto ambiental.

En el caso de España, en 2016 se depositaron en vertedero 13,3 Mt de residuos, de ellas 7,8 millones corresponden a rechazos de las instalaciones de tratamiento, 4,2 a RSU mezclados, 1,3 Mt a otros residuos y 0,06 millones a lodos de EDAR (MITECO, 2019). Estos valores suponen que el $54,8 \%$ de los RSU generados en España en 2016 se destinaron a estas instalaciones.

\subsection{Microvertederos.}

El primer método adoptado por el ser humano para eliminar los residuos, por ser simple y barato, ha sido durante muchos años el uso de puntos de acopio de residuos en las cercanías de los núcleos de población. Sin embargo, estos espacios han acabado convirtiéndose en auténticos vertederos incontrolados. Hoy en día sigue presente esta costumbre, aunque ha derivado más hacia el abandono de residuos voluminosos que no caben en los contenedores de los núcleos urbanos o que no pueden depositarse en los mismos y que, en su lugar, deberían ser depositados en los puntos limpios habilitados por las administraciones locales o supramunicipales. Por esta razón, sigue habiendo numerosos puntos de vertido a lo largo de los términos municipales, a los que se les puede denominar microvertederos incontrolados (Figura 2.2).

En los siguientes apartados se analiza la problemática de la gestión de los microvertederos. En primer lugar se enumeran las diferentes tipologías de vertederos y sus características. A continuación, se describe el marco de competencias para la gestión de los mismos así como las actuaciones que generalmente se llevan a cabo en las administraciones locales al respecto. Posteriormente, se describen los factores que inciden en dicha gestión, y finalmente se desarrollan los problemas ambientales y sociales que supone la existencia de estos vertederos.

\subsubsection{Tipología de microvertederos.}

Los residuos depositados en los microvertederos incontrolados proceden tanto de particulares como de pequeñas empresas, como por ejemplo las de mantenimiento de jardines o las empresas de construcción y reformas. Además, se pueden distinguir distintos tipos de residuos según su tamaño, ubicación, diversidad, composición y estado de conservación.

En cuanto a su tamaño, se pueden encontrar principalmente dos tipos de microvertederos: 
- Los de gran superficie, en los que se vierten grandes cantidades de residuos de forma continuada.

- Los de carácter puntual, de pequeño tamaño y en los que se acumulan cantidades pequeñas.

Por su ubicación, estos espacios de vertidos incontrolados se encuentran en muy diversas localizaciones, generalmente en zonas periféricas de las ciudades, que pueden ser las siguientes:

- Bordes de caminos rurales.

- Debajo de puentes de vías de comunicación donde cruzan caminos rurales.

- Terrenos baldíos.

- Zonas forestales.

- Junto a contenedores de RSU.

- Márgenes de cursos de agua.

- Solares de polígonos industriales.
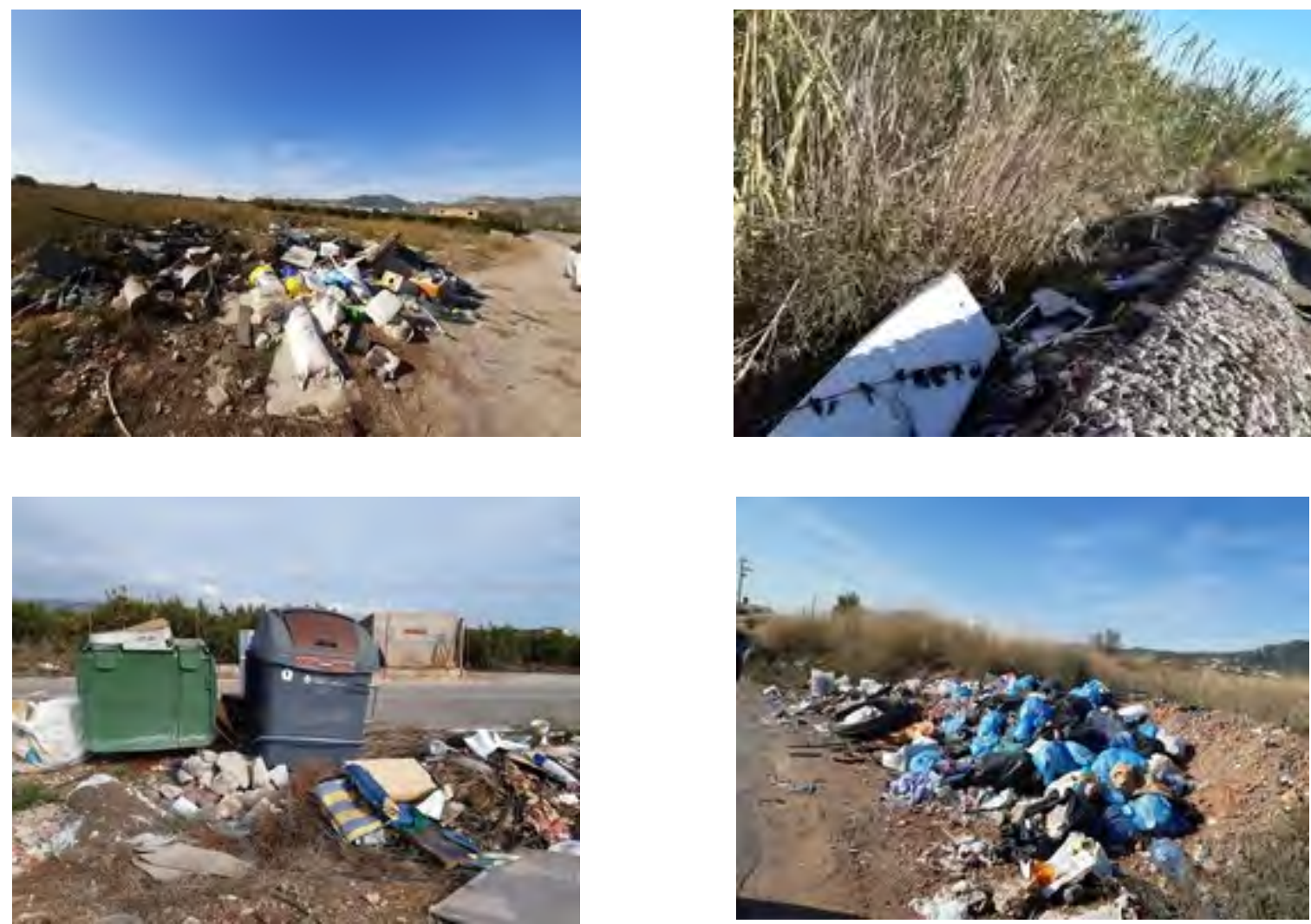

Figura 2.2: Ejemplos de microvertederos. 
Estos lugares suelen ser recurrentes, es decir, que si alguien realiza un vertido otras personas lo harán también, convirtiéndose en zonas en las que permanentemente hay residuos, aunque los servicios municipales los limpien de forma frecuente, incluso aun habiendo carteles disuasorios.

En estos puntos de vertidos descontrolados se encuentran diversos tipos de residuos (Figura 2.3):

- Domésticos, en menor cantidad. En la mayoría de los casos pueden deberse a que en lugar de comprimir y plegar los residuos de gran tamaño como cajas o botellas de plástico para que quepan en los contenedores, por comodidad las personas prefieren dejarlos abandonados en estos puntos.

- Residuos que deberían ser depositados en el punto limpio móvil o punto limpio fijo porque no se encuentran dentro de ninguna de las fracciones que se recogen en los contenedores de calle, como pueden ser las pilas, barnices, pinturas o lámparas. Sin embargo, también se puede dar el caso de que por su peligrosidad, o por no estar incluidos en la lista de residuos admisibles, no hayan sido aceptados en dichas instalaciones y aparezcan de forma incontrolada en el término municipal.

- Residuos considerados voluminosos, son aquellos residuos que por sus dimensiones deben ser objeto de un tipo de recogida especial y de un tratamiento distinto dependiendo de sus características:

- Escombros: residuos procedentes de obras de demolición y construcción.

- Restos vegetales: procedentes de podas y trabajos de mantenimiento de jardines.

- Muebles, electrodomésticos y otros enseres domésticos.

- Grandes Aparatos Eléctricos y Electrónicos.

- Neumáticos y otros residuos de talleres mecánicos.
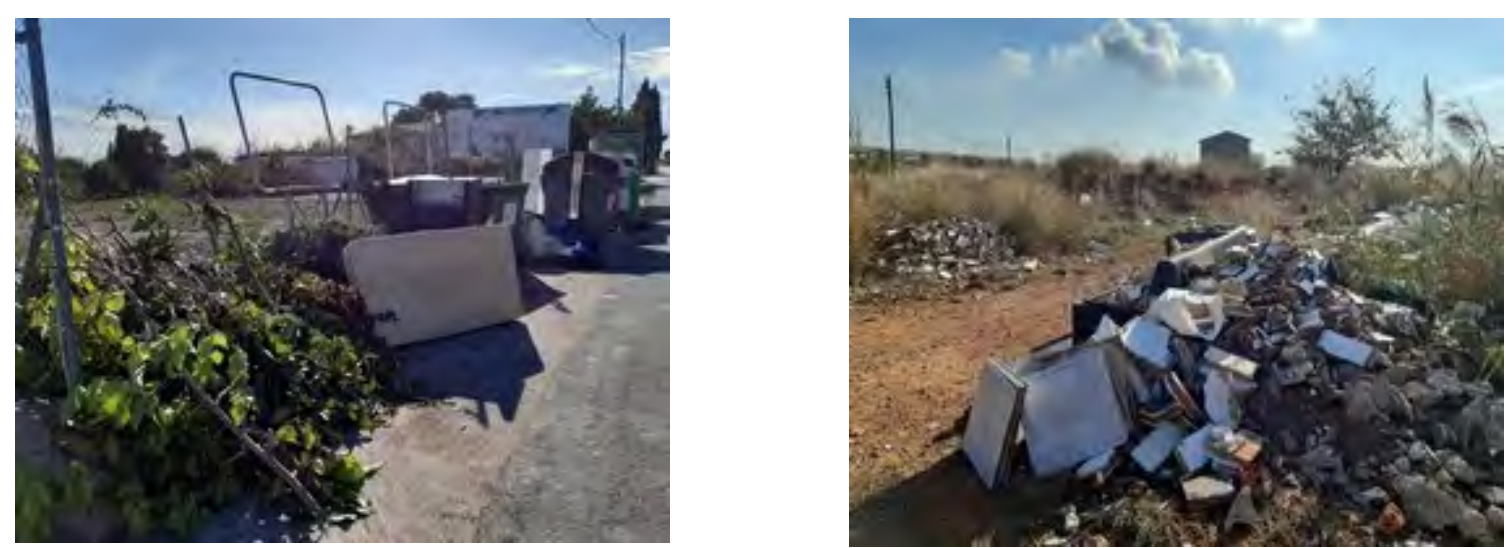

Figura 2.3: Tipos de residuos encontrados en microvertederos. 
En cuanto a la composición de los residuos, pueden agruparse en:

- Inertes, como los envases metálicos o escombros.

- Fermentables, como los restos vegetales.

- Combustibles, como la madera, el plástico o los restos textiles.

Estas características pueden influir sobre los problemas ambientales que se podrían generar, como en el caso de los residuos que son combustibles, ya que podrían originar incendios.

Por otro lado, según su estado de conservación, si se gestionaran adecuadamente su destino podría ser uno de los siguientes:

- Ser directamente reutilizables.

- Estar en buen estado: nuevos o sin estrenar.

- Ser reparables.

- Ser inservibles y, por tanto, no pueden ser reutilizables y serán eliminados.

En general, la mayor parte de los residuos que se depositan en estos vertederos, por su heterogeneidad y estado de conservación son inservibles. Sin embargo, no deben despreciarse aquellas otras partes que sí podrían ser reaprovechadas.

\subsubsection{Competencias en la gestión.}

En el marco de la Unión Europea, la Directiva 2018/251 considera que "los Estados miembros deben tomar medidas encaminadas a prevenir todas las formas de abandono, vertido, gestión incontrolada u otras formas de desecho de residuos". Para ello, en la misma se establece que se debe de incrementar la tasa de reciclado de residuos municipales, que incluyen los residuos voluminosos, como colchones y muebles, en un 55\% para 2025; un 60\% para 2030 ; y un $65 \%$ para 2035.

En este sentido, la Ley 22/2011 de residuos y suelos contaminados recoge las competencias en cuanto a la gestión de los diferentes tipos de residuos. Se establecen en el artículo 12 y dice que corresponde a las Comunidades Autónomas la elaboración de programas, planes, la autorización y vigilancia de los residuos y otras competencias en materia de gestión de residuos.

En cuanto a las Entidades Locales, les corresponde la recogida y el tratamiento de residuos domésticos, así como el ejercicio de la potestad de vigilancia e inspección, y la potestad sancionadora en el ámbito de sus competencias". Pudiendo asumir otras competencias si figuran en sus ordenanzas. 
Por tanto, las administraciones locales tienen las competencias en la gestión de una forma u otra sobre casi todos los residuos de los vertederos incontrolados como los muebles, ropa, residuos de aparatos eléctricos y electrónicos, residuos de construcción y demolición (siempre que se trate de obras menores), etc, y aunque no tienen competencias en la gestión de residuos industriales (como los neumáticos) sí pueden y deben ejercer la vigilancia, inspección y sanción.

\subsubsection{Gestión municipal.}

Para ejercer las competencias mencionadas anteriormente, los municipios desarrollan ordenanzas en las que regulan las prohibiciones de vertido y los procedimientos para deshacerse de los diferentes tipos de residuos, incluyendo los residuos que suelen encontrarse en los vertederos incontrolados y que se han mencionado anteriormente.

Como consecuencia de la existencia continuada de vertederos incontrolados, ha sido necesario que los ayuntamientos destinaran servicios, instalaciones y presupuestos para poder llevar a cabo su gestión, de manera que actualmente cuentan con uno o más de los servicios siguientes:

- Servicio municipal de recogida compuesto por camiones no compactadores, volquetes y/o grúas y varios operarios (Figura 2.4). Este servicio puede realizar tanto recogidas programadas como no programadas.

- Recogida programada en el domicilio que puede solicitarse a través de un número municipal de atención telefónica habilitado al efecto. En el mismo se indicará al interesado cómo debe depositar los residuos informándole sobre el lugar, fecha, horarios y otras condiciones que se hayan establecido. En la mayoría de los municipios, este servicio se presta de forma gratuita, con los medios descritos en el apartado anterior.

- Depósito en los Puntos Limpios y/o Puntos Limpios móviles. Estas instalaciones reciben aquellas fracciones de residuos que no disponen de otros sistemas de recogida mediante contenedores específicos en la vía urbana. El productor se desplaza hasta las instalaciones y se accede generalmente mediante vehículo.

- Con efecto disuasorio se colocan carteles indicando que está prohibido el depósito de residuos y en muchos casos se refiere a la sanción aplicable recogida en la ordenanza correspondiente por el mismo (Figura 2.4).

- Organización de mercadillos de intercambio y segunda mano o, incluso, últimamente, plataformas de internet y/o aplicaciones móviles que permiten a los usuarios reservar 
objetos a través de un catálogo y publicar sus productos para su intercambio, venta o regalo.
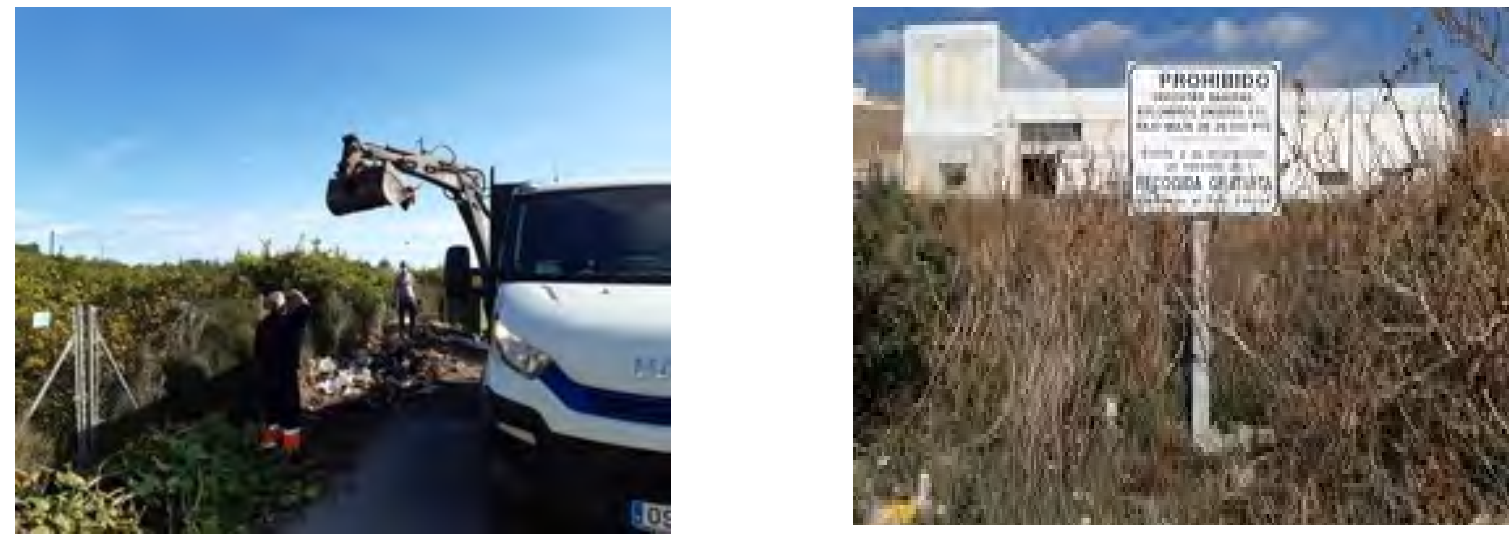

Figura 2.4: Servicios municipales de recogida de microvertederos y prohibiciones.

\subsubsection{Factores que influyen en la aparición de microvertederos.}

Existe una gran variedad de factores que inciden en la proliferación de vertederos incontrolados, como son los marcados a continuación:

- Insuficiente infraestructura para la gestión de residuos.

- Escasez de medios de control de las administraciones públicas y, por ello, respuesta no inmediata ante la aparición de este tipo de vertederos.

- Escasa responsabilidad social y ambiental de empresas que reducen costes mediante la gestión de sus residuos a través de vertederos ilegales, en lugar de contratar a un gestor autorizado.

- Falta de responsabilidad de dueños de terrenos convertidos en vertederos.

- Falta de concienciación y dejadez de ciudadanos que recurren a este tipo de vertederos. Resultando más cómodo, por cercanía, y rápido, por no tener que depender de horarios de apertura. Incluso, en los casos en los que se han instalado carteles disuasorios, transcurrido un tiempo de su colocación, pierden su eficacia bien porque se indica que se impondrán sanciones y finalmente no es así, o bien por esta falta de concienciación.

- Ausencia de campañas de sensibilización.

- Desconocimiento, por parte de la ciudadanía, de la legislación vigente y de la existencia de gestores autorizados para la recogida de residuos. 


\subsubsection{Problemas medioambientales de los microvertederos.}

Los vertidos incontrolados constituyen un importante problema, tanto para la salud humana como para el equilibrio medioambiental. Por esta razón, la vigilancia y corrección de estas actividades resulta primordial. Los problemas asociados se describen en los siguientes apartados:

- Contaminación de suelos.

El abandono de residuos genera situaciones graves de contaminación con el agravante de que la mezcla y la difusión en el terreno multiplican aún más el alcance final de la contaminación. Suponen un enorme riesgo que lleva implícito el carecer de cualquier tipo de medidas de protección ambiental y de vigilancia. La característica común a todos ellos es su enorme heterogeneidad tanto en sus dimensiones como en la naturaleza de los contaminantes que se pueden encontrar en los mismos. De hecho, suelen llevar una gran cantidad de elementos de todo tipo, desde metales pesados hasta plásticos, que al ser depositados sobre la tierra son susceptibles de ser atacados por la acción de la lluvia y de las corrientes superficiales, dando lugar a la lixiviación.

- Contaminación de aguas.

El contacto de residuos o vertidos con el agua de lluvia puede producir el arrastre de materiales contaminantes contenidos en los residuos que se van degradando con el paso del tiempo y las inclemencias meteorológicas, como el plomo o el mercurio (presentes en algunos tipos de residuo). Esto favorece que se infiltren contaminantes hacia el subsuelo con la consecuente contaminación de acuíferos subterráneos. Al mismo tiempo, puede presentarse el arrastre de residuos hacia cursos de agua superficial como ríos, ramblas, acequias o canales de regadío.

En las ubicaciones de vertederos incontrolados de márgenes de cursos de agua, se puede producir además el arrastre de los mismos en las crecidas de agua, lo que supone la contaminación de la cuenca receptora. 
- Contaminación del aire.

Muchos de los residuos que se abandonan en los vertederos incontrolados pueden emitir gases tóxicos. En el caso de los frigoríficos y aparatos de refrigeración, en el circuito generador de frío y en las espumas aislantes situadas en todo el perímetro de la carcasa contienen CFCs, compuestos que atacan la capa de ozono. Por ello deben ser tratados mediante un gestor autorizado que extrae dichos compuestos y separa además los ácidos, aceites y agua que contienen los gases refrigerantes.

La descomposición y fermentación de la materia orgánica contenida en los residuos abandonados puede generar biogás a la atmósfera que provocan niebla tóxica (smog), efecto invernadero, lluvia ácida o daños en la capa de ozono. Además, hay que tener en cuenta los malos olores que producen.

- Riesgo de incendios.

Los restos abandonados que pueden ser fermentables pueden llevar a producir una elevación de la temperatura que dé lugar a una autocombustión. Además, el metano acumulado en el vertedero puede provocar explosiones. Esto puede generar muchos problemas, tanto en el propio lugar donde se produce la combustión como a una cierta distancia, pudiendo afectar a zonas agrarias o forestales colindantes, ya que las partículas que se producen pasan a estar en suspensión, produciendo cortinas de humo en carreteras cercanas, con los problemas de tráfico que esto conlleva, además de la fuerte contaminación atmosférica que genera.

- Riesgos para la salud pública.

Los riesgos para la salud pública vienen derivados de los problemas anteriores provocados tanto por la contaminación atmosférica, generando enfermedades respiratorias, como la contaminación de aguas superficiales y subterráneas, ya que pueden llegar a masas de agua destinadas al abastecimiento urbano. Pero, además, se puede producir una transmisión directa de enfermedades debido a individuos que vayan a estos puntos con el fin de extraer partes de estos residuos, como cobre o cartones.

- Impacto paisajístico.

Este impacto ambiental puede suponer una verdadera alteración del paisaje y un impacto visual significativo, ya que se produce un empobrecimiento del paisaje. 
- Afección a espacios naturales protegidos.

Los vertederos incontrolados ubicados en zonas protegidas por las distintas figuras existentes a nivel tanto estatal, como de las comunidades autónomas o locales. Estas figuras pueden ser espacios incluidos en la Red Natura 2000: los LICs (Lugares de Importancia Comunitaria) y ZEPAs (Zona de Especial Protección para las Aves), o los Espacios Naturales Protegidos de las Comunidades Autónomas u otras figuras de protección, como pueden ser los Parajes Naturales Municipales. Dados los objetivos de conservación de estos espacios, en su normativa se establecen infracciones por el vertido o abandono de residuos que alteren uno o más factores del medio y, por tanto, puedan producir daños en los valores en él contenidos.

- Alteraciones de la fauna.

Estos puntos son un foco de atracción de insectos y animales. Su presencia, junto a otros agentes contaminantes, hacen que tanto estos lugares como su entorno sean insalubres. Puede existir ganado doméstico o salvaje así como pequeños animales como roedores que vayan a alimentarse al vertedero, con lo que pueden ser transmisores de enfermedades. Las aves también pueden ser vectores de enfermedades a grandes distancias pudiendo trasladarlas a otros ecosistemas y desencadenar enfermedades en otros seres vivos. Además, la bioacumulación de sustancias perjudiciales en algunas especies puede acabar en la cadena trófica, e incluso llegar a los seres humanos.

Cabe mencionar especialmente la proliferación de mosquitos. Estos lugares suponen un ambiente adecuado para la cría de mosquitos, ya que se pueden producir acumulaciones de agua en los objetos abandonados en los que las hembras ponen sus huevos.

- Desaparición de los recursos naturales.

No reciclar y reutilizar tiene como consecuencia un aumento de la producción de los productos que se precisan. Además, se estarán desperdiciando recursos naturales que podrían reutilizarse. También supone la desaparición y/o fragmentación de algunos ecosistemas y hábitats naturales.

- Mayor coste energético.

Si no se recicla o reutiliza correctamente y se desechan sin más los residuos, se necesitará un mayor consumo de energía para producir las materias primas de nuevo. 
- Necesidad de separar posteriormente.

La existencia de estos puntos de vertido supone la existencia de un servicio por el cual se tiene que recoger, transportar y separar todo lo que se haya vertido, lo que supone un sobrecoste para la ciudadanía por la gestión de los mismos.

- Gasto económico para su recuperación posterior.

Una vez clausuradas estas zonas, puede ser necesario realizar un plan de descontaminación por considerarse zonas degradadas y ser necesaria su delimitación, limpieza y recuperación.

- Amenaza para el empleo y fomento de una competencia desleal.

Se produce una competencia desleal hacia las empresas que sí gestionan sus residuos a través de gestores autorizados, ya que el vertido ilegal es más barato (Figura 2.5).
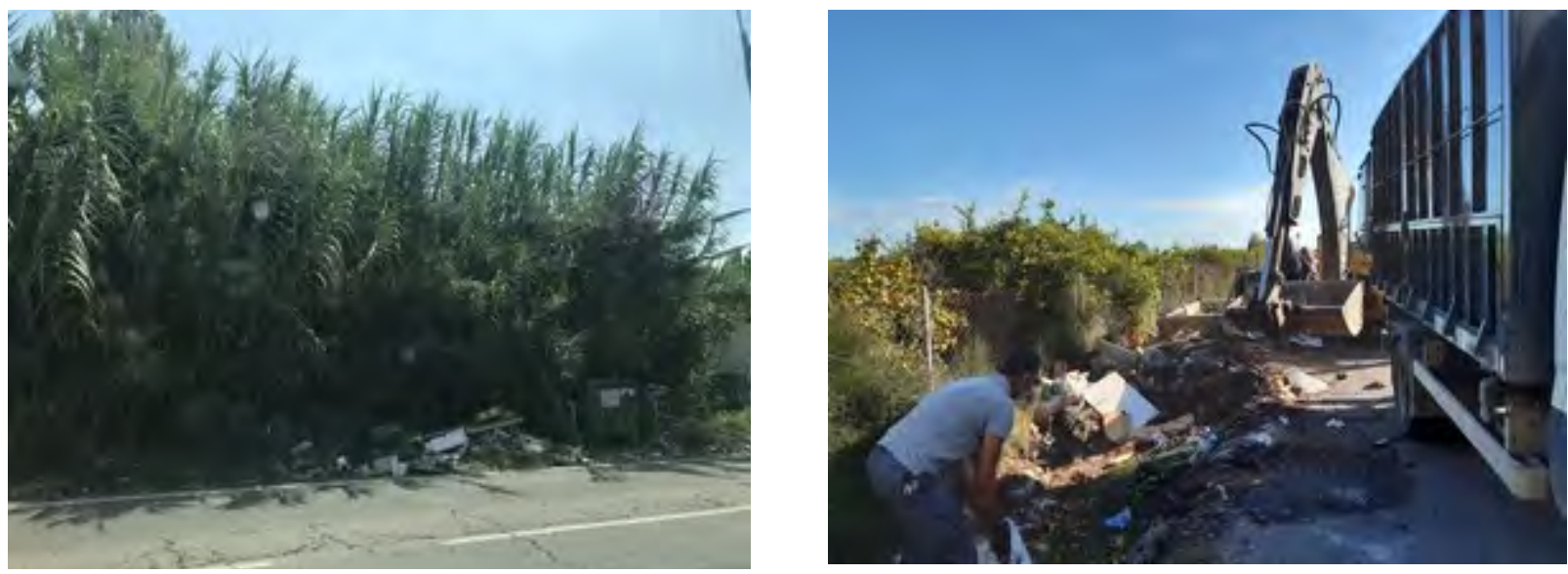

Figura 2.5: Ejemplos de mala praxis empresarial en la gestión de residuos.

Los microvertederos incontrolados son uno de los problemas ambientales más importantes en la gestión de los municipios españoles. Éstos suponen una amenaza para el medio ambiente local y la salud de la ciudadanía.

Para asegurar el cumplimiento de todas las obligaciones derivadas de la legislación, relacionadas con el vertido incontrolado de residuos y conseguir así reducir los problemas ambientales asociados, las administraciones locales necesitan más recursos económicos y de personal para llevar a cabo las actividades de inspección, control y vigilancia. Además, es necesaria la colaboración con otras administraciones en el ámbito de sus competencias en la materia.

Entre las acciones a desarrollar en este sentido, conviene priorizar la aplicación de medidas preventivas, que incluyan un censo de los vertederos incontrolados para su mejor control y seguimiento; y conseguir la implicación ciudadana y de las empresas locales a través de la 
visualización de la gestión de residuos mediante el desarrollo de campañas de sensibilización y concienciación.

\subsection{La recogida sostenible de residuos sólidos urbanos.}

La recogida y transporte de los residuos domésticos y comerciales se compone de las operaciones necesarias para retirar los residuos desde el momento en el que se depositan inicialmente hasta la descarga o entrega en la planta de tratamiento de residuos. Dentro del sistema de gestión de RSU, la recogida constituye la fase de mayor peso y en algunos casos puede llegar a representar una de las partes económicamente más significativas del servicio. Por ello, algunos autores han utilizado técnicas de programación matemática, como la programación lineal entera, para resolver la optimización de la recogida de los RSU (Bonomo et al., 2009). Para elaborar un plan de recogida y conseguir que las operaciones sean rápidas y eficaces es básico considerar los siguientes aspectos:

- Características de los residuos.

- Estacionalidad de la cantidad de generación de los residuos producidos en el área de recogida.

- Infraestructura urbana y acceso a los lugares de recogida.

- Distancia al centro de tratamiento, valorización y/o eliminación.

- Características de los contenedores en que se depositan los residuos.

El sistema de recogida de mayor implantación actual en España es el mecanizado, que emplea contenedores distribuidos por manzanas o grupos de viviendas, de forma que se reducen considerablemente los tiempos en las operaciones de recogida y se aumenta el rendimiento de los procesos.

\subsubsection{Sistemas tradicionales de recogida domiciliaria.}

Son sistemas en los que la recogida se realiza de manera indistinta de todos los residuos domésticos en el mismo lugar de su generación. Según el grado de colaboración de los ciudadanos y usuarios, se pueden establecer tres tipos:

- Recogida puerta a puerta: Recogida casa por casa de las bolsas de basura que han sido sacadas al exterior. Es el sistema más costoso, ya que exige más tiempo de recogida y mayor mano de obra. Hoy en día, está generalizado en países como Inglaterra, pero en 
España se está volviendo a implantar en algunas ciudades, ya que es el sistema que mejores porcentajes de recogida selectiva obtiene. Como contrapartida, es un sistema inviable cuando la densidad de población es muy elevada (edificios, torres, etc.) y más conveniente instalarlo en zonas de viviendas unifamiliares.

En Suecia, Dahlén et al., 2007 compararon tres sistemas de recogida implantados en 6 ciudades diferentes. Los resultados demostraron que la ciudad con un mayor grado de separación en origen fue en la que los residuos reciclables y biodegradables se recogieron a nivel de acera, siendo además la única ciudad con un sistema de pago de tasas por kilogramo de residuo de resto generado.

- Locales destinados al almacenaje de residuos: Consiste en zonas habilitadas para el acopio de residuos de un determinado grupo de viviendas. Es un tipo frecuente en construcciones como rascacielos, que disponen de sótanos con contenedores. En España apenas existe este tipo de sistema ya que requiere de su previsión en el momento de la construcción. El inconveniente es que se necesita mayor tiempo en la retirada de los residuos, pero como ventaja se evita tener en la vía pública contenedores.

- Recogida mecanizada en contenedores especiales para manzanas o grupos de viviendas: Como se ha citado con anterioridad es el sistema más utilizado en la actualidad en España. Requiere el desplazamiento de los usuarios hasta depositar los residuos en los contenedores, además de necesitar espacio accesible para los camiones. Los contenedores más empleados para depositar los residuos y permanecer almacenados hasta el paso de los camiones de recogida municipal son:

- Contenedores de ruedas: Este sistema está implantado por su gran eficacia. Los contenedores poseen una gran maniobrabilidad, lo que simplifica las operaciones de recogida, su rapidez y su resistencia. Es el sistema más habitual en las ciudades y núcleos urbanos.

- Contenedores de carga lateral: Se trata de contenedores de entre 2 y $3 \mathrm{~m}^{3}$ de capacidad, cuya carga se realiza con un camión equipado con un robot que permite al operario realizar la recogida sin bajarse del camión. Su principal inconveniente es que los camiones sólo pueden cargar a uno de los dos lados (derechas o izquierdas).

- Contenedores de carga bilateral: Sistema similar al anterior, pero con la posibilidad de cargar a ambos lados, ya que el camión cuenta con una pluma autocargante. 
- Contenedores de gran capacidad: estos contenedores son los de mayor capacidad respecto a los anteriores, de 5 a $30 \mathrm{~m}^{3}$ de capacidad, y van equipados con un sistema autocompactador que permite una reducción del volumen $2 / 3$ del total. Se pueden depositar residuos de gran volumen y se emplean principalmente en grandes conjuntos de viviendas, mercados, hospitales, así se reduce el número de transportes.

\subsubsection{La recogida selectiva contenerizada.}

Los buenos resultados de las plantas de reciclaje o de las operaciones de reutilización de residuos estarán condicionados a la buena selección previa de los residuos susceptibles de reciclaje, separándolos de aquéllos que no lo sean. La implantación de un sistema de recogida selectiva exige las siguientes condiciones:

- Colaboración ciudadana, ya que es el ciudadano el que debe depositar en bolsas distintas los diferentes tipos de residuos. Los contenedores de recogida selectiva están diseñados para recibir de forma exclusiva un único tipo de residuo (vidrio, papel-cartón, envases ligeros y biorresiduos, generalmente) y se instalan por la ciudad para favorecer la recogida selectiva.

- La recogida separativa de los residuos, exige colocar vehículos distintos o bien usar vehículos compartimentados.

- El servicio de recogida es más complejo, ya que se incrementan los tiempos en las rutas, los costes de mano de obra y la especialización de los vehículos.

- El tiempo de implantación es largo, debido a que requiere la educación de los ciudadanos con el fin de crear hábitos de seleccionar los residuos.

Como ejemplo, en Portugal, Gomes et al, 2008, establecieron una comparación económica de tres alternativas de recogida de residuos de materia orgánica. Las alternativas fueron: 1 , la recogida sin separación de materia orgánica; 2, la separación de materia orgánica en todo el municipio; y 3 , la separación de materia orgánica en los principales núcleos urbanos y compostaje doméstico en el resto. Se cuantificaron los costes de recogida y transporte en los tres escenarios y se obtuvo que, respecto al primero que era el que estaba implantado en la zona de estudio, con el segundo los costes no serían necesariamente superiores, y con el tercero los costes podrían llegar a ser inferiores.

Además, también se consigue una fracción orgánica de los RSU libre de metales y otras sustancias inertes y en consecuencia de mejor calidad para la producción de compost. 
A partir de la entrada en vigor de la Ley 10/1998 de residuos, todos los municipios con una población superior a 5.000 habitantes se vieron obligados a implantar sistemas de recogida selectiva, siendo obligatoria a partir del 1 de Enero de 2001 y aún sigue vigente en la actual Ley 22/2011 de 28 de julio, de residuos y suelos contaminados.

A continuación, se describen las fracciones con mayor implantación en cuanto a recogida contenerizada, en las ciudades españolas:

Recogida de vidrio.

El vidrio es un componente muy difícil de separar mecánicamente del resto de los materiales de la basura, por lo que su separación a posteriori es complicada. No obstante, es el sistema más aceptado por la población en la separación de los residuos.

Para la recogida del vidrio, es habitual encontrar contenedores iglú de $2,5-3 \mathrm{~m}^{3}$ con capacidad de $900 \mathrm{~kg}$, y se distribuye uno cada 200 habitantes según el nuevo PIRCV en núcleos de alta densidad poblacional. En los establecimientos productores de grandes cantidades de vidrio se recurre a otros sistemas de recogida, en la que los envases o botellas de vidrio se recogen en el momento de entrega de productos. Para el caso de la hostelería, los distribuidores entregan las cajas con producto y los hosteleros las vacías para su retorno a fábrica.

Es importante destacar que el $99 \%$ del vidrio recogido en el contenedor es reciclado y que puede ser reciclado en infinitas ocasiones, sin pérdidas de calidad en los procesos dando lugar a envases con las mismas características.

\section{$\underline{\text { Recogida de envases. }}$}

En la Ley 11/1997 de 24 de Abril de Envases y Residuos de Envases, se define envase como "todo producto fabricado con materiales de cualquier naturaleza y que se utilice para contener, proteger, manipular, distribuir y presentar mercancías, desde materias primas hasta artículos terminados, en cualquier fase de la cadena de fabricación, distribución y consumo. Se considerarán también envases todos los artículos desechables utilizados con este mismo fin. Dentro de este concepto se incluyen únicamente los envases de venta o primarios, los envases colectivos o secundarios y los envases de transporte o terciarios".

Igual que en la recogida de vidrio, la entrada en vigor de la Ley 11/1997 obligó a los ayuntamientos a realizar una recogida selectiva y/o separación de los residuos de envases del flujo de basuras.

El sistema empleado para la recogida de residuos de envases es similar al de vidrio y papel/cartón, y según los últimos Convenios se ubican contenedores por cada 600 habitantes que 
a continuación se llevan a plantas de clasificación de materiales, antes de llegar a las plantas de reciclaje. En las plantas de clasificación se separan los materiales, se embalan y se transportan a las plantas recicladoras.

Se trata de la última fracción contenerizada instalada en España, y por ello no todos los municipios disponen de ésta. Existe mucha variedad en cuanto a contenedores y frecuencias de recogida en función de las necesidades de cada municipio.

Como ejemplo, en un estudio realizado en Córdoba se compararon dos tipos de sistemas de recogida para la recogida separada de materia orgánica (contenedor gris) y envases, restos domiciliarios y restos de inertes (contenedor amarillo): contenedores para la recogida de envases con tapa abierta frente a tapa cerrada. Los resultados mostraron que con el sistema de contenedores amarillos de tapa abierta se recogía una cantidad de residuos de envases superior a la recogida con los contenedores de tapa cerrada, sin embargo la calidad de estos residuos de envases fue inferior, es decir, presentaron una elevada proporción de materiales depositados inadecuadamente (impropios) (Berbel et al., 2001).

Los productores de envases, pueden cumplir con la legislación vigente de dos formas; una es poniendo a disposición de los consumidores un sistema de retorno/reutilización de envases y la otra es adherirse al SIG de residuos de envases.

El Sistema Integrado de Gestión de ECOEMBES cuenta con 12.100 empresas adheridas de las que 1.688 son valencianas. Cada vez más, la implicación ciudadana en el problema del plástico es mayor, ya que según el último informe de la organización ECOEMBES, el 82\% de los valencianos afirma separar sus residuos convencidos de que esta labor es un deber social para el cuidado del Medio Ambiente. (Ecoembes, 2019).

\section{Recogida de papel y cartón.}

El papel y cartón significa un porcentaje importante en el total de los residuos urbanos, siendo recuperable como materia prima para la fabricación de más cartón y papel. Las ventajas de la recogida selectiva de esta fracción son:

- Se disminuye la importación de materias primas para la producción de papel (madera, pastas de papel, etc.). El reciclado del cartón tiene evidentes ventajas medioambientales, ya que en el reciclado se usa menos materia prima virgen, se utiliza menos agua y se genera una carga contaminante menor. Básicamente consiste en la suspensión en agua y la disgregación de las fibras, formando una pasta que ha de ser depurada de las impurezas que contiene, como polvo, plásticos y flejes de las balas, mediante filtros y 
centrifugación. Los adhesivos o el alquitrán son dispersados mediante un disgregador en caliente. La utilización de pasta virgen es necesaria porque con la repetición de ciclo de reciclaje las fibras se acortan y se disminuye su resistencia (Mendoza, Montañés y Palomares, 1998).

- Supone un ahorro energético ya que la fabricación de papel reciclado requiere menor consumo de energía y por tanto se reduce la contaminación atmosférica. Además, el ahorro de agua con el uso de papel reciclado representa un $60 \%$ sobre el valor destinado a la fabricación de la pasta y se reduce un $40 \%$ el volumen de los residuos.

- Reduce el consumo de recursos naturales y con ello, la deforestación.

El sistema de recogida es similar al de vidrio y envases, mediante la colocación de contenedores metálicos de $3 \mathrm{~m}^{3}$ con carga superior en vía pública, para los cuales se necesitan vehículos con apertura superior y una grúa de carga del contenedor (carga superior).

Se han desarrollado modelos econométricos, que concluyen que la densidad de un país presentaba un efecto positivo sobre la tasa de recuperación de papel (mayor densidad, mayor recuperación de papel) (Berglund et al., 2002).

\section{Pilas usadas.}

La Directiva 2006/66/CE, relativa a las pilas y acumuladores y a los residuos de pilas y acumuladores, incorporada al ordenamiento español mediante el Real Decreto 106/2008, de 1 de febrero, que establece medidas para fomentar la valoración y eliminación controlada de las pilas y acumuladores.

Igualmente que en los neumáticos, la responsabilidad de la eliminación de estos residuos, corresponde a aquéllos que los ponen en el mercado. No obstante, dada la peligrosidad de estos residuos, las Administraciones vienen colaborando para facilitar su recogida.

Por ello, se suelen colocar contenedores en la vía pública (mobiliario urbano, paradas de autobús, etc., y en edificios públicos) para tal fin.

Los residuos se corresponden con los códigos de la Lista Europea de Residuos (LER) que se relacionan a continuación:

- 1606 Pilas y acumuladores.

- $160602 *$ Acumuladores de Ni-Cd.

- $160603^{*}$ Pilas que contienen mercurio.

- 160604 Pilas alcalinas [excepto las del código 1606 03].

- 160605 Otras pilas y acumuladores. 
- 1606 06* Electrolito de pilas y acumuladores recogido selectivamente.

- 2001 33* Baterías y acumuladores especificados en los códigos 1606 01, 160602 ó 16 0603 y baterías y acumuladores sin clasificar que contienen esas baterías.

- 200134 Baterías y acumuladores distintos de los especificados en el código 200133.

La empresas gestoras deben contar con todas las autorizaciones administrativas necesarias para desarrollar esta actividad, especialmente aquellas referidas al transporte y la eliminación.

Ropa usada.

La recogida de textiles y ropa usada (código LER 2001 10) en los contenedores situados al efecto en el casco urbano facilita a los vecinos la gestión del residuo textil generado en sus domicilios particulares mediante la ubicación de contenedores de recogida selectiva próximos. El contenido de los mismos es destinado a la reutilización, reciclado y aprovechamiento, lo cual tiene como efectos el cierre del ciclo del textil y calzado, la reducción sustancial de las cantidades de materiales depositados en vertedero y de las entradas a incineración, y el aumento de la sensibilidad ciudadana en relación a la gestión de los residuos y a la protección del medio ambiente.

Además, promueve procesos de transformación social, ya que, gracias a la recogida selectiva de textil y ropa con un marcado carácter solidario, se fomenta la creación de empleo, la generación de alternativas de consumo y las prácticas respetuosas con el medio ambiente.

Es un servicio complementario a los servicios habituales de recogida selectiva, incluyendo una nueva fracción que tendrá como destino final la reutilización, reciclado y valorización con gestores autorizados que dispongan de las autorizaciones necesarias.

En la mayoría de municipios, por su marcado carácter social se suele prestar el servicio mediante contratos reservados, a través de empresas de inserción o centros especiales de empleo. 


\section{Aceite vegetal.}

Se trata de un producto utilizado en todos los hogares y echarlo por el fregadero supone un impacto ambiental y un desperdicio de recursos.

El aceite vegetal es contaminante y difícil de tratar ya que se solidifica y se queda pegado a los desagües y a la red general de alcantarillado con riesgo de embozos. También complica el proceso de tratamiento de las aguas residuales por parte de las depuradoras.

La cantidad de aceite vegetal recogida en los puntos limpios municipales y/o comarcales cada vez es más representativa, y además se complementa mediante la colocación de contenedores en vía pública para este tipo de residuo.

Al tratarse de un residuo líquido puede generar derrames y suciedad en el entorno de los contenedores, por ello suele haber indicaciones en los mismos para que se deposite en botellas debidamente cerradas.

El aceite recuperado se destina a planta de tratamiento, para su transformación en combustible evitando el consumo de combustibles fósiles.

\section{RAEE.}

Según el Real Decreto 110/2015, de 20 de febrero, los residuos de aparatos eléctricos y electrónicos o RAEE son todos los aparatos eléctricos y electrónicos que pasan a ser residuos de acuerdo con la definición que consta en el artículo 3.a) de la Ley 22/2011, de 28 de julio. Esta definición comprende todos aquellos componentes, subconjuntos y consumibles que forman parte del producto en el momento en que se desecha.

Los RAEE pueden contener sustancias peligrosas, como cadmio, mercurio, plomo, arsénico, fósforo, aceites peligrosos y gases que agotan la capa de ozono o que afectan al calentamiento global como los clorofluorocarbonos (CFC), hidroclorofluorocarbonos (HCFC), hidrofluorocarbonos (HFC), hidrocarburos $(\mathrm{HC})$ o amoniaco $(\mathrm{NH} 3)$, que si bien son necesarias para garantizar su funcionalidad, pueden emitirse al medio ambiente o ser perjudiciales para la salud humana si, una vez que se convierten en residuos, los aparatos no se gestionan y se tratan adecuadamente (Ecolec, 2020). 


\subsection{Los puntos limpios.}

Como se ha descrito, los RSU están compuestos por una gran variedad de productos o subproductos de los que no todos deben acabar en el contenedor de la recogida ordinaria. En España, cuando un ciudadano pretende desprenderse de residuos distintos a los meramente habituales, se debe recurrir a un punto limpio.

Los puntos limpios son instalaciones cerradas y controladas, diseñadas para recibir residuos domésticos y de comercios en las que los ciudadanos pueden depositar gratuitamente aquellos residuos que genere y para los que no exista un contenedor específico. Con esta solución se evitan, principalmente, los vertidos incontrolados, ya que existe una solución para deshacerse de residuos voluminosos o que requieran un tratamiento especial, como baterías o aceites usados.

La característica fundamental de los puntos limpios es que el propio ciudadano es quien transporta el residuo y lo deposita en el centro, siendo ésta una instalación fija. La instalación está compuesta por un módulo de acceso, con un punto de control e información al usuario y de una zona de vertido de residuos dotada de contenedores específicos para cada producto. También contemplan muelles dotados de grandes contenedores para vertidos de mayor volumen directamente desde el vehículo del usuario.

Como ejemplo de residuos generalmente aceptados en los puntos limpios fijos están las pilas de todo tipo, baterías, electrodomésticos usados (incluso de gran tamaño), restos de pintura, aceites de cocina y de motor, halógenos o lámparas fluorescentes gastadas, aerosoles, muebles y otros objetos voluminosos como escombros y chatarra.

En Europa el concepto de punto limpio está muy extendido. No obstante, existen algunas diferencias a nivel de instalaciones y funcionamiento según el país o la región. En todos ellos, se trata también de una instalación cerrada donde los usuarios llevan residuos que no tienen cabida en otro sistema de recogida selectiva. En Francia toman el nombre de "déchettèrie", en Alemania de "recyclinghof", en Italia de "cicicleria" o "stazione ecologiche" y en Reino Unido de "recycling centre" o "civic ametitie".

En los puntos limpios no se suelen admitir residuos industriales ya que para éstos existe el canal de tratamiento adecuado. Estas instalaciones están a disposición de los ciudadanos de los municipios y de los pequeños comercios, oficinas o servicios cuyos residuos puedan asimilarse al domiciliario. 
En general, un punto limpio puede recibir todo tipo de residuos para los que no existe un contenedor específico. A continuación, como ejemplo, se muestra una lista de la Entidad Metropolitana de Tratamiento de Residuos (EMTRE) con los residuos admisibles y la limitación en cuanto a aportaciones diarias como se observa en la Tabla 2.5.

\begin{tabular}{|c|c|c|c|c|}
\hline \multicolumn{5}{|c|}{ RESIDUOS ADMITIDOS EN LOS ECOPARQUES DEL EMTRE } \\
\hline \multirow{3}{*}{ Residuo } & \multicolumn{4}{|c|}{ Cantidad máxima admitida } \\
\hline & \multicolumn{2}{|c|}{ Peso o volumen } & \multicolumn{2}{|c|}{ Unidades } \\
\hline & Usuario/día & Usuario/mes & Usuario/día & Usuario/mes \\
\hline Aceites y grasas vegetales & 101 & & & \\
\hline Aceites de motor & 101 & & & \\
\hline Aerosoles & & & 10 & \\
\hline Aluminio & $100 \mathrm{~kg}$ & & & \\
\hline Aparatos electrodomésticos & & & 4 & \\
\hline Aparatos informáticos & & & 4 & \\
\hline Baterías de automóvil & & & 2 & \\
\hline Baterías de teléfonos, RAEEs & & & 5 & \\
\hline Cables de cobre & $10 \mathrm{~kg}$ & & & \\
\hline Electrónicos & & & 20 & \\
\hline Metales & $100 \mathrm{~kg}$ & & & \\
\hline Colchones & & & 2 & 6 \\
\hline Cintas de vídeo & & & 20 & 40 \\
\hline DVD y CD & & & 20 & 40 \\
\hline Escombros & $300 \mathrm{~kg}$ & $900 \mathrm{~kg}$ & & \\
\hline Voluminosos & $100 \mathrm{~kg}$ & $200 \mathrm{~kg}$ & & \\
\hline $\begin{array}{l}\text { Tubos fluorescentes y lámparas de } \\
\text { mercurio }\end{array}$ & & & 10 & \\
\hline Maderas y podas & $100 \mathrm{~kg}$ & & & \\
\hline Neumáticos & & & 4 & 4 \\
\hline Papel y cartón & $100 \mathrm{~kg}$ & & & \\
\hline Plaguicidas & & & 5 & 5 \\
\hline Pilas & & & 20 & \\
\hline Plástico & $50 \mathrm{~kg}$ & & & \\
\hline Radiografías & & & 20 & \\
\hline Envases de plástico contaminados & & & 10 & 30 \\
\hline Envases de metal contaminados & & & 10 & 30 \\
\hline Restos de pintura, tintas y barnices & & & 10 & 30 \\
\hline
\end{tabular}




\begin{tabular}{|l|c|c|c|c|}
\hline \multirow{2}{*}{ RESIDUOS ADMITIDOS EN LOS ECOPARQUES DEL EMTRE } \\
\hline \multirow{2}{*}{ Residuo } & \multicolumn{3}{|c|}{ Cantidad máxima admitida } \\
\cline { 2 - 5 } & \multicolumn{2}{|c|}{ Peso o volumen } & \multicolumn{2}{c|}{ Unidades } \\
\cline { 2 - 5 } & Usuario/día & Usuario/mes & Usuario/día & Usuario/mes \\
\hline Tóner y tintas impresoras & & & 10 & 30 \\
\hline Vidrio plano & $50 \mathrm{~kg}$ & & & \\
\hline
\end{tabular}

Tabla 2.5: Residuos admitidos en los ecoparques del EMTRE. Fuente: Normas de uso y gestión de los ecoparques integrantes de la red de ecoparques de gestión metropolitana. EMTRE.

Los puntos limpios son una solución ideal para que la ciudadanía pueda retirar de manera selectiva residuos peligrosos y otros de gran volumen, como muebles o restos de materiales de construcción por una reforma. Así, estas instalaciones quedan a disposición de las personas para aquellos residuos que puedan generarse eventualmente o con menor frecuencia.

Las características de los puntos limpios no son homogéneas ya que se adaptan a las necesidades de los municipios, al espacio disponible y a la inversión que se realice. No existe una normativa que regule en toda España las características que tienen que tener los puntos limpios aunque recientemente el RD 110/2015 sobre la gestión de los RAEES, introduce requisitos específicos que condicionarán la construcción y forma de gestionar de los puntos limpios existentes y como se construirán los futuros.

Además, la Memoria del Plan Nacional Integrado de Residuos 2008-2015 establece a los puntos limpios como destino de los residuos peligrosos de origen doméstico y de los RAEE. Así, prescribe la creación de puntos de recogida de residuos peligrosos de origen doméstico en ciudades, en función de su población:

- Poblaciones entre 10.000 y 100.000 habitantes, al menos 1 punto.

- Poblaciones entre 100.000 y 500.000 habitantes, al menos 2 puntos.

- Poblaciones entre 500.000 y 1.000 .000 habitantes, al menos 3 puntos.

- Poblaciones de más de 1.000 .000 habitantes, al menos 1 punto por cada 350.000 habitantes.

Como complemento a estas medidas, se permite la implantación del servicio de recogida de residuos peligrosos de origen doméstico mediante puntos limpios móviles en todas las poblaciones comprendidas entre 1.000 y 10.000 habitantes.

Los puntos limpios necesitan de espacio que no siempre está disponible o es tan valioso que se destina a otros usos, de tal manera que habitualmente los puntos limpios están ubicados en la 
periferia de los cascos urbanos, en zonas industriales o aprovechando el suelo de antiguos vertederos sellados. Esta lejanía dificulta el uso por parte de los ciudadanos. Para solucionar esto se usan puntos limpios móviles que, sobre camión o en un contenedor, se sitúan en puntos diversos en días y horas determinadas, aceptando los residuos que establece cada Ayuntamiento según sus necesidades.

El uso de los puntos limpios evita que residuos peligrosos acaben en otros flujos de recogida de residuos municipales, disminuyen la cantidad de residuos voluminosos a recoger en acera, y aumentan la posibilidad de realizar recogidas separadas para el reciclaje de materiales que de otra manera acabarían en la fracción resto. Las administraciones públicas, cada vez más, están tratando de incentivar su utilización para conseguir sus beneficios incluso con bonificaciones sobre la tasa de basura.

En la normativa que se ha ido citando con anterioridad y que se completa en el apartado siguiente, se hace referencia a la norma vigente en términos de recogida y gestión de los residuos domésticos y asimilables. Sin embargo, dentro de este grupo, el PEMAR diferencia la recogida de determinados residuos, que no son objeto de recogida mediante sistemas puerta a puerta o de contenerización, sino que se deben depositar en los denominados puntos limpios.

En el ámbito de la Comunidad Valenciana, la regulación de los puntos limpios viene determinada por el Plan Integral de Residuos (PIR-CVA). En esta norma se hace referencia a que los consorcios de residuos y los entes locales son competentes de la transferencia y gestión de los ecoparques, y que toda la información relativa a éstos deberá estar dispuesta en formato digital para garantizar la transparencia. Además, especifica que esta información se deberá actualizar anualmente.

De forma más detallada, en el artículo 20 del propio PIR-CVA se desarrolla toda la información sobre los puntos limpios (ecoparques en la comunidad valenciana) y los criterios de ubicación actualizados, así como la aparición de la figura del ecoparque móvil, como complemento a los ecoparques fijos para posibilitar alcanzar las cifras de recogida deseadas. Más adelante, en el artículo 36 de la misma norma, se hace referencia al modelo de ordenanza reguladora de los ecoparques, que se desarrolla en el anexo 1.1. de la citada norma.

En este último apartado, se desarrolla de manera más precisa todo aquello relativo a los ecoparques; su construcción, organización, las instalaciones que deben tener, los tipos de ecoparques existentes o los residuos admisibles en este tipo de instalaciones. En la Tabla 2.6 se recoge la información que detalla el PIR-CVA sobre las características de estos puntos. 
Por lo que respecta a la tipología de ecoparques, el PIR-CVA 2019-2022 establece cinco modelos diferentes en función de la población, la superficie o el número de contenedores existentes en la instalación. En la Tabla 2.6 se observan los tipos y sus características.

\begin{tabular}{|c|c|c|c|c|c|}
\hline Ecoparque & $\begin{array}{c}\text { Población } \\
\text { potencial }\end{array}$ & Disposición & $\begin{array}{c}\text { Superficie } \\
\left(\mathbf{m}^{2}\right)\end{array}$ & $\begin{array}{c}\text { Número de } \\
\text { contenedores }\end{array}$ & $\begin{array}{c}\text { Tamaño } \\
\text { contenedores }\end{array}$ \\
\hline TIPO A & Hasta 1.000 & 1 cota & $300-500$ & $4-6$ & $9 \mathrm{~m}^{3}$ \\
\hline TIPO B & $1.001-5.000$ & 1 cota & $500-1.000$ & $6-8$ & $9 / 18 \mathrm{~m}^{3}$ \\
\hline TIPO C & $5.001-10.000$ & 2 cotas & $1.500-3.000$ & $8-10$ & $18 / 26 \mathrm{~m}^{3}$ \\
\hline TIPO D & Más de 10.001 & 2 cotas & $2.500-5.000$ & $10-15$ & $18 / 26 \mathrm{~m}^{3}$ \\
\hline Móvil & $\begin{array}{c}\text { Según } \\
\text { necesidades }\end{array}$ & - & $($ Camión) & - & Según gestores \\
\hline
\end{tabular}

Tabla 2.6: Tipos de ecoparques. Fuente: Elaboración propia a partir del PIR-CVA 2019-2022.

A partir de estos datos, el PIR-CVA 2019-2022 establece una estimación según las áreas de gestión existentes. La Tabla 2.7 muestra la estimación del número de ecoparques fijos de cada Plan Zonal, recogida en el PIR.

\begin{tabular}{|c|c|c|c|c|c|}
\hline Área de gestión & $\begin{array}{l}\text { Nomenclatura } \\
\text { anterior }\end{array}$ & Tipo A & Tipo B & Tipo C & Tipo D \\
\hline C1 & I & 15 & 12 & 5 & 5 \\
\hline $\mathrm{C} 2$ & II, IV, V & 20 & 8 & 2 & 7 \\
\hline $\mathrm{C} 3 / \mathrm{V} 1$ & AG2 III, VIII & 5 & 5 & 2 & 4 \\
\hline $\mathrm{C} 3 / \mathrm{V} 1$ & AG2 III, VIII & & 3 & 1 & 1 \\
\hline V2 & AG1 III, VIII & & 1 & & 13 \\
\hline V3 & VI, VII, IX & 16 & 26 & 1 & 9 \\
\hline V4 & AG2 X, XI, XII & 1 & 9 & 11 & 10 \\
\hline V5 & AG2 X, XI, XII & 13 & 33 & 6 & 5 \\
\hline A1 & $x V$ & 3 & 4 & 4 & 13 \\
\hline A2 & XIV & 1 & 7 & 1 & 7 \\
\hline A3 & XIII & 1 & 4 & 5 & 4 \\
\hline A4 & $\mathrm{XVI}$ & & & & 4 \\
\hline
\end{tabular}




\begin{tabular}{|c|c|c|c|c|c|}
\hline Área de gestión & $\begin{array}{c}\text { Nomenclatura } \\
\text { anterior }\end{array}$ & Tipo A & Tipo B & Tipo C & Tipo D \\
\hline A5 & XVIII & 1 & 4 & 1 & 6 \\
\hline A6 & XVII & & 2 & 1 & 9 \\
\hline
\end{tabular}

Tabla 2.7: Estimación del número de ecoparques es la Comunidad Valenciana. Fuente: Elaboración propia a partir del PIR-CVA 2019-2022.

Se debe destacar que la función de los puntos limpios no se limita a la recogida y tratamiento de los residuos que se depositan, sino que también juegan un papel importante en fomentar la reutilización de éstos. Según la normativa vigente, los puntos limpios deberán facilitar la preparación para la reutilización o reciclaje de los residuos, en especial los RAEE, que deberán tener su propio almacén y cumplir con una serie de requisitos específicos. Además, para la realización de estas acciones, se podrán apoyar en entidades de economía social autorizadas.

Por lo que respecta al ámbito competencial, como se ha comentado anteriormente, la normativa establece que la gestión y tratamiento de los residuos forma parte del ámbito municipal.

En la Ley 22/2011, de 28 de julio, de residuos y suelos contaminados y, en concreto, en el artículo 12, se establecen las competencias administrativas en dicha materia. La distribución engloba desde el Consejo de Ministros, que aprobará el Plan Nacional marco de gestión de residuos propuesto por el Ministerio competente; hasta las funciones de las Comunidades Autónomas, que desarrollarán los planes autonómicos de prevención y gestión de residuos; y, por último, las entidades locales, que se encargarán de la recogida, el transporte y el tratamiento de los residuos domésticos dentro de sus propios Planes de Gestión de residuos.

\subsubsection{Legislación en materia de puntos limpios.}

A continuación, se muestra un listado de la normativa en materia de puntos limpios en España, tanto en el ámbito nacional como en el autonómico.

\section{Legislación Nacional.}

- Plan Estatal Marco de Gestión de Residuos (PEMAR) 2016-2022, aprobado por Resolución de 16 de noviembre de 2015, de la Dirección General de Calidad y Evaluación Ambiental y Medio Natural.

- Programa Estatal de Prevención de Residuos 2014-2020. 
- Ley 22/2011, de 28 de julio, de residuos y suelos contaminados.

- Real Decreto 110/2015, de 20 de febrero, sobre residuos de aparatos eléctricos y electrónicos.

- Orden APM/1007/2017, de 10 de octubre, sobre normas generales de valorización de materiales naturales excavados para su utilización en operaciones de relleno y obras distintas a aquéllas en las que se generaron.

- Real Decreto 105/2008, de 1 de febrero, por el que se regula la producción y gestión de los residuos de construcción y demolición.

- Real Decreto 710/2015, de 24 de julio, por el que se modifica el Real Decreto 106/2008, de 1 de febrero, sobre pilas y acumuladores y la gestión ambiental de sus residuos.

- Real Decreto 833/1988, de 20 de julio, por el que se aprueba el Reglamento para la ejecución de la Ley 20/1986 básica de residuos tóxicos y peligrosos.

- Orden de 13 de octubre de 1989, por la que se determinan los métodos de caracterización de los residuos tóxicos y peligrosos.

- Real Decreto 952/1997, de 20 de junio, por el que se modifica el Reglamento para la ejecución de la Ley 20/1986, de 14 de mayo, Básica de Residuos Tóxicos y Peligrosos, aprobado mediante Real Decreto 833/1988 de 20 de julio.

- Orden MAM/304/2002, de 8 de febrero, por la que se publican las operaciones de valorización y eliminación de residuos y la lista europea de residuos.

- Orden AAA/699/2016, de 9 de mayo, por la que se modifica la operación R1 del anexo II de la Ley 22/2011, de 28 de julio, de residuos y suelos contaminados.

\section{Legislación Autonómica.}

Galicia.

- Plan de Gestión de Residuos Urbanos de Galicia PGRUG 2010-2022.

- Ley 6/2021, de 17 de Febrero, de Residuos y Suelos Contaminados de Galicia.

Asturias.

- Plan Estratégico de Residuos del Principado de Asturias 2017-2024 PERPA.

- Anteproyecto de Ley de Sostenibilidad y Protección Ambiental.

Cantabria.

- Plan de Residuos de la Comunidad Autónoma de Cantabria 2017-2023. 
- Ley 8/1993, de 18 de noviembre, del Plan de Gestión de Residuos Sólidos Urbanos de Cantabria.

- Decreto $15 / 2010$, de 4 de marzo, por el que se aprueban los Planes Sectoriales de Residuos que desarrollan el Plan de Residuos de Cantabria 2006-2010 y, en su virtud se fijan los objetivos del mismo para el período 2010-2014.

País Vasco.

- Plan de Prevención y Gestión de Residuos de la Capv 2020.

- Programa Marco Ambiental de la CAPV 2020.

- Ley 3/1998, de 27 de febrero, General de Protección del Medio Ambiente del País Vasco.

- Reglamento de los Gargbigunes Bizkaia.

La Rioja.

- Plan Director de Residuos de La Rioja 2016-2026.

- Ley 10/2017, de 27 de octubre, por la que se consolidan las disposiciones legales de la Comunidad Autónoma de La Rioja en materia de impuestos propios y tributos cedidos.

Castilla y León.

- Plan Integral de Residuos de Castilla y León 2014-2020.

- Ley 9/2002, de 10 de julio, para la declaración de proyectos regionales de infraestructuras de residuos de singular interés para la Comunidad.

- Manual de Buenas Prácticas para la explotación de puntos limpios en Castilla y León.

Navarra.

- Plan de Residuos de Navarra 2017-2027.

- Ley Foral 6/1990, de 2 de julio, de Administración Local de Navarra.

- Ley Foral 4/2005, de 22 de marzo, de Intervención para la Protección Ambiental.

- Decreto Foral 23/2011, de 28 de marzo, sobre Residuos de Construcción y Demolición.

- Ley Foral 14/2018 de Residuos y su fiscalidad.

Aragón

- Plan de Gestión Integral de Residuos de Aragón 2018-2022.

- Manual: Guía para la prevención y gestión de los residuos domésticos en Aragón (2019).

Cataluña.

- Programa General De Prevención y Gestión de Residuos y Recursos de Cataluña 2020. 
- Ley 8/2008, de 10 de julio, de financiación de las infraestructuras de gestión de los residuos y de los cánones sobre la disposición del desperdicio de los residuos.

- Ley 20/2009, de 4 de diciembre, de Prevención y control ambiental de las actividades.

- Decreto 87/2010, de 29 de junio, por el que se aprueba el Programa de gestión de residuos municipales de Cataluña (PROGREMIC) y se regula el procedimiento de distribución de la recaudación de los cánones sobre la eliminación de los residuos municipales.

- Decreto 16/2010, de 16 de febrero, por el que se aprueba el Plan territorial sectorial de infraestructuras de gestión de residuos municipales.

- Decreto 89/2010, de 29 de junio, por el que se aprueba el Programa de gestión de residuos de la construcción de Cataluña (PROGROC), se regula la producción y gestión de los residuos de la construcción y demolición, y el canon sobre la deposición controlada de los residuos de la construcción.

- Decreto Legislativo $1 / 2009$, de 21 de Julio, por el que se aprueba el texto refundido de la Ley reguladora de los residuos.

- Norma Tècnica Deixalleries 2019.

Comunidad Valenciana.

- Plan Integral de Residuos de la Comunitat Valenciana (PIRCVA) 2013-2022.

- Ley 10/2000, De 12 De Diciembre, de Residuos de la Comunidad Valenciana.

- Norma Técnica Reguladora de la Implantación y funcionamiento de los Ecoparques (Anexo 1.1. del PIRCVA).

Castilla La Mancha.

- Plan Integrado de Gestión de Residuos de Castilla-La Mancha (2009-2019).

Murcia.

- Plan de Residuos de la Región de Murcia 2016-2020.

- Ley 10/1998, de 21 de Abril, de Residuos.

- Manual "Gestión de la Red de Ecoparques de la Región de Murcia".

Andalucía.

- Plan Director Territorial de Residuos No Peligrosos de Andalucía 2010-2019, aprobado por el Decreto 397/2010, de 2 de noviembre.

- Ley 7/2007, de 9 de julio de Integrada de la Calidad Ambiental. 
- Decreto 7/2012, de 17 de enero, por el que se aprueba el Plan de Prevención y Gestión de Residuos Peligrosos de Andalucía 2012-2020.

- Decreto 73/2012, de 22 de Marzo, por el que se aprueba el Reglamento de Residuos de Andalucía.

Extremadura.

- Plan Integrado de Residuos de Extremadura 2016-2022 (PIREX).

- Manual para la correcta gestión de un Punto Limpio.

Madrid.

- Plan de Gestión de Residuos Domésticos y Comerciales (2017 - 2024).

- Ley 6/2003, de 20 de marzo, del Impuesto sobre Depósito de Residuos.

- Ley 5/2003, de 20 de Marzo, de Residuos de la Comunidad de Madrid.

Islas Baleares.

- Mallorca: Plan Director Sectorial de Residuos sólidos urbanos. Revisión aprobada por el Pleno de 6 de febrero de 2006.

- Mallorca: Plan Director Sectorial para la Gestión de los Residuos de Construcción, Demolición, Voluminosos y Neumáticos fuera de uso de la isla de Mallorca.

- Menorca: Plan Director Sectorial para la gestión de los residuos no peligrosos de Menorca.

- Ibiza y Formentera: Plan Director Sectorial para la gestión de los residuos urbanos de Eivissa y Formentera. Aprobado definitivamente mediante Decreto 46/2001, de 30 de marzo.

- Ley $13 / 2012$, de 20 de noviembre, de medidas urgentes para la activación económica en materia de industria y energía, nuevas tecnologías, residuos, aguas, otras actividades y medidas tributarias.

- Ley 8/2019, de 19 de Febrero, de Residuos y suelos contaminados de las Illes Balears.

Islas Canarias.

- Plan Integral de Residuos de Canarias 2001. Se están desarrollando planes de ámbito insular. Ya están aprobados Planes insulares en materia de residuos, en Tenerife y Fuerteventura.

- Ley 1/1999, de 29 de Enero, de Residuos de Canarias.

- Decreto 29/2002, De 25 De Marzo, por el que se regula el funcionamiento de las instalaciones denominadas Puntos Limpios. 


\subsection{Referencias.}

Arena, U., Di Gregorio, F., Amorese, C., Mastellone, M.L., 2011. A techno-economic comparison of fluidized bed gasification of two mixed plastic wastes. Waste Manag. 31, 1494-1504. https://doi.org/10.1016/J.WASMAN.2011.02.004 .

Bandara, J. P. A. Hettiaratchi, S. C.Wirasinghe, y S. Pilapiiya, Relation of waste generation and composition to socio-economic factors: a case study, Environmental Monitoring Assessment, 135:31-39, 2007.

Benito, V. 2001. Modelos de gestión de residuos industriales. Gestión de residuos industriales. Conselleria de Medio Ambiente.

Berbel, J. P. nuelas, J. Ortiz, y M. Gómez, Análisis comparado de modelos de recogida selectiva de envases/orgánico, Residuos, (59):52- 57, 2001.

Berglund, P. Söderholm, y M. Nilsson, A note on inter-country differences in waste paper recovery and utilization, Resources, Conservation and Recycling, 34:175-191, 2002.

Bonomo, G. Durán, F. Larumbe, y J. Marenco, Optimización de la recolección de residuos en la zona sur de la ciudad de Buenos Aires, Revista Ingeniería de Sistemas, 23:71-87, 2009.

Bosch, M. Büchele, y D. Gee, Environmental indicators: typology and overview, Technical report 25, European Environmental Agency, 1999.

Buekens, A., Cen, K., 2011. Waste incineration, PVC, and dioxins. J. Mater. Cycles Waste Manag. 13, 190-197. https://doi.org/10.1007/s10163-011-0018-9.

Cerisuelo, A; Piquer, O. 2009. Subproductos agroindustriales en alimentación animal: herramientas para su utilización. Jornada: Aprovechamiento de subproductos y Tratamiento de Residuos de la Industria Alimentaria y la Producción Animal. Centro de Investigación y Tecnología Animal (CITAIVIA), Universidad CEU Cardenal Herrera. Conselleria d'Agricultura, Pesca i Alimentació.

Colomer, F.J., Gallardo, A., 2007. Tratamiento y gestión de residuos sólidos. Editorial Universidad Politécnica de Valencia, Valencia, España.

Crillesen, K., Skaarup, J., 2006. Management of Bottom Ash from WTE Plants (ISWA-WG Thermal Treatment Subgroup Bottom Ash from WTE-Plants). International Solid Waste Association (ISWA).

Dahlén, S. Vukicevic, J. Meijer, y A. Lagerkvist, Comparison of different collection systems for sorted household waste in Sweden, Waste Management, 27(10):1298-1305, 2007.

Declaración de la Conferencia de las Naciones Unidas sobre el Medio Humano, Estocolmo, Suecia 1972. 
Edo-Alcon, N. 2019. Diseño de una metodología para el control de calidad de los rechazos producidos en plantas de tratamiento mecánico-biológico de residuos sólidos urbanos. Tesis Doctoral. Universitat Jaume I.

EU DGE. 2012. Preparing a Waste Management Plan. A methodological guidance note. European Commission, DG Environment. http://ec.europa.eu/environment/waste/plans/index.htm

Fundación Conde del Valle de Salaza (FUCOVASA), Federación Española de Municipios (FEMP), ECOEMBES (Eds.), 2015. Guía técnica: La gestión de residuos municipales, 2nd ed. Editorial MIC, Madrid, España.

Fundación Ecolec, Información y Recursos sobre los RAEE, www.ecolec.es.

Gallardo, A., Edo-Alcón, N., Sánchez-López, I., 2019. Producción de combustibles sólidos a partir de residuos domiciliarios, in: Gallardo Izquierdo, A., Colomer Mendoza, F.J., Campos Rodríguez, R., Arias Aguilar, D. (Eds.), Aprovechamiento Energético de Residuos. Publicaciones de la Universitat Jaume I, Castellón de la Plana, España, pp. 39-68.

Gomes, M. Matos, y I. Carvalho, Separate collection of the biodegradable fraction of msw: An economic assessment, Waste Management, 28(10):1711-1719, 2008.

H. A. Abu-Qdais, M. F. Hamoda, y J. Newham, Analysis of residential solid waste at generation sites, Waste Management and Research, 15:395-406, 1997.

Honaria. E. y Zamorano M., Fundamentos del Manejo de los Residuos Urbanos, 2000.

Instituto Nacional de Estadística. Encuesta sobre generación de residuos, año 2018.

Jimena, L. 2001. Producción y gestión de residuos en el sector industrial. Gestión de residuos industriales. Conselleria de Medio Ambiente.

Kisuk CPE, 1998. Solid waste incineration (Report TI 814-21). U.S. Corps. of Engineers, Engineering Division, Washington D.C.

MAGRAMA, 2015. Plan Estatal Marco de Gestión de Residuos (PEMAR) 2016-2022. Ministerio de Agricultura, Alimentación y Medio Ambiente. Boletín Of. Estado 117395117397.

McKay, G., 2002. Dioxin characterisation, formation and minimisation during municipal solid waste (MSW) incineration: Review. Chem. Eng. J. 86, 343-368. https://doi.org/10.1016/S1385-8947(01)00228-5

Mendoza, J.A.; Montañés, M.T.; Palomares, A.E..1998. Ciència i tecnologia del medi ambient. Monografies de la Universitat Politècnica de València. 
Ministerio de agricultura, alimentación y medio ambiente. 2015. PLAN ESTATAL MARCO DE GESTIÓN DE RESIDUOS (PEMAR) 2016-2022. (https://www.miteco.gob.es/es/calidad-yevaluacion-ambiental/planes-y-estrategias/pemaraprobado6noviembrecondae_tcm30170428.pdf).

MITECO, 2019. Memoria anual de generación y gestión de residuos: residuos de competencia municipal, 2016. Ministerio para la Transición Ecológica, Madrid, España.

Moreno, J; Vargas-García, C; López, M.J.; Suárez-Estrella, F. 2008. Biodegradación de la materia orgánica: la clave invisible. Dpto. Biología Aplicada. Universidad de Almería.

Montejo Méndez, C., 2015. Optimización en el tratamiento de las fracciones orgánica y de rechazo procedentes de residuos urbanos (Tesis Doctoral). Universidad de Salamanca.

Oppelt, E.T., 1986. Hazardous Waste Destruction: Thermal Techniques will be Increasingly Used as Legal Restrictions on Land Disposal Take Effect. Environ. Sci. Technol. 20, 312318.

Psomopoulos, C.S., Bourka, A., Themelis, N.J., 2009. Waste-to-energy: A review of the status and benefits in USA. Waste Manag. 29, 1718-1724. https://doi.org/10.1016/J.WASMAN.2008.11.020

Rodríguez, H., Gestión Integral de Residuos Sólidos Urbanos, Fundación Universitaria del Área Andina, 2012.

Rodríguez-Martín, A., Palomo-Zurdo, R., González-Sánchez, F., Transparencia y economía circular: análisis y valoración de la gestión municipal de los residuos sólidos urbanos, CIRIEC-España, Revista de Economía Pública, Social y Cooperativa, 2020.

Sastre, S., Llopart, J., Puig Ventosa, I., 2018. Mind the gap: A model for the EU recycling target applied to the Spanish regions. Waste Manag. 79, 415-427. https://doi.org/10.1016/J.WASMAN.2018.07.046 .

Soriano, C. 2001. Gestión de residuos dentro de la gestión medioambiental. Gestión de residuos industriales.

Tchobanoglous, G., Theisen, H., Vigil, S.A., 1994. Gestión integral de residuos sólidos. McGraw-Hill, Madrid, España. 

CAPítulo 3. InFLUENCIA DE LOS PUNTOS LIMPIOS EN LA DISMINUCIÓN DE MICROVERTEDEROS INCONTROLADOS. ESTUDIOS DEL CASO DE CASTELLÓ. 



\section{INFLUENCIA DE LOS PUNTOS LIMPIOS EN LA DISMINUCIÓN DE MICROVERTEDEROS INCONTROLADOS. ESTUDIO DEL CASO DE CASTELLÓ.}

\subsection{Introducción.}

A pesar de que desde el año 2001 la legislación española prohíbe el vertido incontrolado de residuos, en las periferias de las ciudades todavía aparecen microvertederos, en los que se produce el vertido ilegal de residuos, siendo una fuente de contaminación y otros problemas.

Un microvertedero incontrolado es un lugar en el que, sin estar preparado para ello y $\sin$ consideraciones medioambientales, es elegido por algún vecino para depositar algunos residuos. Éstos suelen aparecer en caminos, cunetas, ramblas, barrancos, solares, etc., e incluso en espacios naturales protegidos. En ellos se vierten escombros, poda, enseres viejos, electrodomésticos y todo tipo de residuos urbanos de diferente naturaleza. Su aparición suele deberse principalmente a la comodidad de los ciudadanos o empresas de no llevar los residuos hasta el punto limpio correspondiente, aunque también puede ser ocasionado por falta de una política de retirada de enseres a domicilio por parte del ayuntamiento y por la falta de conciencia ambiental.

Es habitual que un microvertedero comience con el vertido de escombros, podas o enseres, pero poco a poco atraerá residuos más peligrosos, como pueden ser: electrodomésticos, aceites, pinturas, disolventes, etc. Las principales problemáticas de los mismos, además del impacto visual, son: la contaminación de los suelos, del aire y de las aguas; la producción de olores; el vuelo y dispersión de las fracciones más ligeras; la proliferación de vectores, e incluso riesgo de explosiones e incendios (Sharma et al. 2008). Como consecuencia, los ayuntamientos deben habilitar brigadas de limpieza para la retirada continua de estos residuos, con el consiguiente coste económico que ello supone.

Para poder minimizar esta problemática, es muy importante conocer las causas que provocan este fenómeno, lo que permitirá establecer medidas correctivas, así como su localización. Son muy pocos los trabajos publicados sobre el tema de la gestión y solución a los microvertederos incontrolados. En este sentido, Silvestri y Omri (2008) diseñaron un método, basado en teledetección mediante sensores remotos y sistemas de información geográfica, con el objetivo de identificar los vertederos incontrolados en grandes áreas y que después validaron en el noroeste de Italia. Otro trabajo utilizó la teledetección, sistemas de información geográfica y el análisis 
multicriterio espacial para la identificación de áreas potencialmente contaminadas y que podrían albergar vertederos incontrolados, obteniendo como resultado un mapa que describe las probabilidades de que existan vertederos ilegales (Biotto et al. 2009).

Por su parte, Jordá, Ruiz y Lucendo (2013) estudiaron los factores territoriales de localización y características de los vertederos incontrolados o ilegales en Andalucía mediante un análisis exploratorio y multifactorial. Como resultados obtuvieron que, a escala regional, los factores que caracterizan la localización de los vertederos ilegales vienen definidos por variables socioeconómicas del territorio y de sensibilidad ambiental de las instituciones competentes en la materia, mientras que a escala local tienen que ver con la presencia de desigualdades sociales, tipos de residuos existentes, eficiencia de la gestión de éstos y con los rasgos litológicosgeomorfológicos del emplazamiento. Este mismo estudio agrupa las principales variables que afectan a la localización de microvertederos y vertederos incontrolados en 4 grandes tipos (Jordá, Ruiz y Lucendo 2013):

- Geofísicas: variables relacionadas con los aspectos geomorfológicos, litoestructurales, vegetación, pendientes, hidrología (cursos de aguas, aguas subterráneas), tipos de uso del suelo, las áreas protegidas, etc.

- De gestión y actividad: variables relacionadas con el entorno de los vertederos como son la accesibilidad y visibilidad o las características y tipo de residuos.

- Socioeconómicas: población residente, renta, infraestructuras viarias, actividades económicas, etc.

- Otras: como son la proximidad a zonas urbanas, áreas residenciales e industriales, las infraestructuras físicas y vías de comunicación existentes o la naturaleza catastral del lugar donde se encuentra el vertedero.

Cevallos Uve (2014) realizó un estudio en el que tuvo en cuenta la problemática ambiental que generan los microvertederos, especialmente en las condiciones higiénico sanitarias y de contaminación de aguas, donde se ponía el foco en el problema que suponen éstos en la contaminación del agua y el suelo y sus efectos sobre la biodiversidad. Como principales conclusiones destacaba la importancia de elaborar e implantar planes de gestión de la contaminación y el diseño de un programa de educación ambiental que atienda los asuntos clave de gestión ambiental.

Más recientemente, Emilio et al. (2019) realizaron entrevistas a los vecinos de la comunidad localizada en la circunscripción n 81 , reparto Álvaro Barba, de Cuba, con el objetivo de analizar la situación higiénico-sanitaria, política, social y cultural que puede acarrear la degradación medioambiental para una comunidad por parte de los microvertederos. En concreto, la comunidad 
fue sometida a un diagnóstico mediante el método de observación directa e indirecta con el objetivo de diagnosticar la situación de dos microvertederos. Se utilizaba una escala de valoración de Alto (A), Medio (M) y Bajo (B), basada en los siguientes indicadores:

- Nivel de conocimiento de los vecinos acerca de los factores que influyen en la formación de un microvertedero.

- Nivel de conocimiento de los vecinos sobre temáticas medioambientales.

- Nivel de conocimiento de los vecinos de los daños higiénico-sanitarios aportados por un microvertedero.

- Nivel de conocimiento de los vecinos sobre acciones realizadas para la eliminación de microvertedero.

- Nivel de disposición de los vecinos ante el trabajo para la erradicación del microvertedero.

Los resultados de este estudio sobre las características que definen un microvertedero, evidenciaron que un $45,7 \%$ de los encuestados tenían alto conocimiento acerca del tema, siendo capaces de ofrecer una definición aceptada. Sin embargo, al preguntar la relación entre la existencia de microvertederos y la proliferación de enfermedades, el $78,6 \%$ señalaron un alto conocimiento, asegurando que éstos aumentan los riesgos de enfermedades en sus proximidades.

En cuanto a la eliminación o minimización de este tipo de problemática, Alfonzo et al. (2013) analizaron en una ciudad argentina la posibilidad de erradicar los microvertederos y su sustitución por espacios verdes públicos. Para ello realizaron encuestas a los vecinos de las zonas afectadas obteniendo que, a pesar de conocer la problemática e ilegalidad de los microvertederos, no existe un compromiso por parte de los vecinos y que éstos no creen que sean los responsables de su erradicación. Por su parte, Apostol y Mihai (2011) realizaron en Rumania una revisión territorial sobre el cierre y rehabilitación de vertederos y microvertederos rurales incontrolados, encontrando que la principal opción es la compactación y posterior cubrimiento con tierra, mientras que sólo una pequeña parte se traslada a vertederos controlados.

En este capítulo se presenta un trabajo de investigación en el que se intenta probar la hipótesis de que una herramienta útil para la eliminación de los microvertederos incontrolados de una población, puede ser la instalación de puntos limpios. El trabajo se desarrolla en el término municipal de Castelló de la Plana y para su desarrollo se ha contado con la colaboración de su Ayuntamiento y de la empresa contratista del servicio de limpieza y recogida de basura de la ciudad. 


\subsection{Estudio de la influencia del punto limpio en la disminución de microvertederos en Castelló de la Plana.}

Como se ha citado en el capítulo anterior, el primer método adoptado por el ser humano para eliminar los residuos, por economía y simplicidad, era durante muchos años el uso de puntos de acopio de residuos en las cercanías de los núcleos de población. Sin embargo, estos espacios han acabado convirtiéndose en auténticos problemas de salubridad en zonas urbanas. Hoy en día sigue presente esta problemática, aunque ha derivado fundamentalmente hacia el abandono de residuos voluminosos que no caben en los contenedores de los núcleos urbanos o que no pueden depositarse en los mismos y que, en su lugar, deberían ser depositados en los puntos limpios o ecoparques habilitados por las administraciones locales o supramunicipales.

Por ese motivo, continúan existiendo numerosos microvertederos a lo largo de los términos municipales, siendo muy difícil obtener datos representativos de cada municipio, dado que existen pocos estudios en la materia. No obstante, debe recordarse que el abandono de residuos, sea cual sea su composición, es motivo de sanción, proporcional según sus características, según la Ley $22 / 2011$, de 28 de julio, de residuos y suelos contaminados.

\subsubsection{Antecedentes.}

El primer trabajo sobre microvertederos realizado en Castelló de la Plana se llevó a cabo en el año 1998. Lo realizaron Martínez y Adsuara (1998) y su objetivo era determinar el número y las características de los microvertederos incontrolados que existían en el término municipal. Como resultado, se encontraron 48 microvertederos con un volumen total estimado de $13.042 \mathrm{~m}^{3}$ (Tabla 3.1). Su distribución espacial se puede observar en la Figura 3.9. En cuanto a su composición, se estableció una clasificación de siete tipos de vertederos, en función de su composición mayoritaria. En 20 de ellos predominaban los residuos de construcción y en 15, los residuos peligrosos. En el resto había residuos de diferente índole: muebles, electrodomésticos, poda, etc., como se puede ver en la Tabla 3.2.

En el año 2001, el Ayuntamiento construyó un punto limpio a las afueras de la ciudad, en la zona oeste; con ello pretendía eliminar el gran número de microvertederos incontrolados que tenía el término y que suponían, además de un impacto ambiental grave, un coste económico importante.

En el año 2003, Gallardo et al. (2006) realizaron un estudio de investigación para determinar cuál había sido la influencia de la construcción del punto limpio en la disminución de microvertederos y en la reducción de su volumen. Los resultados obtenidos fueron los siguientes: 
- El número total de vertederos se redujo en un $29 \%$. El total de vertederos encontrados en 1998 fue de 48 y en el año 2003 fue de 34. Destaca la reducción de número de vertederos de tamaño medio (entre 50 y $1.000 \mathrm{~m}^{3}$ ) que en cinco años se ha reducido en un $50 \%$.

- La capacidad total de los microvertederos también se redujo en un 9\%. La evolución de la capacidad y la distribución de tamaños se pueden observar en la Tabla 3.1.

- La composición de los residuos encontrados en los vertederos fue muy variada. No obstante, es muy destacable la reducción en cuanto a residuos de la construcción y demolición (RCD) y de los residuos peligrosos experimentada en dicho periodo. La composición y el número de vertederos de cada tipo se detallan en la Tabla 3.2.

- Respecto a la distribución geográfica de los microvertederos, continuó siendo muy variable. No obstante, se observó una reducción de vertederos en la zona oeste de la ciudad (ver Figura 3.9).

\begin{tabular}{|l|r|r|r|r|}
\hline \multirow{2}{*}{ Capacidad $\left(\mathbf{m}^{\mathbf{3}}\right)$} & \multicolumn{2}{|c|}{ Número de microvertederos } & \multicolumn{2}{c|}{ Capacidad total $\left(\mathbf{m}^{\mathbf{3}}\right)$} \\
\cline { 2 - 5 } & \multicolumn{1}{|c|}{ Año 1998 } & Año 2003 & Año 1998 & Año 2003 \\
\hline $50<$ & 24 & 18 & 414,5 & 289 \\
\hline $50-300$ & 15 & 5 & $2.432,5$ & 640 \\
\hline $300-500$ & 2 & 3 & 720 & 950 \\
\hline $500-1000$ & 3 & 4 & 2.050 & 2.250 \\
\hline$>1000$ & 4 & 4 & 4.800 & 7.725 \\
\hline Total & 48 & 34 & 13.042 & 11.854 \\
\hline
\end{tabular}

Tabla 3.1: Distribución de tamaños de los microvertederos y capacidad total en 1998 y en 2003. Martínez y Adsuara (1998) y Gallardo et al. (2006).

\begin{tabular}{|l|r|r|}
\hline \multicolumn{1}{|c|}{ Tipo de microvertedero } & \multicolumn{2}{c|}{ Número de microvertederos } \\
\cline { 2 - 3 } & Año 1998 & \multicolumn{1}{|c|}{ Año 2003 } \\
\hline Construcción & 20 & 2 \\
\hline Mezcla (todos los tipos sin peligrosos) & 8 & 14 \\
\hline Mezcla Peligrosos (todos los tipos más peligrosos) & 15 & 8 \\
\hline Construcción, muebles y electrodomésticos & 1 & 5 \\
\hline Poda y siega & 2 & 5 \\
\hline Agrícolas & 1 & 0 \\
\hline Plásticos & 1 & 0 \\
\hline Total & 48 & 34 \\
\hline
\end{tabular}

Tabla 3.2: Categorías y número de vertederos de cada tipo en 1998 y en 2003. Martínez y Adsuara (1998) y Gallardo et al. (2006).

En el año 2014 se decidió realizar un nuevo el estudio de los microvertederos incontrolados del término municipal de la ciudad de Castelló de la Plana, con el fin de comprobar su evolución en el tiempo, y a partir de aquí establecer una relación definitiva entre la existencia del punto limpio y la disminución de microvertederos. 


\subsubsection{Descripción de los puntos limpios de la ciudad de Castelló de la Plana.}

La ciudad de Castelló de la Plana está situada en la provincia de Castellón y cuenta actualmente con una población de 170.264 habitantes (INE 2019). El conjunto del término municipal tiene una superficie de $108,50 \mathrm{~km}^{2}$.

En referencia a la gestión de los residuos y, en concreto, al servicio de puntos limpios que se presta actualmente en la ciudad, Castelló cuenta con tres puntos de aportación en total: un punto limpio y dos móviles, de propiedad municipal. De esta manera, los puntos limpios móviles complementan a la instalación fija y permiten ofrecer un servicio más próximo que llegue a la totalidad de la población.

\section{Punto limpio fijo.}

La instalación del punto limpio fijo se inauguró en 2001 con el objetivo recibir y almacenar aquellos residuos que no se recogen mediante el sistema de contenerización de la ciudad. Según la Conselleria de Infraestructuras, Territorio y Medio Ambiente, la tipología de esta instalación es de tipo $D$, que es la de mayor superficie y está ideada para una población potencial de más de 10.001 personas.

El punto limpio fijo tiene una superficie de más de $6.000 \mathrm{~m}^{2}$ y cuenta con dos niveles de distribución, para así facilitar la aportación de residuos según su tipología y clasificarlos correctamente en los contenedores. La distribución es la siguiente: las zonas de circulación y los contenedores de 18 y $26 \mathrm{~m}^{3}$ están situados en la planta superior, mientras que el resto de los elementos que componen la instalación se encuentran en el nivel inferior.

Como se observa en la Figura 3.1, el punto limpio está situado a las afueras del núcleo urbano, aunque está bien comunicado por carretera para facilitar su acceso a todos los vecinos. En la Figura 3.2 tenemos un esquema de la distribución en planta del punto limpio fijo. 


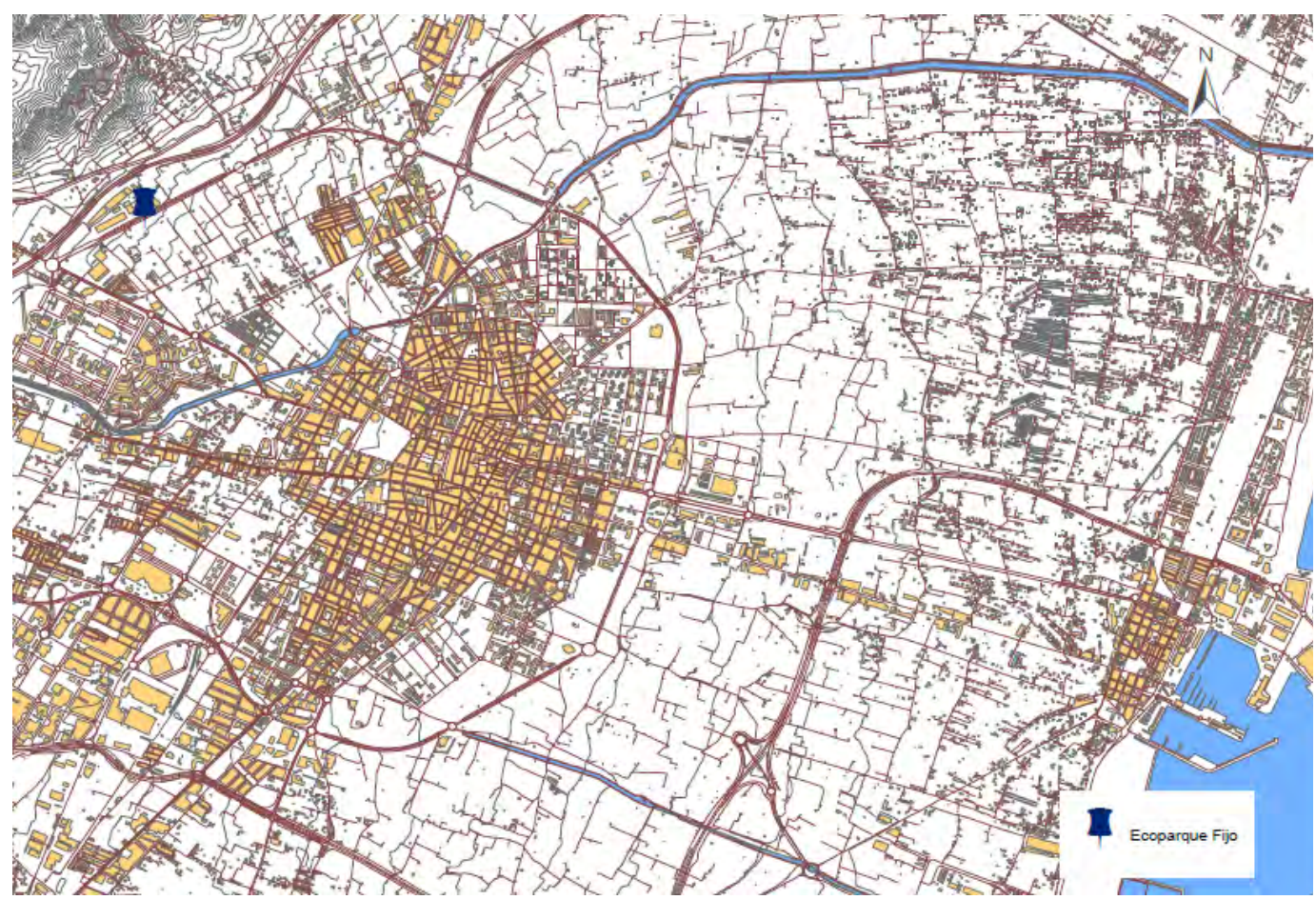

Figura 3.1: Ubicación del punto limpio de Castelló de la Plana.

El horario de servicio establecido en el punto limpio fijo para dar servicio a la ciudadanía viene establecido en la Tabla 3.3.

\begin{tabular}{|c|l|}
\hline \multicolumn{2}{|c|}{ SERVICIO PUNTO LIMPIO FIJO } \\
\hline $\begin{array}{c}\text { Invierno. } \\
\text { (de 1 de octubre a 31 de mayo) }\end{array}$ & $\begin{array}{l}\text { Lunes a sábado: 9:00 a 14:00 y de 15:30 a 18:00. } \\
\text { Domingos y festivos: 9:00 a 14:00. }\end{array}$ \\
\hline $\begin{array}{c}\text { Verano. } \\
\text { (de 1 de junio a 30 de septiembre) }\end{array}$ & $\begin{array}{l}\text { Lunes a sábado: 9:00 a 13:30 y de 16:00 a 19:00. } \\
\text { Domingos y festivos: 9:00 a 14:00. }\end{array}$ \\
\hline
\end{tabular}

Tabla 3.3: Horario de apertura del punto limpio fijo de Castelló de la Plana. Fuente: Ayuntamiento de Castelló de la Plana.

Para garantizar el correcto almacenamiento y gestión de los residuos depositados por los particulares en el punto limpio, la normativa de la propia instalación ha realizado una clasificación de los residuos admisibles y no admisibles, que se recoge en la Tabla 3.4. 


\begin{tabular}{|c|c|}
\hline ADMISIBILIDAD & FRACCIONES DE RESIDUOS \\
\hline \multirow{3}{*}{$\begin{array}{l}\text { Residuos } \\
\text { admisibles }\end{array}$} & $\begin{array}{l}\text { RESIDUOS BANALES } \\
\text { Envases de brik } \\
\text { Latas } \\
\text { Vidrio: transparente, de color y vidrio plano. } \\
\text { Papel y cartón } \\
\text { Metales: aluminio y chatarra diversa. } \\
\text { Plásticos: blanco, de color y transparente. } \\
\text { Textiles }\end{array}$ \\
\hline & $\begin{array}{l}\text { RESIDUOS VOLUMINOSOS } \\
\text { Maderas (maderas limpias usadas) } \\
\text { Enseres } \\
\text { Grandes electrodomésticos } \\
\text { Electrodomésticos de frío } \\
\text { Pequeños electrodomésticos } \\
\text { Restos de ropa } \\
\text { Escombros (de pequeñas obras/reformas) }\end{array}$ \\
\hline & $\begin{array}{l}\text { RESIDUOS PELIGROSOS } \\
\text { Aceites: vegetales y minerales. } \\
\text { Baterías } \\
\text { Pilas/acumuladores } \\
\text { Pantallas } \\
\text { Fluorescentes } \\
\text { Radiografías }\end{array}$ \\
\hline $\begin{array}{l}\text { Residuos no } \\
\text { admisibles }\end{array}$ & $\begin{array}{l}\text { Residuos en mal estado o no identificables. } \\
\text { Neumáticos usados. } \\
\text { Vehículos fuera de uso o partes de ellos. } \\
\text { Residuos de la fracción orgánica. } \\
\text { Residuos sanitarios. } \\
\text { Residuos radioactivos. } \\
\text { Residuos generados por las actividades mineras o extractivas. } \\
\text { Materiales explosivos (pirotécnica o airbags). } \\
\text { Residuos mezclados. } \\
\text { Aceites usados procedentes de talleres de reparación de } \\
\text { automóviles. }\end{array}$ \\
\hline
\end{tabular}

Tabla 3.4: Clasificación de los residuos según su admisibilidad en el punto limpio fijo de Castelló de la Plana. Fuente: Ayuntamiento de Castelló de la Plana.

El servicio de punto limpio se ciñe a la ciudadanía y pequeñas empresas (autónomos fundamentalmente), ya que los municipios en colaboración con los Consorcios son los que tienen la competencia de recogida y gestión de los residuos domésticos y asimilables a domésticos generados por la ciudadanía. Por esta razón, forman parte de los residuos no admitidos en los puntos limpios aquellos provenientes de una actividad empresarial o industrial, ya que la responsabilidad de su tratamiento y gestión es de la propia empresa, y debe gestionar los residuos generados fruto de su actividad a través de gestores autorizados. Para evitar el uso indebido de las instalaciones de los puntos limpios, las cantidades de aportación de determinadas fracciones de residuos están limitadas. 
Por último, además del servicio prestado por el punto limpio fijo, el Ayuntamiento de Castelló ofrece un servicio gratuito puerta a puerta para la recogida de enseres domésticos de gran tamaño. Este servicio se realiza a demanda y con aviso previo; de manera que, para ofrecer un buen servicio, el ciudadano deberá informar de la tipología del residuo que desea que se le recoja, facilitar su información personal y el día deseado para realizar la recogida.

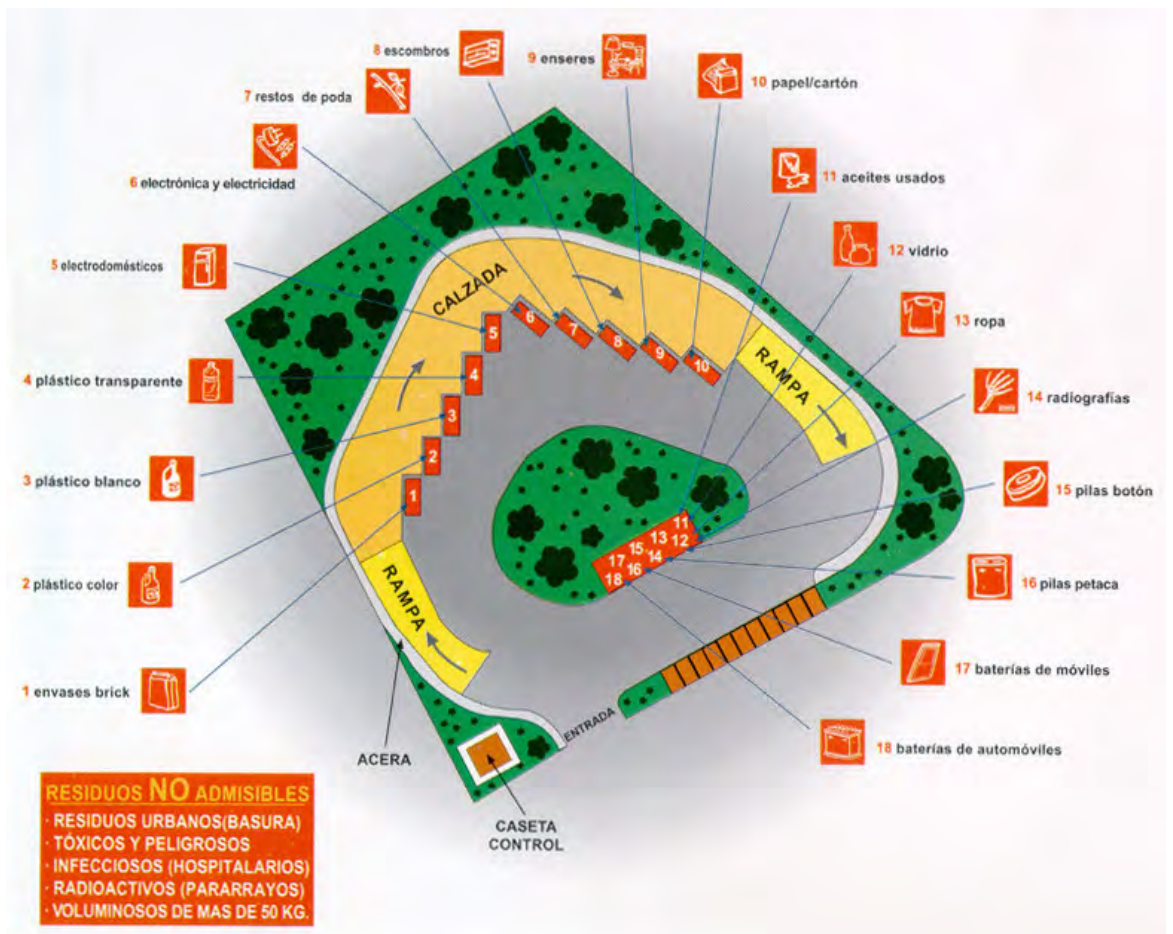

Figura 3.2: Distribución del punto limpio Fijo de Castelló de la Plana. Fuente: Ayuntamiento de Castelló de la Plana. 


\section{Puntos limpios móviles.}

Para poder complementar el servicio del punto limpio fijo y aproximar estas instalaciones a la ciudadanía, la ciudad dispone de dos ecoparques móviles que diariamente se instalan en diferentes puntos de la ciudad con un horario establecido.

Uno de los ecoparques móviles se trata de un camión con espacios habilitados para el depósito de las fracciones de residuo admitidas. El segundo, consiste en una caja móvil que se transporta por un camión y se instala en los puntos habilitados y contemplados para ofrecer el servicio. En su interior, también están habilitados los diferentes contenedores para el depósito de los residuos. Las imágenes de la Figura 3.3 muestran ambas instalaciones móviles.
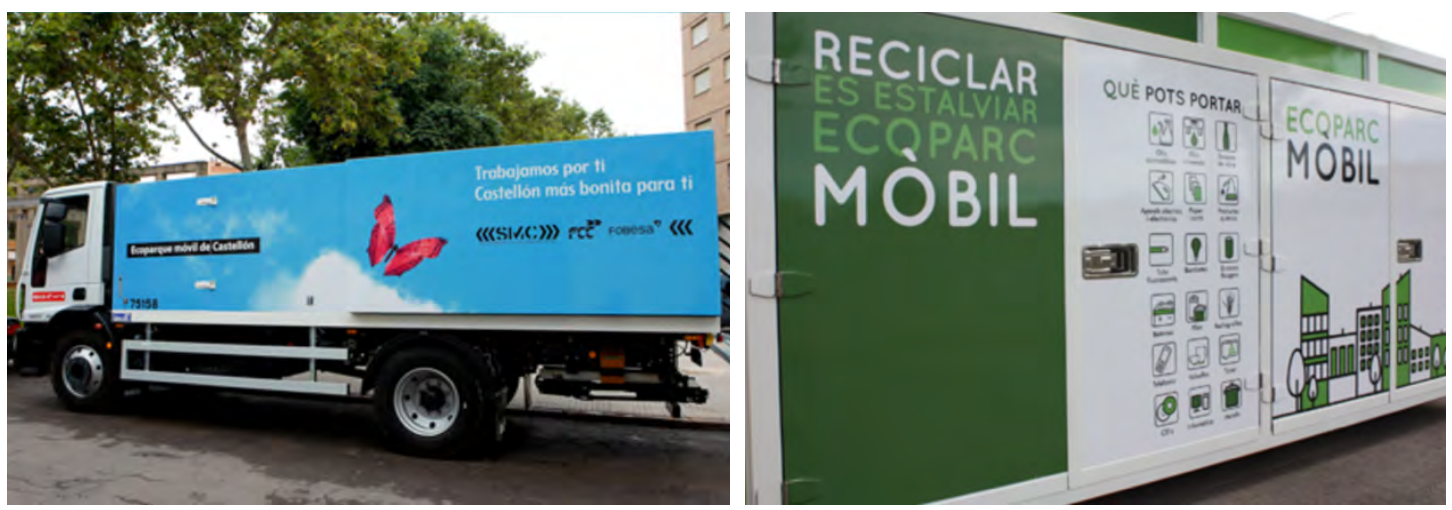

Figura 3.3: Ecoparques móviles, camión y caja móvil, respectivamente, de Castelló de la Plana. Fuente: Ayuntamiento de Castelló de la Plana.

Los ecoparques móviles posibilitan que aquellas personas que no puedan desplazarse a la instalación fija para depositar las fracciones de residuos que no se recogen en los contenedores, puedan hacerlo en estas instalaciones y posibilitar su correcta gestión.

Para lograr aproximar estos puntos a toda la población, el Ayuntamiento ha establecido unos puntos de ubicación para cada uno de los ecoparques, intentando proporcionar servicio a todos los distritos de la ciudad. En algunos de los puntos definidos, el punto limpio móvil se instala durante todo el día, y en otros se presta el servicio en horario de mañana o tarde. Los horarios se adjuntan en las Tablas 3.5 y 3.6 y sus ubicaciones en las Figuras 3.4 y 3.5. Además, en las ubicaciones definidas para los sábados por la mañana, se presta el servicio en semanas alternas, es decir, con una frecuencia quincenal. A continuación, se recogen las ubicaciones establecidas para cada uno de los ecoparques. 
Influencia de los puntos limpios en la disminución de microvertederos incontrolados. Estudio del caso de Castelló.

\begin{tabular}{|c|c|c|c|c|c|c|}
\hline \multicolumn{7}{|c|}{ PUNTO LIMPIO SOBRE CAMIÓN } \\
\hline & LUNES & MARTES & MIÉRCOLES & JUEVES & VIERNES & SÁBADO \\
\hline \multirow{2}{*}{$\begin{array}{l}\text { Mañana } \\
7: 30- \\
13: 15 \mathrm{~h}\end{array}$} & \multirow{2}{*}{$\begin{array}{l}\text { C/Jesús } \\
\text { Martí Martín } \\
\text { - Paseo } \\
\text { Universidad }\end{array}$} & \multirow{2}{*}{$\begin{array}{l}\text { Av. Chatelerault } \\
-M^{a} \text { Teresa } \\
\text { González Justo }\end{array}$} & \multirow{2}{*}{ Pz. España } & \multirow{2}{*}{$\begin{array}{l}\text { Primer Molí - } \\
\text { Av. } \\
\text { Capuchinos }\end{array}$} & \multirow{2}{*}{$\begin{array}{l}\text { Tenencia } \\
\text { Alcaldía Grao. } \\
\text { P. Buenavista }\end{array}$} & $\begin{array}{l}\text { Av. Rey } \\
\text { D.Jaime }\end{array}$ \\
\hline & & & & & & $\begin{array}{l}\text { Instituto Fco. } \\
\text { Ribalta }\end{array}$ \\
\hline $\begin{array}{l}\text { Tarde } \\
14: 15- \\
19: 45 h\end{array}$ & $\begin{array}{l}\text { Pz. Herrero } \\
\text { Tejedor }\end{array}$ & $\begin{array}{l}\text { C/Maestro } \\
\text { Ripollés - } \\
\text { C/ Clara } \\
\text { Campoamor }\end{array}$ & $\begin{array}{l}\text { Pz- Santa } \\
\text { Clara - } \\
\text { C/Mayor }\end{array}$ & $\begin{array}{l}\text { C/Onda-C/ } \\
\text { Río Navia }\end{array}$ & Pz. Libertad & $\begin{array}{l}\text { Pz. Illes } \\
\text { Columbretes }\end{array}$ \\
\hline
\end{tabular}

Tabla 3.5: Ubicaciones y horarios establecidos para el punto limpio sobre camión.

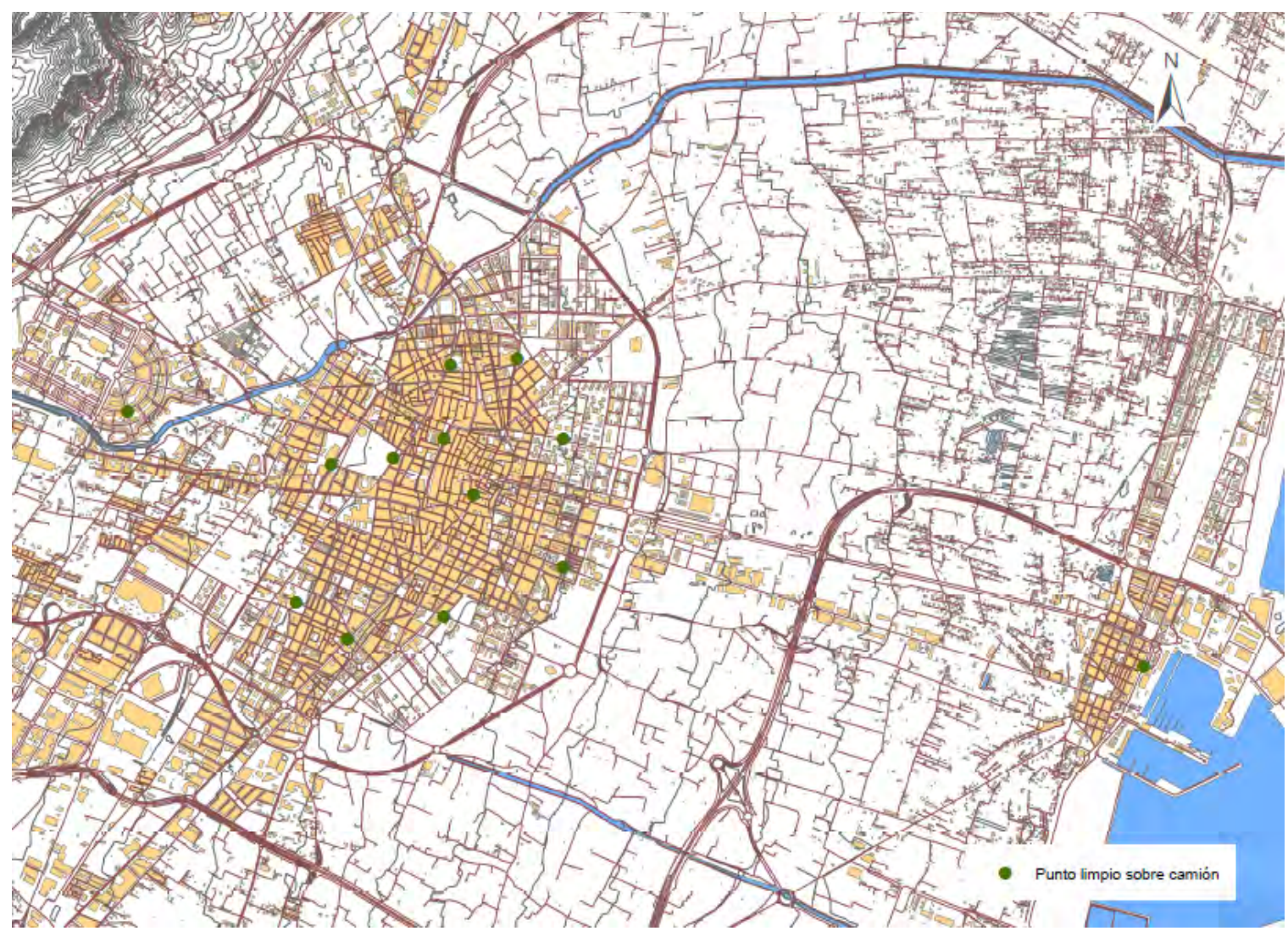

Figura 3.4: Localización de ubicaciones del Punto limpio sobre camión. Fuente: Ayuntamiento de Castelló de la Plana. 


\begin{tabular}{|c|c|c|c|c|c|c|}
\hline \multicolumn{7}{|c|}{ PUNTO LIMPIO CAJA MÓVIL } \\
\hline & LUNES & MARTES & MIÉRCOLES & JUEVES & VIERNES & SÁBADO \\
\hline Mañana & Camino & \multirow{3}{*}{ C/ L'llla } & \multirow{3}{*}{$\begin{array}{l}\text { C/ Pintor } \\
\text { Carbó }\end{array}$} & \multirow{3}{*}{ C/Guardamar } & \multirow{3}{*}{ C/ Huesca } & AAVV Marjalería \\
\hline $13: 15 \mathrm{~h}$ & Caminás & & & & & $\begin{array}{l}\text { S. Agustín - } \\
\text { S. Marcos }\end{array}$ \\
\hline $\begin{array}{l}\text { Tarde } \\
14: 15- \\
19: 45 \mathrm{~h}\end{array}$ & $\begin{array}{l}\text { C/Río Sella } \\
\text { (Palau de la } \\
\text { Festa) }\end{array}$ & & & & & $\begin{array}{l}\text { Plaza } \\
\text { Comunicaciones }\end{array}$ \\
\hline
\end{tabular}

Tabla 3.6: Ubicaciones y horarios establecidos para el punto limpio caja móvil. Fuente: Ayuntamiento de Castelló de la Plana.

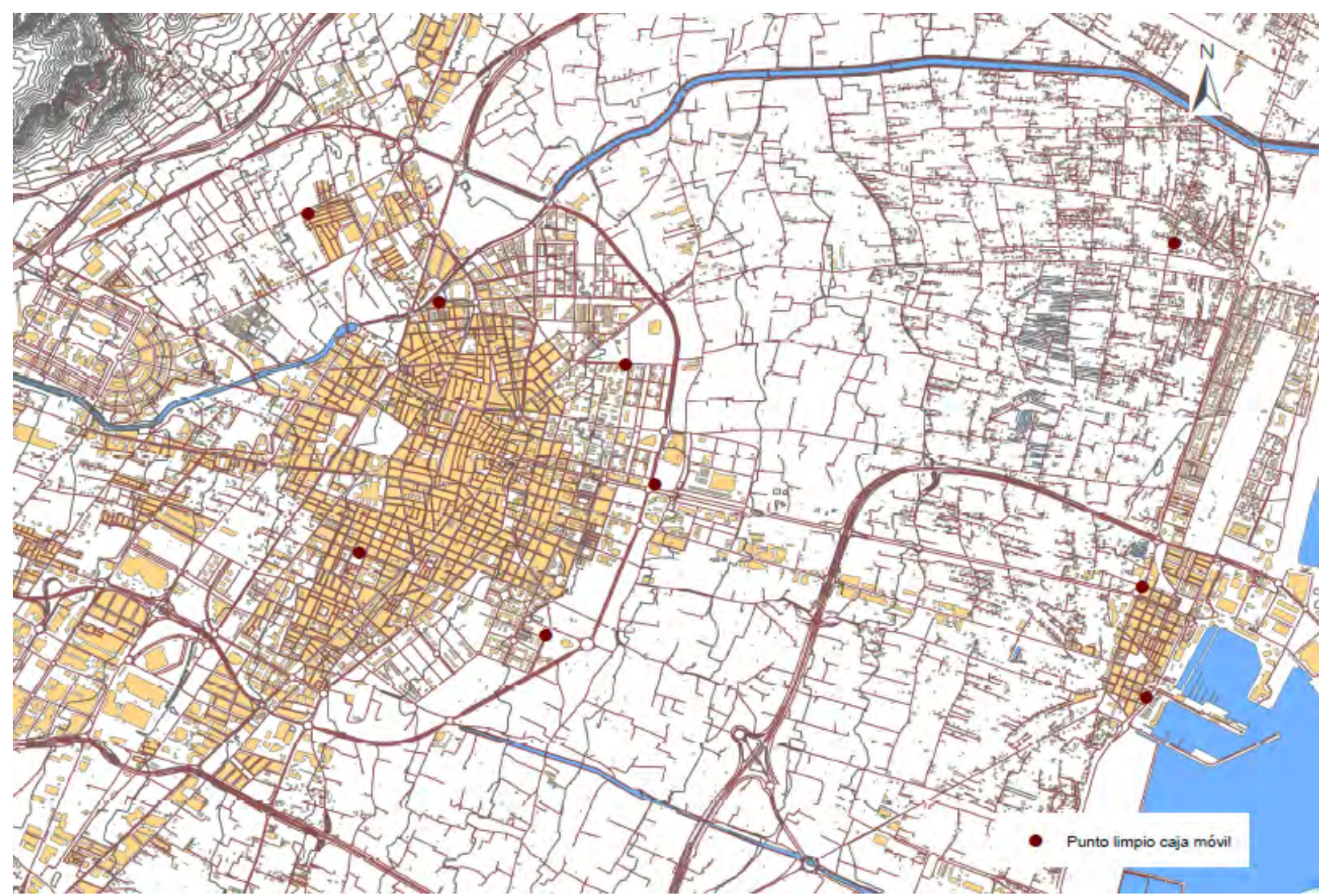

Figura 3.5: Localización de ubicaciones del Punto limpio caja móvil. Fuente: Ayuntamiento de Castelló. Fuente: Ayuntamiento de Castelló de la Plana

Por lo que respecta a la tipología de residuos admitidos, se debe tener en cuenta que quedan excluidos aquellos residuos voluminosos, puesto que la capacidad de los ecoparques móviles es limitada. Por ello, el Ayuntamiento de Castelló presta el servicio de recogida de esta tipología de residuos a demanda a toda la población, como se ha descrito anteriormente. 
Por último, al igual que con el punto limpio fijo, el público objetivo de estas instalaciones es la ciudadanía, por lo que se excluyen de su uso grandes empresas e industrias. Sin embargo, en el caso de los puntos limpios móviles, se incluyen también los comercios y las oficinas como usuarios de estas instalaciones. Este servicio consigue aproximar a todos los vecinos el punto limpio y así incentivar la correcta gestión e incrementar la cantidad y el porcentaje de los residuos recogidos de manera separada en el municipio.

A continuación, se muestra el alcance del servicio de ecoparques móviles en la ciudad de Castelló. Para ello, se ha definido un área de acción en cada una de las ubicaciones de los ecoparques móviles de 200 metros de radio, que es una estimación de la distancia máxima que un ciudadano recorrería para depositar sus residuos en el punto limpio móvil. El resultado se muestra en la Figura 3.6.

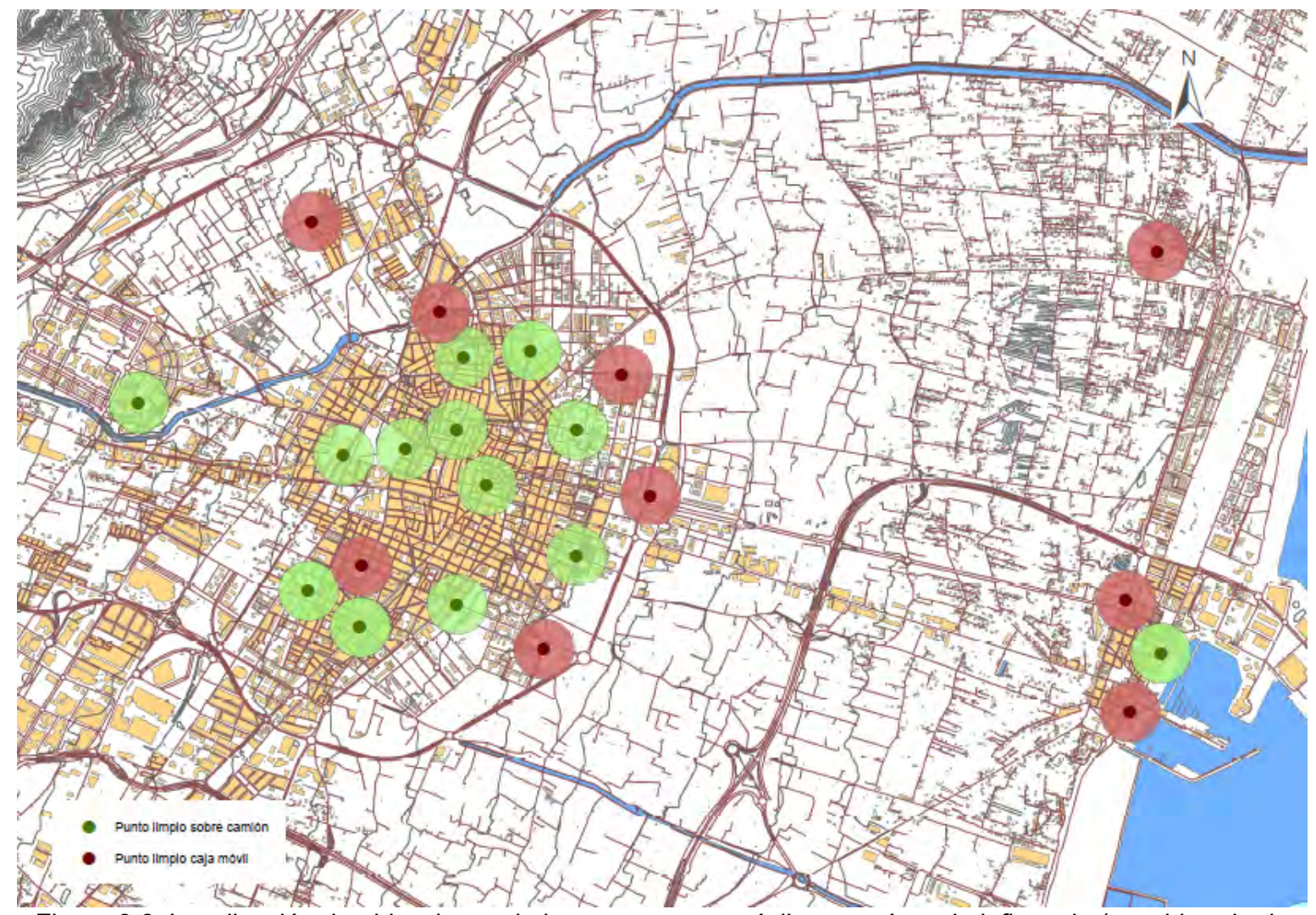

Figura 3.6: Localización de ubicaciones de los ecoparques móviles y su área de influencia (considerada de 200 m). Fuente: Elaboración propia a partir de la información del Ayuntamiento de Castelló. 
La Figura 3.6 permite identificar qué zonas del casco urbano no se encuentran a una distancia de 200 metros o inferior de alguna de las ubicaciones existentes de los ecoparques móviles. Se observa que con el servicio actual de ecoparques móviles se presta un servicio próximo a la mitad del casco urbano con una frecuencia semanal, con lo que sería aconsejable ampliar el número de ubicaciones.

Este servicio se ofrece de manera fija a lo largo del año, no existiendo ninguna variación del servicio de los ecoparques móviles, por ejemplo, en los meses de verano.

\section{Recogida de residuos en los ecoparques.}

Respecto a la cantidad de residuos gestionados, durante el año 2019 los tres puntos limpios operativos recogieron un total de $6.105 \mathrm{t}$, cifra que supone una aportación de $35,55 \mathrm{~kg}$ por habitante. En el Gráfico 3.1 se representa la evolución anual.

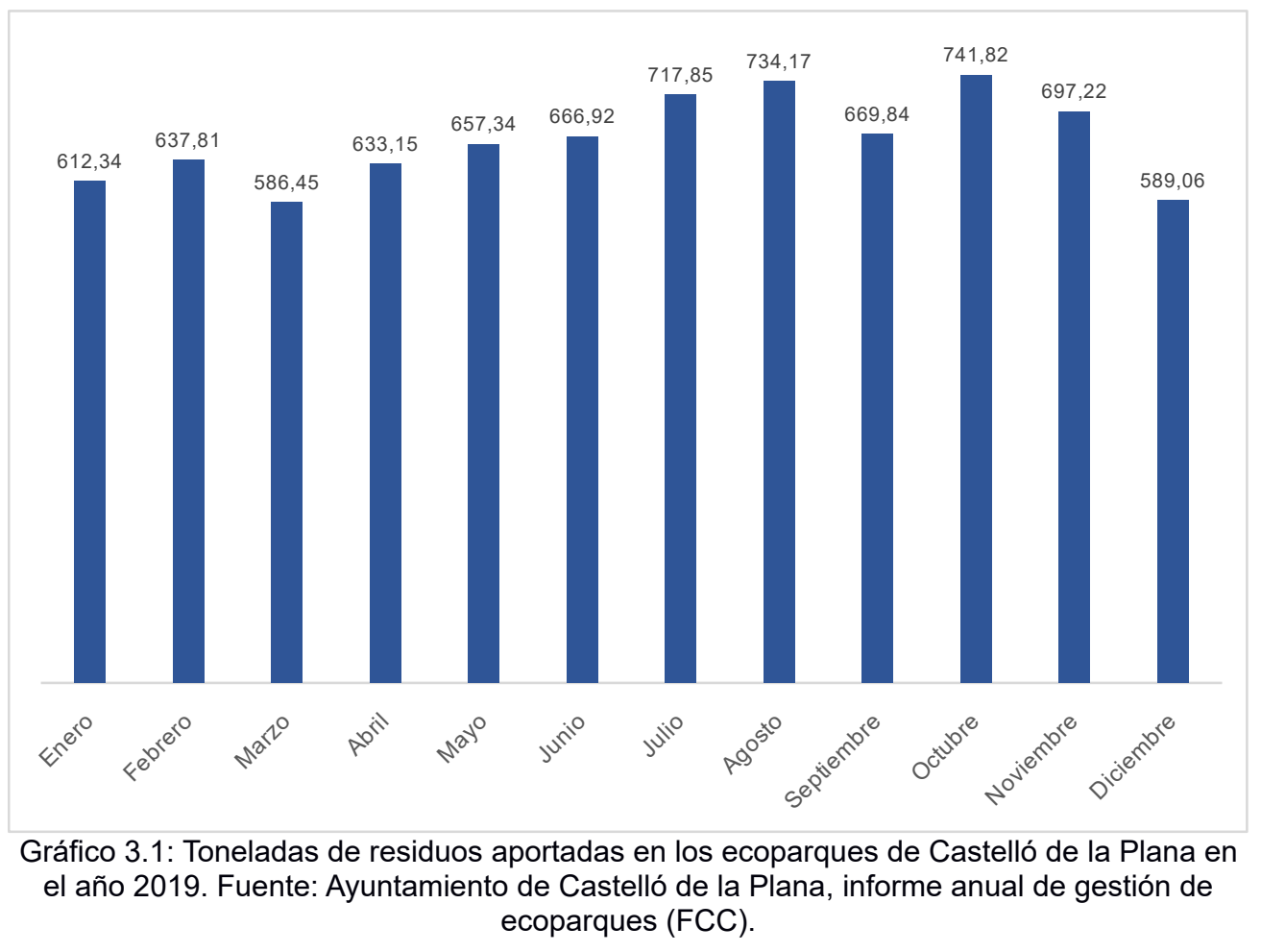

A lo largo de 2020 los ecoparques de la ciudad de Castelló de la Plana recogieron un total de $5.964 \mathrm{t}$, que se traduce en una aportación de 34,23 kg por habitante. En comparación con las cifras del 2019, se muestra una reducción que puede responder a la situación sanitaria y al confinamiento domiciliario vivido en este año. A continuación, en el Gráfico 3.2 se muestra la evolución anual. 


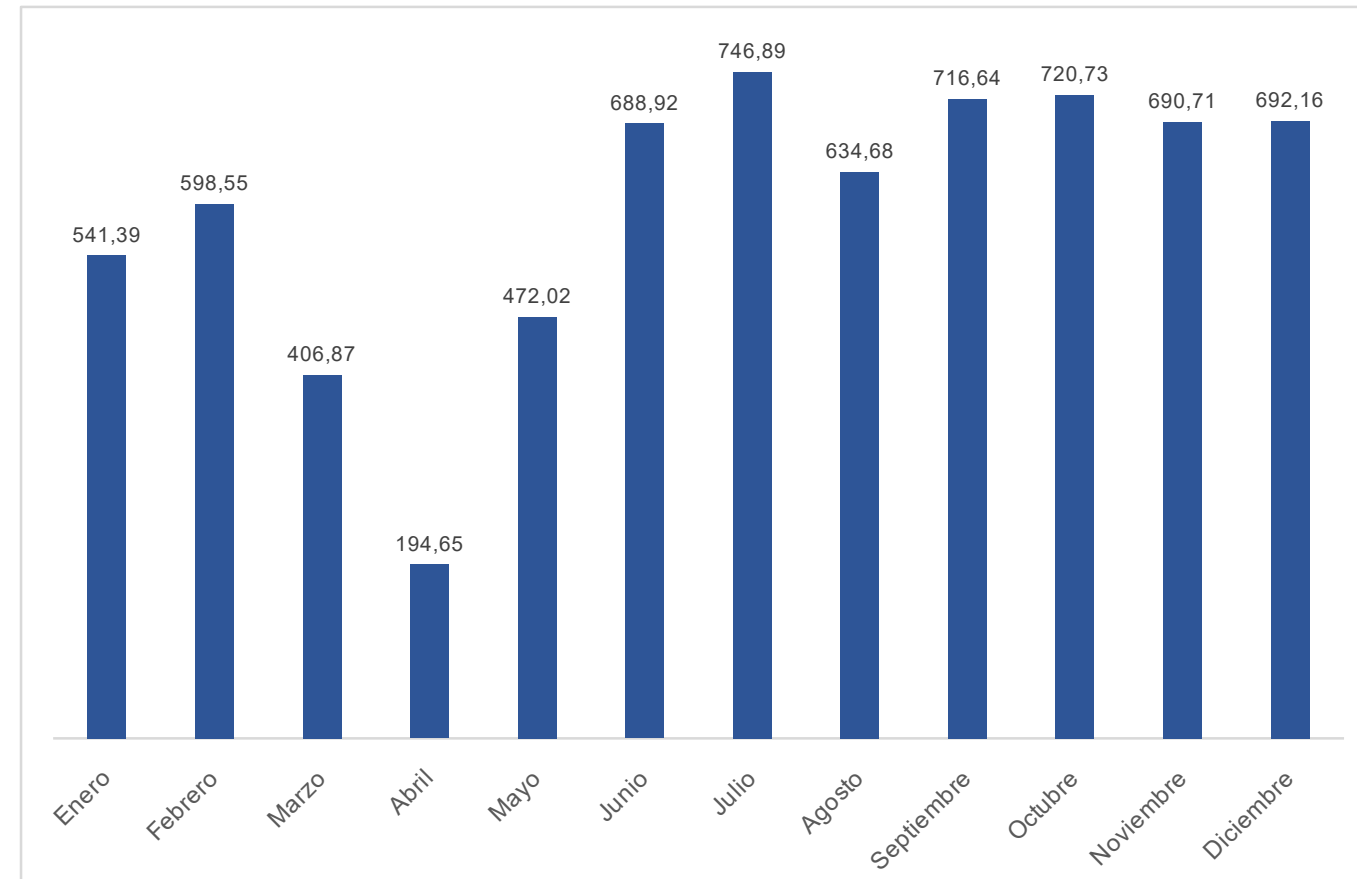

Gráfico 3.2: Toneladas de residuos aportadas en los ecoparques de Castelló de la Plana en el año 2020. Fuente: Ayuntamiento de Castelló de la Plana, informe anual de gestión de ecoparques (FCC).

Como se observa en el año 2019, la aportación total de residuos a los ecoparques a lo largo del año fue bastante regular; no se refleja una fuerte variación estacional en la aportación de residuos por parte de los vecinos a lo largo del año. Respecto al 2020, se observan grandes variaciones a lo largo del año; el uso de las instalaciones de los ecoparques no ha sido normal debido a la situación de emergencia sanitaria y al periodo de confinamiento vivido.

Por tanto, a modo de conclusión se puede afirmar que, como reflejan las cifras del último año normalizado del uso de ecoparques, no existe una gran variación estacional de la aportación de residuos a los ecoparques de Castelló a lo largo del año.

\section{Composición de los residuos recogidos en los Ecoparques.}

Atendiendo a la tipología de residuos recogidos y a sus cantidades, destacan notablemente las fracciones de escombros, madera y voluminosos. En los Gráficos 3.3 y 3.4 se muestran los rankings de recogida por toneladas recogidas en función del tipo de residuo. 


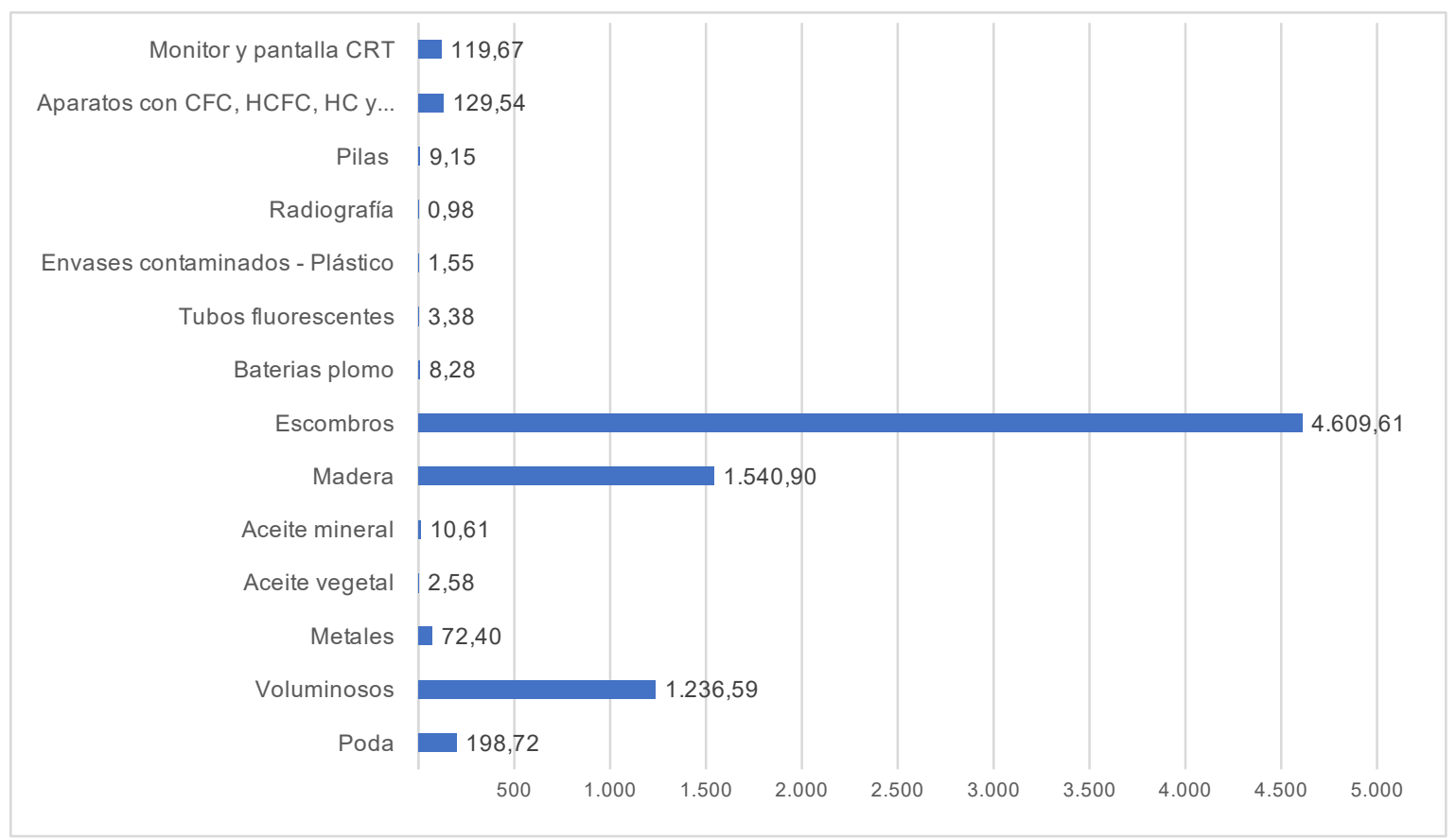

Gráfico 3.3: Toneladas de residuos aportadas según su tipología en el punto limpio de Castelló de la Plana en el año 2019. Fuente: Ayuntamiento de Castelló de la Plana, informe anual de gestión de ecoparques (FCC).

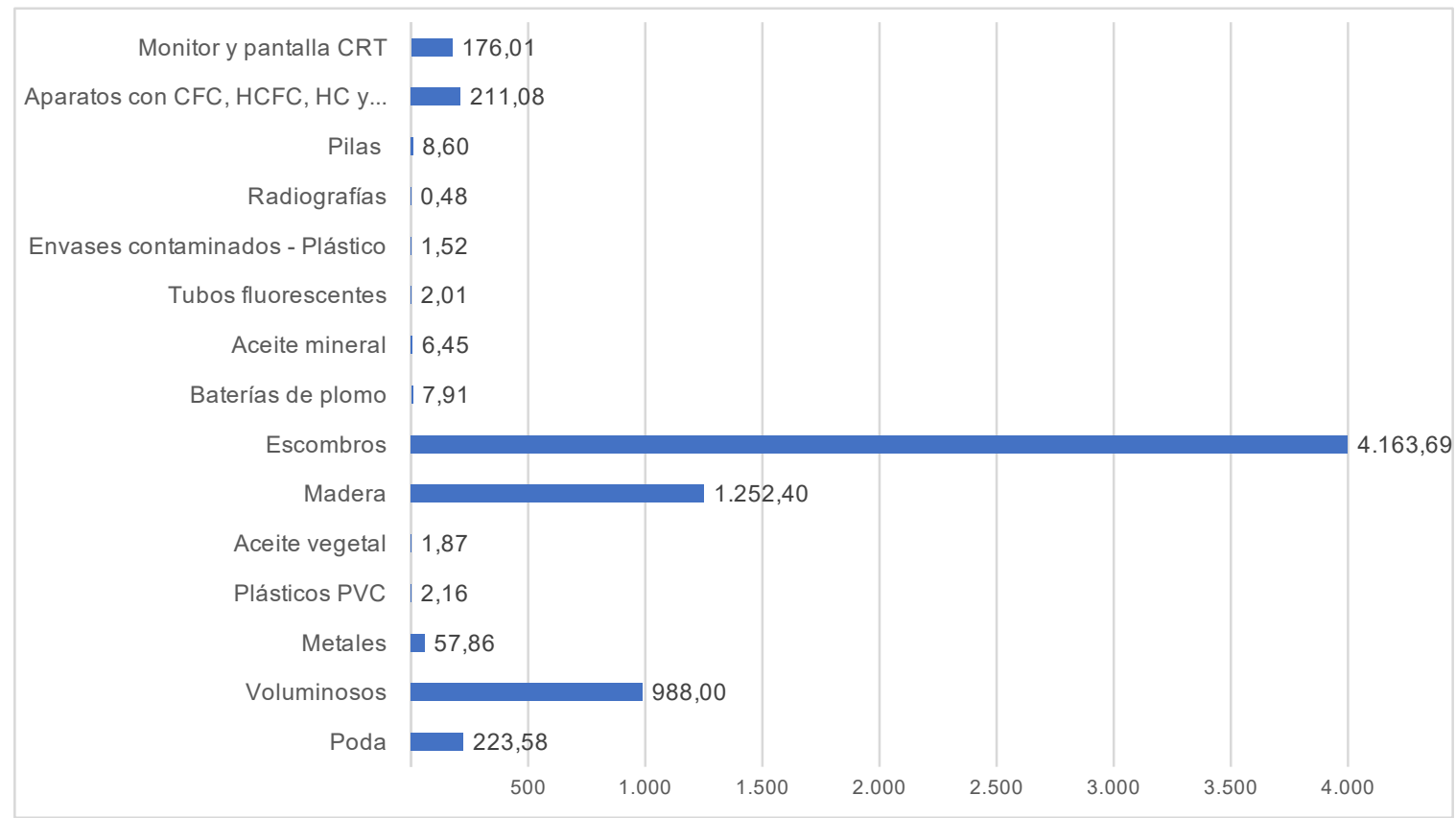

Gráfico 3.4: Toneladas de residuos aportadas según su tipología en el punto limpio de Castelló de la Plana en el año 2020. Fuente: Ayuntamiento de Castelló de la Plana, informe anual de gestión de ecoparques (FCC). 
Las fracciones de residuo recogidas en mayor cantidad por parte de los ecoparques coinciden en los dos años estudiados. En primer lugar, los escombros, con una cantidad muy superior al resto de las fracciones, seguidos de la madera y los residuos voluminosos, con cantidades superiores a las 1.000 toneladas anuales. También debe destacarse la presencia de pantallas, televisores y electrodomésticos con gases refrigerantes nocivos para el medio ambiente y que tienen asegurada su gestión mediante los convenios correspondientes de Residuos de Aparatos Eléctricos y Electrónicos (RAEE), así como los restos vegetales.

\subsubsection{Estudio de la influencia del punto limpio en la disminución de microvertederos en Castelló.}

Para comprobar si ha mejorado la situación de los microvertederos en el término municipal de Castelló de la Plana respecto a la que estudiaron Gallardo et al. (2006) en el año 2003, se procedió a realizar un estudio similar en el año 2014.

La situación de la ciudad y las condiciones de los servicios de recogida de residuos han variado notablemente desde 2003, año en el que se hizo el último estudio de Gallardo et al. (2006). La ciudad dispone de un punto limpio, ya consolidado, en la zona oeste, de un sistema de punto limpio móvil que presta servicio en diferentes zonas y barrios y de 6 minipuntos limpios repartidos por la ciudad. Por otra parte, la población se ha incrementado hasta los 173.841 habitantes (padrón municipal de 2014).

En este estudio, para localizar y caracterizar los microvertederos del término municipal se realizó una primera etapa de búsqueda de información. Las fuentes utilizadas fueron: los servicios de limpieza del Ayuntamiento, el Consejo Agrario Municipal y la Guardia Civil. Con todo ello se obtuvo la información necesaria para plantear el trabajo, además de un conjunto de mapas y direcciones sobre los posibles microvertidos incontrolados. Posteriormente, rastreado todo el término, se realizó el análisis de los datos.

Para estudiar las características y composición de los microvertederos, se planteó un trabajo de campo importante (durante 6 meses), realizando una visita mensual a cada uno de estos puntos, teniendo en cuenta factores como los periodos vacacionales, los traslados a segundas residencias, o los periodos de poda, para aforar su capacidad y se realizaron análisis visuales para definir sus características fundamentales. Estas características, que posteriormente serán objeto de análisis, fueron las siguientes:

- Ubicación geográfica: Mediante las visitas de campo y con las aplicaciones móviles necesarias se obtuvieron las coordenadas UTM necesarias para después poder realizar un 
mapa de "puntos negros" de la ciudad, diferenciando la titularidad del suelo, ya que ello determinará el poseedor del residuo.

- Superficie ocupada: Se procedió a medir el perímetro ocupado por estos vertederos tratando de conocer su extensión media aproximada.

- Volumen: Es difícil determinar con exactitud esta variable, dada la diversidad de residuos, así como de la densidad de cada uno. Una inspección visual permite estimar los medios mecánicos necesarios para su retirada.

- Composición: Para tipificar los microvertederos en base a la composición, se han creado las siguientes reglas:

- Si existe una tipología de residuo con más el $50 \%$ en volumen, este punto se considerará de dicha tipología.

- Si no existe una tipología superior al $50 \%$, se tendrán en cuenta siempre las dos tipologías mayoritarias para su clasificación.

- Si la tercera tipología de residuos supera el $20 \%$ en volumen, ésta se tendrá en consideración como una fracción nueva, y se realizará la misma aplicación para la cuarta tipología.

- Si la tercera tipología de residuo no supera el $20 \%$ en volumen, ésta y las siguientes tipologías se agrupan en fracción resto.

En base a las dimensiones observadas de los vertederos en las diferentes visitas, se han realizado los promedios de su aforamiento para establecer sus capacidades. Una vez propuestas las capacidades de cada punto se ha establecido una regla para distinguir entre microvertederos de baja y de alta capacidad: baja densidad cuando la capacidad es menor de $100 \mathrm{~m}^{3}$ y alta cuando es superior.

Con las clasificaciones efectuadas según estas reglas se han realizado gráficos en forma de disco para cada vertedero (Figura 3.10) con las siguientes características:

- Si el fondo del disco es verde, corresponde a puntos con baja capacidad (menos de 100 $\left.\mathrm{m}^{3}\right)$.

- Si el fondo del disco es rojo, corresponde a puntos de alta capacidad (superior a $100 \mathrm{~m}^{3}$ ).

- El disco puede tener diferentes porciones, en función de su composición y los criterios de clasificación mencionados anteriormente, que pueden ser: residuos de construcción, residuos de enseres y voluminosos, residuos vegetales, residuos plásticos y residuos resto. 
En la Figura 3.7 se muestra una de las rutas de inspección realizadas en el trabajo de campo y en la Figura 3.8 algunas imágenes de los microvertederos encontrados en el término municipal.

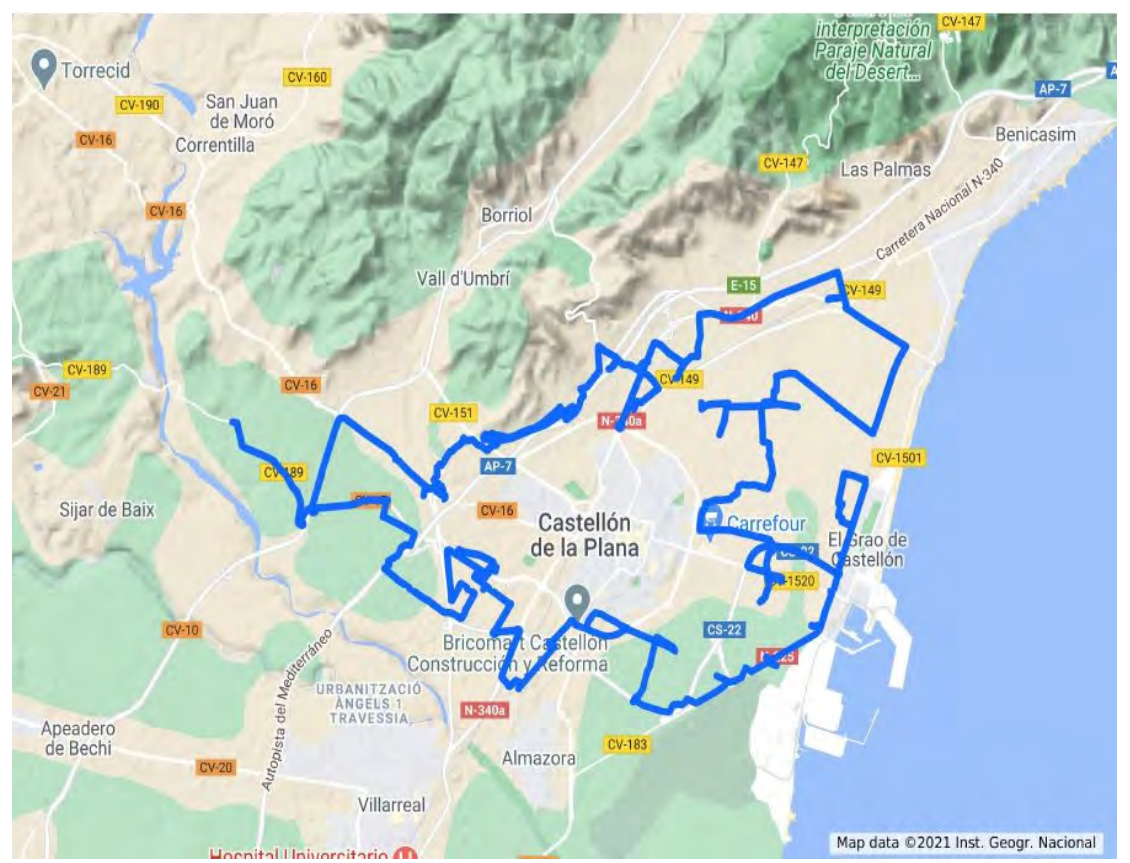

Figura 3.7: Ejemplo ruta inspección servicios municipales de limpieza de Castelló.
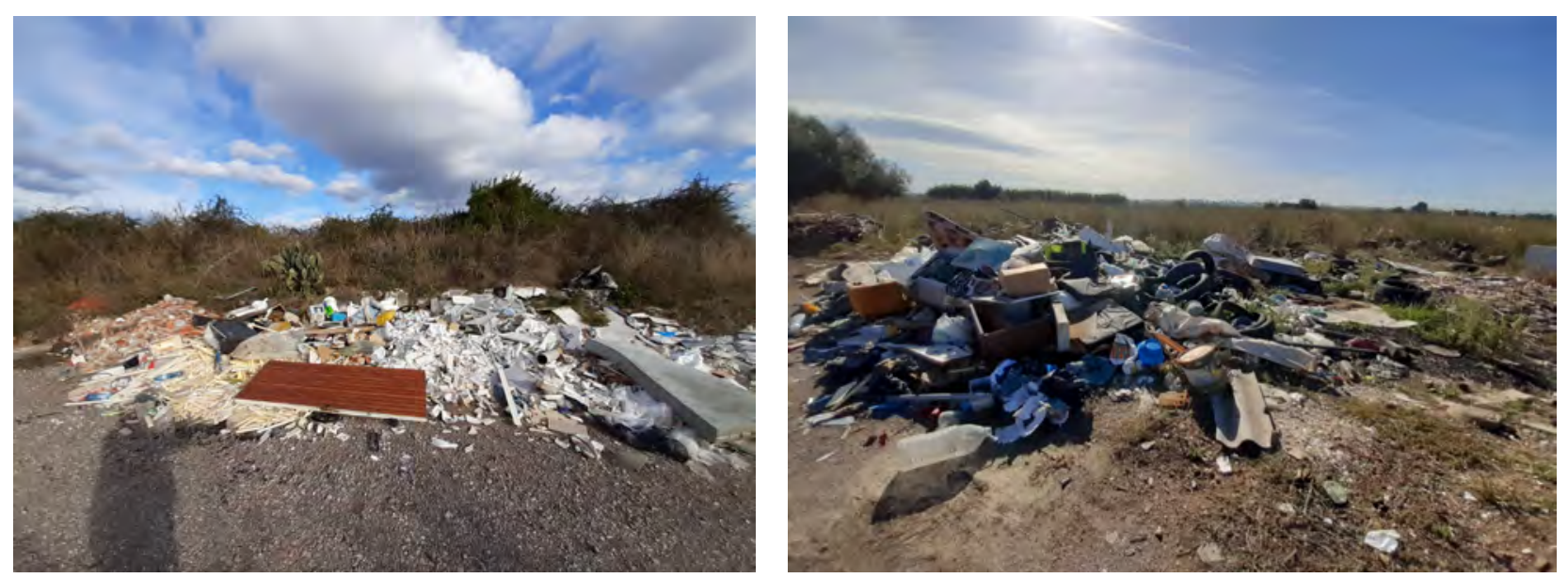

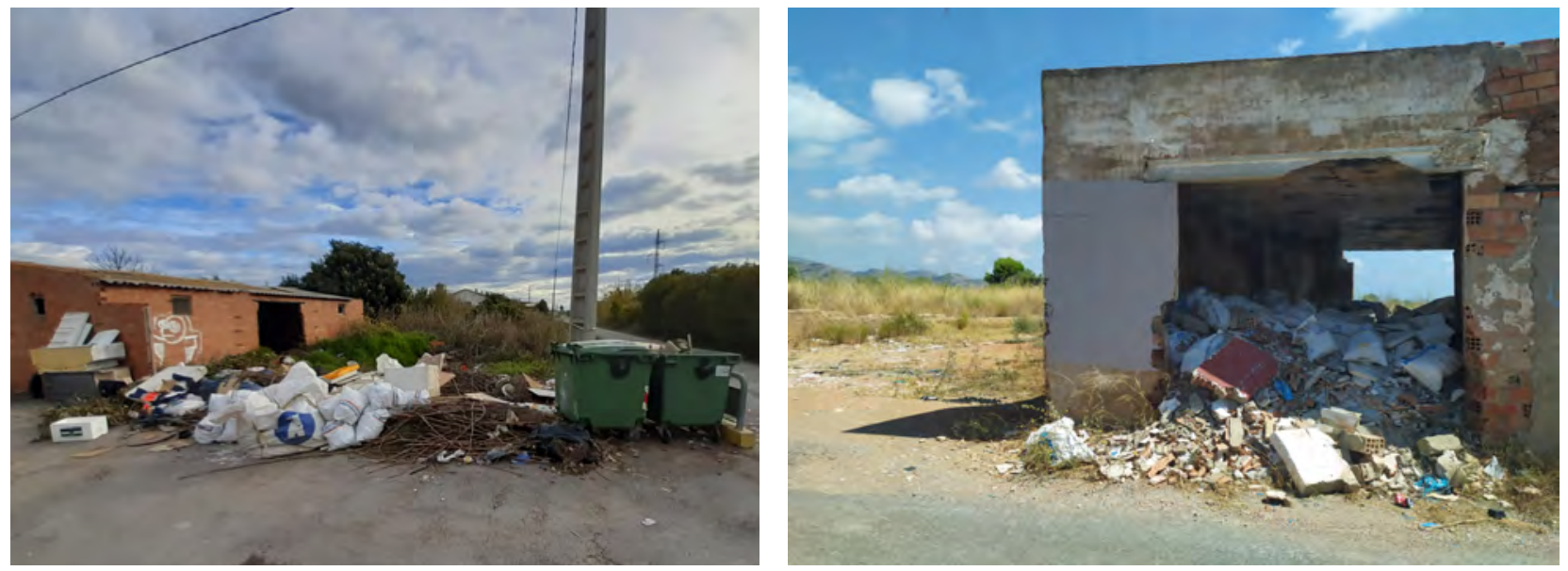

Figura 3.8: Microvertederos en bordes de caminos, junto a contenedores y en solares en los que se abandonan principalmente Residuos de Construcción y Demolición y enseres voluminosos.

\subsubsection{Resultados y discusión.}

Una vez obtenidos los resultados del estudio, se analizaron y se extrajeron las siguientes conclusiones:

1. Respecto a la variación de la distribución geográfica de los microvertederos que se muestra en los últimos años, se puede observar en la Figura 3.9 que han ido desapareciendo del Oeste (zona más próxima al punto limpio) del término municipal y se han concentrado en el Este, donde no existe ningún punto limpio. Por otro lado, la zona de mayor concentración, a lo largo de todos estos años, es la que se encuentra entre Castellón y el núcleo poblacional del Grao de Castellón, conocida como "Marjalería". Esta zona es un espacio de viviendas diseminadas donde no existe consolidación urbana de infraestructuras, tales como caminos o calles asfaltadas, alumbrado público o drenajes y saneamiento. También en las zonas de la periferia de la ciudad se encuentran puntos de microvertidos; en estos espacios tampoco existen infraestructuras básicas. En este aspecto, las conclusiones obtenidas son similares a las dadas por Jordá, Ruiz y Lucena (2013) en su estudio sobre vertederos incontrolados.

2. El número de microvertederos en 1998 era de 48, pasando a 34 puntos en el año 2003 y en 2014 se han encontrado 25 (Tablas 3.1 y 3.7), lo que indica una evolución positiva de la situación a lo largo de todos estos años. Puede observarse, por tanto, una tendencia a la baja en cuanto al número de microvertederos y especialmente en cuanto a la capacidad total de los mismos, que se reduce en un 70\% respecto a la del año 1998 . 


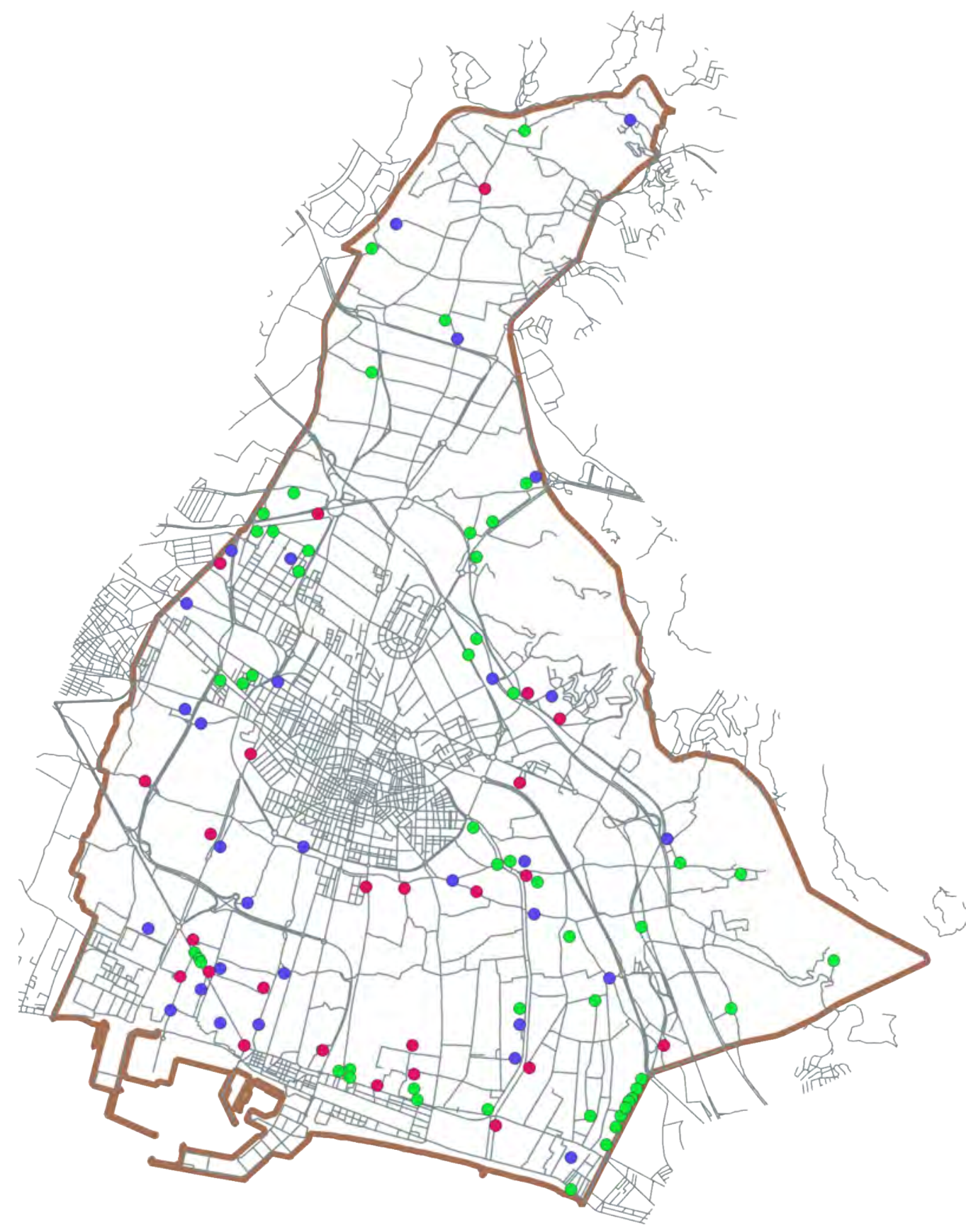

- Inventario microvertederos 1998

- Inventario microvertederos 2003

- Inventario microvertederos 2014

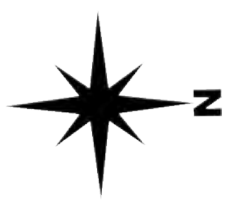

Figura 3.9: Evolución histórica de los microvertederos en diferentes años. 
3. Respecto a la caracterización de los microverterderos, como se observa en la Tabla 3.7, la mayor parte de residuos corresponden a RCD y a voluminosos. Están formados por inertes provenientes de pequeñas obras y reformas y por enseres viejos domésticos provenientes de las mismas. Estos resultados son similares a los obtenidos por Jordá, Ruiz y Lucendo (2013) en Andalucía, donde los RCD suponían un 60\%, los residuos urbanos, un 35\% y otros residuos como neumáticos fuera de uso, residuos plásticos agrícolas e industriales suponían un $5 \%$. También debe destacarse la importancia de los vertidos de enseres y voluminosos, ya que representan un porcentaje importante de los residuos hallados, probablemente por la dificultad que presenta para los particulares llevarlos hasta el punto limpio, o adaptarse a los horarios y cantidades diarias que establece el servicio de recogida municipal.

El residuo vegetal es también muy común en estos microvertederos. Esto es debido a la tipología de edificación con jardines y árboles que son normalmente mantenidos por los propietarios. Debe destacarse, llegados a este punto, que la morfología urbanística de la ciudad de Castelló de la Plana afecta en gran medida a este tipo de vertido. Ello se justifica en que los servicios de recogida municipales realizan una recogida de la poda "puerta a puerta" y en ocasiones el acceso a todas las viviendas es inviable para vehículos pesados (caminos estrechos, firmes no compactados, etc.). Por ello, en la ciudad existen zonas de acopio limitadas en cuanto a cantidad por persona y debiendo ser usadas previo aviso telefónico. La realidad actual es que estas zonas se han convertido en puntos de vertido de poda "a granel" por parte de empresas que hacen un uso indebido de un servicio que es exclusivo para el ciudadano.

Finalmente, del estudio también se desprende que no hay una cantidad significativa de residuos peligrosos en los microvertederos.

4. La capacidad total de los microvertederos encontrados en 2014 es de $4.206 \mathrm{~m}^{3}$, cifra sensiblemente inferior a la de los estudios anteriores. Además, de los 25 microvertederos localizados en 2014,17 son inferiores a $100 \mathrm{~m}^{3}$, siendo la cantidad total en esta tipología similar a la del año 1998.

Los 8 restantes que son de capacidad superior y suponen casi el 90\% en capacidad total anual de residuos, se han reducido en un $75 \%$. En cuanto a su composición en el año 2014, 14 de ellos están formados por residuos de construcción y 5 corresponden a enseres y voluminosos, el resto son fundamentalmente residuos procedentes de poda y vertederos de diferentes composición (Tabla 3.7). 
Influencia de los puntos limpios en la disminución de microvertederos incontrolados. Estudio del caso de Castelló.

\begin{tabular}{|c|c|c|c|c|c|c|c|}
\hline \multirow[b]{2}{*}{ Puntos } & \multirow{2}{*}{$\begin{array}{c}\text { Capacidad } \\
\left(\mathrm{m}^{3}\right)\end{array}$} & \multicolumn{5}{|c|}{ Composición (\%) } & \multirow[b]{2}{*}{ Tipo } \\
\hline & & $\begin{array}{l}\text { Construcción } \\
\text { RCD }\end{array}$ & $\begin{array}{c}\text { Enseres } \\
\text { voluminosos }\end{array}$ & Vegetales & Plásticos & Resto & \\
\hline 1 & 150 & 55 & & 20 & & 25 & Construcción/RCD's \\
\hline 2 & 750 & 40 & 20 & & & 40 & Construcción/RCD's \\
\hline 3 & 12 & 50 & 35 & & & 15 & Construcción/RCD's \\
\hline 4 & 108 & 40 & 25 & & & 35 & Construcción/RCD's \\
\hline 5 & 25 & & 65 & & & 35 & Enseres voluminosos \\
\hline 6 & 35 & & 55 & 20 & 20 & 5 & Enseres voluminosos \\
\hline 7 & 150 & 55 & & & & 45 & Construcción/RCD's \\
\hline 8 & 24 & 60 & 20 & 10 & & 10 & Construcción/RCD's \\
\hline 9 & 30 & & 70 & 20 & & 10 & Enseres voluminosos \\
\hline 10 & 120 & 40 & 30 & & & 30 & Construcción/RCD's \\
\hline 11 & 30 & 75 & & & & 25 & Construcción/RCD's \\
\hline 12 & 2000 & 80 & & & & 20 & Construcción/RCD's \\
\hline 13 & 25 & 100 & & & & & Construcción/RCD's \\
\hline 14 & 330 & 50 & & & & 50 & Construcción/RCD's \\
\hline 15 & 30 & 45 & & 30 & & 25 & $\begin{array}{l}\text { Construcción/RCD's } \\
\text { Vegetales }\end{array}$ \\
\hline 16 & 150 & 35 & & 40 & & 25 & $\begin{array}{l}\text { Construcción/RCD's } \\
\text { Vegetales }\end{array}$ \\
\hline 17 & 36 & 85 & & & & 15 & Construcción/RCD's \\
\hline 18 & 25 & 20 & & 70 & & 10 & Vegetales \\
\hline 19 & 35 & & 75 & & & 25 & Enseres voluminosos \\
\hline 20 & 25 & 60 & 20 & 10 & & 10 & Construcción/RCD's \\
\hline 21 & 36 & 50 & 30 & 10 & & 10 & Construcción/RCD's \\
\hline 22 & 25 & 0 & 80 & & & 20 & Enseres voluminosos \\
\hline 23 & 9 & 90 & & & & 10 & Construcción/RCD's \\
\hline 24 & 16 & 40 & 40 & & & 20 & $\begin{array}{l}\text { Construcción/RCD's } \\
\text { Enseres voluminosos }\end{array}$ \\
\hline 25 & 30 & 40 & 40 & & & 20 & $\begin{array}{l}\text { Construcción/RCD's } \\
\text { Enseres voluminosos }\end{array}$ \\
\hline
\end{tabular}

Tabla 3.7: Distribución de tamaños de los microvertederos, composición y capacidad total de cada categoría en 2014. 


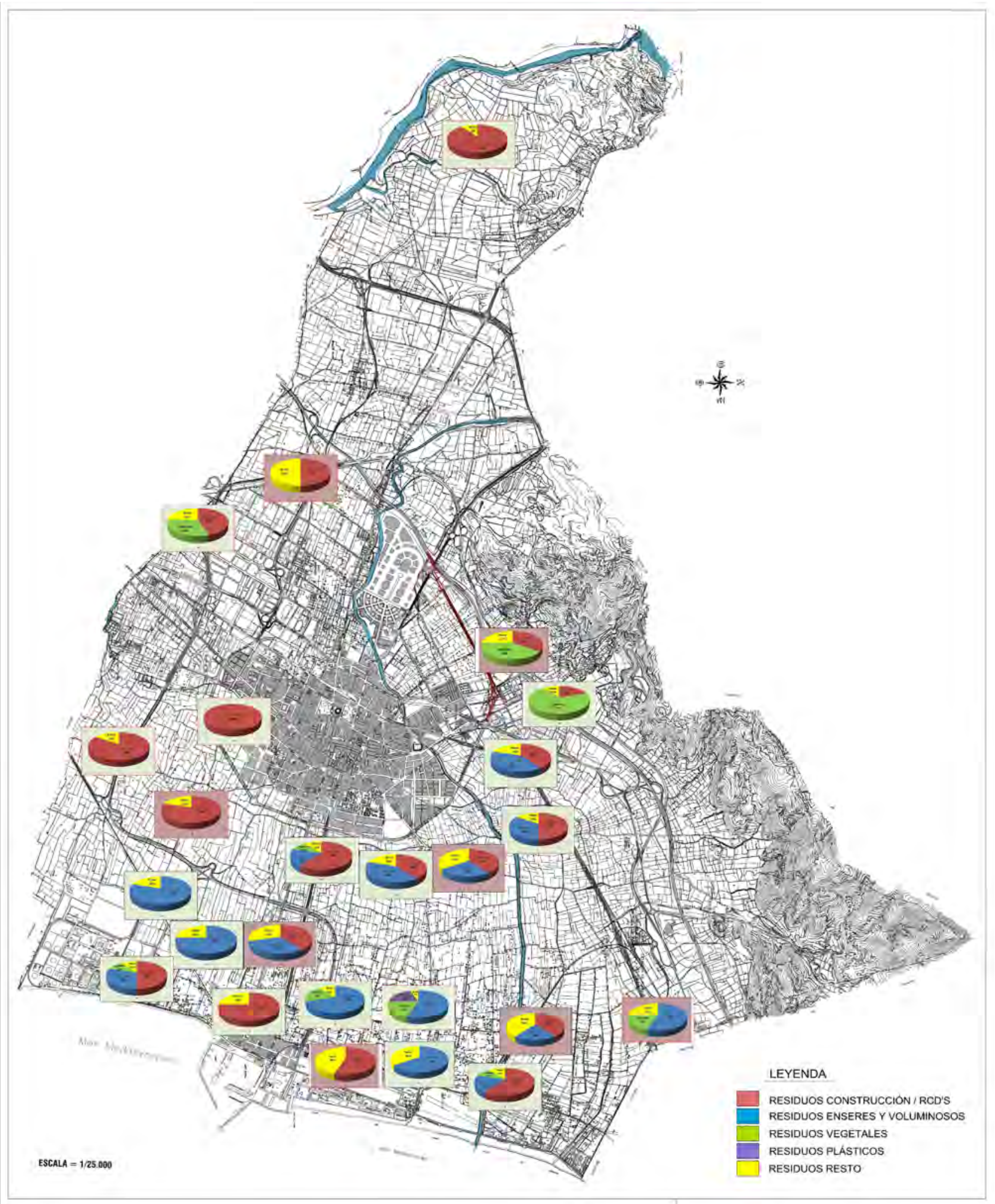

Figura 3.10: Distribución y composición de los microvertederos en el año 2014. 


\subsection{Conclusiones.}

Del estudio de seguimiento de la evolución de los microvertederos llevado a cabo del año 1998 al 2014 en el término municipal de Castelló de la Plana, se ha llegado a las siguientes conclusiones:

- Su número se ha reducido del año 1998 al 2014, aunque sin llegar a desaparecer.

- La instalación del punto limpio fijo (zona oeste de la ciudad) ha influido de forma clara en la disminución del número de microvertederos cercanos a dicha instalación.

- El tipo de residuo que predomina son los RCD, seguidos de voluminosos y restos de poda.

- En cuanto al tamaño, la mayoría de los vertidos incontrolados actualmente son menores a $100 \mathrm{~m}^{3}$. El tamaño de los microvertederos no ha disminuido de forma importante a lo largo de estos años.

Dada la consolidación del punto limpio actual y el efecto positivo que ha provocado, la construcción de un segundo punto limpio en la ciudad, en la zona donde hay una mayor densidad de microvertederos, sería una de las mejores medidas a futuro para la solución del problema. No obstante, la ubicación de un punto limpio no puede atender únicamente a este criterio.

Es por ello que deberán estudiarse otras variables, que puedan influir en el rendimiento y uso del punto limpio y que tengan como objeto ayudar a modelizarlo. Estas variables se han analizado en los capítulos siguientes, siendo el objetivo principal el de disponer de la mayor cantidad de información posible en aras a conseguir un punto limpio con unas cuotas de utilización elevadas, lo que se traducirá en una mejor separación en origen y en consecuencia en una mejor gestión de los RSU en fases posteriores.

\subsection{Referencias.}

Alfonzo, G. N., Arenas, F. F., Conforti, M., Salcovsky, N. M. \& Valerio, H. G. (2013). Erradicación de microbasurales en González Catán. Revista de Investigaciones del Departamento de Ciencias Económicas de La Universidad Nacional de la Matanza. (http://rince.unlam.edu.ar).

Apostol, L \& Mihail, F (2011). The process of closing down rural landfills. Case study: Neamt County. Present Environment And Sustainable Development, 5 (2), 167-174.

Ayuntamiento de Castelló de la Plana, www.castello.es/medioambiente.

Biotto, G., Silvestri, S., Gobbo, L., Furlan, E., Valenti, S. \& Rosselli, R. (2009). GIS, multicriteria and multi-factor spatial analysis for the probability assessment of the existence of 
illegal landfills. International Journal of Geographical Information Science, 23 (10), 12331244.

Cevallos Uve, E. (2014). Análisis de los Problemas Ambientales en el Cantón La Concordia, Provincia Santo Domingo De Los Tsáchilas, Ecuador.

Emilio, E., Betancourt, A., Alejandro, P., \& García, V. (n.d.). Educación Ambiental en la Comunidad: mitigación de micro-vertederos en zonas residenciales.

Gallardo, A., García, A., Bovea, M.D. \& Colomer, F.J. (2006). Metodología para la ubicación de ecoparques. Aplicación al término municipal de Castellón. XVII Congreso Internacional de Dirección e Ingeniería de Proyectos (pp. 1250 - 1261), Valencia.

Instituto Nacional de Estadística, www.ine.es

Jordá, R., Ruiz, F. \& Lucendo, A. L. (2013). Factores territoriales de localización y caracterización de los vertederos incontrolados en Andalucía. Scripta Nova, Revista Electrónica de Geografía y Ciencias sociales de la Universidad de Barcelona, 15 (435).

Martínez M.D. \& Adsuara G. (1998). Vertederos ilegales en el término municipal de Castellón. Colección de trabajos de la asignatura de Residuos Sólidos, INGRES, Universitat Jaume I, Castellón de la Plana.

Sharma, A., Meesa, S., Pant, S. \& Alappat, B.J. (2008). Formulation of a landfill pollution potential index to compare pollution potential of uncontrolled landfills. Waste Management \& Research, 26 (5), 474-83.

Silvestri, S. \& Omri, M. (2008). A method for the remote sensing identification of uncontrolled landfills: formulation and validation. International Journal of Remote Sensing, 29 (4), 975989. 


\section{CAPÍTULO 4. IDENTIFICACIÓN DE VARIABLES QUE INFLUYEN EN LA UBICACIÓN Y DISEÑO DE UN PUNTO LIMPIO.}





\section{IDENTIFICACIÓN DE VARIABLES QUE INFLUYEN EN LA UBICACIÓN Y DISEÑO DE UN PUNTO LIMPIO.}

La implantación de puntos limpios en las ciudades españolas para la recogida de residuos domiciliarios especiales y/o peligrosos se ha generalizado en los últimos años, debido al incremento de la concienciación social por los temas ambientales. Por otro lado, el diseño de estas instalaciones también ha ido evolucionando, intentando adaptarse a la realidad de cada zona o municipio y a sus posibilidades geográficas y económicas. Es indudable que las características y el funcionamiento de cada instalación repercuten en la utilización y el éxito de las mismas.

\subsection{Introducción.}

El desarrollo sostenible de las ciudades requiere una estrategia integral de gestión de los RSU que tenga en cuenta todas las etapas, desde la generación hasta la disposición final (Aranda et al. 2013). La etapa de tratamiento de los residuos es, para Oribe-García et al. (2015), la más importante de la gestión y está directamente relacionada con la cantidad y composición de los residuos, por lo que una estimación inexacta de las mismas generará dificultades a la hora de optimizar el diseño de las infraestructuras e instalaciones requeridas.

La separación de los residuos en los hogares se justifica por cuatro puntos principales (Uk.wastewatch.org, 2003): la reducción de la demanda de materias primas vírgenes; la reducción de los impactos ambientales derivados de la extracción, procesamiento y transporte; la elaboración de productos nuevos a partir de material reciclable, y la disminución del número de residuos que son eliminados por envejecimiento. La separación en los hogares es una actividad en gran medida voluntaria $\mathrm{y}$, por tanto, es importante comprender los factores que motivan la práctica del reciclaje, para que alcance su máximo potencial y se convierta en parte de la rutina cotidiana de los hogares.

La disponibilidad de infraestructuras eficaces que permitan a los hogares separar sus residuos es, según Martin et al. (2006), una parte crucial de cualquier sistema de gestión de residuos; pero también son muchos otros los factores que motivan a los hogares a hacer uso de éstas. Los puntos limpios desempeñan un papel importante en el conjunto de estas infraestructuras, a la hora a aumentar las ratios de recogida selectiva de ciertos residuos (Gallardo et al., 2010). 
Según el Plan integral de Residuos de la Comunitat Valenciana -Anexo I- (PIRCV), un punto limpio es una instalación municipal cerrada y vigilada, destinada a la recepción y almacenamiento temporal y separado de aquellos residuos urbanos especiales que no son objeto de recogida en acera, con la finalidad de facilitar y garantizar una adecuada gestión de los mismos. Son usuarios de los puntos limpios los particulares, así como las personas físicas o jurídicas titulares de comercios, oficinas y/o servicios en el ámbito territorial a que dé servicio el punto limpio. Este tipo de instalación debe servir también como equipamiento de educación ambiental, con el objetivo de informar y sensibilizar a los usuarios sobre los beneficios ambientales de una correcta segregación de los residuos.

La recogida mediante puntos limpios con sistemas redundantes (puntos fijos y móviles conjuntamente) da un mayor servicio al ciudadano y además aumenta las tasas de recogida y con ello la eficiencia del sistema (Gallardo et al. 2015). Esto repercute directamente en la mejora de la eficiencia de otros circuitos de recogida y en la reducción de vertidos incontrolados, por lo que se aconseja la instalación de estas infraestructuras.

Son muchas las variables, que a priori, pueden tener influencia en la utilización de los puntos limpios:

- Localización. Más o menos próxima al casco urbano.

- Accesos. Calles o vías de servicio con capacidad para un vehículo por sentido y que se encuentren en buen estado de conservación, con buena iluminación, etc.

- Señalización. Clara y suficiente mediante placas, letreros o similar. Su colocación se ha de realizar en base a un estudio previo de los posibles itinerarios a crear en la ciudad.

- Horario. Adaptar el horario de apertura de las instalaciones al de los ciudadanos (apertura en franja horaria de tardes y fines de semana).

- Difusión. Campañas de comunicación para hacer propaganda de la instalación y su función dentro de la ciudad, facilitando información de localización, horarios, formas de llegar, residuos admitidos y no admitidos, etc.

- Accesibilidad. Inclusión de paradas o línea de autobús que tenga un trayecto próximo a las instalaciones.

El objetivo de este capítulo es realizar un análisis documental de las diferentes variables que influyen en la utilización de los puntos limpios. A partir de aquí, se determinarán las que intervienen en el diseño de la localización, funcionamiento y mantenimiento de estas instalaciones, con el objetivo final de la mejora de sus rendimientos. 


\subsection{Análisis de variables.}

Las principales variables que influyen en la motivación de los ciudadanos para utilizar los puntos limpios son la disponibilidad de puntos cercanos y la diversidad de residuos admitidos en esas instalaciones (Moliner et al. (2010). El mayor inconveniente es la falta de espacio para almacenar temporalmente los residuos en los domicilios. Sin embargo, esta falta de espacio puede compensarse aumentando la frecuencia con la que se trasladan los residuos a los puntos limpios por parte de los ciudadanos. Las variables de situación, la disponibilidad física, las campañas publicitarias o las normas legales, que facilitan las conductas proambientales, tienen una influencia alta en el uso de estas instalaciones (Gallardo et al, 2016).

Para abordar este capítulo, además de una búsqueda bibliográfica en revistas internacionales y españolas, también se ha consultado normativa nacional y regional, así como Pliegos de Condiciones Técnicas (PCT) de Ayuntamientos relativos la gestión y explotación de puntos limpios, en los cuales se especifican diferentes consideraciones a la hora de licitar la construcción y la gestión de los mismos.

La normativa consultada en la que aparecen referenciados aspectos que hay que tener en cuenta en el diseño y funcionamiento de los puntos limpios es:

- Ámbito Comunitario:

- Directiva 2012/19/UE, de Residuos de aparatos eléctricos y electrónicos.

- Decisión 2000/532/CE, de la Comisión, de 3 de mayo mediante la que se aprueba la Lista Europea de Residuos modificada por las Decisiones de la Comisión, 2001/118/CE de 16 de enero y 1001/119, de 22 de enero y por la Decisión del Consejo 2001/573 de 23 julio.

- Ámbito Estatal:

- Real Decreto 110/2015, de 20 de febrero, sobre residuos de aparatos eléctricos y electrónicos (BOE N 45, 21 de febrero de 2015).

- Plan Estatal Marco de Gestión de Residuos (PEMAR) 2016-2022, pretende ser el instrumento para orientar la política de residuos en España, impulsando las medidas necesarias para mejorar las deficiencias detectadas y promover las actuaciones que proporcionen un mejor resultado ambiental y que aseguren la consecución de los objetivos legales.

- Plan Nacional Integrado de Residuos para el período 2008- 2015 (PNIR) que se aprobó mediante Resolución de 20 de enero de 2009.

- Ley 22/2011 de residuos y suelos contaminados. 
- Ámbito autonómico: En la Tabla 4.1 se enumera, de forma resumida, la normativa autonómica en materia de puntos limpios.

\begin{tabular}{|c|c|c|c|}
\hline $\begin{array}{l}\text { Comunidad } \\
\text { Autónoma }\end{array}$ & Planificación & Normativa & Normativa Técnica Ecoparques \\
\hline Galicia & $\begin{array}{l}\text { Plan de Gestión de Residuos } \\
\text { Urbanos de Galicia PGRUG } \\
\text { 2010-2022 }\end{array}$ & $\begin{array}{l}\text { Ley } 6 / 2021 \text {, de } 17 \text { de Febrero, de } \\
\text { Residuos y Suelos Contaminados de } \\
\text { Galicia }\end{array}$ & \\
\hline Asturias & $\begin{array}{l}\text { Plan Estratégico de Residuos } \\
\text { del Principado de Asturias 2017- } \\
2024 \text { PERPA }\end{array}$ & $\begin{array}{l}\text { Anteproyecto de Ley de } \\
\text { Sostenibilidad y Protección Ambiental }\end{array}$ & \\
\hline Cantabria & $\begin{array}{l}\text { Plan de Residuos de la } \\
\text { Comunidad Autónoma de } \\
\text { Cantabria 2017-2023. }\end{array}$ & & \\
\hline País Vasco & $\begin{array}{l}\text { Plan de Prevención y Gestión } \\
\text { de Residuos de la CAPV } 2020\end{array}$ & $\begin{array}{l}\text { Titulo III. Capítulo II, Residuos. Ley } \\
\text { 3/1998, de } 27 \text { de febrero, General de } \\
\text { Protección del Medio Ambiente del } \\
\text { País Vasco }\end{array}$ & $\begin{array}{l}\text { No hay para toda la Comunidad pero sí } \\
\text { para la provincia de Bizkaia: } \\
\text { Reglamento de los Gargbigunes } \\
\text { Bizkaia }\end{array}$ \\
\hline La Rioja & $\begin{array}{l}\text { Plan Director de Residuos de La } \\
\text { Rioja 2016-2026 }\end{array}$ & & \\
\hline Castilla y León & $\begin{array}{l}\text { Plan Integral de Residuos de } \\
\text { Castilla Y León 2014-2020 }\end{array}$ & & $\begin{array}{l}\text { Manual de Buenas Prácticas para la } \\
\text { explotación de puntos limpios en } \\
\text { Castilla y León }\end{array}$ \\
\hline Navarra & $\begin{array}{l}\text { Plan de Residuos de Navarra } \\
\text { 2017-2027 }\end{array}$ & $\begin{array}{l}\text { Ley Foral 14/2018 de Residuos y su } \\
\text { fiscalidad }\end{array}$ & \\
\hline Aragón & $\begin{array}{l}\text { Plan de Gestión Integral de } \\
\text { Residuos de Aragón 2018-2022 }\end{array}$ & & \\
\hline Cataluña & $\begin{array}{l}\text { Programa General De } \\
\text { Prevención y Gestión de } \\
\text { Residuos y Recursos de } \\
\text { Cataluña } 2020\end{array}$ & $\begin{array}{l}\text { Decreto Legislativo } 1 / 2009 \text {, de } 21 \text { de } \\
\text { Julio, por el que se aprueba el texto } \\
\text { refundido de la Ley reguladora de los } \\
\text { residuos. }\end{array}$ & Norma Tècnica Deixalleries 2019 \\
\hline $\begin{array}{l}\text { Comunidad } \\
\text { Valenciana }\end{array}$ & $\begin{array}{l}\text { Plan Integral de Residuos de la } \\
\text { Comunitat Valenciana (PIRCVA) } \\
\text { 2013-2022 }\end{array}$ & $\begin{array}{l}\text { Ley 10/2000, De } 12 \text { De Diciembre, De } \\
\text { Residuos De La Comunidad } \\
\text { Valenciana }\end{array}$ & $\begin{array}{l}\text { Norma Técnica Reguladora de la } \\
\text { Implantación y funcionamiento de los } \\
\text { Ecoparques (Anexo 1.1. del PIRCVA) }\end{array}$ \\
\hline $\begin{array}{l}\text { Castilla La } \\
\text { Mancha }\end{array}$ & $\begin{array}{l}\text { Plan Integrado de Gestión de } \\
\text { Residuos de Castilla-La Mancha }\end{array}$ & & \\
\hline Murcia & $\begin{array}{l}\text { Plan de Residuos de la Región } \\
\text { de Murcia 2016-2020 }\end{array}$ & $\begin{array}{l}\text { Ley 10/1998, De } 21 \text { De Abril, De } \\
\text { Residuos }\end{array}$ & $\begin{array}{l}\text { No existe, pero se ha editado un } \\
\text { manual "Gestión de la Red de } \\
\text { Ecoparques de la Región de Murcia" }\end{array}$ \\
\hline Andalucía & $\begin{array}{l}\text { Decreto } 397 / 2010 \text {, de } 2 \text { de } \\
\text { noviembre, por el que se } \\
\text { aprueba el Plan Director } \\
\text { Territorial de Residuos No } \\
\text { Peligrosos de Andalucía 2010- } \\
2019\end{array}$ & $\begin{array}{l}\text { Decreto } 73 / 2012 \text {, de } 22 \text { de Marzo, por } \\
\text { el que se aprueba el Reglamento de } \\
\text { Residuos de Andalucía. }\end{array}$ & \\
\hline Extremadura & $\begin{array}{l}\text { Plan Integrado de Residuos de } \\
\text { Extremadura 2016-2022 } \\
\text { (PIREX) }\end{array}$ & & $\begin{array}{l}\text { Se ha editado un "Manual para la } \\
\text { correcta gestión de un Punto Limpio" }\end{array}$ \\
\hline Madrid & $\begin{array}{l}\text { Plan de Gestión de Residuos } \\
\text { Domésticos y Comerciales } \\
(2017-2024)\end{array}$ & $\begin{array}{l}\text { Ley } 5 / 2003 \text {, de } 20 \text { de Marzo, de } \\
\text { Residuos de la Comunidad de Madrid. }\end{array}$ & \\
\hline Islas Baleares & & $\begin{array}{l}\text { Ley } 8 / 2019 \text {, de } 19 \text { de Febrero, de } \\
\text { Residuos y Suelos Contaminados de } \\
\text { las Illes Balears }\end{array}$ & \\
\hline Islas Canarias & $\begin{array}{l}\text { Plan Integral de Residuos de } \\
\text { Canarias } 2001\end{array}$ & $\begin{array}{l}\text { Ley } 1 / 1999 \text {, de } 29 \text { de Enero, de } \\
\text { Residuos de Canarias }\end{array}$ & $\begin{array}{l}\text { Decreto 29/2002, De } 25 \text { De Marzo, por } \\
\text { el que se regula el funcionamiento de } \\
\text { Las instalaciones denominadas Puntos } \\
\text { Limpios }\end{array}$ \\
\hline
\end{tabular}

Tabla 4.1: Resumen de la normativa autonómica relativa a puntos limpios. 
Una vez revisada toda la documentación, se ha determinado el conjunto de variables que afectan a los puntos limpios. Éstas se han clasificado en tres categorías, teniendo en cuenta que se trata de una instalación industrial de recepción de residuos sólidos urbanos (Tabla 4.2).

\begin{tabular}{|l|l|l|}
\hline \multirow{2}{*}{$\begin{array}{c}\text { VARIABLES OBJETO } \\
\text { DE ESTUDIO }\end{array}$} & VARIABLES DE LOCALIZACIÓN & Ubicación de la instalación \\
\cline { 2 - 3 } $\begin{array}{l}\text { VARIABLES DE FUNCIONAMIENTO } \\
\text { VARIABLES DE LA INFRAESTRUCTURA }\end{array}$ & Horarios de la instalación \\
\cline { 3 - 3 } & Mantenimiento de la instalación \\
\cline { 2 - 3 } & Difusión / Concienciación \\
\cline { 2 - 3 } & Empleo de tasas o incentivos \\
\hline
\end{tabular}

Tabla 4.2: Variables objeto de estudio.

En los siguientes apartados se van a desarrollar cada una de estas variables, así como realizar un análisis de lo que prescribe la normativa autonómica de varias comunidades para cada una de ellas.

\subsubsection{Variables de localización.}

Estas variables están referidas a la ubicación de la instalación y todas las circunstancias que la rodean. En este caso se han considerado las variables "ubicación de la instalación" y "accesos/tiempo a la instalación".

Los puntos limpios deben estar bien comunicados, no sólo en relación al transporte privado, sino también en relación al transporte público y peatonal. En la mayoría de casos los puntos limpios se ubican en las afueras de los núcleos urbanos, por lo que es necesario que estén correctamente señalizados en todo el municipio. También se recomienda la adecuación de los caminos de acceso en caso de que no estén en buen estado para soportar un tránsito de vehículos continuado, e incluso, valorar la accesibilidad a pie y adecuar a tal fin la iluminación y las zonas de tránsito peatonal. 


\subsubsection{Ubicación de la instalación.}

Esta variable se refiere a la distancia que el ciudadano tiene que recorrer para utilizar la instalación del punto limpio. Por ejemplo, en la Comunidad Valenciana el criterio seguido según el PIRCV para estimar el número de puntos limpios (ecoparques en la comunidad Valenciana) necesarios, teniendo en cuenta la población de derecho del municipio y/o comarca y su dispersión geográfica para zonas rurales con baja densidad de población, es que la instalación se ubique en el municipio de mayor población de cada plan zonal con un área de influencia de 5 kilómetros. En función del número de habitantes a los que dé servicio, se determinará el número y tipo de instalaciones a construir. Este procedimiento se aplicará progresivamente hasta que todos los cascos urbanos municipales queden incluidos en un área de influencia y tengan asignados al menos una instalación.

Según el manual para la gestión de la red de punto limpio, en la región de Murcia, por ejemplo, la distancia máxima que se prevé que está dispuesto a recorrer un usuario para hacer uso de estas instalaciones, oscila entre los 2 y $5 \mathrm{~km}$ en zonas urbanas y entre 5 y $10 \mathrm{~km}$ en zonas rurales.

Según la aprobación del Plan Territorial de Residuos del Cabildo de Gran Canaria, son los Planes Insulares de Ordenación los que determinarán los criterios de ubicación de los puntos limpios a establecer en cada isla, en los lugares de mayor producción de esta clase de residuos. En este sentido, se localizarán en suelo urbano con destino industrial, terciario o residencial, en emplazamientos que minimicen su posible impacto ambiental y conforme a las estrategias de recogida de los residuos existentes en los municipios.

Por su parte, la Agencia Catalana de Residuos (ACR), respecto a la ubicación establece que la más adecuada será la que facilite en mayor medida el acceso a los usuarios, en aras a fomentar la participación y el uso de la instalación, puesto que son los propios usuarios los que "asumirán" el transporte de los residuos hasta dicha instalación. Del mismo modo, considera al punto limpio como un equipamiento necesario, bien municipal o supramunicipal, recomendando su integración en zonas urbanas para facilitar las aportaciones, teniendo en cuenta cuestiones como la proximidad a zonas comerciales, estaciones de transporte público, polígonos industriales, aparcamientos, zonas de paso, etc.

En cuanto a la bibliografía consultada, se ha comprobado que hay muy poca que hable sobre la ubicación de estas instalaciones. Respecto a la distancia al punto limpio, Walo et al. (2001) en su trabajo de investigación observaron que la mayoría de los ciudadanos opinan que es una buena solución para los residuos domésticos especiales la implantación de puntos limpios y propusieron incrementar su número e instalarlos más cerca. 


\subsubsection{Accesos/tiempo a la instalación.}

La variable accesos/tiempo está referida tanto a las características de la vía como al tiempo necesario para llegar a la instalación. Será importante la accesibilidad cómoda con vehículo desde los viales principales del municipio tanto para usuarios como para transportistas.

EI PIRCV también define esta variable y propone zonas de fácil acceso para los usuarios de acuerdo con los siguientes criterios:

- Se ubicarán preferentemente en el casco urbano o urbanizable y si ello no fuera posible, se estimará un trayecto máximo de unos 15 minutos. La distancia recorrida en este tiempo está directamente relacionada con las condiciones de tránsito de la zona y, por tanto, depende de la densidad de población y de la red viaria. Se pueden aprovechar localizaciones cercanas a las zonas industriales o de ocio del municipio, nudos de comunicación viaria o zonas de paso.

- La instalación deberá estar bien comunicada por carretera y en la medida de lo posible se preverán rutas peatonales, parada de transporte público y carril bici.

- Los accesos deberán disponer de una iluminación correcta, especialmente las rutas peatonales.

- Los accesos deberán ser diseñados y señalizados convenientemente para evitar situaciones peligrosas.

En la región de Murcia, además, se tiene en cuenta una conectividad adecuada basada en conexiones directas con los núcleos de población a los que se les pretende dar servicio, que puede incluso prevalecer respecto a la distancia.

En Extremadura, por ejemplo, se valora que su ubicación se encuentre en un área fácilmente accesible a los ciudadanos teniendo en cuenta el tipo de suelo en que esté previsto ubicarse, dando preferencia al suelo industrial y con un acceso directo mediante un vial asfaltado.

Si se compara con la Comunidad Autónoma vecina, Cataluña, en su Norma Técnica sobre "Deixalleries" (puntos limpios en la Comunidad Catalana), de la ACR se establece que los accesos se deben conservar en perfecto estado de limpieza. Además, se destaca la importancia de la separación entre viales para particulares y los propios de los camiones de recogida de contenedores. 


\subsubsection{Variables de funcionamiento.}

Las variables de funcionamiento están referidas al desarrollo y explotación de las actividades que se llevan a cabo en una instalación y todas las circunstancias que en definitiva afectan a la operatividad de la misma. En este caso se han considerado las variables "horario", "mantenimiento", "difusión/concienciación" y la existencia de "incentivos" por utilización.

\subsubsection{Horario de la instalación.}

El horario de la instalación es el tiempo que la instalación permanece abierta y en el cual los ciudadanos pueden hacer uso de la misma. Los puntos limpios deberán disponer del horario más amplio posible, facilitando así su utilización por parte de los ciudadanos. Según Diez (2002), es precisamente los fines de semana cuando mayor número de usuarios frecuentan las instalaciones, puesto que es también cuando, en general, se incrementa la disponibilidad de tiempo libre de los ciudadanos.

Es importante también ajustar la temporalidad y la franja horaria de apertura. Según Gallardo et al. (2015), en primavera se registra el mayor número de usuarios en este tipo de instalaciones; siendo los jueves, viernes y sábados los días de mayor afluencia y, la franja de 10 a 12 horas, el horario más utilizado.

Según la normativa de la región de Murcia, los horarios de la instalación se han de adaptar a los horarios de los posibles usuarios, de lunes a viernes en horario de mañana y de tarde y durante el fin de semana, cuando menos el sábado. En el caso de las poblaciones con segundas residencias (zona costera), hay que considerar la posibilidad de abrir el punto limpio también la mañana de los domingo y días "punta" (sábados y viernes) de utilización del punto limpio, para los cuales se puede considerar la ampliación del horario del servicio.

Igualmente, en Extremadura se establece que las instalaciones tendrán un horario de apertura y cierre que facilite el acceso de los usuarios a los puntos limpios. La regulación del horario se establecerá para cada uno de los puntos limpios en función del número de habitantes, características y costumbre de la población en que se localice el centro de recogida.

El horario de apertura en Canarias, según el Decreto 29/2002, de 25 de marzo, por el que se regula el funcionamiento de las instalaciones denominadas Puntos Limpios, no será inferior a 60 horas semanales, repartidas entre los siete días de la semana excepto festivos. La regulación del horario podrá establecerse por cada Corporación Insular a través de su correspondiente ordenanza reguladora. 
Según la ACR, como norma general los puntos limpios deben adecuarse a las necesidades potenciales de los usuarios en cuanto a horarios se refiere. Por ello, se recomienda la apertura los fines de semana, como mínimo uno de los dos días. Además, es esencial que los puntos limpios estén abiertos, aunque sea parcialmente, fuera del horario laboral habitual. Deben diferenciarse los horarios del personal con los de apertura de la instalación, considerando las tareas necesarias para la limpieza y mantenimiento de la instalación, siendo necesario establecer un sistema de explotación coherente en el que se prioricen las necesidades de los usuarios.

\subsubsection{Mantenimiento de la instalación.}

Esta variable se refiere a conservar en buen estado de uso la instalación. Cuanto mejores son las condiciones de confort y seguridad en las que se encuentre, mejor será la predisposición de uso. Según Barahona et al. (2010), para potenciar los servicios de un punto limpio es necesaria la implementación de un plan de mantenimiento sustentado bajo la opinión de los principales usuarios de las instalaciones.

Las tareas de limpieza y mantenimiento del punto limpio son un punto clave para el logro de tres objetivos fundamentales:

- Evitar situaciones de rechazo de la instalación por parte del vecindario próximo.

- Mostrar el punto limpio como un lugar atractivo para los usuarios, de manera que se pueda promocionar su uso.

- Mantener tanto las instalaciones como el equipamiento del punto limpio en condiciones óptimas para evitar fugas, derrames, accidentes o situaciones de emergencia.

Para lograr estos objetivos hace falta que las operaciones de limpieza y mantenimiento del punto limpio no se limiten solamente al espacio interior de la valla que delimita la instalación y todos los elementos que la componen, sino que abarquen también el entorno próximo.

En la región de Murcia, según su normativa, se debe efectuar un control del estado de limpieza de las instalaciones centrado especialmente en evitar los residuos esparcidos, el desarrollo de insectos y roedores, así como la obturación de la red de recogida de aguas pluviales. Asimismo, se realizará un correcto mantenimiento de todo el equipamiento del punto limpio y de la zona ajardinada existente en la parcela.

En Extremadura se establece que la instalación y su entorno deberán mantenerse en un estado de limpieza adecuado y realizar las labores de mantenimiento necesarias. Las operaciones de 
limpieza deben incluir, además de la instalación, los accesos desde el exterior, el entorno inmediato y la maquinaria y los equipos.

En los pliegos de Prescripciones Técnicas del Servicio de explotación de los puntos limpios de los Cabildos Canarios se incluye que los contratistas deberán mantener, en todo momento, un correcto estado de limpieza y mantenimiento de las instalaciones, extendiéndose la limpieza a los accesos y entorno exterior inmediatamente próximo a las instalaciones, incluyendo la eliminación de malas hierbas.

En la Norma Técnica de la ACR, se pone de manifiesto la necesidad de mantener en las mejores condiciones la instalación (equipamiento, mobiliario, zonas verdes, contenedores, etc.), evitando que se pueda convertir en un punto de vertido incontrolado. En caso de necesidad, se realizarán los tratamientos de plagas o roedores necesarios para garantizar la salubridad del punto limpio. Además, será necesario que las instalaciones cumplan la normativa de Seguridad y Salud, en concreto la Ley 31/1995 de Prevención de Riesgos Laborales. Para ello, se garantizará la adecuada evacuación de aguas, así como el control de vertidos accidentales que se puedan producir durante las operaciones de carga y descarga. Igualmente, en los muelles de descarga se dispondrá de las medidas necesarias para evitar caídas a distinto nivel. Respecto a ruidos y olores, se deberán cumplir las normativas existentes en estas materias.

\subsubsection{Difusión/Concienciación.}

Las campañas informativas para difundir la existencia de los puntos limpios entre la población beneficiaria es una tarea importante, aún más si la instalación se encuentra alejada del núcleo urbano.

Tras la apertura de la instalación, se debe realizar una campaña para dar a conocer su existencia entre los ciudadanos a través de hojas informativas, pancartas y carteles y medios de comunicación local. Cuando la instalación ya esté en funcionamiento, se deben hacer campañas periódicas de refuerzo para mantener y, si es posible, aumentar el grado de participación.

El encargado de la instalación, además de sus funciones propias, realiza tareas de educador ambiental, informando sobre la gestión que se hace de los residuos en la instalación y aclarando dudas a los usuarios. Por otra parte, se pueden organizar actividades educativas en la instalación: visitas guiadas, talleres sobre residuos, charlas de temática ambiental, etc. que no estén dirigidas sólo hacia el público infantil, sino también al público adulto. 
En casi todos los casos se presenta en la web del gobierno de la comunidad autónoma un apartado sobre los puntos limpios, las ubicaciones y horarios de los mismos y los residuos admisibles.

La participación ciudadana es fundamental, según Calatayud et al. (2011), para asegurar el éxito de los programas de reciclaje. De ahí el interés de los estudios que tratan de determinar cuáles son las actitudes, los comportamientos y la valoración de los ciudadanos en relación con el medio ambiente y, sobre todo, las variables que inciden de forma directa en el reciclaje, puesto que éstas deben ser tomadas como referentes para la puesta en marcha de las políticas de reciclaje. Así pues, la difusión capaz de aumentar esta participación será clave para el buen funcionamiento de estas instalaciones.

La falta de información sobre cantidades recogidas en estas instalaciones y composición de los residuos es otro aspecto a considerar en la difusión/concienciación. Si los ciudadanos dispusieran de esta información de forma sencilla y rápida, por ejemplo, a partir de "portales de transparencia", podría ser algo motivador y con ello aumentar su participación.

En Murcia, por ejemplo, se indica que en cuanto se haya culminado la construcción del punto limpio se ha de impulsar una campaña informativa para difundir su existencia entre la población beneficiaria. Esta tarea será aún más importante si la instalación se encuentra alejada del núcleo urbano. Una vez que el punto limpio se encuentre en funcionamiento, se deberán realizar campañas periódicas de refuerzo para conseguir mantener y, si fuera posible, aumentar el grado de participación ciudadana.

En Extremadura, se recomienda llevar a cabo actuaciones dirigidas a la población cercana a la zona donde se pretenda ubicar el centro de recogida mediante charlas informativas con las asociaciones de vecinos y de comerciantes de la zona, tanto al inicio de su puesta en marcha como durante su funcionamiento. Además, se considera importante el papel educador del encargado así como la posibilidad de realizar actividades educativas de distintos tipos, según el público al que vayan dirigidas.

Para la divulgación de las funciones y el correcto uso de las instalaciones, en Canarias se facilitará a los usuarios la información suficiente a través del personal del centro. Además, se promoverán actividades educativas y visitas que desde los centros de educación se soliciten realizar en los puntos limpios. Se permitirá la toma de imágenes, fotografías o vídeo del interior de las instalaciones, para su uso en reportajes fotográficos, medios de comunicación, etc., previa autorización por la Administración competente para la explotación de los mismos. 


\subsubsection{Tasas/ Incentivos.}

EI PEMAR propone el desarrollo y aplicación de instrumentos económicos con el fin de incentivar la aplicación de la jerarquía de residuos y avanzar en el cumplimento del objetivo comunitario en materia de reciclado. Entre ellos, se contempla el establecimiento de un marco sobre fiscalidad ambiental tanto desincentivador como incentivador que se pueden traducir, por ejemplo, en tasas por generación o descuentos, en función del uso del punto limpio.

Para Puig (2004) los instrumentos fiscales deben jugar un papel central en la consecución de una gestión más ecológica de los residuos municipales y, a escala local, el instrumento con mayor capacidad en este sentido es la tasa de basuras. Además, para que ésta pueda convertirse en un elemento que incentive la buena gestión ambiental, su importe debe depender de la cantidad y tipo de los residuos generados, de modo que a menor generación y mayor reciclaje la cuota disminuya. Este tipo de tasas se llama de "pago por generación". En este sentido, para Gallardo et al. (2015), la incentivación de la participación ciudadana mediante acciones en las que se gratifica la participación puede repercutir positivamente en el aumento de las tasas de recogida en los puntos limpios.

En Murcia, para el sistema de tasas se prevén dos modelos, que se pueden combinar entre sí:

- Tasas según el tipo de usuario, que establece la gratuidad del servicio para los particulares y las tasas se aplicarían a los comercios, oficinas, etc.

- Tasas según la cantidad de residuos aportados, fijando una cantidad máxima de cada residuo o sólo de determinados tipos de residuos que se pueden aportar al punto limpio de manera gratuita, independientemente del tipo de usuario. En caso de sobrepasar dicha cantidad, el usuario pagaría una tasa proporcional por el exceso de material aportado.

El Plan Integrado de Residuos de Extremadura 2016-2022 promueve la introducción de bonificaciones por el uso de puntos limpios, para lo cual la Junta de Extremadura, en el marco de sus competencias, colaborará con las Entidades Locales en su desarrollo.

En Canarias, no se establecen tasas ni incentivos, sino que el servicio es gratuito. No obstante se menciona la posibilidad de incluir en el futuro tasas por generación. 


\subsubsection{Variables de infraestructura.}

Las variables de infraestructura son las intrínsecas de la instalación y están relacionadas directamente con su diseño, tanto por las necesidades del municipio como por la normativa autonómica o nacional que pueda condicionar dicho diseño. Por ello, en esta ocasión se han tenido en cuenta las variables "tamaño de la instalación" y "la señalización" que pueda existir sobre la misma.

\subsubsection{Tamaño de la instalación.}

El tamaño de la instalación está relacionado con la variedad de categorías de residuos admitidas en el punto limpio. A mayor tamaño, mayor número de contenedores $\mathrm{y}$, por tanto, mayor número de categorías admitidas. Como se ha mencionado anteriormente, según Moliner et al. (2010), la diversidad de materiales admitidos en estas instalaciones aumenta su utilización.

Por ejemplo, el PIRCV distingue entre 4 tipologías de instalación fijas y una móvil, en función del número de habitantes potenciales a los que preste servicio (Tabla 4.3). Para cada tipología de punto limpio se define la superficie, la disposición y el número de contenedores y el tamaño de los mismos.

\begin{tabular}{|c|c|c|c|c|c|}
\hline Ecoparque & $\begin{array}{c}\text { Población } \\
\text { Potencial }\end{array}$ & Disposición & $\begin{array}{l}\text { Superficie } \\
\left(\mathrm{m}^{2}\right)\end{array}$ & $\begin{array}{c}\mathbf{N}^{\circ} \text { de } \\
\text { contenedores }\end{array}$ & $\begin{array}{l}\text { Tamaño de } \\
\text { contenedores }\end{array}$ \\
\hline Tipo A & Hasta 1.000 & 1 Cota & $300-500$ & $4-6$ & $9 \mathrm{~m}^{3}$ \\
\hline Tipo B & $1.001-5.000$ & 1 Cota & $500-1.000$ & $6-8$ & $9 / 18 \mathrm{~m}^{3}$ \\
\hline Tipo C & $5.001-10.000$ & 2 Cotas & $1.500-3000$ & $8-10$ & $18 / 26 \mathrm{~m}^{3}$ \\
\hline Tipo D & Mas de 10.001 & 2 Cotas & $2.500-5000$ & $10-15$ & $18 / 26 \mathrm{~m}^{3}$ \\
\hline Móvil & $\begin{array}{l}\text { Según } \\
\text { necesidades }\end{array}$ & --- & Camión & --- & Según gestores \\
\hline
\end{tabular}

Tabla 4.3: Clasificación de instalaciones según PIRCV. 
Estas prescripciones son similares a las establecidas en Cataluña, donde la clasificación es la que se muestra en la Tabla 4.4.

\begin{tabular}{|c|c|c|}
\hline Deixalleria & Habitantes potenciales por Deixalleria & Superficie $\left(\mathbf{m}^{2}\right)$ \\
\hline Básica & $<5.000 \mathrm{~h}$. & $225 \mathrm{~m}^{2}$ \\
\hline Tipo A & $5.000-10.000 \mathrm{~h}$. & $625 \mathrm{~m}^{2}$ \\
\hline Tipo B & $10.000-70.000 \mathrm{~h}$. & $2.275 \mathrm{~m}^{2}$ \\
\hline Tipo C & $>70.000 \mathrm{~h}$ & $4.500 \mathrm{~m}^{2}$ \\
\hline Móvil & A estudiar según necesidades & - \\
\hline Minideixalleries & A estudiar según necesidades & - \\
\hline
\end{tabular}

Tabla 4.4: Clasificación de instalaciones según ACR.

Como se puede observar en la Tabla 4.4, en este caso también se establece la posibilidad de dotaciones móviles o de "minideixalleries" para zonas donde sus características demográficas o geográficas así lo aconsejen. En cualquier caso, el tipo de punto limpio estará condicionado por la población a la que se destine, las necesidades particulares y la densidad demográfica de cada una de ellas.

En Murcia, además de los puntos limpios fijos y los móviles, se prevé la puesta en marcha de "puntos limpios agrícolas", así como otro tipos de puntos limpios adaptados a otros sectores de producción como el industrial. En cuanto a su tamaño, la superficie global del punto limpio modelo es de unos $1.200 \mathrm{~m}^{2}$ basada en un diseño modular básico comprendido por edificios, zonas verdes, aparcamientos y áreas de recogida de residuos.

En Extremadura, se definen tres tipos de puntos limpios según el tamaño de los municipios a los que sirvan atendiendo a los intervalos de: menos de 5.000 , entre 5.000 y 20.000 y más de 20.000 habitantes. La superficie óptima recomendada para el correcto funcionamiento de cada tipo de instalación, en función de la población a la que va a servir, se establece de la siguiente manera:

- Punto limpio Tipo A: $215 \mathrm{~m}^{2}$

- Punto limpio Tipo B: $1.400 \mathrm{~m}^{2}$

- Punto limpio Tipo C: $3.000 \mathrm{~m}^{2}$

La superficie mínima y el equipamiento del punto limpio en Canarias también son proporcionales al número de habitantes por centro de recogida, pudiendo existir, a tal efecto, tres tipos de instalaciones:

- Punto Limpio Tipo A: $2.600 \mathrm{~m}^{2}$ y de 5.000 a 10.000 habitantes por centro de recogida.

- Punto Limpio Tipo B: $3.100 \mathrm{~m}^{2}$ y de 30.000 a 50.000 habitantes por centro de recogida.

- Punto Limpio Tipo C: $4.100 \mathrm{~m}^{2}$ y hasta 100.000 habitantes por centro de recogida. 


\subsubsection{Señalización de la instalación.}

Esta variable contempla la información necesaria para facilitar a los ciudadanos el uso de los puntos limpios, dejando al margen lo relativo a las campañas de sensibilización. En relación a este tema son cuatro las claves para el usuario:

1. Señalización de acceso para conducir a los usuarios por el itinerario adecuado hasta llegar al punto limpio. Es competencia de la administración correspondiente la correcta señalización vial, de acuerdo con la legislación vigente en materia de carreteras.

2. Señalización sobre la información general del punto limpio en el interior o en la valla de entrada.

3. Señalización de cada cada contenedor.

4. Información que proporciona el personal del centro.

La variable de señalización responde a la información disponible dentro y fuera de la propia instalación para su uso por parte de los ciudadanos. Por ejemplo, la señalización tanto de la ubicación del punto limpio como de sus accesos queda perfectamente definida en el PIRCV. A la entrada de la instalación se dispondrán, en lugares bien visibles, uno o varios carteles informativos que contengan como mínimo la siguiente información:

- Nombre de la instalación.

- Horario de apertura.

La señalización a la llegada de la instalación también debe contener información como:

- Limitaciones cuantitativas y cualitativas de aportación.

- Tasas administrativas que procedan.

- Entidad responsable de la explotación de la instalación.

- Datos de contacto (teléfono, fax, página web, correo electrónico, etc.).

Asimismo, la instalación dispondrá de la señalización interna necesaria para facilitar la circulación de los usuarios y la identificación de los residuos que se depositan en cada contenedor.

En Murcia, por ejemplo, se diferencian tres tipos de señalización:

- Señalización de accesos a la instalación, con el fin de facilitar el acceso hasta el punto limpio desde cualquiera de los núcleos de población a los que éste da servicio.

- Señalización interior del punto limpio: cartelería identificativa, para los depósitos de residuos y la identificación de la propia instalación unificada para toda la Red de puntos limpios Regional. 
- Información directa al usuario durante el depósito de los residuos, proporcionada por el personal del punto limpio.

En Extremadura, igualmente, el punto limpio debe disponer de una señalización que facilite el uso y minimice el tiempo de estancia en la instalación. Los carteles serán de los siguientes tipos:

- Carteles de acceso a las instalaciones, en el exterior de la instalación.

- Cartel informativo del horario de la instalación, así como los pictogramas de los residuos que se admiten en las instalaciones y las cantidades.

- Carteles de información del uso y empleo de los contenedores, situados junto a cada uno de ellos.

En Canarias, se indica que se dispondrá de señalización vertical consistente en carteles informativos tanto en la parte interior como exterior de las instalaciones dependiendo de su función concreta, ajustándose a las dimensiones y características especificadas en la normativa. Los diferentes tipos de carteles son:

- Carteles de acceso.

- Cartel informativo del horario de la instalación con los pictogramas de los residuos que se admiten.

- Carteles de información del uso y empleo de los contenedores, situados junto a cada uno de ellos.

En Cataluña, por acabar con el mismo ejemplo, la ACR considera conveniente la colocación de carteles bien visibles con los datos citados anteriormente, así como con otros como los residuos admitidos. También plantea la importancia de los puntos limpios como centros de educación ambiental donde se potencie la información y la sensibilización en esta materia. Además, establece que en casos de grandes instalaciones es muy recomendable la dotación de planos y señalética a la entrada para facilitar el acceso a cada fracción, que además estará debidamente identificada mediante texto y dibujos explicativos. 


\subsection{Discusión de las variables y sus valores.}

En este punto se resumen, en la Tabla 4.5, las variables y sus valores encontrados en la bibliografía y normativa estudiada para las diferentes comunidades autónomas.

\begin{tabular}{|c|c|c|c|c|c|c|}
\hline & & C. VALENCIANA & R. DE MURCIA & EXTREMADURA & CANARIAS & CATALUÑA \\
\hline \multirow{2}{*}{$\begin{array}{l}\text { VARIABLES DE } \\
\text { LOCALIZACIÓN }\end{array}$} & $\begin{array}{l}\text { Ubicación de la } \\
\text { instalación }\end{array}$ & $\begin{array}{l}\text { Área de } \\
\text { influencia }<5 \\
\text { km }\end{array}$ & $\begin{array}{l}\text { Urbanas: } \\
\text { Entre } 2 \text { y } 5 \\
\text { km } \\
\text { Rurales: } \\
\text { Entre } 5 \text { y } 10 \\
\text { km }\end{array}$ & - & $\begin{array}{l}\text { Según } \\
\text { PGOU } \\
\text { municipal }\end{array}$ & $\begin{array}{l}\text { Próximas al } \\
\text { usuario para } \\
\text { facilitar } \\
\text { aportaciones }\end{array}$ \\
\hline & $\begin{array}{l}\text { Accesos / } \\
\text { Tiempo a la } \\
\text { instalación }\end{array}$ & $\begin{array}{l}\text { Máx. } 15 \text { min. } \\
\text { Bien } \\
\text { comunicada }\end{array}$ & $\begin{array}{l}\text { Buena } \\
\text { conectividad }\end{array}$ & $\begin{array}{l}\text { Buen acceso. } \\
\text { Preferible en } \\
\text { suelo } \\
\text { industrial }\end{array}$ & - & $\begin{array}{l}\text { Buenos } \\
\text { accesos y } \\
\text { perfecto } \\
\text { estado de } \\
\text { conservación }\end{array}$ \\
\hline \multirow{4}{*}{$\begin{array}{l}\text { VARIABLES DE } \\
\text { FUNCIONAMIENTO }\end{array}$} & $\begin{array}{l}\text { Horarios de la } \\
\text { instalación }\end{array}$ & - & $\begin{array}{l}\text { De Lunes a } \\
\text { Sábado, } \\
\text { Mañanas y } \\
\text { tardes. } \\
\text { Domingo, } \\
\text { Mañanas en } \\
\text { zonas } \\
\text { costeras }\end{array}$ & $\begin{array}{l}\text { Según } \\
\text { características } \\
\text { del municipio }\end{array}$ & $\begin{array}{l}\text { Min. } 60 \\
\text { h/semana } \\
\text { Excepto } \\
\text { festivos }\end{array}$ & $\begin{array}{l}\text { De unes a } \\
\text { Viernes, } \\
\text { Mañanas y } \\
\text { tardes } \\
\text { Sábado o } \\
\text { Domingo }\end{array}$ \\
\hline & $\begin{array}{l}\text { Mantenimiento } \\
\text { de la instalación }\end{array}$ & $\begin{array}{l}\text { Buena } \\
\text { conservación }\end{array}$ & $\begin{array}{l}\text { Buena } \\
\text { conservación } \\
\text { interior y } \\
\text { exteriores }\end{array}$ & - & - & $\begin{array}{l}\text { Se incide en } \\
\text { la } \\
\text { importancia } \\
\text { de la } \\
\text { conservación }\end{array}$ \\
\hline & $\begin{array}{l}\text { Difusión / } \\
\text { Concienciación }\end{array}$ & - & $\begin{array}{l}\text { Campañas } \\
\text { informativas } \\
\text { de la } \\
\text { instalación. } \\
\text { Inicial y } \\
\text { periódicas } \\
\end{array}$ & $\begin{array}{l}\text { Campañas } \\
\text { dirigidas a la } \\
\text { población } \\
\text { cercana }\end{array}$ & $\begin{array}{l}\text { A través del } \\
\text { personal de } \\
\text { la } \\
\text { instalación }\end{array}$ & - \\
\hline & $\begin{array}{l}\text { Empleo de tasas } \\
\text { o incentivos }\end{array}$ & $\begin{array}{l}\text { Se podrán } \\
\text { diseñar }\end{array}$ & $\begin{array}{l}\text { Tasas según } \\
\text { tipo de } \\
\text { usuario, o por } \\
\text { cantidades }\end{array}$ & $\begin{array}{l}\text { Se preverán } \\
\text { bonificaciones }\end{array}$ & $\begin{array}{l}\text { El servicio } \\
\text { es } 100 \% \\
\text { gratuito }\end{array}$ & - \\
\hline \multirow[b]{2}{*}{$\begin{array}{l}\text { VARIABLES DE LA } \\
\text { INFRAESTRUCTURA }\end{array}$} & $\begin{array}{l}\text { Tamaño de la } \\
\text { instalación }\end{array}$ & $\begin{array}{l}4 \text { tipos, } \\
\text { según } \\
\text { tamaño de la } \\
\text { población }\end{array}$ & $\begin{array}{l}\text { Prevé PL } \\
\text { agrícolas e } \\
\text { industriales }\end{array}$ & $\begin{array}{l}3 \text { tipos, según } \\
\text { tamaño de la } \\
\text { población }\end{array}$ & $\begin{array}{l}3 \text { tipos, } \\
\text { según } \\
\text { tamaño de } \\
\text { la población }\end{array}$ & $\begin{array}{l}6 \text { tipos, } \\
\text { según } \\
\text { tamaño de la } \\
\text { población }\end{array}$ \\
\hline & $\begin{array}{l}\text { Señalización de } \\
\text { las instalaciones }\end{array}$ & $\begin{array}{l}\text { Debe } \\
\text { definirse de } \\
\text { manera clara } \\
\text { (nombre, } \\
\text { horarios, } \\
\text { tasas, límites, } \\
\text { etc.) }\end{array}$ & $\begin{array}{l}\text { Distingue } 3 \\
\text { tipos: Acceso, } \\
\text { horarios, } \\
\text { usos }\end{array}$ & $\begin{array}{l}\text { Distingue } 3 \\
\text { tipos: Acceso, } \\
\text { horarios, usos }\end{array}$ & $\begin{array}{l}\text { Distingue } 3 \\
\text { tipos: } \\
\text { Acceso, } \\
\text { horarios, } \\
\text { usos }\end{array}$ & $\begin{array}{l}\text { Conveniente } \\
\text { cartelería } \\
\text { para } \\
\text { potenciar la } \\
\text { sensibilidad }\end{array}$ \\
\hline
\end{tabular}

Tabla 4.5: Resumen de variables por CC.AA. 
Respecto la ubicación de la instalación, la distancia máxima propuesta por las normativas es de $10 \mathrm{~km}$, aunque la comunidad de Murcia hace una distinción entre en las zonas rurales y urbanas, acortando en éstas últimas la distancia. En Canarias y Cataluña, no se establece una distancia máxima, pero sí se pone el foco en la importancia de la proximidad ya que son los propios usuarios los que deben desplazarse a la instalación.

Para el acceso a las instalaciones, la normativa de la Comunidad Valenciana es la que más incide en la facilidad de comunicación, comodidad, así como de las características de la vía (diseño, alumbrado, etc). En la región de Murcia, igualmente, se tiene en cuenta una conectividad adecuada, que puede incluso prevalecer respecto a la distancia hasta la instalación. En Extremadura, se da preferencia al suelo industrial por el acceso de vehículos pesados, mientras que en Cataluña lo que prima es la importancia en disponer de circuitos diferenciados para usuarios y gestores de residuos.

En cuanto a los horarios, en todas las Comunidades Autónomas se incide en la importancia de que éstos sean acordes a la disponibilidad de los usuarios; siendo obligatoria la apertura los fines de semana, al menos uno de los dos días, en Canarias, Cataluña y Murcia. En Extremadura, la potestad de establecer horarios se delega en cada municipio según las necesidades y al objeto de que se maximicen las visitas.

El mantenimiento del punto limpio, se considera clave en Cataluña para el buen rendimiento de la instalación, tanto visualmente como en la práctica. Así, en esta comunidad se pone especial interés en la limpieza, la ausencia de plagas o la adecuada evacuación de aguas. Otras comunidades autónomas como Murcia y Extremadura, sin llegar a desarrollar tanto estos aspectos, sí que resaltan la importancia de una buena conservación del punto limpio.

Respecto a las campañas informativas para difundir la existencia de los puntos limpios, siendo fundamental en este aspecto la figura del encargado del punto limpio, en Canarias, Extremadura y Murcia, además, se establece la obligatoriedad de realizar campañas a la puesta en funcionamiento de la instalación, así como de manera periódica a modo de recordatorio.

En cuanto a las tasas o incentivos, no existe mucha información en la normativa consultada. Destacan los dos modelos de tasas previstos en la normativa murciana: tasas según usuario (particular o empresa) o tasas por aportaciones (estableciendo un máximo gratuito). Por su parte, el Plan Integrado de Residuos de Extremadura 2016-2022 promueve la introducción de bonificaciones por el uso de puntos limpios. En Canarias, actualmente no existen incentivos, pero 
el servicio es totalmente gratuito; no obstante, se menciona la posibilidad de incluir en el futuro tasas por aportación.

En lo referente al tamaño del punto limpio, todas las normativas autonómicas consultadas establecen tipos de puntos limpios (entre 3 y 6 ), según la población asociada. Es decir, el tamaño del punto limpio vendrá condicionado por la población a la que preste servicio. Además, en Murcia, Cataluña y Comunidad Valenciana, se prevé la existencia de puntos limpios móviles para zonas alejadas de los núcleos poblacionales.

Por último, en cuanto a la señalización de la instalación, Murcia, Extremadura y Canarias establecen tres tipologías de carteles: de horarios de funcionamiento, de los accesos a la instalación y del uso de cada contenedor. La normativa de la Comunidad Valenciana es la que más desarrolla este extremo, detallando el contenido de cada uno de los carteles. En Cataluña, por su parte, se resalta la importancia de dotar de planos y señalética en caso de grandes instalaciones.

\subsection{Conclusiones.}

En la actualidad, existe poca información publicada sobre el funcionamiento de los puntos limpios. Donde más información se ha encontrado es en la normativa y en los Pliegos de Condiciones Técnicas. No obstante, se ha determinado el conjunto de variables que afectan al funcionamiento de los puntos limpios y que han sido estudiadas por otros autores o relacionadas como importantes en documentos oficiales. También se ha definido cuál es su influencia en cada caso, como se resume a continuación.

Respecto a la ubicación de la instalación, se ha puesto de manifiesto la importancia de la proximidad a los núcleos poblacionales, dado que son los ciudadanos los que deben transportar los residuos hasta los puntos limpios. Asimismo, la comodidad en la accesibilidad al punto limpio y su circulación interior es importante a la hora de su diseño, debiendo tenerse en cuenta que pueden coincidir turismos con vehículos pesados Por ello, pese a que se coincide en la importancia de que las instalaciones se ubiquen en suelo urbano y próximas a los núcleos, también hay comunidades que las prefieren en suelo industrial.

Referente al funcionamiento de la instalación, ha quedado plasmado que su horario debe permitir el uso del máximo número de usuarios, siendo importante la apertura en horario laboral y en fines de semana, al menos, uno de los días. En lo que a mantenimiento concierne, éste debe ser el adecuado a través de la implantación de un plan anual, ya que una imagen de dejadez o la falta 
de acciones correctivas fomentarán las críticas y el desuso de la instalación. Del mismo modo, se ha puesto de manifiesto la importancia de la participación ciudadana y de la información y concienciación a los usuarios, de modo que estén motivados para utilizar estas instalaciones, ya que el transporte genera un rechazo inicial a su utilización. En este sentido, puede resultar de vital importancia el empleo de tasas o incentivos, que además de maximizar el uso del punto limpio, redundará en una reducción de los abandonos de enseres en la vía pública, junto al contenedor.

Respecto a la infraestructura propiamente dicha, su tamaño dependerá de la población potencial a la que esté destinada, estableciéndose varios tipos de punto limpio (entre tres y seis) en función de ésta. Además, se ha destacado la importancia de la información exterior e interior en los puntos limpios, y hasta en algunas referencias consultadas, se ha observado que el tratamiento de estas instalaciones pretende asemejarse a centros de educación y sensibilización en materia de residuos.

Por último, en la búsqueda de la mejora del rendimiento de estas instalaciones, pueden existir más variables que sean capaces de influir en el funcionamiento del punto limpio, tales como:

- El tamaño de la población a la que da servicio.

- La antigüedad de la instalación y los servicios de los que dispone.

- El número de carriles de los que disponga, en uno o varios sentidos.

- La comunicación con el núcleo urbano mediante transporte público, carril bici u otros.

- La posibilidad de que las pequeñas y medianas empresas puedan hacer uso de la instalación.

- La limitación en cuanto a aportaciones diarias se refiere.

- La existencia de puntos limpios móviles que de alguna manera puedan complementar en la ciudad el servicio prestado por el punto limpio fijo.

En el capítulo siguiente se desarrolla un estudio de campo para ampliar el número de variables que pueden afectar a la ubicación y diseño del punto limpio.

\subsection{Referencias.}

Aranda Usón, A., Ferreira, G., Zambrana Vásquez, D., Zabalza Bribián, I., Llera Sastre, E. (2013) Environmental-benefit analysis of two urban waste collection systems. Science of The Total Environment, Volumes 463-464, Pages 72-77.

Barahona, Ana Marcela and Campos Ramírez, Karla Tatiana and Rojas Esquivel, Yanis Patricia (2010) Diseño de un plan de mantenimiento de las instalaciones, que permita 
potenciar los servicios del Ecoparque El Espino en el Municipio de Antiguo Cuscatlán, Departamento de La Libertad. Bachelor thesis, Universidad de EI Salvador.

DECRETO 29/2002, de 25 de marzo, por el que se regula el funcionamiento de las instalaciones denominadas Puntos Limpios. Consejería de Política Territorial y Medio Ambiente del Gobierno de Canarias.

Calatayud, V.A., Alcaide,G., Andrés, C. (2011) Percepción social sobre la gestión de residuos urbanos: el caso del municipio de Puçol (Valencia). Observatorio Medioambiental; Madrid 14: 95-106.

Diez Ros, R (2002). Una experiencia de educación ambiental a través de la geografía: La visita al ecoparque municipal de Alicante. Investigaciones Geográficas, $n^{\circ}$ 27, pp 191-203. Instituto Universitario de Geografía. Universidad de Alicante

Gallardo A, Bovea MD, Colomer FJ, Prades M, Carlos M, (2010) Comparison of different collection systems for sorted household waste in Spain. Waste Management, Volumen 30, Issue 12, December 2010, Pages 2430-2439.

Gallardo A, Edo N, Colomer FJ, Carlos M, (2015). Estudio de la eficiencia en la recogida de residuos domiciliarios.19 Congreso internacional de proyectos de ingeniería.

Gallardo A, Edo N, Badenes C, Fas N, Prades M, Carlos M, (2016) Eficiencia de la recogida de RSU mediante puntos limpios en Castellón de la Plana. VI Simposio Iberoamericano en ingeniería de residuos sólidos.

Gestión de la red de ecoparques de la región de Murcia, Consejería de Agricultura y Agua de la Región de Murcia, enero 2009.

LEY 22/2011, de 28 de julio, de residuos y suelos contaminados.

Manual para la correcta gestión de un punto limpio en Extremadura, Promedio 2019.

Martin, M, Williams, I.D., Clark, M. (2006) Social, cultural and structural influences on household waste recycling: A case study. Resources, Conservation and Recycling 48, 357395.

Moliner, E.; Muñoz, C.; Garraín, D.; Vidal, R. (2010) Sistemas de información geográfica para evaluar la disponibilidad de puntos limpios en la provincia de Castellón. En XIV Congreso de Ingeniería de Proyectos (AEIPRO), Madrid p. 1263-1274.

Norma Técnica sobre Deixalleríes, 2019. Agencia Catalana de Residuos. https://residus.gencat.cat.

Oribe-García, I., Kamara-Esteban, O., Martin, C., Macarulla-Arenaza, A.M., Alonso-Vicario, A. (2015) Identification of influencing municipal characteristics regarding household waste generation and their forecasting ability in Biscay. Waste Management, Volume 39, Pages 26-34. 
Plan Estatal Marco de Gestión de Residuos (PEMAR) 2016-2022.

Plan Integral de Residuos de la Comunitat Valenciana (PIRCV) Anexo I que desarrolla el contenido de la Norma Técnica reguladora de la implantación y funcionamiento de los ecoparque.

Pliego de cláusulas administrativas particulares que ha de regir en el contrato de servicios denominado "gestión del punto limpio municipal e instalación y gestión de mini-puntos limpios en el término municipal de Mejorada del Campo (Madrid). https://contrataciondelestado.es.

Pliego de condiciones técnicas para la contratación del servicio de gestión del punto limpio municipal del Ayuntamiento de Loeches. https://contrataciondelestado.es.

Pliego de prescripciones técnicas del Servicio público de gestión de la red de los puntos limpios y plantas de transferencia de Gran Canaria. https://contrataciondelestado.es.

Reglamento de explotación del punto limpio municipal. Delegación de medio ambiente y protección animal. Diputación de Granada. https://dipgra.es.

Puig, I., (2004) La tasa de basuras por generación. El caso de Torrelles de llobregat. Crónica tributaria 111, pp135-148 Instituto de Estudios Fiscales.

Uk.wastewatch.org (2003). [online] Available at: https://uk.wastewatch.org/_[Accessed 20 Oct. 2003].

Walo, W.M.; Hess, S. (2001) Preocupación ambiental, conocimiento y uso de los Puntos Limpios en estudiantes universitarios. Medio ambiente y comportamiento humano: Revista Internacional de Psicología Ambiental, ISSN 1576-6462, Vol. 2, №. 2, 2001, págs. 39-56. 


\section{CAPÍTULO 5. ESTUdIO DE LOS PUNTOS LIMPIOS IMPLANTADOS EN ESPAÑA.}





\section{ESTUDIO DE LOS PUNTOS LIMPIOS IMPLANTADOS EN ESPAÑA.}

Con el objetivo de determinar los factores que influyen en el grado de funcionamiento de los puntos limpios y con ello poder incrementar la gestión diferenciada de las distintas fracciones de residuos mediante su separación en origen, se estudian las características y condiciones de funcionamiento de los puntos limpios instalados a lo largo de la geografía española, en cuanto a visitas recibidas y cantidades de residuos depositadas en los mismos.

Con este objetivo, se elabora una encuesta mediante la cual se pueda recabar información relativa a las características que, a priori, puedan resultar relevantes para los resultados de gestión de los puntos limpios.

\subsection{Metodología de la encuesta.}

La metodología llevada a cabo para el estudio de situación actual de los puntos limpios en España se divide en las siguientes etapas:

- Elaboración de una encuesta piloto.

- Elaboración de la encuesta definitiva.

- Lanzamiento de la encuesta.

- Recogida de información y obtención de resultados.

- Análisis de los resultados.

La información recabada en la encuesta será útil para el análisis de las condiciones y resultados de funcionamiento de los puntos limpios, que permita definir los parámetros óptimos con los que se obtengan resultados satisfactorios en la recogida de residuos.

A continuación se describe cada una de estas etapas de la metodología.

\subsubsection{Elaboración de una encuesta piloto.}

En primer lugar, se elaboró una encuesta piloto que contemplaba diferentes aspectos de la gestión municipal de residuos, especialmente dirigida a la captación de información relacionada con las características y funcionamiento de los puntos limpios. Se adjunta la encuesta piloto como ANEXO A5.1). 
Esta encuesta piloto se remitió a municipios próximos, en los que se contaba con interlocutores con una relación más fluida, al efecto de que aportaran sus valoraciones y opciones de mejora de la encuesta piloto. Los municipios que participaron fueron Benicassim, Castelló de la Plana y Algimia de Alfara. El objetivo de esta consulta previa es detectar carencias o errores en los aspectos planteados en la encuesta.

\subsubsection{Elaboración de la encuesta definitiva.}

Tras la finalización de la encuesta piloto se diseña la encuesta definitiva, en la que se incluyen cuestiones relativas al funcionamiento de los puntos limpios:

- Cantidades de residuos gestionados anualmente.

- Número de visitas anuales.

Y a factores que afectan tanto a la cantidad de residuos recogidos como al número de visitas:

- Información general: municipio, número de puntos limpios y año de referencia.

- Datos de la instalación: nombre del punto limpio, dirección y año de construcción.

- Gestión: pública o privada, población potencial y horarios.

- Características de diseño: localización, distancia al núcleo urbano, superficie aproximada en $\mathrm{m}^{2}$, contenerización y equipamientos y existencia de punto limpio móvil.

Se adjunta el documento de la encuesta definitiva como ANEXO A5.2.

\subsubsection{Lanzamiento de la encuesta.}

Definido el contenido de la encuesta, se establece que las contestaciones a la misma serán registradas en una hoja de cálculo o base de datos, que posibilite el tratamiento posterior de la información. Con el objetivo de facilitar la recopilación de datos mediante la cumplimentación de la encuesta, se considera que lo más adecuado es el diseño de un formulario a través de una página web (Figuras 5.1 y 5.2), que será remitida por correo electrónico. Para disponer de datos homogéneos, deberá indicarse que la información debe tomar como año de referencia 2017. 


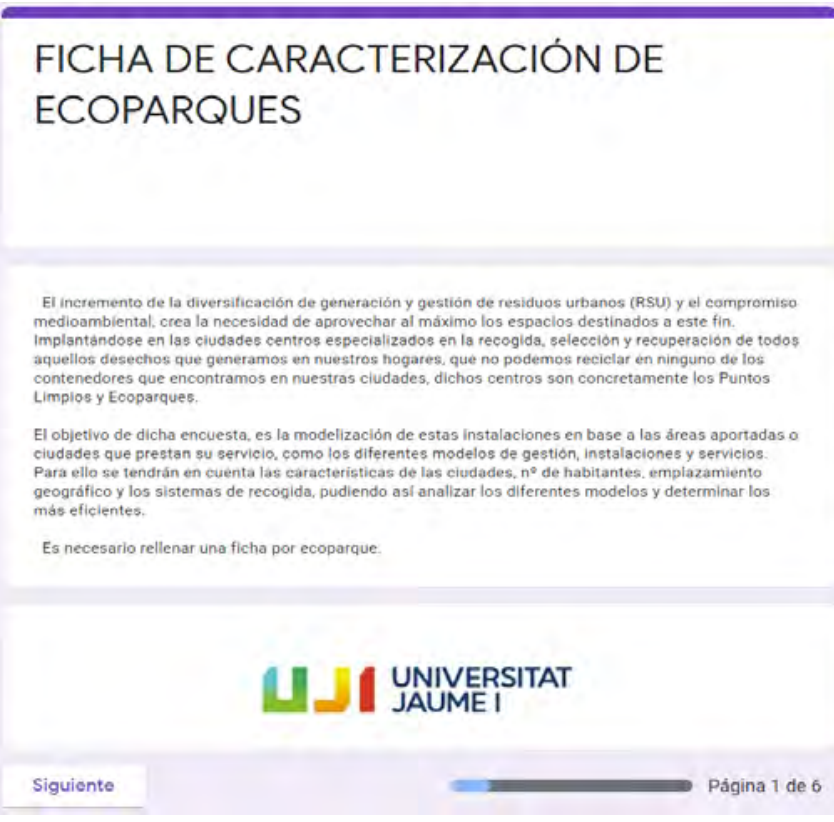

Figura 5.1: Presentación del formulario de la encuesta definitiva.

\section{FICHA DE CARACTERIZACIÓN DE ECOPARQUES}

\section{INFORMACIÓN GENERAL}

NO DE ECOPARQUES:

Tu respuesta

CIUDAD:

Tu respuesta

\section{AÑO DE REFERENCIA:}

Turespuesta

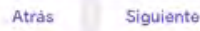

Página 2 de 6

Figura 5.2: Formulario "1. Información general" de la encuesta definitiva.

El siguiente paso es establecer el número mínimo de poblaciones a las que enviar la misma, para que los resultados sean estadísticamente representativos. De acuerdo con el Instituto Nacional de Estadística, España cuenta con 8.131 municipios. Considerando que existe una correlación entre el número de municipios y el de puntos limpios, el tamaño de la muestra en poblaciones finitas se determina utilizando la misma expresión que Rojas (Rojas, 2008):

$$
n=\frac{Z^{2} \cdot P \cdot q \cdot N}{\mathrm{e}^{2} \cdot(N-1)+Z^{2} \cdot P \cdot q}
$$

Expresión 5.1: Cálculo de tamaño de muestra en poblaciones finitas.

Donde:

$Z=$ nivel de confianza

e = error máximo permitido para la media muestral, expresado en tanto por uno.

$\mathrm{N}=$ tamaño del universo total.

$\mathrm{P}=$ porcentaje de veces que se supone que ocurre un fenómeno en el universo total, expresado en tanto por uno.

$q$ = la no ocurrencia del fenómeno (1-P). 
Pehlken (Pehlken et al., 2000) estima adecuado que en los muestreos en materia de RSU se considere un nivel de confianza del $95 \%$ y un error del $10 \%$; en cuanto a la ocurrencia del fenómeno, la situación más conservadora es aquella en que se estima que éste ocurre el $50 \%$ de las veces, y respecto a $\mathrm{N}$, se considera el total de las poblaciones españolas (8.131 municipios). Por tanto, los valores que toman los parámetros de la Expresión 5.1 son:

$$
\begin{aligned}
& Z=1,96 \\
& e=0,1 \\
& N=8.131 \\
& P=0,5 \\
& q=0,5
\end{aligned}
$$

Resultando un tamaño de muestra de 95 puntos limpios con un nivel de confianza del 95\% y un error del $10 \%$.

Considerando los trabajos de Everett (1993) y Gallardo (2000), que enviaron sendas encuestas para obtener información sobre recogida selectiva de RSU en ayuntamientos, alcanzando respectivamente un porcentaje de participación de $37,1 \%$ y $51,1 \%$, se ha considerado el envío de 180 encuestas.

Si se tiene en cuenta que el Plan Nacional de Residuos Urbanos fija que, a partir del año 2015, deberá dotarse de punto limpio sólo a los municipios con población superior a 2.000 habitantes, el universo se reduce a 2.259 municipios en España; con estos valores alternativos, según la Expresión 5.1, el tamaño de la muestra representativa se reduciría a 92 casos. No obstante, se tomará el valor de 95 registros, ya que se considera que aquellas poblaciones que estén obligadas a tener más de un punto limpio estarán compensadas por las menores de 2.000 habitantes que no dispongan de éstos.

\subsubsection{Recogida de información y obtención de resultados.}

Definidos el contenido, formato de la encuesta y el tamaño de la muestra representativa, a continuación se procede a la recopilación de datos de contacto de las entidades a encuestar, para la remisión de la misma.

En primer lugar, se debe proceder a la identificación de municipios que cuenten con punto limpio. Este proceso se lleva a cabo mediante consultas genéricas a través de internet, tanto visitando páginas web de organismos autonómicos como municipales y supramunicipales. Estas consultas generales permiten la creación de una base de datos de entidades con punto limpio, en la que se incorporen las direcciones de correo electrónico disponibles para la remisión de la encuesta y, si 
esto no es posible, de números de teléfono para la posterior solicitud de dirección electrónica. La identificación de municipios se ha realizado de forma proporcional y abarcando geográficamente el mayor número de comunidades autónomas posibles. El proceso de generación de la base de datos es de dos meses.

A continuación, se elabora un mensaje tipo, en el que se detallan los objetivos de la encuesta, remitiendo la dirección de acceso a la misma y las instrucciones de cumplimentación de la información requerida. Inicialmente, se establece un periodo de un mes para que los organismos correspondientes puedan recabar la información necesaria para la cumplimentación de la encuesta.

Mientras se desarrolla este proceso y transcurrido el periodo previsto, se realizan seguimientos de la información aportada por los diferentes encuestados, con el objetivo de verificar si, en términos globales, es está recibiendo la información deseada. En aquellos casos en que la información es insuficiente, se procede a realizar contactos personalizados, además de consultar páginas web en que pueda disponerse de dicha información, con el objetivo de reiterar la petición únicamente sobre aquellos aspectos respecto de los cuales la única fuente de información sea la contactada. Este proceso lleva aparejada la ampliación de la consulta a entidades que, sin ser gestoras o titulares de los servicios de puntos limpios, dispongan de datos relevantes para la encuesta, como consejerías y direcciones generales. En ningún caso el seguimiento consiste en la validación o posible descarte de la información recibida, sino que se disponga de datos suficientes para poder realizar el estudio de influencia de condiciones de los puntos limpios sobre sus resultados en materia de gestión de residuos. Este proceso de complementar la información recibida es de aproximadamente tres meses.

\subsubsection{Análisis de resultados.}

Una vez registrados todos los datos será necesario realizar un estudio estadístico con el objetivo de obtener resultados significativos. Éste se va a realizar mediante el análisis de las distribuciones estadísticas de la muestra para las variables consideradas, respecto de los distintos factores tenidos en cuenta, y la afección que el valor de los mismos tenga sobre cada submuestra, constituida por los elementos de la muestra para los cuales el valor del factor analizado es el mismo; es decir, se crearán subgrupos de la muestra, formados por los elementos que comparten el mismo valor del factor analizado, y se determinarán sus principales magnitudes estadísticas, que serán comparadas con las correspondientes a la totalidad de la muestra, determinando así si resultan factores significativos para la variable analizada. 
La comparación entre submuestras, y de éstas con la muestra, se realizará mediante un análisis de medias y de varianza de medias, lo que permitirá deducir si las distribuciones de los individuos que las constituyen son equivalentes. En función de los posibles valores que tome el factor analizado, el número de submuestras a comparar entre sí y con la muestra total será de dos o más. Así, el tipo de test adecuado para el análisis de comparación de medias y varianzas en esta situación es el Análisis de Varianza o ANOVA.

Puesto que la base de datos de la muestra contiene registros de los que no se dispone de información relativa a todos los campos solicitados, se dará la circunstancia de que, para el estudio de significación de determinados factores de comparación, deban descartarse los casos en que el campo requerido se encuentre en blanco, con el objetivo de que el análisis no añada un escenario adicional, para aquellos casos sin información de partida. Por tanto, se requiere de un proceso previo de preparación de los datos, de manera que en cada punto se analicen únicamente los casos con información del factor cuya significación se esté estudiando. A continuación, la muestra filtrada se someterá a los test que proceda, para lo que se emplearán los programas PSPP, versión 1.4.1. y R, versión 4.0.4.

A continuación se describen los tests de que se hará uso en el presente estudio, en función de las características de la distribución y de la prueba a que se someta a la misma.

\subsubsection{Test ANOVA.}

El test ANOVA es un método estadístico que permite comparar resultados obtenidos en dos o más muestras para condiciones de origen distintas. Los resultados obtenidos constituyen las variables y las condiciones de origen, los factores. El test permite realizar un análisis factorial, mediante la comparación de las variables con respecto a uno o varios factores, a través del estudio de la varianza de las medias, tanto entre las distintas muestras como para la totalidad de los casos de las mismas.

El test ANOVA parte de los siguientes supuestos:

- Las observaciones son independientes.

- La distribución de los residuos del modelo sigue una distribución normal.

- Existe homogeneidad de varianzas entre los grupos de muestras comparadas (homocedasticidad).

La hipótesis nula en el análisis de las muestras comparadas es que los grupos corresponden a la misma población y, por tanto, sus medias son iguales. Si el análisis proporciona un resultado para el nivel se significación ( $p$-valor) inferior al error de la hipótesis nula, se rechaza dicha hipótesis y, 
por tanto, las muestras pertenecen a poblaciones distintas: el factor de análisis resulta significativo $y$, en función del valor que toma el mismo, el comportamiento de la variable en cada submuestra es distinto. El valor de significación se establece en 0,05.

\subsubsection{Test de ANOVA-Welch.}

Esta prueba permite realizar el estudio de comparación de varianzas de las medias en aquellos en casos en que no puede afirmarse que existe homogeneidad de varianzas. De los resultados del test se obtiene un p-valor, cuya comparación con el valor de significación determina si las diferencias entre las medias son estadísticamente significativas. Si el p-valor es inferior al valor de significación fijado $(0,05)$, los resultados son estadísticamente significativos $\mathrm{y}$, por tanto, las medias de las distribuciones comparadas no son iguales.

\subsubsection{Prueba de Bonferroni.}

Se trata de una prueba post-hoc, que permite detectar la significación entre grupos, cuando los resultados del análisis de varianza de medias (ANOVA, ANOVA-Welch) proporcionan un valor de significación inferior al error de la hipótesis nula $(0,05)$. En este caso, el resultado indica que existen al menos 2 grupos de los comparados que presentan diferencias significativas entre sí pero, si el número de grupos analizados es superior a 2, no informa entre cuáles detecta las diferencias, pudiendo existir grupos entre los cuales la comparación no presente significación. Esta prueba realiza comparaciones entre parejas de grupos, indicando para cada una de ellas el valor de significación resultante de la comparación.

Este análisis de significación de variable entre grupos mediante comparación múltiple puede realizarse mediante los test Scheffé, BSD de Bonferroni, LSD de Fisher o HSD de Tukey. En general, el LSD de Fisher es el que proporciona más diferencias significativas, seguido del HSD de Tukey, lo que incrementa el riesgo de concluir que existen diferencias significativas cuando en realidad no es así (falsos rechazos de la hipótesis nula). Además, estas pruebas se recomiendan cuando el número de comparaciones a realizar es elevado. En cambio, el test de Scheffé es más conservador, menos sensible a la detección de diferencias. El test BSD de Bonferroni resulta más adecuado cuando el número de comparaciones a realizar es reducido, con un menor riesgo de falsos rechazos. Puesto que el número de grupos sobre los que se aplicará el test post-hoc es de 3 , se ha decidido emplear esta técnica. 


\subsubsection{Test de Levene.}

El test de Levene es una prueba estadística que compara las varianzas de dos o más muestras y, por tanto, se emplea para la validación del supuesto de homocedasticidad. En este caso, la hipótesis nula es que las varianzas de los grupos comparados son iguales, con grados de libertad entre grupos d1 e intragrupos d2. Si el valor de significación es inferior al considerado $(0,05)$, se rechaza la hipótesis nula y, por tanto, las varianzas de los grupos de muestras son distintas. La misma conclusión puede extraerse mediante el análisis del estadístico de Levene resultante: si éste es superior al valor de la distribución $F$ de Snedecor, con d1 y d2 grados de libertad, se rechaza la hipótesis nula.

\subsubsection{Prueba H de Kruskal-Wallis.}

Se trata de una prueba no paramétrica, que permite validar la hipótesis nula de $\mathrm{k}$ grupos que pertenecen a una misma población y, por tanto, sus medianas son iguales, en el caso de que la variable estudiada no siga una distribución normal, o el número de observaciones sea muy pequeño y no sea posible determinar su normalidad. Si el valor de significación es inferior al considerado para la hipótesis nula $(0,05)$, ésta se rechaza y, por tanto, los subgrupos analizados no pertenecen a la misma población.

\subsubsection{Coeficiente de correlación de Pearson.}

El coeficiente de correlación de Pearson permite estudiar la relación existente entre 2 variables, estando su resultado comprendido entre $-1 \mathrm{y}+1$. Si el valor del coeficiente es mayor que cero, existe correlación positiva y, si es menor que cero, correlación negativa, correspondiendo a +1 y -1 las correlaciones lineales positiva y negativa, respectivamente. Si el valor de significación de los resultados de la prueba es inferior al fijado $(0,05)$, se rechaza la hipótesis nula y, por tanto, no puede afirmarse que exista correlación lineal entre las variables analizadas.

\subsubsection{Test de Kolmogorov-Smirnov.}

El test de Kolmogorov-Smirnov es una prueba estadística que contrasta la bondad de ajuste de dos distribuciones de probabilidad entre sí. Este test se aplicará a las variables para validar la hipótesis de normalidad de distribución de las mismas. Si el p-valor es inferior al valor de significación $(0,05)$, se rechaza la hipótesis nula de normalidad de la distribución. 


\subsection{Resultados de la encuesta.}

En este apartado se presentan los resultados obtenidos de las encuestas. De las remitidas inicialmente, se recibieron respuestas de 74 municipios, por lo que hubo de recurrirse a entidades supramunicipales, así como a realizar consultas telefónicas a los destinatarios, con el objetivo de completar la información. Con esto, se llegó a disponer de datos de 81 municipios.

A continuación se recurrió a información publicada en diferentes páginas web por municipios y otros organismos, alcanzando la base de datos a 108 municipios, con un total de 91 puntos limpios. Todo el proceso se prolongó por un periodo de 8 meses.

En la Tabla 5.1 se muestra el número de municipios que contestaron a la encuesta remitida, por comunidad autónoma.

\begin{tabular}{|c|c|c|}
\hline Comunidad autónoma & Municipios & Puntos limpios \\
\hline Comunidad Valenciana & 61 & 60 \\
\hline Cataluña & 13 & 12 \\
\hline Castilla-La Mancha & 1 & 1 \\
\hline País Vasco & 23 & 5 \\
\hline Navarra & 1 & 1 \\
\hline Andalucía & 9 & 12 \\
\hline TOTAL & $\mathbf{1 0 8}$ & $\mathbf{9 1}$ \\
\hline
\end{tabular}

Tabla 5.1: Distribución de municipios y puntos limpios de la muestra por Comunidad Autónoma.

Como se observa en la Tabla 5.1, el número de municipios es superior al de puntos limpios. Esto se debe a que en algunos casos los puntos limpios son mancomunados. También se da el caso contrario, ya que algunos municipios (Bilbao, Sevilla, Torrent) disponen de más de una instalación. Se observa que el $66 \%$ de los puntos limpios de los que se ha recibido información corresponden a la Comunidad Valenciana. Esto puede ser debido a diversos factores: por un lado, la proximidad geográfica existente permite que puedan establecerse contactos con mayor facilidad, al existir mayor probabilidad de relaciones personales directas e indirectas con personal que pueda dar traslado de la relevancia de la información solicitada para el estudio; asimismo, esta misma proximidad geográfica proporciona cierto sentido de pertenencia, que hace más proclive al receptor de la solicitud a contestar a la información requerida.

El 32\% de los puntos limpios informados (93\% del resto de la muestra) pertenecen a Cataluña, Andalucía y el País Vasco, comunidades autónomas en las que la media de habitantes por municipio se encuentra entre 8.000 y 11.000 , por lo que es más probable que las políticas de 
implantación de puntos limpios se encuentren más desarrolladas. A este respecto, destacar la ausencia de municipios de la Comunidad de Madrid, con una demografía media de más de 37.000 habitantes por municipio. En cuanto a las comunidades autónomas que no han aportado datos, o con representación menor en los resultados de la encuesta, la población media es inferior a 3.200 habitantes por municipio, y en el $86 \%$ de sus municipios la población es inferior a 2.000 habitantes, por lo que es previsible que el número de puntos limpios existentes sea muy inferior al del resto de comunidades autónomas.

Con respecto al porcentaje de respuestas a cada una de las preguntas de la encuesta, en la Tabla 5.2 se presentan los resultados obtenidos. Por lo que respecta al número de puntos limpios que han aportado información, las respuestas a las preguntas oscilan entre un $8,79 \%$ (8 puntos limpios), que informan de las cantidades gestionadas a través de los puntos limpios móviles, hasta el $100 \%$, que se ha alcanzado en 6 de las preguntas.

En general, las respuestas han sido altamente satisfactorias, puesto que en 30 de las 39 preguntas se ha obtenido más de un $90 \%$ de respuesta.

\begin{tabular}{|c|c|c|c|}
\hline Aspecto & $\%$ respuesta & Aspecto & $\%$ respuesta \\
\hline Año de construcción & $84,62 \%$ & Admisión de voluminosos & $100,00 \%$ \\
\hline N. ${ }^{\circ}$ visitas anuales & $76,92 \%$ & Admisión de RCD & $97,80 \%$ \\
\hline N..$^{\circ}$ visitas foráneas & $14,29 \%$ & Admisión de PC, EELL, V & $98,90 \%$ \\
\hline Distancia a núcleo urbano & $100,00 \%$ & Admisión de F. Resto & $98,90 \%$ \\
\hline N. ${ }^{\circ}$ carriles circulación por sentido & $92,31 \%$ & Admisión de RRPP & $100,00 \%$ \\
\hline Transporte público cercano & $98,90 \%$ & t/año voluminosos recogidas & $89,01 \%$ \\
\hline Carril bici & $98,90 \%$ & t/año RCD recogidas & $83,52 \%$ \\
\hline N. ${ }^{\circ}$ cotas & $95,60 \%$ & t/año selectiva recogidas & $79,12 \%$ \\
\hline Superficie aproximada & $93,41 \%$ & t/año F. Resto recogidas & $69,23 \%$ \\
\hline N. ${ }^{\circ}$ contenedores caja abierta & $96,70 \%$ & t/año RRPP recogidas & $86,81 \%$ \\
\hline Otros contenedores & $73,63 \%$ & Total t/año recogidas & $100,00 \%$ \\
\hline Cerramiento perimetral & $98,90 \%$ & Pago de tasas & $96,70 \%$ \\
\hline Oficina, recepción, aseo & $92,31 \%$ & Existencia de incentivos & $96,70 \%$ \\
\hline Zona RRPP cubierta y ventilada & $80,22 \%$ & Detalle de incentivos & $45,05 \%$ \\
\hline Zona RAEE antiderrame & $80,22 \%$ & Autorización acceso empresas & $90,11 \%$ \\
\hline Báscula & $89,01 \%$ & Límites de aportación & $90,11 \%$ \\
\hline Gestión & $100,00 \%$ & Punto limpio móvil asociado & $97,80 \%$ \\
\hline Días apertura & $100,00 \%$ & t/año punto limpio móvil & $8,79 \%$ \\
\hline Hora apertura & $97,80 \%$ & Generación RSU municipio t/año & $46,15 \%$ \\
\hline Hora cierre & $97,80 \%$ & & \\
\hline
\end{tabular}

Tabla 5.2: Porcentaje de contestación a las preguntas de la encuesta. 
Teniendo en cuenta el número de respuestas obtenidas para cada pregunta, es posible determinar el error existente en el análisis de cada uno de los aspectos, y cuyo valor se muestra en la Tabla 5.3. El error se calcula con la Expresión 5.1, para un intervalo de confianza del $95 \%$ y considerando que el tamaño de la muestra se corresponde con el número de respuestas recibidas.

\begin{tabular}{|l|l|l|l|}
\hline \multicolumn{1}{|c|}{ Aspecto } & $\%$ error & \multicolumn{1}{c|}{ Aspecto } & $\%$ error \\
\hline Año de construcción & $11,12 \%$ & Admisión de voluminosos & $10,22 \%$ \\
\hline N. ${ }^{\circ}$ visitas anuales & $11,66 \%$ & Admisión de RCD & $10,33 \%$ \\
\hline N. ${ }^{\circ}$ visitas foráneas & $27,16 \%$ & Admisión de PC, EELL, V & $10,27 \%$ \\
\hline Distancia a núcleo urbano & $10,22 \%$ & Admisión de F. Resto & $10,27 \%$ \\
\hline N. ${ }^{\circ}$ carriles circulación por sentido & $10,64 \%$ & Admisión de RRPP & $10,22 \%$ \\
\hline Transporte público cercano & $10,27 \%$ & t/año voluminosos recogidas & $10,83 \%$ \\
\hline Carril bici & $10,27 \%$ & t/año RCD recogidas & $11,19 \%$ \\
\hline N. ${ }^{\circ}$ cotas & $10,45 \%$ & t/año selectiva recogidas & $11,50 \%$ \\
\hline Superficie aproximada & $10,57 \%$ & t/año F. Resto recogidas & $12,30 \%$ \\
\hline N. ${ }^{\circ}$ contenedores caja abierta & $10,39 \%$ & t/año RRPP recogidas & $10,97 \%$ \\
\hline Otros contenedores & $11,92 \%$ & Total t/año recogidas & $10,22 \%$ \\
\hline Cerramiento perimetral & $10,27 \%$ & Pago de tasas & $10,39 \%$ \\
\hline Oficina, recepción, aseo & $10,64 \%$ & Existencia de incentivos & $10,39 \%$ \\
\hline Zona RRPP cubierta y ventilada & $11,42 \%$ & Detalle de incentivos & $15,27 \%$ \\
\hline Zona RAEE antiderrame & $11,42 \%$ & Autorización acceso empresas & $10,77 \%$ \\
\hline Báscula & $10,83 \%$ & Límites de aportación & $10,77 \%$ \\
\hline Gestión & $10,22 \%$ & Punto limpio móvil asociado & $10,33 \%$ \\
\hline Días apertura & $10,22 \%$ & t/año punto limpio móvil & $34,63 \%$ \\
\hline Hora apertura & $10,33 \%$ & Generación RSU municipio t/año & $15,08 \%$ \\
\hline Hora cierre & $10,33 \%$ & & \\
\hline
\end{tabular}

Tabla 5.3: Error de la muestra en poblaciones finitas para cada pregunta encuestada.

Se observa que en 27 de los 39 aspectos solicitados, el error se encuentra entre el $10 \%$ y el $11 \%$, y en 3 de ellos, lo hace por encima del 15\% ("número de visitas foráneas", "detalle de incentivos aplicados" y "toneladas gestionadas a través del punto limpio móvil asociado"). De forma general, debido a que se ha obtenido un número elevado de respuestas, el error en cada una de ellas es similar al propuesto inicialmente.

Respecto a cuestiones dicotómicas de la encuesta (20), hay un grupo de 7 que presentan una alta homogeneidad en las respuestas (ver Tabla 5.4). Esto quiere decir que los aspectos por los que se ha preguntado coinciden en la mayoría de los puntos limpios, por lo que el análisis de influencia de estas variables no será analizado. 


\begin{tabular}{|l|c|c|}
\hline \multicolumn{1}{|c|}{ Aspecto } & $\begin{array}{c}\text { Respuesta } \\
\text { mayoritaria }\end{array}$ & \% homogeneidad \\
\hline Cerramiento perimetral & $\mathrm{SI}$ & $100,00 \%$ \\
\hline Oficina, recepción, aseo & $\mathrm{SI}$ & $98,81 \%$ \\
\hline Zona RRPP cubierta y ventilada & $\mathrm{SI}$ & $97,26 \%$ \\
\hline Admisión de voluminosos & $\mathrm{SI}$ & $100,00 \%$ \\
\hline Admisión de RCD & $\mathrm{SI}$ & $98,88 \%$ \\
\hline Admisión de PC, EELL, V & $\mathrm{SI}$ & $96,67 \%$ \\
\hline Admisión de RRPP & $\mathrm{SI}$ & $95,60 \%$ \\
\hline
\end{tabular}

Tabla 5.4: Homogeneidad de respuestas a preguntas dicotómicas.

Por lo que se refiere a las variables "cantidad de residuos anuales" y número de visitas recibidas", en la Tabla 5.5 se incluyen los resultados obtenidos.

\begin{tabular}{|c|c|c|c|c|c|c|c|c|}
\hline Ciudad & $\begin{array}{c}N^{\circ} \text { de } \\
\text { visitas/año }\end{array}$ & $t$ anuales & Ciudad & $\begin{array}{c}N^{0} \text { de } \\
\text { visitas/año }\end{array}$ & $t$ anuales & Ciudad & $\begin{array}{c}N^{0} \text { de } \\
\text { visitas/año }\end{array}$ & $t$ anuales \\
\hline Albal & 7.402 & $1.450,21$ & $\begin{array}{l}\text { Coves de } \\
\text { Vinromà }\end{array}$ & 761 & 265,69 & $\begin{array}{l}\text { Sant Adrià de } \\
\text { Besòs }\end{array}$ & 100 & $178.631,00$ \\
\hline $\begin{array}{l}\text { Albalat Dels } \\
\text { Sorells }\end{array}$ & 3.950 & 547,14 & Crevillent & & 484,26 & $\begin{array}{l}\text { Sant Andreu } \\
\text { de la Barca }\end{array}$ & 4.054 & $4.043,00$ \\
\hline Albocàsser & 511 & 136,71 & Cuenca & 5.700 & 714,00 & $\begin{array}{l}\text { Sant Boi de } \\
\text { Llobregat }\end{array}$ & 8.124 & $8.121,00$ \\
\hline Alboraya & 34.330 & $9.422,41$ & $\begin{array}{l}\text { El Prat de } \\
\text { Llobregat }\end{array}$ & 21.435 & $21.434,00$ & Sant Jordi & 374 & 67,40 \\
\hline $\begin{array}{l}\text { Alcalà de } \\
\text { Xivert }\end{array}$ & 902 & 586,09 & $\begin{array}{l}\text { Esplugues } \\
\text { de Llobregat } \\
\text { - Sant Joan } \\
\text { Despí } \\
\end{array}$ & 15.553 & $15.537,00$ & $\begin{array}{l}\text { Sant Rafael } \\
\text { del Riu }\end{array}$ & 418 & 60,62 \\
\hline $\begin{array}{l}\text { Aldaia y } \\
\text { Alaquàs }\end{array}$ & 26.015 & $4.987,72$ & Estivella & 888 & 344,18 & \begin{tabular}{|l|} 
Santa \\
Coloma de \\
Gramenet
\end{tabular} & 7.688 & $7.688,00$ \\
\hline $\begin{array}{l}\text { Algimia De } \\
\text { Alfara }\end{array}$ & 516 & 353,01 & Gilet & 1.308 & 954,77 & \begin{tabular}{|l|} 
Santa \\
Magdalena \\
de Pulpis
\end{tabular} & 556 & 67,25 \\
\hline Alicante & 11.070 & $3.793,07$ & Guadix & & 549,95 & Sedaví & 17.697 & $2.803,12$ \\
\hline Almàssera & 11.203 & $2.058,40$ & $\begin{array}{l}\text { Hospitalet } \\
\text { De Llobregat }\end{array}$ & 9.929 & $9.927,00$ & Sevilla & & $6.804,00$ \\
\hline Almazora & & 491,28 & L'Alcora & & 235,32 & Sevilla & & $4.502,00$ \\
\hline Almenara & 804 & 394,51 & La Salzadella & 567 & 56,07 & Sevilla & & $6.190,00$ \\
\hline $\begin{array}{l}\text { Área } \\
\text { Metropolitana } \\
\text { de Valencia }\end{array}$ & 48.910 & $6.666,00$ & $\begin{array}{l}\text { La Torre d'En } \\
\text { Doménec }\end{array}$ & 86 & 13,63 & Sevilla & & $6.956,00$ \\
\hline $\begin{array}{l}\text { Badia del } \\
\text { Vallès } \\
\end{array}$ & & $419.580,00$ & \begin{tabular}{|l|} 
Las Cabezas \\
De San Juan
\end{tabular} & & 843,48 & Silla & 7.341 & $1.225,01$ \\
\hline Benassal & 97 & 178,44 & Málaga & & 843,48 & Soneja & 228 & 921,94 \\
\hline Benicarló & 5.035 & $1.980,51$ & $\begin{array}{l}\text { Mancomunidad } \\
\text { Sasieta (22 } \\
\text { Municipios) }\end{array}$ & & $12.314,00$ & Tarragona & 8.071 & 636,24 \\
\hline Benidorm & 10.000 & & Manises & 8.178 & $1.426,90$ & Torreblanca & 2.172 & $1.364,19$ \\
\hline Benlloch & 628 & 139,74 & Massamagrell & 8.057 & $1.749,42$ & Torrent & 16.684 & $3.146,14$ \\
\hline Bilbao & 12.244 & $5.815,00$ & Meliana & 9.117 & $1.064,30$ & Torrent & 6.471 & $1.193,52$ \\
\hline
\end{tabular}


Estudio de los puntos limpios implantados en España.

\begin{tabular}{|c|c|c|c|c|c|c|c|c|}
\hline Ciudad & $\begin{array}{c}\mathrm{N}^{\circ} \text { de } \\
\text { visitas/año }\end{array}$ & $t$ anuales & Ciudad & $\begin{array}{c}\mathrm{N}^{\circ} \text { de } \\
\text { visitas/año }\end{array}$ & $t$ anuales & Ciudad & $\begin{array}{c}N^{\circ} \text { de } \\
\text { visitas/año }\end{array}$ & $t$ anuales \\
\hline Bilbao & 11.412 & $5.261,00$ & \begin{tabular}{|l} 
Molins de \\
Rei
\end{tabular} & 14.782 & $14.725,00$ & Tudela & & $4.550,06$ \\
\hline Bilbao & 16.731 & $10.674,00$ & Morella & 1.973 & 384,22 & Utrera & & $3.338,48$ \\
\hline Bilbao & 9.094 & $5.624,00$ & Nules & 1.063 & 447,26 & Vall d'Uixó & 576 & 763,80 \\
\hline Cabanes & 1.010 & 224,87 & Onda & & 443,25 & $\begin{array}{l}\text { Valverde del } \\
\text { Camino }\end{array}$ & & 20,67 \\
\hline Càlig & 694 & 119,46 & $\begin{array}{l}\text { Paiporta y } \\
\text { Picanya }\end{array}$ & 24.311 & $3.965,74$ & Viladecans & 11.511 & $11.511,00$ \\
\hline Canals & & 761,71 & Paterna & 2.110 & 578,45 & $\begin{array}{l}\text { Vilanova } \\
\text { d'Alcolea }\end{array}$ & 229 & 36,41 \\
\hline Canet lo Roig & 482 & 90,59 & Peñíscola & 7.299 & $1.626,95$ & $\begin{array}{l}\text { Villafranca } \\
\text { del Cid }\end{array}$ & 1.799 & 226,54 \\
\hline Castalla & & 567,82 & Picassent & 22.861 & $2.522,77$ & Vinaròs & 4.872 & $3.488,20$ \\
\hline Castellón & 40.423 & $6.487,49$ & Puçol & 10.059 & $1.508,63$ & Xàtiva & & $1.451,71$ \\
\hline Catarroja & 12.635 & $2.561,67$ & $\begin{array}{l}\text { Puerto de } \\
\text { Santa María }\end{array}$ & 19.732 & 20,67 & Xert & 525 & 79,49 \\
\hline $\begin{array}{l}\text { Cervera del } \\
\text { Maestre }\end{array}$ & 141 & 31,84 & $\begin{array}{l}\text { Quart de Les } \\
\text { Valls }\end{array}$ & 1.824 & 420,55 & Xirivella & 16.705 & $3.792,03$ \\
\hline $\begin{array}{l}\text { Churriana de } \\
\text { La Vega }\end{array}$ & & 301,24 & \begin{tabular}{|l|} 
Rincón de La \\
Victoria
\end{tabular} & & $3.338,48$ & & & \\
\hline $\begin{array}{l}\text { Cornellà de } \\
\text { Llobregat }\end{array}$ & 10.007 & & Rossell & 833 & 85,70 & & & \\
\hline
\end{tabular}

Tabla 5.5: Valores de las variables en estudio para los puntos limpios de la muestra.

En la Tabla 5.5 se presenta la totalidad de los municipios que han participado en la encuesta. Se puede observar que el $97,80 \%$ de los encuestados ha contestado a la pregunta sobre cantidad anual de residuos recogida en el punto limpio, mientras que el $75,82 \%$ ha contestado al número de visitas anuales a las instalaciones. Los elevados porcentajes de respuesta en estas dos variables permitirá realizar un estudio más completo.

En los Gráficos 5.1 y 5.2 se presentan las variables "Cantidades depositadas frente a población” y "Visitas recibidas frente a población". El Gráfico 5.1 se representa con el eje de ordenadas en escala logarítmica, puesto que existen puntos limpios con cantidades depositadas muy superiores al resto de puntos limpios, con lo que la representación en escala lineal no aporta información. 


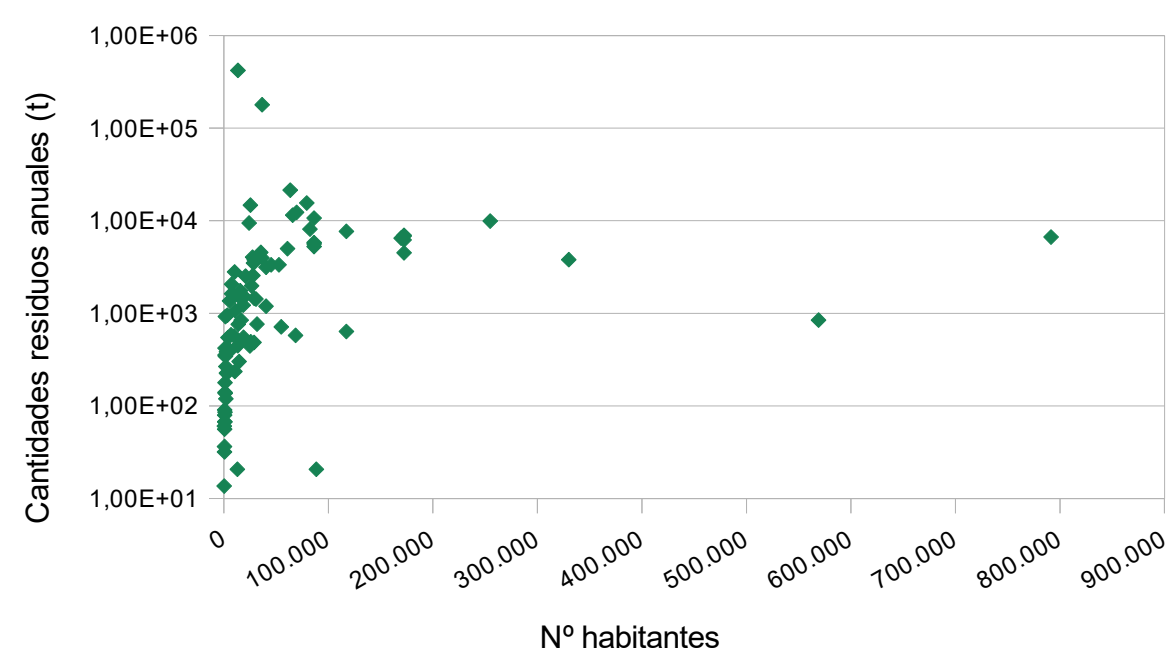

Gráfico 5.1: Cantidades anuales de residuos depositadas en los puntos limpios.

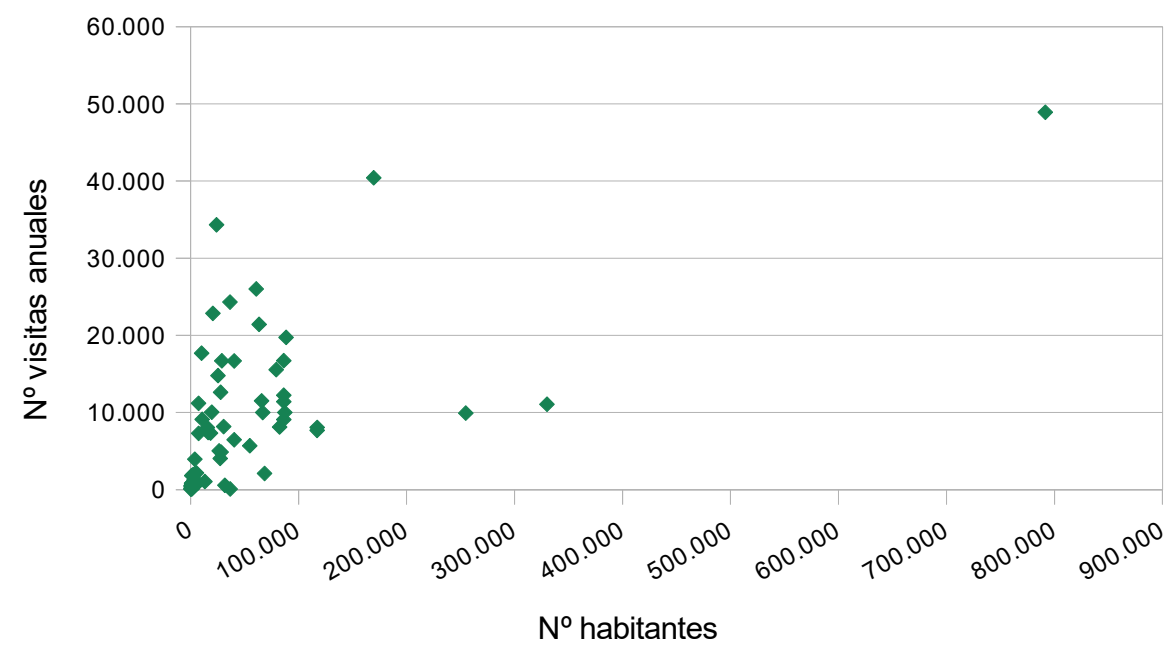

Gráfico 5.2: Visitas anuales recibidas en los puntos limpios.

Como puede observarse en los Gráficos 5.1 y 5.2, como norma general, tanto las cantidades de residuos depositadas en los puntos limpios y el número de visitas recibidas son superiores en los municipios con mayor población. No obstante, para un análisis comparativo será necesario presentar estos valores en per cápita.

Finalmente, como ANEXO A5.3 se adjunta una tabla en que se presentan todos los valores obtenidos en las diferentes variables de todas las poblaciones que han colaborado. 


\subsection{Análisis de los resultados.}

A partir de los datos ofrecidos por los municipios que constituyen la muestra, se desea determinar la influencia de las variables consideradas sobre los resultados de explotación de los puntos limpios.

Las variables correspondientes a las preguntas del cuestionario han sido las siguientes:

- Variables de localización:

- Población adscrita.

- Distancia al núcleo urbano.

- Disponibilidad de transporte público.

- Disponibilidad de carril bici.

- Variables de infraestructuras:

- Año de construcción.

- Número de carriles de circulación.

- Número de cotas constructivas.

- Número de contenedores caja abierta.

- Superficie.

- Existencia de punto limpio móvil asociado.

- Variables de funcionamiento:

- Horario de apertura.

- Autorización de acceso a empresas.

- Incentivación mediante beneficios por su utilización.

- Limitación en las cantidades aportadas.

- Gestión directa o indirecta.

- Admisión de fracción resto.

- Disponibilidad de zona de almacenamiento de RAEE.

Para determinar cómo afectan estas variables a la explotación de los puntos limpios en cuanto al grado de utilización de los mismos y cantidades de residuos recuperados, se consideran estas dos variables:

- Número de visitas anuales al punto limpio.

- Cantidades anuales de residuos recibidas. 
Debido a la disparidad existente entre los tamaños de los municipios, para poder comparar los resultados, éstas no se expresan en cantidades absolutas, sino por habitante y año:

- Tasa de Visitas (TV): visitas al año por cada 100 habitantes, expresado en visitas/100 habitantes/año.

- Tasa de Recogida (TR): cantidad anual de residuos recibidos en el punto limpio por habitante, expresado en $\mathrm{kg} /$ habitante/año.

La variable referente a las visitas se calcula como número de visitas anuales por cada 100 habitantes, para que los valores resultantes presenten magnitudes en rangos significativos, puesto que el cálculo por habitante resulta en valores muy bajos.

\subsubsection{Análisis de TR y TV.}

En primer lugar hay que conocer si las variables siguen una distribución normal, con el objetivo de la aplicación correcta de los diferentes test del posterior análisis.

En segundo lugar es necesario determinar la relación entre TR y TV y conocer si son o no dependientes entre ellas, puesto que si son dependientes no será necesario estudiar la afección de todos los factores considerados para ambos casos.

\subsubsection{Prueba de normalidad de la variable TR.}

Los resultados de TR son los que se observan en el Gráfico 5.3, en el que se aplica escala logarítmica al eje de ordenadas, al existir valores extremos cuyo efecto en un gráfico con escala lineal no permite apreciar el comportamiento del resto de datos de la muestra. 


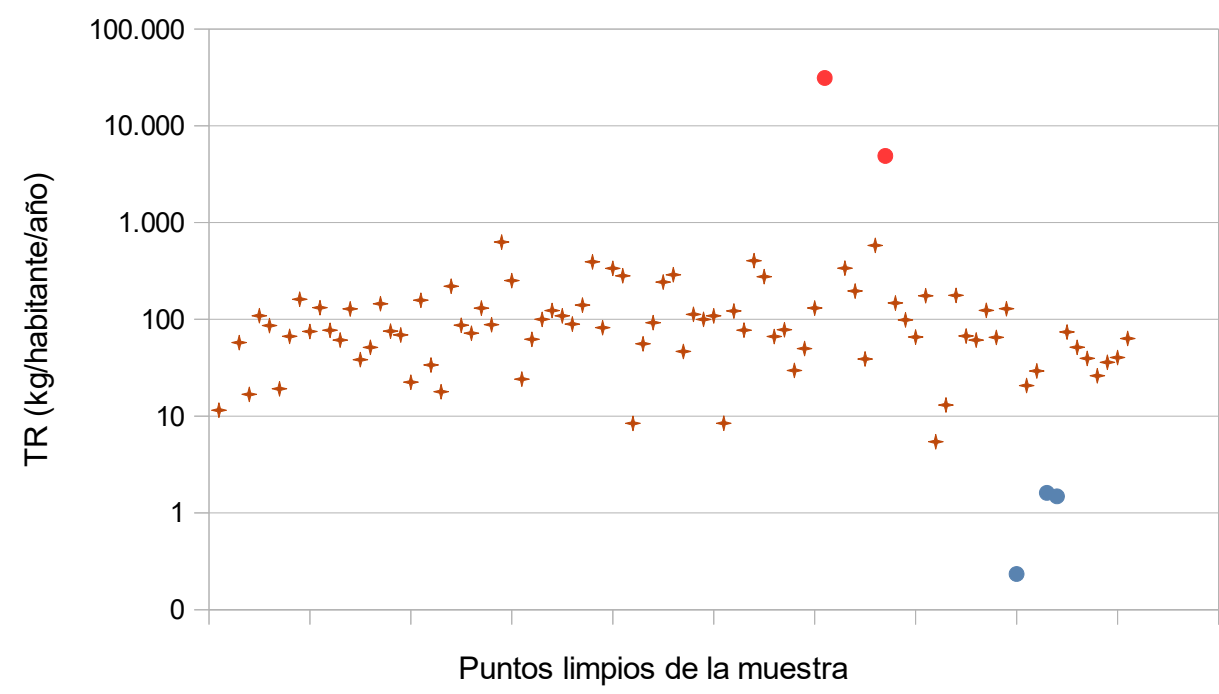

Gráfico 5.3: TR (kg/habitante/año) de los puntos limpios.

Se observa que existen valores anormales, marcados en el Gráfico 5.3 mediante puntos rojos, con tasas de varias toneladas por habitante, muy alejadas de los resultados para el resto de la muestra; estos puntos limpios corresponden a:

- Badia del Vallès: 31.158 kg/habitante/año.

- Sant Adrià de Besòs: 4.877 kg/habitante/año.

Asimismo, se observa que existen 3 puntos limpios, representados en el Gráfico 5.3 mediante

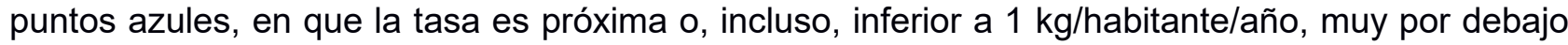
del resto de la muestra:

- Puerto de Santa María: 0,23 kg/habitante/año.

- Valverde del Camino: 1,61 kg/habitante/año.

- Málaga: 1,48 kg/habitante/año.

Sin información de TR se encuentran los puntos limpios de Benidorm y Cornellà de Llobregat. Todos estos puntos se eliminan debido a que presentan valores de TR anómalos tanto por exceso como por defecto. Así, el tamaño de la muestra que se empleará para analizar la normalidad de TR es de 84.

Para la validación de la hipótesis de normalidad de TR se realiza el Test de Kolmogorov-Smirnov. Los resultados del test son los que se muestran en la Tabla 5.6. 


\begin{tabular}{|l|l|r|}
\hline \multicolumn{2}{|c|}{ TR (kg/habitante/año) } \\
\hline N & Media & 84 \\
\hline \multirow{2}{*}{ Parámetros Normal } & Desviación Estándar & 116,51 \\
\hline \multirow{2}{*}{ Z de Kolmogorov-Smirnov } & 116,35 \\
\hline Sig. Asint. (2-colas) & 1,92 \\
\hline
\end{tabular}

Tabla 5.6: Resultados del test de Kolmogorov-Smirnov de normalidad de TR.

Se observa que el valor de significación es $0,001(<0,05)$, por lo que puede afirmarse que la variable TR no posee una distribución normal. Por tanto, el análisis de significación de factores sobre la variable no puede realizarse haciendo uso del Test ANOVA, debiendo utilizarse pruebas no paramétricas, como el test de Kruskal-Wallis.

Gráficamente, el comportamiento de la variable y su comparación con una distribución normal es el mostrado en el Gráfico 5.4.

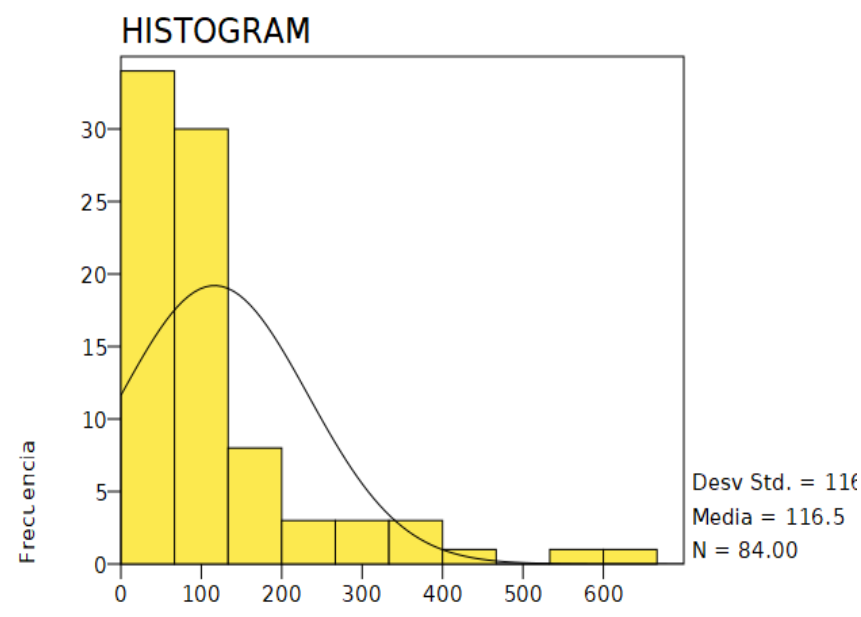

kg_hab_año

Gráfico 5.4: Comparación de TR con la distribución normal. 


\subsubsection{Prueba de normalidad de la variable TV.}

Los resultados de TV son los que se observan en el Gráfico 5.5.

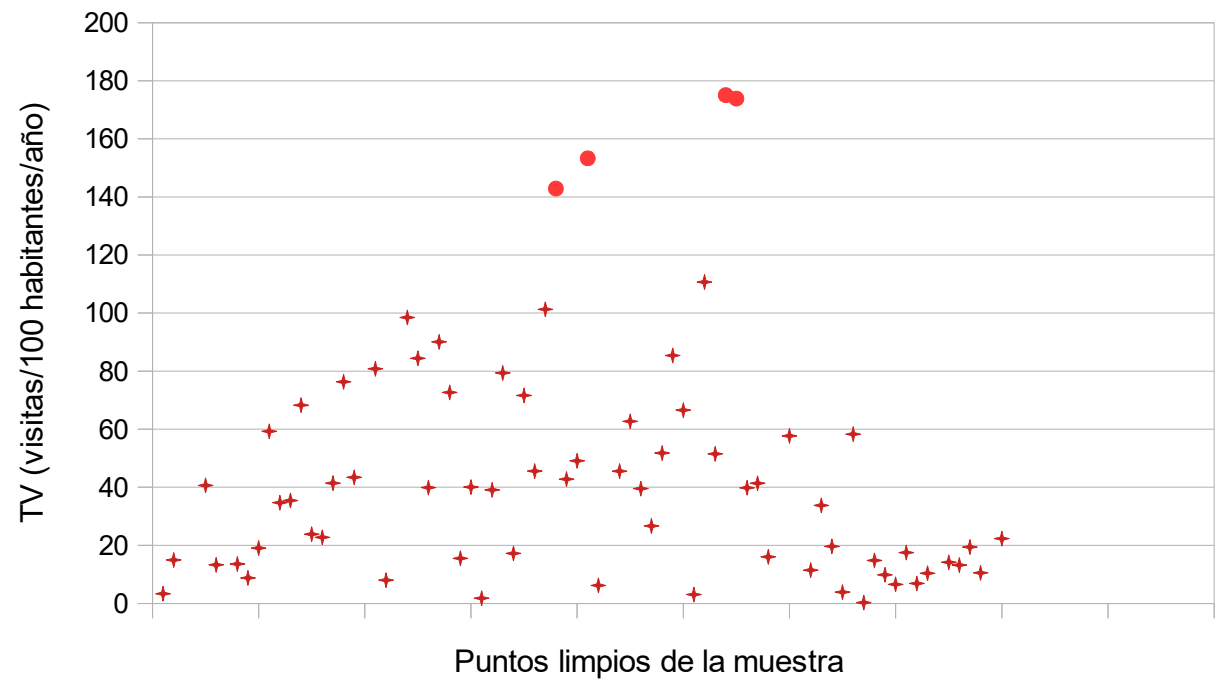

Gráfico 5.5: TV (visitas/100 habitantes/año) de los puntos limpios.

Se observa que pueden considerarse anómalos los casos, señalados con punto rojo, que presentan valores de TV más alejados de la media, por encima de 120 visitas/100 habitantes, y que serán descartados del análisis. Estos puntos corresponden a:

- Alboraya: 142,86 visitas/año/100 habitantes.

- Almàssera: 153,30 visitas/año/100 habitantes.

- Quart de les Valls: 175,05 visitas/año/100 habitantes.

- Sedaví: 173,86 visitas/año/100 habitantes.

Para detectar valores anormalmente bajos, se presenta a continuación el Gráfico 5.6, con escala logarítmica en el eje de ordenadas. 


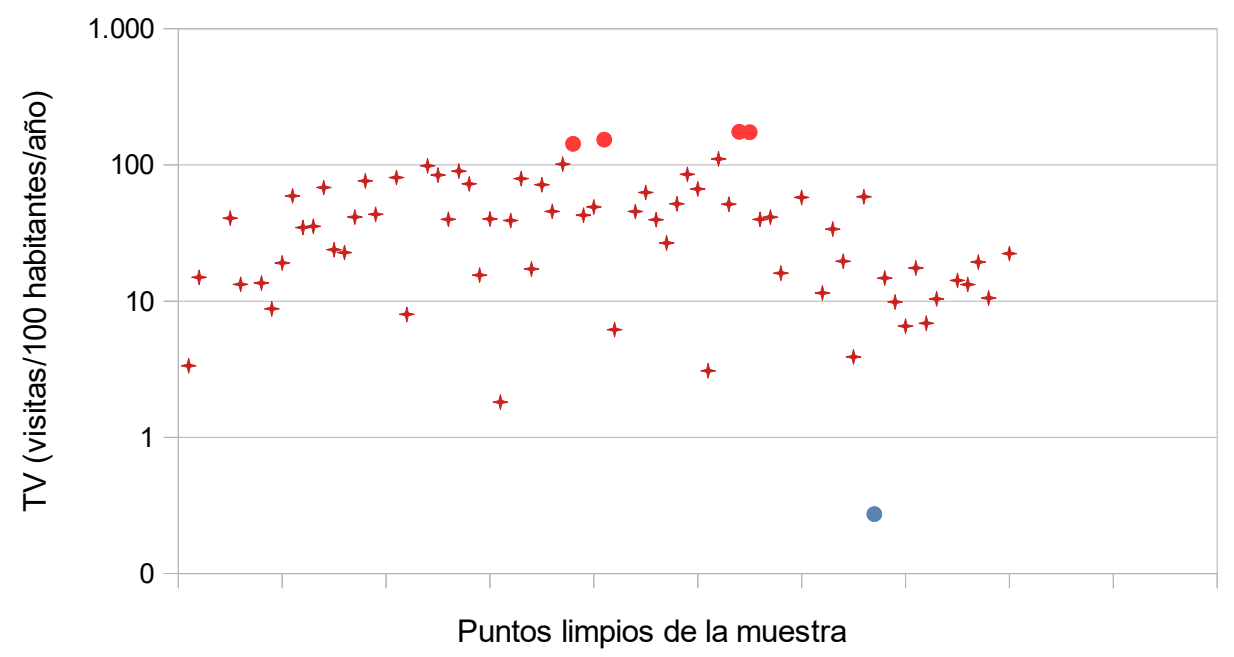

Gráfico 5.6: TV (visitas/100 habitantes/año) de los puntos limpios. Escala logarítmica.

Se considera asimismo oportuno descartar del análisis el punto limpio, representado con un punto azul, para el cual el valor de TV es inferior a 1, correspondiente a Sant Adrià de Besòs $(0,27$ visitas/año/100 habitantes).

Sin datos de visitas anuales al punto limpio, se encuentran los siguientes 18 municipios: Castalla, Crevillent, Almazora, L'Alcora, Onda, Canals, Xàtiva, Badia del Vallès, Mancomunidad Sasieta, Tudela, Churriana de la Vega, Guadix, Valverde del Camino, Málaga, Rincón de la Victoria, Las Cabezas de San Juan, Sevilla (4 puntos limpios) y Utrera. Por lo que el tamaño de la muestra a analizar es de 65 puntos limpios.

Para la validación de la hipótesis de normalidad de TV se realiza el Test de Kolmogorov-Smirnov. Los resultados de la prueba son los que se muestran en la Tabla 5.7.

\begin{tabular}{|l|l|r|}
\hline \multicolumn{2}{|c|}{ TV (Visitas/100 habitantes/año) } \\
\hline N & Media & 65 \\
\cline { 2 - 3 } Parámetros Normal & Desviación Estándar & 38,06 \\
\hline Z de Kolmogorov-Smirnov & 28,37 \\
\hline Sig. Asint. (2-colas) & 1,15 \\
\hline
\end{tabular}

Tabla 5.7: Resultados del test de Kolmogorov-Smirnov de normalidad de TV.

Se observa que el valor de significación es 0,126, superior a 0,05. Por tanto, se acepta la hipótesis nula y la variable sigue una distribución normal, y se podrá realizar el test ANOVA, siempre y 
cuando se cumpla el supuesto de homocedasticidad; en caso contrario, se empleará el test ANOVA-Welch.

En el Gráfico 5.7 se muestra la distribución de TV y su comparación con la distribución normal.

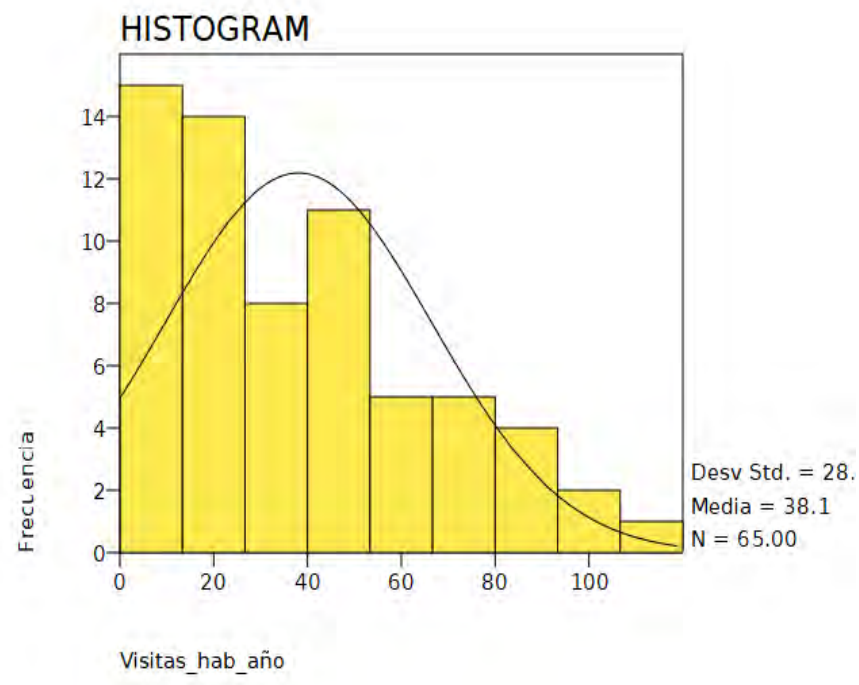

Gráfico 5.7: Comparación de TV con la distribución normal.

\subsubsection{Relación entre TR y TV.}

Como medida inicial de aproximación al análisis de los resultados de gestión de residuos a través de los puntos limpios, se analiza la posible relación entre las variables TR y TV. Como se ha indicado anteriormente, se han considerado para el análisis de TR un total de 84 casos considerados aptos, mientras que se dispone de 65 casos válidos en el caso de TV.

El Gráfico 5.8 muestra la relación existente entre ambas variables, TR y TV, de los 62 casos en que se ha considerado que ambas variables toman valores no anómalos. 


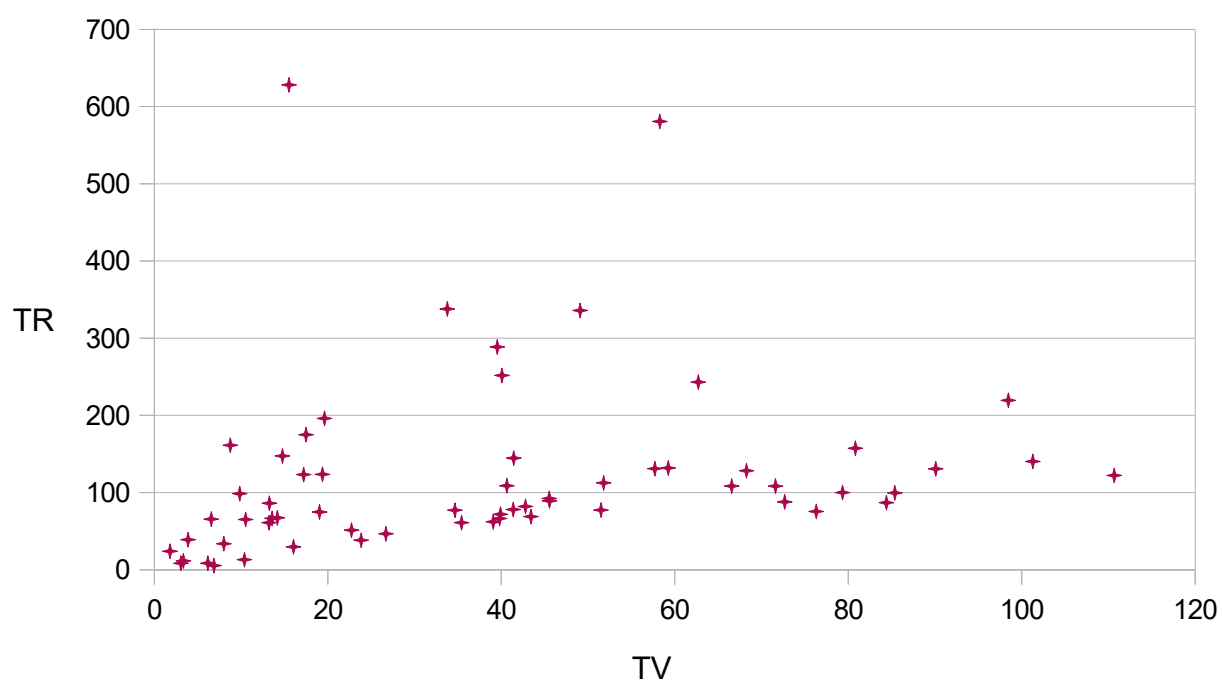

Gráfico 5.8: Relación entre TR y TV.

Para estudiar la correlación entre las variables TR y TV se aplica el método de correlación de Pearson, cuyos resultados se muestran en la Tabla 5.8.

\begin{tabular}{|c|c|c|c|}
\hline & & TR & TV \\
\hline \multirow{3}{*}{ TR } & Correlación de Pearson & 1,00 & 0,206 \\
\hline & Sig. & & 0,08 \\
\hline & $\mathrm{N}$ & 62 & 62 \\
\hline \multirow{3}{*}{ TV } & Correlación de Pearson & 0,206 & 1,00 \\
\hline & Sig. & 0,108 & \\
\hline & $\mathrm{N}$ & 62 & 62 \\
\hline
\end{tabular}

Tabla 5.8: Resultados del test de correlación de Pearson para TR y TV.

La correlación entre TR y TV toma el valor de 0,206, por lo que existe una muy baja correlación lineal positiva entre TR y TV. Asimismo, el resultado de significación es de 0,108, superior a 0,05, por lo que se admite la hipótesis nula de correlación lineal entre ambas variables. Así pues, aunque exista una baja relación de dependencia se ha decidido estudiar de forma independiente ambas variables. Se ha tomado esta decisión porque resulta interesante analizar la influencia de todas las variables de las que se ha obtenido información sobre el comportamiento de TR y TV. 


\subsubsection{Análisis de TR y TV en función de los factores de localización de los puntos limpios.}

En este punto se va a estudiar si las variables TR y TV siguen comportamientos homogéneos independientemente de diferentes parámetros relacionados con la localización de los puntos limpios, mediante la comparación de medias y varianzas de la muestra y de los subgrupos de la misma, o submuestras, constituidos por los datos que comparten los valores que toman dichos parámetros o factores.

Para cada una de las variables analizadas, la muestra se segregará en subgrupos, en función de los valores que tome en cada caso el factor de comparación, y se compararán los grupos creados entre sí y con la totalidad de la muestra.

Los casos que conforman la muestra son independientes, puesto que los datos proceden de la observación de resultados de funcionamiento de puntos limpios sin relación entre sí, situados en diferentes municipios, de distintas provincias y comunidades autónomas, por lo que tanto TR como TV cumplen con este supuesto. En el punto 5.3.1.1 y 5.3.1.2 se ha analizado la normalidad de TR y TV, respectivamente, concluyéndose que TV sí sigue una distribución normal, por lo que se aplicará el test ANOVA, no así TR, por lo que el estudio se realizará mediante el test de Kruskal-Wallis.

En el ANEXO A5.4 se detalla el estudio estadístico de influencia de las variables relacionadas en el punto 5.3 sobre TR y TV, cuyas conclusiones se presentan a continuación.

\subsubsection{Población adscrita.}

Con objeto de analizar la posible incidencia del factor demográfico sobre las variables TR y TV, debe realizarse una segmentación de la muestra en diferentes subgrupos, y comparar el comportamiento de éstos entre sí y respecto a la totalidad de la muestra.

De los diferentes criterios de clasificación de los municipios por tamaño de población, se ha elegido el criterio de Ecoembes y Ecovidrio, ya que están relacionados con la gestión de residuos.

- Población Rural: inferior a 5.000 habitantes.

- Población Semiurbana: entre 5.000 y 50.000 habitantes.

- Población Urbana: superior a 50.000 habitantes.

Los valores obtenidos de media y desviación estándar de TR en la muestra de los tres subgrupos analizados se muestran en la Tabla 5.9. 


\begin{tabular}{|c|c|c|c|c|c|c|c|c|c|}
\hline & \multirow[t]{2}{*}{ Grupo } & \multirow[t]{2}{*}{$\mathbf{N}$} & \multirow[t]{2}{*}{ Media } & \multirow{2}{*}{$\begin{array}{l}\text { Desviación } \\
\text { Estándar }\end{array}$} & \multirow{2}{*}{$\begin{array}{c}\text { Error } \\
\text { Estándar }\end{array}$} & \multicolumn{2}{|c|}{$\begin{array}{c}\text { Intervalo de } \\
\text { Confianza 95\% } \\
\text { para la Media }\end{array}$} & \multirow[t]{2}{*}{ Mínimo } & \multirow[t]{2}{*}{ Máximo } \\
\hline & & & & & & $\begin{array}{c}\text { Límite } \\
\text { Inferior }\end{array}$ & $\begin{array}{c}\text { Límite } \\
\text { Superior }\end{array}$ & & \\
\hline \multirow{4}{*}{ TR } & RURAL & 24 & 160,56 & 134,61 & 27,48 & 103,72 & 217,40 & 51,35 & 628,02 \\
\hline & SEMIURBANO & 37 & 112,28 & 116,21 & 19,10 & 73,53 & 151,03 & 16,79 & 580,66 \\
\hline & URBANO & 23 & 77,33 & 79,24 & 16,52 & 43,06 & 111,60 & 5,43 & 337,77 \\
\hline & Total & 84 & 116,51 & 116,35 & 12,69 & 91,26 & 141,76 & 5,43 & 628,02 \\
\hline
\end{tabular}

Tabla 5.9: Media, desviación estándar, error estándar e intervalo de confianza de TR (kg/habitante/año) para los grupos de población adscrita.

Se observa un aparente descenso de TR a medida que aumenta el tamaño de la población. No obstante, para validar dicha variación se ha aplicado el test $\mathrm{H}$ de Kruskal-Wallis, con un resultado de significación de 0,002 $(<0,05)$, por lo que se demuestra que existen al menos dos grupos entre los que se dan diferencias significativas, aunque sin especificar entre cuáles de ellos.

A continuación se aplica la prueba $\mathrm{H}$ de Kruskal-Wallis mediante emparejamiento de los grupos entre sí, con el fin de determinar las semejanzas y las diferencias significativas. Los resultados son los que se muestran en la Tabla 5.10.

\begin{tabular}{|l|l|r|r|r|}
\hline \multicolumn{2}{|c|}{ TR (kg/habitante/año) } & Chi-cuadrado & df & Sign. Asint. \\
\hline \multirow{2}{*}{ Rural } & Semiurbano & 5,72 & 1 & 0,017 \\
\cline { 2 - 5 } & Urbano & 11,02 & 1 & 0,001 \\
\hline \multirow{2}{*}{ Semiurbano } & Rural & 5,72 & 1 & 0,017 \\
\cline { 2 - 6 } & Urbano & 2,48 & 1 & 0,116 \\
\hline \multirow{2}{*}{ Urbano } & Rural & 11,02 & 1 & 0 \\
\cline { 2 - 5 } & Semiurbano & 2,48 & 1 & 0,116 \\
\hline
\end{tabular}

Tabla 5.10: Resultados del test $\mathrm{H}$ de Kruskal-Wallis de TR entre grupos de población adscrita.

Como conclusión, la variable población adscrita resulta significativa, con un efecto de reducción de TR conforme aumenta la variable población, existiendo diferencias significativas entre los puntos limpios con población adscrita inferior a 5.000 habitantes y los de población adscrita superior. Entre grupos con población superior a 5.000 habitantes, las diferencias detectadas no resultan significativas. Así, pueden establecerse 2 grupos, para los cuales TR toma un valor diferente, siendo 160,56 para rural y 98,88 para el grupo semiurbano/urbano. En el mundo rural se realizan mayores aportes de residuos, que puede ser debido a la mayor concienciación de los habitantes en estas poblaciones. 
En cuanto a TV, realizando la misma agrupación de datos de la muestra que la detallada para TR, se observa igualmente un aparente descenso del valor de la variable para poblaciones adscritas crecientes. Los valores de media y desviación estándar de TV de los grupos estudiados son los mostrados en la Tabla 5.11.

\begin{tabular}{|c|c|c|c|c|c|c|c|c|c|}
\hline \multirow{2}{*}{\multicolumn{2}{|c|}{ Grupo }} & \multirow[t]{2}{*}{$\mathbf{N}$} & \multirow[t]{2}{*}{ Media } & \multirow{2}{*}{$\begin{array}{l}\text { Desviación } \\
\text { Estándar }\end{array}$} & \multirow{2}{*}{$\begin{array}{c}\text { Error } \\
\text { Estándar }\end{array}$} & \multicolumn{2}{|c|}{$\begin{array}{c}\text { Intervalo de } \\
\text { Confianza } 95 \% \\
\text { para la Media }\end{array}$} & \multirow[t]{2}{*}{ Mínimo } & \multirow[t]{2}{*}{ Máximo } \\
\hline & & & & & & $\begin{array}{l}\text { Límite } \\
\text { Inferior }\end{array}$ & $\begin{array}{c}\text { Límite } \\
\text { Superior }\end{array}$ & & \\
\hline \multirow{4}{*}{ TV } & RURAL & 23 & 54,66 & 24,86 & 5,18 & 43,90 & 65,41 & 8,77 & 101,28 \\
\hline & SEMIURBANO & 22 & 41,97 & 29,53 & 6,30 & 28,87 & 55,06 & 1,82 & 110,66 \\
\hline & URBANO & 20 & 14,69 & 10,26 & 2,30 & 9,89 & 19,50 & 3,08 & 42,79 \\
\hline & Total & 65 & 38,09 & 28,37 & 3,52 & 31,04 & 45,09 & 1,82 & 110,66 \\
\hline
\end{tabular}

Tabla 5.11: Media, desviación estándar, error estándar e intervalo de confianza de TV para los grupos de población adscrita.

Puesto que los resultados del test de Levene indican que no se cumple el supuesto de homocedasticidad, al obtenerse un valor de significación de 0,001, el análisis de varianza de las medias se lleva a cabo mediante el test ANOVA-Welch, con un resultado de significación de $3,136 \mathrm{E}-8$, por lo que se rechaza la hipótesis nula de igualdad entre grupos, existiendo diferencias entre al menos dos de ellos. Con el objetivo de determinar si existen grupos que puedan considerarse iguales, y entre cuáles existen diferencias significativas, se realiza la prueba BSD de Bonferroni, cuyos resultados se muestran en la Tabla 5.12.

\begin{tabular}{|l|l|r|r|r|}
\hline \multirow{2}{*}{ TV } & Diferencia de media & Error Estándar & \multicolumn{1}{l|}{ Sign. } \\
\hline \multirow{2}{*}{ RURAL } & SEMIURBANO & 12,69 & 6,97 & 0,221 \\
\cline { 2 - 5 } & URBANO & 39,96 & 7,15 & 0,000 \\
\hline \multirow{2}{*}{ SEMIUBANO } & RURAL & $-12,69$ & 6,97 & 0,221 \\
\cline { 2 - 5 } & URBANO & 27,27 & 7,23 & 0,001 \\
\hline \multirow{2}{*}{ URBANO } & RURAL & $-39,96$ & 7,15 & 0,000 \\
\cline { 2 - 5 } & SEMIURBANO & $-27,27$ & 7,23 & 0,001 \\
\hline
\end{tabular}

Tabla 5.12: Resultados de la prueba de significación sobre TV entre grupos de población adscrita.

Por tanto, existe significación estadística sobre TV si la población adscrita al punto limpio es inferior o superior a 50.000 habitantes, pudiendo considerarse comportamientos similares para los puntos limpios con población adscrita inferior a 5.000 y con entre 5.000 y 50.000 habitantes. La media de TV es claramente superior en los puntos limpios con población adscrita inferior a 50.000 habitantes, que en aquéllos con población adscrita superior. Para cada subgrupo de la variable población, TV toma el valor medio diferente, siendo 14,69 para urbano y 48,46 para el grupo 
rural/semiurbano. Esto puede ser debido a que en zonas rurales y semiurbanas las distancias y los tiempos para llegar a los puntos limpios son cortos, mientras que en las poblaciones de más de 50.000 habitantes son mayores.

\subsubsection{Distancia al núcleo urbano.}

En este punto se analiza la influencia de la distancia del punto limpio a los principales núcleos urbanos a los que se encuentran adscritos. La encuesta consultaba a este respecto la distancia a los mismos, admitiendo como posibles respuestas las siguientes:

- Distancia de hasta $0,5 \mathrm{~km}$.

- Distancia de entre 0,5 y $1,5 \mathrm{~km}$.

- Distancia de entre 1,5 y $5 \mathrm{~km}$.

- Distancia superior a $5 \mathrm{~km}$.

Por lo que el criterio de agrupación de los puntos limpios ya quedaba definido en la propia encuesta. Del análisis de la tabla incluida como ANEXO A5.3 se observa que la muestra no incluye ningún punto limpio situado a más de $5 \mathrm{~km}$ del núcleo urbano.

Los valores de media y desviación estándar de TR para los tres subgrupos analizados son los que se detallan en la Tabla 5.13 .

\begin{tabular}{|c|c|c|c|c|c|c|c|c|c|}
\hline & \multirow[t]{2}{*}{ Grupo } & \multirow[t]{2}{*}{$\mathbf{N}$} & \multirow[t]{2}{*}{ Media } & \multirow{2}{*}{$\begin{array}{l}\text { Desviación } \\
\text { Estándar }\end{array}$} & \multirow{2}{*}{$\begin{array}{c}\text { Error } \\
\text { Estándar }\end{array}$} & \multicolumn{2}{|c|}{$\begin{array}{c}\text { Intervalo de } \\
\text { Confianza } 95 \% \\
\text { para la Media }\end{array}$} & \multirow[t]{2}{*}{ Mínimo } & \multirow[t]{2}{*}{ Máximo } \\
\hline & & & & & & $\begin{array}{c}\text { Límite } \\
\text { Inferior }\end{array}$ & $\begin{array}{c}\text { Límite } \\
\text { Superior }\end{array}$ & & \\
\hline \multirow{4}{*}{ TR } & $0-0,5 \mathrm{~km}$ & 42 & 140,70 & 117,76 & 18,17 & 104,00 & 177,39 & 13,01 & 580,66 \\
\hline & $0,5-1,5 \mathrm{~km}$ & 35 & 99,78 & 119,04 & 20,12 & 58,89 & 140,67 & 5,43 & 628,02 \\
\hline & $1,5-5 \mathrm{~km}$ & 7 & 54,98 & 45,42 & 17,17 & 12,97 & 96,99 & 17,87 & 147,37 \\
\hline & Total & 84 & 116,51 & 116,35 & 12,69 & 91,26 & 141,76 & 5,43 & 628,02 \\
\hline
\end{tabular}

Tabla 5.13: Media, desviación estándar, error estándar e intervalo de confianza de TR (kg/habitante/año) para los grupos de distancia a núcleo urbano.

Se observa un aparente descenso en los valores de TR a medida que se incrementa la distancia del punto limpio al núcleo urbano. Los resultados del test $\mathrm{H}$ de Kruskal-Wallis muestran que la distancia al núcleo urbano influye significativamente sobre TR, de manera que existen diferencias entre al menos dos grupos, puesto que el valor de significación del test es de 0,009, inferior a 0,05 . Realizando la misma prueba entre parejas de grupos, se obtienen los resultados incluidos en la Tabla 5.14. 


\begin{tabular}{|l|l|r|r|r|}
\hline \multicolumn{2}{|c|}{ TR (kg/habitante/año) } & Chi-cuadrado & df & Sign. Asint. \\
\hline \multirow{2}{*}{$0-0,5 \mathrm{~km}$} & $0,5-1,5 \mathrm{~km}$ & 5,54 & 1 & 0,019 \\
\cline { 2 - 5 } & $1,5-5 \mathrm{~km}$ & 6,32 & 1 & 0,012 \\
\hline \multirow{2}{*}{$0,5-1,5 \mathrm{~km}$} & $0-0,5 \mathrm{~km}$ & 5,54 & 1 & 0,019 \\
\cline { 2 - 5 } & $1,5-5 \mathrm{~km}$ & 1,06 & 1 & 0,303 \\
\hline \multirow{2}{*}{$1,5-5 \mathrm{~km}$} & $0-0,5 \mathrm{~km}$ & 6,32 & 1 & 0,012 \\
\cline { 2 - 5 } & $0,5-1,5 \mathrm{~km}$ & 1,06 & 1 & 0,303 \\
\hline
\end{tabular}

Tabla 5.14: Resultados del test de Kruskal-Wallis de TR entre grupos de distancia al núcleo urbano.

Se concluye que existen diferencias significativas entre los puntos limpios situados a distancia inferior a $0,5 \mathrm{~km}$ y el resto de instalaciones, pudiendo considerarse que los comportamientos de TR son similares en el resto de grupos de puntos limpios. La variable distancia al núcleo urbano puede por tanto dividirse en dos subgrupos, con valores de TR de 140,70 para distancias menores de $0,5 \mathrm{~km}$ y 92,31 para las distancias mayores. Estos valores de media son lógicos, ya que ofrecen mayor número de aporte de residuos cuanto más cerca se tiene la instalación. También se puede observar que el límite de $0,5 \mathrm{~km}$ representa una barrera real para la utilización de la instalación.

En cuanto a la variable TV, en la Tabla 5.15 se observa que la media y desviación estándar de la variable disminuyen a medida que aumenta la distancia del punto limpio al núcleo urbano.

\begin{tabular}{|c|c|c|c|c|c|c|c|c|c|}
\hline & \multirow[t]{2}{*}{ Grupo } & \multirow[t]{2}{*}{$\mathbf{N}$} & \multirow[t]{2}{*}{ Media } & \multirow{2}{*}{$\begin{array}{l}\text { Desviación } \\
\text { Estándar }\end{array}$} & \multirow{2}{*}{$\begin{array}{c}\text { Error } \\
\text { Estándar }\end{array}$} & \multicolumn{2}{|c|}{$\begin{array}{c}\text { Intervalo de } \\
\text { Confianza } 95 \% \\
\text { para la Media }\end{array}$} & \multirow[t]{2}{*}{ Mínimo } & \multirow[t]{2}{*}{ Máximo } \\
\hline & & & & & & $\begin{array}{l}\text { Límite } \\
\text { Inferior }\end{array}$ & $\begin{array}{l}\text { Límite } \\
\text { Superior }\end{array}$ & & \\
\hline \multirow{4}{*}{ TV } & $0-0,5 \mathrm{~km}$ & 30 & 51,58 & 27,85 & 5,09 & 41,18 & 61,98 & 6,56 & 110,66 \\
\hline & $0,5-1,5 \mathrm{~km}$ & 30 & 28,25 & 24,97 & 4,56 & 18,92 & 37,57 & 1,82 & 90,09 \\
\hline & $1,5-5 \mathrm{~km}$ & 5 & 15,88 & 4,90 & 2,19 & 9,80 & 21,97 & 10,54 & 23,85 \\
\hline & Total & 65 & 38,06 & 28,37 & 3,52 & 31,04 & 45,09 & 1,82 & 110,66 \\
\hline
\end{tabular}

Tabla 5.15: Media, desviación estándar, error estándar e intervalo de confianza de TV para los grupos de distancia a núcleo urbano.

Los resultados del test de Levene indican que no se cumple el requisito de homogeneidad de varianzas, necesario para la aplicación de la prueba ANOVA, al obtenerse un valor de significación de 0,033 , por lo que se realiza el test ANOVA-Welch. El valor de significación de la prueba es 6,845E-7, por lo que existen diferencias entre grupos de TV en función del valor de la variable de distancia al núcleo urbano. Con el objetivo de determinar si existen grupos que puedan 
considerarse iguales, y entre cuáles existen diferencias significativas, se realiza la prueba BSD de Bonferroni, cuyos resultados se muestran en la Tabla 5.16.

\begin{tabular}{|l|l|r|r|r|}
\hline \multicolumn{2}{|c|}{ TV } & Diferencia de media & Error Estándar & \multicolumn{1}{c|}{ Sign. } \\
\hline \multirow{2}{*}{$0-0,5 \mathrm{~km}$} & $0,5-1,5 \mathrm{~km}$ & 23,33 & 6,61 & 0,002 \\
\cline { 2 - 5 } & $1,5-5 \mathrm{~km}$ & 35,70 & 12,37 & 0,016 \\
\hline \multirow{2}{*}{$0,5-1,5 \mathrm{~km}$} & $0-0,5 \mathrm{~km}$ & $-23,33$ & 6,61 & 0,002 \\
\cline { 2 - 5 } & $1,5-5 \mathrm{~km}$ & 12,37 & 12,37 & 0,964 \\
\hline \multirow{2}{*}{$1,5-5 \mathrm{~km}$} & $0-0,5 \mathrm{~km}$ & $-35,70$ & 12,37 & 0,016 \\
\cline { 2 - 5 } & $0,5-1,5 \mathrm{~km}$ & $-12,37$ & 12,37 & 0,964 \\
\hline
\end{tabular}

Tabla 5.16: Resultados de la prueba de significación sobre TV entre grupos de distancia al núcleo urbano.

Se observa que el valor de significación es superior a 0,05 en la comparación entre los grupos de puntos limpios situados a entre 0,5 y $1,5 \mathrm{~km}$, y entre 1,5 y $5 \mathrm{~km}$, por lo que se acepta la hipótesis nula de igualdad de grupos para esta comparación. En el resto de casos, es decir, entre puntos limpios situados a menos de $0,5 \mathrm{~km}$, y todos aquellos situados a más de $0,5 \mathrm{~km}$, existen diferencias significativas en TV, obteniéndose valores de TV superiores en los puntos limpios más próximos al núcleo urbano. Para cada subgrupo de la variable distancia al núcleo urbano, teniendo en cuenta los resultados de significación de la prueba, la variable TR toma el valor medio diferente, siendo 51,58 para distancias menores de $0,5 \mathrm{~km}$ y 26,48 para las distancias mayores. Estos valores de media son lógicos, ya que ofrecen mayor número de visitas cuanto más cerca se tiene la instalación. Y de la misma forma que sucede con TR, también se puede observar que el límite de 0,5 km representa una barrera real para la utilización de la instalación.

\subsubsection{Transporte público.}

Se analiza en este punto la influencia que pueda representar la disponibilidad o no de transporte público hasta el punto limpio, en la medida en que éste puede facilitar el acceso de los usuarios al mismo.

Pese a existir una aparente influencia del valor de la variable sobre los resultados de TR, tal y como se observa en la Tabla 5.17, en que tanto la media como la desviación estándar son superiores en los puntos limpios que disponen de transporte público en sus proximidades, los resultados de la prueba $\mathrm{H}$ de Kruskal-Wallis proporcionan un valor de significación de 0,857, superior a 0,05 , por lo que se valida la hipótesis nula de igualdad de grupos y, por tanto, la variable no es estadísticamente significativa sobre TR. 


\begin{tabular}{|c|c|c|c|c|c|c|c|c|c|}
\hline & \multirow[t]{2}{*}{ Grupo } & \multirow[t]{2}{*}{$\mathbf{N}$} & \multirow[t]{2}{*}{ Media } & \multirow{2}{*}{$\begin{array}{l}\text { Desviación } \\
\text { Estándar }\end{array}$} & \multirow{2}{*}{$\begin{array}{c}\text { Error } \\
\text { Estándar }\end{array}$} & \multicolumn{2}{|c|}{$\begin{array}{c}\text { Intervalo de } \\
\text { Confianza } 95 \% \\
\text { para la Media }\end{array}$} & \multirow[t]{2}{*}{ Mínimo } & \multirow[t]{2}{*}{ Máximo } \\
\hline & & & & & & $\begin{array}{l}\text { Límite } \\
\text { Inferior }\end{array}$ & $\begin{array}{l}\text { Límite } \\
\text { Superior }\end{array}$ & & \\
\hline \multirow{3}{*}{ TR } & SIN Tpte Púb & 66 & 110,95 & 107,70 & 13,26 & 84,47 & 137,42 & 8,42 & 628,02 \\
\hline & CON Tpte Púb & 17 & 139,51 & 149,58 & 36,28 & 62,60 & 216,41 & 5,43 & 580,66 \\
\hline & Total & 83 & 116,80 & 117,03 & 12,85 & 91,24 & 142,35 & 5,43 & 628,02 \\
\hline
\end{tabular}

Tabla 5.17: Media, desviación estándar, error estándar e intervalo de confianza de TR para los grupos de disponibilidad de transporte público.

En cuanto a la relación entre las variables TV y disponibilidad de transporte público, los valores de media y desviación estándar de TV para cada grupo de división de la muestra se incluyen en la Tabla 5.18. Se observa una aparente reducción de los valores de TV en los puntos limpios que disponen de transporte público.

\begin{tabular}{|c|c|c|c|c|c|c|c|c|c|}
\hline & \multirow[t]{2}{*}{ Grupo } & \multirow[t]{2}{*}{$\mathbf{N}$} & \multirow[t]{2}{*}{ Media } & \multirow{2}{*}{$\begin{array}{l}\text { Desviación } \\
\text { Estándar }\end{array}$} & \multirow{2}{*}{$\begin{array}{l}\text { Error } \\
\text { Estándar }\end{array}$} & \multicolumn{2}{|c|}{$\begin{array}{c}\text { Intervalo de } \\
\text { Confianza } 95 \% \\
\text { para la Media }\end{array}$} & \multirow[t]{2}{*}{ Mínimo } & \multirow[t]{2}{*}{ Máximo } \\
\hline & & & & & & $\begin{array}{l}\text { Límite } \\
\text { Inferior }\end{array}$ & $\begin{array}{l}\text { Límite } \\
\text { Superior }\end{array}$ & & \\
\hline \multirow{3}{*}{ TV } & SIN Tpte Púb & 51 & 40,75 & 28,71 & 4,02 & 32,68 & 48,83 & 1,82 & 110,66 \\
\hline & CON Tpte Púb & 13 & 26,95 & 26,25 & 7,28 & 11,09 & 42,81 & 6,56 & 98,46 \\
\hline & Total & 64 & 37,95 & 28,58 & 3,57 & 30,81 & 45,09 & 1,82 & 110,66 \\
\hline
\end{tabular}

Tabla 5.18: Media, desviación estándar, error estándar e intervalo de confianza de TV para los grupos de disponibilidad de transporte público.

Tras la aplicación del test de Levene, se concluye que existe homogeneidad de varianzas entre los grupos, al obtenerse un resultados de significación de 0,406 $(>0,05)$. Tras la posterior realización del test ANOVA, se valida la hipótesis nula de igualdad de grupos, con un resultado de significación de 0,121 $(>0,05)$.

En resumen, los resultados del estudio muestran que no existen influencias significativas entre la variable de disponibilidad de transporte público y los resultados de TR y TV. Una de las posibles causas de la no significación puede ser que la acción de llevar los residuos (voluminosos, RAEE, $\mathrm{RCD}$, etc) a través del transporte público, no parece cómodo o aceptado para los usuarios. No obstante, se considera recomendable que los puntos limpios puedan disponer de transporte público en las proximidades, puesto que resulta representativo de la conectividad e integración del punto limpio en el entramado urbanístico. 


\subsubsection{Carril bici.}

En este punto se analiza la relevancia que pueda representar la existencia de carril bici hasta el punto limpio sobre los resultados de gestión de residuos de la instalación.

En la Tabla 5.19 puede observarse que el 93,98\% de los puntos limpios no son accesibles mediante carril bici; asimismo, tanto la media como la desviación estándar de TR observadas son superiores en los puntos limpios que no cuentan con carril bici.

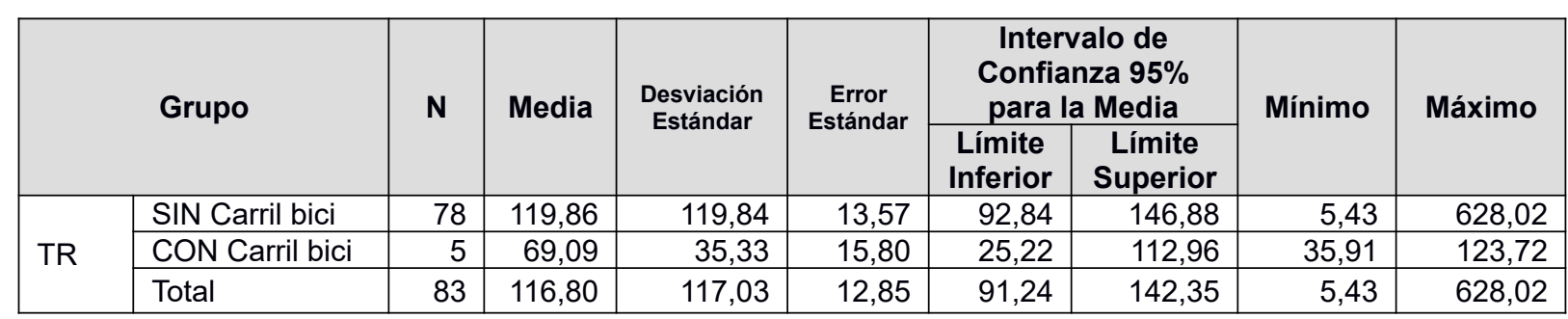

Tabla 5.19: Media, desviación estándar, error estándar e intervalo de confianza de TR para los grupos de disponibilidad de carril bici.

Los resultados de la prueba $\mathrm{H}$ de Kruskal-Wallis, para validar la hipótesis nula de homogeneidad de grupos de la relación entre las variables TR y disponibilidad de carril bici, permiten concluir que no existe relación significativa entre ambas, puesto que el valor de significación es de 0,467, superior a 0,05 y, por tanto, los subgrupos de la muestra son iguales.

Los valores de media y desviación estándar de TV son los que se muestran en la Tabla 5.20.

Tras la aplicación del test de Levene se valida el supuesto de homogeneidad de varianzas entre grupos, con un valor de significación de 0,081, y el de igualdad de grupos, con un valor de significación del test ANOVA entre la variable de disponibilidad de carril bici y TV de 0,267, ambos superiores a 0,05. Así pues, el estudio concluye que no existen influencias significativas entre la variable de disponibilidad de carril bici y los resultados de TV.

\begin{tabular}{|c|c|c|c|c|c|c|c|c|c|}
\hline \multirow{2}{*}{\multicolumn{2}{|c|}{ Grupo }} & \multirow[t]{2}{*}{$\mathbf{N}$} & \multirow[t]{2}{*}{ Media } & \multirow{2}{*}{$\begin{array}{l}\text { Desviación } \\
\text { Estándar }\end{array}$} & \multirow{2}{*}{$\begin{array}{c}\text { Error } \\
\text { Estándar }\end{array}$} & \multicolumn{2}{|c|}{$\begin{array}{c}\text { Intervalo de } \\
\text { Confianza } 95 \% \\
\text { para la Media }\end{array}$} & \multirow[t]{2}{*}{ Mínimo } & \multirow[t]{2}{*}{ Máximo } \\
\hline & & & & & & $\begin{array}{l}\text { Límite } \\
\text { Inferior }\end{array}$ & $\begin{array}{c}\text { Límite } \\
\text { Superior }\end{array}$ & & \\
\hline \multirow{3}{*}{ TV } & SIN Carril bici & 60 & 38,98 & 29,09 & 3,76 & 31,46 & 46,49 & 1,82 & 110,66 \\
\hline & CON Carril bici & 4 & 22,48 & 12,81 & 6,40 & 2,10 & 42,86 & 14,19 & 41,38 \\
\hline & Total & 64 & 37,95 & 28,58 & 3,57 & 30,81 & 45,09 & 1,82 & 110,66 \\
\hline
\end{tabular}

Tabla 5.20: Media, desviación estándar, error estándar e intervalo de confianza de TV para los grupos de disponibilidad de carril bici. 
De los resultados de TR y TV se desprende que, pese a que en el punto limpio pueden ser depositados residuos con un relativamente pequeño volumen (pequeños electrodomésticos, pilas), que podrían ser transportados a bordo de medios de transporte que pueden hacer uso del carril bici, y que previsiblemente incrementarían el número de visitas recibidas en el punto limpio, esta solución no parece ser la más común. Una de las posibles causas de la no influencia puede ser que la acción de llevar los residuos (voluminosos, RAEE, RCD, etc) a través de la bici, no parece cómodo o aceptado para los usuarios. No obstante, debido a la creciente demanda ciudadana de infraestructuras de carril bici, que están promoviendo una rápida evolución en la movilidad urbana, se considera recomendable que los puntos limpios se localicen en ubicaciones que dispongan, o puedan disponer, de ello sin grandes desarrollos de infraestructura viaria específica.

\subsubsection{Análisis de TR y TV en función de los factores de infraestructuras de los puntos limpios.}

En este punto se estudia la influencia que presentan sobre las variables TR y TV los aspectos relacionados con las características constructivas de los puntos limpios y el equipamiento de los mismos.

\subsubsection{Año de construcción del punto limpio.}

El año de construcción del punto limpio presenta diversos valores, por lo que se hace necesario agrupar los datos para poder realizar el estudio de influencia entre variables. En este caso, el criterio adoptado obedece a cambios en la legislación y políticas de gestión de residuos:

- Puntos limpios construidos antes de 1998.

- Puntos limpios construidos entre 1998 y 2010.

- Puntos limpios construidos a partir de 2011.

Los resultados de influencia del factor sobre TR, tras la aplicación de la prueba $\mathrm{H}$ de KruskalWallis, concluyen que no existe significación estadística entre la antigüedad del punto limpio y los resultados de TR, al obtenerse un valor de significación de 0,158. En la Tabla 5.21 se observa que los valores de la media de TR son similares en los tres grupos en que se ha dividido la muestra.

Al no existir diferencias estadísticamente significativas, todos los valores pertenecen a la misma media, cuyo valor es 102,99. 


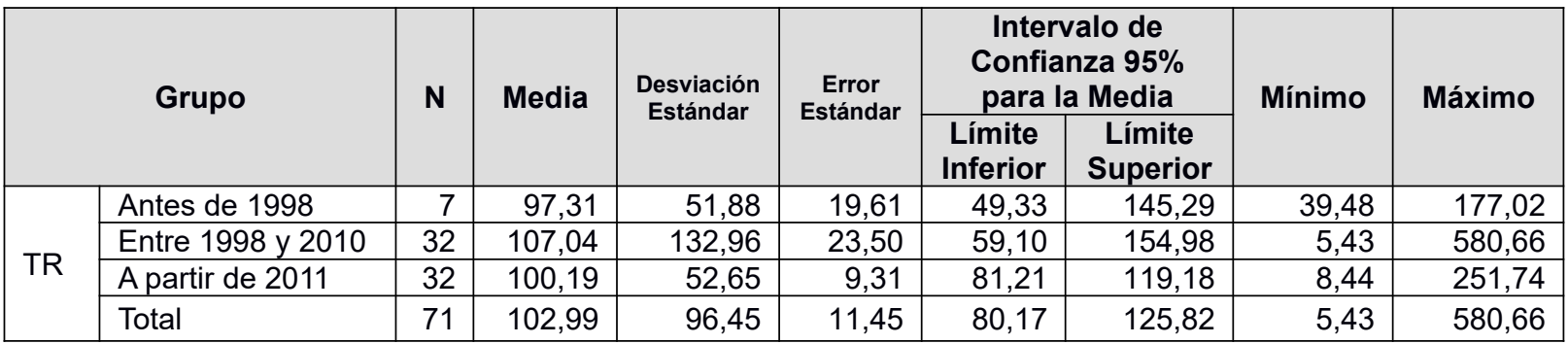

Tabla 5.21: Media, desviación estándar, error estándar e intervalo de confianza de TR para los grupos de antigüedad del punto limpio.

Por lo que se refiere a TV, en la Tabla 5.22 se observa un aparente crecimiento de la variable para los puntos limpios más nuevos, y valores de desviación estándar similares para las instalaciones construidas a partir de 1998.

\begin{tabular}{|c|c|c|c|c|c|c|c|c|c|}
\hline \multirow{2}{*}{\multicolumn{2}{|c|}{ Grupo }} & \multirow[t]{2}{*}{$\mathbf{N}$} & \multirow[t]{2}{*}{ Media } & \multirow{2}{*}{$\begin{array}{l}\text { Desviación } \\
\text { Estándar }\end{array}$} & \multirow[t]{2}{*}{$\begin{array}{c}\text { Error } \\
\text { Estándar }\end{array}$} & \multicolumn{2}{|c|}{$\begin{array}{c}\text { Intervalo de } \\
\text { Confianza } 95 \% \\
\text { para la Media }\end{array}$} & \multirow[t]{2}{*}{ Mínimo } & \multirow[t]{2}{*}{ Máximo } \\
\hline & & & & & & $\begin{array}{c}\text { Límite } \\
\text { Inferior }\end{array}$ & $\begin{array}{c}\text { Límite } \\
\text { Superior }\end{array}$ & & \\
\hline \multirow{4}{*}{ TV } & Antes de 1998 & 5 & 14,43 & 3,22 & 1,44 & 10,43 & 18,42 & 10,54 & 19,39 \\
\hline & Entre 1998 y 2010 & 22 & 28,96 & 29,26 & 6,24 & 15,99 & 41,93 & 1,82 & 110,66 \\
\hline & A partir de 2011 & 29 & 49,62 & 28,59 & 5,31 & 38,75 & 60,49 & 3,08 & 101,28 \\
\hline & Total & 56 & 38,36 & 29,96 & 4,00 & 30,34 & 46,39 & 1,82 & 110,66 \\
\hline
\end{tabular}

Tabla 5.22: Media, desviación estándar, error estándar e intervalo de confianza de TV para los grupos de antigüedad del punto limpio.

El resultado del test de Levene, para la validación de la hipótesis de homogeneidad de varianzas, es de 0,020, por lo que se rechaza la hipótesis. Así, la comprobación de la hipótesis de igualdad entre los grupos no puede realizarse a través del test ANOVA, sino mediante el test ANOVAWelch. El valor de significación de la prueba es 7,529E-7, por lo que existen diferencias entre grupos de TV en función del año de construcción del punto limpio. Con el objetivo de determinar si existen grupos que puedan considerarse iguales, y entre cuáles existen diferencias significativas, se realiza la prueba BSD de Bonferroni, cuyos resultados se muestran en la Tabla 5.23.

\begin{tabular}{|l|l|r|r|r|}
\hline \multicolumn{2}{|c|}{ TV (visitas/100habitantes/año) } & Diferencia de media & Error Estándar & \multicolumn{1}{c|}{ Sign. } \\
\hline \multirow{2}{*}{ Antes de 1998 } & Entre 1998 y 2010 & $-14,53$ & 13,76 & 0,887 \\
\cline { 2 - 5 } & A partir de 2011 & $-35,19$ & 13,45 & 0,035 \\
\hline \multirow{2}{*}{ Entre 1998 y 2010 } & Antes de 1998 & 14,53 & 13,76 & 0,887 \\
\cline { 2 - 5 } & A partir de 2011 & $-20,66$ & 7,85 & 0,033 \\
\hline \multirow{2}{*}{ A partir de 2011 } & Antes de 1998 & 35,19 & 13,45 & 0,035 \\
\cline { 2 - 5 } & Entre 1998 y 2010 & 20,66 & 7,85 & 0,033 \\
\hline
\end{tabular}

Tabla 5.23: Resultados de la prueba de significación sobre TV entre grupos de antigüedad del punto limpio. 
Se observa que el valor de significación es superior a 0,05 en la comparación entre los grupos de puntos limpios construidos antes de 1998 y entre 1998 y 2010, por lo que se acepta la hipótesis nula de igualdad de grupos únicamente para esta comparación. En el resto de casos, es decir, entre puntos limpios construidos hasta 2010 y a partir de 2011, existen diferencias significativas en TV, siendo la media de TV superior en este último caso. Por tanto a partir del año 2011 la media de TV es de 49,62 visitas/100habitantes/año y para los anteriores es de 26,27.

La justificación de estos valores puede deberse a que, cuanto más reciente es el punto limpio, aunque no recoge más residuos, sí que recibe más visitas, por la proximidad, las mejores y actualizadas instalaciones, las vías de comunicación o la mayor concienciación de su utilización, aunque los usuarios realizan menos aportes en cada visita a la instalación.

\subsubsection{Número de carriles de circulación por sentido.}

Se trata de un aspecto relacionado con la organización de los flujos de circulación y accesibilidad interna a los puntos de entrega de residuos, y que tiene influencia sobre los gastos de inversión en cuanto a superficie necesaria y costes de construcción, así como en los gastos de mantenimiento de la infraestructura. Los puntos limpios de la muestra disponen, mayoritariamente, de 1 único carril de circulación por sentido, representando un 8,33\% las instalaciones con 2 carriles.

En el caso de TR, los valores de media y desviación estándar son los que se incluyen en la Tabla 5.24 .

\begin{tabular}{|c|c|c|c|c|c|c|c|c|c|}
\hline \multirow{2}{*}{\multicolumn{2}{|c|}{ Grupo }} & \multirow[t]{2}{*}{$\mathbf{N}$} & \multirow[t]{2}{*}{ Media } & \multirow{2}{*}{$\begin{array}{l}\text { Desviación } \\
\text { Estándar }\end{array}$} & \multirow[t]{2}{*}{$\begin{array}{c}\text { Error } \\
\text { Estándar }\end{array}$} & \multicolumn{2}{|c|}{$\begin{array}{c}\text { Intervalo de } \\
\text { Confianza } 95 \% \\
\text { para la Media }\end{array}$} & \multirow[t]{2}{*}{ Mínimo } & \multirow[t]{2}{*}{ Máximo } \\
\hline & & & & & & $\begin{array}{l}\text { Límite } \\
\text { Inferior }\end{array}$ & $\begin{array}{l}\text { Límite } \\
\text { Superior }\end{array}$ & & \\
\hline \multirow{3}{*}{ TR } & 1 carril & 73 & 121,46 & 120,38 & 14,09 & 93,37 & 149,55 & 8,42 & 628,02 \\
\hline & 2 carriles & 7 & 77,42 & 91,69 & 34,66 & $-7,38$ & 162,22 & 5,43 & 275,38 \\
\hline & Total & 80 & 117,61 & 118,34 & 13,23 & 91,27 & 143,94 & 5,43 & 628,00 \\
\hline
\end{tabular}

Tabla 5.24: Media, desviación estándar, error estándar e intervalo de confianza de TR para los grupos de $n^{\circ}$ de carriles de circulación.

Al tratase de una variable no normal, se realiza la prueba $\mathrm{H}$ de Kruskal-Wallis, obteniéndose el resultado de no existencia de diferencias entre ambos grupos (valor de significación de 0,136). 
En la Tabla 5.25 se incluyen los resultados de media y desviación estándar de TV en función del valor que toma la variable asociada al número de carriles de circulación. El estudio realizado muestra que sí se cumple el supuesto de homocedasticidad, con un valor de significación en el test de Levene de 0,393. Tras la aplicación del test ANOVA, se concluye que se cumple la hipótesis nula de igualdad entre grupos, al resultar un valor de significación de 0,642.

\begin{tabular}{|c|c|c|c|c|c|c|c|c|c|}
\hline & \multirow{2}{*}{ Grupo } & \multirow[t]{2}{*}{$\mathbf{N}$} & \multirow{2}{*}{ Media } & \multirow{2}{*}{$\begin{array}{l}\text { Desviación } \\
\text { Estándar }\end{array}$} & \multirow{2}{*}{$\begin{array}{c}\text { Error } \\
\text { Estándar }\end{array}$} & \multicolumn{2}{|c|}{$\begin{array}{c}\text { Intervalo de } \\
\text { Confianza 95\% } \\
\text { para la Media }\end{array}$} & \multirow{2}{*}{ Mínimo } & \multirow{2}{*}{ Máximo } \\
\hline & & & & & & $\begin{array}{l}\text { Límite } \\
\text { Inferior }\end{array}$ & $\begin{array}{l}\text { Límite } \\
\text { Superior }\end{array}$ & & \\
\hline \multirow{3}{*}{ TV } & 1 carril & 61 & 38,68 & 28,93 & 3,70 & 31,27 & 46,09 & 1,82 & 110,66 \\
\hline & 2 carriles & 3 & 30,74 & 20,86 & 12,04 & $-21,07$ & 82,55 & 6,89 & 45,53 \\
\hline & Total & 64 & 38,31 & 28,52 & 3,57 & 31,19 & 45,44 & 1,82 & 110,66 \\
\hline
\end{tabular}

Tabla 5.25: Media, desviación estándar, error estándar e intervalo de confianza de TV para los grupos de $n^{\circ}$ de carriles de circulación.

Por tanto, el número de carriles de circulación por sentido con que cuenta el punto limpio no presenta significación estadística sobre las variables TR y TV. Así pues, ante el nulo efecto de disponer de dos carriles, y dada la inversión económica y en espacio que esto supone, es preferible que los puntos limpios dispongan de un único carril interno.

\subsubsection{Cotas de construcción.}

Los puntos limpios, como norma general, pueden ser construidos con todos los equipamientos y vías de circulación al mismo nivel (1 cota), o con los equipamientos accesibles al usuario a un nivel, y los necesarios para los vehículos del servicio de transporte, a un nivel inferior (2 cotas); en el primer caso, los costes de construcción son inferiores y, en el segundo, el diseño de los flujos de circulación interna resulta menos invasivo, quedando segregadas las áreas accesibles por los usuarios de las necesarias para la logística del servicio, y mejorando además la accesibilidad de los usuarios a los contenedores de alta capacidad, puesto que las entregas de residuos de gran volumen y/o masa no requieren ser realizadas mediante la elevación de los mismos a alturas por encima de la cintura.

En función de si los puntos limpios se encuentran construidos a 1 ó 2 cotas, los valores de media y desviación estándar de TR registrados son los mostrados en la Tabla 5.26. 
Estudio de los puntos limpios implantados en España.

\begin{tabular}{|c|c|c|c|c|c|c|c|c|c|}
\hline & Grupo & $\mathbf{N}$ & Media & Desviación & $\begin{array}{c}\text { Error } \\
\text { Estźndar }\end{array}$ & $\begin{array}{r}\text { Inter } \\
\text { Confia } \\
\text { para I }\end{array}$ & $\begin{array}{l}\text { alo de } \\
\text { 1za 95\% } \\
\text { Media }\end{array}$ & Mínimo & Máximo \\
\hline & & & & & & $\begin{array}{l}\text { Límite } \\
\text { Inferior }\end{array}$ & $\begin{array}{l}\text { Límite } \\
\text { Superior }\end{array}$ & & \\
\hline & 1 cota & 28 & 119,69 & 145,27 & 27,45 & 63,36 & 176,02 & 5,43 & 628,02 \\
\hline TR & 2 cotas & 53 & 114,68 & 102,40 & 14,07 & 86,45 & 142,90 & 8,42 & 403,60 \\
\hline & Total & 81 & 116,41 & 118,09 & 13,12 & 90,30 & 142,52 & 5,43 & 628,02 \\
\hline
\end{tabular}

Tabla 5.26: Media, desviación estándar, error estándar e intervalo de confianza de TR para los grupos de $n^{\circ}$ de cotas de construcción.

Los resultados de la prueba $\mathrm{H}$ de Kruskal-Wallis muestran que no existen diferencias estadísticas significativas en TR en función del número de cotas de construcción, puesto que el valor de significación de la prueba es de 0,945, superior a 0,05 y, por tanto, se valida la hipótesis de igualdad entre grupos.

Los resultados de media y desviación estándar de TV se muestran en la Tabla 5.27. Así pues, se valida la hipótesis de igualdad de varianzas entre los grupos, al obtener un resultado de significación en el test de Levene de 0,877. En cuanto a la validación se la hipótesis de igualdad entre grupos, los resultados del test ANOVA muestran un valor de significación de 0,210 , superior a 0,05 , validándose la hipótesis nula.

\begin{tabular}{|c|c|c|c|c|c|c|c|c|c|}
\hline \multirow{2}{*}{\multicolumn{2}{|c|}{ Grupo }} & \multirow[t]{2}{*}{$\mathbf{N}$} & \multirow[t]{2}{*}{ Media } & \multirow[t]{2}{*}{$\begin{array}{l}\text { Desviación } \\
\text { Estándar }\end{array}$} & \multirow[t]{2}{*}{$\begin{array}{c}\text { Error } \\
\text { Estándar }\end{array}$} & \multicolumn{2}{|c|}{$\begin{array}{c}\text { Intervalo de } \\
\text { Confianza 95\% } \\
\text { para la Media }\end{array}$} & \multirow[t]{2}{*}{ Mínimo } & \multirow[t]{2}{*}{ Máximo } \\
\hline & & & & & & $\begin{array}{l}\text { Límite } \\
\text { Inferior }\end{array}$ & $\begin{array}{c}\text { Límite } \\
\text { Superior }\end{array}$ & & \\
\hline \multirow{3}{*}{ TV } & 1 cota & 24 & 43,87 & 28,10 & 5,74 & 32,00 & 55,73 & 6,89 & 98,46 \\
\hline & 2 cotas & 41 & 34,67 & 28,31 & 4,42 & 25,73 & 43,60 & 1,82 & 110,66 \\
\hline & Total & 65 & 38,06 & 28,37 & 3,52 & 31,04 & 45,09 & 1,82 & 110,66 \\
\hline
\end{tabular}

Tabla 5.27: Media, desviación estándar, error estándar e intervalo de confianza de TV para los grupos de $n^{\circ}$ de cotas de construcción.

Por tanto, el número de cotas no influye en el valor de TR y TV. Dada la inversión que supone realizar dos cotas sólo se justificará en términos de seguridad de circulaciones en el interior de la instalación.

\subsubsection{Número de contenedores caja abierta.}

Para un correcto funcionamiento del servicio, el número de contenedores debe estar dimensionado de manera que permita el almacenamiento temporal de las cantidades de 
materiales depositados en los mismos, con una gestión logística lo más homogénea posible, y sin unos excesivos costes de inversión.

En términos de producción de residuos, las fracciones mayoritarias son las de:

- Residuos voluminosos y colchones (almacenamiento conjunto o segregado).

- Residuos de construcción y demolición.

- Residuos vegetales.

Que, generalmente, son almacenados en contenedores de tipo caja abierta, de capacidad variable; en función del tamaño del municipio, actividades económicas, condiciones de funcionamiento, etc, es frecuente que se instalen contenedores de este tipo para otras fracciones:

- Residuos metálicos.

- Residuos de plástico distinto de envases.

- Papel y cartón.

El número de contenedores caja abierta puede tomar múltiples valores. En el Gráfico 5.9 se muestra el número de contenedores caja abierta con que cuentan los puntos limpios de la muestra (entre 4 y 21 unidades) y cuántos de ellos se encuentran en cada una de las situaciones informadas en la encuesta, haciéndose patente la necesidad de establecer criterios de agrupación de los puntos limpios, con el objetivo de poder analizar la significación estadística de la variable sobre TR y TV.

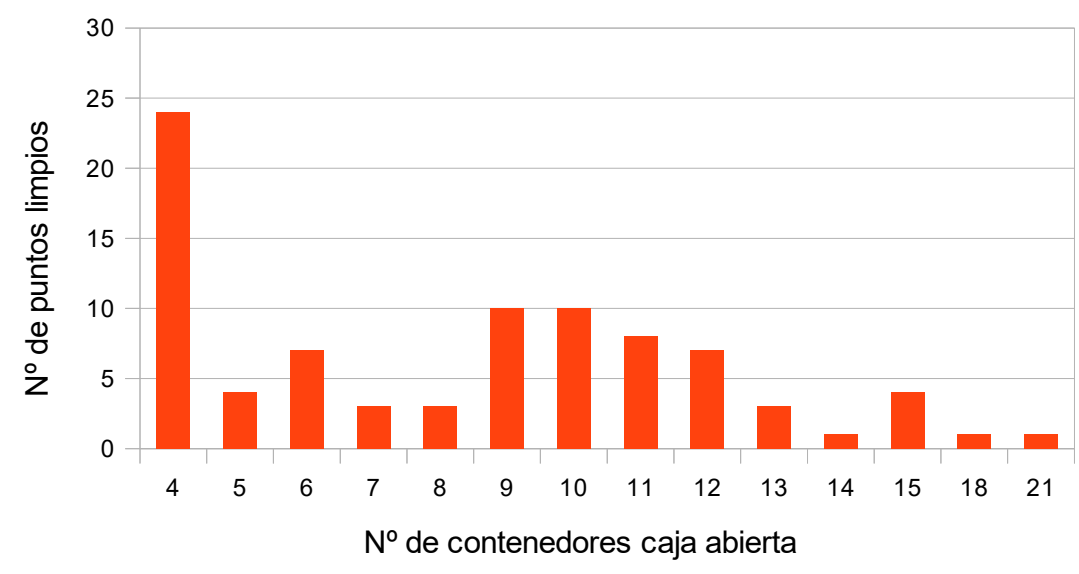

Gráfico 5.9: Número de puntos limpios por cantidad de contenedores caja abierta. 
Además, puesto que las necesidades de almacenamiento dependen de la producción de residuos en el área de influencia, directamente relacionada con la población adscrita, el estudio se realiza teniendo en cuenta el factor demográfico, según los criterios fijados en el punto 5.3.2.1. En función del comportamiento de la variable "número de contenedores caja abierta" para cada grupo de puntos limpios, según su población adscrita, los subgrupos para el estudio de significación se configuran atendiendo al criterio que se indica en la Tabla 5.28.

\begin{tabular}{|l|c|c|c|c|}
\hline \multicolumn{1}{|c|}{ Tamaño } & Grupo 1 & Grupo 2 & Grupo 3 & Grupo 4 \\
\hline Rural & \multicolumn{2}{|c|}{$=4$} & $=11$ & $>11$ \\
\hline Semiurbano & $<8$ & $8 \leq \mathrm{x} \leq 10$ & $10<\mathrm{x} \leq 14$ & $>14$ \\
\hline Urbano & $<7$ & $7 \leq \mathrm{x} \leq 10$ & 4 \\
\hline
\end{tabular}

Tabla 5.28: Clasificación de puntos limpios por número de contenedores y tamaño de población adscrita.

Para los puntos limpios con población adscrita inferior a 5.000 habitantes, se obtienen los valores de media y desviación estándar de TR que se muestran en la Tabla 5.29.

\begin{tabular}{|c|c|c|c|c|c|c|c|c|c|}
\hline \multirow{2}{*}{\multicolumn{2}{|c|}{ Grupo }} & \multirow[t]{2}{*}{$\mathbf{N}$} & \multirow[t]{2}{*}{ Media } & \multirow{2}{*}{$\begin{array}{l}\text { Desviación } \\
\text { Estándar }\end{array}$} & \multirow{2}{*}{$\begin{array}{c}\text { Error } \\
\text { Estándar }\end{array}$} & \multicolumn{2}{|c|}{$\begin{array}{c}\text { Intervalo de } \\
\text { Confianza } 95 \% \\
\text { para la Media }\end{array}$} & \multirow[t]{2}{*}{ Mínimo } & \multirow[t]{2}{*}{ Máximo } \\
\hline & & & & & & $\begin{array}{l}\text { Límite } \\
\text { Inferior }\end{array}$ & $\begin{array}{c}\text { Límite } \\
\text { Superior }\end{array}$ & & \\
\hline \multirow{3}{*}{ TR } & 4 cont. C.Ab. & 20 & 147,35 & 96,64 & 21,61 & 102,12 & 192,58 & 51,35 & 403,60 \\
\hline & $>4$ cont. C.Ab. & 4 & 226,62 & 269,78 & 134,89 & $-202,66$ & 655,90 & 60,98 & 628,02 \\
\hline & Total & 24 & 160,56 & 134,61 & 27,48 & 103,72 & 217,40 & 51,35 & 328,02 \\
\hline
\end{tabular}

Tabla 5.29: Media, desviación estándar, error estándar e intervalo de confianza de TR para los grupos de $n^{\circ}$ de contenedores caja abierta para puntos limpios rurales.

La prueba $\mathrm{H}$ de Kruskal-Wallis resulta con un valor de significación de 0,938 , por lo que se valida la hipótesis de igualdad entre grupos.

Para los puntos limpios con población adscrita de entre 5.000 y 50.000 habitantes, los valores de media y desviación estándar de TR son los mostrados en la Tabla 5.30. 


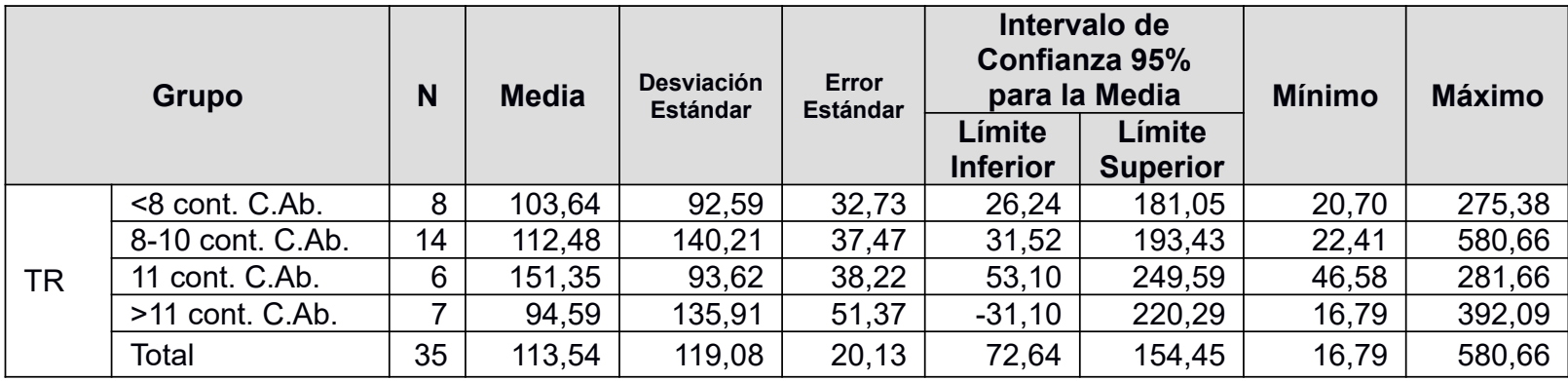

Tabla 5.30: Media, desviación estándar, error estándar e intervalo de confianza de TR para los grupos de $n^{\circ}$ de contenedores caja abierta para puntos limpios semiurbanos.

En este caso, el valor de significación de la prueba $\mathrm{H}$ de Kruskal-Wallis es de 0,234, por lo que se valida la hipótesis de igualdad entre grupos.

Para los puntos limpios con población adscrita superior a 50.000 habitantes, la media y desviación estándar de TR son las que se detallan en la Tabla 5.31.

\begin{tabular}{|c|c|c|c|c|c|c|c|c|c|}
\hline \multirow{2}{*}{\multicolumn{2}{|c|}{ Grupo }} & \multirow[t]{2}{*}{$\mathbf{N}$} & \multirow[t]{2}{*}{ Media } & \multirow{2}{*}{$\begin{array}{l}\text { Desviación } \\
\text { Estándar }\end{array}$} & \multirow{2}{*}{$\begin{array}{c}\text { Error } \\
\text { Estándar }\end{array}$} & \multicolumn{2}{|c|}{$\begin{array}{c}\text { Intervalo de } \\
\text { Confianza } 95 \% \\
\text { para la Media }\end{array}$} & \multirow[t]{2}{*}{ Mínimo } & \multirow[t]{2}{*}{ Máximo } \\
\hline & & & & & & $\begin{array}{l}\text { Límite } \\
\text { Inferior }\end{array}$ & $\begin{array}{c}\text { Límite } \\
\text { Superior }\end{array}$ & & \\
\hline \multirow{5}{*}{ TR } & <7 cont. C.Ab. & 5 & 76,13 & 26,71 & 11,94 & 42,96 & 109,29 & 60,98 & 123,72 \\
\hline & 7-10 cont. C.Ab. & 6 & 58,49 & 68,19 & 27,84 & $-13,07$ & 130,06 & 13,01 & 196,09 \\
\hline & $11-14$ cont. C.Ab. & 6 & 93,36 & 124,49 & 50,82 & $-37,28$ & 224,00 & 8,42 & 337,77 \\
\hline & $>14$ cont. C.Ab. & 5 & 61,97 & 70,30 & 31,44 & $-25,32$ & 149,26 & 5,43 & 175,00 \\
\hline & Total & 22 & 72,80 & 78,00 & 16,63 & 38,22 & 107,38 & 5,43 & 337,77 \\
\hline
\end{tabular}

Tabla 5.31: Media, desviación estándar, error estándar e intervalo de confianza de TR para los grupos de $n^{\circ}$ de contenedores caja abierta para puntos limpios urbanos.

El valor de significación de la prueba $\mathrm{H}$ de Kruskal-Wallis es de 0,598 , por lo que, nuevamente, se cumple la hipótesis de igualdad entre grupos, no resultando estadísticamente significativo el valor de la variable "número de contenedores caja abierta" sobre TR.

Por tanto, la mayor inversión en contenedores caja abierta no proporciona resultados de TR superiores, por lo que la dotación adecuada de contenedores para cada tipo de punto limpio es de entre 4 y 5 para los que tienen una población adscrita inferior a 5.000 habitantes, entre 4 y 11 si la población adscrita es de entre 5.000 y 50.000 habitantes, y entre 11 y 14 contenedores caja abierta para puntos limpios con población adscrita superior a 50.000 habitantes.

Por lo que se refiere al análisis de significación sobre la variable TV, en las Tablas 5.32, 5.33 y 5.34 se muestran los valores de media y desviación estándar de TV para los puntos limpios 
rurales (menos de 5.000 habitantes), semiurbanos (entre 5.000 y 50.000 habitantes) y urbanos (más de 50.000 habitantes), respectivamente.

\begin{tabular}{|c|c|c|c|c|c|c|c|c|c|}
\hline & \multirow{2}{*}{ Grupo } & \multirow{2}{*}{$\mathbf{N}$} & \multirow{2}{*}{ Media } & \multirow{2}{*}{$\begin{array}{l}\text { Desviación } \\
\text { Estándar }\end{array}$} & \multirow{2}{*}{$\begin{array}{c}\text { Error } \\
\text { Estándar }\end{array}$} & \multicolumn{2}{|c|}{$\begin{array}{c}\text { Intervalo de } \\
\text { Confianza } 95 \% \\
\text { para la Media }\end{array}$} & \multirow{2}{*}{ Mínimo } & \multirow{2}{*}{ Máximo } \\
\hline & & & & & & $\begin{array}{l}\text { Límite } \\
\text { Inferior }\end{array}$ & $\begin{array}{c}\text { Límite } \\
\text { Superior }\end{array}$ & & \\
\hline \multirow{3}{*}{ TV } & 4 cont. C.Ab. & 19 & 56,33 & 22,45 & 5,15 & 45,50 & 67,15 & 8,77 & 90,09 \\
\hline & $>4$ cont. C.Ab. & 4 & 46,73 & 37,52 & 18,76 & $-12,97$ & 106,42 & 15,53 & 101,28 \\
\hline & Total & 23 & 54,66 & 24,86 & 5,18 & 43,90 & 65,41 & 8,77 & 101,28 \\
\hline
\end{tabular}

Tabla 5.32: Media, desviación estándar, error estándar e intervalo de confianza de TV para los grupos de $n^{\circ}$ de contenedores caja abierta para puntos limpios rurales.

\begin{tabular}{|c|c|c|c|c|c|c|c|c|c|}
\hline & \multirow[t]{2}{*}{ Grupo } & \multirow[t]{2}{*}{$\mathbf{N}$} & \multirow[t]{2}{*}{ Media } & \multirow{2}{*}{$\begin{array}{l}\text { Desviación } \\
\text { Estándar }\end{array}$} & \multirow{2}{*}{$\begin{array}{c}\text { Error } \\
\text { Estándar }\end{array}$} & \multicolumn{2}{|c|}{$\begin{array}{c}\text { Intervalo de } \\
\text { Confianza } 95 \% \\
\text { para la Media }\end{array}$} & \multirow[t]{2}{*}{ Mínimo } & \multirow[t]{2}{*}{ Máximo } \\
\hline & & & & & & $\begin{array}{c}\text { Límite } \\
\text { Inferior }\end{array}$ & $\begin{array}{c}\text { Límite } \\
\text { Superior }\end{array}$ & & \\
\hline \multirow{5}{*}{ TV } & $<8$ cont. C.Ab. & 3 & 41,77 & 49,10 & 28,35 & $-80,19$ & 163,73 & 13,27 & 98,46 \\
\hline & 8-10 cont. C.Ab. & 11 & 44,78 & 33,42 & $\frac{20,00}{10,08}$ & 22,33 & 67,23 & 1,82 & 110,66 \\
\hline & 11 cont. C.Ab. & 5 & 36,78 & 14,11 & 6,31 & 18,75 & 53,78 & 17,22 & 51,80 \\
\hline & $>11$ cont. C.Ab. & 3 & 41,34 & 25,26 & 14,58 & $-21,41$ & 104,08 & 16,05 & 66,57 \\
\hline & Total & 22 & 41,97 & 29,53 & 6,30 & 28,87 & 55,06 & 1,82 & 110,66 \\
\hline
\end{tabular}

Tabla 5.33: Media, desviación estándar, error estándar e intervalo de confianza de TV para los grupos de $n^{\circ}$ de contenedores caja abierta para puntos limpios semiurbanos.

\begin{tabular}{|c|c|c|c|c|c|c|c|c|c|}
\hline \multirow{2}{*}{\multicolumn{2}{|c|}{ Grupo }} & \multirow[t]{2}{*}{$\mathbf{N}$} & \multirow[t]{2}{*}{ Media } & \multirow{2}{*}{$\begin{array}{l}\text { Desviación } \\
\text { Estándar }\end{array}$} & \multirow{2}{*}{$\begin{array}{c}\text { Error } \\
\text { Estándar }\end{array}$} & \multicolumn{2}{|c|}{$\begin{array}{c}\text { Intervalo de } \\
\text { Confianza 95\% } \\
\text { para la Media }\end{array}$} & \multirow[t]{2}{*}{ Mínimo } & \multirow[t]{2}{*}{ Máximo } \\
\hline & & & & & & $\begin{array}{l}\text { Límite } \\
\text { Inferior }\end{array}$ & $\begin{array}{c}\text { Límite } \\
\text { Superior }\end{array}$ & & \\
\hline \multirow{5}{*}{ TV } & $<7$ cont. C.Ab. & 4 & 14,34 & 3,71 & 1,85 & 8,44 & 20,24 & 10,54 & 19,39 \\
\hline & 7-10 cont. C.Ab. & 5 & 15,75 & 5,14 & 2,30 & 9,37 & 22,14 & 10,39 & 22,31 \\
\hline & 11-14 cont. C.Ab. & 6 & 13,93 & 12,13 & 4,95 & 1,21 & 26,66 & 3,35 & 33,78 \\
\hline & $>14$ cont. C.Ab. & 5 & 14,83 & 16,66 & 7,45 & $-5,85$ & 35,51 & 3,08 & 42,79 \\
\hline & Total & 20 & 14,69 & 10,26 & 2,30 & 9,39 & 19,50 & 3,08 & 42,79 \\
\hline
\end{tabular}

Tabla 5.34: Media, desviación estándar, error estándar e intervalo de confianza de TV para los grupos de $n^{\circ}$ de contenedores caja abierta para puntos limpios urbanos.

Para los puntos limpios con población adscrita inferior a 5.000 habitantes, el valor de significación del test Levene es de 0,256, superior a 0,05, por lo que se valida el supuesto de homocedasticidad. En cuanto a la igualdad entre grupos, el valor de significación del test ANOVA es de 0,496 $(>0,05)$, por lo que se valida la hipótesis nula.

En cuanto a los puntos limpios con población adscrita de entre 5.000 y 50.000 habitantes, el valor de significación del test de Levene es de 0,188 $(>0,05)$, por lo que existe homogeneidad de 
varianzas entre los grupos. El valor de significación de la prueba ANOVA es $0,968 \quad(>0,05)$, validándose igualmente la hipótesis nula de igualdad entre grupos.

Los subgrupos en los que se ha dividido la muestra de puntos limpios con población adscrita superior a 50.000 habitantes presentan homogeneidad de varianzas (valor de significación del test de Levene de 0,062). A continuación, se valida asimismo la hipótesis de igualdad entre grupos mediante el test ANOVA, cuyo resultado de significación es 0,994 $(>0,05)$.

Por tanto, el aumento de dotación de contenedores caja abierta no influye de forma significativa sobre los resultados de TV en los tres grupos analizados. Así, el número de contenedores caja abierta adecuado para cada tamaño de punto limpio es de 4 unidades en puntos limpios rurales, entre 8 y 10 para los semiurbanos, y entre 7 y 10 para los urbanos.

Teniendo en cuenta los resultados de la variable sobre TR y sobre TV, en la Tabla 5.35 se muestran los valores óptimos de número de contenedores para cada tamaño de población adscrita al punto limpio.

\begin{tabular}{|c|c|}
\hline Tamaño población & N. $^{\circ}$ contenedores caja abierta \\
\hline$<5.000 \mathrm{hab}$ & $4-5$ \\
\hline $5.000-50.000 \mathrm{hab}$. & $4-11$ \\
\hline$>50.000 \mathrm{hab}$ & $7-14$ \\
\hline
\end{tabular}

Tabla 5.35: Número de contenedores caja abierta adecuado por población adscrita.

\subsubsection{Superficie del punto limpio.}

La superficie necesaria para la instalación del punto limpio será uno de los factores que condicione en mayor medida la determinación de la localización final, en función de la disponibilidad de suelo con que cuente la Administración competente; además, se encuentra íntimamente ligada al diseño y distribución interior, así como con el equipamiento con que se dotará a la instalación, por lo que constituye uno de los parámetros básicos de partida para el proyecto de un punto limpio. La variable presenta en la muestra 55 valores distintos, tal y como puede observarse en el Gráfico 5.10. 


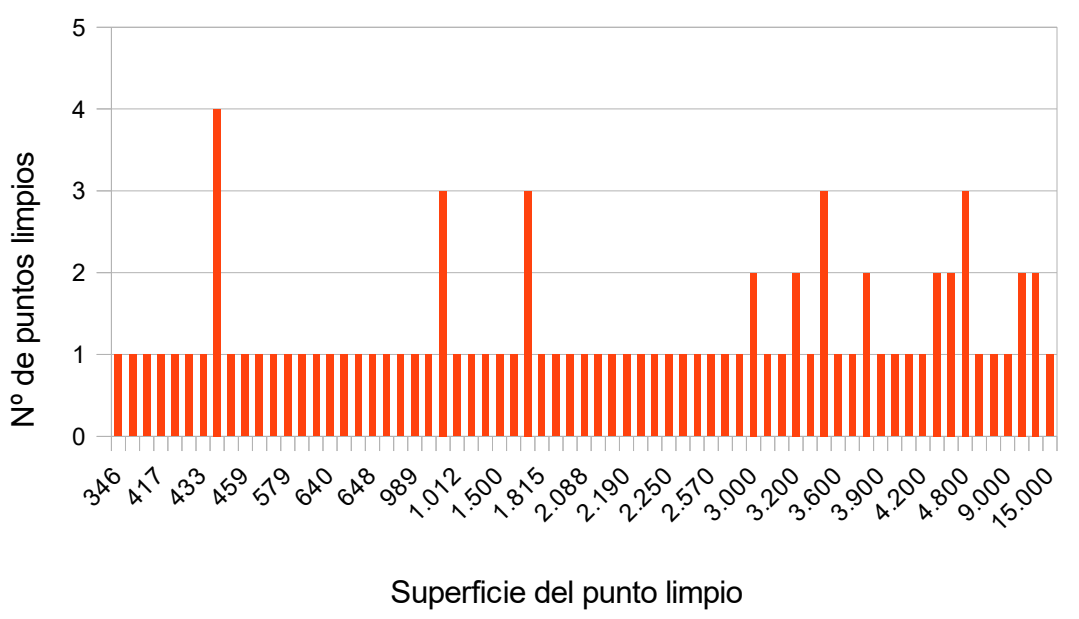

Gráfico 5.10: Número de puntos limpios por superficie.

Resulta evidente la necesidad de establecer criterios de agrupación de los puntos limpios, con el objetivo de poder llevar a cabo los análisis de significación de la variable sobre TR y TV. Además, puesto que a igualdad de dichas variables, los valores absolutos de visitas recibidas y cantidades de residuos gestionados mantienen una relación de proporcionalidad respecto de la población adscrita, las necesidades de espacio disponible se verán incrementadas en la medida en que la población adscrita sea superior, por lo que, como sucedía con la variable número de contenedores caja abierta, se establece un primer nivel de agrupación en función de la población adscrita. En la Tabla 5.36 se indican los grupos en que se dividirá la muestra.

\begin{tabular}{|l|c|c|c|c|}
\hline \multicolumn{1}{|c|}{ Tamaño } & Grupo 1 & Grupo 2 & Grupo 3 & Grupo 4 \\
\hline Rural & $<450 \mathrm{~m}^{2}$ & \multicolumn{2}{|c|}{$450 \leq \mathrm{x} \leq 900 \mathrm{~m}^{2}$} & $>900 \mathrm{~m}^{2}$ \\
\hline Semiurbano & $<1.800 \mathrm{~m}^{2}$ & $1.800 \leq \mathrm{x} \leq 3.000 \mathrm{~m}^{2}$ & $3.000 \leq \mathrm{x} \leq 4.100 \mathrm{~m}^{2}$ & $>4.100 \mathrm{~m}^{2}$ \\
\hline Urbano & $<1.800 \mathrm{~m}^{2}$ & $1.800 \leq \mathrm{x} \leq 3.200 \mathrm{~m}^{2}$ & $3.200 \leq \mathrm{x} \leq 4.500 \mathrm{~m}^{2}$ & $>4.500 \mathrm{~m}^{2}$ \\
\hline
\end{tabular}

Tabla 5.36: Clasificación de puntos limpios por superficie y tamaño de población adscrita.

Para los puntos limpios con población adscrita inferior a 5.000 habitantes, se obtienen los valores de media y desviación estándar de TR que se muestran en la Tabla 5.37. 


\begin{tabular}{|c|c|c|c|c|c|c|c|c|c|}
\hline & Grupo & $\mathbf{N}$ & Media & $\begin{array}{l}\text { Desviación } \\
\text { Estándar }\end{array}$ & $\begin{array}{c}\text { Error } \\
\text { Estándar }\end{array}$ & $\begin{array}{r}\text { Inter } \\
\text { Confia } \\
\text { para I }\end{array}$ & $\begin{array}{l}\text { lo de } \\
\text { za } 95 \% \\
\text { Media }\end{array}$ & Mínimo & Máximo \\
\hline & & & & & & $\begin{array}{l}\text { Límite } \\
\text { Inferior }\end{array}$ & $\begin{array}{l}\text { Límite } \\
\text { Superior }\end{array}$ & & \\
\hline & $<450 \mathrm{~m}^{2}$ & 11 & 107,16 & 34,78 & 10,49 & 83,79 & 130,53 & 51,35 & 161,34 \\
\hline & $450-900 \mathrm{~m}^{2}$ & 7 & 143,64 & 40,98 & 40,98 & 43,38 & 243,91 & 60,98 & 335,88 \\
\hline TR & $>900 \mathrm{~m}^{2}$ & 6 & 278,20 & 85,19 & 85,19 & 59,22 & 497,19 & 99,93 & 628,02 \\
\hline & Total & 24 & 160,56 & 134,61 & 27,48 & 103,72 & 217,40 & 51,35 & 628,02 \\
\hline
\end{tabular}

Tabla 5.37: Media, desviación estándar, error estándar e intervalo de confianza de TR para los grupos de superficie para puntos limpios rurales.

La prueba $\mathrm{H}$ de Kruskal-Wallis resulta con un valor de significación de 0,118 , por lo que se acepta la hipótesis de igualdad entre grupos.

Para los puntos limpios con población adscrita de entre 5.000 y 50.000 habitantes, los valores de media y desviación estándar de TR son los mostrados en la Tabla 5.38.

\begin{tabular}{|c|c|c|c|c|c|c|c|c|c|}
\hline & \multirow[t]{2}{*}{ Grupo } & \multirow[t]{2}{*}{$\mathbf{N}$} & \multirow[t]{2}{*}{ Media } & \multirow{2}{*}{$\begin{array}{l}\text { Desviación } \\
\text { Estándar }\end{array}$} & \multirow{2}{*}{$\begin{array}{c}\text { Error } \\
\text { Estándar }\end{array}$} & \multicolumn{2}{|c|}{$\begin{array}{c}\text { Intervalo de } \\
\text { Confianza } 95 \% \\
\text { para la Media }\end{array}$} & \multirow[t]{2}{*}{ Mínimo } & \multirow[t]{2}{*}{ Máximo } \\
\hline & & & & & & $\begin{array}{l}\text { Límite } \\
\text { Inferior }\end{array}$ & $\begin{array}{l}\text { Límite } \\
\text { Superior }\end{array}$ & & \\
\hline \multirow{5}{*}{ TR } & $<1.800 \mathrm{~m}^{2}$ & 7 & 121,48 & 88,48 & 33,44 & 39,65 & 203,31 & 55,88 & 275,38 \\
\hline & $1.800-3.000 \mathrm{~m}^{2}$ & 12 & 144,37 & 167,77 & 48,43 & 37,78 & 250,97 & 22,41 & 580,66 \\
\hline & $3.000-4.100 \mathrm{~m}^{2}$ & 9 & 77,50 & 88,61 & 29,54 & 9,38 & 145,61 & 16,79 & 281,66 \\
\hline & $>4.100 \mathrm{~m}^{2}$ & 8 & 93,14 & 75,33 & 26,63 & 30,16 & 156,11 & 20,70 & 251,74 \\
\hline & Total & 36 & 111,82 & 117,82 & 19,64 & 71,95 & 151,68 & 16,79 & 580,66 \\
\hline
\end{tabular}

Tabla 5.38: Media, desviación estándar, error estándar e intervalo de confianza de TR para los grupos de superficie para puntos limpios semiurbanos.

En este caso, el valor de significación de la prueba $\mathrm{H}$ de Kruskal-Wallis es de 0,406 , por lo que se acepta la hipótesis de igualdad entre grupos.

Para los puntos limpios con población adscrita superior a 50.000 habitantes, la media y desviación estándar de TR son las que se detallan en la Tabla 5.39. 
Estudio de los puntos limpios implantados en España.

\begin{tabular}{|c|c|c|c|c|c|c|c|c|c|}
\hline \multirow{2}{*}{\multicolumn{2}{|c|}{ Grupo }} & \multirow[t]{2}{*}{$\mathbf{N}$} & \multirow[t]{2}{*}{ Media } & \multirow{2}{*}{$\begin{array}{l}\text { Desviación } \\
\text { Estándar }\end{array}$} & \multirow{2}{*}{$\begin{array}{c}\text { Error } \\
\text { Estándar }\end{array}$} & \multicolumn{2}{|c|}{$\begin{array}{c}\text { Intervalo de } \\
\text { Confianza } 95 \% \\
\text { para la Media }\end{array}$} & \multirow[t]{2}{*}{ Mínimo } & \multirow[t]{2}{*}{ Máximo } \\
\hline & & & & & & $\begin{array}{l}\text { Límite } \\
\text { Inferior }\end{array}$ & $\begin{array}{c}\text { Límite } \\
\text { Superior }\end{array}$ & & \\
\hline \multirow{5}{*}{ TR } & $<1.800 \mathrm{~m}^{2}$ & 5 & 66,06 & 39,26 & 17,56 & 17,30 & 114,81 & 13,01 & 123,72 \\
\hline & $1.800-3.200 \mathrm{~m}^{2}$ & 7 & 135,83 & 108,83 & 41,13 & 35,17 & 236,48 & 38,27 & 337,77 \\
\hline & $3.200-4.500 \mathrm{~m}^{2}$ & 5 & 39,19 & 26,39 & 11,80 & 6,41 & 71,96 & 11,49 & 82,04 \\
\hline & $>4.500 \mathrm{~m}^{2}$ & 4 & 29,79 & 26,60 & 13,30 & $-12,53$ & 72,12 & 8,42 & 63,35 \\
\hline & Total & 21 & 76,01 & 78,42 & 17,11 & 40,31 & 111,71 & 8,42 & 337,77 \\
\hline
\end{tabular}

Tabla 5.39: Media, desviación estándar, error estándar e intervalo de confianza de TR para los grupos de superficie para puntos limpios urbanos.

El valor de significación de la prueba $\mathrm{H}$ de Kruskal-Wallis es de 0,056, por lo que, nuevamente, se cumple la hipótesis de igualdad entre grupos, no resultando estadísticamente significativo el valor de la variable superficie sobre TR.

Por tanto, en ningún caso la mayor dotación de superficie para la construcción del punto limpio presenta significación sobre TR, por lo que es posible establecer rangos de superficie para los cuales los resultados son satisfactorios: en puntos limpios con población adscrita inferior a 5.000 habitantes, los mejores resultados se obtienen con superficies superiores a $450 \mathrm{~m}^{2}$; para puntos limpios con población adscrita de entre 5.000 y 50.000 habitantes, la superficie máxima deberá ser de $3.000 \mathrm{~m}^{2}$; mientras que para puntos limpios con más de 50.000 habitantes, los valores de TR máximos se obtienen si la superficie es de entre 1.800 y $3.200 \mathrm{~m}^{2}$.

Por lo que se refiere al análisis de significación sobre la variable TV, en las Tablas 5.40, 5.41 y 5.42 se muestran los valores de media y desviación estándar de TV para cada los puntos limpios rurales (menos de 5.000 habitantes), semiurbanos (entre 5.000 y 50.000 habitantes) y urbanos (más de 50.000 habitantes), respectivamente. En el grupo intermedio se ha efectuado una reagrupación de las instalaciones en 2 segmentos, debido al reducido número de casos disponibles, mientras que en los puntos limpios con más de 50.000 habitantes el número de grupos se ha reducido a 3 por el mismo motivo.

\begin{tabular}{|c|c|c|c|c|c|c|c|c|c|}
\hline & \multirow[t]{2}{*}{ Grupo } & \multirow[t]{2}{*}{$\mathbf{N}$} & \multirow[t]{2}{*}{ Media } & \multirow{2}{*}{$\begin{array}{l}\text { Desviación } \\
\text { Estándar }\end{array}$} & \multirow[t]{2}{*}{$\begin{array}{c}\text { Error } \\
\text { Estándar }\end{array}$} & \multicolumn{2}{|c|}{$\begin{array}{c}\text { Intervalo de } \\
\text { Confianza } 95 \% \\
\text { para la Media }\end{array}$} & \multirow[t]{2}{*}{ Mínimo } & \multirow[t]{2}{*}{ Máximo } \\
\hline & & & & & & $\begin{array}{l}\text { Límite } \\
\text { Inferior }\end{array}$ & $\begin{array}{l}\text { Límite } \\
\text { Superior }\end{array}$ & & \\
\hline \multirow{4}{*}{ TV } & $<450 \mathrm{~m}^{2}$ & 11 & 57,77 & 26,15 & 7,88 & 40,21 & 75,34 & 8,77 & 90,09 \\
\hline & $450-900 \mathrm{~m}^{2}$ & 7 & 49,32 & 16,93 & 6,40 & 33,67 & 64,98 & 34,67 & 80,83 \\
\hline & $>900 \mathrm{~m}^{2}$ & 5 & 55,27 & 34,41 & 15,39 & 12,54 & 98,00 & 15,53 & 101,28 \\
\hline & Total & 23 & 54,66 & 24,86 & 5,18 & 43,90 & 65,41 & 8,77 & 101,28 \\
\hline
\end{tabular}

Tabla 5.40: Media, desviación estándar, error estándar e intervalo de confianza de TV para los grupos de superficie para puntos limpios rurales. 


\begin{tabular}{|c|c|c|c|c|c|c|c|c|c|}
\hline & Grupo & $\mathbf{N}$ & Media & Desviación & $\begin{array}{l}\text { Error } \\
\text { Estándar }\end{array}$ & $\begin{array}{c}\text { Inter } \\
\text { Confia } \\
\text { para }\end{array}$ & $\begin{array}{l}\text { alo de } \\
\text { Iza } 95 \% \\
\text { Media }\end{array}$ & Mínimo & Máximo \\
\hline & & & & & & $\begin{array}{l}\text { Límite } \\
\text { Inferior }\end{array}$ & $\begin{array}{c}\text { Límite } \\
\text { Superior }\end{array}$ & & \\
\hline & $<3.000 \mathrm{~m}^{2}$ & 13 & 52,36 & 31,43 & 8,72 & 33,36 & 71,35 & 13,27 & 110,66 \\
\hline TV & $>3.000 \mathrm{~m}^{2}$ & 9 & 26,95 & 19,44 & 6,48 & 12,01 & 41,90 & 1,82 & 57,70 \\
\hline & Total & 22 & 41,96 & 29,53 & 6,30 & 28,87 & 55,06 & 1,82 & 110,66 \\
\hline
\end{tabular}

Tabla 5.41: Media, desviación estándar, error estándar e intervalo de confianza de TV para los grupos de superficie para puntos limpios semiurbanos.

\begin{tabular}{|c|c|c|c|c|c|c|c|c|c|}
\hline \multirow{2}{*}{\multicolumn{2}{|c|}{ Grupo }} & \multirow[t]{2}{*}{$\mathbf{N}$} & \multirow[t]{2}{*}{ Media } & \multirow{2}{*}{$\begin{array}{l}\text { Desviación } \\
\text { Estándar }\end{array}$} & \multirow{2}{*}{$\begin{array}{c}\text { Error } \\
\text { Estándar }\end{array}$} & \multicolumn{2}{|c|}{$\begin{array}{c}\text { Intervalo de } \\
\text { Confianza 95\% } \\
\text { para la Media }\end{array}$} & \multirow[t]{2}{*}{ Mínimo } & \multirow[t]{2}{*}{ Máximo } \\
\hline & & & & & & $\begin{array}{l}\text { Límite } \\
\text { Inferior }\end{array}$ & $\begin{array}{l}\text { Límite } \\
\text { Superior }\end{array}$ & & \\
\hline \multirow{4}{*}{ TV } & $<1.800 \mathrm{~m}^{2}$ & 5 & 13,55 & 3,66 & 1,64 & 9,00 & 18,10 & 10,39 & 19,39 \\
\hline & $1.800-3.200 \mathrm{~m}^{2}$ & 6 & 18,53 & 9,81 & 4,01 & 8,23 & 28,83 & 6,56 & 33,78 \\
\hline & $>3.200 \mathrm{~m}^{2}$ & 6 & 13,60 & 16,08 & 6,56 & $-3,27$ & 30,48 & 3,08 & 42,79 \\
\hline & Total & 17 & 15,33 & 10,96 & 2,66 & 9,69 & 20,96 & 3,08 & 42,79 \\
\hline
\end{tabular}

Tabla 5.42: Media, desviación estándar, error estándar e intervalo de confianza de TV para los grupos de superficie para puntos limpios urbanos.

Para los puntos limpios con población adscrita inferior a 5.000 habitantes, el valor de significación del test Levene es de 0,131, superior a 0,05 , por lo que se valida el supuesto de homocedasticidad. En cuanto a la igualdad entre grupos, el valor de significación del test ANOVA es de 0,795 $(>0,05)$, por lo que se acepta la hipótesis nula.

En cuanto a los puntos limpios con población adscrita de entre 5.000 y 50.000 habitantes, el valor de significación del test de Levene es de 0,290 (>0,05), por lo que existe homogeneidad de varianzas entre los grupos. El valor de significación de la prueba ANOVA es $0,044(<0,05)$, por lo que existe significación de la variable superficie sobre TV, siendo la media superior en los puntos limpios con menos de $3.000 \mathrm{~m}^{2}$; la superficie media de estas instalaciones es de $1.800 \mathrm{~m}^{2}$.

Los subgrupos en que se ha dividido la muestra de puntos limpios con población adscrita superior a 50.000 habitantes presentan homogeneidad de varianzas (valor de significación del test de Levene de 0,051). A continuación, se valida asimismo la hipótesis de igualdad entre grupos mediante el test ANOVA, cuyo resultado de significación es 0,701 .

Por tanto, únicamente se observa significación de la variable superficie sobre TV en los puntos limpios de entre 5.000 y 50.000 habitantes, en que se obtienen mejores resultados en las instalaciones con superficie inferior a $3.000 \mathrm{~m}^{2}$, por lo que el aumento de superficie no conlleva un incremento de los valores de TV. 
Teniendo en cuenta los resultados de la variable sobre TR y sobre TV, en la Tabla 5.43 se muestran los valores óptimos de superficie para cada tamaño de población adscrita al punto limpio.

\begin{tabular}{|c|c|}
\hline Tamaño población & Superficie \\
\hline$<5.000$ hab & $450 \leq x \leq 900 \mathrm{~m}^{2}$ \\
\hline $5.000-50.000$ hab. & $\mathrm{x} \leq 3.000 \mathrm{~m}^{2}$ \\
\hline$>50.000 \mathrm{hab}$ & $1.800 \leq \mathrm{x} \leq 3.200 \mathrm{~m}^{2}$ \\
\hline
\end{tabular}

Tabla 5.43: Superficies adecuadas por población adscrita.

Para los puntos limpios con entre 5.000 y 50.000 habitantes, los valores máximos de TR y TV se alcanzan para el grupo de puntos limpios con entre 1.800 y $3.000 \mathrm{~m}^{2}$, por tanto, se considera que la superficie mínima deseable es de $1.800 \mathrm{~m}^{2}$.

En cuanto a los puntos limpios de menos de 5.000 habitantes, la superficie media de la muestra es de $700 \mathrm{~m}^{2}$, debido a la existencia de instalaciones con hasta $2.475 \mathrm{~m}^{2}$ de superficie, valor que se encuentra demasiado alejado de las conclusiones del estudio realizado. En los casos en que se prevea una elevada afluencia de usuarios o de recepción de residuos, la superficie mínima de la instalación podría incrementarse hasta los $700 \mathrm{~m}^{2}$ de la media de la muestra, sin elevar la superficie máxima, puesto que se ha comprobado que no resulta eficiente; en estos casos, es más recomendable realizar una correcta planificación de los servicios que presta el punto limpio.

Idéntica reflexión puede realizarse para los puntos limpios de más de 50.000 habitantes, para los que existen casos en la muestra que cuentan con hasta $9.900 \mathrm{~m}^{2}$. En este caso, la superficie mínima podría incrementarse hasta los $2.500 \mathrm{~m}^{2}$ de la media, descartados los 2 puntos limpios con 9.000 y $9.900 \mathrm{~m}^{2}$, pero la dotación de más de $3.200 \mathrm{~m}^{2}$ no resulta eficiente.

\subsubsection{Punto limpio móvil asociado.}

Los puntos limpios objeto de la encuesta han sido en todos los casos instalaciones fijas. En este punto se estudia si el hecho de que dichas instalaciones cuenten con un servicio complementario de punto limpio móvil, resulta significativo para el grado de utilización y cantidades de residuos depositadas en los puntos limpios fijos.

Podría esperarse que, si se dispone de punto limpio móvil, en el que pueden depositarse pequeñas cantidades de residuos, principalmente de origen doméstico, más habituales (pilas, bombillas, pequeños electrodomésticos), las variables TR y TV aumenten. Además, considerando 
que la proximidad que aportan los puntos limpios móviles puede mejorar los niveles de concienciación de los usuarios y conocimiento del servicio, podría esperarse que los resultados de las variables fuesen superiores en los casos en que se dispone de punto limpio móvil.

En la Tabla 5.44 se muestran los valores de media y desviación estándar de TR en función de si los puntos limpios cuentan con punto limpio móvil asociado.

\begin{tabular}{|c|c|c|c|c|c|c|c|c|c|}
\hline & \multirow[t]{2}{*}{ Grupo } & \multirow[t]{2}{*}{$\mathbf{N}$} & \multirow[t]{2}{*}{ Media } & \multirow{2}{*}{$\begin{array}{l}\text { Desviación } \\
\text { Estándar }\end{array}$} & \multirow{2}{*}{$\begin{array}{c}\text { Error } \\
\text { Estándar }\end{array}$} & \multicolumn{2}{|c|}{$\begin{array}{c}\text { Intervalo de } \\
\text { Confianza } 95 \% \\
\text { para la Media }\end{array}$} & \multirow[t]{2}{*}{ Mínimo } & \multirow[t]{2}{*}{ Máximo } \\
\hline & & & & & & $\begin{array}{l}\text { Límite } \\
\text { Inferior }\end{array}$ & $\begin{array}{l}\text { Límite } \\
\text { Superior }\end{array}$ & & \\
\hline \multirow{3}{*}{ TR } & SIN PL móvil & 38 & 109,74 & 123,83 & 20,09 & 69,04 & 150,44 & 13,01 & 628,02 \\
\hline & CON PL móvil & 44 & 120,69 & 113,09 & 17,05 & 86,31 & 155,07 & 5,43 & 580,66 \\
\hline & Total & 82 & 115,62 & 117,57 & 12,98 & 89,78 & 141,45 & 5,43 & 628,02 \\
\hline
\end{tabular}

Tabla 5.44: Media, desviación estándar, error estándar e intervalo de confianza de TR para los grupos de disponibilidad de punto limpio móvil asociado.

Pese a observarse una media de TR superior y una desviación estándar inferior en los puntos limpios que cuentan con punto limpio móvil asociado, el resultado de significación de la prueba $\mathrm{H}$ de Kruskal-Wallis es de 0,320, por lo que se da por buena la hipótesis nula de igualdad entre grupos. Por tanto, no hay diferencias en las cantidades recogidas cuando se dispone de punto limpio móvil asociado.

En cuanto a TV, el comportamiento aparente observado es el contrario: la media de TV disminuye y la desviación estándar aumenta para los puntos limpios con punto limpio móvil asociado. Los valores se muestran en la Tabla 5.45 .

\begin{tabular}{|c|c|c|c|c|c|c|c|c|c|}
\hline & \multirow{2}{*}{ Grupo } & \multirow{2}{*}{$\mathbf{N}$} & \multirow{2}{*}{ Media } & \multirow{2}{*}{$\begin{array}{l}\text { Desviación } \\
\text { Estándar }\end{array}$} & \multirow{2}{*}{$\begin{array}{c}\text { Error } \\
\text { Estándar }\end{array}$} & \multicolumn{2}{|c|}{$\begin{array}{c}\text { Intervalo de } \\
\text { Confianza } 95 \% \\
\text { para la Media }\end{array}$} & \multirow{2}{*}{ Mínimo } & \multirow{2}{*}{ Máximo } \\
\hline & & & & & & $\begin{array}{l}\text { Límite } \\
\text { Inferior }\end{array}$ & $\begin{array}{c}\text { Límite } \\
\text { Superior }\end{array}$ & & \\
\hline \multirow{3}{*}{ TV } & SIN PL móvil & 27 & 40,43 & 27,61 & 5,31 & 29,51 & 51,35 & 1,82 & 90,09 \\
\hline & CON PL móvil & 37 & 36,77 & 29,45 & 4,84 & 26,95 & 46,59 & 3,08 & 110,66 \\
\hline & Total & 64 & 38,31 & 28,52 & 3,57 & 31,19 & 45,44 & 1,82 & 110,66 \\
\hline
\end{tabular}

Tabla 5.45: Media, desviación estándar, error estándar e intervalo de confianza de TV para los grupos de disponibilidad de punto limpio móvil asociado.

El resultado del test de Levene de homogeneidad de varianzas es 0,973 $(>0,05)$, lo que valida la hipótesis nula. A continuación, tras la aplicación del test ANOVA, el resultado de significación es de 0,616 , por lo que se considera válida la hipótesis nula de igualdad entre grupos. Por tanto, la 
variable de disponibilidad de punto limpio móvil asociado no presenta significación estadística sobre TV, por lo que la existencia de punto limpio móvil asociado no modifica los resultados de dicha variable.

La existencia de punto limpio móvil no altera el funcionamiento del punto limpio fijo. No obstante se considera como refuerzo al servicio principal y en algunos casos solución para atender áreas diseminadas o no atendidas. Además, al realizar ese servicio de forma más próxima y poder recoger residuos de tamaño menor, se evitan desplazamientos al punto limpio fijo con lo que ello supone de reducción de flujos de vehículos y reducción de la contaminación.

\subsubsection{Análisis de TR y TV en función de los factores de funcionamiento de los puntos limpios.}

En este apartado se estudia la relevancia estadística de factores relacionados con las condiciones de funcionamiento de los puntos limpios sobre los resultados de TR y TV.

\subsubsection{Horario de apertura.}

Se analiza en este punto la influencia sobre la frecuencia de uso del punto limpio y la cantidad de residuos depositados en el mismo, considerando como factor los días de la semana en que la instalación se encuentra abierta. El objetivo es tratar de determinar si existen patrones de frecuencia de uso, en función del día de la semana que se trate, que maximizan la afluencia de usuarios a los puntos limpios.

En la Tabla 5.46 se muestra la cantidad de instalaciones que están abiertas o cerradas cada día de la semana. Se observa que el mayor número de instalaciones cierra los domingos (56), seguido con un elevado número de instalaciones cerradas los lunes (17).

\begin{tabular}{|l|r|r|r|r|r|r|r|}
\hline \multicolumn{1}{|c|}{ Apertura } & Lunes & Martes & Miércoles & Jueves & Viernes & \multicolumn{1}{c|}{ Sábado } & Domingo \\
\hline Abierto & 67 & 80 & 81 & 80 & 82 & 79 & 28 \\
\hline Cerrado & 17 & 4 & 3 & 4 & 2 & 5 & 56 \\
\hline Total & 84 & 84 & 84 & 84 & 84 & 84 & 84 \\
\hline
\end{tabular}

Tabla 5.46: TR. Número de puntos limpios abiertos y cerrados por día de la semana.

Se observa que entre el $94 \%$ y el $98 \%$ de los puntos limpios se encuentran abiertos los martes, miércoles, jueves, viernes y sábado, al integrarse en los respectivos grupos que conforman la parte de la muestra correspondiente a los puntos limpios que se encuentran cerrados únicamente 
entre 2 y 5 casos, por lo que el estudio estadístico de significación para estos días no resulta viable. Por lo que se refiere a los lunes, es mayoritario el grupo de puntos limpios que se encuentran abiertos, mientras que los domingos se encuentran, en su mayoría, cerrados. Así pues, se analizará la significación sobre TR de la apertura del punto limpio en lunes y en domingo.

En las Tablas 5.47 y 5.48 se presentan los valores de media y desviación estándar de TR en cada uno de los casos analizados.

\begin{tabular}{|c|c|c|c|c|c|c|c|c|c|}
\hline & \multirow[t]{2}{*}{ Lunes } & \multirow[t]{2}{*}{$\mathbf{N}$} & \multirow[t]{2}{*}{ Media } & \multirow{2}{*}{$\begin{array}{l}\text { Desviación } \\
\text { Estándar }\end{array}$} & \multirow{2}{*}{$\begin{array}{c}\text { Error } \\
\text { Estándar }\end{array}$} & \multicolumn{2}{|c|}{$\begin{array}{c}\text { Intervalo de } \\
\text { Confianza 95\% } \\
\text { para la Media }\end{array}$} & \multirow[t]{2}{*}{ Mínimo } & \multirow[t]{2}{*}{ Máximo } \\
\hline & & & & & & $\begin{array}{l}\text { Límite } \\
\text { Inferior }\end{array}$ & $\begin{array}{l}\text { Límite } \\
\text { Superior }\end{array}$ & & \\
\hline \multirow{3}{*}{ TR } & Cerrado & 17 & 71,56 & 54,73 & 13,27 & 43,42 & 99,70 & 11,49 & 161,34 \\
\hline & Abierto & 67 & 127,91 & 125,08 & 15,28 & 97,40 & 158,42 & 5,43 & 628,02 \\
\hline & Total & 84 & 116,51 & 116,35 & 12,69 & 91,26 & 141,76 & 5,43 & 628,02 \\
\hline
\end{tabular}

Tabla 5.47: Media, desviación estándar, error estándar e intervalo de confianza de TR para los grupos de apertura en lunes.

Para validar la hipótesis nula de igualdad de los subgrupos, se realiza la prueba $\mathrm{H}$ de KruskalWallis, cuyos resultados proporcionan un valor de significación de 0,065 $(>0,05)$, por lo que en términos estadísticos, no resulta significativo sobre TR que el punto limpio se encuentre abierto o cerrado los lunes, aunque sí se observa una influencia próxima a la significación, con la media de TR superior para los puntos limpios que se encuentran abiertos. Por tanto, se considera adecuado la apertura de las instalaciones en lunes para aumentar los resultados de TR.

\begin{tabular}{|c|c|c|c|c|c|c|c|c|c|}
\hline & \multirow[t]{2}{*}{ Domingo } & \multirow[t]{2}{*}{$\mathbf{N}$} & \multirow[t]{2}{*}{ Media } & \multirow{2}{*}{$\begin{array}{l}\text { Desviación } \\
\text { Estándar }\end{array}$} & \multirow{2}{*}{$\begin{array}{c}\text { Error } \\
\text { Estándar }\end{array}$} & \multicolumn{2}{|c|}{$\begin{array}{c}\text { Intervalo de } \\
\text { Confianza } 95 \% \\
\text { para la Media }\end{array}$} & \multirow[t]{2}{*}{ Mínimo } & \multirow[t]{2}{*}{ Máximo } \\
\hline & & & & & & $\begin{array}{l}\text { Límite } \\
\text { Inferior }\end{array}$ & $\begin{array}{l}\text { Límite } \\
\text { Superior }\end{array}$ & & \\
\hline \multirow{3}{*}{ TR } & Cerrado & 56 & 116,05 & 106,14 & 14,18 & 87,62 & 144,47 & 5,43 & 628,02 \\
\hline & Abierto & 28 & 117,42 & 136,62 & 25,82 & 64,44 & 170,40 & 8,42 & 580,66 \\
\hline & Total & 84 & 116,51 & 116,35 & 12,69 & 91,26 & 141,76 & 5,43 & 628,02 \\
\hline
\end{tabular}

Tabla 5.48: Media, desviación estándar, error estándar e intervalo de confianza de TR para los grupos de apertura en domingo.

Respecto al domingo, para validar la hipótesis nula de igualdad de los subgrupos, se realiza la prueba $\mathrm{H}$ de Kruskal-Wallis, cuyo resultado de significación es $0,263(>0,05)$, por lo que en términos estadísticos, no resulta significativo sobre TR que el punto limpio se encuentre abierto o cerrado los domingos. Se observa que los valores de la media de TR son similares. 
Por lo que respecta a la significación estadística sobre TV del horario de apertura de la instalación, en primer lugar se analiza la homogeneidad de respuestas, con el objetivo de establecer las situaciones cuyo análisis es viable en términos estadísticos. En la Tabla 5.49 se muestra el número de puntos limpios que disponen de valor considerado válido de TV y se encuentran abiertos cada día de la semana.

\begin{tabular}{|l|r|r|r|r|r|r|r|}
\hline \multicolumn{1}{|c|}{ Apertura } & \multicolumn{1}{c|}{ Lunes } & \multicolumn{1}{c|}{ Martes } & Miércoles & Jueves & Viernes & Sábado & Domingo \\
\hline Abierto & 53 & 61 & 62 & 61 & 63 & 60 & 22 \\
\hline Cerrado & 12 & 4 & 3 & 4 & 2 & 5 & 43 \\
\hline & 65 & 65 & 65 & 65 & 65 & 65 & 65 \\
\hline
\end{tabular}

Tabla 5.49: TV. Número de puntos limpios abiertos y cerrados por día de la semana.

Se observa que entre el $92 \%$ y el $97 \%$ de los puntos limpios se encuentran abiertos los martes, miércoles, jueves, viernes y sábado, permaneciendo cerrados entre 2 y 5 puntos limpios, por lo que el estudio de significación estadística para estos días no resulta viable. En cuanto a los lunes, es mayoritario el grupo de puntos limpios que se encuentran abiertos, mientras que los domingos se encuentran, en su mayoría, cerrados. Por tanto, se analizará la igualdad de grupos de la muestra, teniendo en cuenta la apertura del punto limpio en lunes y en domingo y los valores de TV.

En las Tablas 5.50 y 5.51 se muestran los resultados de media y desviación estándar de TV para cada una de las situaciones analizadas.

\begin{tabular}{|c|c|c|c|c|c|c|c|c|c|}
\hline & \multirow[t]{2}{*}{ Lunes } & \multirow[t]{2}{*}{$\mathbf{N}$} & \multirow[t]{2}{*}{ Media } & \multirow{2}{*}{$\begin{array}{l}\text { Desviación } \\
\text { Estándar }\end{array}$} & \multirow{2}{*}{$\begin{array}{c}\text { Error } \\
\text { Estándar }\end{array}$} & \multicolumn{2}{|c|}{$\begin{array}{c}\text { Intervalo de } \\
\text { Confianza } 95 \% \\
\text { para la Media }\end{array}$} & \multirow[t]{2}{*}{ Mínimo } & \multirow[t]{2}{*}{ Máximo } \\
\hline & & & & & & $\begin{array}{l}\text { Límite } \\
\text { Inferior }\end{array}$ & $\begin{array}{l}\text { Límite } \\
\text { Superior }\end{array}$ & & \\
\hline \multirow{3}{*}{ TV } & Cerrado & 12 & 37,37 & 30,16 & 8,71 & 18,21 & 56,54 & 1,82 & 90,09 \\
\hline & Abierto & 53 & 38,22 & 28,25 & 3,88 & 30,43 & 46,01 & 3,08 & 110,66 \\
\hline & Total & 65 & 38,06 & 28,37 & 3,52 & 31,04 & 45,09 & 1,82 & 110,66 \\
\hline
\end{tabular}

Tabla 5.50: Media, desviación estándar, error estándar e intervalo de confianza de TV para los grupos de apertura en lunes.

Validada la hipótesis de igualdad de varianzas con el test de Levene (valor de significación de 0,931>0,05), se aplica el test ANOVA, cuyo resultado de significación es 0,927 (>0,05), por lo que la hipótesis nula de igualdad de grupos se considera válida, y TV no presenta significación respecto de la apertura de los lunes. 


\begin{tabular}{|c|c|c|c|c|c|c|c|c|c|}
\hline & ningo & $\mathbf{N}$ & Media & Desviación & Error & $\begin{array}{c}\text { Inte } \\
\text { Confi } \\
\text { para }\end{array}$ & $\begin{array}{l}\text { alo de } \\
\text { 1za } 95 \% \\
\text { Media }\end{array}$ & Mínimo & Máximo \\
\hline & & & & & & $\begin{array}{l}\text { Límite } \\
\text { Inferior }\end{array}$ & $\begin{array}{l}\text { Límite } \\
\text { Superior }\end{array}$ & & \\
\hline & Cerrado & 43 & 41,71 & 28,64 & 4,37 & 32,90 & 50,52 & 3,90 & 101,28 \\
\hline TV & Abierto & 22 & 30,94 & 27,06 & 5,77 & 18,94 & 42,94 & 1,82 & 110,66 \\
\hline & Total & 65 & 38,06 & 28,37 & 3,52 & 31,04 & 45,09 & 1,82 & 110,66 \\
\hline
\end{tabular}

Tabla 5.51: Media, desviación estándar, error estándar e intervalo de confianza de TV para los grupos de apertura en domingo.

En este caso se aplica el test de Levene, con un resultado de significación de 0,621 $(>0,05)$ y, puesto que se cumple el supuesto de homocedasticidad, se realiza la prueba ANOVA, dando como resultado un nivel de significación de 0,149 $(>0,05)$, por lo que la hipótesis nula se considera válida, y TV no presenta significación respecto de la apertura de los domingos.

En conclusión, desde el punto de vista de TR se considera óptimo abrir los lunes frente a los domingos, puesto que hay una mayor recogida de residuos, aunque desde el punto de vista estadístico no se ha podido demostrar que el número de visitas (TV) sea mayor.

\subsubsection{Acceso a empresas.}

Como norma general, los puntos limpios son instalaciones concebidas para su uso únicamente por parte de particulares. Sin embargo, existen entidades que permiten el depósito en los puntos limpios de residuos asimilables a domésticos por parte de empresas, facilitándoles la gestión de residuos producidos por sus actividades, y como medida tendente a evitar la gestión incorrecta de los mismos.

Si se autoriza el depósito de residuos en los puntos limpios a las empresas, las cantidades anuales gestionadas a través de los mismos se incrementan, con una media de TR de 29,02 $\mathrm{kg} / \mathrm{habitante/año} \mathrm{para} \mathrm{la} \mathrm{parte} \mathrm{de} \mathrm{la} \mathrm{muestra} \mathrm{constituida} \mathrm{por} \mathrm{los} \mathrm{puntos} \mathrm{limpios} \mathrm{en} \mathrm{que} \mathrm{no} \mathrm{se}$ autoriza el depósito de residuos a las empresas, y de 132,07 kg/habitante/año en los casos en que sí se autoriza el acceso de las empresas, tal y como se observa en la Tabla 5.52. 
Estudio de los puntos limpios implantados en España.

\begin{tabular}{|c|c|c|c|c|c|c|c|c|c|}
\hline \multirow{2}{*}{\multicolumn{2}{|c|}{ Grupo }} & \multirow[t]{2}{*}{$\mathbf{N}$} & \multirow[t]{2}{*}{ Media } & \multirow{2}{*}{$\begin{array}{l}\text { Desviación } \\
\text { Estándar }\end{array}$} & \multirow{2}{*}{$\begin{array}{c}\text { Error } \\
\text { Estándar }\end{array}$} & \multicolumn{2}{|c|}{$\begin{array}{c}\text { Intervalo de } \\
\text { Confianza 95\% } \\
\text { para la Media }\end{array}$} & \multirow[t]{2}{*}{ Mínimo } & \multirow[t]{2}{*}{ Máximo } \\
\hline & & & & & & $\begin{array}{l}\text { Límite } \\
\text { Inferior }\end{array}$ & $\begin{array}{l}\text { Límite } \\
\text { Superior }\end{array}$ & & \\
\hline \multirow{3}{*}{ TR } & NO Acc. Empresas & 10 & 29,02 & 18,46 & 5,84 & 15,82 & 42,22 & 8,42 & 57,49 \\
\hline & SI Acc. Empresas & 68 & 132,07 & 122,51 & 14,86 & 102,42 & 161,73 & 5,43 & 628,02 \\
\hline & Total & 78 & 118,86 & 119,59 & 13,54 & 91,90 & 145,83 & 5,43 & 628,02 \\
\hline
\end{tabular}

Tabla 5.52: Media, desviación estándar, error estándar e intervalo de confianza de TR para los grupos de acceso a empresas.

El valor de significación de la prueba $\mathrm{H}$ de Kruskal-Wallis es de 0,000 , por lo que sí existe significación estadística de la variable representativa de la autorización de acceso a empresas.

En la Tabla 5.53 se presentan los valores de media y desviación estándar de TV para los puntos limpios, en función de la autorización de acceso a empresas a la instalación.

\begin{tabular}{|c|c|c|c|c|c|c|c|c|c|}
\hline \multirow{2}{*}{\multicolumn{2}{|c|}{ Grupo }} & \multirow[t]{2}{*}{$\mathbf{N}$} & \multirow[t]{2}{*}{ Media } & \multirow{2}{*}{$\begin{array}{l}\text { Desviación } \\
\text { Estándar }\end{array}$} & \multirow[t]{2}{*}{$\begin{array}{l}\text { Error } \\
\text { Estándar }\end{array}$} & \multicolumn{2}{|c|}{$\begin{array}{c}\text { Intervalo de } \\
\text { Confianza 95\% } \\
\text { para la Media }\end{array}$} & \multirow[t]{2}{*}{ Mínimo } & \multirow[t]{2}{*}{ Máximo } \\
\hline & & & & & & $\begin{array}{l}\text { Límite } \\
\text { Inferior }\end{array}$ & $\begin{array}{l}\text { Límite } \\
\text { Superior }\end{array}$ & & \\
\hline \multirow{3}{*}{ TV } & NO Acc. Empresas & 2 & 8,28 & 2,97 & 2,10 & $-18,44$ & 35,01 & 6,18 & 10,39 \\
\hline & SI Acc. Empresas & 62 & 39,28 & 28,45 & 3,61 & 32,05 & 46,50 & 1,82 & 110,66 \\
\hline & Total & 64 & 38,31 & 28,52 & 3,57 & 31,19 & 45,44 & 1,82 & 110,66 \\
\hline
\end{tabular}

Tabla 5.53: Media, desviación estándar, error estándar e intervalo de confianza de TV para los grupos de acceso a empresas.

Los resultados del test de Levene muestran que existe homogeneidad de varianzas entre los grupos, al obtenerse un resultado de significación superior a 0,05 $(0,073)$. A continuación, los resultados del test ANOVA validan la hipótesis nula de igualdad entre grupos, puesto que el resultado de significación es $0,131(>0,05)$.

En resumen, puede concluirse que las empresas que depositan residuos en los puntos limpios en que se les autoriza el acceso, entregan grandes cantidades de residuos por visita, mientras que los usuarios particulares realizan un elevado número de visitas con poco peso específico por visita, provocando que la variable resulte significativa para TR y no para TV. 


\subsubsection{Incentivos por utilización.}

Para la correcta gestión de los residuos, se han constituido diferentes Sistemas Integrados de Gestión (SIG) o Sistemas Colectivos de Responsabilidad Ampliada del Productor (SCRAP), que perciben ingresos de fabricantes que ponen en el mercado los productos que acabarán generando residuos, con los que incentivan la recuperación de los residuos tras su uso, mediante la aportación de cantidades económicas a los actores que intervienen en los procesos de almacenamiento, transporte, clasificación y valorización de dichos residuos. Puesto que los puntos limpios realizan operaciones de almacenamiento de residuos, es posible que puedan percibir bonificaciones por esta actividad como consecuencia de aportaciones económicas por parte de los SCRAP, en función de los materiales recuperados. A su vez, estos ingresos percibidos pueden trasladarse al usuario que realice las aportaciones de residuos en el punto limpio, por lo que se ha estudiado la significación de esta variable sobre los resultados de TR y TV.

Como conclusión del estudio, se observa que los valores de TR en los puntos limpios en que existen incentivos para los usuarios duplican, de media, los resultados de aquéllos en que no hay incentivos por uso del punto limpio. En la Tabla 5.54 puede observarse el detalle de estos resultados.

\begin{tabular}{|c|c|c|c|c|c|c|c|c|c|}
\hline \multirow{2}{*}{\multicolumn{2}{|c|}{ Grupo }} & \multirow[t]{2}{*}{$\mathbf{N}$} & \multirow[t]{2}{*}{ Media } & \multirow{2}{*}{$\begin{array}{l}\text { Desviación } \\
\text { Estándar }\end{array}$} & \multirow{2}{*}{$\begin{array}{c}\text { Error } \\
\text { Estándar }\end{array}$} & \multicolumn{2}{|c|}{$\begin{array}{c}\text { Intervalo de } \\
\text { Confianza } 95 \% \\
\text { para la Media }\end{array}$} & \multirow[t]{2}{*}{ Mínimo } & \multirow[t]{2}{*}{ Máximo } \\
\hline & & & & & & $\begin{array}{l}\text { Límite } \\
\text { Inferior }\end{array}$ & $\begin{array}{c}\text { Límite } \\
\text { Superior }\end{array}$ & & \\
\hline \multirow{3}{*}{ TR } & NO incentivación & 43 & 75,52 & 77,35 & 11,80 & 51,71 & 99,32 & 5,43 & 392,09 \\
\hline & SI incentivación & 39 & 159,83 & 137,94 & 22,09 & 115,11 & 204,54 & 24,07 & 628,02 \\
\hline & Total & 82 & 115,62 & 117,57 & 12,98 & 89,78 & 141,45 & 5,43 & 628,02 \\
\hline
\end{tabular}

Tabla 5.54: Media, desviación estándar, error estándar e intervalo de confianza de TR para los grupos de incentivos por uso.

En cuanto a la igualdad entre grupos, el valor de significación de la prueba $\mathrm{H}$ de Kruskal-Wallis es 0,000, por lo que no se acepta la hipótesis de igualdad.

En cuanto a la variable TV, en la Tabla 5.55 se comprueba que los resultados son similares. Sometida la muestra al test de Levene, se acepta la hipótesis de homogeneidad de varianzas, al obtenerse un resultado de significación de 0,718 (>0,05). A continuación se realiza el test ANOVA, con un resultado de significación de 0,664, por lo que se acepta la hipótesis nula de igualdad entre grupos. 
Estudio de los puntos limpios implantados en España.

\begin{tabular}{|c|c|c|c|c|c|c|c|c|c|}
\hline \multirow{2}{*}{\multicolumn{2}{|c|}{ Grupo }} & \multirow[t]{2}{*}{$\mathbf{N}$} & \multirow[t]{2}{*}{ Media } & \multirow{2}{*}{$\begin{array}{l}\text { Desviación } \\
\text { Estándar }\end{array}$} & \multirow{2}{*}{$\begin{array}{c}\text { Error } \\
\text { Estándar }\end{array}$} & \multicolumn{2}{|c|}{$\begin{array}{c}\text { Intervalo de } \\
\text { Confianza } 95 \% \\
\text { para la Media }\end{array}$} & \multirow[t]{2}{*}{ Mínimo } & \multirow[t]{2}{*}{ Máximo } \\
\hline & & & & & & $\begin{array}{l}\text { Límite } \\
\text { Inferior }\end{array}$ & $\begin{array}{l}\text { Límite } \\
\text { Superior }\end{array}$ & & \\
\hline \multirow{3}{*}{ TV } & NO incentivación & 25 & 36,35 & 30,26 & 6,05 & 23,86 & 48,84 & 3,08 & 110,66 \\
\hline & SI incentivación & 39 & 39,57 & 27,68 & 4,43 & 30,59 & 48,54 & 1,82 & 98,46 \\
\hline & Total & 64 & 38,31 & 28,52 & 3,57 & 31,19 & 45,44 & 1,82 & 110,66 \\
\hline
\end{tabular}

Tabla 5.55: Media, desviación estándar, error estándar e intervalo de confianza de TV para los grupos de incentivos por uso.

Por tanto, se concluye que las cantidades de residuos depositados en los puntos limpios se incrementan si el usuario que realiza la entrega obtiene algún incentivo a cambio de dicha gestión. Sin embargo, la existencia de incentivos no presenta significación estadística sobre el número de visitas. Esto obedece al objetivo perseguido con los incentivos, que no es otro que incrementar el número de residuos depositados en el punto limpio pero sin necesidad de que aumente la afluencia de visitas de los habitantes.

\subsubsection{Límites de aportación.}

Con el objetivo de ordenar el funcionamiento de los puntos limpios, para evitar usos inadecuados, saturación de la gestión del servicio y costes asumidos por la administración, en ocasiones se establecen límites, en peso o en volumen de residuos aportados, a los usuarios y por periodo, que puede ser diario, semanal, mensual o anual.

Los valores de media y desviación estándar de TR en función de si existen límites de aportación son los que se muestran en la Tabla 5.56, en la que se observa que ambas son menores en los puntos limpios en que existen límites a la aportación de residuos.

\begin{tabular}{|c|c|c|c|c|c|c|c|c|c|}
\hline & \multirow[t]{2}{*}{ Grupo } & \multirow[t]{2}{*}{$\mathbf{N}$} & \multirow[t]{2}{*}{ Media } & \multirow{2}{*}{$\begin{array}{l}\text { Desviación } \\
\text { Estándar }\end{array}$} & \multirow{2}{*}{$\begin{array}{c}\text { Error } \\
\text { Estándar }\end{array}$} & \multicolumn{2}{|c|}{$\begin{array}{c}\text { Intervalo de } \\
\text { Confianza } 95 \% \\
\text { para la Media }\end{array}$} & \multirow[t]{2}{*}{ Mínimo } & \multirow[t]{2}{*}{ Máximo } \\
\hline & & & & & & $\begin{array}{l}\text { Límite } \\
\text { Inferior }\end{array}$ & $\begin{array}{c}\text { Límite } \\
\text { Superior }\end{array}$ & & \\
\hline \multirow{3}{*}{ TR } & NO se limita & 9 & 186,48 & 175,39 & 58,46 & 51,66 & 321,29 & 38,27 & 580,66 \\
\hline & SI se limita & 69 & 110,04 & 109,05 & 13,13 & 83,84 & 136,24 & 5,43 & 628,02 \\
\hline & Total & 78 & 118,86 & 119,59 & 13,54 & 91,90 & 145,83 & 5,43 & 628,02 \\
\hline
\end{tabular}

Tabla 5.56: Media, desviación estándar, error estándar e intervalo de confianza de TR para los grupos de límites de aportación.

No obstante, el valor de significación de la prueba $\mathrm{H}$ de Kruskal-Wallis es de 0,131 $(>0,05)$, por lo que se acepta la hipótesis nula de igualdad entre grupos. 
Respecto a TV, en la Tabla 5.57 se presentan los resultados de media y desviación estándar.

\begin{tabular}{|c|c|c|c|c|c|c|c|c|c|}
\hline & \multirow[t]{2}{*}{ Grupo } & \multirow[t]{2}{*}{$\mathbf{N}$} & \multirow[t]{2}{*}{ Media } & \multirow{2}{*}{$\begin{array}{l}\text { Desviación } \\
\text { Estándar }\end{array}$} & \multirow{2}{*}{$\begin{array}{c}\text { Error } \\
\text { Estándar }\end{array}$} & \multicolumn{2}{|c|}{$\begin{array}{c}\text { Intervalo de } \\
\text { Confianza } 95 \% \\
\text { para la Media }\end{array}$} & \multirow[t]{2}{*}{ Mínimo } & \multirow[t]{2}{*}{ Máximo } \\
\hline & & & & & & $\begin{array}{l}\text { Límite } \\
\text { Inferior }\end{array}$ & $\begin{array}{c}\text { Límite } \\
\text { Superior }\end{array}$ & & \\
\hline \multirow{3}{*}{ TV } & NO se limita & 9 & 20,90 & 16,73 & 5,58 & 8,04 & 33,77 & 3,90 & 58,29 \\
\hline & SI se limita & 55 & 41,16 & 29,14 & 3,93 & 33,28 & 49,04 & 1,82 & 110,66 \\
\hline & Total & 64 & 38,31 & 28,52 & 3,57 & 31,19 & 45,44 & 1,82 & 110,66 \\
\hline
\end{tabular}

Tabla 5.57: Media, desviación estándar, error estándar e intervalo de confianza de TV para los grupos de límites de aportación.

El estudio de influencia sobre TV resulta en un valor de significación del test de Levene de 0,047, por lo que no se cumple el supuesto de homogeneidad de varianzas. La validación de la hipótesis nula de igualdad entre grupos se realiza mediante el testo ANOVA-Welch. El resultado de significación de la prueba es 8,497E-3, por lo que se rechaza la hipótesis nula de igualdad entre grupos. Por tanto, los resultados de TV presentan significación respecto de la variable de limitación a las cantidades aportadas, obteniéndose, como puede observarse en la Tabla 5.57, valores de TV superiores si se limita la aportación de residuos por usuario.

Por tanto, no existen diferencias estadísticas significativas en cuanto a las cantidades de residuos recogidos con o sin límites de aportación. Sin embargo, se ha demostrado que cuando existen limites de aportación aumenta el número de visitas, siendo previsible que se deba a que haya usuarios que se vean en la necesidad de fraccionar sus entregas.

\subsubsection{Tipo de gestión.}

La gestión de los puntos limpios puede realizarse, principalmente, a través de una de las siguientes opciones:

- Gestión directa por parte de la administración competente.

- Gestión indirecta mediante concesión.

Se ha observado que para los puntos limpios de la muestra, la opción elegida por la administración competente ha sido distinta dependiendo del tamaño de la población, tal y como se resume en la Tabla 5.58 . 


\begin{tabular}{|l|l|r|r|}
\hline Tamaño punto limpio & \multicolumn{1}{|c|}{ Gestión } & $\mathbf{N}^{\mathbf{0}}$ casos (TR) & $\mathbf{N}^{\mathbf{0}}$ casos (TV) \\
\hline \multirow{2}{*}{ RURAL } & CONCESIÓN & 24 & 23 \\
\cline { 2 - 5 } & DIRECTA & 0 & 0 \\
\hline \multirow{2}{*}{ SEMIURBANO } & CONCESIÓN & 37 & 22 \\
\cline { 2 - 5 } & DIRECTA & 0 & 0 \\
\hline \multirow{2}{*}{ URBANO } & DIRECTA & 10 & 6 \\
\cline { 2 - 5 } & CONCESIÓN & 13 & 12 \\
\hline TOTAL & $\mathbf{8 1}$ & $\mathbf{6 5}$ \\
\hline
\end{tabular}

Tabla 5.58: Número de casos por tamaño de población adscrita y tipo de gestión.

Por tanto, el estudio de significación sobre TR y TV se realiza únicamente para los puntos limpios con población adscrita superior a 50.000 habitantes, no siendo posible en el resto de situaciones.

En el caso de TR, los resultados de cada grupo de la muestra son los que se presentan en la Tabla 5.59. En ella se observa que tanto la media como la desviación estándar son muy superiores en los puntos limpios gestionados mediante concesión. Sin embargo, el resultado de significación de la prueba $\mathrm{H}$ de Kruskal-Wallis es 0,901 , por lo que se acepta la hipótesis nula de igualdad entre grupos.

\begin{tabular}{|c|c|c|c|c|c|c|c|c|c|}
\hline & \multirow[t]{2}{*}{ Grupo } & \multirow[t]{2}{*}{$\mathbf{N}$} & \multirow[t]{2}{*}{ Media } & \multirow{2}{*}{$\begin{array}{l}\text { Desviación } \\
\text { Estándar }\end{array}$} & \multirow{2}{*}{$\begin{array}{c}\text { Error } \\
\text { Estándar }\end{array}$} & \multicolumn{2}{|c|}{$\begin{array}{c}\text { Intervalo de } \\
\text { Confianza } 95 \% \\
\text { para la Media }\end{array}$} & \multirow[t]{2}{*}{ Mínimo } & \multirow[t]{2}{*}{ Máximo } \\
\hline & & & & & & $\begin{array}{l}\text { Límite } \\
\text { Inferior }\end{array}$ & $\begin{array}{c}\text { Límite } \\
\text { Superior }\end{array}$ & & \\
\hline \multirow{3}{*}{ TR } & Directa & 10 & 57,07 & 33,81 & 10,69 & 32,89 & 81,25 & 13,01 & 123,72 \\
\hline & Concesión & 13 & 92,92 & 100,25 & 27,80 & 32,34 & 153,50 & 5,43 & 337,77 \\
\hline & Total & 23 & 77,33 & 79,24 & 16,52 & 43,06 & 111,60 & 5,43 & 337,77 \\
\hline
\end{tabular}

Tabla 5.59: Media, desviación estándar, error estándar e intervalo de confianza de TR para los grupos de tipo de gestión en puntos limpios urbanos.

En cuanto a TV, los resultados de la variable para cada grupo de puntos limpios son los que se incluyen en la Tabla 5.60. Al igual que se observaba en TR, tanto la media como la desviación estándar de TV son claramente superiores en los puntos limpios gestionados mediante concesión. 


\begin{tabular}{|c|c|c|c|c|c|c|c|c|c|}
\hline & Grupo & $\mathbf{N}$ & Media & $\begin{array}{l}\text { Desviación } \\
\text { Estándar }\end{array}$ & $\begin{array}{c}\text { Error } \\
\text { Estándar }\end{array}$ & $\begin{array}{r}\text { Inter } \\
\text { Confia } \\
\text { para I }\end{array}$ & \begin{tabular}{|l} 
alo de \\
1za 95\% \\
Media
\end{tabular} & Mínimo & Máximo \\
\hline & & & & & & $\begin{array}{l}\text { Límite } \\
\text { Inferior }\end{array}$ & $\begin{array}{l}\text { Límite } \\
\text { Superior }\end{array}$ & & \\
\hline & Directa & 6 & 12,93 & 3,61 & 1,47 & 9,15 & 16,72 & 9,86 & 19,39 \\
\hline TV & Concesión & 14 & 15,45 & 12,12 & 3,24 & 8,45 & 22,45 & 3,08 & 42,79 \\
\hline & Total & 20 & 14,69 & 10,26 & 2,30 & 9,89 & 19,50 & 3,08 & 42,79 \\
\hline
\end{tabular}

Tabla 5.60: Media, desviación estándar, error estándar e intervalo de confianza de TV para los grupos de tipo de gestión en puntos limpios urbanos.

El resultado de significación del test de Levene es 0,029 , por lo que no se cumple el supuesto de igualdad de varianzas entre grupos, por lo que debe aplicarse el test ANOVA-Welch. El resultado de significación de la prueba es de 0,4893 , por lo que se acepta la hipótesis nula de igualdad entre grupos, no presentando significación estadística el tipo de gestión de los puntos limpios con población adscrita superior a 50.000 habitantes sobre los valores de TV.

Así pues, desde el punto de vista demográfico, los sistemas de gestión directa son dominantes, como es lógico, en los municipios de mayor tamaño, puesto que en los municipios menores se suelen prestar dichos servicios a través de diputaciones, consorcios o entidades supramunicipales que asumirán su gestión con sistemas concesionados.

\subsubsection{Admisión de fracción Resto.}

En general, los puntos limpios disponen de contenedores para el depósito de residuos de las fracciones de recogida selectiva presentes en la vía pública. En la muestra sobre la que se ha realizado la encuesta, en 1 caso no se informa al respecto, y en 3 de ellos la instalación no cuenta con contenedores específicos para estas fracciones, por lo que en el $96 \%$ de los casos los puntos limpios cuentan con contenedores para la recogida selectiva de envases ligeros, papel y cartón y vidrio. No obstante, en cuanto a la fracción resto la situación es más dispar, por lo que se considera conveniente analizar la relevancia de dicha decisión sobre los resultados de utilización de los puntos limpios.

En la Tabla 5.61 se incluyen los valores de TR para los puntos limpios analizados, en función del criterio de admisión de fracción resto. 
Estudio de los puntos limpios implantados en España.

\begin{tabular}{|c|c|c|c|c|c|c|c|c|c|}
\hline & \multirow[t]{2}{*}{ Grupo } & \multirow[t]{2}{*}{$\mathbf{N}$} & \multirow[t]{2}{*}{ Media } & \multirow{2}{*}{$\begin{array}{l}\text { Desviación } \\
\text { Estándar }\end{array}$} & \multirow{2}{*}{$\begin{array}{c}\text { Error } \\
\text { Estándar }\end{array}$} & \multicolumn{2}{|c|}{$\begin{array}{c}\text { Intervalo de } \\
\text { Confianza } 95 \% \\
\text { para la Media }\end{array}$} & \multirow[t]{2}{*}{ Mínimo } & \multirow[t]{2}{*}{ Máximo } \\
\hline & & & & & & $\begin{array}{l}\text { Límite } \\
\text { Inferior }\end{array}$ & $\begin{array}{l}\text { Límite } \\
\text { Superior }\end{array}$ & & \\
\hline \multirow{3}{*}{ TR } & PL sin F. Resto & 32 & 86,34 & 86,27 & 15,25 & 55,24 & 117,44 & 5,43 & 392,09 \\
\hline & PL con F. Resto & 51 & 135,91 & 129,92 & 18,19 & 99,37 & 172,45 & 11,49 & 628,02 \\
\hline & Total & 83 & 116,80 & 117,03 & 12,85 & 91,24 & 142,35 & 5,43 & 628,02 \\
\hline
\end{tabular}

Tabla 5.61: Media, desviación estándar, error estándar e intervalo de confianza de TR para los grupos de admisión de fracción resto.

Se observa que tanto la media como la desviación estándar de TR son superiores en los puntos limpios que admiten fracción resto. Para determinar si la diferencia es significativa se aplica la prueba $\mathrm{H}$ de Kruskal-Wallis, que resulta en un grado de significación de 0,022 $(<0,05)$, por lo que no se acepta la hipótesis nula de igualdad entre grupos.

Sin embargo, la mayoría de los puntos limpios informaban de las cantidades de fracción resto gestionadas a través de la instalación, por lo que se ha definido la variable TR_noR como la diferencia entre las cantidades de residuos totales depositados en los puntos limpios menos las cantidades correspondientes a la fracción resto, por habitante y año. Los resultados son los que se muestran en la Tabla 5.62. Se observa que las diferencias resultantes son inferiores.

\begin{tabular}{|c|c|c|c|c|c|c|c|c|c|}
\hline & \multirow{2}{*}{ Grupo } & \multirow[t]{2}{*}{$\mathbf{N}$} & \multirow[t]{2}{*}{ Media } & \multirow{2}{*}{$\begin{array}{l}\text { Desviación } \\
\text { Estándar }\end{array}$} & \multirow{2}{*}{$\begin{array}{c}\text { Error } \\
\text { Estándar }\end{array}$} & \multicolumn{2}{|c|}{$\begin{array}{c}\text { Intervalo de } \\
\text { Confianza } 95 \% \\
\text { para la Media }\end{array}$} & \multirow{2}{*}{ Mínimo } & \multirow{2}{*}{ Máximo } \\
\hline & & & & & & $\begin{array}{l}\text { Límite } \\
\text { Inferior }\end{array}$ & $\begin{array}{l}\text { Límite } \\
\text { Superior }\end{array}$ & & \\
\hline \multirow{3}{*}{ TR_noR } & PL sin F. Resto & 28 & 87,34 & 91,86 & 17,36 & 51,72 & 122,96 & 5,43 & 392,09 \\
\hline & PL con F. Resto & 43 & 123,05 & 117,24 & 17,88 & 86,97 & 159,13 & 11,59 & 628,02 \\
\hline & Total & 71 & 108,97 & 108,68 & 12,90 & 83,25 & 134,69 & 5,43 & 628,02 \\
\hline
\end{tabular}

Tabla 5.62: Media, desviación estándar, error estándar e intervalo de confianza de TR_noR para los grupos de admisión de fracción resto.

Para determinar si hay diferencias significativas entre ambas situaciones se ha aplicado la prueba $\mathrm{H}$ de Kruskal-Wallis, con un resultado de significación de 0,065 $(>0,05)$, por lo que sí existe igualdad entre grupos.

Por lo que respecta a TV, en la Tabla 5.63 se muestran sus resultados para cada grupo de puntos limpios, dependiendo si hay o no admisión de residuos de fracción resto. Se observa que los valores de media y desviación estándar de TV son similares entre los grupos y respecto de la muestra total. 


\begin{tabular}{|c|c|c|c|c|c|c|c|c|c|}
\hline & \multirow[t]{2}{*}{ Grupo } & \multirow[t]{2}{*}{$\mathbf{N}$} & \multirow[t]{2}{*}{ Media } & \multirow{2}{*}{$\begin{array}{l}\text { Desviación } \\
\text { Estándar }\end{array}$} & \multirow{2}{*}{$\begin{array}{c}\text { Error } \\
\text { Estándar }\end{array}$} & \multicolumn{2}{|c|}{$\begin{array}{c}\text { Intervalo de } \\
\text { Confianza } 95 \% \\
\text { para la Media }\end{array}$} & \multirow[t]{2}{*}{ Mínimo } & \multirow[t]{2}{*}{ Máximo } \\
\hline & & & & & & $\begin{array}{l}\text { Límite } \\
\text { Inferior }\end{array}$ & $\begin{array}{l}\text { Límite } \\
\text { Superior }\end{array}$ & & \\
\hline \multirow{3}{*}{ TV } & PL sin F. Resto & 22 & 38,41 & 31,05 & 6,62 & 24,64 & 52,18 & 3,07 & 110,66 \\
\hline & PL con F. Resto & 42 & 37,71 & 27,58 & 4,26 & 29,11 & 46,30 & 1,82 & 98,46 \\
\hline & Total & 64 & 37,95 & 28,58 & 3,57 & 30,81 & 45,09 & 1,82 & 110,46 \\
\hline
\end{tabular}

Tabla 5.63: Media, desviación estándar, error estándar e intervalo de confianza de TV para los grupos de admisión de fracción resto.

Los resultados del test de Levene proporcionan un valor de significación de 0,670 $(>0,05)$, por lo que se acepta la hipótesis nula de homocedasticidad. A continuación se aplica el test ANOVA, con un resultado de significación de 0,970 $(>0,05)$, por lo que se acepta la hipótesis nula de igualdad entre los grupos.

Por tanto, se concluye que si el análisis se lleva a cabo considerando las cantidades totales de residuos, descontando las depositadas de fracción resto, este factor no resulta significativo en términos estadísticos y, dado que este tipo de fracción dispone de otros circuitos de recogida, no se recomienda su implantación en el punto limpio.

\subsubsection{Depósito de RAEE.}

Resulta cada vez más habitual que los puntos limpios cuenten con áreas específicas para el almacenamiento de RAEE, que pueden, a su vez, segregarse en depósitos diferenciados en función de sus características: tamaño y tipo aparato eléctrico o electrónico original. En este apartado se analiza si el hecho de que los puntos limpios dispongan de una zona específica para el almacenamiento de RAEE, representa un factor diferenciador para los resultados de gestión de residuos a través del punto limpio.

Los valores de TR de los puntos limpios, dependiendo de la disponibilidad de un área acondicionada para el almacenamiento de RAEE, se muestran en la Tabla 5.64, sin que se observen diferencias significativas entre los grupos y con la muestra total. 
Estudio de los puntos limpios implantados en España.

\begin{tabular}{|c|c|c|c|c|c|c|c|c|c|}
\hline \multirow{2}{*}{\multicolumn{2}{|c|}{ Grupo }} & \multirow[t]{2}{*}{$\mathbf{N}$} & \multirow[t]{2}{*}{ Media } & \multirow{2}{*}{$\begin{array}{l}\text { Desviación } \\
\text { Estándar }\end{array}$} & \multirow{2}{*}{$\begin{array}{c}\text { Error } \\
\text { Estándar }\end{array}$} & \multicolumn{2}{|c|}{$\begin{array}{c}\text { Intervalo de } \\
\text { Confianza } 95 \% \\
\text { para la Media }\end{array}$} & \multirow[t]{2}{*}{ Mínimo } & \multirow[t]{2}{*}{ Máximo } \\
\hline & & & & & & $\begin{array}{l}\text { Límite } \\
\text { Inferior }\end{array}$ & $\begin{array}{l}\text { Límite } \\
\text { Superior }\end{array}$ & & \\
\hline \multirow{3}{*}{ TR } & PL sin zona_RAEE & 17 & 104,87 & 107,21 & 26,00 & 49,75 & 159,99 & 13,01 & 392,09 \\
\hline & PL con zona_RAEE & 52 & 111,90 & 110,51 & 15,32 & 81,14 & 142,67 & 5,43 & 628,02 \\
\hline & Total & 69 & 110,17 & 108,96 & 13,12 & 84,00 & 136,35 & 5,43 & 628,02 \\
\hline
\end{tabular}

Tabla 5.64: Media, desviación estándar, error estándar e intervalo de confianza de TR para los grupos de disponibilidad de zona para RAEE.

Para demostrar el hecho anterior se ha aplicado la prueba $\mathrm{H}$ de Kruskal-Wallis, dando un grado de significación de 0,549 $(>0,05)$, por lo que se acepta la hipótesis de igualdad entre grupos, tal y como era de esperar.

En cuanto a la influencia sobre TV, en la Tabla 5.65 se incluyen la media y desviación estándar de la variable para la totalidad de la muestra y los subgrupos definidos en función de la disponibilidad de zona acondicionada para el almacenamiento de RAEE. Se observan valores similares de media, con la desviación estándar ligeramente superior en los puntos limpios que cuentan con la zona con antiderrame para RAEE.

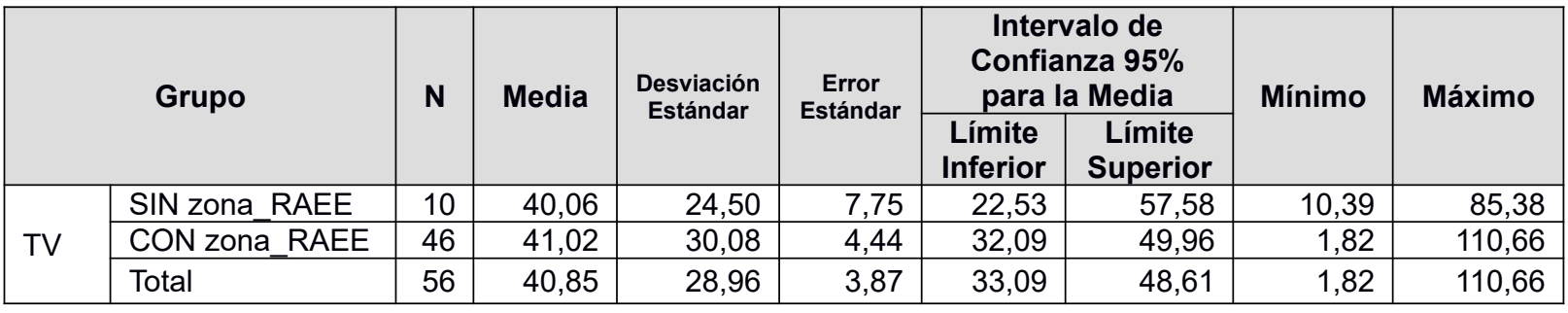

Tabla 5.65: Media, desviación estándar, error estándar e intervalo de confianza de TV para los grupos de disponibilidad de zona para RAEE.

Para comprobar la hipótesis de igualdad de grupos, en primer lugar se ha aplicado el test de Levene a la muestra, validando la homocedasticidad $(0,361>0,05)$ y posteriormente el test ANOVA, que presenta un valor de significación de 0,925 $(>0,05)$, por lo que se acepta la hipótesis nula de igualdad entre grupos, como también era de esperar.

La existencia de la fracción RAEE ha quedado demostrado que no tiene influencia en las cantidades depositadas o en las visitas al punto limpio, si bien tratándose de un residuo con regulación propia es necesaria su admisión. 


\subsection{Conclusiones.}

En este capítulo se ha realizado un estudio exhaustivo de los puntos limpios implantados en España, a partir de la obtención de una muestra significativa del total de municipios. Para ello se diseñó una encuesta con un total de 39 preguntas, que fue enviada a todos ellos por vía telemática. Se obtuvieron 91 respuestas, suficientes para realizar el análisis estadístico de los resultados de cada una de las preguntas con un nivel de confianza del 95\% y un error del 10 al $15 \%$ en 37 de las preguntas.

El estudio realizado a lo largo del capítulo ha permitido determinar, desde un punto de vista estadístico, la influencia de las variables asociadas a la localización, infraestructuras y condiciones de funcionamiento de dichas instalaciones sobre la gestión de los puntos limpios en España, expresado mediante las cantidades de residuos depositados (TR) y número de visitas recibidas (TV).

En primer lugar, se ha comprobado que existe una muy baja correlación lineal entre TR y TV. Este hecho demuestra que existe una gran variabilidad en las cantidades aportadas por visita, presumiblemente debido tanto a la diferente densidad de las fracciones admisibles (restos vegetales, RCD, RAEE, residuos peligrosos, etc.), como al origen de éstas (relacionado con el criterio de autorización o no del acceso a empresas, cuya capacidad de aportación por visita es muy superior a la de particulares).

En cuanto a variables de localización, se ha podido concluir que existen diferencias estadísticamente significativas entre los puntos limpios con población adscrita inferior a 5.000 habitantes y aquéllos con población superior a 50.000 habitantes, consiguiendo resultados de TR y TV superiores los puntos limpios más pequeños. Los que cuentan con población intermedia, entre 5.000 y 50.000 habitantes, presentan un resultado mixto, con resultados de TR similares a los puntos limpios más grandes (se reducen las cantidades aportadas, probablemente debido a la coexistencia de servicios de recogida de residuos voluminosos en vía pública, habituales en los municipios de mayor tamaño), mientras que los de TV son similares a los de los puntos limpios más pequeños (se mantiene un grado de afluencia alto, probablemente por los menores tiempos de desplazamiento hasta la instalación). La distancia del punto limpio al núcleo urbano también presenta significación estadística, con valores de TR y TV superiores en las instalaciones situadas a menos de $0,5 \mathrm{~km}$ del núcleo urbano. Sin embargo, no se han detectado diferencias significativas sobre las variables "disponibilidad de transporte público" y "existencia de carril bici" en las proximidades de los puntos limpios, probablemente debido a que a los usuarios no les resultan medios de transporte cómodos para llevar los residuos susceptibles de depósito en dichas instalaciones. 
Por lo que se refiere a las variables de infraestructura de los puntos limpios, no se han detectado diferencias estadísticamente significativas respecto a los aspectos como el "número de carriles de circulación dentro del recinto", "número de cotas de construcción", "número de contenedores caja abierta" o "disponibilidad de punto limpio móvil asociado", por lo que se concluye que una mayor inversión en infraestructuras no tiene como resultado directo un mayor grado de uso del servicio del punto limpio fijo. Se ha estudiado asimismo la influencia de la variable "superficie", donde se ha encontrado diferencias significativas en la variable TV para las poblaciones semiurbanas, reportando un mayor número de visitas los puntos limpios menores a $3.000 \mathrm{~m}^{2}$.

En este mismo apartado, se ha estudiado la influencia de la antigüedad de la instalación, concluyéndose que únicamente se presentan diferencias estadísticamente significativas respecto a TV, que presenta valores más altos para las instalaciones construidas a partir de 2011. Este comportamiento observado puede deberse a la mayor adecuación de las instalaciones más recientes, con un catálogo de residuos admisibles más amplio y una mejor accesibilidad, que favorecen la afluencia de visitas.

Respecto a las variables de funcionamiento, se han detectado diferencias estadísticamente significativas en "la autorización de acceso a empresas", "la implantación de un sistema de incentivos por uso" y "la existencia de límites de aportación". En el primer caso, se produce un claro incremento de las cantidades depositadas al tener acceso las empresas a los puntos limpios, lo que favorecerá la disminución de vertidos incontrolados y el tamaño de éstos. En cuanto a los incentivos, se observa asimismo un incremento en las cantidades de residuos recuperados cuando existe algún tipo de incentivo, por lo que se puede concluir que es una medida favorable a los objetivos perseguidos con la implantación de los puntos limpios. La fijación de límites de aportación no afecta significativamente a los resultados de TR, pero sí a la TV, aumentando el número de visitas cuando hay límites en la aportación de residuos, probablemente debido a un fraccionamiento de los depósitos realizados. En cuanto a la variable "residuos admisibles", se ha observado que la disponibilidad de contenedores de fracción resto incrementa significativamente las cantidades totales de residuos gestionadas en los puntos limpios, pero este efecto se debe únicamente a las aportaciones de dicha fracción, no existiendo incremento en las cantidades de otros tipos de residuos. Respecto a la disponibilidad o no de zona para el depósito de RAEE, tampoco afecta a los valores de TR y TV.

En cuanto a la variable "tipo de gestión del punto limpio", no se detecta diferencia significativa entre gestión directa o mediante concesión. Los horarios de apertura ha sido otro aspecto estudiado Se ha podido analizar únicamente la influencia del estado de apertura o cierre en lunes y en domingo, sin que existan diferencias significativas respecto a la mejora en la TR y TV. No 
obstante, sí se ha observado que los resultados son mejores si la instalación permanece cerrada en domingo en lugar de en lunes.

\subsection{Referencias.}

Badenes Catalán, C., Gallardo Izquierdo, A. 2020, Influencia de la gestión (directa o indirecta) en el rendimiento de los puntos limpios de recogida de residuos sólidos urbanos. 24th International Congress on Project Management and Engineering.

Gallardo, A., 2000. Metodología para el diseño de redes de recogida selectiva de RSU utilizando sistemas de información geográfica. Creación de una base de satos aplicable a España. Universidad Politécnica de Valencia.

Everett,J.W. y Peirce, J.J. (1.993). Curbside recycling in the U.S.A. : convenience and mandatory participation. Waste Managment \& Research V11 pp 49-61.

Pehlken, A., Von Blottnitz, H., Pretz, T., 2000. Requirements for the sampling of residual waste - Approach to developing a new sampling model. Aufbereit. Tech. 41, 409-415.

Prades M. , 2014. Modelización de la eficiencia de la recogida selectiva de los residuos sólidos urbanos en España. Tesis Doctoral. Universitat Jaume I. España.

Rojas, L.D. 2008. La importancia de la participación ciudadana en los programas de recogida selectiva de residuos sólidos urbanos. Análisis de la población inmigrante de la ciudad de valencia, España. Tesis Doctoral. Universidad de Valencia. España. 


\section{Capítulo 6. Metodología para LA UBICACIÓN Y DISEÑO DE UN PUNTO LIMPIO.}





\section{METODOLOGÍA PARA LA UBICACIÓN Y DISEÑO DE UN PUNTO LIMPIO.}

Como se ha descrito hasta aquí, los puntos limpios son instalaciones ubicadas en zonas urbanas o periurbanas, en las que se dispone de contenedores específicos para la recogida selectiva de aquellos residuos sólidos urbanos que requieren una recogida y tratamiento especializados. Según la Ley 22/2011 de residuos y suelos contaminados, corresponde a las Comunidades Autónomas la elaboración de los programas autonómicos de prevención de residuos y de los planes autonómicos de gestión de residuos. En este sentido, dichos planes pueden incluir una guía para la adopción de ordenanzas por las entidades locales, quienes son las competentes en la gestión de los residuos domésticos, así como para la implementación de la red de puntos limpios, cuyo desarrollo y gestión corresponderá asimismo a las entidades locales o, en función de lo previsto en el Plan Autonómico, a entidades supramunicipales. El PNIR estableció entre sus medidas, la ampliación de la red actual de puntos limpios, introduciendo que "se dotará a todos los municipios de más de 5.000 habitantes antes del 2010 y a todos los de más de 2.000 habitantes antes de $2015 "$.

El objetivo del presente capítulo es diseñar una metodología para ayudar a la localización, diseño y funcionamiento de un punto limpio, con la finalidad de obtener una instalación eficiente y con un elevado uso por parte de los ciudadanos. Esta metodología pretende ser una herramienta útil en la planificación de la recogida y gestión de los RSU a través de estas instalaciones.

En primer lugar se definen los factores a considerar en la localización, diseño y funcionamiento del punto limpio, considerando los valores obtenidos del trabajo experimental, y en segundo lugar se propone la metodología.

La metodología propuesta no exime del cumplimiento de lo previsto en la legislación vigente en materia de gestión de residuos, entre la cual se encuentran los Planes de Residuos, tanto estatal como autonómica, así como lo establecido por organismos de ámbito inferior con competencias delegadas (entidades supramunicipales como mancomunidades y consorcios), en aquellos aspectos en que la legislación resulte más restrictiva o contemple requisitos no considerados en la metodología. 


\subsection{Factores de diseño del punto limpio.}

En capítulos anteriores se ha realizado un análisis sobre las diferentes variables que afectan al diseño de los puntos limpios. En la Tabla 6.1 se presentan las diferentes variables, agrupadas en factores, sobre las que se debe tomar una decisión para optimizar la instalación y que han sido desarrolladas en los apartados siguientes.

\begin{tabular}{|c|c|c|}
\hline \multirow{19}{*}{$\begin{array}{l}\text { FACTORES DEL } \\
\text { PUNTO LIMPIO }\end{array}$} & \multirow{5}{*}{ LOCALIZACIÓN } & Análisis de distribución de microvertederos \\
\hline & & Definición del número de instalaciones \\
\hline & & Distancia al núcleo urbano \\
\hline & & Disponibilidad de transporte público \\
\hline & & Disponibilidad de carril bici \\
\hline & \multirow{8}{*}{ INFRAESTRUCTURA } & Cerramiento perimetral \\
\hline & & N. ${ }^{\circ}$ de carriles de circulación \\
\hline & & N. ${ }^{\circ}$ de cotas constructivas \\
\hline & & Contenedores caja abierta \\
\hline & & Oficina de atención al público \\
\hline & & Báscula \\
\hline & & Superficie \\
\hline & & Punto limpio móvil asociado \\
\hline & \multirow{6}{*}{ FUNCIONAMIENTO } & Horario de apertura \\
\hline & & Autorización de acceso a empresas \\
\hline & & Incentivación mediante beneficios por su utilización \\
\hline & & Limitación en las cantidades aportadas \\
\hline & & Gestión directa o indirecta \\
\hline & & Admisión de residuos \\
\hline
\end{tabular}

Tabla 6.1: Factores de ubicación, infraestructura y funcionamiento de puntos limpios.

\subsubsection{Factores de localización del punto limpio.}

Los aspectos que definirán la localización de los puntos limpios y, por tanto, el número de instalaciones necesarias, son:

- Demográfico: la generación de residuos susceptibles de depósito en puntos limpios está relacionada con la cantidad de población adscrita del mismo.

- Geográfico: el número de instalaciones necesarias para la prestación del servicio dependerá de la distancia a los núcleos urbanos existentes y las distancias entre los mismos. En este punto, además, debe considerarse la necesidad de eliminación de posibles microvertederos incontrolados. 


\subsubsection{Análisis y distribución de microvertederos.}

De los resultados obtenidos en el análisis del capítulo 3 se desprende que la ubicación de un punto limpio en las proximidades de los vertederos incontrolados tiene un efecto de minimización de éstos muy importante. Por lo tanto, en primer lugar se deberá estudiar la existencia o no de estos puntos, determinar las áreas donde están ubicados y declararlas como zonas prioritarias de ubicación de punto limpio.

\subsubsection{Definición del número de instalaciones.}

Se ha observado que tanto el número de visitas anuales a los puntos limpios como la cantidad de residuos depositados en los mismos se reducen en la medida en que aumenta el tamaño de la población adscrita a los mismos, y que dicha variación es lo suficientemente importante como para considerarla estadísticamente significativa.

La población a adscribir al punto limpio, en ningún caso, deberá ser superior a 50.000 habitantes, ya que los valores de TR y TV serían muy bajos. Si la población del área para la que se está diseñando el servicio de puntos limpios es superior a 50.000 habitantes, deberán segregarse las zonas de influencia, dotándose de los puntos limpios necesarios conforme a este criterio.

Según la clasificación de población adscrita y teniendo en cuenta lo dicho anteriormente, en la Tabla 6.2 se presentan los resultados de TR y TV esperados en base a la investigación realizada.

\begin{tabular}{|c|c|c|c|c|}
\hline Clasificación & $\mathbf{N}^{{ }^{\circ}}$ de habitantes & $\mathbf{N}^{\circ}$ de Instalaciones & $\begin{array}{c}\text { TV } \\
\text { (Visitas/100 } \\
\text { hab/año) }\end{array}$ & $\begin{array}{c}\text { TR } \\
\text { (kg/hab/año) }\end{array}$ \\
\hline RURAL & $\leq 5.000$ & 1 & 55 & 160 \\
\hline SEMIURBANO & $5.000<\mathrm{x} \leq 50.000$ & 1 & 42 & 112 \\
\hline URBANO & $>50.000$ & 1 por cada 50.000 & 14 & 77 \\
\hline
\end{tabular}

Tabla 6.2: Valores de TR y TV en función de la población adscrita. 


\subsubsection{Distancia al núcleo urbano.}

En cuanto a la localización del punto limpio, ha quedado comprobado que la distancia de la instalación a los núcleos urbanos resulta significativa sobre el grado de mejora en la correcta gestión de residuos. A menor distancia del núcleo urbano a la instalación, se han observado un mayor número de visitas realizadas, así como un incremento en las cantidades depositadas.

Los mejores resultados se obtienen en los casos en que el punto limpio se sitúa a menos de 500 metros del núcleo urbano, reduciéndose los índices conforme aumenta la distancia. En el estudio realizado en el capítulo 5 se ha evidenciado que ninguno de los puntos limpios de la muestra se encontraba situado a distancia superior a 5.000 metros respecto del casco urbano, de lo que puede desprenderse que no resultan eficientes desde el punto de vista de mejora de gestión de los residuos. En la Tabla 6.3 se presentan los resultados de TR y TV esperados respecto a las distancias del punto limpio al núcleo urbano.

\begin{tabular}{|c|c|c|}
\hline Distancia & TV & TR \\
\hline$<0,5 \mathrm{~km}$ & 51 & 140 \\
\hline $0,5 \mathrm{~km}<\mathrm{d} \leq 1,5 \mathrm{~km}$ & 28 & 99 \\
\hline $1,5 \mathrm{~km}<\mathrm{d} \leq 5 \mathrm{~km}$ & 16 & 55 \\
\hline$>5 \mathrm{~km}$ & - & - \\
\hline
\end{tabular}

Tabla 6.3: Valores de TR y TV en función de la distancia al núcleo urbano.

\subsubsection{Disponibilidad de transporte público.}

Las comunicaciones viarias a un punto limpio deben ser siempre adecuadas, y así permitirán a su vez que el punto limpio cuente con paradas de los servicios de transporte públicos en sus proximidades; no obstante, como se ha comprobado en el capítulo 5 , no se ha observado que la presencia de dicho servicio aporte resultados significativos sobre el grado de utilización de estas instalaciones.

Por tanto, pese a que puede resultar de interés para ciertos sectores de la población, no constituye requisito exigible la oferta de servicio de transporte público hasta el punto limpio. 


\subsubsection{Disponibilidad de carril bici.}

Un tratamiento similar al previsto en el apartado anterior puede darse a la infraestructura de acceso por carril bici. Pese a que la movilidad en las ciudades está transformándose en las últimas fechas, mediante el fomento de la incorporación de nuevos medios de transporte más sostenibles, como la bicicleta o el patinete, no se ha observado que la dotación de infraestructura viaria de carril bici hasta los puntos limpios presente relevancia estadística sobre los resultados de gestión de los mismos.

Por tanto, pese a que puede resultar de interés para ciertos sectores de la población, la oferta de carril bici hasta el punto limpio no constituye requisito exigible.

\subsubsection{Factores de infraestructura del punto limpio.}

A continuación se definen las variables consideradas en el diseño de la infraestructura de los puntos limpios.

\subsubsection{Cerramiento perimetral.}

El punto limpio deberá contar con un cerramiento perimetral, de manera que se protejan las instalaciones interiores, delimite el espacio ocupado por el mismo y posibilite la ordenación de accesos a la instalación.

El $100 \%$ de las instalaciones consultadas han informado que contaban con cerramiento perimetral. Así pues, no puede obviarse en la fase de construcción que los límites de la parcela en que se instale el punto limpio deben estar debidamente establecidos.

\subsubsection{Número de carriles de circulación.}

El número de carriles existentes para la circulación interior de los usuarios es un factor que mejora la accesibilidad a las diferentes áreas de aportación de residuos. Sin embargo, presenta asimismo como contrapartida el incremento de superficie no útil desde el punto de vista estricto del servicio de almacenamiento.

En el análisis realizado en el capítulo 5, se ha observado que la gran mayoría de instalaciones de la muestra que aportaban información al respecto, el 91\% disponía únicamente de 1 carril de circulación por sentido, sin que el incremento a 2 carriles presentara resultados significativos. 
Por tanto, el punto limpio se diseñará con un único carril de circulación, dotando de áreas de estacionamiento adecuadas para la manipulación y depósito de residuos en condiciones de seguridad para los usuarios.

\subsubsection{Número de cotas constructivas.}

Los puntos limpios construidos en 2 cotas permiten segregar los flujos de circulación de manera más eficiente y con menos riesgo para todos los actores; además, posibilitan la instalación de contenedores de mayor capacidad de almacenamiento para materiales cuya manipulación por parte del usuario puede resultar incómoda. Por otro lado, la construcción en 2 cotas presenta costes de ejecución superiores, que pueden resultar difíciles de asumir para municipios o áreas con menor población.

En el estudio del capítulo 5 se ha evidenciado que los puntos limpios presentan resultados de gestión similares independientemente de si se construyen en 1 ó 2 cotas. No obstante, basándose en la reflexión anterior de seguridad/coste y en el análisis normativo vigente, siempre que la población adscrita sea superior a 5.000 habitantes, se aconseja que los puntos limpios se construyan en 2 cotas.

\subsubsection{Número de contenedores de caja abierta.}

Los contenedores caja abierta se emplean, generalmente, para el depósito de residuos que, por las cantidades aportadas o sus características físicas (tamaño y densidad), no pueden ser depositados en contenedores de menor capacidad. Estos materiales son, fundamentalmente:

- Colchones.

- Residuos voluminosos.

- Residuos de demolición.

- Residuos vegetales.

En el capítulo 5 se ha comprobado que los resultados de gestión de los puntos limpios no están directamente relacionados con el mayor número de contenedores de caja abierta. No obstante, sí hay una relación entre la clasificación de población y número de contenedores. En la Tabla 6.4 se presenta el número de contenedores de caja abierta en función de la población adscrita, que pueden ser tomados como referencia. 
Metodología para la ubicación y diseño de un punto limpio.

\begin{tabular}{|c|c|c|}
\hline Clasificación & $\mathbf{N}^{\circ}{ }^{\circ}$ habitantes & Contenedores caja abierta \\
\hline RURAL & $\leq 5.000$ & $4-5$ \\
\hline SEMIURBANO & $5.000<x \leq 50.000$ & $4-11$ \\
\hline URBANO & $>50.000$ & $7-14$ \\
\hline
\end{tabular}

Tabla 6.4: Número de contenedores de caja abierta en función de la población adscrita.

\subsubsection{Oficina de atención al público y aseo.}

El punto limpio deberá contar con oficina de atención al público, así como aseo, tanto para el personal del servicio como para los usuarios de la instalación. La oficina de atención al público es necesaria para la correcta gestión del servicio, ya que ésta incluye la elaboración de estadísticas de uso y registro de operaciones, tanto de aportación como de logística de residuos a través de los gestores $\mathrm{y}$, pese a que gran parte de los registros pueden ser realizados a través de dispositivos portátiles, la disponibilidad de un espacio físico en que se centralice la gestión de la instalación es indispensable.

Por otro lado, tratándose de un espacio de uso público, es necesario que éste disponga, como infraestructura mínima, de un aseo, dotado de botiquín, para la posible resolución de incidencias durante las operaciones de manipulación llevadas a cabo en la instalación, tanto por los usuarios como por los diferentes operarios y operadores.

El 99\% de las instalaciones consultadas han informado que contaban con estas instalaciones. Así pues no puede obviarse en la fase de construcción, debiendo preverse la construcción tanto de oficina de atención al público como de aseo.

\subsubsection{Báscula.}

Con el objetivo de disponer de una adecuada trazabilidad de la gestión realizada en el punto limpio, es necesario que la instalación cuente con báscula de pesaje, tanto para registrar las aportaciones realizadas por los usuarios, como las salidas a los centros de tratamiento.

El 56\% de las instalaciones consultadas han informado que contaban con báscula; no obstante, basándose en la reflexión del coste/utilización y los datos obtenidos en el estudio de campo, siempre que la población adscrita sea superior a 5.000 habitantes, se aconseja que los puntos limpios dispongan de este servicio. 


\subsubsection{Superficie.}

La superficie total disponible en el punto limpio permitirá acoger y distribuir interiormente las infraestructuras necesarias para el óptimo desarrollo de la actividad que en él se lleva cabo. Sin embargo, constituye asimismo un factor limitante en cuanto a las posibilidades de ubicación de la instalación, en función de la disponibilidad de suelo de la Administración, además de estar directamente relacionado con los costes de construcción.

Así, una alta disponibilidad de superficie aumenta las posibilidades de almacenamiento y de número de fracciones, así como de organización de flujos internos de operación; por contra, se incrementan los costes de construcción y de mantenimiento de la instalación.

En el capítulo 5 se ha demostrado que el tamaño de la población influye en el tamaño del punto limpio. En la Tabla 6.5 se presentan las superficies recomendadas en función de la población.

\begin{tabular}{|c|c|c|}
\hline Clasificación & N. $^{\circ}$ habitantes & Superficie $\left(\mathbf{m}^{\mathbf{2}}\right)$ \\
\hline RURAL & $\leq 5.000$ & entre 450 y 900 \\
\hline SEMIURBANO & $5.000<x \leq 50.000$ & entre 1.000 y 3.000 \\
\hline URBANO & $>50.000$ & entre 1.800 y 3.200 \\
\hline
\end{tabular}

Tabla 6.5: Valores de superficie en función de la población adscrita.

\subsubsection{Punto limpio móvil asociado.}

El punto limpio móvil puede resultar un complemento de servicio adecuado para:

- Núcleos urbanos o urbanizados aislados, con poca población, no atendidos por el punto limpio fijo.

- Áreas urbanas atendidas en que, por la actividad comercial desarrollada y su generación propia de residuos o por la baja dotación de contenedores de residuos minoritarios (aceite, pilas, bombillas), resulte conveniente aproximar el servicio de punto limpio móvil.

- Mejorar la separación en origen de otros residuos sin contenedor específico (metales, radiografías, consumibles de impresión), para los que pueden existir sistemas integrados de gestión (SIG) específicos a través de locales comerciales, pero de los que se haya detectado su presencia como impropio en contenedores de recogida selectiva.

Los estudios realizados en el capítulo 5, sobre la relevancia que supone que el servicio de punto limpio sea complementado por un punto limpio móvil, indican que se trata de un factor nada significativo en cuanto al aumento de TR y TV. 
No obstante, se ha comprobado en las encuestas de campo que el 55\% de los puntos limpios lo tiene asociado, con el objetivo de mejorar el servicio. Por tanto, sería recomendable, basado en los datos de la encuesta, implantarlo en poblaciones mayores de 50.000 habitantes y para atender a núcleos aislados con poca población.

\subsubsection{Factores de funcionamiento del punto limpio.}

A continuación se definen las variables consideradas en el diseño del funcionamiento de los puntos limpios.

\subsubsection{Horario de apertura.}

Los resultados del análisis del capítulo 5 muestran que, entre martes y sábado, más del 94\% de los puntos limpios de la muestra se encontraban abiertos. En cambio los domingos, únicamente prestaban servicio el $33 \%$ de las instalaciones y los lunes el $80 \%$.

Se ha comprobado que, pese a que en la mayoría de las comparaciones efectuadas (días de la semana) no existen diferencias significativas, esto no sucede cuando se analiza el comportamiento de los puntos limpios en función de si los lunes la instalación permanece abierta o cerrada. Así, se ha observado que las cantidades depositadas en los puntos limpios son superiores si la instalación se encuentra abierta los lunes.

Por tanto, en caso de que la instalación deba cerrarse al público algún día de la semana, por motivos de mantenimiento o gestión del personal, no se recomienda que sea el lunes.

\subsubsection{Autorización de acceso a empresas.}

La gestión de residuos debidos a actividades productivas es responsabilidad del productor. Sin embargo, esta gestión supone costes, tanto operacionales como económicos, que determinadas empresas asumen de manera desigual, lo que ocasiona que se produzcan vertidos no deseados, tanto en contenedores para cuyo uso no están previstos, como a través de microvertederos. En el capítulo 3 se ha comprobado que la composición de los microvertederos es mayoritaria en residuos de construcción y demolición, cuya producción, por la magnitud de los vertidos, no es de origen doméstico. 
En el análisis realizado en el capítulo 5 se ha observado que, si se autoriza a las empresas la utilización de los puntos limpios, se incrementan las cantidades depositadas en los mismos, que se multiplican por hasta 4,6 veces.

Por tanto, es recomendable la autorización de acceso a empresas a estas instalaciones. La Administración competente podrá establecer las condiciones en las que se permita el depósito de residuos en el punto limpio.

\subsubsection{Incentivación mediante beneficios por su utilización.}

De los datos de las encuestas, se desprende que casi en el $50 \%$ de los casos se incentiva la utilización de los puntos limpios mediante la activación de beneficios para los usuarios, que pueden ser:

- Acumulación de puntos para descuento en la tasa del año siguiente (70\%).

- Descuento en la tasa de tratamiento del año siguiente, si se hace uso del servicio hasta en unas determinadas veces al año (22\%).

- Bonificación en el recibo del agua $(2,7 \%)$.

- Descuento en la tasa de tratamiento $(2,7 \%)$.

- Descuentos en la tasa no especificados $(2,7 \%)$.

Observándose como resultado de estas medidas que las cantidades medias recogidas se incrementan hasta un $100 \%$ con respecto a los casos en que no se incentiva la utilización del servicio, pese a que el incremento en el número de visitas no resulta significativo.

Por tanto, se recomienda que se diseñe un sistema de incentivos, que ofrezca al usuario bonificaciones que le resulten atractivas. Es deseable que dichas bonificaciones estén directamente relacionadas con la gestión ambiental municipal (descuentos en tasas del servicio de recogida de residuos, de tratamiento de residuos, etc), de modo que el usuario perciba que su dedicación le reporta ventajas relacionadas con la gestión que está realizando. 


\subsubsection{Limitación en las cantidades aportadas.}

Que se limiten las cantidades depositadas por usuario, bien en cada aportación, bien en términos anuales, permite mejoras en el servicio basadas en:

- Detectar condiciones de uso inadecuado del servicio.

- Atenuar las aportaciones diarias totales de residuos.

- Posibilitar que mayor número de usuarios pueda realizar aportaciones diariamente.

Como podemos comprobar en al capítulo 5, a pesar de que el establecimiento de límites de aportación no resulta significativo desde el punto de vista estadístico en términos de cantidades depositadas en el punto limpio, sí lo es desde la óptica de las visitas, que se duplican.

Por tanto, si la aplicación de estas limitaciones no supone un incremento de TR, pero sí de TV, y con el objetivo de mejorar la gestión y organización el servicio, se recomienda limitar las aportaciones bien por cantidad de depósito o bien por asistencias de usuario. En caso de que se autorice el depósito a empresas, podrán establecerse límites distintos para usos particulares y empresas, tratando de evitar la saturación del servicio.

\subsubsection{Gestión directa o indirecta.}

En el capítulo 5 se ha determinado que los resultados de gestión de los puntos limpios son más satisfactorios si la gestión de los mismos se realiza a través de una concesión (gestión indirecta), que si la lleva a cabo directamente la administración titular del servicio. Se ha comprobado asimismo que, realizando el análisis por clasificación de población (rural, semiurbano y urbano), los resultados indican que el factor no es significativo para los puntos limpios de mayor tamaño (más de 50.000 habitantes), sin obtenerse resultados para puntos limpios de menor tamaño.

\subsubsection{Admisión de residuos.}

Dentro de la encuesta realizada se ha preguntado por los tipos de residuos admitidos en los puntos limpios, siendo los resultados los siguientes:

- Residuos voluminosos: $100 \%$.

- Residuos de construcción y demolición: 99\%.

- Fracciones de recogida selectiva (envases ligeros, papel y cartón, vidrio): 97\%.

- Residuos peligrosos: 96\%.

- RAEE: $75 \%$. 
- Resto: $65 \%$.

De las cuatro primeras fracciones, según los datos obtenidos resulta indiscutible su admisibilidad en el diseño del punto limpio. Sin embargo, sí se ha analizado la necesidad de recoger fracción Resto y RAEE.

En cuanto a los residuos peligrosos, la Ley 22/2011, de residuos y suelos contaminados, establece que el tiempo de almacenamiento no deberá ser superior a seis meses, periodo en el que deberán estar correctamente envasados, etiquetados y almacenados conforme a al Real Decreto 833/1988, lo que incluye la utilización de envases homologados, correcto etiquetado en el que se identifique el residuo contenido y su peligrosidad, y almacenamiento en zona diferenciada, en la que se eviten las mezclas entre residuos.

En cuanto a la fracción resto, pese a que la admisión de esta fracción incrementa las cantidades depositadas de residuos, este efecto se debe únicamente a dicha fracción. Por tanto, al no conseguir con la admisión de esta fracción elevar los TV o los TR de otras fracciones y debido a que el objetivo principal de un punto limpio es la recuperación de materiales distintos a los que son recogidos a través del servicio en vía pública, se recomienda que en los puntos limpios no se instalen contenedores de fracción resto.

En cuanto a los RAEE, se ha comprobado que con su admisión en las instalaciones no se mejora la aportación de materiales a los puntos limpios por el hecho de que éstos dispongan de un área acondicionada para el almacenamiento de RAEE. Así pues, a pesar de que tampoco mejoran los rendimientos de la instalación, y siendo que la legislación obliga a su recogida, procede la admisibilidad de esta fracción.

Los requisitos de almacenamiento de RAEE, se harán conforme al Real Decreto 110/2015, que incluye la pavimentación mediante superficies impermeables, dotación de sistemas de recogida de derrames y almacenamiento bajo cubierta. 


\subsection{Diseño de la metodología.}

En este punto se presenta la metodología para ayudar a la localización, diseño y funcionamiento de un punto limpio en una determinada área geográfica. En la Figura 6.1 se define el proceso lógico que hay que seguir para su diseño.

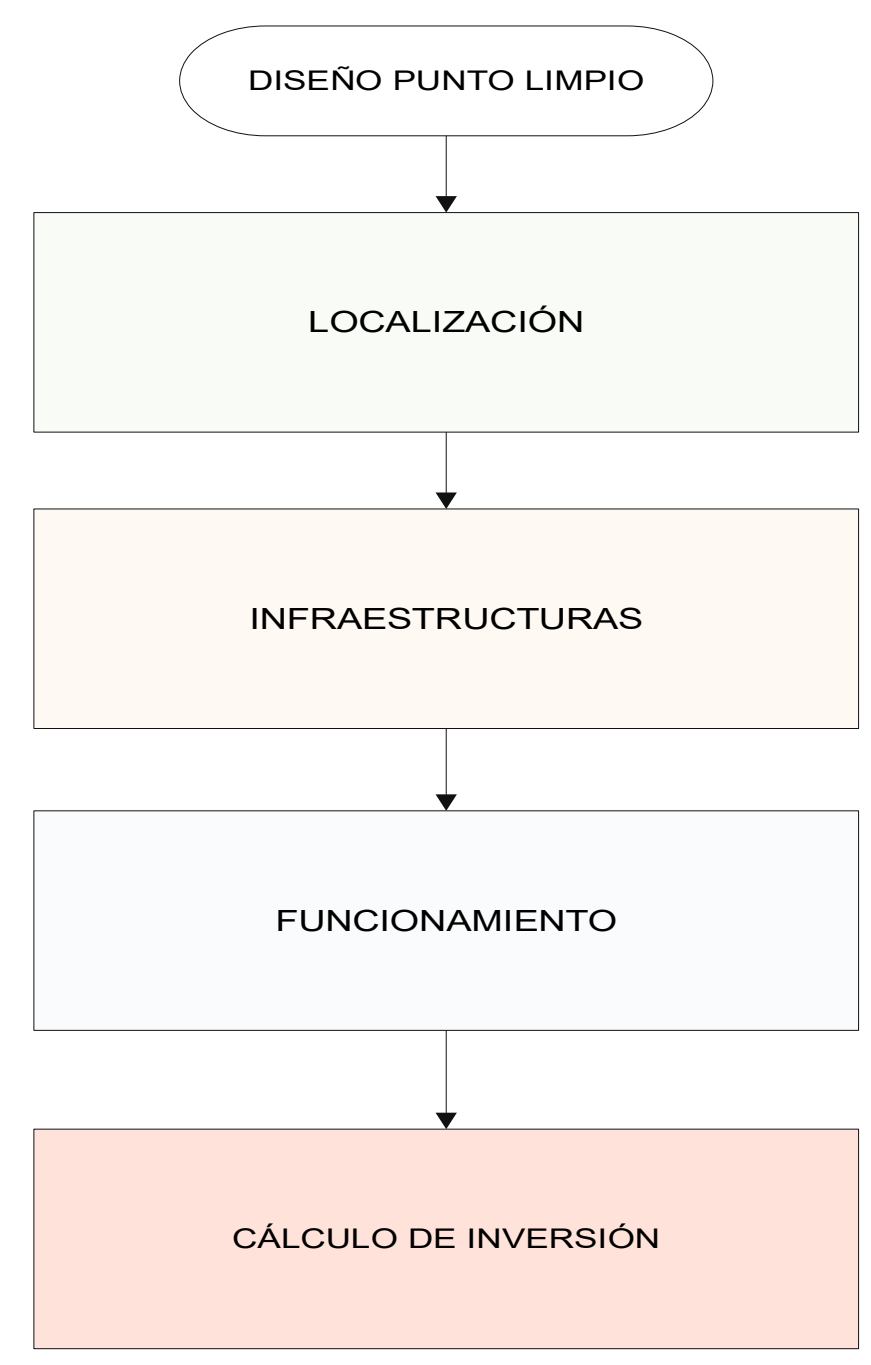

Figura 6.1: Esquema de la metodología.

Como se indica en la Figura 6.1, en primer lugar será necesario buscar una localización adecuada para esta instalación. Una vez está ubicada, habrá que concretar y definir las infraestructuras (superficie, número de contenedores, etc.) que la instalación debe tener. En siguiente lugar hay 
que definir las condiciones de funcionamiento y gestión del punto limpio (horarios, fracciones admisibles, incentivos, etc). Por último sera necesario calcular la inversión de construcción de la instalación.

A continuación se detalla cada una una de estas etapas en las Figuras 6.2, 6.3 y 6.4, donde figuran los diagramas de flujo a seguir para el diseño del punto limpio.

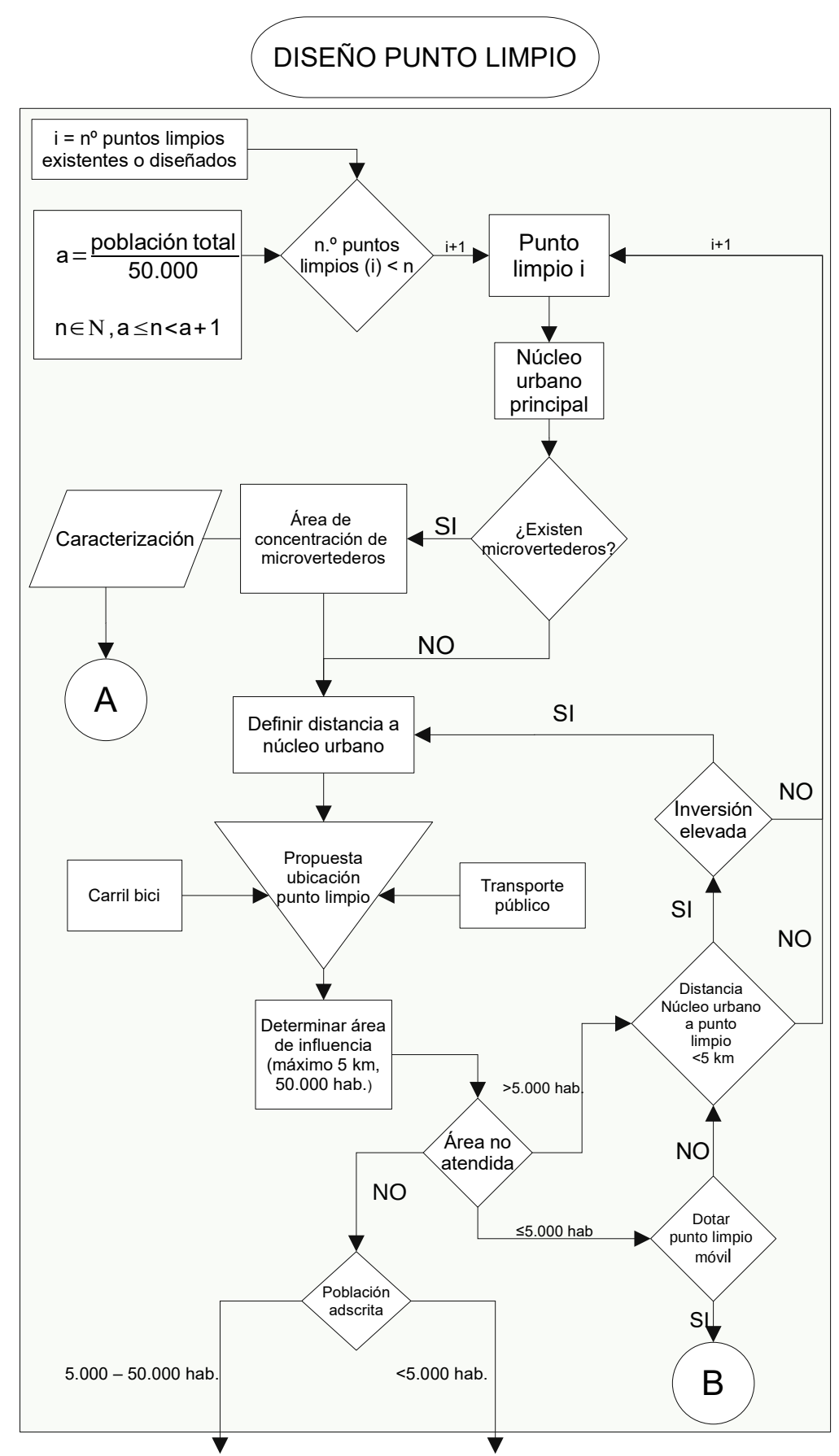

Figura 6.2: Diagrama de flujo de la etapa de localización. 


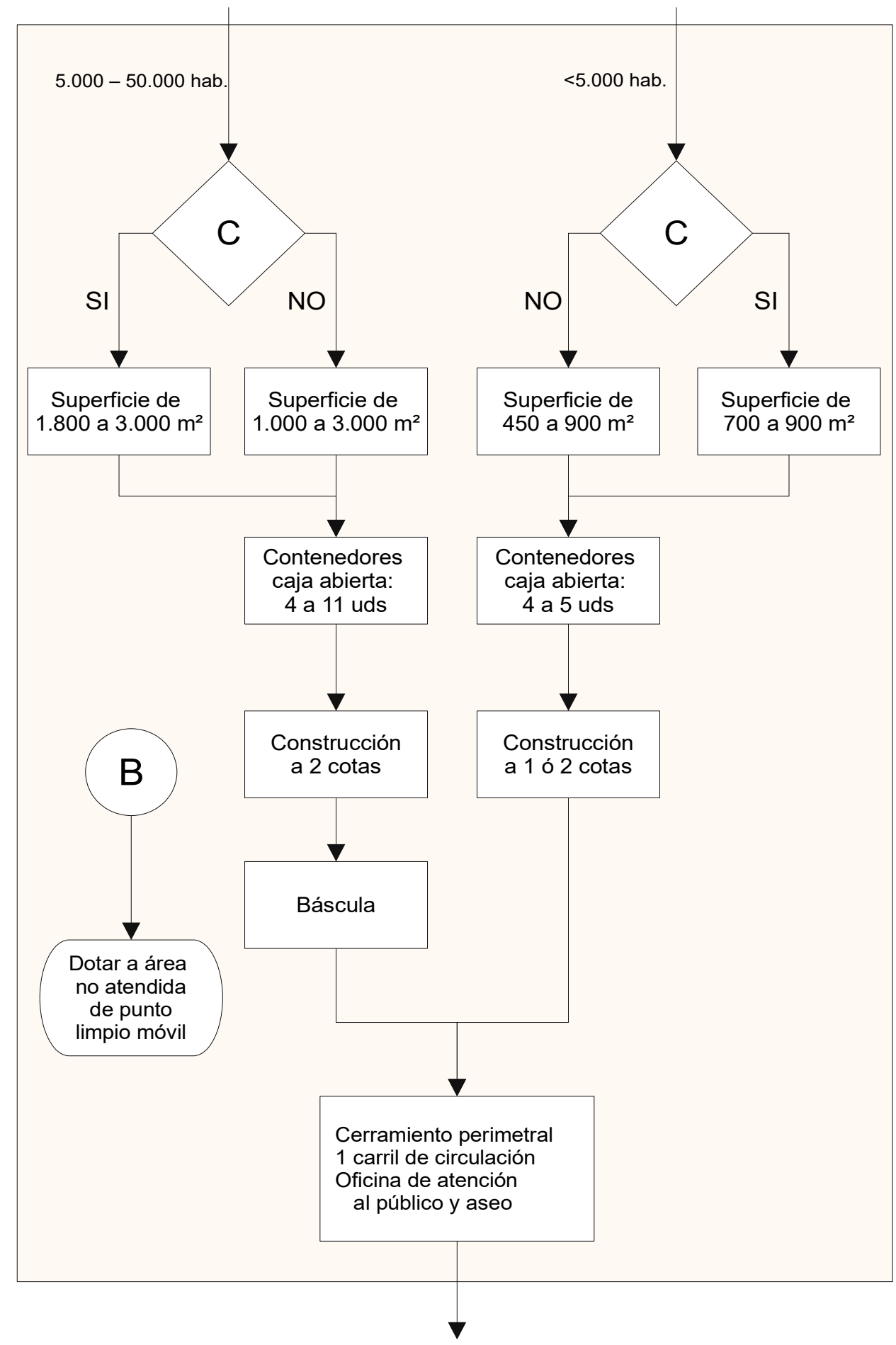

Figura 6.3: Diagrama de flujo de la etapa de infraestructura. 


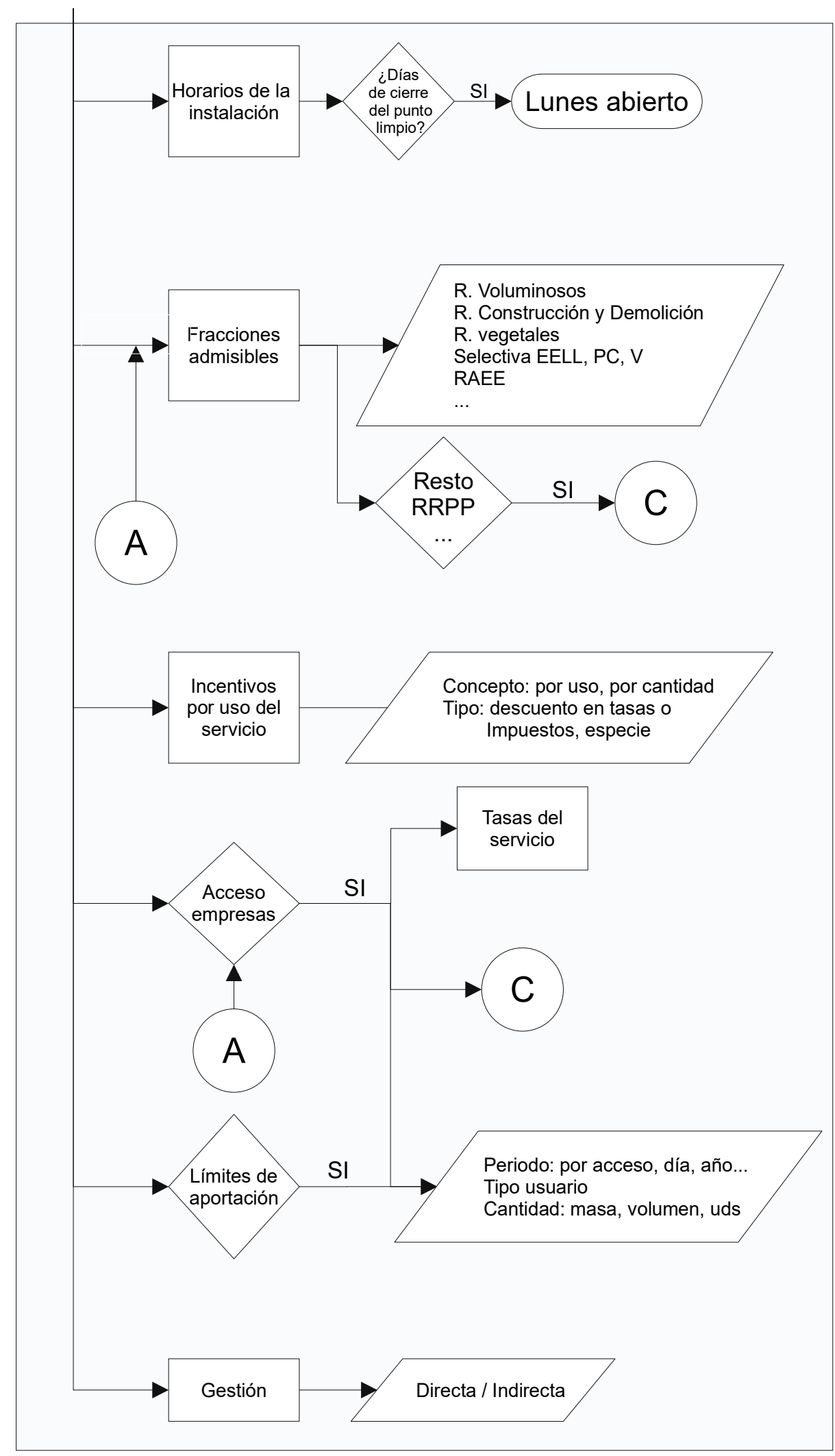

Figura 6.4: Diagrama de flujo de la etapa de funcionamiento. 
En la Figura 6.2 se presenta el diagrama para la localización de la instalación. En primer lugar, hay que definir el número de puntos limpios a instalar en el municipio, que estará en función de si la zona es rural, semiurbana o urbana (clasificación) y del número de habitantes de la zona de estudio (Tabla 6.2). En el caso de que al municipio le corresponda la instalación de más de un punto limpio, se definirá el número de habitantes asignado a cada instalación (siempre menor de 50.000 habitantes) y habrá que repetir el diagrama en sus diferentes etapas para cada una de las instalaciones a implementar.

Para cada instalación, habrá que definir la distancia a la que se instalará el punto limpio respecto al núcleo urbano. En función de las TR y TV que se deseen, se decidirá según la Tabla 6.3.

La distancia elegida definirá un área de influencia, en la que habrá que comprobar la existencia o no de áreas de concentración de microvertederos. En el caso de existir, procederá la caracterización de los mismos (dará información para diseñar posteriormente las fracciones admisibles de residuos; esto queda indicado en el diagrama con la salida señalada con la letra "A") y según el punto 6.1.1.1 se procederá a la localización próxima a los mismos. Una vez analizada la existencia de estos microvertederos y teniendo en cuenta la disponibilidad de carril bici y transporte público se procederá a la propuesta de ubicación del punto limpio. En ambos casos se tendrá en cuenta que disponga de buena conectividad y que el tiempo de llegada no supere los 15 minutos.

Con la ubicación propuesta, se determina el área de influencia del punto limpio, que no deberá de tener nunca un radio mayor de $5 \mathrm{~km}$. Si se observa que queda fuera de dicha área una población mayor a 5.000 habitantes (área no atendida), podrá redefinirse la distancia al núcleo urbano, si ésta fuese inferior a $5 \mathrm{~km}$, o definir un punto limpio adicional, mientras que si la población que queda fuera del área de aportación es menor de 5.000 habitantes se puede atender esta zona incluyendo un punto limpio móvil (salida indicada con la letra "B" en el diagrama de la Figura 6.2). En el caso de no poder disponer de esta instalación móvil, podrá modificarse la distancia al núcleo urbano, si ésta fuese inferior a $5 \mathrm{~km}$, o definirse un punto limpio adicional. En cualquier caso, la decisión de prestar servicio al área no atendida mediante la modificación de la distancia del punto limpio al núcleo urbano o dotar de un nuevo punto limpio vendrá condicionada por los criterios de ubicación ya enumerados y los resultados de análisis de disponibilidad de suelo y económicos. Una vez determinada el área de influencia, el valor de la población a la que presta servicio ayudará a definir los siguientes factores de infraestructura. 
En la Figura 6.3 aparece el diseño de las infraestructuras para cada tipo de punto limpio. En el caso de que la población sea menor de 5.000 habitantes, la superficie de la instalación deberá encontrarse entre 450 y $900 \mathrm{~m}^{2}$ (Tabla 6.5) y disponer de entre 4 y 5 contenedores de caja abierta (Tabla 6.4). Para el diseño de las cotas de la instalación, dado el tamaño de la población, se podrá optar por la construcción a 1 ó 2 cotas, según lo visto en el apartado 6.1.2.3.

En el caso de que la población se encuentre entre 5.000 y 50.000 habitantes, la superficie de la instalación deberá encontrarse entre 1.000 y $3.000 \mathrm{~m}^{2}$ (Tabla 6.5) y disponer de entre 4 y 11 contenedores de caja abierta (Tabla 6.4). Para el diseño de las cotas de la instalación, dado el tamaño de la población, la construcción deberá de ser de 2 cotas, según lo visto en el apartado 6.1.2.3.

En ambos casos hay que tener en cuenta que, en función de las fracciones admisibles, así como de si está permitido el uso de la instalación a empresas, aparece en el diagrama la entrada representada por la letra "C", que modifica el criterio general de superficie mínima necesaria, incrementándolo a $700 \mathrm{~m}^{2}$ para las poblaciones adscritas inferiores a 5.000 habitantes, y a 1.800 $\mathrm{m}^{2}$ si dicha población es de entre 5.000 y 50.000 habitantes.

En este apartado habrá que proceder al diseño del cerramiento perimetral, la oficina de atención al público y el aseo, los cuales serán obligatorios para cualquier instalación de cualquier población adscrita. También habrá que definir la existencia de los carriles de circulación, que según el punto 6.1.2.2 se diseñarán con un único carril de circulación, dotado de áreas de estacionamiento para la manipulación y depósito de los residuos en condiciones de seguridad.

Respecto la existencia de báscula, el apartado 6.1.2.6 aconseja que sean los puntos limpios de más de 5.000 habitantes los que dispongan de ella.

En el diagrama aparece la entrada señalada con la letra "B", la incorporación como infraestructura del punto limpio móvil, en aquellos casos que así se haya definido para dar servicio a áreas no atendidas de menos de 5.000 habitantes. Esta infraestructura mejora siempre el servicio del ecoparque fijo, no siendo necesaria la existencia de un área no atendida para que se implemente; aunque representa un inversión importante, además de necesitar un espacio para su cuidado y mantenimiento.

En la Figura 6.4 se presenta el diagrama para definir el funcionamiento de la instalación. En él se relacionan diferentes aspectos comunes a todos los puntos limpios que definen sus condiciones de funcionamiento.

En cuanto al horario, en el apartado 6.1.3.1 ha quedado establecido que el punto limpio deberá permanecer abierto los lunes, por lo que, si fuese necesario definir un día de la semana para 
realizar paradas técnicas, de mantenimiento o de gestión de personal, deberán programarse en un día de la semana distinto.

Las fracciones admisibles en los puntos limpios, en general, deberán incluir los residuos voluminosos, de construcción y demolición, vegetales, de selectiva (envases ligeros, papel-cartón y vidrio) y de aparatos eléctricos y electrónicos, así como cualquier otra fracción relevante procedente del estudio de microvertederos (entrada señalada mediante la letra "A"). En el punto 6.1.3.6 se ha incluido la recomendación de no admitir fracción resto en los puntos limpios. No obstante, si se decidiese su admisión, así como la de otras fracciones como consecuencia de la admisión de residuos procedentes de empresas, hay que tener en cuenta que las necesidades mínimas de espacio van a ser superiores (salida señalada con la letra "C").

Para mejorar la recuperación de residuos a través de los puntos limpios, se recomienda que se implanten mecanismos de incentivación al usuario, tal y como se indica en el punto 6.1.3.3, en el que se indica que es deseable que los beneficios que obtenga el usuario obedezcan a aspectos relacionados con la gestión que se está realizando.

La utilización del servicio por parte de empresas es una decisión que corresponde al titular del servicio. Uno de los criterios que deberá considerarse para esta toma de decisión es la detección, en la identificación y caracterización de residuos en microvertederos, de gestión incorrecta de fracciones de residuos cuyo origen pueda atribuirse a la gestión inadecuada por parte de empresas (entrada "A"). En caso de autorizarse, deberá tenerse en cuenta el incremento esperado en las cantidades de residuos que serán gestionadas a través del punto limpio, por lo que la superficie mínima necesaria para su construcción será superior, (salida "C"). Además, la autorización de uso del punto limpio a empresas deberá llevar aparejado el establecimiento de tasas por el servicio para dichos usuarios, así como de límites de aportación.

Por otro lado, en el punto 6.1.3.4 se ha indicado que la fijación de límites de aportación no afecta a los valores de TR, aunque sí de TV, por lo que se recomienda que existan limitaciones que racionalicen y homogeneicen el servicio. Si se ha autorizado el acceso de empresas, estos límites podrán ser distintos de los establecidos para los usuarios particulares.

En cuanto a la gestión, en el punto 6.1.3.5 se indica que se ha comprobado que los resultados son más satisfactorios si la gestión es indirecta que directa, aunque para los puntos limpios de menos de 50.000 habitantes no ha sido posible realizar el análisis en detalle.

Finalmente, definidos la localización del punto limpio y todos sus parámetros de diseño y funcionamiento, debe acometerse el capítulo correspondiente a inversiones. Debido a la magnitud de la instalación, con una importante necesidad de espacio físico e infraestructuras internas, tanto 
fijas como móviles, supone afrontar un elevado coste de implantación para el titular, por lo que es deseable que sea de utilidad a largo plazo (en el capítulo 5 se ha observado que existen instalaciones en uso desde el año 1988), que permitan amortizar el desembolso realizado de forma amortiguada.

El primer concepto a considerar es el coste del suelo en que se va a instalar el punto limpio, directamente relacionado con la superficie necesaria. Este coste puede reducirse si el titular es ya propietario de los terrenos, o mediante la firma de convenios con el sector privado.

A continuación, debe realizarse el proyecto constructivo, que tenga en cuenta todos los aspectos evaluados en la metodología. Esta fase incluye tanto los trabajos de adecuación de los terrenos, pavimentación, construcción de infraestructuras auxiliares (oficinas, aseos, cubiertas), como equipamientos para el almacenamiento de residuos (contenedores tipo caja abierta, contenedores específicos para residuos de menor tamaño, residuos peligrosos, etc) y servicios (electricidad, agua, comunicaciones). A continuación se relacionan las principales partidas presupuestarias de la fase de proyecto:

I. Movimiento de tierras.

II. Muros de contención.

III. Firmes, pavimentos y urbanización.

IV. Red de saneamiento.

V. Red de lixiviados.

VI. Electricidad, alumbrado, telefonía.

VII. Casetas y cubiertas de contenedores.

VIII. Cerramientos y señalización.

IX. Equipamiento.

X. Protección caída muelle.

XI. Vigilancia y control.

XII. Seguridad y salud.

XIII. Control de calidad.

Este cálculo de inversión se refiere a la construcción e instalación del punto limpio, a estos costes se deben añadir los propios de la gestión y el mantenimiento de la instalación, tales como suministros, gastos de personal, etc. 


\subsection{Conclusiones.}

Partiendo de las conclusiones del capítulo 3, de influencia de los puntos limpios en la existencia de microvertederos y del capítulo 5, sobre la relación entre las variables de localización, infraestructuras y funcionamiento de puntos limpios, se ha desarrollado una metodología sencilla que permite definir los parámetros básicos de las instalaciones, con los que se consiguen resultados óptimos en términos de uso de la instalación.

La metodología desarrollada consiste en un proceso de determinación inicial del número de puntos limpios necesarios, realizando un recorrido a lo largo de criterios para la ubicación de la instalación, definición de parámetros de la infraestructura (constructivos y de equipamiento) y detección de necesidades complementarias. Así como la definición de aspectos relacionados con el funcionamiento: horarios de apertura, tipo de usuario de la instalación, catálogo de residuos admitidos y condiciones de aceptación de los mismos. Finalmente, se relacionan las principales partidas de inversión que deberán valorarse para la construcción del punto limpio.

Esta metodología se basa en la información del amplio estudio de campo realizado y teniendo en cuenta los casos de éxito de las instalaciones de este tipo que existen en la actualidad. Pretende ofrecerse una herramienta de gran ayuda para el personal técnico que se encuentre ante la situación de diseñar este tipo de instalaciones. 

CAPítulo 7. VALIDACIÓN DE LA METODOLOGÍA. DISEÑO DE UN SEGUNDO PUNTO LIMPIO EN LA CIUDAD DE CASTELLÓ. 



\section{VALIDACIÓN DE LA METODOLOGÍA. DISEÑO DE UN SEGUNDO PUNTO LIMPIO EN LA CIUDAD DE CASTELLÓ.}

Una vez analizado el contexto actual en materia de generación y gestión de residuos, los objetivos y estrategias establecidos por las diferentes Administraciones, el papel que desempeñan los puntos limpios como infraestructura de recuperación de materiales y los factores que influyen sobre el diseño y funcionamiento de los puntos limpios y desarrollada la metodología propuesta para la ubicación y diseño de un punto limpio, en este capítulo se aplicará dicha metodología para el diseño de un punto limpio en la ciudad de Castelló de la Plana.

\subsection{Diseño según la metodología establecida.}

Como ya se ha indicado en el capítulo 3, Castelló de la Plana cuenta con un punto limpio situado en la zona Oeste del término municipal, en una ubicación próxima al casco urbano, cuya superficie es de aproximadamente $6.300 \mathrm{~m}^{2}$. Además, la ciudad dispone de 2 puntos limpios móviles, que prestan servicio en localizaciones situadas a lo largo del término municipal, principalmente en puntos de los cascos urbanos de Castellón y el Grao.

La ciudad de Castelló de la Plana pertenece a la provincia de Castellón, en la Comunidad Valenciana; por tanto, en términos legales, la estrategia de implantación de puntos limpios obedece a lo previsto en el Plan Integral de Residuos de la Comunitat Valenciana (PIRCV), actualizado en el año 2019. Conforme a lo previsto en el citado PIRCV, la ciudad de Castellón cuenta con un punto limpio tipo $D$, y la normativa no prevé que se dote a la ciudad de un segundo punto limpio fijo; no obstante, analizando la producción y recuperación de residuos de la ciudad, y comparándolas con los datos globales en términos autonómicos, se observa que los objetivos se sitúan en un horizonte que recomienda reconsiderar la estrategia actual.

De acuerdo con los datos publicados por el Instituto Nacional de Estadística, las cantidades de residuos urbanos recogidos en el ámbito de la Comunidad Valenciana en el año 2018 han sido las que se detallan en la Tabla 7.1. 


\begin{tabular}{|l|r|}
\hline \multicolumn{1}{|c|}{ Fracción } & \multicolumn{1}{c|}{ t } \\
\hline 10.1.1 Residuos domésticos y similares (domésticos y vías públicas) & 2.050 .369 \\
\hline 10.1.2 Residuos domésticos voluminosos mezclados (enseres domésticos) & 100.906 \\
\hline 06 Residuos metálicos & 2.052 \\
\hline 07.1 Residuos de vidrio & 85.018 \\
\hline 07.2 Residuos de papel y cartón & 70.106 \\
\hline 07.4 Residuos de plásticos & 1.761 \\
\hline 07.5 Residuos de Madera & 17.433 \\
\hline 07.6 Residuos textiles & 7.237 \\
\hline 08.2 y 08.43 Equipos eléctricos desechados y Componentes de equipos electrónicos \\
desechados & 3.212 \\
\hline 08.41 Residuos de pilas y acumuladores & 123 \\
\hline 09. Residuos animales y vegetales & 74.512 \\
\hline 10.21 Envases mixtos y embalajes mezclados & 52.925 \\
\hline 11 Lodos comunes (secos) & 0 \\
\hline 12 Residuos minerales (incluye residuos de construcción y demolición) & 78.893 \\
\hline 18 Otros & 327 \\
\hline TOTAL RESIDUOS MEZCLADOS & 2.151 .275 \\
\hline TOTAL RESIDUOS DE RECOGIDA SEPARADA & 393.599 \\
\hline TOTAL RESIDUOS & 2.544 .874 \\
\hline
\end{tabular}

Tabla 7.1: Cantidades anuales de residuos recogidos en la Comunidad Valenciana en 2018.

De la Tabla 7.1 los residuos urbanos no susceptibles de recuperación a través de los puntos limpios son los siguientes:

- Resto (10.1.1).

- Vidrio (7.1).

- Papel y cartón (7.2).

- Envases ligeros (10.21).

Por tanto, la cantidad de residuos objetivo para los puntos limpios disponibles ese año ascendería a 286,456 t; puesto que la población censada en la Comunidad Valenciana en 2018 es de 4.963.703 habitantes, la cantidad de residuos susceptibles es de 57,70 kg/habitante/año.

Tal y como se ha expuesto en el Capítulo 3, la aportación de residuos a los puntos limpios de Castelló ascendió en 2019 a 35,55 kg/habitante, mientras que en 2020, el valor de esta tasa es de $34,23 \mathrm{~kg} /$ habitante. 
Por tanto, existe una diferencia lo suficientemente significativa entre la aportación por habitante en los ámbitos autonómico y municipal como para concluir que es necesario adoptar medidas tendentes a incrementar la tasa de recuperación de residuos a través de los puntos limpios en la ciudad de Castellón; por este motivo, en este capítulo se aborda la validación de la metodología desarrollada en el capítulo 6, para la implantación de un segundo punto limpio en la ciudad.

\subsubsection{Localización del punto limpio.}

Siguiendo el diagrama de la metodología de diseño establecida en el capítulo 6, se analizan a continuación los criterios relacionados con la localización del punto limpio en proceso de diseño.

\subsubsection{Número de puntos limpios.}

A la ciudad de Castelló de la Plana, según su población (174.264 habitantes), le corresponden 4 instalaciones de punto limpio. En la actualidad la ciudad dispone ya de una instalación. En este capítulo de pretende diseñar la segunda instalación necesaria, dejando para un futuro el estudio de las tercera y cuarta.

En la Figura 7.1 se muestra el área de influencia del punto limpio actual, señalado en naranja, de acuerdo con la distancia máxima hasta el punto limpio establecida en la metodología del capítulo 6 (5.000 metros). 


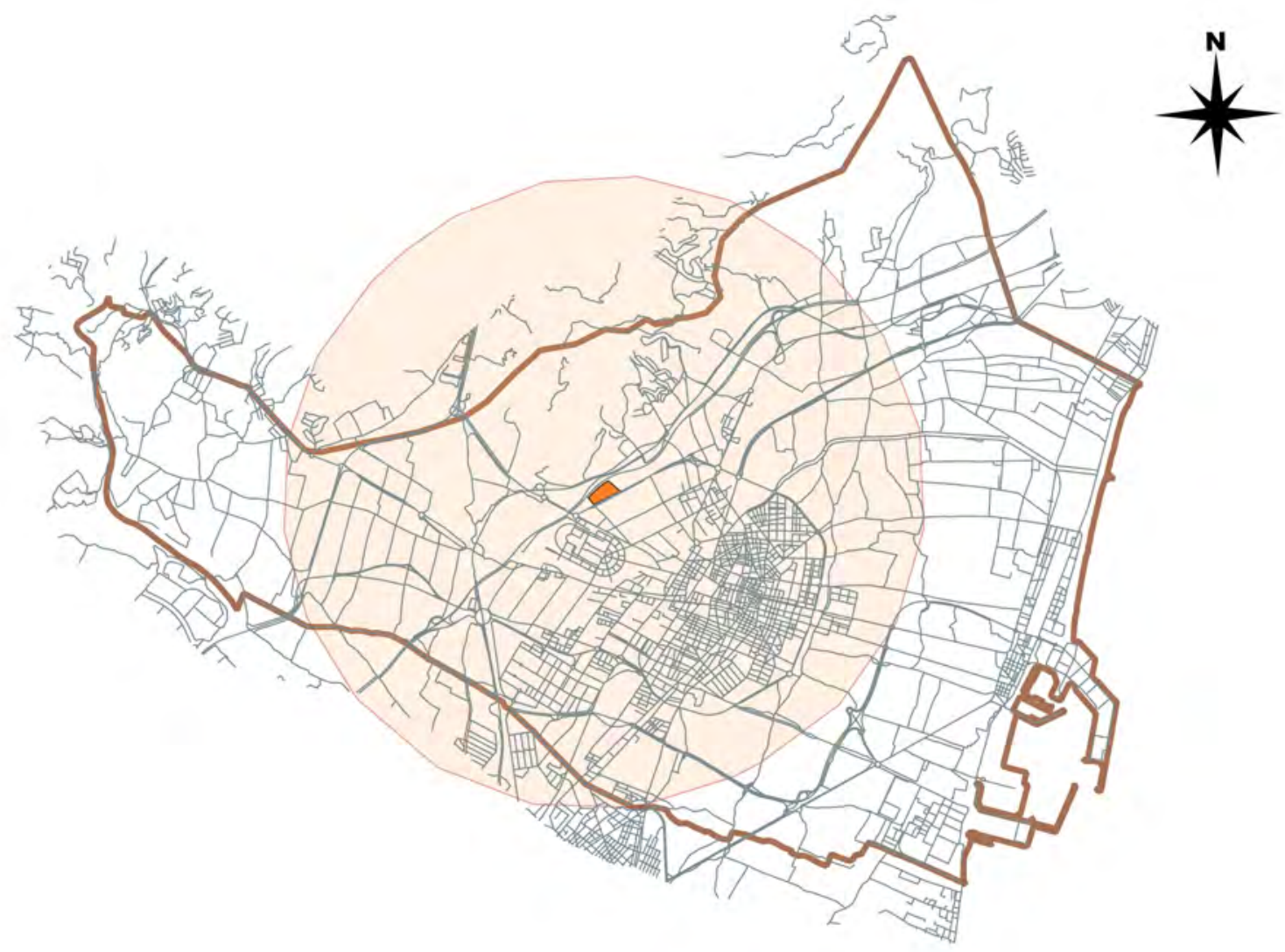

Figura 7.1: Término municipal de Castelló y área atendida por punto limpio actual.

Se observa que la zona urbana de la ciudad de Castelló de la Plana se encuentra dentro del área de influencia delimitada por dicha distancia máxima a la instalación.

De acuerdo con los datos del Instituto Nacional de Estadística, a 1 de enero de 2020 la población de Castellón se agrupa en 3 grandes núcleos:

\begin{tabular}{|l|r|}
\hline \multicolumn{1}{|c|}{ NÚCLEO } & \multicolumn{2}{|c|}{ POBLACIÓN } \\
\hline Castellón & 147.001 \\
\hline Grao & 15.243 \\
\hline Diseminado & 12.020 \\
\hline
\end{tabular}

Tabla 7.2: Población de la ciudad de Castelló por núcleos urbanizados.

Por tanto, el área no atendida actual se estima que cuenta con una población máxima de 27.263 habitantes, correspondiente al Grao y el Diseminado de Castellón. Para esta población, la cantidad de puntos limpios según la metodología es de uno.

Por otro lado, se observa que la población atendida por el punto limpio actual es superior a los 50.000 habitantes señalados en la metodología, por lo que, en función de la ubicación elegida, 
podría realizarse una reasignación de parte de la población adscrita al punto limpio actual, alcanzándose una población total adscrita al punto limpio en diseño de 50.000 habitantes.

\subsubsection{Estudio local de microvertederos.}

En el capítulo 3 se ha observado que la presencia de microvertederos en el término municipal de Castellón ha evolucionado en los últimos años, tanto cuantitativamente como en lo que respecta a su distribución geográfica: se han reducido en la zona situada al oeste del casco urbano, concentrándose alrededor de la mitad oriental del casco urbano, y en la sección del término municipal situada entre el límite Este del casco urbano y el límite del término municipal con la costa del mar Mediterráneo.

Asimismo, la caracterización de los restos abandonados en los microvertederos muestra que su composición está formada, principalmente, por:

- Residuos de Construcción y Demolición (RCD).

- Residuos voluminosos.

- Restos vegetales.

Como ya se desprendía en estudios anteriores, cualitativamente, el tipo de microvertederos presentes en el término municipal no ha variado.

Por tanto, atendiendo al criterio de análisis de microvertederos, el nuevo punto limpio deberá construirse en una localización cuya área de influencia se sitúe en la zona de mayor presencia de microvertederos; es decir, al Este del casco urbano de la ciudad. En la Figura 7.2 se muestra la zona en que se concentran los microvertederos en el área en estudio. 


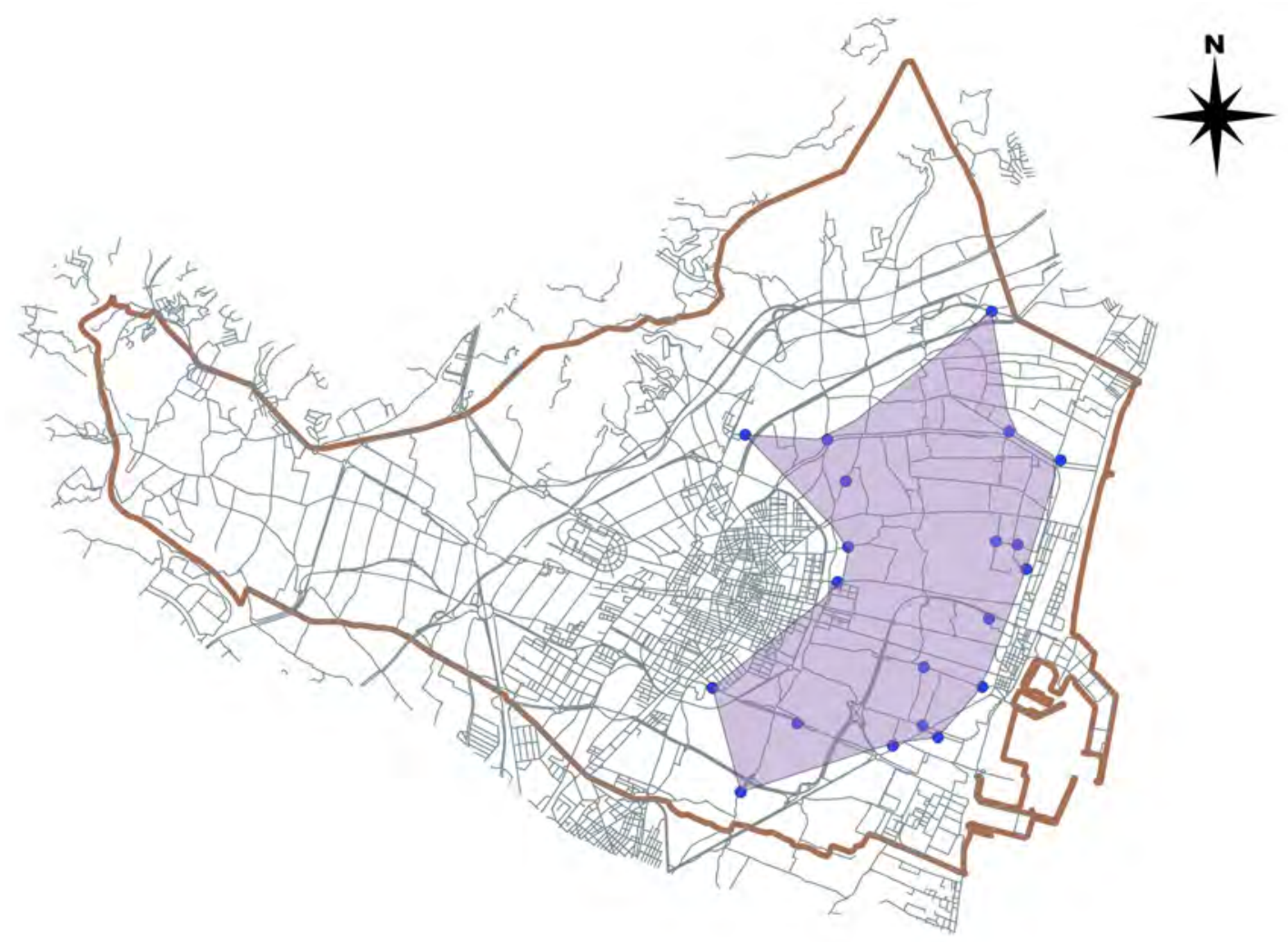

Figura 7.2: Microvertederos al Este de la ciudad de Castelló.

La caracterización de los residuos abandonados deberá tenerse en consideración más adelante, para la definición de condiciones de funcionamiento en los puntos 7.1.1.7 y 7.1.3.4.

\subsubsection{Distancia al núcleo urbano.}

En la Figura 7.3 se muestran, señalados en color verde oscuro, los núcleos urbanizados no atendidos por el punto limpio actual y, en color rojo, el principal núcleo urbano, correspondiente al Grao. Debido a la morfología de las áreas no atendidas, se prevé que no resulte posible adscribir la población de toda el área no atendida al nuevo punto limpio.

Puesto que se ha observado que los resultados de gestión del punto limpio disminuyen a medida que aumenta la distancia de la instalación al núcleo urbano al que se encuentran asociados, con una distancia máxima de $5 \mathrm{~km}$, y dada la morfología del núcleo urbano del Grao, que discurre longitudinalmente en dirección norte-sur, se considera que lo más adecuado es que la distancia entre el perímetro del núcleo urbano y el punto limpio no sea superior a 1,5 km. Esta zona aparece en la Figura 7.3 marcada en color azul. 


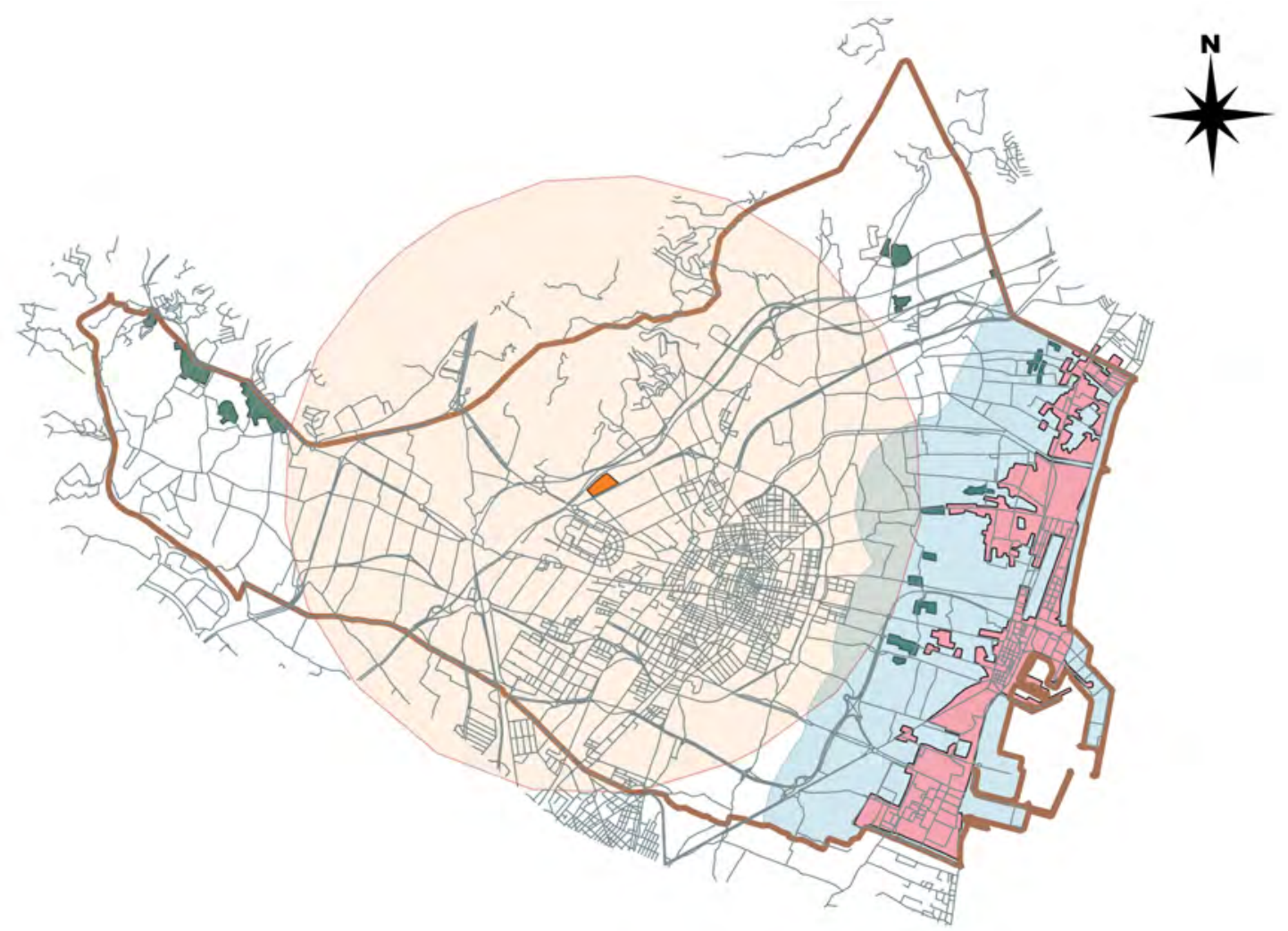

Figura 7.3: Núcleos urbanos no atendidos por punto limpio actual y distancia límite de la instalación.

\subsubsection{Transporte público.}

El servicio de transporte público constituye un aspecto sobre el que existe una recomendación, que sugiere que la localización disponga de servicio de transporte público en las proximidades. En la Figura 7.4 se muestra la infraestructura actual de este servicio, en el ámbito geográfico de estudio. 


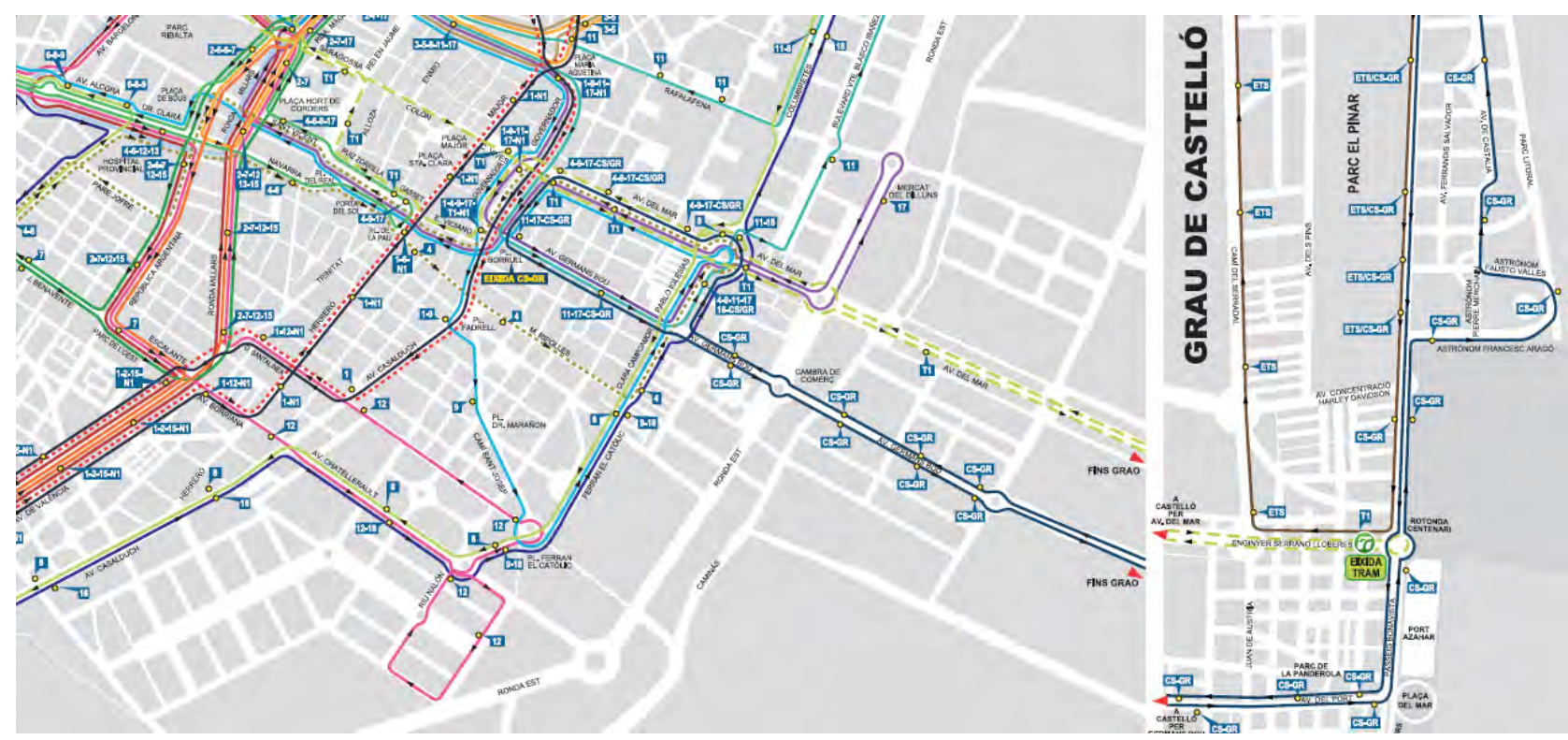

Figura 7.4: Transporte público en la ciudad de Castelló.

\subsubsection{Carril bici.}

Como en el punto anterior, la disponibilidad de carril bici en las proximidades es una recomendación contemplada en la metodología, bien teniendo en cuenta la infraestructura existente, bien mediante la localización del punto limpio en proximidades de vías susceptibles de dotación futura de carril bici.

Actualmente, la ciudad de Castellón se encuentra en un proceso de desarrollo de la infraestructura municipal de carril bici, que se está llevando a cabo principalmente en el ámbito de los núcleos urbanos, y mediante la mejora de la conectividad entre ellos.

Teniendo en cuenta los apartados anteriores, el punto limpio de nueva instalación deberá localizarse en las proximidades del núcleo urbano del Grao, entre éste y el núcleo de Castellón, por lo que el desarrollo de infraestructura de carril bici en el interior de ambos núcleos no constituye, a priori, un factor determinante, al contrario de la disponibilidad de carril bici que conecte ambos núcleos, o éstos con parte del diseminado.

En la Figura 7.5 se muestra, coloreada en verde, la infraestructura actual de carril bici en la zona objeto de estudio. 


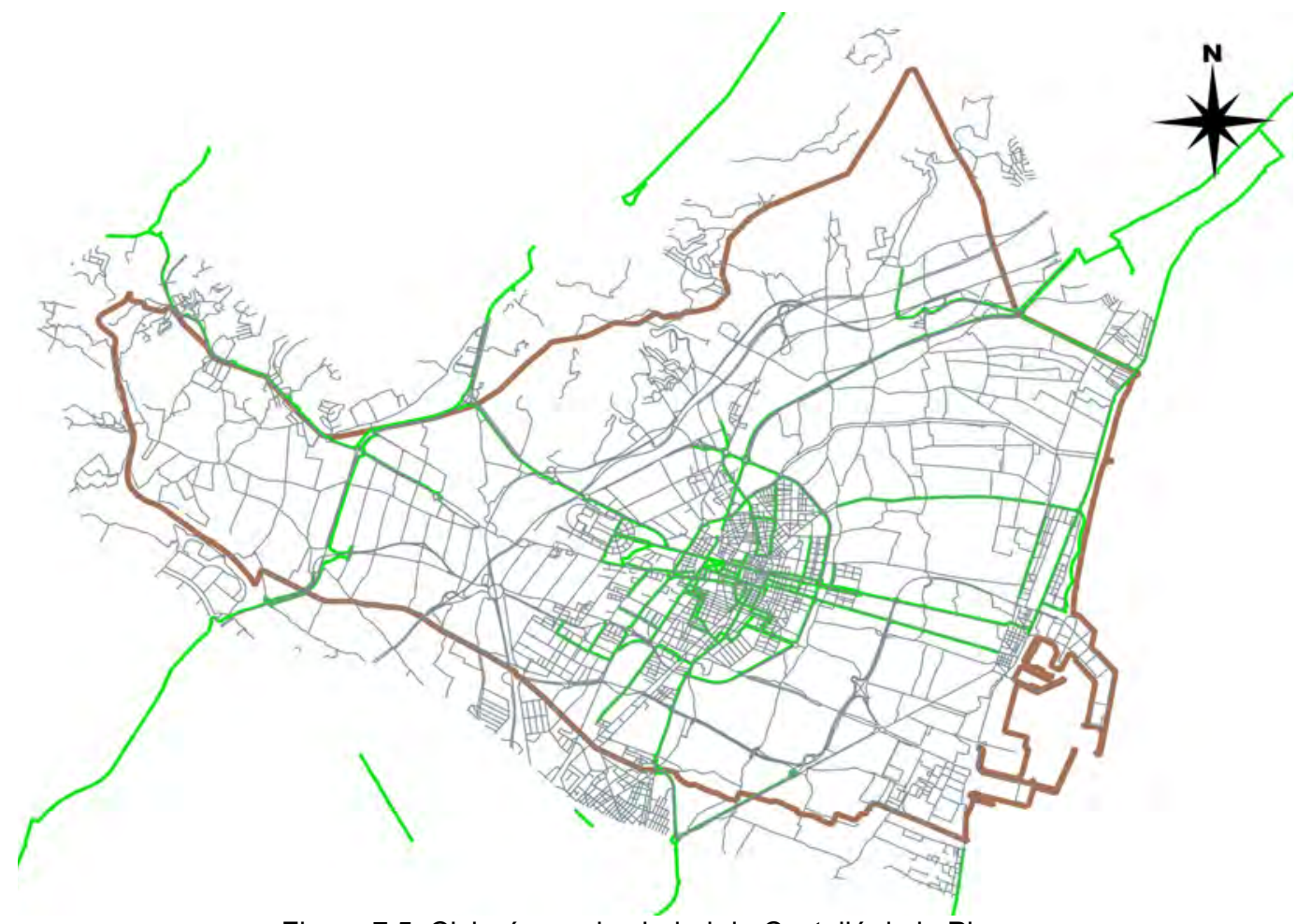

Figura 7.5: Ciclovías en la ciudad de Castelló de la Plana.

\subsubsection{Propuestas de localización}

Teniendo en cuenta los puntos anteriores, en la Figura 7.6 se muestran, marcadas en amarillo, posibles ubicaciones para el punto limpio objeto de diseño. Éstas tienen en cuenta las condiciones descritas en las Figuras 7.2, 7.3, 7.4 y 7.5. Además, en este caso también se tiene en consideración a la disponibilidad de suelo dotacional donde la compatibilidad urbanística de esta instalación sea favorable. Obteniendo 5 posibles ubicaciones de diferentes superficies. 


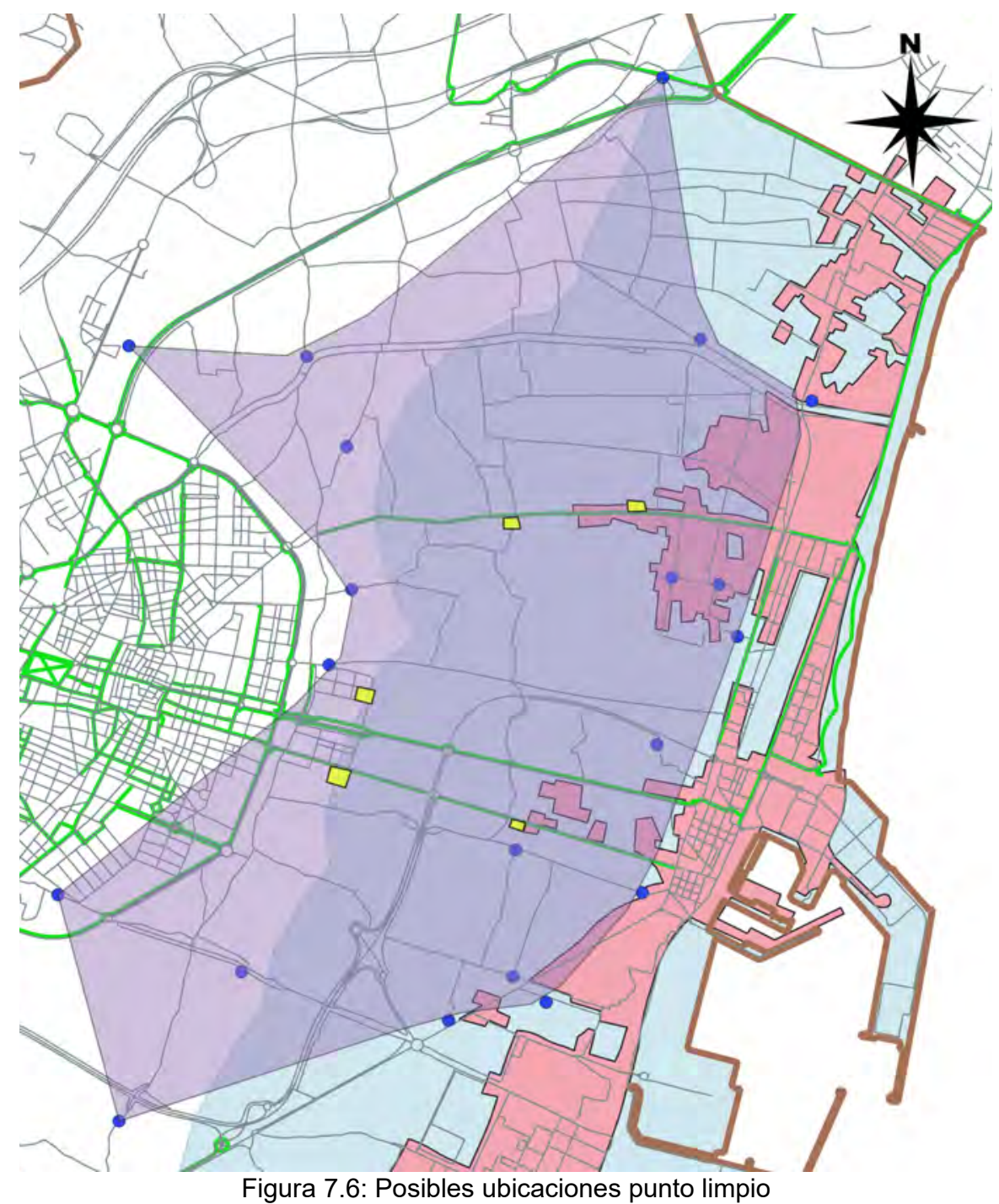

\subsubsection{Población adscrita y áreas no atendidas.}

Puesto que el frente litoral tiene un extensión de aproximadamente $9 \mathrm{~km}$, la única solución que permitiría incluir dentro del área de influencia del punto limpio la totalidad de la población del Grao sería la instalación del mismo en el interior del núcleo urbano. Teniendo en cuenta las áreas de influencia mostradas en la Figura 7.7 y la distribución de población de la Tabla 7.2, podría considerarse que la adscripción al área de influencia, en cualquiera de estas ubicaciones, incluiría al $90 \%$ de la población del Grao y al $60 \%$ de la población del Diseminado; es decir, a 20.931 habitantes, más parte de la actualmente adscrita al punto limpio existente, por lo que la población no atendida ascendería a 6.332 habitantes, repartidos entre los núcleos del Grao (1.524 habitantes) y los diseminados (4.808 habitantes). 


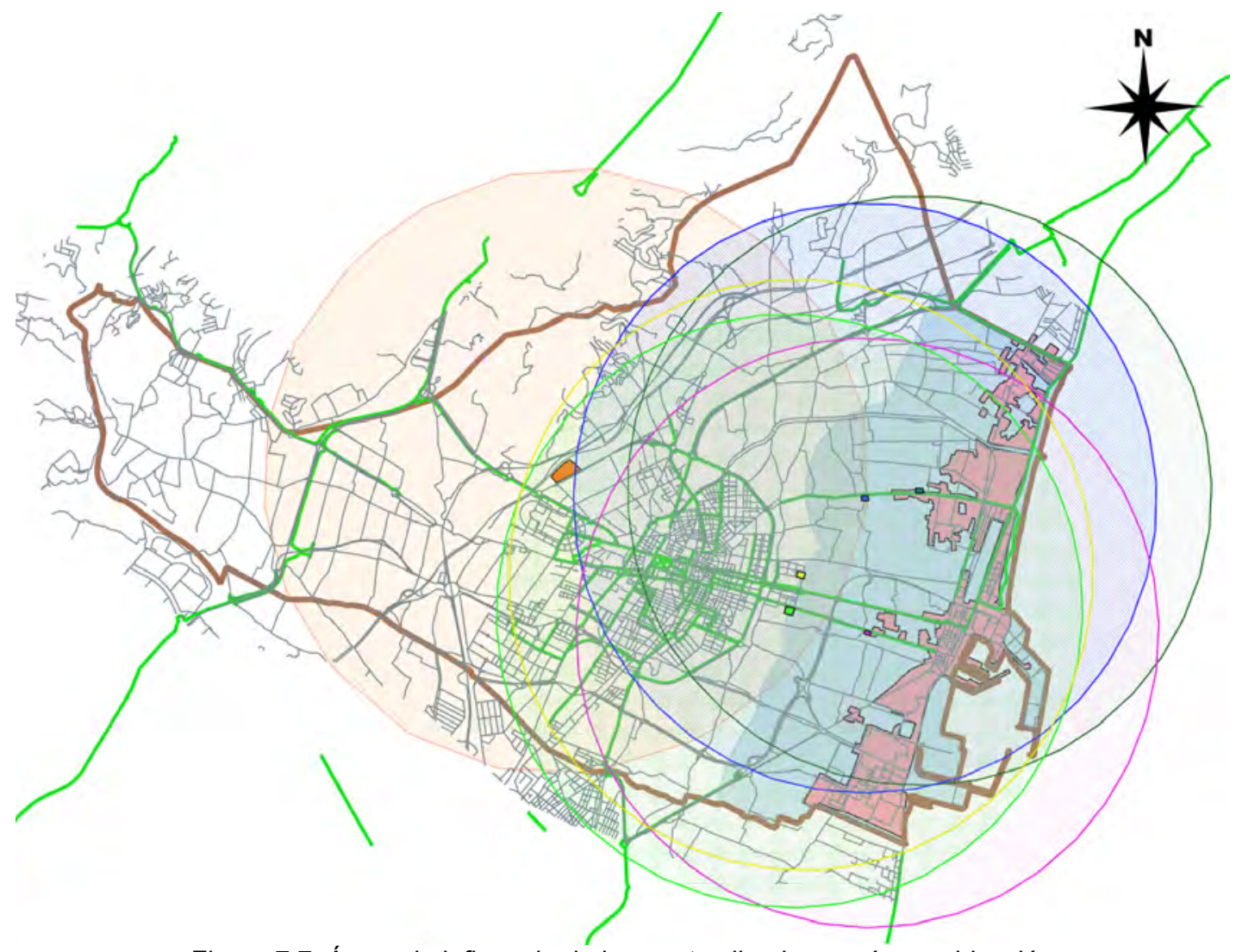

Figura 7.7: Áreas de influencia de los puntos limpios según su ubicación

La ubicación definitiva dependerá de la disponibilidad de terrenos, clasificación, superficie necesaria y costes de adquisición, entre otros. Definida ésta, deberá tenerse en cuenta la adscripción de parte de la población del núcleo urbano de Castelló, en función de la delimitación definitiva del área de influencia.

Para la población no adscrita, inferior a 5.000 habitantes y que corresponde a diferentes núcleos urbanos de pequeño tamaño, se considera que lo más adecuado es establecer un servicio mediante punto limpio móvil, que permita aproximar el servicio con la frecuencia que se establezca a cada núcleo. Este aspecto se tendrá en cuenta en el apartado 7.1.2.8 de Infraestructuras. 


\subsubsection{Infraestructuras del punto limpio.}

Se desarrolla a continuación el proceso de definición de las infraestructuras con que deberá contar el punto limpio, tanto desde el punto de vista de sus dimensiones como de servicios asociados.

\subsubsection{Superficie del punto limpio.}

Puesto que la población adscrita se sitúa entre 5.000 y 50.000 habitantes, la cantidad de suelo necesario para su implementación deberá ser de entre 1.000 y $3.000 \mathrm{~m}^{2}$. Teniendo en cuenta el amplio catálogo de residuos admisibles definido en el punto 7.1.1.7, el criterio de autorización de acceso a empresas del punto 7.1.3.4 y el número de contenedores definido en el punto 7.1.2.2, la superficie necesaria para la construcción del punto limpio es de $3.000 \mathrm{~m}^{2}$.

\subsubsection{Contenedores caja abierta.}

Para el almacenamiento de los diferentes residuos admisibles, el punto limpio deberá contar con un mínimo de 4 contenedores de gran volumen tipo caja abierta, y un máximo de 11. No obstante, teniendo en cuenta el criterio de autorización de acceso a empresas del punto 7.1.3.4, se prevé que las cantidades de RCD, voluminosos y restos de poda depositadas en el punto limpio sean elevadas, por lo que se requerirá una alta frecuencia de transporte a gestor autorizado de estos tipos de residuos. Por tanto, y con el objetivo de no afectar a la disponibilidad de espacio para el depósito de estos residuos, se dispondrá de 2 contenedores adicionales para su instalación en los fosos de aportación de estas fracciones cuando el contenedor se haya retirado para el transporte del material al gestor de tratamiento.

Además, teniendo en cuenta las fracciones de residuos admisibles que definidas en el punto 7.1.1.7, se deberá dotar a la instalación de contenedores de capacidad variable para el depósito de pilas, aceite, pinturas y disolventes, aceite motor, envases contaminados. En el caso de los depósitos para el almacenamiento de residuos peligrosos (pinturas, aceite motor), los contenedores deberán contar con las especificaciones y certificados de homologación correspondientes (doble pared, sistemas de retención de vertidos accidentales). 


\subsubsection{Número de cotas constructivas.}

Teniendo en cuenta la población adscrita, el punto limpio se construirá a 2 cotas; es decir:

- Nivel de circulación para usuarios de la instalación.

- Nivel de circulación para vehículos del servicio.

\subsubsection{Báscula.}

Al contar con población adscrita superior a 5.000 habitantes, la instalación deberá contar con una báscula para el pesaje de los vehículos del servicio, de manera que puedan registrarse las cantidades de residuos derivadas a los correspondientes gestores.

Puesto que el punto limpio contará con 2 cotas, la báscula deberá situarse en el nivel previsto para los vehículos del servicio; se recomienda que la báscula se encuentre conectada con la oficina de atención a los usuarios, centralizando así la información en un único punto.

Por otro lado, deberá contar con una báscula que permita medir las aportaciones realizadas por los usuarios.

\subsubsection{Cerramiento perimetral.}

En la fase de diseño del punto limpio, se deberá tener en cuenta que el perímetro de la instalación se encontrará delimitado, de manera que los equipamientos se encuentren protegidos, y pueda ordenarse de manera adecuada el uso que se hace de la instalación.

\subsubsection{Número de carriles de circulación.}

El número de carriles de circulación en cada uno de los sentidos en que ésta se ordene será de 1; con el objetivo de no afectar a la circulación del resto de usuarios, deberán preverse las zonas de detención de vehículos en cada punto de aportación.

\subsubsection{Oficina de atención al público y aseo.}

La instalación se diseñará de manera que cuente con una oficina de atención al público; por optimización del servicio, ésta se situará en las proximidades de la entrada a la instalación de los usuarios. Esta oficina realizará también las funciones de sala de concienciación e información para los usuarios. 
Se dotará además de aseos para los usuarios, estableciendo los pasos peatonales necesarios, debidamente señalizados, a fin de evitar accidentes.

\subsubsection{Puntos limpios móviles.}

Como se ha indicado en el punto 7.1.1.2, existe un área no atendida, formada por los pequeños núcleos urbanos y diseminados de la zona Oeste del término municipal y parte de los diseminados de la zona Este, cuya población se estima inferior a 5.000 habitantes, para la que se considera lo más adecuado definir un servicio a través de punto limpio móvil.

Este servicio podrá prestarse mediante la modificación de la programación del servicio actual, o a través de la incorporación de un punto limpio móvil adicional, que posibilite dar servicio a dicha área no atendida sin alterar el servicio que se presta actualmente.

\subsubsection{Condiciones de funcionamiento del punto limpio.}

Se enumeran a continuación los aspectos que deben considerarse para la fase de funcionamiento del servicio, que permitan optimizar las tasas de recuperación de residuos a través del punto limpio.

\subsubsection{Horarios de la instalación.}

No se han definido criterios relativos al horario de apertura y cierre o estacionalidad del mismo para los puntos limpios, por lo que éstos se establecerán basándose en la experiencia que posee el municipio a través de la instalación existente.

No obstante, sí se han establecido criterios referentes a los días de apertura, puesto que se ha observado que los puntos limpios que permanecen abiertos en lunes presentan mejores resultados que aquéllos que cierran en dicho día.

Por tanto, en caso de que, por cuestiones económicas y organizativas, la Administración considere que no es posible la prestación del servicio de punto limpio en esta instalación todos los días de la semana, deberá tenerse en cuenta que los lunes sí deberá abrir al público. Vistos los índices de correlación entre la apertura en un día concreto de la semana y los resultados de TR y TV del capítulo 5, el cierre semanal tendrá lugar los jueves. 


\subsubsection{Fracciones admisibles.}

Teniendo en cuenta que la caracterización de los microvertederos, estudiados en el capítulo 3, muestra que los residuos vertidos en los mismos están principalmente formados por:

- Residuos de Construcción y Demolición.

- Residuos voluminosos.

- Restos vegetales.

Se admitirán dichas fracciones, cuyo depósito, dadas las características físicas de estos residuos, se realizará en contenedores tipo caja abierta. Además, se instalarán contenedores de la misma tecnología que la empleada por el servicio de recogida municipal en vía pública para el depósito de residuos de papel-cartón, envases ligeros y vidrio.

Teniendo en cuenta además que los puntos limpios están convirtiéndose en infraestructuras para la recuperación de cada vez mayor diversidad de residuos, dando así respuesta a la creciente sensibilización ciudadana, que demanda de este tipo de servicios, que permiten reducir las cantidades de residuos depositados en los contenedores de fracción resto, se incorporarán las siguientes fracciones al catálogo de residuos admitidos:

- Residuos de Aparatos Eléctricos y Electrónicos (incluidas bombillas y tubos fluorescentes).

- Pilas.

- Aceite doméstico.

- Residuos metálicos.

- Plástico (no envase).

- Cartón voluminoso.

- Residuos peligrosos: pinturas y disolventes, aceite motor, envases vacíos contaminados.

Deberán tenerse en cuenta las condiciones de almacenamiento de RAEE, conforme a las indicaciones de la metodología. Puesto que se han incorporado al catálogo de residuos admisibles los residuos peligrosos, se tendrán en cuenta las condiciones de envasado, etiquetado y almacenamiento que sean de aplicación. En cuanto a la fracción resto, se ha considerado que esta fracción no forme parte del catálogo de residuos admitidos.

En función de las decisiones que se han adoptado respecto de las fracciones indicadas anteriormente, la superficie mínima del punto limpio es de $1.800 \mathrm{~m}^{2}$. Este resultado ya ha sido tenido en cuenta en el punto 7.1.2.1. 


\subsubsection{Incentivos por uso del servicio.}

Deberá configurarse un sistema de incentivación de uso de la instalación, que fomente el uso del servicio para la mejora de la gestión municipal de residuos. Ejemplos de estos incentivos son:

- Bonificación en tasas de servicio de recogida de residuos.

- Bonificación en tasas de servicios de tratamiento de residuos.

- Bonificaciones en especie, mediante acuerdo con comercios o establecimientos.

Puesto que, de acuerdo con el punto 7.1.2.4, la instalación contará con báscula para cuantificar las cantidades aportadas, la bonificación podrá establecerse de manera variable, en función de las cantidades depositadas, o de la cantidad de visitas realizadas. La definición concreta del tipo de incentivo corresponderá también a aspectos de decisión política del ayuntamiento.

\subsubsection{Acceso a empresas.}

Dado el volumen de residuos depositados en los microvertederos detectados en el capítulo 3 y la caracterización de los mismos del punto 5.1, se concluye que el origen mayoritario de los mismos, principalmente en lo que concierne a las fracciones de RCD y restos vegetales, se debe a la actividad de pequeñas y medianas empresas locales, por lo que en el punto limpio objeto de diseño se autorizará el acceso a empresas a la instalación, con objeto de ofrecer un mejor servicio, puesto que en la instalación actual no existe esta posibilidad. Por tanto deberá considerarse la definición de tasas por la utilización del servicio. Éstas podrán establecerse por número de visitas, fracción y cantidad de residuos depositados, o cualquier otro criterio que se considere.

Esta condición de funcionamiento del punto limpio implica que, de acuerdo con la metodología del capítulo 6, la superficie mínima necesaria para la dotación del punto limpio se incrementa hasta los $1.800 \mathrm{~m}^{2}$. Este resultado ya ha sido tenido en cuenta en el punto 7.1.2.1.

Para la racionalización en el uso del servicio y evitar la afección sobre los usuarios particulares por el depósito de residuos generados por las empresas, deberán establecerse límites de aportación (ver punto 7.1.3.5). 


\subsubsection{Límites de aportación.}

Los limites de aportación podrán fijarse en base a cantidades aportadas, atendiendo tanto a criterios de usuario:

- Particular.

- Empresas.

De cantidades aportadas en el periodo que se establezca:

- Diarias.

- Semanales.

- Mensuales.

- Anuales.

Se ha decidido no fijar limites de aportación en ningún caso a los particulares. Por contra las empresas tendrán un limite de aportación semanal en cantidades que definirán posteriormente las autoridades.

\subsubsection{Gestión.}

No existen criterios que permitan establecer un modelo de gestión (directa o indirecta) más óptimo para puntos limpios del tamaño a construir, por lo que la Administración podrá adoptar la opción que considere más idónea. Si bien al encontrarse el punto limpio existente gestionado por empresa privada a través de modelo de concesión, parece coherente hacer lo propio con el nuevo. 


\subsection{Resultados.}

Como resultado de la aplicación de la metodología diseñada en el capítulo 6, se han definido las condiciones de ubicación e infraestructuras necesarias del punto limpio con que debe dotarse a la ciudad, así como de funcionamiento del mismo.

Teniendo en cuenta la disponibilidad de suelo dotacional de propiedad municipal, la ubicación propuesta es la mostrada en la Figura 7.8 en color rojo.

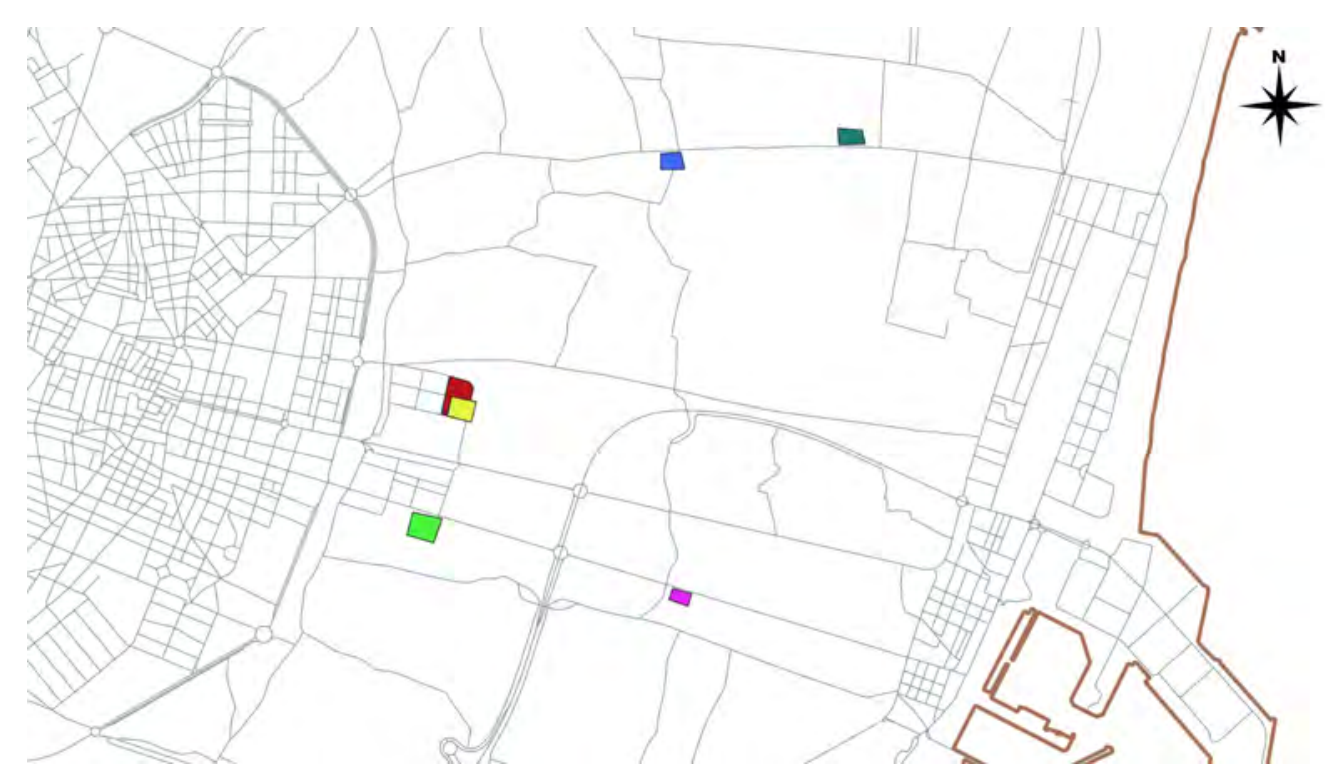

Figura 7.8: Propuestas iniciales y parcela disponible para instalación

Se trata de una parcela con una superficie de aproximadamente $25.000 \mathrm{~m}^{2}$, capaz de albergar la construcción del punto limpio definido; atendiendo a la disponibilidad existente, puede realizarse una reserva por la superficie definida en el punto 7.1.2.1, de $3.000 \mathrm{~m}^{2}$. La localización cumple con el requisito de ubicación en zona de concentración de microvertederos y se sitúa a $1,5 \mathrm{~km}$ del principal núcleo urbano de adscripción (Grao de Castelló), disponiendo de servicio de transporte público y carril bici en las proximidades.

Teniendo en cuenta las fracciones de residuos admisibles y el número de contenedores caja abierta establecidos en los puntos 7.1.1.7 y 7.1.2.2, respectivamente, así como el resto de especificaciones de la instalación definidas a lo largo del presente capítulo, en la Figura 7.9 se muestra la distribución en planta del punto limpio diseñado conforme a la metodología desarrollada en el capítulo 6 , cuya implantación daría servicio a las principales áreas no atendidas por el punto limpio actual de Castelló. 


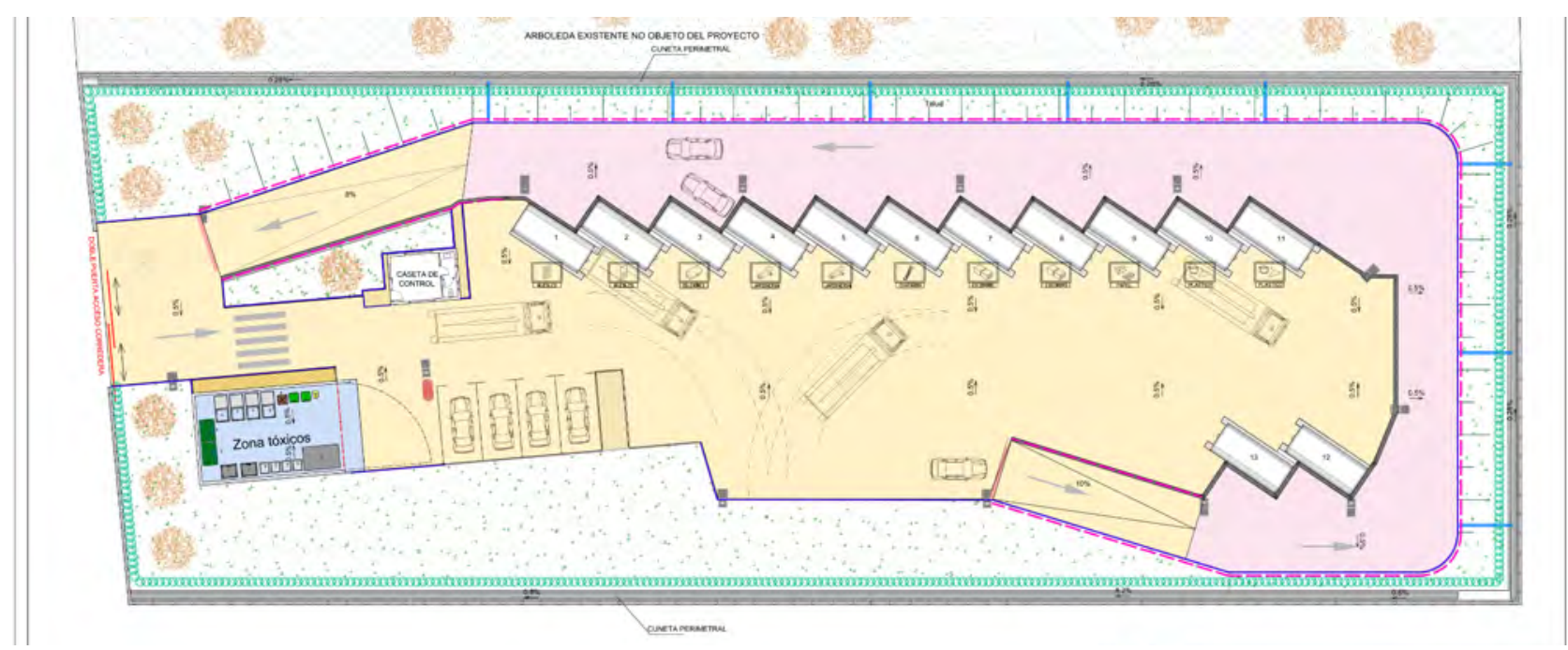

Figura 7.9: Distribución en planta del punto limpio.

En la Figura 7.9 se puede comprobar que en la entrada a la instalación se ha dispuesto una oficina de control de accesos y atención al público con aseo. Se trata de un punto limpio diseñado con construcción a 2 cotas, que dispone de 11 contenedores caja abierta para el depósito de las diferentes fracciones de residuos más voluminosos y con mayor cantidades de aportación esperadas, más 2 contenedores de reserva para mantener las condiciones de prestación del servicio durante las operaciones de transporte a los gestores autorizados. Asimismo, el punto limpio cuenta con un carril de circulación para los vehículos de los usuarios, con áreas de detención diseñadas de manera que permiten el depósito de residuos en los contenedores de caja abierta sin afectar a la circulación de otros usuarios.

La instalación cuenta con un área segregada para el depósito de residuos peligrosos, con una zona de estacionamiento de vehículos de usuarios anexa, frente a la oficina. Entre las zonas de tránsito y el cerramiento perimetral se han dispuesto áreas ajardinadas.

Teniendo en cuenta todos los parámetros de construcción y equipamiento del punto limpio y la distribución en planta diseñada, se ha elaborado un presupuesto que contempla todos los costes de movimiento de tierras, pavimentación, servicios (agua, saneamiento, electricidad, comunicaciones) y dotación de contenedores para el servicio, cuyo detalle se adjunta como Anexo A7.1. No se han contemplado los costes de adquisición de los terrenos. A continuación se incluye el resumen del presupuesto. 
1. Movimiento de tierras:

$75.393,06 €$

2. Muros de contención

$32.835,43 €$

3. Firmes, pavimentos y urbanización

$112.457 .49 €$

4. Red de saneamiento

$33.608,19 €$

5. Red de lixiviados

$2.692,50 €$

6. Electricidad, alumbrado, telefonía

$43.048,70 €$

7. Casetas y cubiertas de contenedores

$112.718,74 €$

8. Cerramientos y señalización

$43.634,59 €$

9. Equipamiento

$75.984,57 €$

10. Protección caída muelle

$7.232,62 €$

11. Vigilancia y control

$13.000,00 €$

12. Seguridad y salud

$5.249,76 €$

13. Control de calidad

$3.817,90 €$

PRESUPUESTO DE EJECUCIÓN MATERIAL

$561.673,55 €$

Por tanto, el presupuesto previsto asciende a quinientos sesenta y uno mil seiscientos setenta y tres euros y cincuenta y cinco céntimos, más IVA. 


\subsection{Conclusiones.}

La principal conclusión de este capitulo es que se ha comprobado la validación de la metodología propuesta para un caso concreto, definiendo todas las variables de localización, diseño y funcionamiento del punto limpio, resultando la aplicación con éxito.

Respecto de la aplicación concreta al caso de de Castelló de la Plana, destacar, que esta ciudad presenta 2 aspectos por los que se considera adecuado aplicar la metodología de diseño de puntos limpios, que permita mejorar la gestión de residuos de la ciudad:

- Presencia de microvertederos, concentrados en la zona Este del término municipal.

- Existencia de núcleos urbanos no atendidos por el punto limpio actual.

Se ha validado también para el caso de Castelló de la Plana, la prestación de servicio complementaria a través de punto limpio móvil a las áreas no atendidas por la infraestructura existente y la proyectada.

Además de las características definidas, deberá tenerse en consideración lo previsto en la legislación vigente que sea de aplicación, en este caso el PIRCV, en aquellos aspectos no previstos en la metodología o que no entren en contradicción con la misma. 

CAPítulo 8. Conclusiones. 



\section{CONCLUSIONES.}

\subsection{Introducción.}

En la presente Tesis se ha abordado la gestión de los residuos sólidos urbanos particularizando en aquellos que por su naturaleza no disponen de un circuito específico para su recogida. Se ha centrado en el caso particular de los puntos limpios, instalaciones diseñadas para la recogida de este tipo de residuos. Se ha estudiado la problemática existente de los microvertederos no autorizados y cómo este tipo de instalaciones puede minimizarla. Finalmente, se ha desarrollado una metodología para la definición de parámetros asociados a la localización, las infraestructuras y las condiciones de funcionamiento de los puntos limpios, así como su validación mediante su aplicación a la ciudad de Castelló de la Plana. Dicha metodología se ha apoyado en un estudio a nivel nacional sobre los puntos limpios existentes, del que se han obtenido las variables más importantes a tener en cuenta en el diseño.

Se ha analizado la problemática medioambiental que supone, a nivel global, la gestión de los residuos sólidos urbanos, motivada principalmente por el incremento de la utilización de productos de un solo uso y la falta de concienciación ciudadana en la materia. En el ámbito del territorio nacional, se ha realizado un análisis de la generación poniendo el foco en las áreas urbanas.

En lo referente a los aspectos legales de aplicación, se han analizado las normativas europea, nacional y autonómica en materia de residuos, especialmente en lo que concierne a la instalación de puntos limpios como unidad de gestión, así como las políticas y estrategias comunitarias de economía circular.

\subsection{Conclusiones.}

En el presente apartado se presentan las principales conclusiones obtenidas en cada uno de los diferentes capítulos de la Tesis.

En el Capítulo 3 se ha estudiado la influencia de los puntos limpios sobre la evolución de los microvertederos incontrolados en su área de influencia, a través del análisis del caso particular de Castelló de la Plana, mediante la comparativa de tres estudios desarrollados en distintos años. A este respecto, se ha observado una evolución positiva, con una reducción en el número de vertederos incontrolados en la ciudad entre los años 1998 y 2014, aunque sin que el efecto haya supuesto su desaparición definitiva. Este mismo estudio ha puesto de manifiesto que la instalación 
del punto limpio fijo, en la zona oeste de la ciudad, ha influido de forma clara en la disminución del número de microvertederos en las proximidades de la instalación. En cuanto a la composición y tamaño de los vertederos, se ha observado que el tipo de residuo predominante es el RCD, seguido de voluminosos y restos de poda, con un tamaño de vertido inferior a $100 \mathrm{~m}^{3}$. Como principal conclusión de este capítulo, se puede decir que la ubicación de un punto limpio en un área de influencia determinada reduce de forma significativa los microvertederos incontrolados, y este hecho puede ser generalizado a cualquier población.

Sin embargo, la ubicación de un punto limpio no puede atender únicamente al criterio de proximidad de microvertederos; es por ello que se debían estudiar otros factores que puedan presentar relevancia sobre el rendimiento y uso del punto limpio, ayudando a la modelización del mismo.

En el capítulo 4 se han identificado las variables que afectan al funcionamiento de un punto limpio. En primer lugar, se han analizado diferentes normativas autonómicas y se ha obtenido una relación de variables que, atendiendo tanto a estudios realizados por otros autores como a documentos legales y normativos oficiales, se consideran de especial relevancia en el diseño y ubicación de estas instalaciones. Estas variables se han clasificado en tres grupos: localización, infraestructuras y funcionamiento.

Para la localización, se ha puesto de manifiesto la importancia de la proximidad a los núcleos poblacionales, dado que son los ciudadanos los que deben transportar los residuos hasta los puntos limpios. También la comodidad en la accesibilidad al punto limpio y su circulación interior es importante a la hora de su diseño.

En cuanto a su funcionamiento, ha quedado demostrado que es importante la apertura en horario laboral y en fines de semana, al menos, uno de los días; así como disponer de un buen mantenimiento de la instalación. Del mismo modo, se ha demostrado de vital importancia el empleo de incentivos, que además de maximizar el uso del punto limpio, redundará en una reducción de los abandonos de residuos en la vía pública.

Respecto a la infraestructura, ha quedado demostrado que su tamaño dependerá de la población potencial a la que esté destinada, estableciéndose varios tipos de puntos limpios en función de ésta. Se ha destacado la importancia de la información exterior e interior y se propone que estas instalaciones actúen como dinamizadores medioambientales, asemejándose a centros de educación y sensibilización en materia de residuos.

Finalmente, se ha puesto de manifiesto que, en la actualidad, existe poca información publicada sobre el funcionamiento de los puntos limpios, resultando como principales fuentes documentales 
los textos legales y los Pliegos de Condiciones Técnicas de los contratos de explotación de estas instalaciones.

En el capítulo 5 se ha realizado un importante estudio de los puntos limpios implantados en España. Para ello, se envió una encuesta a una muestra representativa de poblaciones y se obtuvieron 91 respuestas, suficientes para realizar el análisis estadístico con unos niveles de confianza y error aceptables para este tipo de trabajos.

Se ha demostrado la influencia de las variables asociadas a la localización, infraestructuras y condiciones de funcionamiento de dichas instalaciones sobre las cantidades de residuos depositados (TR) y número de visitas recibidas (TV).

Respecto a la población adscrita a cada punto limpio, se han establecido de tres rangos poblacionales (rural, semiurbano y urbano), ya que se ha demostrado que las variables analizadas tienen una influencia distinta en función del tamaño del municipio.

En cuanto a variables de localización, se ha podido concluir que respecto al tamaño de población, los municipios menores de 5.000 habitantes presentan valores medios más altos de TR y TV. En cuanto a la distancia del punto limpio al núcleo urbano, se ha demostrado que las instalaciones situadas a menos de $0,5 \mathrm{~km}$ son las que presentan valores de TR y TV superiores.

Respecto las variables de infraestructura de los puntos limpios, se ha detectado influencia en la variable "superficie", donde se han encontrado diferencias significativas en la variable TV para las poblaciones semiurbanas, reportando un mayor número de visitas los puntos limpios menores a $3.000 \mathrm{~m}^{2}$.

También se ha encontrado influencia de la "antigüedad de la instalación", concluyéndose que únicamente se presentan diferencias estadísticamente significativas respecto a TV, que presenta valores más altos para las instalaciones construidas a partir de 2011.

Respecto a las variables de funcionamiento, se han detectado diferencias estadísticamente significativas en "autorización de acceso a empresas", "implantación de un sistema de incentivos por uso" y "existencia de límites de aportación". En el primer caso, se produce un claro incremento de las cantidades depositadas al tener acceso las empresas a los puntos limpios. En cuanto a los incentivos, se observa asimismo un incremento en las cantidades de residuos recuperados cuando existe algún tipo de incentivo. La fijación de límites de aportación afecta significativamente a los resultados TV, aumentando el número de visitas cuando hay límites en la aportación de residuos. En cuanto a los residuos admisibles, se ha observado que la disponibilidad de contenedores de fracción resto incrementa significativamente las cantidades totales de residuos 
gestionadas en los puntos limpios, pero este efecto se debe únicamente a las aportaciones de dicha fracción.

Respecto a los horarios de apertura, se ha estudiado la influencia de abrir los lunes y domingos, y aunque no se han encontrado diferencias significativas respecto a la mejora en la TR y TV, se recomienda que en caso de existir día de cierre éste no sea el lunes.

Con los resultados anteriores, en el capítulo 6, se ha elaborado una metodología a través de la cual se establecen las condiciones de localización, infraestructuras y funcionamiento de los puntos limpios. La metodología desarrolla cada uno de los aspectos que deben ser considerados para el diseño de los puntos limpios de nueva construcción, quedando resumida en un diagrama de proceso. Esta metodología se basa en la información del amplio estudio de campo realizado en el capítulo 5, teniendo en cuenta los casos de éxito de las instalaciones existentes. Así, se ha conseguido una herramienta de gran ayuda para el personal técnico a la hora diseñar este tipo de instalaciones.

Por último, en el capítulo 7 se ha validado la metodología mediante su aplicación al caso práctico de Castelló de la Plana, partiendo de las infraestructuras con que cuenta actualmente la ciudad y su ámbito geográfico de influencia. Como resultado de la aplicación del procedimiento diseñado, se concluye que es necesario dotar a la ciudad de nuevos puntos limpios. Teniendo en cuenta la necesidad detectada de puntos limpios para la ciudad de Castelló de la Plana, se ha desarrollado la propuesta de diseño para una de estas instalaciones, así como su valoración aproximada del coste. Se han obtenido las características que debe cumplir el punto limpio en cuanto a localización, infraestructuras de la instalación y funcionamiento del servicio, estableciendo igualmente la ubicación exacta. Por tanto, ha quedado demostrada la validez de la metodología propuesta en la presente Tesis.

\subsection{Desarrollos futuros.}

Tras la finalización de la Tesis, se han obtenido resultados interesantes que pueden dar pie a futuras investigaciones. A continuación, se mencionan aquellas que se consideran más inmediatas como prolongación natural al presente trabajo:

- A partir del desarrollo conceptual de la metodología debería desarrollarse una herramienta informática, preferiblemente bajo un entorno se sistema de información geográfica, de forma que se obtuviera una herramienta más ágil para la ayuda a la hora de diseño de los puntos limpios. 
- Por otro lado, puesto que el $14 \%$ de los municipios de España cuenta con poblaciones entre 5.000 y 50.000 habitantes, podría realizarse un estudio más específico sobre este tipo de municipios, que permitiese establecer subgrupos para los que definir de manera más acotada los factores de infraestructura del punto limpio.

- En esta tesis se han definido dos factores clave sobre los que se han estudiado todas las variables: la tasa de visitas y la tasa de recogida por habitante y año. Tal vez podrían analizarse otros factores de circularidad que pudieran favorecer la eficiencia del punto limpio desde el punto de vista la economía circular.

- De la investigación realizada, ha quedado demostrada la importancia de la incentivación para el uso de los puntos limpios. Ello, sumado al rápido desarrollo de las tecnologías de la información, debe conducir hacia un modelo en el que además del pago por generación, se disponga de un histórico de datos que permitan analizar tendencias e incluso prever comportamientos ciudadanos en cuanto a la gestión de residuos domésticos. Deben generarse herramientas encaminadas a la integración de todos estos aspectos.

Por último, éste y otros análisis realizados en materia de residuos sólidos urbanos deben servir para continuar fomentando la investigación en el campo de los residuos, ya que sin duda, comprende uno de los ejes principales tanto a nivel de desarrollo normativo, como a nivel medioambiental y de desarrollo sostenible de las ciudades en los próximos años. 

ANEXOS. 



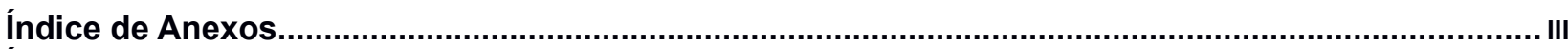

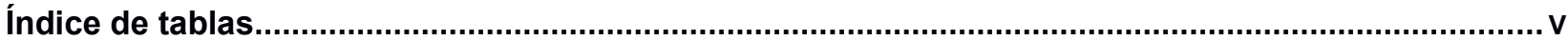

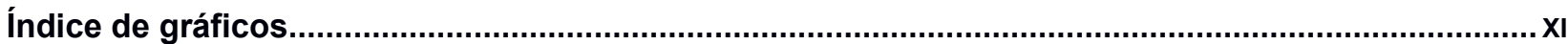

ANEXO A5.1. ENCUESTA PILOTO

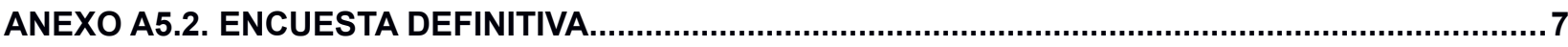

ANEXO A5.3. TABLA DE RESPUESTAS A LA ENCUESTA

ANEXO A5.4. ESTUDIO DE INFLUENCIA DE VARIABLES SOBRE LOS RESULTADOS DE TR Y TV

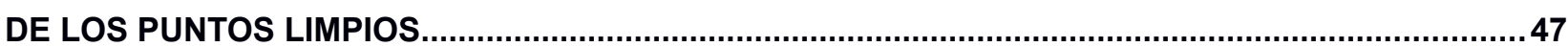

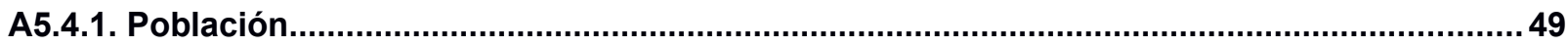

A5.4.1.1. Análisis de TR considerando factor de comparación la población....................................49

A5.4.1.2. Análisis de TV considerando factor de comparación la población.....................................53

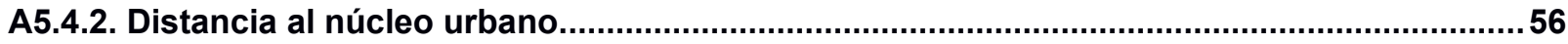

A5.4.2.1. Análisis de TR considerando factor de comparación la distancia al núcleo urbano...........56

A5.4.2.2. Análisis de TV considerando factor de comparación la distancia al núcleo urbano.............59

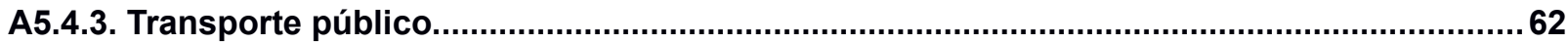

A5.4.3.1. Análisis de TR considerando factor de comparación la disponibilidad de transporte público.

A5.4.3.2. Análisis de TV considerando factor de comparación la disponibilidad de transporte público.

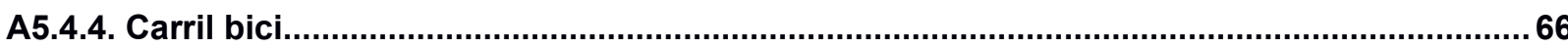

A5.4.4.1. Análisis de TR considerando factor de comparación la existencia de carril bici.................66

A5.4.4.2. Análisis de TV considerando factor de comparación la existencia de carril bici.................68

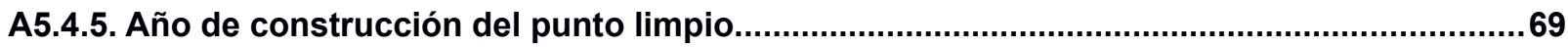

A5.4.5.1. Análisis de TR considerando factor de comparación el año de construcción......................70

A5.4.5.2. Análisis de TV considerando factor de comparación el año de construcción......................73

A5.4.6. Número de carriles de circulación por sentido..................................................................76

A5.4.6.1. Análisis de TR considerando factor de comparación el número de carriles de circulación..77

A5.4.6.2. Análisis de TV considerando factor de comparación el número de carriles de circulación.. 78

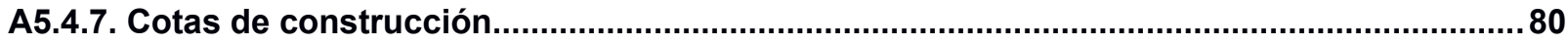

A5.4.7.1. Análisis de TR considerando factor de comparación el número de cotas constructivas......81

A5.4.7.2. Análisis de TV considerando factor de comparación el número de cotas constructivas......82

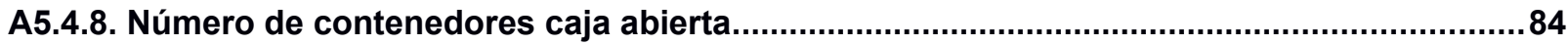

A5.4.8.1. Análisis de TR considerando factor de comparación el número de contenedores caja

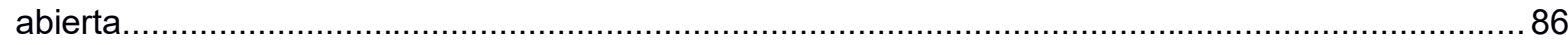

A5.4.8.2. Análisis de TV considerando factor de comparación el número de contenedores caja

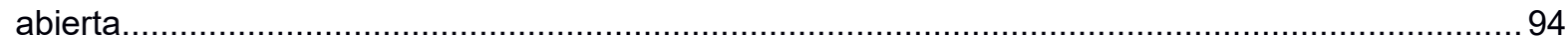

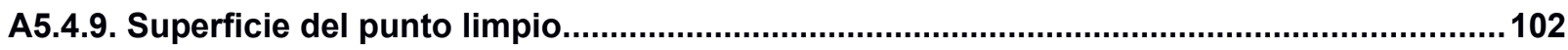

A5.4.9.1. Análisis de TR considerando factor de comparación la superficie del punto limpio...........104

A5.4.9.2. Análisis de TV considerando factor de comparación la superficie del punto limpio...........112

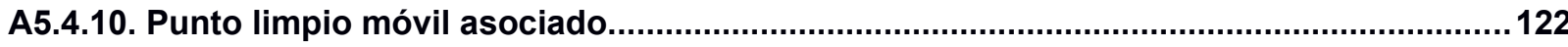

A5.4.10.1. Análisis de TR considerando factor de comparación la presencia de punto limpio móvil

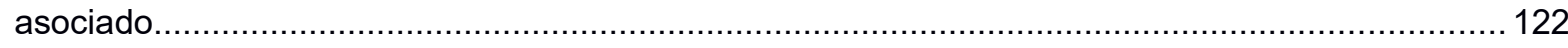

A5.4.10.2. Análisis de TV considerando factor de comparación la presencia de punto limpio móvil asociado. 
A5.4.11. Horario de apertura.

A5.4.11.1. Análisis de TR considerando factor de comparación el horario de apertura......

A5.4.11.2. Análisis de TV considerando factor de comparación los días de apertura semanal........130

A5.4.12. Acceso a empresas.

A5.4.12.1. Análisis de TR considerando factor de comparación la autorización de acceso a empresas.

A5.4.12.2. Análisis de TV considerando factor de comparación la autorización de acceso a empresas.

A5.4.13. Incentivos por utilización.

A5.4.13.1. Análisis de TR considerando factor de comparación la existencia de incentivos por utilización.

A5.4.13.2. Análisis de TV considerando factor de comparación la existencia de incentivos por utilización.

A5.4.14. Límites de aportación

A5.4.14.1. Análisis de TR considerando factor de comparación la limitación de cantidades aportadas.

A5.4.14.2. Análisis de TV considerando factor de comparación la limitación de cantidades aportadas.

A5.4.15. Tipo de gestión.

A5.4.15.1. Análisis de TR considerando factor de comparación la gestión de la instalación.............148

A5.4.15.2. Análisis de TV considerando factor de comparación la gestión de la instalación............151

A5.4.16. Admisión de fracción resto

A5.4.16.1. Análisis de TR considerando factor de comparación la disponibilidad de contenedores de resto

A5.4.16.2. Análisis de TV considerando factor de comparación la disponibilidad de contenedores de resto.

A5.4.17. Depósito de RAEE.

A5.4.17.1. Análisis de TR considerando factor de comparación la zona de almacenamiento de RAEE

A5.4.17.2. Análisis de TV considerando factor de comparación la zona de almacenamiento de RAEE. 
Tabla 5.4.1: Media, desviación estándar, error estándar e intervalo de confianza de TR para los grupos de población adscrita.

Tabla 5.4.2: Kruskal-Wallis. No de elementos y rango medio de TR en cada grupo de población adscrita.......................52

Tabla 5.4.3: Resultados del test de Kruskal-Wallis de significación de TR respecto de la población adscrita..................52

Tabla 5.4.4: Resultados del test de Kruskal-Wallis de TR entre grupos de población....................................................52

Tabla 5.4.5: Media, desviación estándar, error estándar e intervalo de confianza de TV para los grupos de población adscrita

Tabla 5.4.6: Resultados del test de Levene para TV y tamaño de población adscrita..................................................54

Tabla 5.4.7: Resultados del test ANOVA-Welch para TV y tamaño de población adscrita.............................................55

Tabla 5.4.8: Resultados de las pruebas post-hoc de significación de TV entre grupos de población adscrita..................55 Tabla 5.4.9: Media, desviación estándar, error estándar e intervalo de confianza de TR para los grupos de distancia a

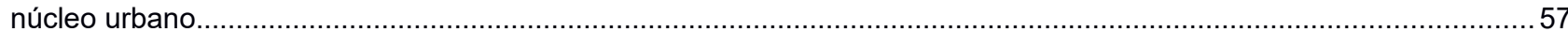

Tabla 5.4.10: Kruskal-Wallis. No de elementos y rango medio de TR en cada grupo de distancia a núcleo urbano..........57 Tabla 5.4.11: Resultados de significación del test de Kruskal-Wallis de TR respecto de la distancia al núcleo urbano.....58 Tabla 5.4.12: Resultados del test de Kruskal-Wallis de TR entre grupos de distancia al núcleo urbano..........................58 Tabla 5.4.13: Media, desviación estándar, error estándar e intervalo de confianza de TV para los grupos de distancia a núcleo urbano

Tabla 5.4.14: Resultados del test de Levene para TV y distancia al núcleo urbano.....................................................60

Tabla 5.4.15: Resultados del test ANOVA-Welch para TV y distancia al núcleo urbano................................................60 Tabla 5.4.16: Resultados de las pruebas post-hoc de significación de TV entre grupos de distancia a núcleo urbano.....61 Tabla 5.4.17: Media, desviación estándar, error estándar e intervalo de confianza de TR para los grupos de disponibilidad de transporte público

Tabla 5.4.18: Kruskal-Wallis. $N^{\circ}$ de elementos y rango medio de TR en cada grupo de disponibilidad de transporte público

Tabla 5.4.19: Resultados de significación del test de Kruskal-Wallis de TR respecto de la disponibilidad de transporte público.

Tabla 5.4.20: Media, desviación estándar, error estándar e intervalo de confianza de TV para los grupos de disponibilidad de transporte público

Tabla 5.4.21: Resultados del test de Levene para TV y disponibilidad de transporte público..........................................65

Tabla 5.4.22: Resultados test ANOVA para TV y disponibilidad de transporte público...............................................65

Tabla 5.4.23: Media, desviación estándar, error estándar e intervalo de confianza de TR para los grupos de

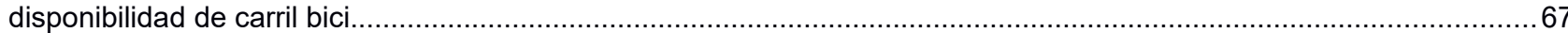

Tabla 5.4.24: Kruskal-Wallis. No de elementos y rango medio de TR en cada grupo de disponibilidad de carril bici.........67 Tabla 5.4.25: Resultados de significación del test de Kruskal-Wallis de TR respecto de la disponibilidad de carril bici....67 Tabla 5.4.26: Media, desviación estándar, error estándar e intervalo de confianza de TV para los grupos de disponibilidad de carril bici....

Tabla 5.4.27: Resultados del test de Levene para TV y disponibilidad de carril bici................................................69

Tabla 5.4.28: Resultados test ANOVA para TV y disponibilidad de carril bici......................................................69

Tabla 5.4.29: Media, desviación estándar, error estándar e intervalo de confianza de TR para los grupos de antigüedad

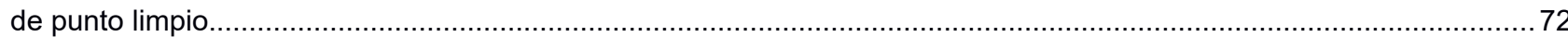
Tabla 5.4.30: Kruskal-Wallis. $\mathrm{N}^{\circ}$ de elementos y rango medio de TR en cada grupo de antigüedad de punto limpio........72 Tabla 5.4.31: Resultados de significación del test de Kruskal-Wallis de TR respecto de la antigüedad de punto limpio.. .72 Tabla 5.4.32: Media, desviación estándar, error estándar e intervalo de confianza de TV para los grupos de antigüedad de punto limpio

Tabla 5.4.33: Resultados del test de Levene para TV y antigüedad del punto limpio....................................................74

Tabla 5.4.34: Resultados del test ANOVA-Welch para TV y antigüedad del punto limpio............................................75 Tabla 5.4.35: Resultados de las pruebas post-hoc de significación de TV entre grupos de antigüedad del punto limpio..75 Tabla 5.4.36: Media, desviación estándar, error estándar e intervalo de confianza de TR para los grupos de $n^{\circ}$ de carriles

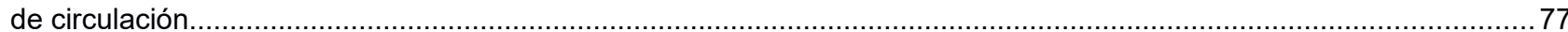

Tabla 5.4.37: Kruskal-Wallis. $N^{\circ}$ de elementos y rango medio de TR en cada grupo de $n^{\circ}$ de carriles de circulación........78 Tabla 5.4.38: Resultados de significación del test de Kruskal-Wallis de TR respecto del $n^{\circ}$ de carriles de circulación......78 
Tabla 5.4.39: Media, desviación estándar, error estándar e intervalo de confianza de TV para los grupos de $n^{\circ}$ de carriles

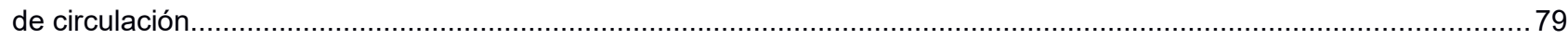

Tabla 5.4.40: Resultados del test de Levene para TV y $\mathrm{n}^{\circ}$ de carriles de circulación.......................................................79

Tabla 5.4.41: Resultados test ANOVA para TV y $\mathrm{n}^{\circ}$ de carriles de circulación..............................................................80

Tabla 5.4.42: Media, desviación estándar, error estándar e intervalo de confianza de TR para los grupos de $n^{\circ}$ de cotas

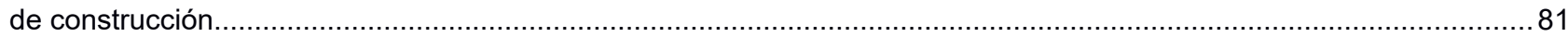

Tabla 5.4.43: Kruskal-Wallis. $N^{\circ}$ de elementos y rango medio de TR en cada grupo de $n^{\circ}$ de cotas de construcción.......82

Tabla 5.4.44: Resultados de significación del test de Kruskal-Wallis de TR respecto del $n^{\circ}$ de cotas de construcción.....82

Tabla 5.4.45: Media, desviación estándar, error estándar e intervalo de confianza de TV para los grupos de $n^{\circ}$ de cotas de construcción.

Tabla 5.4.46: Resultados del test de Levene para TV y $n^{\circ}$ de cotas de construcción....................................................83

Tabla 5.4.47: Resultados test ANOVA para TV y $\mathrm{n}^{\circ}$ de cotas de construcción............................................................84

Tabla 5.4.48: Clasificación de puntos limpios por número de contenedores y tamaño de población adscrita...................86

Tabla 5.4.49: Cantidad de puntos limpios rurales por número de contenedores caja abierta........................................87

Tabla 5.4.50: Media, desviación estándar, error estándar e intervalo de confianza de TR para los grupos de $n^{\circ}$ de

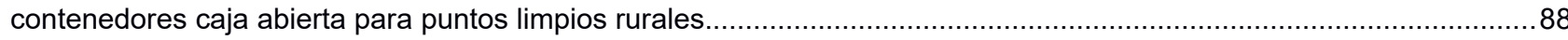
Tabla 5.4.51: Kruskal-Wallis. $N^{\circ}$ de elementos y rango medio de TR en cada grupo de $\mathrm{n}^{\circ}$ de contenedores caja abierta y

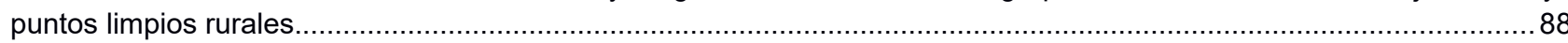
Tabla 5.4.52: Resultados de significación del test de Kruskal-Wallis de TR respecto del $\mathrm{n}^{\circ}$ de contenedores caja abierta para puntos limpios rurales.

Tabla 5.4.53: Kruskal-Wallis. $N^{\circ}$ de elementos y rango medio de TR en cada grupo de $\mathrm{n}^{\circ}$ de contenedores caja abierta y

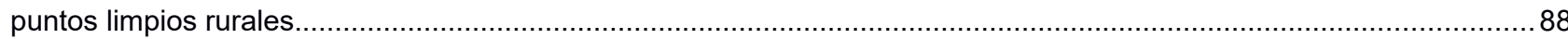

Tabla 5.4.54: Resultados de significación del test de Kruskal-Wallis de TR respecto del $\mathrm{n}^{\circ}$ de contenedores caja abierta

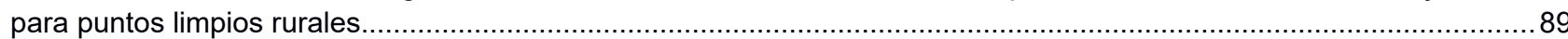

Tabla 5.4.55: Media, desviación estándar, error estándar e intervalo de confianza de TR para los grupos de $n^{\circ}$ de contenedores caja abierta para puntos limpios semiurbanos .......................................................................91

Tabla 5.4.56: Kruskal-Wallis. $N^{\circ}$ de elementos y rango medio de TR en cada grupo de $\mathrm{n}^{\circ}$ de contenedores caja abierta y puntos limpios semiurbanos.

Tabla 5.4.57: Resultados de significación del test de Kruskal-Wallis de TR respecto del $\mathrm{n}^{\circ}$ de contenedores caja abierta para puntos limpios semiurbanos.

Tabla 5.4.58: Media, desviación estándar, error estándar e intervalo de confianza de TR para los grupos de $n^{\circ}$ de

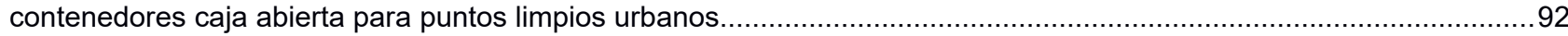
Tabla 5.4.59: Kruskal-Wallis. $N^{\circ}$ de elementos y rango medio de TR en cada grupo de $\mathrm{n}^{\circ}$ de contenedores caja abierta y

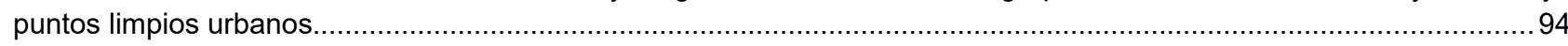
Tabla 5.4.60: Resultados de significación del test de Kruskal-Wallis de TR respecto del $\mathrm{n}^{\circ}$ de contenedores caja abierta para puntos limpios urbanos.

Tabla 5.4.61: Media, desviación estándar, error estándar e intervalo de confianza de TV para los grupos de $n^{\circ}$ de

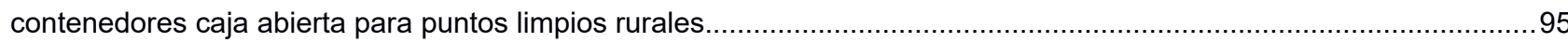

Tabla 5.4.62: Resultados del test de Levene para TV y $\mathrm{n}^{\circ}$ de contenedores caja abierta en puntos limpios rurales..........96

Tabla 5.4.63: Resultados test ANOVA para TV y $\mathrm{n}^{\circ}$ de contenedores caja abierta en puntos limpios rurales...................96 Tabla 5.4.64: Media, desviación estándar, error estándar e intervalo de confianza de TV para los grupos de $n^{\circ}$ de contenedores caja abierta para puntos limpios semiurbanos.

Tabla 5.4.65: Resultados del test de Levene para TV y $n^{\circ}$ de contenedores caja abierta en puntos limpios semiurbanos.

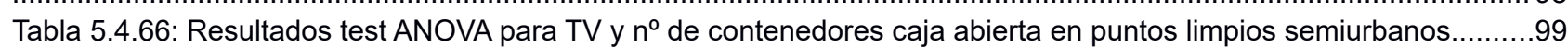
Tabla 5.4.67: Media, desviación estándar, error estándar e intervalo de confianza de TV para los grupos de $n^{\circ}$ de contenedores caja abierta para puntos limpios urbanos............................................................................101 Tabla 5.4.68: Resultados del test de Levene para TV y $n^{\circ}$ de contenedores caja abierta en puntos limpios urbanos.....101 Tabla 5.4.69: Resultados test ANOVA para TV y $\mathrm{n}^{\circ}$ de contenedores caja abierta en puntos limpios urbanos...............101 Tabla 5.4.70: Clasificación de puntos limpios por superficie y tamaño de población adscrita......................................104 Tabla 5.4.71: Cantidad de puntos limpios rurales por superficie...................................................................... 105 Tabla 5.4.72: Media, desviación estándar, error estándar e intervalo de confianza de TR para los grupos de superficie

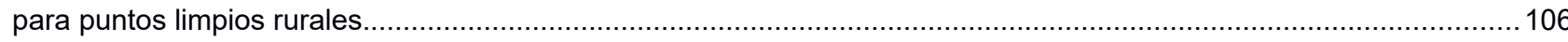
Tabla 5.4.73: Kruskal-Wallis. $N^{\circ}$ de elementos y rango medio de TR en cada grupo de superficie de puntos limpios rurales. 
Tabla 5.4.74: Resultados de significación del test de Kruskal-Wallis de TR respecto de la superficie para puntos limpios rurales.

Tabla 5.4.75: Media, desviación estándar, error estándar e intervalo de confianza de TR para los grupos de superficie para puntos limpios semiurbanos.

Tabla 5.4.76: Kruskal-Wallis. $N^{\circ}$ de elementos y rango medio de TR en cada grupo de superficie de puntos limpios semiurbanos...

Tabla 5.4.77: Resultados de significación del test de Kruskal-Wallis de TR respecto de la superficie para puntos limpios

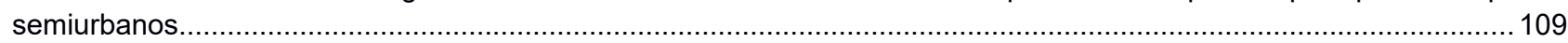

Tabla 5.4.78: Media, desviación estándar, error estándar e intervalo de confianza de TR para los grupos de superficie para puntos limpios urbanos

Tabla 5.4.79: Kruskal-Wallis. $\mathrm{N}^{\circ}$ de elementos y rango medio de TR en cada grupo de superficie de puntos limpios urbanos.

Tabla 5.4.80: Resultados de significación del test de Kruskal-Wallis de TR respecto de la superficie para puntos limpios

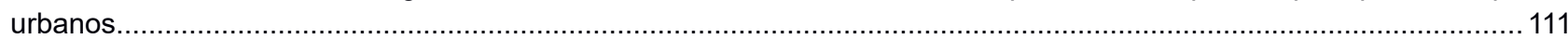

Tabla 5.4.81: Media, desviación estándar, error estándar e intervalo de confianza de TV para los grupos de superficie

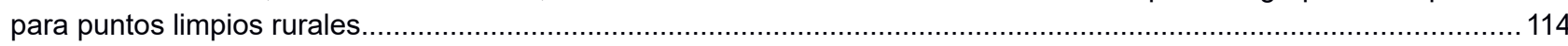

Tabla 5.4.82: Resultados del test de Levene para TV y superficie en puntos limpios rurales......................................114

Tabla 5.4.83: Resultados test ANOVA para TV y superficie en puntos limpios rurales................................................115

Tabla 5.4.84: Media, desviación estándar, error estándar e intervalo de confianza de TV para los grupos de superficie para puntos limpios semiurbanos

Tabla 5.4.85: Resultados del test de Levene para TV y superficie en puntos limpios semiurbanos..............................117

Tabla 5.4.86: Resultados test ANOVA para TV y superficie en puntos limpios semiurbanos..........................................117

Tabla 5.4.87: Media, desviación estándar, error estándar e intervalo de confianza de TV para puntos limpios semiurbanos de superficie superior e inferior a $3.000 \mathrm{~m}^{2}$.

Tabla 5.4.88: Resultados del test de Levene para TV para puntos limpios semiurbanos de superficie superior e inferior a

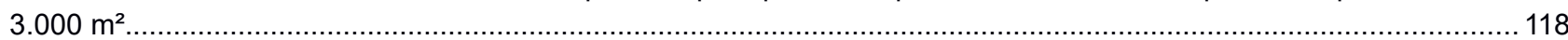

Tabla 5.4.89: Resultados test ANOVA para TV y superficie en puntos limpios semiurbanos..........................................118 Tabla 5.4.90: Media, desviación estándar, error estándar e intervalo de confianza de TV para los grupos de superficie

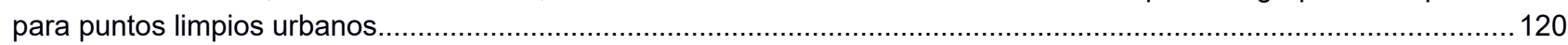
Tabla 5.4.91: Media, desviación estándar, error estándar e intervalo de confianza de TV para los grupos de superficie

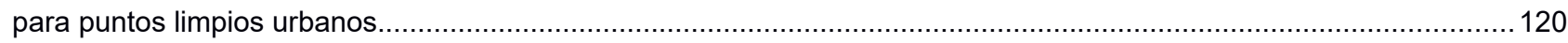

Tabla 5.4.92: Resultados del test de Levene para TV y superficie en puntos limpios urbanos...................................121

Tabla 5.4.93: Resultados test ANOVA para TV y superficie en puntos limpios urbanos................................................121

Tabla 5.4.94: Media, desviación estándar, error estándar e intervalo de confianza de TR para los grupos de disponibilidad de punto limpio móvil asociado

Tabla 5.4.95: Kruskal-Wallis. № de elementos y rango medio de TR en cada grupo de disponibilidad de punto limpio móvil asociado

Tabla 5.4.96: Resultados de significación del test de Kruskal-Wallis de TR respecto de la disponibilidad de punto limpio

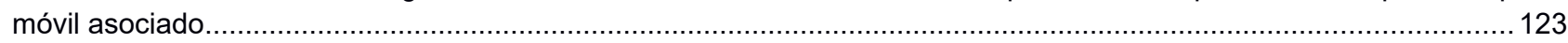

Tabla 5.4.97: Media, desviación estándar, error estándar e intervalo de confianza de TV para los grupos de disponibilidad de punto limpio móvil asociado.

y disponibilidad de punto

Tabla 5.4.98: Resultados del test de Levene para TV y disponibilidad de punto limpio móvil asociado........................125

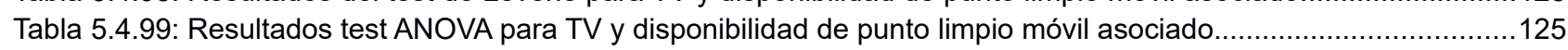

Tabla 5.4.100: TR. Número de puntos limpios abiertos y cerrados por día de la semana...........................................127

Tabla 5.4.101: Media, desviación estándar, error estándar e intervalo de confianza de TR para los grupos de apertura en

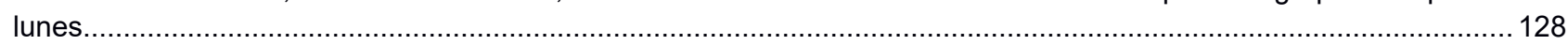

Tabla 5.4.102: Kruskal-Wallis. $N^{\circ}$ de elementos y rango medio de TR en cada grupo de apertura en lunes....................128

Tabla 5.4.103: Resultados de significación del test de Kruskal-Wallis de TR respecto de la apertura en lunes..............129 Tabla 5.4.104: Media, desviación estándar, error estándar e intervalo de confianza de TR para los grupos de apertura en

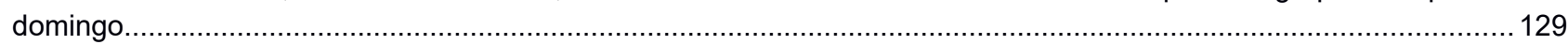

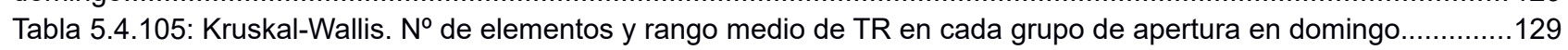

Tabla 5.4.106: Resultados de significación del test de Kruskal-Wallis de TR respecto de la apertura en domingo.........130

Tabla 5.4.107: TV. Número de puntos limpios abiertos y cerrados por día de la semana..........................................131 Tabla 5.4.108: Media, desviación estándar, error estándar e intervalo de confianza de TV para los grupos de apertura en

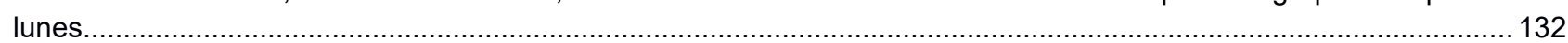
Tabla 5.4.109: Resultados del test de Levene para TV y apertura en lunes....................................................... 132 
Tabla 5.4.110: Resultados test ANOVA para TV y apertura en lunes

Tabla 5.4.111: Media, desviación estándar, error estándar e intervalo de confianza de TV para los grupos de apertura en

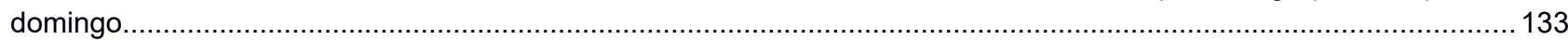

Tabla 5.4.112: Resultados del test de Levene para TV y apertura en domingo....................................................133

Tabla 5.4.113: Resultados test ANOVA para TV y apertura en domingo............................................................ 134

Tabla 5.4.114: Media, desviación estándar, error estándar e intervalo de confianza de TR para los grupos de acceso a

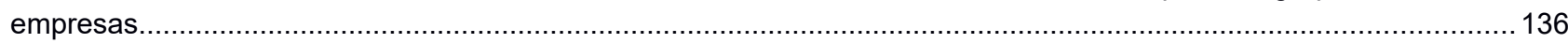

Tabla 5.4.115: Kruskal-Wallis. № de elementos y rango medio de TR en cada grupo de acceso a empresas...............136

Tabla 5.4.116: Resultados de significación del test de Kruskal-Wallis de TR respecto de acceso a empresas...............136

Tabla 5.4.117: Media, desviación estándar, error estándar e intervalo de confianza de TV para los grupos de acceso a

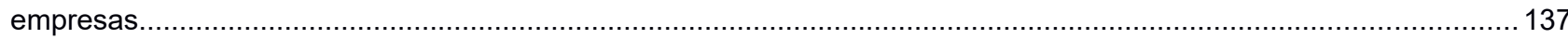

Tabla 5.4.118: Resultados del test de Levene para TV y acceso a empresas........................................................138

Tabla 5.4.119: Resultados test ANOVA para TV y acceso a empresas...................................................................138

Tabla 5.4.120: Media, desviación estándar, error estándar e intervalo de confianza de TR para los grupos de incentivos

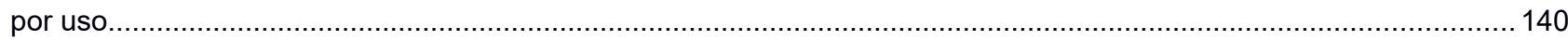

Tabla 5.4.121: Kruskal-Wallis. $N^{\circ}$ de elementos y rango medio de TR en cada grupo de incentivos por uso.................140

Tabla 5.4.122: Resultados de significación del test de Kruskal-Wallis de TR respecto de incentivos por uso.................141

Tabla 5.4.123: Media, desviación estándar, error estándar e intervalo de confianza de TV para los grupos de incentivos

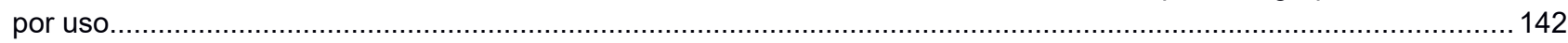

Tabla 5.4.124: Resultados del test de Levene para TV e incentivos por uso....................................................... 142

Tabla 5.4.125: Resultados test ANOVA para TV e incentivos por uso.............................................................. 143

Tabla 5.4.126: Media, desviación estándar, error estándar e intervalo de confianza de TR para los grupos de límites de

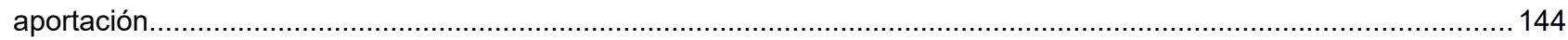

Tabla 5.4.127: Kruskal-Wallis. № de elementos y rango medio de TR en cada grupo de límites de aportación..............145

Tabla 5.4.128: Resultados de significación del test de Kruskal-Wallis de TR respecto de límites de aportación.............145

Tabla 5.4.129: Media, desviación estándar, error estándar e intervalo de confianza de TV para los grupos de límites de

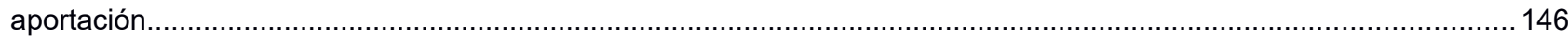

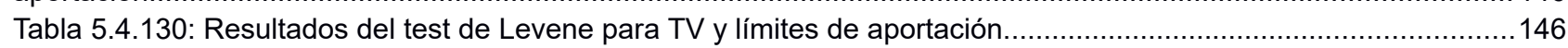

Tabla 5.4.131: Resultados del test ANOVA-Welch para TV y límites de aportación.................................................147

Tabla 5.4.132: Media, desviación estándar, error estándar e intervalo de confianza de TR para los grupos de tipo de

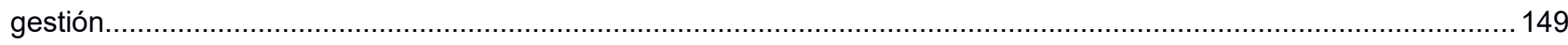

Tabla 5.4.133: Kruskal-Wallis. № de elementos y rango medio de TR en cada grupo de tipo de gestión......................149

Tabla 5.4.134: Resultados de significación del test de Kruskal-Wallis de TR respecto de tipo de gestión......................149

Tabla 5.4.135: TR. Número de casos por tamaño de población adscrita y tipo de gestión..............................................150

Tabla 5.4.136: Media, desviación estándar, error estándar e intervalo de confianza de TR en puntos limpios urbanos

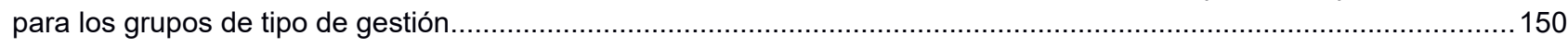

Tabla 5.4.137: Kruskal-Wallis. $N^{\circ}$ de elementos y rango medio de TR en cada grupo de tipo de gestión para puntos

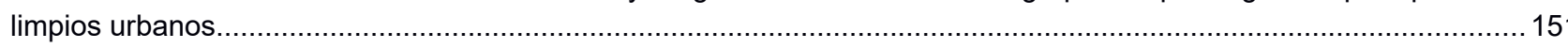

Tabla 5.4.138: Resultados de significación del test de Kruskal-Wallis de TR respecto de tipo de gestión para puntos

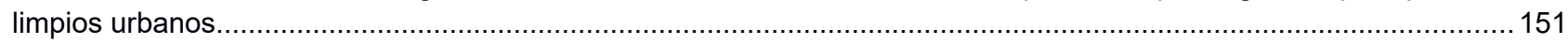

Tabla 5.4.139: Media, desviación estándar, error estándar e intervalo de confianza de TV para los grupos de tipo de

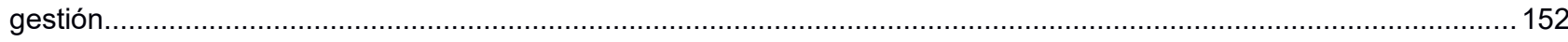

Tabla 5.4.140: Resultados del test de Levene para TV y tipo de gestión................................................................ 152

Tabla 5.4.141: Resultados del test ANOVA-Welch para TV y tipo de gestión.........................................................153

Tabla 5.4.142: TV. Número de casos por tamaño de población adscrita y tipo de gestión.............................................153

Tabla 5.4.143: Media, desviación estándar, error estándar e intervalo de confianza de TV en puntos limpios urbanos para

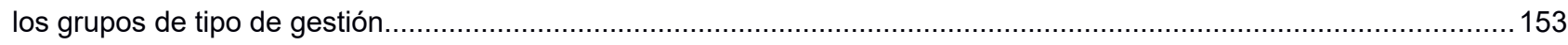

Tabla 5.4.144: Resultados del test de Levene para TV y tipo de gestión para puntos limpios urbanos.........................154

Tabla 5.4.145: Resultados del test ANOVA-Welch para TV y tipo de gestión para puntos limpios urbanos....................154

Tabla 5.4.146: Media, desviación estándar, error estándar e intervalo de confianza de TR para los grupos de admisión

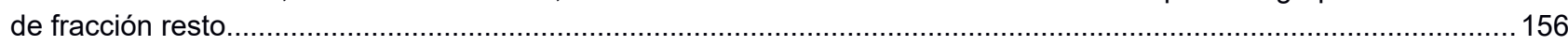

Tabla 5.4.147: Kruskal-Wallis. № de elementos y rango medio de TR en cada grupo de admisión de fracción resto......156

Tabla 5.4.148: Resultados de significación del test de Kruskal-Wallis de TR respecto de admisión de fracción resto....156

Tabla 5.4.149: Media, desviación estándar, error estándar e intervalo de confianza de TR_noR para los grupos de admisión de fracción resto. 
Tabla 5.4.150: Kruskal-Wallis. $N^{\circ}$ de elementos y rango medio de TR_noR en cada grupo de admisión de fracción resto. 158 Tabla 5.4.151: Resultados de significación del test de Kruskal-Wallis de TR_noR respecto de admisión de fracción resto. 158

Tabla 5.4.152: Media, desviación estándar, error estándar e intervalo de confianza de TV para los grupos de admisión de

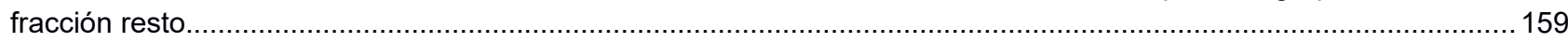

Tabla 5.4.153: Resultados del test de Levene para TV y admisión de fracción resto.................................................159

Tabla 5.4.154: Resultados test ANOVA para TV y admisión de fracción resto........................................................160

Tabla 5.4.155: Media, desviación estándar, error estándar e intervalo de confianza de TR para los grupos de

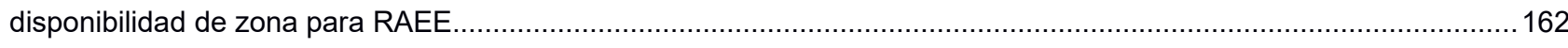

Tabla 5.4.156: Kruskal-Wallis. $\mathrm{N}^{\circ}$ de elementos y rango medio de TR en cada grupo de disponibilidad de zona para

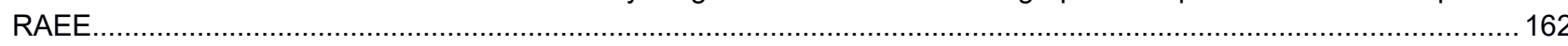

Tabla 5.4.157: Resultados de significación del test de Kruskal-Wallis de TR respecto de disponibilidad de zona para

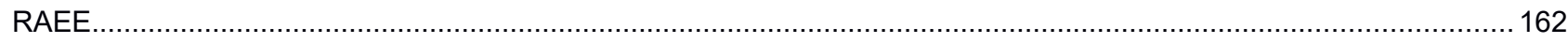

Tabla 5.4.158: Media, desviación estándar, error estándar e intervalo de confianza de TV para los grupos de

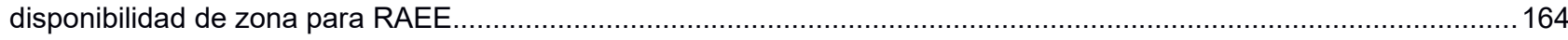

Tabla 5.4.159: Resultados del test de Levene para TV y disponibilidad de zona para RAEE...................................164

Tabla 5.4.160: Resultados test ANOVA para TV y disponibilidad de zona para RAEE............................................ 164 



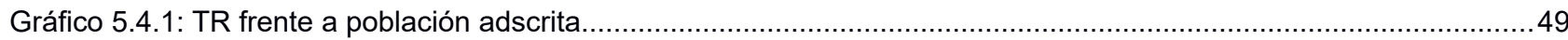

Gráfico 5.4.2: TR frente a tamaño de población adscrita..............................................................................

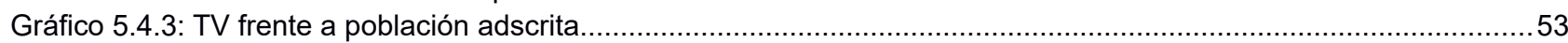

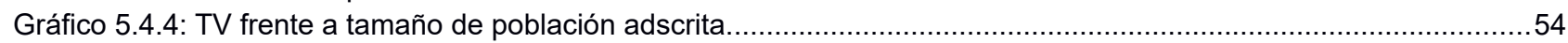

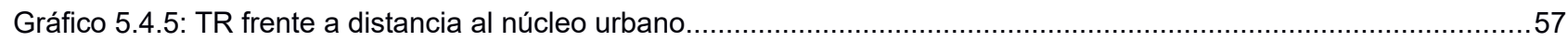

Gráfico 5.4.6: TV frente a distancia a núcleo urbano..................................................................................

Gráfico 5.4.7: TR frente a disponibilidad de transporte público...........................................................................62

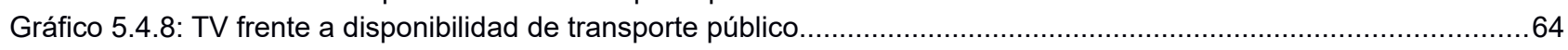

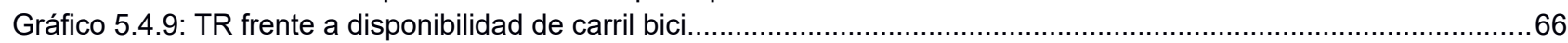

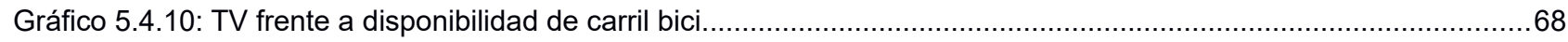

Gráfico 5.4.11: TR frente a año de construcción del punto limpio....................................................................

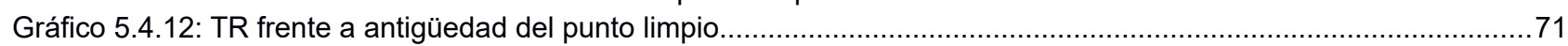

Gráfico 5.4.13: TV frente a año de construcción del punto limpio............................................................................73

Gráfico 5.4.14: TV frente a antigüedad del punto limpio..................................................................................... 74

Gráfico 5.4.15: TR frente a número de carriles de circulación por sentido.............................................................77

Gráfico 5.4.16: TV frente al número de carriles de circulación por sentido...........................................................79

Gráfico 5.4.17: TR frente al número de cotas de construcción...........................................................................

Gráfico 5.4.18: TV frente al número de cotas de construcción...........................................................................83

Gráfico 5.4.19: Número de puntos limpios por cantidad de contenedores caja abierta................................................85

Gráfico 5.4.20: Número de contenedores caja abierta frente a tamaño de población adscrita.........................................86

Gráfico 5.4.21: TR frente a número de contenedores caja abierta.................................................................. 87

Gráfico 5.4.22: Distribución de TR en puntos limpios rurales frente a número de contenedores caja abierta..................89

Gráfico 5.4.23: Número de contenedores caja abierta en puntos limpios semiurbanos.............................................90

Gráfico 5.4.24: TR para grupos de $\mathrm{n}^{\circ}$ de contenedores caja abierta y puntos limpios semiurbanos...............................

Gráfico 5.4.25: Número de contenedores caja abierta en puntos limpios urbanos...................................................93

Gráfico 5.4.26: TR para grupos de $\mathrm{n}^{\circ}$ de contenedores caja abierta y puntos limpios urbanos...................................93

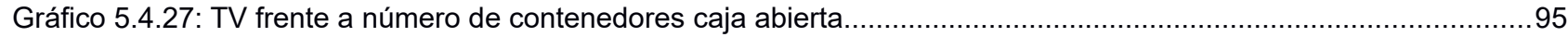

Gráfico 5.4.28: Número de contenedores caja abierta en puntos limpios semiurbanos.............................................97

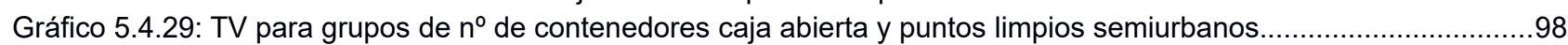

Gráfico 5.4.30: Número de contenedores caja abierta en puntos limpios urbanos................................................100

Gráfico 5.4.31: TV para grupos de $\mathrm{n}^{\circ}$ de contenedores caja abierta y puntos limpios urbanos..................................100

Gráfico 5.4.32: Número de puntos limpios por superficie ocupada................................................................ 103

Gráfico 5.4.33: Superficie ocupada por el punto limpio frente a tamaño de población adscrita...................................103

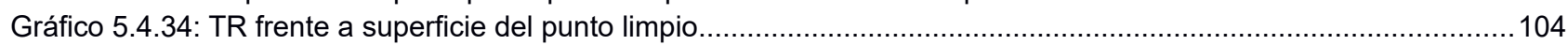

Gráfico 5.4.35: Superficie de punto limpio en puntos limpios rurales................................................................. 105

Gráfico 5.4.36: TR para grupos de superficie ocupada y puntos limpios rurales...................................................106

Gráfico 5.4.37: Superficie de punto limpio en puntos limpios semiurbanos....................................................... 108

Gráfico 5.4.38: TR para grupos de superficie ocupada y puntos limpios semiurbanos.............................................108

Gráfico 5.4.39: Superficie de punto limpio en puntos limpios urbanos...............................................................110

Gráfico 5.4.40: TR para grupos de superficie ocupada y puntos limpios urbanos..................................................... 110

Gráfico 5.4.41: TV frente a superficie del punto limpio.................................................................................... 112

Gráfico 5.4.42: Superficie de punto limpio en puntos limpios rurales...............................................................113

Gráfico 5.4.43: TV para grupos de superficie ocupada y puntos limpios rurales..................................................114

Gráfico 5.4.44: Superficie de punto limpio en puntos limpios semiurbanos...............................................................116

Gráfico 5.4.45: TV para grupos de superficie ocupada y puntos limpios semiurbanos..................................................116

Gráfico 5.4.46: Superficie de punto limpio en puntos limpios urbanos....................................................................119

Gráfico 5.4.47: TV para grupos de superficie ocupada y puntos limpios urbanos.................................................. 120

Gráfico 5.4.48: TR frente a disponibilidad de punto limpio móvil asociado............................................................122

Gráfico 5.4.49: TV frente a disponibilidad de punto limpio móvil asociado.......................................................... 124

Gráfico 5.4.50: TR frente a días de apertura semanal de la instalación.................................................................... 127

Gráfico 5.4.51: TV frente a días de apertura semanal de la instalación..............................................................131

Gráfico 5.4.52: TR frente a autorización de acceso a empresas.......................................................................... 135 
Gráfico 5.4.53: TV frente a autorización de acceso a empresas.................................................................... 137

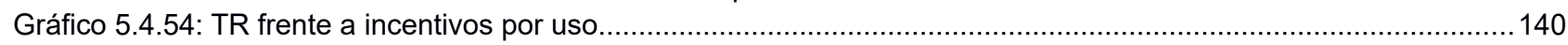

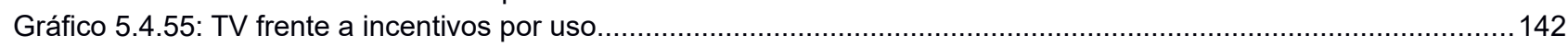

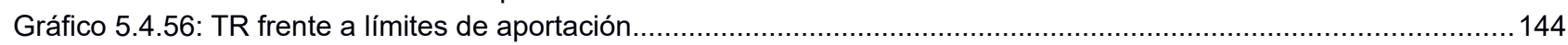

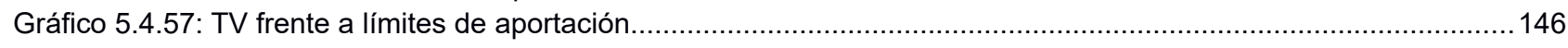

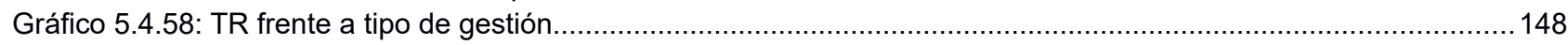

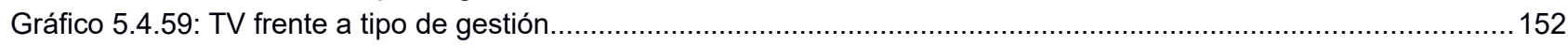

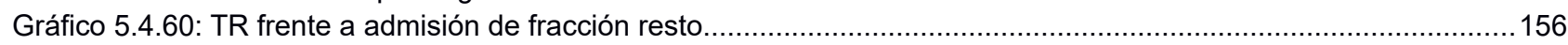

Gráfico 5.4.61: TV frente a admisión de fracción resto........................................................................................ 159

Gráfico 5.4.62: TR frente a disponibilidad de zona para RAEE ....................................................................... 162

Gráfico 5.4.63: TV frente a disponibilidad de zona para RAEE .................................................................... 163 
ANEXO A5.1. ENCUESTA PILOTO. 



\section{A5.1. ENCUESTA PILOTO.}

Las preguntas que se planteaban en el cuestionario inicial y que se englobaban dentro de 5 apartados, eran las siguientes:

1. Información general.

- Número de ecoparques.

- Ciudad.

2. Datos de la instalación.

- Nombre del Ecoparque.

- Dirección.

- Código Postal.

- Teléfono.

- Número de visitas/año.

3. Titularidad.

- Consorcio/Ayuntamiento.

4. Características de diseño.

- Localización.

- Distancia respecto del núcleo urbano.

- $0-5 \mathrm{Km}$.

- Más de $5 \mathrm{Km}$.

- Medios de acceso alternativos.

- Transporte público, paradas bus cercanas.

- Sí.

- No.

- Carril bici.

- Sí.

- No.

- Superficie aprox en $\mathrm{m}^{2}$.

- Contenerización y equipamientos.

- Número de contenedores de caja abierta.

- Cerramiento perimetral. 
- Sí.

- No.

- Oficina de recepción y, al menos un WC.

- Sí.

- No.

- Zona cubierta y ventilada almacenamiento de RRPP.

- Sí.

- No.

- Zona específica antiderrame almacenamiento RAEE.

- Sí.

- No.

5. Características de gestión.

- Gestión.

- Directa.

- Indirecta.

- Población adscrita.

- Días de apertura a la semana.

- 1 a 7.

- Tipología de residuos admitidos.

- Voluminosos.

- Sí.

- No.

- RCD.

- Sí.

- No.

- Reciclables (P/C, EELL, Vidrio).

- Sí.

- No.

- Residuos peligrosos (RRPP).

- Sí.

- No.

- Cantidad de residuos depositados.

- Voluminosos (t/año). 
- RCD (t/año).

- Reciclables (t/año).

- Residuos peligrosos (t/año).

- Tasas.

- Tasas por utilización.

- Sí.

- No.

- Incentivos por utilización.

- Sí.

- No.

- Especifique, si existen incentivos, cuáles son.

- Limitaciones.

- Existen limitaciones cuantitativas y cualitativas de aportación.

- Sí.

- No. 



\section{AneXo A5.2. ENCUESTA DEFINITIVA.}





\section{FICHA DE CARACTERIZACIÓN DE ECOPARQUES}

El incremento de la diversificación de generación y gestión de residuos urbanos (RSU) y el compromiso medioambiental, crea la necesidad de aprovechar al máximo los espacios destinados a este fin.

Implantándose en las ciudades centros especializados en la recogida, selección y recuperación de todos aquellos desechos que generamos en nuestros hogares, que no podemos reciclar en ninguno de los contenedores que encontramos en nuestras ciudades, dichos centros son concretamente los Puntos Limpios y Ecoparques.

El objetivo de dicha encuesta, es la modelización de estas instalaciones en base a las áreas aportadas o ciudades que prestan su servicio, como los diferentes modelos de gestión, instalaciones y servicios. Para ello se tendrán en cuenta las características de las ciudades, $\mathrm{n}^{\circ}$ de habitantes, emplazamiento geográfico y los sistemas de recogida, pudiendo así analizar los diferentes modelos y determinar los más eficientes.

Es necesario rellenar una ficha por ecoparque.

\section{UI UNIVERSTAT}

\section{Página 1 de 6}

\section{Siguiente}

Nunca envíes contraseñas a través de Formularios de Google.

Este contenido no ha sido creado ni aprobado por GoogleaNosio inadecuado - Términos del Servicio Política de Privacidad

\section{Google Formularios}




\section{FICHA DE CARACTERIZACIÓN DE ECOPARQUES}

\section{INFORMACIÓN GENERAL}

N DE ECOPARQUES:

Tu respuesta

CIUDAD:

Tu respuesta

AÑO DE REFERENCIA:

Tu respuesta

Página 2 de 6

Atrás

Siguiente

Nunca envíes contraseñas a través de Formularios de Google.

Este contenido no ha sido creado ni aprobado por GoogleaNosio inadecuado - Términos del Servicio Política de Privacidad

\section{Google Formularios}




\section{FICHA DE CARACTERIZACIÓN DE ECOPARQUES}

2. DATOS DE LA INSTALACIÓN

Nombre del Ecoparque :

Tu respuesta

Dirección:

Tu respuesta

$\mathrm{CP}:$

Tu respuesta

Teléfono:

Tu respuesta

Año de construcción:

Tu respuesta

! 
$\mathrm{N}^{\circ}$ visitas /año:

Tu respuesta

$N^{0}$ visitas foraneas:

Tu respuesta

Página 3 de 6

\section{Atrás Siguiente}

Nunca envíes contraseñas a través de Formularios de Google.

Este contenido no ha sido creado ni aprobado por GoogleaNosio inadecuado - Términos del Servicio Política de Privacidad

\section{Google Formularios}




\section{FICHA DE CARACTERIZACIÓN DE ECOPARQUES}

\section{Titular}

A continuación responda si el titular es público o privado especificando el ayuntamiento o empresa concesionaria:

Público. Ayuntamiento

Tu respuesta

Privado. Empresa concesionaria

Tu respuesta

\section{Página 4 de 6}

Atrás

Siguiente

Nunca envíes contraseñas a través de Formularios de Google.

Este contenido no ha sido creado ni aprobado por GoogleaNosio inadecuado - Términos del Servicio Política de Privacidad

\section{Google Formularios}




\section{FICHA DE CARACTERIZACIÓN DE ECOPARQUES}

4. CARACTERÍSTICAS DE DISEÑO

Localización

Distancia respecto del núcleo urbano:
$0-0.5 \mathrm{Km}$
$5-1,5 \mathrm{Km}$
$5 \mathrm{~km}$
Otro:

Viales de acceso de vehículo particular

$\mathrm{N}^{\circ}$ de carriles de circulación por sentido:

○ 1

○ 2

3

Otro:

!. Medios de acceso alternativos 
Transporte público, paradas bus cercana:

Si

No

Carril bici

Si

No

Disposición

Cotas

○ 1

○ 2

Otro:

Superficie aprox en m2

Tu respuesta

Contenerización y equipamientos 
$\mathrm{N}^{\circ}$ de contenedores de caja abierta

Tu respuesta

Si existen de otro tipo de contenedores,especifique cual:

Tu respuesta

Cerramiento perimetral

Si

No

Oficina de recepción y, al menos un WC

$\mathrm{Si}$

No

Zona cubierta y ventilada almacenamiento de RRPP:

$\mathrm{Si}$

$\bigcirc$ No 
Zona específica c/antiderrame almacenamiento RAEE:

$\mathrm{Si}$

No

Báscula

$\mathrm{Si}$

No

Página 5 de 6

Atrás

Siguiente

Nunca envíes contraseñas a través de Formularios de Google.

Este contenido no ha sido creado ni aprobado por GoogleaNosio inadecuado - Términos del Servicio Política de Privacidad

\section{Google Formularios}




\section{FICHA DE CARACTERIZACIÓN DE ECOPARQUES}

5. CARACTERÍSTICAS DE GESTIÓN

Gestión :

Directa

Concesión

Población potencial:

Invierno: (oct-may)

Tu respuesta

Verano: (Jun-Sep)

Tu respuesta

Horario de apertura

! 
Selecciona los días que se encuentra abierta la instalación:

Lunes

Martes

Miércoles

$\square$ Jueves

$\square$ Viernes

Sábado

Domingo

Hora de apertura

Hora

:

Hora de cierre

Hora

:

TIPOLOGÍA DE RESIDUOS ALMACENADOS

Señale si hay dicho tipo de residuos:

Voluminosos

$\bigcirc \mathrm{Si}$

!

No 


\section{RDC's}

Si

No

Reciclables (P/C, EELL, Vidrio)
$\mathrm{Si}$
No

Fracción de resto

$\mathrm{Si}$

No

Residuos Peligrosos- (RRPP):
Si
No

Cantidad de residuos:

Voluminosos (Tm/año):

Tu respuesta 
RDC's (Tm/año):

Tu respuesta

Reciclables (Tm/año):

Tu respuesta

Fracción de resto (Tm/año):

Tu respuesta

Resto de residuos Peligrosos -(RRPP) (Tm/año):

Tu respuesta

Tasas

Tasas por utilización:

$\bigcirc \mathrm{Si}$

ONO 
Incentivos por utilización:
${ }^{*} \mathrm{Si}$
NO

*Especifique si existen incentivos y cuáles:

Tu respuesta

Acceso

Se permite el acceso de empresas

$\mathrm{Si}$

NO

Limitaciones

Existen limitaciones cuantitativas y cualitativas de aportación:
$\mathrm{Si}$
No

Ecoparque móvil 
Dispone de ecoparque móvil asociado:

$\mathrm{Si}$

No

Cantidad de residuos que acumula el ecoparque móvil (Tm/año):

Tu respuesta

Tm totales de RSU recogidas en la ciudad:

Especifique las $\mathrm{Tm}$ recogidas $\mathrm{RSU}$

Tu respuesta

Página 6 de 6

Atrás

Enviar

Nunca envíes contraseñas a través de Formularios de Google.

Este contenido no ha sido creado ni aprobado por GoogleaNo\$io inadecuado - Términos del Servicio Política de Privacidad

\section{Google Formularios}





\section{ANEXo A5.3. TABLA DE RESPUESTAS A LA ENCUESTA.}





\begin{tabular}{|c|c|c|c|c|c|c|c|c|c|c|}
\hline Ciudad & $\begin{array}{l}\text { Nombre del } \\
\text { Ecoparque }\end{array}$ & Dirección & $\begin{array}{l}\text { Año de } \\
\text { construcción }\end{array}$ & $\begin{array}{c}\mathrm{N}^{0} \mathrm{de} \\
\text { visitas/año }\end{array}$ & $\begin{array}{l}\mathrm{N}^{\circ} \text { de visitas } \\
\text { foráneas }\end{array}$ & $\begin{array}{c}\text { Distancia al } \\
\text { núcleo urbano }\end{array}$ & $\begin{array}{c}N^{\circ} \text { de carriles } \\
\text { de } \\
\text { circulación } \\
\text { por sentido }\end{array}$ & $\begin{array}{l}\text { Disponibilidad } \\
\text { Transporte } \\
\text { público, } \\
\text { paradas bus } \\
\text { cercanas }\end{array}$ & $\begin{array}{l}\text { Disponibilidad } \\
\text { de Carril bici }\end{array}$ & $\begin{array}{l}\text { N. }{ }^{\circ} \text { Cotas } \\
\text { construcción }\end{array}$ \\
\hline Albal & ECOP. ALBAL & $\begin{array}{l}\text { Pol. Ind. Albal, } \\
\text { Sector IV, calle } \\
15\end{array}$ & 2.003 & 7.402 & & $0.5-1.5 \mathrm{~km}$ & 1 & NO & NO & 2 \\
\hline $\begin{array}{l}\text { Albalat Dels } \\
\text { Sorells }\end{array}$ & $\begin{array}{l}\text { ECOP. ALBALAT } \\
\text { DELS SORELLS }\end{array}$ & $\begin{array}{l}\text { Carrer de les } \\
\text { Moreres, } 15\end{array}$ & 2.016 & 3.950 & & $0-0.5 \mathrm{~km}$ & 1 & NO & NO & 2 \\
\hline Albocàsser & $\begin{array}{l}\text { ECOPARQUE DE } \\
\text { ALCOSSEBRE }\end{array}$ & $\begin{array}{l}\text { POLIGONO } 15 \\
\text { PARCELA } 75\end{array}$ & 2.012 & 511 & & $0.5-1.5 \mathrm{~km}$ & 1 & NO & NO & 2 \\
\hline Alboraya & $\begin{array}{l}\text { ECOP. } \\
\text { AALBORAYA }\end{array}$ & $\begin{array}{l}\text { Carrer Partida } \\
\text { Calvet, } 4\end{array}$ & 2.002 & 34.330 & & $0.5-1.5 \mathrm{~km}$ & 1 & NO & NO & 2 \\
\hline Alcalà De Xivert & $\begin{array}{l}\text { ECOPARQUE DE } \\
\text { ALCOSSEBRE }\end{array}$ & $\begin{array}{l}\text { POLIGONO } 16 \\
\text { PARCELA } 202\end{array}$ & 2.012 & 902 & & $0.5-1.5 \mathrm{~km}$ & 1 & NO & NO & 1 \\
\hline Aldaia Y Alaquàs & $\begin{array}{l}\text { ECOP. ALDAIA- } \\
\text { ALAQUAS }\end{array}$ & \begin{tabular}{|c|} 
Carrer Aladrers, \\
s/n -Poligono \\
Bovalar - \\
Alaquàs \\
\end{tabular} & & 26.015 & & $0.5-1.5 \mathrm{~km}$ & 1 & NO & NO & 2 \\
\hline Algimia De Alfara & $\begin{array}{l}\text { ECOPARQUE DE } \\
\text { ALGIMIA DE } \\
\text { ALFARA }\end{array}$ & $\begin{array}{l}\text { POLIGONO } 10 \\
\text { PARCELA } 289\end{array}$ & & 516 & & $0-0.5 \mathrm{~km}$ & 1 & NO & NO & 2 \\
\hline Alicante & Ecoparque Alicante & $\begin{array}{c}\text { Avda Elche 161- } \\
163\end{array}$ & 1.998 & 11.070 & & $0.5-1.5 \mathrm{~km}$ & 1 & NO & NO & 2 \\
\hline Almàssera & $\begin{array}{l}\text { ECOP. } \\
\text { ALMȦSSERA }\end{array}$ & $\begin{array}{l}\text { Partida de la } \\
\text { Mar, 45, }\end{array}$ & 1.999 & 11.203 & & $0-0.5 \mathrm{~km}$ & 1 & NO & NO & 2 \\
\hline Almazora & Ecoparc Almassora & & 2.005 & & & $1.5-5 \mathrm{~km}$ & 1 & NO & NO & 2 \\
\hline Almenara & $\begin{array}{l}\text { ECOPARQUE DE } \\
\text { ALMENARA }\end{array}$ & \begin{tabular}{|c|} 
POL.IND. \\
TRASCASTELL \\
56 C-1
\end{tabular} & 2.013 & 804 & & $0.5-1.5 \mathrm{~km}$ & 1 & NO & NO & 2 \\
\hline $\begin{array}{c}\text { Área } \\
\text { Metropolitana De } \\
\text { Valencia } \\
\end{array}$ & $\begin{array}{c}\text { Valencia-Vara de } \\
\text { Quart }\end{array}$ & $\begin{array}{l}\text { Camino Alquería } \\
\text { de la Morera } s / n\end{array}$ & 2.008 & 48.910 & & $0.5-1.5 \mathrm{~km}$ & 1 & NO & NO & 2 \\
\hline Badia Del Vallès & $\begin{array}{c}\text { Deixalleria de Badia } \\
\text { del Vallès }\end{array}$ & $\underset{\mathrm{s} / \mathrm{n}}{\text { C. Costa Blava, }}$ & 2.000 & & 3.464 & $0-0.5 \mathrm{~km}$ & 1 & SI & SI & 1 \\
\hline Benassal & $\begin{array}{c}\text { ECOPARQUE DE } \\
\text { BENASSAL }\end{array}$ & $\begin{array}{l}\text { POLIGONO } 37 \\
\text { PARCELA } 147\end{array}$ & 2.012 & 97 & & $0-0.5 \mathrm{~km}$ & 1 & NO & NO & 1 \\
\hline Benicarló & $\begin{array}{c}\text { ECOPARQUE DE } \\
\text { BENICARLÓ }\end{array}$ & $\begin{array}{l}\text { CAMI SAN } \\
\text { MATEO } s / n\end{array}$ & & 5.035 & & $0-0.5 \mathrm{~km}$ & 1 & NO & NO & 1 \\
\hline Benidorm & $\begin{array}{l}\text { Ecoparque de } \\
\text { Benidorm }\end{array}$ & $\begin{array}{c}\text { Antigua Crta de } \\
\text { Finestrat } s / n\end{array}$ & 2.002 & 10.000 & & $0.5-1.5 \mathrm{~km}$ & 1 & SI & SI & 2 \\
\hline Benlloch & $\begin{array}{c}\text { ECOPARQUE DE } \\
\text { BENLLOCH }\end{array}$ & $\begin{array}{l}\text { POLIGONO } 18 \\
\text { PARCELA } 137\end{array}$ & 2.012 & 628 & & $0-0.5 \mathrm{~km}$ & 1 & NO & NO & 1 \\
\hline Bilbao & $\begin{array}{l}\text { BILBOGARBI } \\
\text { ELORRIETA }\end{array}$ & \begin{tabular}{|c|} 
RIBERA DE \\
ELORRIETA, No \\
10 JUNTO \\
PARQUE \\
MUNICIPAL \\
\end{tabular} & 1.993 & 12.244 & 0 & $1.5-5 \mathrm{~km}$ & 1 & NO & SI & 2 \\
\hline Bilbao & $\begin{array}{l}\text { BILBOGARBI } \\
\text { LARRASKITU }\end{array}$ & $\begin{array}{c}\text { CAMINO } \\
\text { LARRASKITU } \\
\text { No 5 PARTE } \\
\text { TRASERA } \\
\text { IBERDROLA } \\
\end{array}$ & 1.993 & 11.412 & 0 & $0.5-1.5 \mathrm{~km}$ & 1 & SI & NO & 2 \\
\hline Bilbao & $\begin{array}{l}\text { BILBOGARBI } \\
\text { ZORROZA }\end{array}$ & $\begin{array}{c}\text { CAMINO } \\
\text { ZORROZGOITI } \\
\text { S/N JUNTO } \\
\text { PASO NIVEL } \\
\text { F.E.V.E. } \\
\end{array}$ & 1.993 & 16.731 & 0 & $0.5-1.5 \mathrm{~km}$ & 1 & SI & SI & 1 \\
\hline Bilbao & $\begin{array}{l}\text { BILBOGARBI } \\
\text { ARTXANDA }\end{array}$ & $\begin{array}{c}\text { ALTO DE } \\
\text { SANTO } \\
\text { DOMINGO SIN } \\
\text { JUNTO } \\
\text { CAMBIO } \\
\text { SENTIDO }\end{array}$ & 1.993 & 9.094 & 0 & $1.5-5 \mathrm{~km}$ & 1 & NO & NO & 2 \\
\hline Cabanes & $\begin{array}{l}\text { ECOPARQUE DE } \\
\text { CABANES }\end{array}$ & $\begin{array}{l}\text { C/6 PARCELA } \\
12 \text { SECTOR } 3\end{array}$ & 2.012 & 1.010 & & $0-0.5 \mathrm{~km}$ & 1 & NO & NO & 1 \\
\hline Càlig & $\begin{array}{c}\text { ECOPARQUE DE } \\
\text { CÁLIG }\end{array}$ & $\begin{array}{l}\text { POÍGONO } 4 \\
\text { PARCELA } 198\end{array}$ & 2.012 & 694 & & $0.5-1.5 \mathrm{~km}$ & 1 & NO & NO & 1 \\
\hline Canals & Ecoparc Canals & & 2.011 & & & $0.5-1.5 \mathrm{~km}$ & 1 & NO & NO & 2 \\
\hline Canet Lo Roig & $\begin{array}{l}\text { ECOPARQUE DE } \\
\text { CANET LO ROIG }\end{array}$ & $\begin{array}{l}\text { POLIGONO } 1 \\
\text { PARCELA } 25\end{array}$ & 2.012 & 482 & & $0-0.5 \mathrm{~km}$ & 1 & NO & NO & 1 \\
\hline Castalla & $\begin{array}{c}\text { Ecoparque } \\
\text { Municipal Castalla }\end{array}$ & $\begin{array}{c}\text { Avenida Alcoy } \\
\mathrm{s} / \mathrm{n}\end{array}$ & 2.002 & & & $0-0.5 \mathrm{~km}$ & 1 & NO & NO & 2 \\
\hline Castellón & $\begin{array}{l}\text { Ecoparque de } \\
\text { Castellón }\end{array}$ & $\begin{array}{c}\text { Camino Cuadra } \\
\text { Tercera, } 5\end{array}$ & 2.000 & 40.423 & 0 & $1.5-5 \mathrm{~km}$ & 1 & NO & NO & 2 \\
\hline Catarroja & $\begin{array}{l}\text { ECOP. } \\
\text { CATARROJA }\end{array}$ & $\begin{array}{c}\mathrm{C} / 31, \mathrm{~S} / \mathrm{N} \text { (Pol. } \\
\text { Ind de Catarroja) }\end{array}$ & 2.014 & 12.635 & & $0-0.5 \mathrm{~km}$ & 2 & & & 2 \\
\hline $\begin{array}{l}\text { Cervera Del } \\
\text { Maestre }\end{array}$ & $\begin{array}{l}\text { ECOPARQUE DE } \\
\text { CERVERA DEL } \\
\text { MAESTRE }\end{array}$ & $\begin{array}{l}\text { POLIGONO } 33 \\
\text { PARCELA } 5\end{array}$ & 2.012 & 141 & & $0.5-1.5 \mathrm{~km}$ & 1 & NO & NO & 1 \\
\hline
\end{tabular}




\begin{tabular}{|c|c|c|c|c|c|c|c|c|c|c|}
\hline Ciudad & $\begin{array}{l}\text { Nombre del } \\
\text { Ecoparque }\end{array}$ & Dirección & $\begin{array}{l}\text { Año de } \\
\text { construcción }\end{array}$ & $\begin{array}{c}\mathrm{N}^{0} \text { de } \\
\text { visitas/año }\end{array}$ & $\begin{array}{l}\mathrm{N}^{\circ} \text { de visitas } \\
\text { foráneas }\end{array}$ & $\begin{array}{c}\text { Distancia al } \\
\text { núcleo urbano }\end{array}$ & $\begin{array}{c}N^{\circ} \text { de carriles } \\
\text { de } \\
\text { circulación } \\
\text { por sentido }\end{array}$ & $\begin{array}{l}\text { Disponibilidad } \\
\text { Transporte } \\
\text { público, } \\
\text { paradas bus } \\
\text { cercanas }\end{array}$ & $\begin{array}{l}\text { Disponibilidad } \\
\text { de Carril bici }\end{array}$ & $\begin{array}{l}\mathrm{N} .{ }^{\circ} \text { Cotas } \\
\text { construcción }\end{array}$ \\
\hline $\begin{array}{c}\text { Churriana De La } \\
\text { Vega }\end{array}$ & $\begin{array}{c}\text { Punto Limpio } \\
\text { Churriana de la } \\
\text { Vega }\end{array}$ & $\begin{array}{c}\text { Avda. Cristobal } \\
\text { Colón S/N, } \\
\text { Churriana de la } \\
\text { Vega. }\end{array}$ & 2.016 & & & $0-0.5 \mathrm{~km}$ & & NO & NO & 1 \\
\hline $\begin{array}{c}\text { Cornella De } \\
\text { Llobregat }\end{array}$ & RECIBAIX & $\begin{array}{c}\text { C. Progrés, 18- } \\
20\end{array}$ & 2.000 & 10.007 & & $0.5-1.5 \mathrm{~km}$ & 1 & NO & NO & 1 \\
\hline $\begin{array}{l}\text { Coves De } \\
\text { Vinromà }\end{array}$ & $\begin{array}{c}\text { ECOPARQUE DE } \\
\text { COVES DE } \\
\text { VINROMA } \\
\end{array}$ & $\begin{array}{l}\text { POLIGONO } 20 \\
\text { PARCELA } 133\end{array}$ & 2.012 & 761 & & $0-0.5 \mathrm{~km}$ & 1 & NO & NO & 1 \\
\hline Crevillent & $\begin{array}{l}\text { Ecoparque } \\
\text { Crevillent }\end{array}$ & & 2.002 & & & $0.5-1.5 \mathrm{~km}$ & 1 & NO & NO & 2 \\
\hline Cuenca & EL MIRADOR & $\begin{array}{c}\text { AVDA. DEL } \\
\text { MEDITERRAANE } \\
\text { O, S/N }\end{array}$ & 2.005 & 5.700 & 6.000 & $0-0.5 \mathrm{~km}$ & 1 & SI & NO & 2 \\
\hline $\begin{array}{l}\text { El Prat De } \\
\text { Llobregat }\end{array}$ & $\begin{array}{c}\text { DEIXALLERIA EL } \\
\text { PRAT DE } \\
\text { LLOBREGAT }\end{array}$ & \begin{tabular}{|c|} 
Ronda Llevant, \\
22 EL PRAT DE \\
LLOBREGAT
\end{tabular} & 1.998 & 21.435 & & $0-0.5 \mathrm{~km}$ & 1 & SI & NO & 2 \\
\hline $\begin{array}{l}\text { Esplugues De } \\
\text { Llobregat/Sant } \\
\text { Joan Despí }\end{array}$ & $\begin{array}{c}\text { Deixalleria } \\
\text { d'Esplugues-Sant } \\
\text { Joan Despí }\end{array}$ & \begin{tabular}{|c|} 
C. d'Àngel \\
Guimerà amb \\
av. del Baix \\
Llobregat Sant \\
Joan Despí \\
\end{tabular} & 2.002 & 15.553 & & $0-0.5 \mathrm{~km}$ & 1 & SI & NO & 2 \\
\hline Estivella & $\begin{array}{c}\text { ECOPARQUE DE } \\
\text { ESTIVELLA }\end{array}$ & $\begin{array}{l}\text { POLÍGONO } 6 \\
\text { PARCELA } 14\end{array}$ & & 888 & & $0-0.5 \mathrm{~km}$ & 1 & NO & NO & 2 \\
\hline Gilet & $\begin{array}{c}\text { ECOPARQUE DE } \\
\text { GILET }\end{array}$ & $\begin{array}{c}\text { PLA DE LA } \\
\text { VENTA, POL } 4 \\
\text { PARC } 11 \\
\end{array}$ & & 1.308 & & $0-0.5 \mathrm{~km}$ & 1 & NO & NO & 2 \\
\hline Guadix & $\begin{array}{l}\text { Punto Limpio } \\
\text { Guadix }\end{array}$ & $\begin{array}{l}\text { Av. Montes } \\
\text { Orientales, } \\
\text { Guadix, } \\
\text { Granada }\end{array}$ & 2.008 & & & $0.5-1.5 \mathrm{~km}$ & 1 & NO & NO & 2 \\
\hline $\begin{array}{l}\text { Hospitalet De } \\
\text { Llobregat }\end{array}$ & \begin{tabular}{|c|} 
DEIXALLERIA \\
D'HOSPITALET DE \\
LLOBREGAT \\
\end{tabular} & $\begin{array}{c}\text { C. Arquímedes, } \\
1 \text { Hospitalet de } \\
\text { Llobregat }\end{array}$ & 1.999 & 9.929 & & $0.5-1.5 \mathrm{~km}$ & 1 & NO & NO & 2 \\
\hline L'Alcora & $\begin{array}{c}\text { Ecoparque } \\
\text { municipal L'Alcora }\end{array}$ & Salvador s/n & 2.005 & & & $0.5-1.5 \mathrm{~km}$ & 1 & NO & NO & 1 \\
\hline La Salzadella & $\begin{array}{l}\text { ECOPARQUE DE } \\
\text { LA SALZADELLAA }\end{array}$ & \begin{tabular}{|c|} 
POLIGONO 16 \\
PARCELAS 468 \\
Y 469
\end{tabular} & 2.012 & 567 & & $0.5-1.5 \mathrm{~km}$ & 1 & NO & NO & 1 \\
\hline $\begin{array}{l}\text { La Torre D'en } \\
\text { Doménec }\end{array}$ & $\begin{array}{l}\text { ECOPARQUE DE } \\
\text { LA TORRE D'EN } \\
\text { DOMENEC }\end{array}$ & $\begin{array}{l}\text { POLIGONO } 1 \\
\text { PARCELA } 151\end{array}$ & 2.012 & 86 & & $0-0.5 \mathrm{~km}$ & 1 & NO & NO & 1 \\
\hline $\begin{array}{l}\text { Las Cabezas De } \\
\text { San Juan }\end{array}$ & $\begin{array}{l}\text { Punto Limpio Las } \\
\text { Cabezas de San } \\
\text { Juan }\end{array}$ & $\begin{array}{c}\text { Calle } \\
\text { Escayolista, } 1\end{array}$ & & & & $0-0.5 \mathrm{~km}$ & & NO & NO & \\
\hline Málaga & \begin{tabular}{|c|} 
LIMASA III \\
Servicios de \\
Limpieza Integral de \\
Malaga III, S.A.
\end{tabular} & $\begin{array}{c}\text { Camino } \\
\text { Medioambiental, } \\
\text { 23, Málaga }\end{array}$ & 1.998 & & & $0-0.5 \mathrm{~km}$ & & NO & NO & \\
\hline $\begin{array}{l}\text { Mancomunidad } \\
\text { Sasieta (22 } \\
\text { Municipios) }\end{array}$ & $\begin{array}{c}\text { Sasieta } \\
\text { Mankomunitatea }\end{array}$ & \begin{tabular}{c|} 
Iturraldetxiki \\
Industrialdea 3 | \\
Salbatore auzoa \\
| Beasain \\
\end{tabular} & 1.991 & & & $0.5-1.5 \mathrm{~km}$ & & NO & NO & \\
\hline Manises & ECOP. MANISES & $\begin{array}{l}\text { Carrer del } \\
\text { Comtat, } 46\end{array}$ & 2.002 & 8.178 & & $0.5-1.5 \mathrm{~km}$ & 1 & NO & NO & 2 \\
\hline Massamagrell & $\begin{array}{c}\text { ECOP. } \\
\text { MASSAMAGRELL }\end{array}$ & $\begin{array}{l}\text { Avinguda de } \\
\text { Serra, } 108\end{array}$ & 2.013 & 8.057 & & $0-0.5 \mathrm{~km}$ & 1 & NO & NO & 2 \\
\hline Meliana & ECOP. MELIANA & $\begin{array}{c}\text { Cami del } \\
\text { Cementeri s/n }\end{array}$ & 2.003 & 9.117 & & $0-0.5 \mathrm{~km}$ & 1 & NO & NO & 2 \\
\hline Molins De Rei & $\begin{array}{l}\text { DEIXALLERIA DE } \\
\text { MOLINS DE REI }\end{array}$ & $\begin{array}{c}\text { C. Rector } \\
\text { Colom, 2 bis (al } \\
\text { costat del } \\
\text { cementiri) } \\
\text { Molins de Rei } \\
\end{array}$ & 2.001 & 14.782 & & $0-0.5 \mathrm{~km}$ & 1 & SI & NO & 1 \\
\hline Morella & $\begin{array}{c}\text { ECOPARQUE DE } \\
\text { MORELLA }\end{array}$ & $\begin{array}{l}\text { POLIGONO } 63 \\
\text { PARCELA } 76\end{array}$ & 2.012 & 1.973 & & $0.5-1.5 \mathrm{~km}$ & 1 & NO & NO & 2 \\
\hline Nules & $\begin{array}{c}\text { ECOPARQUE DE } \\
\text { NULES }\end{array}$ & $\begin{array}{c}\text { C/ PLAN } \\
\text { PARCIAL } 1 \\
\text { INDUSTRIAL } 9 \\
\end{array}$ & 2.011 & 1.063 & & $0.5-1.5 \mathrm{~km}$ & 1 & NO & NO & 2 \\
\hline Onda & $\begin{array}{c}\text { Ecoparque } \\
\text { Municipal Onda }\end{array}$ & $\begin{array}{l}\text { Partida de les } \\
\text { Forques } s / n\end{array}$ & 1.999 & & & $1.5-5 \mathrm{~km}$ & 1 & NO & NO & 2 \\
\hline $\begin{array}{l}\text { Paiporta Y } \\
\text { Picanya }\end{array}$ & $\begin{array}{l}\text { ECOP. PAIPORTA- } \\
\text { PICANYA }\end{array}$ & $\begin{array}{l}\text { Cami Mal Pas, } \\
\text { s/n (Junto al } \\
\text { cementerio) } \\
\text { Paiporta } \\
\end{array}$ & 1.998 & 24.311 & & $0-0.5 \mathrm{~km}$ & 1 & NO & NO & 2 \\
\hline Paterna & ECOP. PATERNA & $\begin{array}{l}\text { Carrer de } \\
\text { I'Algepser, 97, } \\
\text { POL. IND. } \\
\text { TÁCTICA }\end{array}$ & 2.017 & 2.110 & & $0.5-1.5 \mathrm{~km}$ & 1 & NO & NO & 2 \\
\hline Peñiscola & $\begin{array}{l}\text { ECOPARQUE DE } \\
\text { PENIISCOLA }\end{array}$ & $\begin{array}{l}\text { C/ PUNTARRO } \\
\text { No2 }\end{array}$ & 2.014 & 7.299 & & $0-0.5 \mathrm{~km}$ & 1 & SI & NO & 1 \\
\hline Picassent & ECOP. PICASSENT & $\begin{array}{c}\text { Av. d'Omet, } 33 \\
\text { (Ctra. CV-4140), } \\
\text { PICASSENT }\end{array}$ & 1.998 & 22.861 & & $0-0.5 \mathrm{~km}$ & 1 & NO & NO & 2 \\
\hline Puçol & ECOP. PUÇOL & C/Teixidors, 4 & 2.003 & 10.059 & & $0.5-1.5 \mathrm{~km}$ & 1 & NO & NO & 2 \\
\hline
\end{tabular}




\begin{tabular}{|c|c|c|c|c|c|c|c|c|c|c|}
\hline Ciudad & $\begin{array}{l}\text { Nombre del } \\
\text { Ecoparque }\end{array}$ & Dirección & $\begin{array}{c}\text { Año de } \\
\text { construcción }\end{array}$ & $\begin{array}{c}\mathrm{N}^{0} \text { de } \\
\text { visitas/año }\end{array}$ & $\begin{array}{l}\mathrm{N}^{\circ} \text { de visitas } \\
\text { foráneas }\end{array}$ & $\begin{array}{c}\text { Distancia al } \\
\text { núcleo urbano }\end{array}$ & $\begin{array}{c}N^{0} \text { de carriles } \\
\text { de } \\
\text { circulación } \\
\text { por sentido }\end{array}$ & $\begin{array}{l}\text { Disponibilidad } \\
\text { Transporte } \\
\text { público, } \\
\text { paradas bus } \\
\text { cercanas }\end{array}$ & $\begin{array}{l}\text { Disponibilidad } \\
\text { de Carril bici }\end{array}$ & $\begin{array}{l}\text { N. }{ }^{\circ} \text { Cotas } \\
\text { construcción }\end{array}$ \\
\hline $\begin{array}{c}\text { Puerto De Santa } \\
\text { Maria }\end{array}$ & $\begin{array}{l}\text { Punto Limpio Puerto } \\
\text { de Santa Maria }\end{array}$ & $\begin{array}{c}\text { Calle Caldera, 4, } \\
\text { El Puerto de Sta } \\
\text { María }\end{array}$ & 2.009 & 19.732 & & $0.5-1.5 \mathrm{~km}$ & & NO & NO & 1 \\
\hline $\begin{array}{l}\text { Quart De Les } \\
\text { Valls }\end{array}$ & $\begin{array}{c}\text { ECOPARQUE DE } \\
\text { LA } \\
\text { MANCOMUNITAT } \\
\text { DE LES VALLS }\end{array}$ & $\begin{array}{l}\text { POLIGONO 3, } \\
\text { PARCELA EL } \\
\text { PLA }\end{array}$ & & 1.824 & & $0-0.5 \mathrm{~km}$ & 1 & NO & NO & 2 \\
\hline $\begin{array}{l}\text { Rincón De La } \\
\text { Victoria }\end{array}$ & $\begin{array}{c}\text { Punto Limpio } \\
\text { Rincón dela Victoria }\end{array}$ & \begin{tabular}{|c|} 
Carr \\
Benagalbón, 10, \\
Rincón de la \\
Victoria, Málaga
\end{tabular} & 2.006 & & & $0-0.5 \mathrm{~km}$ & 1 & NO & NO & 2 \\
\hline Rossell & $\begin{array}{c}\text { ECOPARQUE DE } \\
\text { ROSSELL }\end{array}$ & $\mid \begin{array}{c}\text { C/ CONCORDIA } \\
\text { No2 }\end{array}$ & 2.012 & 833 & & $0-0.5 \mathrm{~km}$ & 1 & NO & NO & 1 \\
\hline $\begin{array}{l}\text { Sant Adrià De } \\
\text { Besòs }\end{array}$ & $\begin{array}{l}\text { ECOPARC DEL } \\
\text { MEDITERRANI, } \\
\text { S.A }\end{array}$ & $\begin{array}{l}\text { AV, EDUARD } \\
\text { MARISTANY } \\
\text { S/N }\end{array}$ & 2.004 & 100 & 25 & $0-0.5 \mathrm{~km}$ & 1 & SI & SI & 1 \\
\hline $\begin{array}{l}\text { Sant Andreu De } \\
\text { La Barca }\end{array}$ & $\begin{array}{c}\text { DEIXALLERIA DE } \\
\text { SANT ANDREU DE } \\
\text { LA BARCA }\end{array}$ & $\begin{array}{c}\text { C. Fusta, s/n } \\
\text { (Pol. Ind. Can } \\
\text { Sunyer) Sant } \\
\text { Andreu de la } \\
\text { Barca }\end{array}$ & 1.997 & 4.054 & & $1.5-5 \mathrm{~km}$ & 1 & NO & NO & 2 \\
\hline $\begin{array}{l}\text { Sant Boi De } \\
\text { Llobregat }\end{array}$ & $\begin{array}{l}\text { DEIXALLERIA DE } \\
\text { SANT BOI DE } \\
\text { LLOBREGAT }\end{array}$ & \begin{tabular}{|c|} 
C. del Doctor \\
Josep Castells \\
amb c. de \\
Múrcia (Pol. Ind. \\
Cal Calderon) - \\
Sant Boi de \\
Llobregat \\
\end{tabular} & 1.999 & 8.124 & & $0.5-1.5 \mathrm{~km}$ & 1 & SI & NO & 2 \\
\hline Sant Jordi & $\begin{array}{l}\text { ECOPARQUE DE } \\
\text { SAN JORDI }\end{array}$ & $\begin{array}{l}\text { POLIGONO } 10 \\
\text { PARCELA } 9001\end{array}$ & 2.012 & 374 & & $0-0.5 \mathrm{~km}$ & 1 & NO & NO & 1 \\
\hline $\begin{array}{c}\text { Sant Rafael Del } \\
\text { Riu }\end{array}$ & $\begin{array}{c}\text { ECOPARQUE DE } \\
\text { SAN RAFAEL DEL } \\
\text { RIU }\end{array}$ & $\begin{array}{l}\text { POLIGONO } 5 \\
\text { PARCELA } 110\end{array}$ & 2.012 & 418 & & $0.5-1.5 \mathrm{~km}$ & 1 & NO & NO & 1 \\
\hline $\begin{array}{c}\text { Santa Coloma De } \\
\text { Gramenet }\end{array}$ & $\begin{array}{l}\text { Ecoparque de } \\
\text { Santa Coloma de } \\
\text { Gramenet }\end{array}$ & $\begin{array}{l}\text { Carretera de la } \\
\text { Roca, km } 6 \\
\text { Santa Coloma } \\
\text { de Gramenet }\end{array}$ & 2.000 & 7.688 & & $0-0.5 \mathrm{~km}$ & 1 & $\mathrm{SI}$ & NO & 2 \\
\hline $\begin{array}{l}\text { Santa Magdalena } \\
\text { De Pulpis }\end{array}$ & $\begin{array}{c}\text { ECOPARQUE DE } \\
\text { SANTA } \\
\text { MAGDALENA DE } \\
\text { PULPIS }\end{array}$ & $\begin{array}{l}\text { POLIGONO } 10 \\
\text { PARCELA } 207\end{array}$ & 2.012 & 556 & & $0-0.5 \mathrm{~km}$ & 1 & NO & NO & 1 \\
\hline Sedaví & ECOP. SEDAVÍ & $\begin{array}{l}\text { C/ Ernesto } \\
\text { Andreu } \\
\text { Minguet, } \mathrm{S} / \mathrm{N}\end{array}$ & 2.001 & 17.697 & & $0-0.5 \mathrm{~km}$ & 2 & SI & NO & 2 \\
\hline Sevilla & $\begin{array}{c}\text { Puntos limpios Los } \\
\text { Olivos }\end{array}$ & C/ Azogue & 1.988 & & 41.100 & $0-0.5 \mathrm{~km}$ & 1 & $\mathrm{SI}$ & NO & 1 \\
\hline Sevilla & $\begin{array}{l}\text { Punto Limpio Los } \\
\text { Pinos }\end{array}$ & $\begin{array}{c}\text { Ctra Sevilla- } \\
\text { Málaga km 1,5 }\end{array}$ & 1.999 & & 27.201 & $0-0.5 \mathrm{~km}$ & 2 & SI & NO & 1 \\
\hline Sevilla & $\begin{array}{l}\text { Punto Limpio Los } \\
\text { Naranjos }\end{array}$ & $\begin{array}{c}\text { Ctra. Su } \\
\text { Eminencia s/n } \\
\text { (esquina a } \\
\text { carretera de } \\
\text { Utrera) } \\
\end{array}$ & 1.999 & & 37.293 & $0-0.5 \mathrm{~km}$ & 2 & SI & SI & 1 \\
\hline Sevilla & $\begin{array}{l}\text { Punto Limpio Las } \\
\text { Jacarandas }\end{array}$ & $\mathrm{C} /$ Ingeniería, 2 & 2.005 & & 41.730 & $0-0.5 \mathrm{~km}$ & 2 & SI & SI & 1 \\
\hline Silla & ECOP. SILLA & $\begin{array}{c}\text { C/ Massanassa } \\
n^{\circ} 7 \text { SILLA }\end{array}$ & & 7.341 & & $0-0.5 \mathrm{~km}$ & 2 & NO & NO & 2 \\
\hline Soneja & $\begin{array}{c}\text { ECOPARQUE DE } \\
\text { SONEJA }\end{array}$ & $\begin{array}{c}\text { POLIGONO 1, } \\
\text { PARCELA } 1106\end{array}$ & & 228 & & $0.5-1.5 \mathrm{~km}$ & 1 & NO & NO & 1 \\
\hline Tarragona & $\begin{array}{l}\text { DEIXALLERIA } \\
\text { MUNICIPAL } \\
\text { TARRAGONA }\end{array}$ & $\begin{array}{c}\text { CARRER } \\
\text { SOFRE - POL. } \\
\text { IND- RIU CLAR }\end{array}$ & 2.002 & 8.071 & 0 & $0.5-1.5 \mathrm{~km}$ & 2 & SI & NO & 1 \\
\hline Torreblanca & $\begin{array}{l}\text { ECOPARQUE DE } \\
\text { TORREBLANCA }\end{array}$ & $\begin{array}{l}\text { POLIGONO } 11 \\
\text { PARCELA } 157\end{array}$ & 2.012 & 2.172 & & $0.5-1.5 \mathrm{~km}$ & 1 & NO & NO & 2 \\
\hline Torrent & $\begin{array}{c}\text { ECOP. TORRENT- } \\
1\end{array}$ & $\begin{array}{c}\text { C/ San Juan } \\
\text { Bautista, s/n } \\
\text { Tortrente I }\end{array}$ & & 16.684 & & $0-0.5 \mathrm{~km}$ & 1 & SI & SI & 2 \\
\hline Torrent & $\begin{array}{l}\text { ECOP. TORRENT- } \\
2\end{array}$ & $\begin{array}{l}\text { Poligono } \\
\text { Industrial Toll } \\
\text { l'Alberca, s/n }\end{array}$ & & 6.471 & & $1.5-5 \mathrm{~km}$ & 1 & NO & NO & 2 \\
\hline Tudela & $\begin{array}{l}\text { Servicios Públicos } \\
\text { de la Ribera de } \\
\text { Navarra S.A. }\end{array}$ & $\begin{array}{l}\text { Paseo Los } \\
\text { Grillos, } 17 \\
\text { TUDELA } \\
\text { (Navarra) } \\
\end{array}$ & & & & $0.5-1.5 \mathrm{~km}$ & & NO & NO & \\
\hline Utrera & Punto Limpio Utrera & $\begin{array}{l}\text { Ronda de los } \\
\text { Torneros s/n. } \\
\text { P.I. El Torno }\end{array}$ & & & & $0-0.5 \mathrm{~km}$ & 1 & NO & NO & 2 \\
\hline Vall D'Uixó & Vall d'Uixó & 4655 & 2.009 & 576 & & $0.5-1.5 \mathrm{~km}$ & 1 & NO & NO & 2 \\
\hline
\end{tabular}


Anexo A5.3.

\begin{tabular}{|c|c|c|c|c|c|c|c|c|c|c|}
\hline Ciudad & $\begin{array}{l}\text { Nombre del } \\
\text { Ecoparque }\end{array}$ & Dirección & $\begin{array}{c}\text { Año de } \\
\text { construcción }\end{array}$ & $\begin{array}{c}\mathrm{N}^{\circ} \text { de } \\
\text { visitas/año }\end{array}$ & $\begin{array}{l}\mathrm{N}^{0} \text { de visitas } \\
\text { foráneas }\end{array}$ & $\begin{array}{c}\text { Distancia al } \\
\text { núcleo urbano }\end{array}$ & $\begin{array}{c}N^{0} \text { de carriles } \\
\text { de } \\
\text { circulación } \\
\text { por sentido }\end{array}$ & $\begin{array}{l}\text { Disponibilidad } \\
\text { Transporte } \\
\text { público, } \\
\text { paradas bus } \\
\text { cercanas }\end{array}$ & $\begin{array}{l}\text { Disponibilidad } \\
\text { de Carril bici }\end{array}$ & $\begin{array}{l}\text { N. }{ }^{\circ} \text { Cotas } \\
\text { construcción }\end{array}$ \\
\hline $\begin{array}{l}\text { Valverde Del } \\
\text { Camino }\end{array}$ & $\begin{array}{c}\text { Punto Limpio Puerto } \\
\text { de Valverde del } \\
\text { Camino }\end{array}$ & \begin{tabular}{|c|} 
Paraje La \\
Coneja. \\
Poligono: 10, \\
parcela: 17 \\
Huelva
\end{tabular} & & & & $0.5-1.5 \mathrm{~km}$ & & NO & NO & 1 \\
\hline Viladecans & $\begin{array}{l}\text { Deixalleria } \\
\text { Viladecans }\end{array}$ & $\begin{array}{l}\text { C. Llobatona } \\
\text { amb c. de } \\
\text { I'Agricultura } \\
\text { Viladecans }\end{array}$ & 2.001 & 11.511 & & $0-0.5 \mathrm{~km}$ & 1 & SI & NO & 2 \\
\hline $\begin{array}{l}\text { Vilanova } \\
\text { D'Alcolea }\end{array}$ & $\begin{array}{l}\text { ECOPARQUE DE } \\
\text { VILANOVA } \\
\text { D'ALCOLEA }\end{array}$ & $\begin{array}{l}\text { POLIGONO } 7 \\
\text { PARCELA } 262\end{array}$ & 2.012 & 229 & & $0.5-1.5 \mathrm{~km}$ & 1 & NO & NO & 1 \\
\hline Villafranca Del Cid & $\begin{array}{c}\text { ECOPARQUE DE } \\
\text { VILLAFRANCA DEL } \\
\text { CID }\end{array}$ & $\begin{array}{l}\text { CTRA. } \\
\text { PORTELL S/N }\end{array}$ & 2.012 & 1.799 & & $0-0.5 \mathrm{~km}$ & 1 & NO & NO & 2 \\
\hline Vinaròs & \begin{tabular}{|c|} 
ECOPARQUE DE \\
VINAROS
\end{tabular} & $\begin{array}{c}\text { POLIGONO SU- } \\
\text { I-6 PARCELA } \\
\text { ZUDI }\end{array}$ & 2.013 & 4.872 & & $0.5-1.5 \mathrm{~km}$ & 1 & NO & NO & 2 \\
\hline Xàtiva & $\begin{array}{l}\text { Ecoparque Xativa. } \\
\text { Punto Limpio }\end{array}$ & & 2.013 & & & $0.5-1.5 \mathrm{~km}$ & 1 & NO & NO & 2 \\
\hline Xert & $\begin{array}{c}\text { ECOPARQUE DE } \\
\text { XERT }\end{array}$ & $\begin{array}{l}\text { POLIGONO } 10 \\
\text { PARCELA } 175\end{array}$ & 2.012 & 525 & & $0.5-1.5 \mathrm{~km}$ & 1 & NO & NO & 1 \\
\hline Xirivella & ECOP. XIRIVELLA & $\begin{array}{l}\text { Calle dels } \\
\text { Seders, } 8\end{array}$ & 2.011 & 16.705 & & $0-0.5 \mathrm{~km}$ & 1 & NO & NO & 2 \\
\hline
\end{tabular}




\begin{tabular}{|c|c|c|c|c|c|c|c|c|}
\hline Ciudad & $\begin{array}{l}\text { Superficie } \\
\text { aprox en } \mathrm{m}^{2}\end{array}$ & $\begin{array}{c}\mathrm{N}^{0} \text { de } \\
\text { contenedores } \\
\text { de caja abierta }\end{array}$ & $\begin{array}{l}\text { Detalla de otro tipo de } \\
\text { contenedores, si existen: }\end{array}$ & $\begin{array}{l}\text { Disponibilidad } \\
\text { cerramiento } \\
\text { perimetral }\end{array}$ & $\begin{array}{l}\text { Disponibilidad } \\
\text { oficina de } \\
\text { recepción y, al } \\
\text { menos un WC }\end{array}$ & $\begin{array}{c}\text { Disponibilidad } \\
\text { Zona cubierta y } \\
\text { ventilada } \\
\text { almacenamiento } \\
\text { de RRPP }\end{array}$ & $\begin{array}{l}\text { Disponibilidad } \\
\text { Zona específica } \\
\text { c/antiderrame } \\
\text { almacenamiento } \\
\text { RAEE }\end{array}$ & $\begin{array}{l}\text { Disponibilidad } \\
\text { Báscula }\end{array}$ \\
\hline Albal & 1690 & 10 & $\begin{array}{l}\text { Baterias, } 120 \mathrm{lts}, 240 \mathrm{Its}, 1000 \mathrm{Its}, \\
\text { jaulas raees, arcon fluorescentes, } \\
600 \mathrm{Its} \text { aceites de motor y cocina }\end{array}$ & SI & SI & SI & NO & NO \\
\hline $\begin{array}{l}\text { Albalat Dels } \\
\text { Sorells }\end{array}$ & 2475 & 9 & $\begin{array}{l}\text { Baterias, } 120 \mathrm{lts}, 240 \mathrm{Its}, 1000 \mathrm{Its}, \\
\text { jaulas raees, arcon fluorescentes, } \\
600 \text { Its aceites de motor y cocina }\end{array}$ & SI & SI & SI & SI & NO \\
\hline Albocàsser & 992 & 4 & $\begin{array}{l}\text { 2, ACEITE MINERAL Y } \\
\text { VEGETAL }\end{array}$ & SI & SI & SI & SI & SI \\
\hline Alboraya & 2570 & 12 & $\begin{array}{l}\text { Baterias, } 120 \text { Its, } 240 \text { Its, } 1000 \text { Its, } \\
\text { jaulas raees, arcon fluorescentes, } \\
600 \text { Its aceites de motor y cocina }\end{array}$ & SI & $\mathrm{SI}$ & SI & NO & $\mathrm{SI}$ \\
\hline Alcalà De Xivert & 580 & 4 & $\begin{array}{l}\text { 2, ACEITE MINERAL Y } \\
\text { VEGETAL }\end{array}$ & SI & SI & SI & SI & SI \\
\hline Aldaia Y Alaquàs & 4500 & 15 & $\begin{array}{l}\text { Baterias, } 120 \text { Its, } 240 \text { Its, } 1000 \text { Its, } \\
\text { jaulas raees, arcon fluorescentes, } \\
600 \text { Its aceites de motor y cocina }\end{array}$ & SI & SI & SI & SI & NO \\
\hline Algimia De Alfara & 640 & 4 & $\begin{array}{l}\text { 2, ACEITE MINERAL Y } \\
\text { VEGETAL }\end{array}$ & SI & SI & SI & SI & SI \\
\hline Alicante & 3688 & 12 & \begin{tabular}{|c|} 
Jaulas para RAEE; bidones para \\
RP; pilas; aceite vegetal; etc
\end{tabular} & SI & SI & SI & SI & NO \\
\hline Almàssera & 3600 & 11 & $\begin{array}{l}\text { Baterias, } 120 \text { Its, } 240 \text { Its, } 1000 \text { Its, } \\
\text { jaulas raees, arcon fluorescentes, } \\
600 \text { Its aceites de motor y cocina }\end{array}$ & SI & SI & SI & NO & NO \\
\hline Almazora & 3400 & 13 & & SI & SI & SI & SI & NO \\
\hline Almenara & 1000 & 6 & $\begin{array}{l}\text { 2, ACEITE MINERAL Y } \\
\text { VEGETAL }\end{array}$ & SI & SI & SI & SI & SI \\
\hline $\begin{array}{c}\text { Área } \\
\text { Metropolitana De } \\
\text { Valencia }\end{array}$ & 5000 & 12 & $\begin{array}{l}\text { Jaulas para RAEES, depósitos } \\
\text { para aceites. }\end{array}$ & SI & $\mathrm{SI}$ & SI & SI & NO \\
\hline Badia Del Vallès & & 12 & $\begin{array}{c}\text { Ropa (jaula cerrada); electrónica } \\
\text { (jaula abierta); iglú (selectiva) }\end{array}$ & SI & SI & SI & SI & SI \\
\hline Benassal & 433 & 4 & $\begin{array}{l}\text { 2, ACEITE MINERAL Y } \\
\text { VEGETAL }\end{array}$ & SI & SI & SI & SI & SI \\
\hline Benicarló & 1815 & 9 & $\begin{array}{l}\text { 2, ACEITE MINERAL Y } \\
\text { VEGETAL }\end{array}$ & SI & $\mathrm{SI}$ & SI & SI & $\mathrm{SI}$ \\
\hline Benidorm & & 10 & 1 compactador cartón & SI & SI & SI & SI & NO \\
\hline Benlloch & 440 & 4 & $\begin{array}{l}\text { 2, ACEITE MINERAL Y } \\
\text { VEGETAL }\end{array}$ & SI & $\mathrm{SI}$ & SI & SI & SI \\
\hline Bilbao & 582,82 & 5 & $\begin{array}{c}\text { COMPACTADOR CARTÓN, } \\
\text { ACEITE, RESIDUOS } \\
\text { PELIGROSOS, JAULAS RAEES, } \\
\text { ETC... }\end{array}$ & SI & $\mathrm{SI}$ & SI & SI & NO \\
\hline Bilbao & 639,93 & 4 & $\begin{array}{l}\text { COMPACTADOR CARTÓN, } \\
\text { ACEITE, RESIDUOS } \\
\text { PELIGROS, JAULAS } \\
\text { RAEES,ETC... }\end{array}$ & SI & SI & SI & SI & NO \\
\hline Bilbao & 641 & 5 & $\begin{array}{l}\text { COMPACTADOR CARTÓN, } \\
\text { ACEITE, RESIDUOS } \\
\text { PELIGROSOS, JAULAS } \\
\text { RAEES,ETC... }\end{array}$ & SI & SI & SI & SI & NO \\
\hline Bilbao & 887,76 & 4 & $\begin{array}{c}\text { COMPACTADOR CARTÓN, } \\
\text { ACEITE, RESIDUOS } \\
\text { PELIGROSOS, JAULAS RAEES, } \\
\text { ETC... }\end{array}$ & $\mathrm{SI}$ & $\mathrm{SI}$ & SI & SI & NO \\
\hline Cabanes & 530 & 6 & $\begin{array}{l}\text { 2, ACEITE MINERAL Y } \\
\text { VEGETAL }\end{array}$ & SI & SI & SI & SI & $\mathrm{SI}$ \\
\hline Càlig & 579 & 5 & $\begin{array}{l}\text { 2, ACEITE MINERAL Y } \\
\text { VEGETAL }\end{array}$ & SI & SI & SI & SI & SI \\
\hline Canals & 1500 & 8 & & SI & SI & SI & SI & NO \\
\hline Canet Lo Roig & 420 & 4 & $\begin{array}{l}\text { 2, ACEITE MINERAL Y } \\
\text { VEGETAL }\end{array}$ & SI & SI & SI & SI & SI \\
\hline Castalla & 1000 & 4 & & SI & SI & NO & NO & NO \\
\hline Castellón & 3000 & 12 & Pequeños & SI & SI & NO & SI & NO \\
\hline Catarroja & 4200 & 11 & $\begin{array}{l}\text { Baterias, } 120 \text { Its, } 240 \text { Its, } 1000 \text { Its, } \\
\text { jaulas raees, arcon fluorescentes, } \\
600 \text { Its aceites de motor y cocina }\end{array}$ & SI & SI & SI & NO & NO \\
\hline $\begin{array}{l}\text { Cervera Del } \\
\text { Maestre }\end{array}$ & 440 & 4 & $\begin{array}{l}\text { 2, ACEITE MINERAL Y } \\
\text { VEGETAL }\end{array}$ & SI & SI & SI & SI & $\mathrm{SI}$ \\
\hline
\end{tabular}




\begin{tabular}{|c|c|c|c|c|c|c|c|c|}
\hline Ciudad & $\begin{array}{l}\text { Superficie } \\
\text { aprox en } \mathrm{m}^{2}\end{array}$ & $\begin{array}{c}\mathrm{N}^{0} \text { de } \\
\text { contenedores } \\
\text { de caja abierta }\end{array}$ & $\begin{array}{l}\text { Detalla de otro tipo de } \\
\text { contenedores, si existen: }\end{array}$ & $\begin{array}{l}\text { Disponibilidad } \\
\text { cerramiento } \\
\text { perimetral }\end{array}$ & $\begin{array}{l}\text { Disponibilidad } \\
\text { oficina de } \\
\text { recepción y, al } \\
\text { menos un WC }\end{array}$ & $\begin{array}{l}\text { Disponibilidad } \\
\text { Zona cubierta y } \\
\text { ventilada } \\
\text { almacenamiento } \\
\text { de RRPP }\end{array}$ & $\begin{array}{l}\text { Disponibilidad } \\
\text { Zona especifica } \\
\text { c/antiderrame } \\
\text { almacenamiento } \\
\text { RAEE }\end{array}$ & $\begin{array}{c}\text { Disponibilidad } \\
\text { Báscula }\end{array}$ \\
\hline $\begin{array}{c}\text { Churriana De La } \\
\text { Vega }\end{array}$ & 4500 & 6 & & SI & NO & & & NO \\
\hline $\begin{array}{c}\text { Cornella De } \\
\text { Llobregat }\end{array}$ & & 7 & 2 compactadora i peligrosos & SI & SI & SI & NO & $\mathrm{SI}$ \\
\hline $\begin{array}{l}\text { Coves De } \\
\text { Vinromà }\end{array}$ & 372 & 4 & $\begin{array}{l}\text { 2, ACEITE MINERAL Y } \\
\text { VEGETAL }\end{array}$ & SI & SI & SI & SI & SI \\
\hline Crevillent & 3800 & 13 & Carga lateral & SI & SI & SI & SI & NO \\
\hline Cuenca & 1400 & 7 & 13 PEQUEÑO TAMAÑO & SI & SI & SI & NO & NO \\
\hline $\begin{array}{l}\text { El Prat De } \\
\text { Llobregat }\end{array}$ & 3000 & 14 & & SI & SI & & & SI \\
\hline $\begin{array}{l}\text { Esplugues De } \\
\text { Llobregat/Sant } \\
\text { Joan Despi }\end{array}$ & 1800 & 10 & & SI & SI & & & SI \\
\hline Estivella & 648 & 4 & $\begin{array}{l}\text { 2, ACEITE MINERAL Y } \\
\text { VEGETAL }\end{array}$ & SI & SI & SI & SI & $\mathrm{SI}$ \\
\hline Gilet & 989 & 4 & $\begin{array}{l}\text { 2, ACEITE MINERAL Y } \\
\text { VEGETAL }\end{array}$ & SI & SI & SI & SI & $\mathrm{SI}$ \\
\hline Guadix & 1800 & 5 & & SI & SI & & & \\
\hline $\begin{array}{l}\text { Hospitalet De } \\
\text { Llobregat }\end{array}$ & 9000 & 15 & & SI & SI & & & \\
\hline L'Alcora & 2000 & 9 & & SI & SI & SI & SI & NO \\
\hline La Salzadella & 440 & 4 & $\begin{array}{l}\text { 2, ACEITE MINERAL Y } \\
\text { VEGETAL }\end{array}$ & SI & SI & SI & SI & SI \\
\hline $\begin{array}{l}\text { La Torre D'en } \\
\text { Doménec }\end{array}$ & 456 & 4 & $\begin{array}{l}\text { 2, ACEITE MINERAL Y } \\
\text { VEGETAL }\end{array}$ & SI & $\mathrm{SI}$ & SI & SI & $\mathrm{SI}$ \\
\hline $\begin{array}{l}\text { Las Cabezas De } \\
\text { San Juan }\end{array}$ & 10000 & & & SI & & & & \\
\hline Málaga & 10000 & & & SI & & & & \\
\hline \multicolumn{9}{|l|}{$\begin{array}{l}\text { Mancomunidad } \\
\text { Sasieta (22 } \\
\text { Municipios) }\end{array}$} \\
\hline Manises & 2230 & 11 & $\begin{array}{l}\text { Baterias, } 120 \mathrm{lts}, 240 \mathrm{Its}, 1000 \mathrm{Its}, \\
\text { jaulas raees, arcon fluorescentes, } \\
600 \mathrm{Its} \text { aceites de motor y cocina }\end{array}$ & SI & SI & SI & NO & NO \\
\hline Massamagrell & 2990 & 11 & $\begin{array}{l}\text { Baterias, } 120 \mathrm{lts}, 240 \mathrm{Its}, 1000 \mathrm{Its}, \\
\text { jaulas raees, arcon fluorescentes, } \\
600 \text { Its aceites de motor y cocina }\end{array}$ & SI & $\mathrm{SI}$ & SI & SI & NO \\
\hline Meliana & 2120 & 10 & $\begin{array}{l}\text { Baterias, } 120 \text { Its, } 240 \text { Its, } 1000 \text { Its, } \\
\text { jaulas raees, arcon fluorescentes, } \\
600 \text { Its aceites de motor y cocina }\end{array}$ & SI & $\mathrm{SI}$ & SI & NO & NO \\
\hline Molins De Rei & 1800 & 9 & & SI & SI & & & SI \\
\hline Morella & 768 & 4 & $\begin{array}{l}\text { 2, ACEITE MINERAL Y } \\
\text { VEGETAL }\end{array}$ & SI & SI & SI & SI & SI \\
\hline Nules & 3500 & 10 & $\begin{array}{l}\text { 2, ACEITE MINERAL Y } \\
\text { VEGETAL }\end{array}$ & SI & SI & SI & SI & SI \\
\hline Onda & 3200 & 12 & & SI & SI & SI & SI & NO \\
\hline $\begin{array}{l}\text { Paiporta Y } \\
\text { Picanya }\end{array}$ & 1935 & 12 & $\begin{array}{l}\text { Baterias, } 120 \text { Its, } 240 \text { Its, } 1000 \text { Its, } \\
\text { jaulas raees, arcon fluorescentes, } \\
600 \text { Its aceites de motor y cocina }\end{array}$ & SI & SI & SI & NO & NO \\
\hline Paterna & 4800 & 18 & $\begin{array}{l}\text { Baterias, } 120 \mathrm{Its}, 240 \mathrm{Its}, 1000 \mathrm{Its}, \\
\text { jaulas raees, arcon fluorescentes, } \\
600 \text { Its aceites de motor y cocina }\end{array}$ & SI & $\mathrm{SI}$ & SI & SI & $\mathrm{SI}$ \\
\hline Peñiscola & 527 & 6 & $\begin{array}{l}\text { 2, ACEITE MINERAL Y } \\
\text { VEGETAL }\end{array}$ & SI & SI & SI & SI & $\mathrm{SI}$ \\
\hline Picassent & 2250 & 10 & $\begin{array}{l}\text { Baterias, } 120 \mathrm{lts}, 240 \mathrm{Its}, 1000 \mathrm{Its}, \\
\text { jaulas raees, arcon fluorescentes, } \\
600 \text { Its aceites de motor y cocina }\end{array}$ & SI & SI & SI & SI & NO \\
\hline Puçol & 2088 & 10 & $\begin{array}{l}\text { Baterias, } 120 \mathrm{lts}, 240 \mathrm{Its}, 1000 \mathrm{Its}, \\
\text { jaulas raees, arcon fluorescentes, } \\
600 \text { Its aceites de motor y cocina }\end{array}$ & SI & SI & SI & NO & NO \\
\hline
\end{tabular}




\begin{tabular}{|c|c|c|c|c|c|c|c|c|}
\hline Ciudad & $\begin{array}{l}\text { Superficie } \\
\text { aprox en } \mathrm{m}^{2}\end{array}$ & $\begin{array}{c}\mathrm{N}^{0} \text { de } \\
\text { contenedores } \\
\text { de caja abierta }\end{array}$ & $\begin{array}{l}\text { Detalla de otro tipo de } \\
\text { contenedores, si existen: }\end{array}$ & $\begin{array}{l}\text { Disponibilidad } \\
\text { cerramiento } \\
\text { perimetral }\end{array}$ & $\begin{array}{l}\text { Disponibilidad } \\
\text { oficina de } \\
\text { recepción y, al } \\
\text { menos un WC }\end{array}$ & $\begin{array}{l}\text { Disponibilidad } \\
\text { Zona cubierta y } \\
\text { ventilada } \\
\text { almacenamiento } \\
\text { de RRPP }\end{array}$ & $\begin{array}{l}\text { Disponibilidad } \\
\text { Zona especifica } \\
\text { c/antiderrame } \\
\text { almacenamiento } \\
\text { RAEE }\end{array}$ & $\begin{array}{l}\text { Disponibilidad } \\
\text { Báscula }\end{array}$ \\
\hline $\begin{array}{l}\text { Puerto De Santa } \\
\text { Maria }\end{array}$ & 9900 & 9 & & SI & & & & \\
\hline $\begin{array}{l}\text { Quart De Les } \\
\text { Valls }\end{array}$ & 1012 & 4 & $\begin{array}{l}\text { 2, ACEITE MINERAL Y } \\
\text { VEGETAL }\end{array}$ & SI & $\mathrm{SI}$ & SI & SI & $\mathrm{SI}$ \\
\hline $\begin{array}{l}\text { Rincón De La } \\
\text { Victoria }\end{array}$ & 4800 & 6 & & SI & & & & \\
\hline Rossell & 346 & 4 & $\begin{array}{l}\text { 2, ACEITE MINERAL Y } \\
\text { VEGETAL }\end{array}$ & SI & SI & SI & SI & SI \\
\hline $\begin{array}{l}\text { Sant Adrià De } \\
\text { Besòs }\end{array}$ & 15000 & & & SI & SI & SI & SI & SI \\
\hline $\begin{array}{l}\text { Sant Andreu De } \\
\text { La Barca }\end{array}$ & 4600 & 8 & & SI & SI & & & SI \\
\hline $\begin{array}{l}\text { Sant Boi De } \\
\text { Llobregat }\end{array}$ & 2700 & 11 & & SI & SI & & & SI \\
\hline Sant Jordi & 417 & 4 & $\begin{array}{l}\text { 2, ACEITE MINERAL Y } \\
\text { VEGETAL }\end{array}$ & SI & SI & SI & SI & $\mathrm{SI}$ \\
\hline $\begin{array}{l}\text { Sant Rafael Del } \\
\text { Riu }\end{array}$ & 423 & 4 & $\begin{array}{l}\text { 2, ACEITE MINERAL Y } \\
\text { VEGETAL }\end{array}$ & SI & SI & SI & SI & SI \\
\hline $\begin{array}{c}\text { Santa Coloma De } \\
\text { Gramenet }\end{array}$ & 3200 & 11 & & SI & SI & & & SI \\
\hline $\begin{array}{l}\text { Santa Magdalena } \\
\text { De Pulpis }\end{array}$ & 440 & 4 & $\begin{array}{l}\text { 2, ACEITE MINERAL Y } \\
\text { VEGETAL }\end{array}$ & SI & SI & SI & SI & SI \\
\hline Sedaví & 1290 & 7 & $\begin{array}{l}\text { Baterias, } 120 \mathrm{lts}, 240 \mathrm{Its}, 1000 \mathrm{Its}, \\
\text { jaulas raees, arcon fluorescentes, } \\
600 \mathrm{lts} \text { aceites de motor y cocina }\end{array}$ & SI & SI & SI & NO & NO \\
\hline Sevilla & 2100 & 8 & $\begin{array}{l}\text { Distintos modelos y volúmenes } \\
\text { para diversos residuos }\end{array}$ & SI & SI & SI & NO & NO \\
\hline Sevilla & 3980 & 9 & $\begin{array}{l}\text { Distintos modelos y volúmenes } \\
\text { para diversos residuos }\end{array}$ & SI & SI & SI & NO & NO \\
\hline Sevilla & 3900 & 9 & $\begin{array}{l}\text { Distintos modelos y volúmenes } \\
\text { para diversos residuos }\end{array}$ & SI & SI & SI & NO & NO \\
\hline Sevilla & 3500 & 10 & $\begin{array}{l}\text { Distintos modelos y volúmenes } \\
\text { para diversos residuos }\end{array}$ & SI & SI & SI & NO & NO \\
\hline Silla & 2190 & 9 & $\begin{array}{l}\text { Baterias, } 120 \text { Its, } 240 \text { Its, } 1000 \text { Its, } \\
\text { jaulas reees, arcon fluorescentes, } \\
600 \text { Its aceites de motor y cocina }\end{array}$ & SI & SI & SI & SI & NO \\
\hline Soneja & 2317 & 6 & $\begin{array}{l}\text { 2, ACEITE MINERAL Y } \\
\text { VEGETAL }\end{array}$ & SI & SI & SI & SI & SI \\
\hline Tarragona & & 15 & $\begin{array}{l}\text { CAJAS COMPACTADORAS - } \\
\text { IGLÚS }\end{array}$ & SI & SI & SI & SI & SI \\
\hline Torreblanca & 4142 & 11 & $\begin{array}{l}\text { 2, ACEITE MINERAL Y } \\
\text { VEGETAL }\end{array}$ & SI & SI & SI & SI & SI \\
\hline Torrent & 4600 & 13 & $\begin{array}{l}\text { Baterias, } 120 \mathrm{lts}, 240 \mathrm{Its}, 1000 \mathrm{Its}, \\
\text { jaulas raees, arcon fluorescentes, } \\
600 \mathrm{lts} \text { aceites de motor y cocina }\end{array}$ & SI & SI & SI & NO & NO \\
\hline Torrent & 6000 & 21 & $\begin{array}{l}\text { Baterias, } 120 \mathrm{lts}, 240 \mathrm{Its}, 1000 \mathrm{Its}, \\
\text { jaulas raees, arcon fluorescentes, } \\
600 \mathrm{lts} \text { aceites de motor y cocina }\end{array}$ & SI & SI & SI & NO & SI \\
\hline Tudela & & & & SI & SI & & & \\
\hline Utrera & 4800 & 6 & & SI & & & & \\
\hline Vall D'Uixó & 3500 & 10 & 2 , aceite mineral y aceite vegetal & SI & SI & SI & SI & SI \\
\hline
\end{tabular}


Anexo A5.3.

\begin{tabular}{|c|c|c|c|c|c|c|c|c|}
\hline Ciudad & $\begin{array}{l}\text { Superficie } \\
\text { aprox en } \mathbf{m}^{2}\end{array}$ & $\begin{array}{c}\mathrm{N}^{0} \text { de } \\
\text { contenedores } \\
\text { de caja abierta }\end{array}$ & $\begin{array}{l}\text { Detalla de otro tipo de } \\
\text { contenedores, si existen: }\end{array}$ & $\begin{array}{l}\text { Disponibilidad } \\
\text { cerramiento } \\
\text { perimetral }\end{array}$ & $\begin{array}{l}\text { Disponibilidad } \\
\text { oficina de } \\
\text { recepción y, al } \\
\text { menos un WC }\end{array}$ & $\begin{array}{l}\text { Disponibilidad } \\
\text { Zona cubierta y } \\
\text { ventilada } \\
\text { almacenamiento } \\
\text { de RRPP }\end{array}$ & $\begin{array}{l}\text { Disponibilidad } \\
\text { Zona especifica } \\
\text { c/antiderrame } \\
\text { almacenamiento } \\
\text { RAEE }\end{array}$ & $\begin{array}{l}\text { Disponibilidad } \\
\text { Báscula }\end{array}$ \\
\hline $\begin{array}{l}\text { Valverde Del } \\
\text { Camino }\end{array}$ & 9900 & 9 & & $\mathrm{SI}$ & & & & \\
\hline Viladecans & 2200 & 15 & & SI & SI & & & SI \\
\hline $\begin{array}{l}\text { Vilanova } \\
\text { D'Alcolea }\end{array}$ & 459 & 4 & $\begin{array}{c}\text { 2, ACEITE MINERAL Y } \\
\text { VEGETAL }\end{array}$ & SI & SI & $\mathrm{SI}$ & SI & SI \\
\hline Villafranca Del Cid & 1000 & 4 & $\begin{array}{l}\text { 2, ACEITE MINERAL Y } \\
\text { VEGETAL }\end{array}$ & $\mathrm{SI}$ & SI & $\mathrm{SI}$ & SI & $\mathrm{SI}$ \\
\hline Vinaròs & 3080 & 11 & $\begin{array}{l}\text { 2, ACEITE MINERAL Y } \\
\text { VEGETAL }\end{array}$ & SI & SI & SI & $\mathrm{SI}$ & SI \\
\hline Xàtiva & 3800 & 9 & Jaulas RAEE & SI & SI & $\mathrm{SI}$ & SI & NO \\
\hline Xert & 399 & 4 & $\begin{array}{l}\text { 2, ACEITE MINERAL Y } \\
\text { VEGETAL }\end{array}$ & SI & SI & $\mathrm{SI}$ & $\mathrm{SI}$ & $\mathrm{SI}$ \\
\hline Xirivella & 3040 & 10 & $\begin{array}{l}\text { Baterias, } 120 \text { Its, } 240 \text { Its, } 1000 \text { Its, } \\
\text { jaulas raees, arcon fluorescentes, } \\
600 \text { Its aceites de motor y cocina }\end{array}$ & $\mathrm{SI}$ & $\mathrm{SI}$ & $\mathrm{SI}$ & $\mathrm{SI}$ & NO \\
\hline
\end{tabular}




\begin{tabular}{|c|c|c|c|c|c|c|c|c|c|c|}
\hline Ciudad & Gestión & $\begin{array}{l}\text { Días que se } \\
\text { encuentra abierta } \\
\text { la instalación }\end{array}$ & $\begin{array}{l}\text { Hora de } \\
\text { apertura }\end{array}$ & $\begin{array}{l}\text { Hora de } \\
\text { cierre }\end{array}$ & $\begin{array}{c}\text { Admisión } \\
\text { Voluminosos }\end{array}$ & $\begin{array}{l}\text { Admisión } \\
\text { RCD's }\end{array}$ & $\begin{array}{l}\text { Admisión } \\
\text { Reciclables } \\
\text { (P/C, EELL, } \\
\text { Vidrio) }\end{array}$ & $\begin{array}{l}\text { Admisión } \\
\text { Fracción } \\
\text { resto }\end{array}$ & $\begin{array}{l}\text { Admisión } \\
\text { Residuos } \\
\text { Peligrosos }\end{array}$ & $\begin{array}{l}\text { Voluminosos } \\
\text { (t/año): }\end{array}$ \\
\hline Albal & Concesión & $\mathrm{L}, \mathrm{M}, \mathrm{X}, \mathrm{J}, \mathrm{V}, \mathrm{S}$ & 09:00 & $18: 00$ & SI & SI & SI & NO & SI & 101,60 \\
\hline $\begin{array}{l}\text { Albalat Dels } \\
\text { Sorells }\end{array}$ & Concesión & $\mathrm{L}, \mathrm{M}, \mathrm{X}, \mathrm{J}, \mathrm{V}, \mathrm{S}$ & 09:00 & 18:00 & SI & SI & SI & NO & SI & 25,32 \\
\hline Albocàsser & Concesión & $\mathrm{M}, \mathrm{X}, \mathrm{J}, \mathrm{V}, \mathrm{S}$ & 09:00 & 18:00 & SI & SI & SI & SI & SI & 50,24 \\
\hline Alboraya & Concesión & L, M, X, J, V, S, D & 08:00 & 21:00 & SI & SI & SI & NO & SI & 374,98 \\
\hline Alcalà De Xivert & Concesión & L, M, X, J, V & 10:00 & 17:00 & SI & SI & SI & SI & SI & 139,90 \\
\hline Aldaia Y Alaquàs & Concesión & L, M, X, J, V, S, D & 08:00 & 21:00 & $\mathrm{SI}$ & SI & $\mathrm{SI}$ & NO & SI & 383,54 \\
\hline Algimia De Alfara & Concesión & L, M, X, J, V & 09:00 & 18:00 & SI & $\mathrm{SI}$ & $\mathrm{SI}$ & $\mathrm{SI}$ & $\mathrm{SI}$ & 87,68 \\
\hline Alicante & Concesión & $\mathrm{M}, \mathrm{X}, \mathrm{J}, \mathrm{V}, \mathrm{S}, \mathrm{D}$ & 09:30 & 19:30 & $\mathrm{SI}$ & $\mathrm{SI}$ & $\mathrm{SI}$ & $\mathrm{SI}$ & SI & 111,74 \\
\hline Almàssera & Concesión & $\mathrm{L}, \mathrm{M}, \mathrm{X}, \mathrm{J}, \mathrm{V}, \mathrm{S}$ & 09:00 & 18:00 & SI & SI & SI & NO & $\mathrm{SI}$ & 88,06 \\
\hline Almazora & Concesión & $\mathrm{M}, \mathrm{X}, \mathrm{J}, \mathrm{V}, \mathrm{S}, \mathrm{D}$ & 10:00 & 19:00 & $\mathrm{SI}$ & $\mathrm{SI}$ & SI & NO & SI & 176,64 \\
\hline Almenara & Concesión & L, M, J, V, S, D & 09:00 & 19:00 & SI & SI & SI & SI & SI & 84,30 \\
\hline $\begin{array}{c}\text { Área } \\
\text { Metropolitana De } \\
\text { Valencia }\end{array}$ & Concesión & L, M, X, J, V, S, D & 09:00 & $21: 00$ & SI & SI & NO & NO & SI & 380,00 \\
\hline Badia Del Vallès & Concesión & $\mathrm{L}, \mathrm{M}, \mathrm{X}, \mathrm{J}, \mathrm{V}, \mathrm{S}$ & 09:30 & 19:00 & SI & SI & SI & SI & SI & $88.400,00$ \\
\hline Benassal & Concesión & $\mathrm{M}, \mathrm{X}, \mathrm{J}, \mathrm{V}, \mathrm{S}$ & $10: 00$ & $20: 00$ & SI & SI & SI & SI & SI & 31,18 \\
\hline Benicarló & Concesión & L, M, X, J, V, S, D & 09:00 & $20: 00$ & SI & SI & SI & $\mathrm{SI}$ & SI & 431,19 \\
\hline Benidorm & Concesión & L, M, X, J, V, S, D & 09:00 & 19:00 & SI & $\mathrm{SI}$ & SI & SI & SI & \\
\hline Benlloch & Concesión & L, M, X, J, V, S & 09:00 & $18: 00$ & SI & SI & SI & SI & SI & 31,42 \\
\hline Bilbao & Directa & $\mathrm{L}, \mathrm{M}, \mathrm{X}, \mathrm{J}, \mathrm{V}, \mathrm{S}, \mathrm{D}$ & $14: 00$ & $20: 30$ & SI & SI & $\mathrm{SI}$ & NO & SI & 158,00 \\
\hline Bilbao & Directa & $\mathrm{L}, \mathrm{M}, \mathrm{X}, \mathrm{J}, \mathrm{V}, \mathrm{S}$ & 07:30 & 13:30 & SI & SI & SI & NO & NO & 116,00 \\
\hline Bilbao & Directa & $\mathrm{L}, \mathrm{M}, \mathrm{X}, \mathrm{J}, \mathrm{V}, \mathrm{S}$ & 07:00 & $20: 30$ & SI & SI & SI & NO & SI & 163,00 \\
\hline Bilbao & Directa & $\mathrm{L}, \mathrm{M}, \mathrm{X}, \mathrm{J}, \mathrm{V}, \mathrm{S}$ & 07:30 & $13: 30$ & SI & SI & SI & NO & NO & 59,00 \\
\hline Cabanes & Concesión & $\mathrm{L}, \mathrm{M}, \mathrm{X}, \mathrm{J}, \mathrm{V}, \mathrm{S}$ & $10: 00$ & 19:00 & $\mathrm{SI}$ & SI & SI & SI & SI & 48,24 \\
\hline Càlig & Concesión & $\mathrm{L}, \mathrm{M}, \mathrm{X}, \mathrm{J}, \mathrm{V}, \mathrm{S}$ & $10: 00$ & $20: 00$ & $\mathrm{SI}$ & $\mathrm{SI}$ & SI & SI & SI & 35,62 \\
\hline Canals & Concesión & $\mathrm{L}, \mathrm{M}, \mathrm{X}, \mathrm{J}, \mathrm{V}, \mathrm{S}$ & 10:00 & 19:00 & $\mathrm{SI}$ & SI & SI & NO & SI & 200,80 \\
\hline Canet Lo Roig & Concesión & $\mathrm{M}, \mathrm{X}, \mathrm{J}, \mathrm{V}$ & 09:00 & 18:00 & $\mathrm{SI}$ & SI & SI & SI & SI & 31,18 \\
\hline Castalla & Concesión & $\mathrm{M}, \mathrm{X}, \mathrm{J}, \mathrm{V}, \mathrm{S}, \mathrm{D}$ & $10: 00$ & 19:00 & $\mathrm{SI}$ & SI & SI & NO & NO & 193,76 \\
\hline Castellón & Concesión & L, M, X, J, V, S, D & 09:30 & 19:00 & $\mathrm{SI}$ & NO & SI & NO & SI & 1,22 \\
\hline Catarroja & Concesión & $\mathrm{L}, \mathrm{M}, \mathrm{X}, \mathrm{J}, \mathrm{V}, \mathrm{S}$ & 09:00 & $18: 00$ & SI & $\mathrm{SI}$ & SI & & SI & 154,76 \\
\hline $\begin{array}{l}\text { Cervera Del } \\
\text { Maestre }\end{array}$ & Concesión & $\mathrm{X}, \mathrm{J}, \mathrm{V}, \mathrm{S}$ & 09:00 & 18:00 & SI & SI & SI & SI & SI & 9,30 \\
\hline
\end{tabular}




\begin{tabular}{|c|c|c|c|c|c|c|c|c|c|c|}
\hline Ciudad & Gestión & $\begin{array}{l}\text { Días que se } \\
\text { encuentra abierta } \\
\text { la instalación }\end{array}$ & $\begin{array}{l}\text { Hora de } \\
\text { apertura }\end{array}$ & $\begin{array}{l}\text { Hora de } \\
\text { cierre }\end{array}$ & $\begin{array}{c}\text { Admisión } \\
\text { Voluminosos }\end{array}$ & $\begin{array}{l}\text { Admisión } \\
\text { RCD's }\end{array}$ & $\begin{array}{c}\text { Admisión } \\
\text { Reciclables } \\
\text { (P/C, EELL, } \\
\text { Vidrio) }\end{array}$ & $\begin{array}{l}\text { Admisión } \\
\text { Fracción } \\
\text { resto }\end{array}$ & $\begin{array}{l}\text { Admisión } \\
\text { Residuos } \\
\text { Peligrosos }\end{array}$ & $\begin{array}{l}\text { Voluminosos } \\
\text { (t/año): }\end{array}$ \\
\hline $\begin{array}{c}\text { Churriana De La } \\
\text { Vega }\end{array}$ & Concesión & $\mathrm{L}, \mathrm{M}, \mathrm{X}, \mathrm{J}, \mathrm{V}, \mathrm{S}$ & $10: 00$ & $20: 00$ & SI & $\mathrm{SI}$ & $\mathrm{SI}$ & SI & $\mathrm{SI}$ & 139,09 \\
\hline $\begin{array}{c}\text { Cornella De } \\
\text { Llobregat }\end{array}$ & Concesión & $\mathrm{L}, \mathrm{M}, \mathrm{X}, \mathrm{J}, \mathrm{V}, \mathrm{S}$ & 09:00 & $20: 00$ & SI & $\mathrm{SI}$ & SI & SI & SI & \\
\hline $\begin{array}{l}\text { Coves De } \\
\text { Vinromà }\end{array}$ & Concesión & $\mathrm{M}, \mathrm{X}, \mathrm{J}, \mathrm{V}, \mathrm{S}$ & $10: 00$ & $20: 00$ & SI & & & SI & SI & 37,10 \\
\hline Crevillent & Concesión & $\mathrm{M}, \mathrm{X}, \mathrm{J}, \mathrm{V}, \mathrm{S}, \mathrm{D}$ & $10: 00$ & $19: 00$ & SI & $\mathrm{SI}$ & SI & NO & $\mathrm{SI}$ & 285,32 \\
\hline Cuenca & Directa & $\mathrm{L}, \mathrm{M}, \mathrm{X}, \mathrm{J}, \mathrm{V}, \mathrm{S}$ & $09: 30$ & $20: 00$ & SI & $\mathrm{SI}$ & SI & NO & NO & 294,00 \\
\hline $\begin{array}{l}\text { El Prat De } \\
\text { Llobregat }\end{array}$ & Concesión & L, M, X, J, V, S, D & $09: 30$ & $20: 00$ & SI & $\mathrm{SI}$ & SI & SI & $\mathrm{SI}$ & \\
\hline $\begin{array}{l}\text { Esplugues De } \\
\text { Llobregat/Sant } \\
\text { Joan Despí }\end{array}$ & Concesión & L, M, X, J, V, S, D & $10: 00$ & $19: 00$ & SI & $\mathrm{SI}$ & SI & SI & SI & \\
\hline Estivella & Concesión & L, M, X, V, S, D & 09:00 & $18: 00$ & SI & $\mathrm{SI}$ & SI & SI & $\mathrm{SI}$ & 55,40 \\
\hline Gilet & Concesión & L, M, J, V, S, D & 09:00 & $19: 00$ & SI & $\mathrm{SI}$ & SI & SI & SI & 194,70 \\
\hline Guadix & Concesión & $\mathrm{L}, \mathrm{M}, \mathrm{X}, \mathrm{J}, \mathrm{V}, \mathrm{S}$ & $17: 00$ & $20: 00$ & SI & $\mathrm{SI}$ & SI & SI & $\mathrm{SI}$ & 181,39 \\
\hline $\begin{array}{l}\text { Hospitalet De } \\
\text { Llobregat }\end{array}$ & Concesión & $\mathrm{L}, \mathrm{M}, \mathrm{X}, \mathrm{J}, \mathrm{V}, \mathrm{S}$ & 09:00 & $20: 00$ & SI & $\mathrm{SI}$ & SI & $\mathrm{SI}$ & $\mathrm{SI}$ & \\
\hline L'Alcora & Concesión & $\mathrm{M}, \mathrm{X}, \mathrm{J}, \mathrm{V}, \mathrm{S}, \mathrm{D}$ & $10: 00$ & $19: 00$ & SI & $\mathrm{SI}$ & NO & NO & $\mathrm{SI}$ & 38,46 \\
\hline La Salzadella & Concesión & $\mathrm{L}, \mathrm{M}, \mathrm{X}, \mathrm{V}$ & $10: 00$ & $20: 00$ & SI & $\mathrm{SI}$ & SI & SI & $\mathrm{SI}$ & 31,74 \\
\hline $\begin{array}{l}\text { La Torre D'en } \\
\text { Doménec }\end{array}$ & Concesión & $\mathrm{X}, \mathrm{V}$ & 09:00 & $18: 00$ & SI & $\mathrm{SI}$ & SI & SI & $\mathrm{SI}$ & 4,36 \\
\hline $\begin{array}{l}\text { Las Cabezas De } \\
\text { San Juan }\end{array}$ & Concesión & $\mathrm{L}, \mathrm{M}, \mathrm{X}, \mathrm{J}, \mathrm{V}, \mathrm{S}$ & $10: 00$ & $20: 00$ & $\mathrm{SI}$ & $\mathrm{SI}$ & SI & SI & $\mathrm{SI}$ & 35,96 \\
\hline Málaga & Concesión & $\mathrm{L}, \mathrm{M}, \mathrm{X}, \mathrm{J}, \mathrm{V}, \mathrm{S}$ & $10: 00$ & $20: 00$ & SI & $\mathrm{SI}$ & $\mathrm{SI}$ & SI & SI & 35,96 \\
\hline $\begin{array}{l}\text { Mancomunidad } \\
\text { Sasieta (22 } \\
\text { Municipios) }\end{array}$ & Concesión & $\mathrm{L}, \mathrm{M}, \mathrm{X}, \mathrm{J}, \mathrm{V}, \mathrm{S}$ & & & $\mathrm{SI}$ & $\mathrm{SI}$ & SI & SI & $\mathrm{SI}$ & 688,00 \\
\hline Manises & Concesión & $\mathrm{L}, \mathrm{M}, \mathrm{X}, \mathrm{J}, \mathrm{V}, \mathrm{S}$ & 09:00 & $18: 00$ & SI & $\mathrm{SI}$ & SI & NO & $\mathrm{SI}$ & 56,92 \\
\hline Massamagrell & Concesión & $\mathrm{L}, \mathrm{M}, \mathrm{X}, \mathrm{J}, \mathrm{V}, \mathrm{S}$ & 09:00 & $18: 00$ & SI & $\mathrm{SI}$ & SI & NO & $\mathrm{SI}$ & 109,58 \\
\hline Meliana & Concesión & $\mathrm{L}, \mathrm{M}, \mathrm{X}, \mathrm{J}, \mathrm{V}, \mathrm{S}$ & 09:00 & $18: 00$ & $\mathrm{SI}$ & $\mathrm{SI}$ & SI & NO & SI & 61,60 \\
\hline Molins De Rei & Concesión & L, M, X, J, V, S, D & 08:00 & $20: 00$ & SI & $\mathrm{SI}$ & SI & SI & SI & \\
\hline Morella & Concesión & $\mathrm{M}, \mathrm{X}, \mathrm{J}, \mathrm{V}, \mathrm{S}$ & $10: 00$ & $20: 00$ & SI & $\mathrm{SI}$ & SI & SI & $\mathrm{SI}$ & 159,78 \\
\hline Nules & Concesión & $\mathrm{M}, \mathrm{X}, \mathrm{J}, \mathrm{V}, \mathrm{S}, \mathrm{D}$ & 09:00 & $18: 00$ & SI & $\mathrm{SI}$ & SI & $\mathrm{SI}$ & SI & 151,85 \\
\hline Onda & Concesión & $\mathrm{M}, \mathrm{X}, \mathrm{J}, \mathrm{V}, \mathrm{S}, \mathrm{D}$ & $10: 00$ & $19: 00$ & SI & SI & NO & NO & SI & 118,16 \\
\hline $\begin{array}{l}\text { Paiporta Y } \\
\text { Picanya }\end{array}$ & Concesión & L, M, X, J, V, S, D & 08:00 & $21: 00$ & SI & $\mathrm{SI}$ & SI & NO & SI & 185,96 \\
\hline Paterna & Concesión & L, M, X, J, V, S, D & 08:00 & $21: 00$ & SI & $\mathrm{SI}$ & SI & NO & $\mathrm{SI}$ & 31,80 \\
\hline Peñiscola & Concesión & $\mathrm{L}, \mathrm{M}, \mathrm{X}, \mathrm{J}, \mathrm{V}, \mathrm{S}$ & $09: 30$ & $19: 00$ & SI & $\mathrm{SI}$ & SI & SI & $\mathrm{SI}$ & 165,66 \\
\hline Picassent & Concesión & L, M, X, J, V, S, D & 08:00 & $21: 00$ & SI & $\mathrm{SI}$ & SI & NO & $\mathrm{SI}$ & 187,40 \\
\hline Puçol & Concesión & $\mathrm{L}, \mathrm{M}, \mathrm{X}, \mathrm{J}, \mathrm{V}, \mathrm{S}$ & 09:00 & $21: 00$ & SI & SI & SI & NO & SI & 81,72 \\
\hline
\end{tabular}




\begin{tabular}{|c|c|c|c|c|c|c|c|c|c|c|}
\hline Ciudad & Gestión & $\begin{array}{l}\text { Días que se } \\
\text { encuentra abierta } \\
\text { la instalación }\end{array}$ & $\begin{array}{l}\text { Hora de } \\
\text { apertura }\end{array}$ & $\begin{array}{l}\text { Hora de } \\
\text { cierre }\end{array}$ & $\begin{array}{c}\text { Admisión } \\
\text { Voluminosos }\end{array}$ & $\begin{array}{l}\text { Admisión } \\
\text { RCD's }\end{array}$ & $\begin{array}{l}\text { Admisión } \\
\text { Reciclables } \\
\text { (P/C, EELL, } \\
\text { Vidrio) }\end{array}$ & $\begin{array}{l}\text { Admisión } \\
\text { Fracción } \\
\text { resto }\end{array}$ & $\begin{array}{l}\text { Admisión } \\
\text { Residuos } \\
\text { Peligrosos }\end{array}$ & $\begin{array}{l}\text { Voluminosos } \\
\text { (t/año): }\end{array}$ \\
\hline $\begin{array}{l}\text { Puerto De Santa } \\
\text { Maria }\end{array}$ & Concesión & L, M, X, J, V, S, D & 08:00 & 21:00 & SI & $\mathrm{SI}$ & $\mathrm{SI}$ & $\mathrm{SI}$ & $\mathrm{SI}$ & 0,48 \\
\hline $\begin{array}{l}\text { Quart De Les } \\
\text { Valls }\end{array}$ & Concesión & L, M, X, J, V, S & 08:00 & 18:00 & SI & SI & SI & SI & $\mathrm{SI}$ & 120,76 \\
\hline $\begin{array}{l}\text { Rincón De La } \\
\text { Victoria }\end{array}$ & Concesión & L, M, X, J, V, S, D & 08:00 & $20: 00$ & SI & SI & SI & SI & SI & $1.522,46$ \\
\hline Rossell & Concesión & $\mathrm{L}, \mathrm{M}, \mathrm{X}, \mathrm{J}, \mathrm{V}, \mathrm{S}$ & 09:00 & 18:00 & SI & SI & SI & SI & SI & 25,28 \\
\hline $\begin{array}{c}\text { Sant Adrià De } \\
\text { Besòs }\end{array}$ & Concesión & L, M, X, J, V, D & 00:00 & 00:00 & SI & SI & SI & SI & SI & $3.550,00$ \\
\hline $\begin{array}{l}\text { Sant Andreu De } \\
\text { La Barca }\end{array}$ & Concesión & $\mathrm{L}, \mathrm{M}, \mathrm{X}, \mathrm{J}, \mathrm{V}, \mathrm{S}$ & 09:00 & 19:00 & SI & SI & SI & SI & SI & \\
\hline $\begin{array}{l}\text { Sant Boi De } \\
\text { Llobregat }\end{array}$ & Directa & $\mathrm{L}, \mathrm{M}, \mathrm{X}, \mathrm{J}, \mathrm{V}, \mathrm{S}$ & 09:00 & 19:00 & SI & SI & SI & SI & SI & \\
\hline Sant Jordi & Concesión & L, M, X, J, S & 09:00 & 18:00 & SI & SI & SI & SI & SI & 32,66 \\
\hline $\begin{array}{l}\text { Sant Rafael Del } \\
\text { Riu }\end{array}$ & Concesión & $\mathrm{X}, \mathrm{J}, \mathrm{V}, \mathrm{S}$ & 10:00 & $20: 00$ & SI & SI & SI & SI & SI & 14,18 \\
\hline $\begin{array}{c}\text { Santa Coloma De } \\
\text { Gramenet }\end{array}$ & Concesión & $\mathrm{L}, \mathrm{M}, \mathrm{X}, \mathrm{J}, \mathrm{V}, \mathrm{S}$ & 08:00 & 18:00 & SI & SI & SI & SI & SI & \\
\hline $\begin{array}{c}\text { Santa Magdalena } \\
\text { De Pulpis }\end{array}$ & Concesión & L, M, J, S & 09:00 & 18:00 & SI & SI & SI & SI & SI & 19,68 \\
\hline Sedaví & Concesión & $\mathrm{L}, \mathrm{M}, \mathrm{X}, \mathrm{J}, \mathrm{V}, \mathrm{S}$ & 09:00 & 18:00 & SI & SI & $\mathrm{SI}$ & NO & SI & 205,30 \\
\hline Sevilla & Directa & $\mathrm{L}, \mathrm{M}, \mathrm{X}, \mathrm{J}, \mathrm{V}, \mathrm{S}$ & $08: 15$ & 21:00 & SI & SI & SI & SI & SI & 171,00 \\
\hline Sevilla & Directa & $\mathrm{L}, \mathrm{M}, \mathrm{X}, \mathrm{J}, \mathrm{V}, \mathrm{S}$ & $08: 15$ & 21:00 & SI & SI & SI & SI & SI & 113,00 \\
\hline Sevilla & Directa & $\mathrm{L}, \mathrm{M}, \mathrm{X}, \mathrm{J}, \mathrm{V}, \mathrm{S}$ & $08: 15$ & 21:00 & SI & SI & SI & SI & SI & 155,00 \\
\hline Sevilla & Directa & $\mathrm{L}, \mathrm{M}, \mathrm{X}, \mathrm{J}, \mathrm{V}, \mathrm{S}$ & $08: 15$ & 21:00 & SI & SI & SI & SI & SI & 174,00 \\
\hline Silla & Concesión & $\mathrm{L}, \mathrm{M}, \mathrm{X}, \mathrm{J}, \mathrm{V}, \mathrm{S}$ & 09:00 & 18:00 & $\mathrm{SI}$ & SI & SI & NO & $\mathrm{SI}$ & 95,60 \\
\hline Soneja & Concesión & $\mathrm{L}, \mathrm{M}, \mathrm{X}, \mathrm{J}, \mathrm{V}, \mathrm{S}$ & $09: 30$ & $18: 30$ & SI & SI & SI & SI & SI & 585,88 \\
\hline Tarragona & Concesión & $\mathrm{L}, \mathrm{M}, \mathrm{X}, \mathrm{J}, \mathrm{V}, \mathrm{S}$ & 08:00 & $20: 00$ & SI & SI & SI & NO & SI & 340,17 \\
\hline Torreblanca & Concesión & $\mathrm{L}, \mathrm{M}, \mathrm{X}, \mathrm{J}, \mathrm{V}, \mathrm{S}$ & 09:00 & 18:00 & SI & SI & SI & SI & SI & 262,38 \\
\hline Torrent & Concesión & L, M, X, J, V, S, D & 08:00 & 21:00 & SI & SI & $\mathrm{SI}$ & NO & SI & 164,98 \\
\hline Torrent & Concesión & $\mathrm{L}, \mathrm{M}, \mathrm{X}, \mathrm{J}, \mathrm{V}, \mathrm{S}$ & 09:00 & $18: 00$ & SI & SI & $\mathrm{SI}$ & NO & SI & 101,34 \\
\hline Tudela & Concesión & $\mathrm{L}, \mathrm{M}, \mathrm{X}, \mathrm{J}, \mathrm{V}, \mathrm{S}$ & & & SI & & SI & SI & SI & $2.221,00$ \\
\hline Utrera & Concesión & L, M, X, J, V, S, D & 08:00 & $20: 00$ & SI & $\mathrm{SI}$ & SI & SI & SI & $1.522,46$ \\
\hline Vall D'Uixó & Concesión & $M, X, J, V, S, D$ & 09:00 & 19:00 & SI & $\mathrm{SI}$ & $\mathrm{SI}$ & $\mathrm{SI}$ & $\mathrm{SI}$ & 206,35 \\
\hline
\end{tabular}


Anexo A5.3.

\begin{tabular}{|c|c|c|c|c|c|c|c|c|c|c|}
\hline Ciudad & Gestión & $\begin{array}{l}\text { Días que se } \\
\text { encuentra abierta } \\
\text { la instalación }\end{array}$ & $\begin{array}{l}\text { Hora de } \\
\text { apertura }\end{array}$ & $\begin{array}{l}\text { Hora de } \\
\text { cierre }\end{array}$ & $\begin{array}{l}\text { Admisión } \\
\text { Voluminosos }\end{array}$ & $\begin{array}{l}\text { Admisión } \\
\text { RCD's }\end{array}$ & $\begin{array}{c}\text { Admisión } \\
\text { Reciclables } \\
\text { (P/C, EELL, } \\
\text { Vidrio) }\end{array}$ & $\begin{array}{l}\text { Admisión } \\
\text { Fracción } \\
\text { resto }\end{array}$ & $\begin{array}{c}\text { Admisión } \\
\text { Residuos } \\
\text { Peligrosos }\end{array}$ & $\begin{array}{l}\text { Voluminosos } \\
\text { (t/año): }\end{array}$ \\
\hline $\begin{array}{l}\text { Valverde Del } \\
\text { Camino }\end{array}$ & Concesión & L, M, X, J, V, S, D & 08:00 & $21: 00$ & SI & SI & $\mathrm{SI}$ & SI & SI & 0,48 \\
\hline Viladecans & Concesión & $\mathrm{L}, \mathrm{M}, \mathrm{X}, \mathrm{J}, \mathrm{V}, \mathrm{S}$ & 09:00 & $19: 00$ & SI & $\mathrm{SI}$ & $\mathrm{SI}$ & SI & SI & \\
\hline $\begin{array}{l}\text { Vilanova } \\
\text { D'Alcolea }\end{array}$ & Concesión & $\mathrm{M}, \mathrm{X}, \mathrm{J}, \mathrm{V}, \mathrm{S}$ & 09:00 & $18: 00$ & SI & $\mathrm{SI}$ & SI & SI & SI & 15,32 \\
\hline Villafranca Del Cid & Concesión & $\mathrm{L}, \mathrm{M}, \mathrm{X}, \mathrm{J}, \mathrm{V}, \mathrm{S}$ & $10: 00$ & $20: 00$ & SI & $\mathrm{SI}$ & SI & SI & SI & 51,52 \\
\hline Vinaròs & Concesión & L, M, X, J, V, S, D & 09:00 & $20: 00$ & SI & $\mathrm{SI}$ & SI & SI & SI & 828,63 \\
\hline Xàtiva & Concesión & $\mathrm{L}, \mathrm{M}, \mathrm{X}, \mathrm{J}, \mathrm{V}, \mathrm{S}$ & $10: 00$ & $19: 00$ & SI & SI & $\mathrm{SI}$ & NO & SI & 322,17 \\
\hline Xert & Concesión & $\mathrm{L}, \mathrm{X}, \mathrm{V}, \mathrm{S}$ & 09:00 & $18: 00$ & SI & $\mathrm{SI}$ & SI & SI & SI & 30,96 \\
\hline Xirivella & Concesión & $L, M, X, J, V, S, D$ & 08:00 & $21: 00$ & SI & $\mathrm{SI}$ & $\mathrm{SI}$ & NO & SI & 165,38 \\
\hline
\end{tabular}




\begin{tabular}{|c|c|c|c|c|c|c|c|c|c|}
\hline Ciudad & RCD's (t/año): & $\begin{array}{l}\text { Reciclables } \\
\text { (t/año): }\end{array}$ & $\begin{array}{l}\text { Fracción } \\
\text { resto (t/año): }\end{array}$ & $\begin{array}{c}\text { Resto de } \\
\text { residuos } \\
\text { Peligrosos } \\
\text { (t/año): }\end{array}$ & TOTAL TM & $\begin{array}{l}\text { Pago de } \\
\text { Tasas por } \\
\text { utilización }\end{array}$ & $\begin{array}{l}\text { Incentivos } \\
\text { por } \\
\text { utilización }\end{array}$ & Detalle incentivos & $\begin{array}{l}\text { Autorización } \\
\text { acceso de } \\
\text { empresas }\end{array}$ \\
\hline Albal & 958,36 & 342,50 & & 47,75 & $1.450,21$ & NO & NO & & SI \\
\hline $\begin{array}{l}\text { Albalat Dels } \\
\text { Sorells }\end{array}$ & 396,48 & 96,72 & & 28,62 & 547,14 & NO & NO & & SI \\
\hline Albocàsser & 17,40 & 49,70 & 12,78 & 6,59 & 136,71 & SI & SI & $\begin{array}{l}\text { Se acumulan puntos y se } \\
\text { descuentan del importe de la } \\
\text { tasa del año siguiente }\end{array}$ & SI \\
\hline Alboraya & $7.472,90$ & $1.476,84$ & & 97,69 & $9.422,41$ & NO & NO & & SI \\
\hline Alcalà De Xivert & 314,76 & 18,91 & 105,01 & 7,51 & 586,09 & SI & SI & $\begin{array}{l}\text { Se acumulan puntos y se } \\
\text { descuentan del importe de la } \\
\text { tasa del año siguiente }\end{array}$ & SI \\
\hline Aldaia Y Alaquàs & $3.366,16$ & $1.126,91$ & & 111,11 & $4.987,72$ & NO & NO & & SI \\
\hline Algimia De Alfara & 125,01 & & 129,36 & 10,96 & 353,01 & SI & SI & $\begin{array}{l}\text { Se acumulan puntos y se } \\
\text { descuentan del importe de la } \\
\text { tasa del año siguiente }\end{array}$ & SI \\
\hline Alicante & $3.209,00$ & 405,81 & 60,66 & 5,86 & $3.793,07$ & NO & NO & & SI \\
\hline Almàssera & $1.516,44$ & 395,40 & & 58,50 & $2.058,40$ & NO & NO & & SI \\
\hline Almazora & 255,58 & 57,64 & & 1,42 & 491,28 & NO & NO & & NO \\
\hline Almenara & 105,86 & 14,00 & 181,53 & 8,82 & 394,51 & SI & SI & $\begin{array}{l}\text { Se acumulan puntos y se } \\
\text { descuentan del importe de la } \\
\text { tasa del año siguiente }\end{array}$ & SI \\
\hline $\begin{array}{c}\text { Área } \\
\text { Metropolitana De } \\
\text { Valencia }\end{array}$ & $6.150,00$ & 0,00 & 0,00 & 136,00 & $6.666,00$ & SI & NO & & NO \\
\hline Badia Del Vallès & $242.780,00$ & & $88.400,00$ & & $419.580,00$ & SI & SI & $\begin{array}{l}\text { Tarjeta gratuita para } \\
\text { descuento en la tasa } \\
\text { metropolitana de residuos }\end{array}$ & SI \\
\hline Benassal & 127,16 & 16,71 & 2,33 & 1,06 & 178,44 & SI & SI & $\begin{array}{l}\text { Se acumulan puntos y se } \\
\text { descuentan del importe de la } \\
\text { tasa del año siguiente }\end{array}$ & SI \\
\hline Benicarló & 654,70 & 54,24 & 795,87 & 44,51 & $1.980,51$ & SI & SI & $\begin{array}{l}\text { Se acumulan puntos y se } \\
\text { descuentan del importe de la } \\
\text { tasa del año siguiente }\end{array}$ & SI \\
\hline Benidorm & & & & & & NO & NO & & $\mathrm{SI}$ \\
\hline Benlloch & 78,52 & 19,13 & 8,21 & 2,46 & 139,74 & SI & SI & $\begin{array}{c}\text { Se acumulan puntos y se } \\
\text { descuentan del importe de la } \\
\text { tasa del año siguiente }\end{array}$ & SI \\
\hline Bilbao & $2.170,00$ & $3.123,00$ & 359,00 & 5,00 & $5.815,00$ & NO & NO & & $\mathrm{SI}$ \\
\hline Bilbao & $1.846,00$ & $2.625,00$ & 671,00 & 3,00 & $5.261,00$ & NO & NO & & SI \\
\hline Bilbao & $4.376,00$ & $5.510,00$ & 621,00 & 4,00 & $10.674,00$ & NO & NO & & SI \\
\hline Bilbao & $2.098,00$ & $2.802,00$ & 331,00 & 334,00 & $5.624,00$ & NO & NO & & SI \\
\hline Cabanes & 92,02 & 18,22 & 61,17 & 5,22 & 224,87 & SI & SI & $\begin{array}{l}\text { Se acumulan puntos y se } \\
\text { descuentan del importe de la } \\
\text { tasa del año siguiente }\end{array}$ & SI \\
\hline Càlig & 59,38 & 11,85 & 9,54 & 3,07 & 119,46 & SI & SI & $\begin{array}{l}\text { Se acumulan puntos y se } \\
\text { descuentan del importe de la } \\
\text { tasa del año siguiente }\end{array}$ & SI \\
\hline Canals & 491,80 & 39,84 & & 29,26 & 761,71 & NO & NO & & NO \\
\hline Canet Lo Roig & 48,31 & 6,62 & 1,57 & 2,91 & 90,59 & SI & SI & $\begin{array}{l}\text { Se acumulan puntos y se } \\
\text { descuentan del importe de la } \\
\text { tasa del año siguiente }\end{array}$ & SI \\
\hline Castalla & 374,06 & & & & 567,82 & NO & NO & & NO \\
\hline Castellón & 0,00 & $6.424,43$ & 0,00 & 61,84 & $6.487,49$ & NO & NO & & SI \\
\hline Catarroja & $1.753,92$ & 575,55 & & 77,44 & $2.561,67$ & NO & NO & & $\mathrm{SI}$ \\
\hline $\begin{array}{l}\text { Cervera Del } \\
\text { Maestre }\end{array}$ & 17,80 & 3,43 & 0,84 & 0,47 & 31,84 & SI & SI & $\begin{array}{l}\text { Se acumulan puntos y se } \\
\text { descuentan del importe de la } \\
\text { tasa del año siguiente }\end{array}$ & SI \\
\hline
\end{tabular}




\begin{tabular}{|c|c|c|c|c|c|c|c|c|c|}
\hline Ciudad & RCD's (t/año): & $\begin{array}{l}\text { Reciclables } \\
\text { (t/año): }\end{array}$ & $\begin{array}{l}\text { Fracción } \\
\text { resto (t/año): }\end{array}$ & $\begin{array}{c}\text { Resto de } \\
\text { residuos } \\
\text { Peligrosos } \\
\text { (t/año): }\end{array}$ & TOTAL TM & $\begin{array}{l}\text { Pago de } \\
\text { Tasas por } \\
\text { utilización }\end{array}$ & $\begin{array}{l}\text { Incentivos } \\
\text { por } \\
\text { utilización }\end{array}$ & Detalle incentivos & $\begin{array}{l}\text { Autorización } \\
\text { acceso de } \\
\text { empresas }\end{array}$ \\
\hline $\begin{array}{c}\text { Churriana De La } \\
\text { Vega }\end{array}$ & 98,44 & 55,84 & 2,67 & 5,20 & 301,24 & NO & NO & & \\
\hline $\begin{array}{c}\text { Cornella De } \\
\text { Llobregat }\end{array}$ & & & & & & SI & SI & $\begin{array}{l}\text { Bonificación en el recibo de } \\
\text { agua anual }\end{array}$ & SI \\
\hline $\begin{array}{l}\text { Coves De } \\
\text { Vinromà }\end{array}$ & 169,42 & 18,75 & 36,84 & 3,58 & 265,69 & SI & SI & $\begin{array}{c}\text { Se acumulan puntos y se } \\
\text { descuentan del importe de la } \\
\text { tasa del año siguiente }\end{array}$ & SI \\
\hline Crevillent & 157,48 & 10,77 & 0,00 & 30,69 & 484,26 & NO & NO & & NO \\
\hline Cuenca & 420,00 & & & & 714,00 & NO & NO & & NO \\
\hline $\begin{array}{l}\text { El Prat De } \\
\text { Llobregat }\end{array}$ & & & & $21.434,00$ & $21.434,00$ & SI & SI & \begin{tabular}{|c|} 
Hasta $14 \%$ de descuento en \\
la tasa de tratamiento si se \\
utiliza hasta 15 veces por año
\end{tabular} & SI \\
\hline $\begin{array}{l}\text { Esplugues De } \\
\text { Llobregat/Sant } \\
\text { Joan Despi }\end{array}$ & & & $15.537,00$ & & $15.537,00$ & SI & SI & $\begin{array}{c}\text { Hasta } 14 \% \text { de descuento en } \\
\text { la tasa de tratamiento si se } \\
\text { utiliza hasta } 15 \text { veces por año }\end{array}$ & SI \\
\hline Estivella & 199,55 & 22,82 & 61,28 & 5,13 & 344,18 & SI & SI & $\begin{array}{c}\text { Se acumulan puntos y se } \\
\text { descuentan del importe de la } \\
\text { tasa del año siguiente }\end{array}$ & SI \\
\hline Gilet & 450,66 & & 297,27 & 12,14 & 954,77 & SI & SI & $\begin{array}{c}\text { Se acumulan puntos y se } \\
\text { descuentan del importe de la } \\
\text { tasa del año siguiente }\end{array}$ & SI \\
\hline Guadix & 19,42 & & 137,14 & 212,00 & 549,95 & NO & NO & & NO \\
\hline $\begin{array}{l}\text { Hospitalet De } \\
\text { Llobregat }\end{array}$ & & & $9.927,00$ & & $9.927,00$ & SI & SI & $\begin{array}{c}\text { Hasta } 14 \% \text { de descuento en } \\
\text { la tasa de tratamiento si se } \\
\text { utiliza hasta } 15 \text { veces por año }\end{array}$ & SI \\
\hline L'Alcora & 192,60 & & & 4,26 & 235,32 & NO & NO & & NO \\
\hline La Salzadella & 9,88 & 10,47 & 2,44 & 1,54 & 56,07 & SI & SI & $\begin{array}{c}\text { Se acumulan puntos y se } \\
\text { descuentan del importe de la } \\
\text { tasa del año siguiente }\end{array}$ & $\mathrm{SI}$ \\
\hline $\begin{array}{l}\text { La Torre D'en } \\
\text { Doménec }\end{array}$ & 8,18 & 0,37 & 0,26 & 0,46 & 13,63 & SI & SI & $\begin{array}{c}\text { Se acumulan puntos y se } \\
\text { descuentan del importe de la } \\
\text { tasa del año siguiente }\end{array}$ & SI \\
\hline $\begin{array}{l}\text { Las Cabezas De } \\
\text { San Juan }\end{array}$ & 572,04 & 149,00 & 49,34 & 37,14 & 843,48 & NO & NO & & \\
\hline Málaga & 572,04 & 149,00 & 49,34 & 37,14 & 843,48 & NO & NO & & \\
\hline $\begin{array}{l}\text { Mancomunidad } \\
\text { Sasieta (22 } \\
\text { Municipios) }\end{array}$ & $2.320,00$ & $4.372,00$ & $4.893,00$ & 41,00 & $12.314,00$ & & & & \\
\hline Manises & $1.108,50$ & 213,79 & & 47,69 & $1.426,90$ & NO & NO & & SI \\
\hline Massamagrell & $1.274,38$ & 309,93 & & 55,53 & $1.749,42$ & NO & NO & & $\mathrm{SI}$ \\
\hline Meliana & 711,04 & 244,31 & & 47,34 & $1.064,30$ & NO & NO & & SI \\
\hline Molins De Rei & & & $14.725,00$ & & $14.725,00$ & SI & SI & $\begin{array}{c}\text { Hasta } 14 \% \text { de descuento en } \\
\text { la tasa de tratamiento si se } \\
\text { utiliza hasta } 15 \text { veces por año }\end{array}$ & SI \\
\hline Morella & 52,88 & 119,52 & 46,24 & 5,80 & 384,22 & SI & SI & $\begin{array}{c}\text { Se acumulan puntos y se } \\
\text { descuentan del importe de la } \\
\text { tasa del año siguiente }\end{array}$ & SI \\
\hline Nules & 70,98 & 16,48 & 200,14 & 7,81 & 447,26 & SI & SI & $\begin{array}{c}\text { Se acumulan puntos y se } \\
\text { descuentan del importe de la } \\
\text { tasa del año siguiente }\end{array}$ & SI \\
\hline Onda & 324,84 & & & 0,25 & 443,25 & NO & NO & & NO \\
\hline $\begin{array}{l}\text { Paiporta Y } \\
\text { Picanya }\end{array}$ & $2.908,82$ & 769,35 & & 101,61 & $3.965,74$ & NO & NO & & SI \\
\hline Paterna & 420,84 & 106,55 & & 19,26 & 578,45 & NO & NO & & SI \\
\hline Peñiscola & 899,30 & 71,13 & 482,91 & 7,95 & $1.626,95$ & SI & SI & $\begin{array}{l}\text { Se acumulan puntos y se } \\
\text { descuentan del importe de la } \\
\text { tasa del año siguiente }\end{array}$ & SI \\
\hline Picassent & $1.696,16$ & 563,79 & & 75,42 & $2.522,77$ & NO & NO & & SI \\
\hline Puçol & $1.037,28$ & 320,16 & & 69,46 & $1.508,63$ & NO & NO & & SI \\
\hline
\end{tabular}




\begin{tabular}{|c|c|c|c|c|c|c|c|c|c|}
\hline Ciudad & RCD's (t/año): & $\begin{array}{l}\text { Reciclables } \\
\text { (t/año): }\end{array}$ & $\begin{array}{l}\text { Fracción } \\
\text { resto (t/año): }\end{array}$ & $\begin{array}{l}\text { Resto de } \\
\text { residuos } \\
\text { Peligrosos } \\
\text { (t/año): }\end{array}$ & TOTAL TM & $\begin{array}{l}\text { Pago de } \\
\text { Tasas por } \\
\text { utilización }\end{array}$ & $\begin{array}{l}\text { Incentivos } \\
\text { por } \\
\text { utilización }\end{array}$ & Detalle incentivos & $\begin{array}{l}\text { Autorización } \\
\text { acceso de } \\
\text { empresas }\end{array}$ \\
\hline $\begin{array}{l}\text { Puerto De Santa } \\
\text { Maria }\end{array}$ & & 0,78 & 0,86 & 18,55 & 20,67 & & & & \\
\hline $\begin{array}{l}\text { Quart De Les } \\
\text { Valls }\end{array}$ & 191,75 & & 102,59 & 5,45 & 420,55 & SI & SI & $\begin{array}{l}\text { Se acumulan puntos y se } \\
\text { descuentan del importe de la } \\
\text { tasa del año siguiente }\end{array}$ & $\mathrm{SI}$ \\
\hline $\begin{array}{l}\text { Rincón De La } \\
\text { Victoria }\end{array}$ & & $1.749,96$ & 40,08 & 25,98 & $3.338,48$ & NO & NO & & \\
\hline Rossell & 49,92 & 5,86 & 3,27 & 1,37 & 85,70 & SI & $\mathrm{SI}$ & $\begin{array}{c}\text { Se acumulan puntos y se } \\
\text { descuentan del importe de la } \\
\text { tasa del año siguiente }\end{array}$ & SI \\
\hline $\begin{array}{l}\text { Sant Adrià De } \\
\text { Besòs }\end{array}$ & $1.051,00$ & $18.000,00$ & $156.000,00$ & 30,00 & $178.631,00$ & SI & NO & & SI \\
\hline $\begin{array}{l}\text { Sant Andreu De } \\
\text { La Barca }\end{array}$ & & & $4.043,00$ & & $4.043,00$ & SI & SI & $\begin{array}{c}\text { Hasta } 14 \% \text { de descuento en } \\
\text { la tasa de tratamiento si se } \\
\text { utiliza hasta } 15 \text { veces por año }\end{array}$ & SI \\
\hline $\begin{array}{l}\text { Sant Boi De } \\
\text { Llobregat }\end{array}$ & & & $8.121,00$ & & $8.121,00$ & SI & SI & $\begin{array}{c}\text { Hasta } 14 \% \text { de descuento en } \\
\text { la tasa de tratamiento si se } \\
\text { utiliza hasta } 15 \text { veces por año }\end{array}$ & SI \\
\hline Sant Jordi & 17,62 & 9,84 & 5,84 & 1,44 & 67,40 & SI & SI & $\begin{array}{c}\text { Se acumulan puntos y se } \\
\text { descuentan del importe de la } \\
\text { tasa del año siguiente }\end{array}$ & SI \\
\hline $\begin{array}{l}\text { Sant Rafael Del } \\
\text { Riu }\end{array}$ & 30,24 & 10,71 & 2,21 & 3,28 & 60,62 & SI & SI & $\begin{array}{c}\text { Se acumulan puntos y se } \\
\text { descuentan del importe de la } \\
\text { tasa del año siguiente }\end{array}$ & SI \\
\hline $\begin{array}{c}\text { Santa Coloma De } \\
\text { Gramenet }\end{array}$ & & & $7.688,00$ & & $7.688,00$ & SI & SI & $\begin{array}{c}\text { Hasta } 14 \% \text { de descuento en } \\
\text { la tasa de tratamiento si se } \\
\text { utiliza hasta } 15 \text { veces por año }\end{array}$ & SI \\
\hline $\begin{array}{l}\text { Santa Magdalena } \\
\text { De Pulpis }\end{array}$ & 39,74 & 2,91 & 2,37 & 2,55 & 67,25 & SI & SI & $\begin{array}{l}\text { Se acumulan puntos y se } \\
\text { descuentan del importe de la } \\
\text { tasa del año siguiente }\end{array}$ & SI \\
\hline Sedaví & $2.071,94$ & 448,96 & & 76,92 & $2.803,12$ & NO & NO & & SI \\
\hline Sevilla & $5.093,00$ & $1.155,00$ & 256,00 & 129,00 & $6.804,00$ & NO & NO & & $\mathrm{SI}$ \\
\hline Sevilla & $3.370,00$ & 764,00 & 169,00 & 86,00 & $4.502,00$ & NO & NO & & SI \\
\hline Sevilla & $4.633,00$ & $1.051,00$ & 233,00 & 118,00 & $6.190,00$ & NO & NO & & SI \\
\hline Sevilla & $5.208,00$ & $1.181,00$ & 261,00 & 132,00 & $6.956,00$ & NO & NO & & $\mathrm{SI}$ \\
\hline Silla & 758,66 & 304,15 & & 66,60 & $1.225,01$ & NO & NO & & SI \\
\hline Soneja & 191,34 & 22,86 & 102,44 & 19,42 & 921,94 & SI & SI & $\begin{array}{c}\text { Se acumulan puntos y se } \\
\text { descuentan del importe de la } \\
\text { tasa del año siguiente }\end{array}$ & SI \\
\hline Tarragona & 203,16 & 81,37 & 0,00 & 11,54 & 636,24 & NO & NO & & SI \\
\hline Torreblanca & 539,50 & 84,98 & 452,54 & 24,79 & $1.364,19$ & SI & SI & $\begin{array}{c}\text { Se acumulan puntos y se } \\
\text { descuentan del importe de la } \\
\text { tasa del año siguiente }\end{array}$ & $\mathrm{SI}$ \\
\hline Torrent & $2.302,18$ & 578,06 & & 100,92 & $3.146,14$ & NO & NO & & SI \\
\hline Torrent & 749,92 & 275,38 & & 66,88 & $1.193,52$ & NO & NO & & $\mathrm{SI}$ \\
\hline Tudela & & 0,11 & $2.328,78$ & 0,17 & $4.550,06$ & & & & \\
\hline Utrera & & $1.749,96$ & 40,08 & 25,98 & $3.338,48$ & NO & NO & & \\
\hline Vall D'Uixó & 220,24 & 33,74 & 291,47 & 12,00 & 763,80 & SI & SI & $\begin{array}{c}\text { Sistema "Si más reciclas } \\
\text { menos pagas" }\end{array}$ & $\mathrm{SI}$ \\
\hline
\end{tabular}


Anexo A5.3.

\begin{tabular}{|c|c|c|c|c|c|c|c|c|c|}
\hline Ciudad & RCD's (t/año): & $\begin{array}{l}\text { Reciclables } \\
\text { (t/año): }\end{array}$ & $\begin{array}{l}\text { Fracción } \\
\text { resto (t/año): }\end{array}$ & $\begin{array}{c}\text { Resto de } \\
\text { residuos } \\
\text { Peligrosos } \\
\text { (t/año): }\end{array}$ & TOTAL TM & $\begin{array}{l}\text { Pago de } \\
\text { Tasas por } \\
\text { utilización }\end{array}$ & $\begin{array}{l}\text { Incentivos } \\
\text { por } \\
\text { utilización }\end{array}$ & Detalle incentivos & $\begin{array}{l}\text { Autorización } \\
\text { acceso de } \\
\text { empresas }\end{array}$ \\
\hline $\begin{array}{l}\text { Valverde Del } \\
\text { Camino }\end{array}$ & & 0,78 & 0,86 & 18,55 & 20,67 & NO & NO & & \\
\hline Viladecans & & & $11.511,00$ & & $11.511,00$ & SI & SI & $\begin{array}{c}\text { Hasta } 14 \% \text { de descuento en } \\
\text { la tasa de tratamiento si se } \\
\text { utiliza hasta } 15 \text { veces por año }\end{array}$ & SI \\
\hline $\begin{array}{l}\text { Vilanova } \\
\text { D'Alcolea }\end{array}$ & 16,82 & 2,39 & 1,25 & 0,63 & 36,41 & SI & SI & $\begin{array}{c}\text { No es seguro, porque es de } \\
\text { sustituciones y hasta el día de } \\
\text { antes no se sabrá }\end{array}$ & SI \\
\hline Villafranca Del Cid & 125,10 & 24,40 & 22,67 & 2,85 & 226,54 & SI & SI & $\begin{array}{c}\text { no es seguro porque es de } \\
\text { sustituciones y hasta el día de } \\
\text { antes no se sabrá }\end{array}$ & SI \\
\hline Vinaròs & $1.246,17$ & 190,68 & $1.193,49$ & 29,23 & $3.488,20$ & SI & SI & $\begin{array}{c}\text { No es seguro, porque es de } \\
\text { sustituciones y hasta el dia de } \\
\text { antes no se sabrá }\end{array}$ & SI \\
\hline Xàtiva & 955,12 & 58,22 & & 116,20 & $1.451,71$ & NO & NO & & NO \\
\hline Xert & 9,80 & 30,89 & 3,10 & 4,74 & 79,49 & SI & SI & $\begin{array}{c}\text { No es seguro, porque es de } \\
\text { sustituciones y hasta el día de } \\
\text { antes no se sabrá }\end{array}$ & SI \\
\hline Xirivella & $2.870,50$ & 673,86 & & 82,28 & $3.792,03$ & NO & NO & & $\mathrm{SI}$ \\
\hline
\end{tabular}




\begin{tabular}{|c|c|c|c|c|c|c|c|c|c|c|}
\hline \multirow{2}{*}{ Ciudad } & \multirow{2}{*}{$\begin{array}{c}\text { Existencia de } \\
\text { limites } \\
\text { cuantitativos } \\
\text { y/o cualitativas } \\
\text { de aportación }\end{array}$} & \multirow{2}{*}{$\begin{array}{l}\text { Disponibilidad } \\
\text { ecoparque } \\
\text { móvil asociado }\end{array}$} & \multirow{2}{*}{$\begin{array}{l}\text { Cantidad de } \\
\text { residuos } \\
\text { ecoparque } \\
\text { móvil (t/año) }\end{array}$} & \multirow{2}{*}{$\begin{array}{l}T \text { anuales } \\
\text { recogida } R S U\end{array}$} & \multirow{2}{*}{$\begin{array}{l}\text { Población } \\
\text { INE }\end{array}$} & \multirow{2}{*}{ kg/hab/año } & \multirow{2}{*}{$\begin{array}{l}\text { Visitas/hab/ } \\
\text { año }\end{array}$} & \multicolumn{3}{|c|}{$\begin{array}{l}\text { Ecoparque } \\
\text { Móvil }\end{array}$} \\
\hline & & & & & & & & Sí & No & $\begin{array}{l}\text { NSI } \\
\text { NC }\end{array}$ \\
\hline Albal & SI & SI & & $4.979,00$ & 16.244 & 89,28 & 45,57 & $\checkmark$ & & \\
\hline $\begin{array}{l}\text { Albalat Dels } \\
\text { Sorells }\end{array}$ & SI & SI & & & 3.900 & 140,29 & 101,28 & $\checkmark$ & & \\
\hline Albocàsser & SI & NO & & 443,00 & 1.257 & 108,76 & 40,65 & & $\checkmark$ & \\
\hline Alboraya & SI & SI & & $9.039,00$ & 24.031 & 392,09 & 142,86 & $\checkmark$ & & \\
\hline Alcalà De Xivert & SI & SI & & $5.873,00$ & 6.796 & 86,24 & 13,27 & $\checkmark$ & & \\
\hline Aldaia Y Alaquàs & SI & SI & & $21.705,00$ & 60.794 & 82,04 & 42,79 & $\checkmark$ & & \\
\hline Algimia De Alfara & SI & NO & & & 1.051 & 335,88 & 49,10 & & $\checkmark$ & \\
\hline Alicante & SI & SI & & $153.556,00$ & 329.988 & 11,49 & 3,35 & $\checkmark$ & & \\
\hline Almàssera & SI & SI & & $3.361,00$ & 7.308 & 281,66 & 153,30 & $\checkmark$ & & \\
\hline Almazora & $\mathrm{SI}$ & NO & & $10.500,00$ & 25.648 & 19,15 & & & $\checkmark$ & \\
\hline Almenara & SI & NO & & $2.459,00$ & 5.920 & 66,64 & 13,58 & & $\checkmark$ & \\
\hline $\begin{array}{c}\text { Área } \\
\text { Metropolitana De } \\
\text { Valencia }\end{array}$ & SI & SI & 80 & $184.580,00$ & 791.413 & 8,42 & 6,18 & $\checkmark$ & & \\
\hline Badia Del Vallès & SI & SI & 595 & & 13.466 & $31.158,47$ & & $\checkmark$ & & \\
\hline Benassal & SI & NO & & & 1.106 & 161,34 & 8,77 & & $\checkmark$ & \\
\hline Benicarló & SI & SI & & & 26.429 & 74,94 & 19,05 & $\checkmark$ & & \\
\hline Benidorm & SI & SI & & & 66.831 & & 14,96 & $\checkmark$ & & \\
\hline Benlloch & SI & NO & & 324,00 & 1.060 & 131,83 & 59,25 & & $\checkmark$ & \\
\hline Bilbao & SI & NO & 3.482 & $153.600,00$ & 86.278 & 67,40 & 14,19 & & $\checkmark$ & \\
\hline Bilbao & SI & NO & 3.296 & $\begin{array}{c}153600 \text { (los } 4 \\
\text { Bilbogarbis) }\end{array}$ & 86.278 & 60,98 & 13,23 & & $\checkmark$ & \\
\hline Bilbao & SI & NO & 6.131 & $\begin{array}{c}153.600 \text { (entre los } 4 \\
\text { Bilbogarbis) }\end{array}$ & 86.278 & 123,72 & 19,39 & & $\checkmark$ & \\
\hline Bilbao & SI & NO & 3.132 & $\begin{array}{c}\text { 153.600 (ENTRE } \\
\text { LOS } 4 \\
\text { bILBOGARBIS) }\end{array}$ & 86.278 & 65,19 & 10,54 & & $\checkmark$ & \\
\hline Cabanes & SI & SI & & & 2.913 & 77,20 & 34,67 & $\checkmark$ & & \\
\hline Càlig & SI & NO & & 561,00 & 1.959 & 60,98 & 35,43 & & $\checkmark$ & \\
\hline Canals & SI & SI & & & 13.631 & 55,88 & & $\checkmark$ & & \\
\hline Canet Lo Roig & SI & NO & & 231,00 & 706 & 128,31 & 68,27 & & $\checkmark$ & \\
\hline Castalla & SI & NO & & $5.086,49$ & 9.876 & 57,49 & & & $\checkmark$ & \\
\hline Castellón & NO & SI & 5 & $69.780,07$ & 169.498 & 38,27 & 23,85 & $\checkmark$ & & \\
\hline Catarroja & SI & SI & 2.611 & $8.962,00$ & 27.752 & 92,31 & 45,53 & $\checkmark$ & & \\
\hline $\begin{array}{l}\text { Cervera Del } \\
\text { Maestre }\end{array}$ & SI & NO & & & 620 & 51,35 & 22,74 & & $\checkmark$ & \\
\hline
\end{tabular}


Anexo A5.3.

\begin{tabular}{|c|c|c|c|c|c|c|c|c|c|c|}
\hline \multirow{2}{*}{ Ciudad } & \multirow{2}{*}{$\begin{array}{l}\text { Existencia de } \\
\text { limites } \\
\text { cuantitativos } \\
\text { y/o cualitativas } \\
\text { de aportación } \\
\end{array}$} & \multirow{2}{*}{$\begin{array}{l}\text { Disponibilidad } \\
\text { ecoparque } \\
\text { móvil asociado }\end{array}$} & \multirow{2}{*}{$\begin{array}{l}\text { Cantidad de } \\
\text { residuos } \\
\text { ecoparque } \\
\text { móvil (t/año) }\end{array}$} & \multirow{2}{*}{$\begin{array}{l}\text { T anuales } \\
\text { recogida RSU }\end{array}$} & \multirow{2}{*}{$\begin{array}{l}\text { Población } \\
\text { INE }\end{array}$} & \multirow{2}{*}{ kg/hab/año } & \multirow{2}{*}{$\begin{array}{l}\text { Visitas/habl } \\
\text { año }\end{array}$} & \multicolumn{3}{|c|}{$\begin{array}{l}\text { Ecoparque } \\
\text { Móvil }\end{array}$} \\
\hline & & & & & & & & Sí & No & $\begin{array}{l}\text { NSI } \\
\text { NC }\end{array}$ \\
\hline $\begin{array}{c}\text { Churriana De La } \\
\text { Vega }\end{array}$ & & NO & & & 14.556 & 20,70 & & & $\checkmark$ & \\
\hline $\begin{array}{c}\text { Cornella De } \\
\text { Llobregat }\end{array}$ & SI & SI & & $2.702 .032,00$ & 87.173 & & 11,48 & $\checkmark$ & & \\
\hline $\begin{array}{l}\text { Coves De } \\
\text { Vinromà }\end{array}$ & SI & NO & & 554,00 & 1.836 & 144,71 & 41,45 & & $\checkmark$ & \\
\hline Crevillent & SI & SI & & $11.631,38$ & 28.836 & 16,79 & & $\checkmark$ & & \\
\hline Cuenca & SI & NO & & $18.750,00$ & 54.876 & 13,01 & 10,39 & & $\checkmark$ & \\
\hline $\begin{array}{l}\text { El Prat De } \\
\text { Llobregat }\end{array}$ & NO & SI & & & 63.457 & 337,77 & 33,78 & $\checkmark$ & & \\
\hline $\begin{array}{l}\text { Esplugues De } \\
\text { Llobregat/Sant } \\
\text { Joan Despi }\end{array}$ & NO & SI & & & 79.235 & 196,09 & 19,63 & $\checkmark$ & & \\
\hline Estivella & SI & NO & & & 1.416 & 243,06 & 62,71 & & $\checkmark$ & \\
\hline Gilet & SI & NO & & & 3.308 & 288,62 & 39,54 & & $\checkmark$ & \\
\hline Guadix & SI & NO & & & 18.799 & 29,25 & & & $\checkmark$ & \\
\hline $\begin{array}{l}\text { Hospitalet De } \\
\text { Llobregat }\end{array}$ & NO & SI & & & 254.804 & 38,96 & 3,90 & $\checkmark$ & 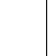 & \\
\hline L'Alcora & SI & NO & & & 10.502 & 22,41 & & & $\checkmark$ & \\
\hline La Salzadella & SI & NO & & & 743 & 75,46 & 76,31 & & $\checkmark$ & \\
\hline $\begin{array}{l}\text { La Torre D'en } \\
\text { Doménec }\end{array}$ & SI & NO & & 62,00 & 198 & 68,84 & 43,43 & & $\checkmark$ & \\
\hline $\begin{array}{l}\text { Las Cabezas De } \\
\text { San Juan }\end{array}$ & & SI & & & 16.418 & 51,38 & & & & $\checkmark$ \\
\hline Málaga & & SI & & & 569.002 & 1,48 & & $\checkmark$ & & \\
\hline $\begin{array}{l}\text { Mancomunidad } \\
\text { Sasieta (22 } \\
\text { Municipios) }\end{array}$ & & & & & 69.561 & 177,02 & & & & $\checkmark$ \\
\hline Manises & SI & SI & & $11.365,00$ & 30.630 & 46,58 & 26,70 & $\checkmark$ & & \\
\hline Massamagrell & SI & SI & & & 15.553 & 112,48 & 51,80 & $\checkmark$ & & \\
\hline Meliana & SI & SI & & $3.640,00$ & 10.678 & 99,67 & 85,38 & $\checkmark$ & & \\
\hline Molins De Rei & NO & SI & & & 25.359 & 580,66 & 58,29 & $\checkmark$ & & \\
\hline Morella & SI & SI & & & 2.441 & 157,40 & 80,83 & $\checkmark$ & & \\
\hline Nules & SI & NO & & $5.304,00$ & 13.266 & 33,71 & 8,01 & & $\checkmark$ & \\
\hline Onda & SI & NO & & $9.253,00$ & 24.807 & 17,87 & & & $\checkmark$ & \\
\hline $\begin{array}{l}\text { Paiporta Y } \\
\text { Picanya }\end{array}$ & SI & SI & & $12.388,00$ & 36.519 & 108,59 & 66,57 & $\checkmark$ & & \\
\hline Paterna & SI & SI & & $29.943,00$ & 68.547 & 8,44 & 3,08 & $\checkmark$ & & \\
\hline Peñiscola & SI & SI & & & 7.413 & 219,47 & 98,46 & $\checkmark$ & & \\
\hline Picassent & SI & SI & & $7.948,00$ & 20.658 & 122,12 & 110,66 & $\checkmark$ & & \\
\hline Puçol & SI & SI & & & 19.531 & 77,24 & 51,50 & $\checkmark$ & & \\
\hline
\end{tabular}




\begin{tabular}{|c|c|c|c|c|c|c|c|c|c|c|}
\hline \multirow{2}{*}{ Ciudad } & \multirow{2}{*}{$\begin{array}{l}\text { Existencia de } \\
\text { limites } \\
\text { cuantitativos } \\
\text { y/o cualitativas } \\
\text { de aportación }\end{array}$} & \multirow{2}{*}{$\begin{array}{l}\text { Disponibilidad } \\
\text { ecoparque } \\
\text { móvil asociado }\end{array}$} & \multirow{2}{*}{$\begin{array}{l}\text { Cantidad de } \\
\text { residuos } \\
\text { ecoparque } \\
\text { móvil (t/año) }\end{array}$} & \multirow{2}{*}{$\begin{array}{c}\text { T anuales } \\
\text { recogida RSU }\end{array}$} & \multirow{2}{*}{$\begin{array}{l}\text { Población } \\
\text { INE }\end{array}$} & \multirow{2}{*}{ kg/hab/año } & \multirow{2}{*}{$\begin{array}{l}\text { Visitas/hab/ } \\
\text { año }\end{array}$} & \multicolumn{3}{|c|}{$\begin{array}{l}\text { Ecoparque } \\
\text { Móvil }\end{array}$} \\
\hline & & & & & & & & Sí & No & $\begin{array}{l}\text { NSI } \\
\text { NC }\end{array}$ \\
\hline $\begin{array}{l}\text { Puerto De Santa } \\
\text { Maria }\end{array}$ & & & & & 88.430 & 0,23 & 22,31 & & & $\checkmark$ \\
\hline $\begin{array}{l}\text { Quart De Les } \\
\text { Valls }\end{array}$ & SI & NO & & & 1.042 & 403,60 & 175,05 & & $\checkmark$ & \\
\hline $\begin{array}{l}\text { Rincón De La } \\
\text { Victoria }\end{array}$ & & SI & & & 45.138 & 73,96 & & $\checkmark$ & & \\
\hline Rossell & SI & NO & & 320,00 & 987 & 86,83 & 84,40 & & $\checkmark$ & \\
\hline $\begin{array}{l}\text { Sant Adrià De } \\
\text { Besòs }\end{array}$ & SI & NO & & $197.000,00$ & 36.624 & $4.877,43$ & 0,27 & & $\checkmark$ & \\
\hline $\begin{array}{l}\text { Sant Andreu De } \\
\text { La Barca }\end{array}$ & NO & SI & & & 27.434 & 147,37 & 14,78 & $\checkmark$ & & \\
\hline $\begin{array}{l}\text { Sant Boi De } \\
\text { Llobregat }\end{array}$ & NO & SI & & & 82.402 & 98,55 & 9,86 & $\checkmark$ & & \\
\hline Sant Jordi & SI & SI & & & 937 & 71,93 & 39,91 & $\checkmark$ & & \\
\hline $\begin{array}{c}\text { Sant Rafael Del } \\
\text { Riu }\end{array}$ & SI & NO & & 154,00 & 464 & 130,65 & 90,09 & & $\checkmark$ & \\
\hline $\begin{array}{c}\text { Santa Coloma De } \\
\text { Gramenet }\end{array}$ & NO & SI & & & 117.153 & 65,62 & 6,56 & $\checkmark$ & & \\
\hline $\begin{array}{c}\text { Santa Magdalena } \\
\text { De Pulpis }\end{array}$ & SI & NO & & 232,00 & 765 & 87,91 & 72,68 & & $\checkmark$ & \\
\hline Sedaví & SI & SI & & $3.927,00$ & 10.179 & 275,38 & 173,86 & $\checkmark$ & & \\
\hline Sevilla & SI & NO & & & 172.359 & 39,48 & & & $\checkmark$ & \\
\hline Sevilla & SI & NO & & & 172.359 & 26,12 & & & $\checkmark$ & \\
\hline Sevilla & SI & NO & & & 172.359 & 35,91 & & & $\checkmark$ & \\
\hline Sevilla & SI & NO & & & 172.359 & 40,36 & & & $\checkmark$ & \\
\hline Silla & SI & SI & & $6.453,00$ & 18.440 & 66,43 & 39,81 & $\checkmark$ & & \\
\hline Soneja & SI & NO & & & 1.468 & 628,02 & 15,53 & & $\checkmark$ & \\
\hline Tarragona & SI & SI & & $59.253,29$ & 117.184 & 5,43 & 6,89 & $\checkmark$ & & \\
\hline Torreblanca & SI & SI & & & 5.419 & 251,74 & 40,08 & $\checkmark$ & & \\
\hline Torrent & SI & SI & & $33.074,00$ & 40.315 & 78,04 & 41,38 & $\checkmark$ & & \\
\hline Torrent & SI & SI & & $33.074,00$ & 40.315 & 29,60 & 16,05 & $\checkmark$ & & \\
\hline Tudela & & SI & & & 35.298 & 128,90 & & & & $\checkmark$ \\
\hline Utrera & & SI & & & 52.701 & 63,35 & & $\checkmark$ & & \\
\hline Vall D'Uixó & SI & NO & & $10.867,00$ & 31.733 & 24,07 & 1,82 & & $\checkmark$ & \\
\hline
\end{tabular}


Anexo A5.3.

\begin{tabular}{|c|c|c|c|c|c|c|c|c|c|c|}
\hline \multirow{2}{*}{ Ciudad } & \multirow{2}{*}{$\begin{array}{l}\text { Existencia de } \\
\text { límites } \\
\text { cuantitativos } \\
\text { y/o cualitativas } \\
\text { de aportación }\end{array}$} & \multirow{2}{*}{$\begin{array}{l}\text { Disponibilidad } \\
\text { ecoparque } \\
\text { móvil asociado }\end{array}$} & \multirow{2}{*}{$\begin{array}{l}\text { Cantidad de } \\
\text { residuos } \\
\text { ecoparque } \\
\text { móvil (t/año) }\end{array}$} & \multirow{2}{*}{$\begin{array}{l}\text { T anuales } \\
\text { recogida RSU }\end{array}$} & \multirow{2}{*}{$\begin{array}{l}\text { Población } \\
\text { INE }\end{array}$} & \multirow{2}{*}{ kg/hab/año } & \multirow{2}{*}{$\begin{array}{l}\text { Visitas/hab/ } \\
\text { año }\end{array}$} & \multicolumn{3}{|c|}{$\begin{array}{l}\text { Ecoparque } \\
\text { Móvil }\end{array}$} \\
\hline & & & & & & & & Sí & No & $\begin{array}{l}\text { NSI } \\
\text { NC }\end{array}$ \\
\hline $\begin{array}{l}\text { Valverde Del } \\
\text { Camino }\end{array}$ & & NO & & & 12.839 & 1,61 & & & $\checkmark$ & \\
\hline Viladecans & NO & SI & & & 65.779 & 175,00 & 17,50 & $\checkmark$ & & \\
\hline $\begin{array}{l}\text { Vilanova } \\
\text { D'Alcolea }\end{array}$ & SI & NO & & 176,00 & 586 & 62,13 & 39,08 & & $\checkmark$ & \\
\hline Villafranca Del Cid & SI & NO & & & 2.267 & 99,93 & 79,36 & & $\checkmark$ & \\
\hline Vinaròs & $\mathrm{SI}$ & SI & & & 28.292 & 123,29 & 17,22 & $\checkmark$ & & \\
\hline Xàtiva & $\mathrm{SI}$ & SI & & & 29.070 & 49,94 & & $\checkmark$ & & \\
\hline Xert & SI & NO & & 213,00 & 733 & 108,44 & 71,62 & & $\checkmark$ & \\
\hline Xirivella & SI & SI & & $9.181,00$ & 28.950 & 130,99 & 57,70 & $\checkmark$ & & \\
\hline
\end{tabular}




\section{ANEXO A5.4. ESTUDIO DE INFLUENCIA DE VARIABLES SOBRE LOS RESULTADOS DE TR $Y$ TV DE LOS PUNTOS LIMPIOS.}





\section{A5.4. ESTUDIO DE INFLUENCIA DE VARIABLES SOBRE LOS RESULTADOS DE TR Y TV DE LOS PUNTOS LIMPIOS.}

En este punto se desarrolla el estudio de influencia de las variables encuestadas que se relacionan en el capítulo 5.3 sobre los resultados de funcionamiento de los puntos limpios, con el objetivo de determinar la significación de cada una de ellas sobre el óptimo funcionamiento de las instalaciones. El estudio se lleva a cabo mediante la aplicación de los tests que se detallan en el capítulo 5.1.5, atendiendo a las características de TR y TV analizadas en el capítulo 5.3.1.

\section{A5.4.1. Población.}

Se estudia a continuación si el tamaño de los municipios, desde el punto de vista demográfico, constituye un factor de influencia sobre las variables TR y TV.

\section{A5.4.1.1. Análisis de TR considerando factor de comparación la población.}

Como puede observarse en el Gráfico 5.4.1, para las poblaciones de mayor tamaño, TR es inferior a $100 \mathrm{~kg} /$ habitante; no obstante, para puntos limpios con población adscrita inferior a 100.000 habitantes, el análisis gráfico no permite la extracción de conclusiones preliminares.

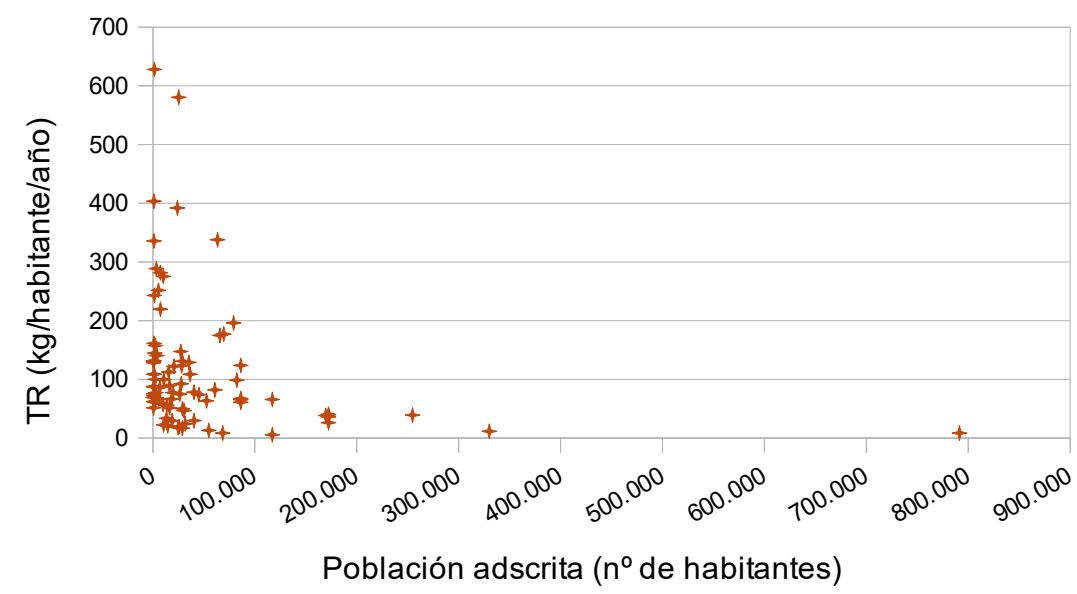

Gráfico 5.4.1: TR frente a población adscrita. 
Con objeto de analizar la posible incidencia del factor demográfico sobre la variable TR, debe realizarse una segmentación de la muestra en diferentes subgrupos, y comparar el comportamiento de éstos entre sí y respecto a la totalidad de la muestra.

Este análisis se realizará mediante una comparación de medias y varianzas, bajo la hipótesis nula de que los subgrupos pertenecen a la misma población y, por tanto, la demografía no es un factor diferenciador, que segmente la población en grupos distintos entre sí.

Actualmente existen diversos criterios de clasificación de los municipios por tamaño de población:

- Clasificación de municipios adoptada por el Instituto Nacional de Estadística, donde existen diez segmentos de población que van desde los municipios de hasta 100 habitantes, de 101 a 500 habitantes, de 501 a 1.000 habitantes, de 1.001 a 2.000 habitantes, de 2.001 a 5.000 habitantes, de 5.001 a 10.000 habitantes, de 10.001 a 20.000 habitantes, de 20.001 a 50.000 habitantes, de 50.001 a 100.000 habitantes, de 100.001 a 500.000 habitantes (de hasta 100 habitantes, hasta los de 500.000 habitantes).

- Segmentación establecida en la Ley 7/1985, de 2 de abril, Reguladora de las Bases de Régimen Local, en la que se establecen segmentos de hasta 5.000 habitantes, de 5.001 a 20.000 habitantes, de 20.001 a 50.000 habitantes, y de más de 50.000 habitantes.

- Segmentación propuesta por Prades M (2014), donde se establecían segmentos de 1.0005.000 habitantes, 5.001-20.000 habitantes, 20.001-50.000 habitantes, 50.001-100.000 habitantes.

- Clasificación de los municipios establecida en los Convenios marco de Ecovidrio y Ecoembes con los distintos gobiernos autonómicos (DOGV, DOCM, BORM), para la gestión de residuos de envases de vidrio, y envases ligeros y de papel-cartón, respectivamente. En este caso, se establecen 3 segmentos: hasta 5.000 habitantes, entre 5.000 y 50.000 habitantes, y de más de 50.000 habitantes.

Puesto que se está realizando un estudio de comportamiento de los municipios en aspectos relacionados con la gestión de residuos, se considera oportuno tener en cuenta la segregación establecida por Ecoembes, que clasifica los municipios en 3 grupos, dependiendo de su población.

La representación de TR de los elementos de la muestra, segmentados conforme a los 3 grupos definidos por el criterio de clasificación de Ecoembes, es la mostrada en el Gráfico 5.4.2. En él se observa aparente descenso de TR a medida que aumenta el tamaño de la población; no obstante, para validar si dicha variación existe y resulta significativa, se realiza el análisis de comparación 
de medias y varianzas. En la Tabla 5.4.1 se incluyen las principales magnitudes de la distribución de TR para la totalidad de la muestra, así como para cada uno de los grupos de comparación.

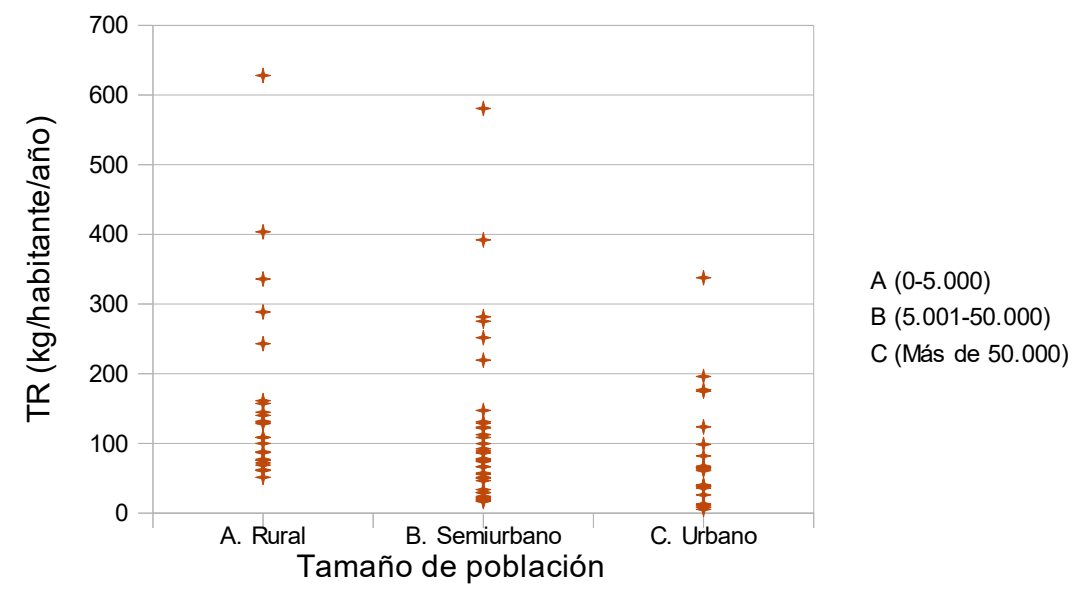

Gráfico 5.4.2: TR frente a tamaño de población adscrita.

\begin{tabular}{|c|c|c|c|c|c|c|c|c|c|}
\hline & \multirow[t]{2}{*}{ Grupo } & \multirow[t]{2}{*}{$\mathbf{N}$} & \multirow[t]{2}{*}{ Media } & \multirow{2}{*}{$\begin{array}{l}\text { Desviación } \\
\text { Estándar }\end{array}$} & \multirow{2}{*}{$\begin{array}{c}\text { Error } \\
\text { Estándar }\end{array}$} & \multicolumn{2}{|c|}{$\begin{array}{c}\text { Intervalo de } \\
\text { Confianza } 95 \% \\
\text { para la Media }\end{array}$} & \multirow[t]{2}{*}{ Mínimo } & \multirow[t]{2}{*}{ Máximo } \\
\hline & & & & & & $\begin{array}{l}\text { Límite } \\
\text { Inferior }\end{array}$ & $\begin{array}{l}\text { Límite } \\
\text { Superior }\end{array}$ & & \\
\hline \multirow{4}{*}{ TR } & RURAL & 24 & 160,56 & 134,61 & 27,48 & 103,72 & 217,40 & 51,35 & 628,02 \\
\hline & SEMIURBANO & 37 & 112,28 & 116,21 & 19,10 & 73,53 & 151,03 & 16,79 & 580,66 \\
\hline & URBANO & 23 & 77,33 & 79,24 & 16,52 & 43,06 & 111,60 & 5,43 & 337,77 \\
\hline & Total & 84 & 116,51 & 116,35 & 12,69 & 91,26 & 141,76 & 5,43 & 628,02 \\
\hline
\end{tabular}

Tabla 5.4.1: Media, desviación estándar, error estándar e intervalo de confianza de TR para los grupos de población adscrita.

Se observa que en los puntos limpios con mayor población adscrita, la media de TR es menor, así como la desviación estándar.

Puesto que TR es una variable que sigue una distribución no normal, se realiza el test $\mathrm{H}$ de Kruskal-Wallis, con el fin de establecer si se cumple la hipótesis nula y los grupos son iguales o si, por el contrario, los grupos en que se ha subdividido la muestra presentan diferencias significativas entre sí, en cuyo caso el factor de clasificación divide la muestra en grupos que se consideran pertenecientes a poblaciones distintas. Los resultados del test se incluyen en las Tablas 5.4.2 y 5.4.3. 


\begin{tabular}{|l|l|r|r|}
\hline \multicolumn{1}{|c|}{ Variable } & \multicolumn{1}{c|}{ Grupo } & N & \multicolumn{1}{c|}{ Rango medio } \\
\hline \multirow{4}{*}{ TR } & RURAL & 24 & 55,75 \\
\cline { 2 - 4 } & SEMIURBANO & 37 & 40,92 \\
\cline { 2 - 4 } & URBANO & 23 & 31,22 \\
\cline { 2 - 4 } & Total & 84 & \\
\hline
\end{tabular}

Tabla 5.4.2: Kruskal-Wallis. $N^{\circ}$ de elementos y rango medio de TR en cada grupo de población adscrita.

\begin{tabular}{|l|r|}
\hline & TR \\
\hline Chi-cuadrado & 12,16 \\
\hline df & 2 \\
\hline Sign. Asint. & 0,002 \\
\hline
\end{tabular}

Tabla 5.4.3: Resultados del test de Kruskal-Wallis de significación de TR respecto de la población adscrita.

Así, existen al menos 2 grupos entre los que se dan diferencias que resultan significativas, por lo que el factor demográfico sí constituye un criterio diferenciador que influye en los resultados de TR del punto limpio.

A continuación se realiza el test de Kruskal-Wallis para cada pareja de grupos en que se ha subdividido la muestra, con el fin de determinar entre cuáles de ellos se dan las diferencias significativas detectadas en el test general. Los resultados se resumen en la Tabla 5.4.4.

\begin{tabular}{|l|l|r|r|r|}
\hline \multicolumn{2}{|c|}{ TR } & Chi-cuadrado & df & Sign. Asint. \\
\hline Rural & Semiurbano & 5,72 & 1 & 0,017 \\
\hline & Urbano & 11,02 & 1 & 0,001 \\
\hline Semiurbano & Rural & 5,72 & 1 & 0,017 \\
\hline & Urbano & 2,48 & 1 & 0,116 \\
\hline Urbano & Rural & 11,02 & 1 & 0,001 \\
\hline & Semiurbano & 2,48 & 1 & 0,116 \\
\hline
\end{tabular}

Tabla 5.4.4: Resultados del test de Kruskal-Wallis de TR entre grupos de población.

Se observa que el valor de significación es inferior a 0,05 en la comparación de los grupos ruralsemiurbano y rural-urbano, no así entre los grupos semiurbano-urbano.

En conclusión, el tamaño de la población adscrita sí resulta ser un factor significativo para la variable TR, representativa de las cantidades de residuos depositadas en los puntos limpios; se observa que la media de TR desciende a medida que aumenta la población adscrita. 


\section{A5.4.1.2. Análisis de TV considerando factor de comparación la población.}

La distribución de la variable TV de los puntos limpios de la muestra, en función de la cantidad de población adscrita a los mismos, es la mostrada en el Gráfico 5.4.3.

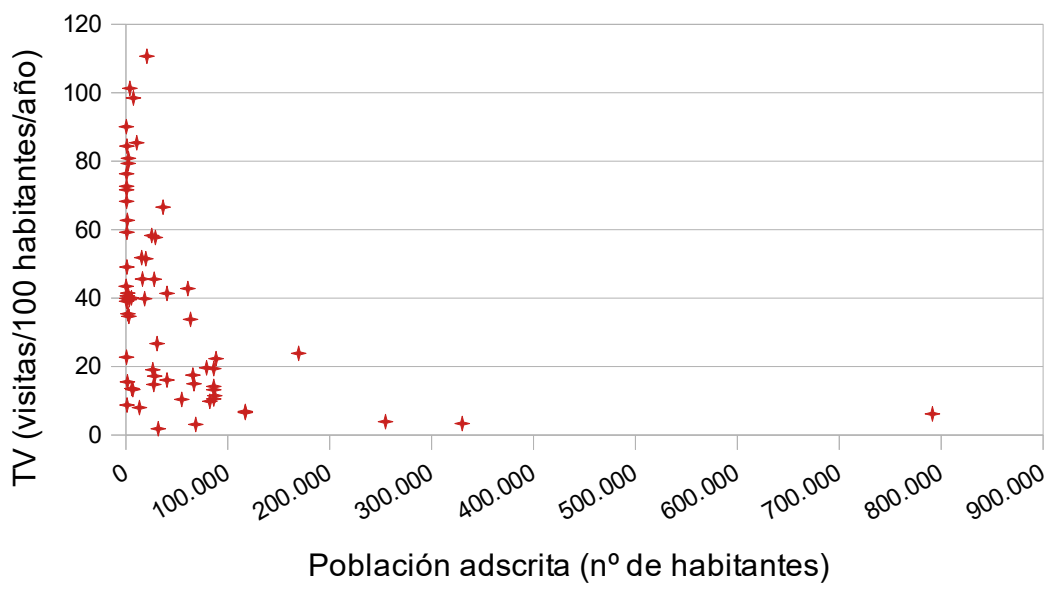

Gráfico 5.4.3: TV frente a población adscrita.

Se observa que los valores de TV son inferiores a 40 para los municipios de mayor tamaño; no obstante, dada la gran cantidad de elementos de la muestra correspondientes a puntos limpios con población adscrita inferior a 100.000 habitantes, el análisis gráfico no permite la extracción de conclusiones.

Agrupando los puntos limpios siguiendo los mismos criterios que en el punto anterior, la representación gráfica de los casos que componen la muestra es la que se observa en el Gráfico 5.4.4. 


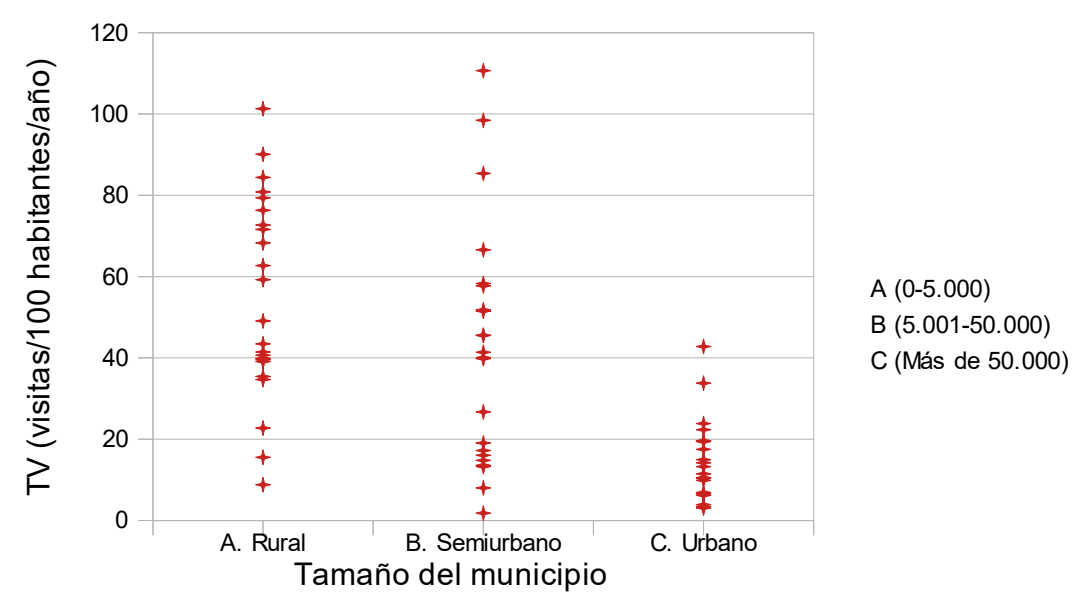

Gráfico 5.4.4: TV frente a tamaño de población adscrita.

Los valores que adoptan las medias y desviación estándar de la variable TV en la totalidad de la muestra y en cada uno de los subgrupos son los que se incluyen en la Tabla 5.4.5.

\begin{tabular}{|c|c|c|c|c|c|c|c|c|c|}
\hline & \multirow[t]{2}{*}{ Grupo } & \multirow[t]{2}{*}{$\mathbf{N}$} & \multirow[t]{2}{*}{ Media } & \multirow{2}{*}{$\begin{array}{l}\text { Desviación } \\
\text { Estándar }\end{array}$} & \multirow{2}{*}{$\begin{array}{c}\text { Error } \\
\text { Estándar }\end{array}$} & \multicolumn{2}{|c|}{$\begin{array}{c}\text { Intervalo de } \\
\text { Confianza } 95 \% \\
\text { para la Media }\end{array}$} & \multirow[t]{2}{*}{ Mínimo } & \multirow[t]{2}{*}{ Máximo } \\
\hline & & & & & & $\begin{array}{l}\text { Límite } \\
\text { Inferior }\end{array}$ & $\begin{array}{l}\text { Límite } \\
\text { Superior }\end{array}$ & & \\
\hline \multirow{4}{*}{ TV } & RURAL & 23 & 54,66 & 24,86 & 5,18 & 43,90 & 65,41 & 8,77 & 101,28 \\
\hline & SEMIURBANO & 22 & 41,97 & 29,53 & 6,30 & 28,87 & 55,06 & 1,82 & 110,66 \\
\hline & URBANO & 20 & 14,69 & 10,26 & 2,30 & 9,89 & 19,50 & 3,08 & 42,79 \\
\hline & Total & 65 & 38,09 & 28,37 & 3,52 & 31,04 & 45,09 & 1,82 & 110,66 \\
\hline
\end{tabular}

Tabla 5.4.5: Media, desviación estándar, error estándar e intervalo de confianza de TV para los grupos de población adscrita.

A continuación se realiza la validación del supuesto de homocedasticidad de la muestra, mediante aplicación del Test de Levene, de homogeneidad de varianzas, cuyos resultados se incluyen en la.

\begin{tabular}{|c|r|r|r|r|}
\hline Variable & $\begin{array}{c}\text { Estadístico de } \\
\text { Levene }\end{array}$ & df1 & df2 & \multicolumn{1}{c|}{ Sign. } \\
\hline TV & 8,42 & 2 & 62 & 0,001 \\
\hline
\end{tabular}

Tabla 5.4.6: Resultados del test de Levene para TV y tamaño de población adscrita.

En este caso, el valor del estadístico es 8,42 , superior a 3,145, valor que toma la $F$ de Snedecor para $\alpha=0,05$, y grados de libertad 2 y 62, mientras que el valor de significación es inferior a 0,05, 
por lo que no se cumple el supuesto de homocedasticidad. Por tanto, no es posible comprobar la varianza de las medias mediante el test ANOVA, debiendo aplicar el test ANOVA-Welch. Los resultados de la prueba se incluyen en la Tabla 5.4.7.

\begin{tabular}{|l|l|r|r|c|}
\hline \multicolumn{2}{|c|}{ Factor } & df & F & Sign. \\
\hline \multirow{2}{*}{ TV } & Entre Grupos & 2 & 29,170 & $3,136 \mathrm{e}-8$ \\
\cline { 2 - 6 } & Intra Grupos & 35,635 & \multicolumn{2}{|c}{} \\
\cline { 1 - 5 } &
\end{tabular}

Tabla 5.4.7: Resultados del test ANOVA-Welch para TV y tamaño de población adscrita.

Puesto que el valor de significación es inferior al error de la hipótesis nula, ésta se rechaza, por lo que no existe igualdad entre grupos. Al existir más de 2 grupos, a continuación se realizan las pruebas post-hoc BSD de Bonferroni, LSD de Fisher, Scheffé y HSD de Tukey, con el objetivo de determinar entre cuáles de ellos existen diferencias significativas. Los resultados de las pruebas son los que se incluyen en la Tabla 5.4.8.

\begin{tabular}{|c|c|c|c|c|c|c|c|}
\hline \multirow[b]{2}{*}{ TV } & & & \multirow{2}{*}{$\begin{array}{l}\text { Diferencia } \\
\text { de media }\end{array}$} & \multirow{2}{*}{$\begin{array}{c}\text { Error } \\
\text { Estándar }\end{array}$} & \multirow{2}{*}{ Sign. } & \multicolumn{2}{|c|}{$\begin{array}{c}\text { Intervalo de } \\
\text { confianza del } 95 \%\end{array}$} \\
\hline & & & & & & $\begin{array}{l}\text { Límite } \\
\text { inferior }\end{array}$ & $\begin{array}{l}\text { Límite } \\
\text { superior }\end{array}$ \\
\hline \multirow{6}{*}{ Bonferroni } & \multirow{2}{*}{ RURAL } & SEMIURBANO & 12,69 & 6,97 & 0,221 & $-4,47$ & 29,85 \\
\hline & & URBANO & 39,96 & 7,15 & 0,000 & 22,37 & 57,56 \\
\hline & \multirow{2}{*}{ SEMIUBANO } & RURAL & $-12,69$ & 6,97 & 0,221 & $-29,85$ & 4,47 \\
\hline & & URBANO & 27,27 & 7,23 & 0,001 & 9,49 & 45,05 \\
\hline & \multirow{2}{*}{ URBANO } & RURAL & $-39,96$ & 7,15 & 0,000 & $-57,56$ & $-22,37$ \\
\hline & & SEMIURBANO & $-27,27$ & 7,23 & 0,001 & $-45,05$ & $-9,49$ \\
\hline \multirow{6}{*}{$\begin{array}{l}\text { LSD } \\
\text { Fisher }\end{array}$} & \multirow{2}{*}{ RURAL } & SEMIURBANO & 12,69 & 6,97 & 0,074 & $-1,25$ & 26,63 \\
\hline & & URBANO & 39,96 & 7,15 & 0,000 & 25,67 & 54,26 \\
\hline & \multirow{2}{*}{ SEMIUBANO } & RURAL & $-12,69$ & 6,97 & 0,074 & $-26,63$ & 1,25 \\
\hline & & URBANO & 27,27 & 7,23 & 0,000 & 12,83 & 41,72 \\
\hline & \multirow{2}{*}{ URBANO } & RURAL & $-39,96$ & 7,15 & 0,000 & $-54,26$ & $-25,67$ \\
\hline & & SEMIURBANO & $-27,27$ & 7,23 & 0,000 & $-41,72$ & $-12,83$ \\
\hline \multirow{6}{*}{ Scheffé } & \multirow{2}{*}{ RURAL } & SEMIURBANO & 12,69 & 6,97 & 0,199 & $-4,80$ & 30,19 \\
\hline & & URBANO & 39,96 & 7,15 & 0,000 & 22,03 & 57,90 \\
\hline & \multirow{2}{*}{ SEMIUBANO } & RURAL & $-12,69$ & 6,97 & 0,199 & $-30,19$ & 4,80 \\
\hline & & URBANO & 27,27 & 7,23 & 0,002 & 9,15 & 45,40 \\
\hline & \multirow{2}{*}{ URBANO } & RURAL & $-39,96$ & 7,15 & 0,000 & $-57,90$ & $-22,03$ \\
\hline & & SEMIURBANO & $-27,27$ & 7,23 & 0,002 & $-45,40$ & $-9,15$ \\
\hline \multirow{6}{*}{$\begin{array}{l}\text { HSD } \\
\text { Tukey }\end{array}$} & \multirow{2}{*}{ RURAL } & SEMIURBANO & 12,69 & 6,97 & 0,172 & $-4,06$ & 29,44 \\
\hline & & URBANO & 39,96 & 7,15 & 0,000 & 22,79 & 57,13 \\
\hline & \multirow{2}{*}{ SEMIUBANO } & RURAL & $-12,69$ & 6,97 & 0,172 & $-29,44$ & 4,06 \\
\hline & & URBANO & 27,27 & 7,23 & 0,001 & 9,92 & 44,62 \\
\hline & \multirow{2}{*}{ URBANO } & RURAL & $-39,96$ & 7,15 & 0,000 & $-57,13$ & $-22,79$ \\
\hline & & SEMIURBANO & $-27,27$ & 7,23 & 0,001 & $-44,62$ & $-9,92$ \\
\hline
\end{tabular}

Tabla 5.4.8: Resultados de las pruebas post-hoc de significación de TV entre grupos de población adscrita. 
Los resultados de significación en cada comparación por parejas son equivalentes, observándose que el test HSD de Tukey y, sobre todo, el LSD de Ficher, detectan mayor proximidad a significación en la comparación Rural-Semiurbano $(>0,05)$. Por otro lado, pese a que el test de Scheffé es menos sensible a la detección de diferencias en la comparación Semiurbano-Urbano $(<0,05)$, se sitúa en un nivel intermedio en la comparación Rural-Semiurbano con respecto a los test BSD de Bonferroni y HSD Tukey. Debido al reducido número de comparaciones y a los resultados obtenidos, se considera que el test de Bonferroni es el más adecuado en este caso.

Teniendo en cuenta el valor de significación del test ANOVA-Welch, el tamaño de la población sí resulta ser un factor que influye significativamente sobre los resultados de TV. Tras la realización de pruebas post-hoc, se detecta que entre los puntos limpios rurales (población adscrita inferior a 5.000 habitantes) y semiurbanos (entre 5.000 y 50.000 habitantes), las diferencias sobre TV no resultan estadísticamente significativas, al obtenerse un valor de significación superior a 0,05. En cambio, los resultados de TV en los puntos limpios cuya población adscrita es superior a 50.000 habitantes sí son significativamente distintos al resto de puntos limpios.

\section{A5.4.2. Distancia al núcleo urbano.}

Se analiza a continuación la influencia de la distancia de los puntos limpios a los principales núcleos urbanos, en la medida en que ésta pueda constituir un factor relevante desde el punto de vista del usuario, en el mayor o menor grado de aceptación y uso del servicio.

En este caso, la variable encuestada se concreta en 4 posibles valores de respuesta:

- Distancia de hasta $0,5 \mathrm{~km}$.

- Distancia de entre 0,5 y $1,5 \mathrm{~km}$.

- Distancia de entre 1,5 y $5 \mathrm{~km}$.

- Distancia superior a $5 \mathrm{~km}$.

\section{A5.4.2.1. Análisis de TR considerando factor de comparación la distancia al núcleo urbano.}

En este caso se dispone de información relativa al factor de estudio para los 84 elementos de la muestra de que se dispone de valor de TR. La distribución de los elementos válidos de la muestra en los 4 subgrupos definidos por las respuestas posibles es la mostrada en el Gráfico 5.4.5. 
Estudio de influencia de variables sobre los resultados de TR y TV de los puntos limpios.

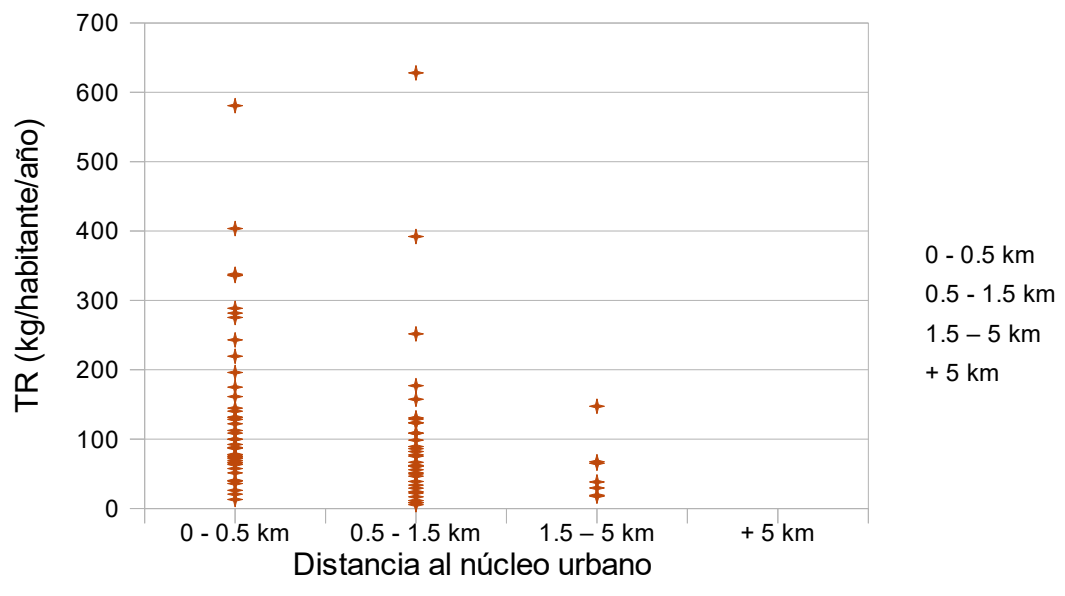

Gráfico 5.4.5: TR frente a distancia al núcleo urbano.

Los valores de media y desviación estándar de TR en la muestra y cada uno de los 3 subgrupos formados son los que se detallan en la Tabla 5.4.9.

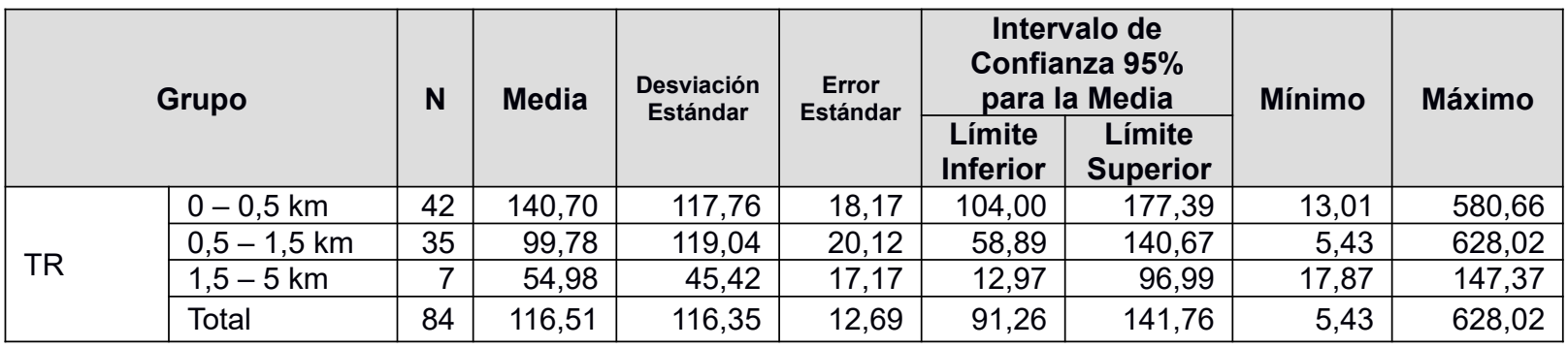

Tabla 5.4.9: Media, desviación estándar, error estándar e intervalo de confianza de TR para los grupos de distancia a núcleo urbano.

Puesto que TR no sigue una distribución normal, la prueba de igualdad de los subgrupos se realiza mediante el test $\mathrm{H}$ de Kruskal-Wallis, cuyos resultados se muestran en las Tablas $5.4 .10 \mathrm{y}$ 5.4.11.

\begin{tabular}{|l|l|r|r|}
\hline \multicolumn{1}{|c|}{ Variable } & \multicolumn{1}{|c|}{ Grupo } & N & Rango medio \\
\hline \multirow{4}{*}{ TR } & $0-0,5 \mathrm{~km}$ & 42 & 50,07 \\
\cline { 2 - 5 } & $0,5-1,5 \mathrm{~km}$ & 35 & 36,80 \\
\cline { 2 - 5 } & $1,5-5 \mathrm{~km}$ & 7 & 25,57 \\
\cline { 2 - 5 } & Total & 84 & \\
\hline
\end{tabular}

Tabla 5.4.10: Kruskal-Wallis. № de elementos y rango medio de TR en cada grupo de distancia a núcleo urbano. 


\begin{tabular}{|l|l|}
\hline & \multicolumn{1}{|c|}{ TR } \\
\hline Chi-cuadrado & 9,33 \\
\hline df & 2 \\
\hline Sign. Asint. & 0,009 \\
\hline
\end{tabular}

Tabla 5.4.11: Resultados de significación del test de Kruskal-Wallis de TR respecto de la distancia al núcleo urbano.

Por tanto, existen al menos 2 grupos entre los que se dan diferencias que resultan significativas, por lo que el factor de distancia del punto limpio al núcleo urbano sí constituye un criterio diferenciador que incluya en los resultados de TR del punto limpio.

A continuación se realiza el test de Kruskal-Wallis para cada pareja de grupos en que se ha subdividido la muestra, con el fin de determinar entre cuáles de ellos se dan las diferencias significativas detectadas en el test general. Los resultados se resumen en la Tabla 5.4.12.

\begin{tabular}{|l|l|r|r|r|}
\hline \multicolumn{2}{|c|}{ TR } & $\mathbf{0 - 0 , 5} \mathbf{~ k m}$ & $\mathbf{0 , 5}-\mathbf{1 , 5} \mathbf{~ k m}$ & $\mathbf{1 , 5} \mathbf{5} \mathbf{~ k m}$ \\
\hline $0-0,5 \mathrm{~km}$ & $0,5-1,5 \mathrm{~km}$ & 5,54 & 1 & 0,019 \\
\hline & $1,5-5 \mathrm{~km}$ & 6,32 & 1 & 0,012 \\
\hline $0,5-1,5 \mathrm{~km}$ & $0-0,5 \mathrm{~km}$ & 5,54 & 1 & 0,019 \\
\hline & $1,5-5 \mathrm{~km}$ & 1,06 & 1 & 0,303 \\
\hline $1,5-5 \mathrm{~km}$ & $0-0,5 \mathrm{~km}$ & 6,32 & 1 & 0,012 \\
\hline & $0,5-1,5 \mathrm{~km}$ & 1,06 & 1 & 0,303 \\
\hline
\end{tabular}

Tabla 5.4.12: Resultados del test de Kruskal-Wallis de TR entre grupos de distancia al núcleo urbano.

Se observa que el valor de significación es superior a 0,05 en la comparación de los grupos de puntos limpios situados a distancias de entre 0,5 y $1,5 \mathrm{~km}$ del núcleo urbano, y los situados a entre 1,5 y $5 \mathrm{~km}$, por lo que la hipótesis de igualdad se cumple entre ellos; en el resto de comparaciones, la hipótesis nula de igualdad no se cumple.

Por tanto, la distancia existente entre el núcleo urbano y el punto limpio sí resulta significativa para los resultados de TR. En general, se observa una disminución de los valores de TR a medida que aumenta la distancia del punto limpio al núcleo urbano. Por otro lado, de acuerdo con los resultados de la Tabla 5.4.12, puede considerarse que el comportamiento de TR es similar en los puntos limpios situados a más de $0,5 \mathrm{~km}$ del núcleo urbano, siendo distinto del observado en los puntos limpios situados a una distancia inferior. 


\section{A5.4.2.2. Análisis de TV considerando factor de comparación la distancia al núcleo urbano.}

En este caso, se analiza la variable de número de visitas al punto limpio en función de la distancia al núcleo urbano. Puesto que no existen en la muestra puntos limpios en que la distancia sea superior a $5 \mathrm{~km}$, los mismos se distribuyen en tres subgrupos, con un total de 65 registros, correspondientes a la totalidad de elementos con valores de TV considerados válidos. La distribución de los elementos de la muestra en los 3 grupos es la que se observa en el Gráfico 5.4.6.

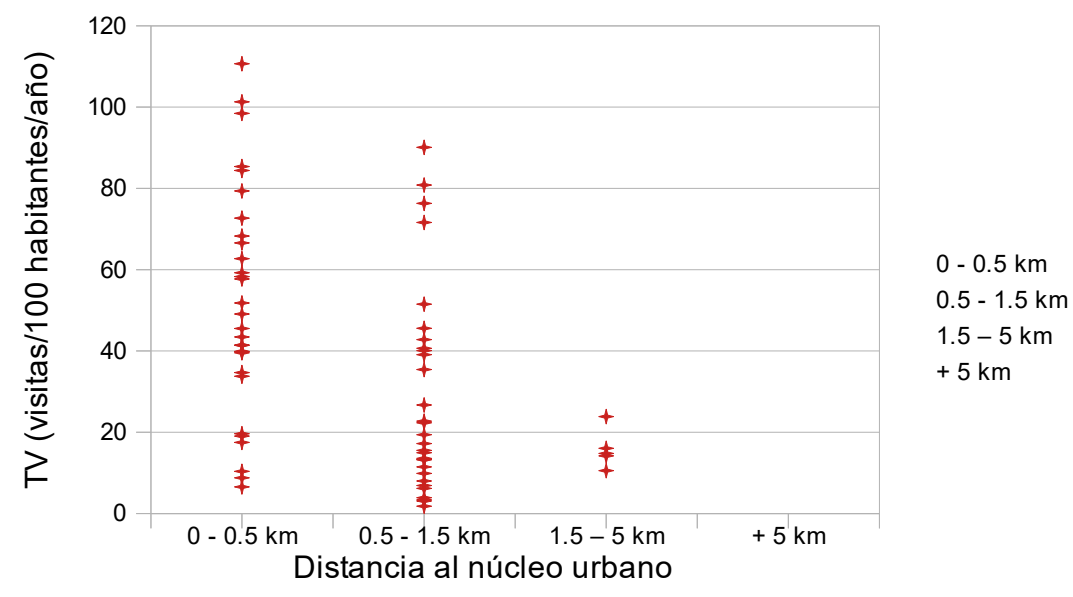

Gráfico 5.4.6: TV frente a distancia a núcleo urbano.

Los valores de media y desviación estándar de TV en cada uno de los grupos en que se ha subdividido la muestra son los que se incluyen en la Tabla 5.4.13.

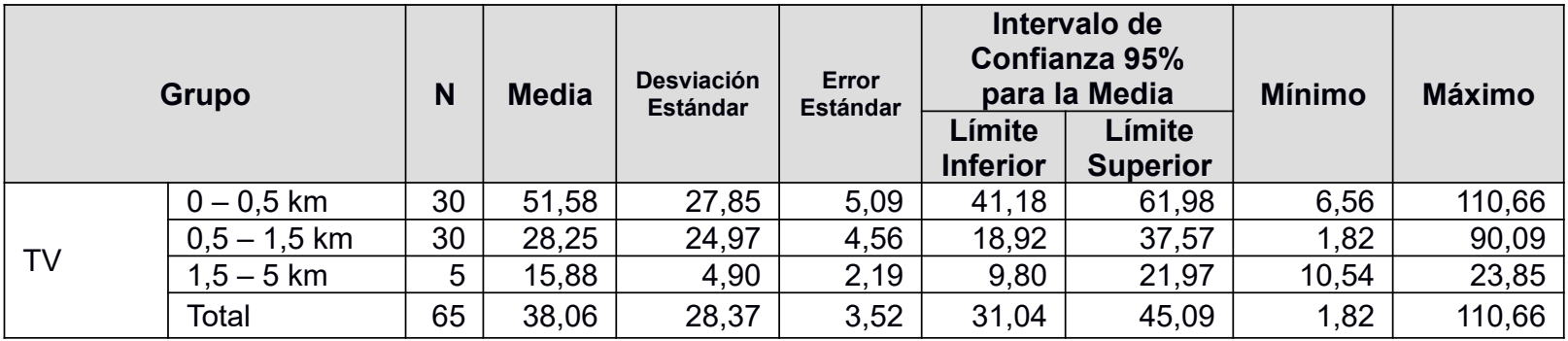

Tabla 5.4.13: Media, desviación estándar, error estándar e intervalo de confianza de TV para los grupos de distancia a núcleo urbano. 
La hipótesis de homogeneidad de varianzas entre los grupos se comprueba mediante aplicación del test de Levene, cuyos resultados se presentan en la Tabla 5.4.14.

\begin{tabular}{|c|r|r|r|r|}
\hline Variable & $\begin{array}{c}\text { Estadístico de } \\
\text { Levene }\end{array}$ & df1 & df2 & \multicolumn{1}{c|}{ Sign. } \\
\hline TV & 3,61 & 2 & 62 & 0,033 \\
\hline
\end{tabular}

Tabla 5.4.14: Resultados del test de Levene para TV y distancia al núcleo urbano.

Se observa que el valor del estadístico es 3,61 , superior a 3,145 , valor que toma la $F$ de Snedecor para $\alpha=0,05$, y grados de libertad 2 y 62 , mientras que el valor de significación es inferior a 0,05, por lo que no se cumple el supuesto de homocedasticidad; es decir, el factor de segregación de la muestra crea subgrupos con diferencias significativas entre sí, de manera que las varianzas no son homogéneas entre ellos $y$, por tanto, pueden considerarse constituidos por poblaciones distintas entre sí.

Puesto que no se cumple la hipótesis de homocedasticidad, la prueba de varianza de las medias debe realizarse mediante la aplicación del test ANOVA-Welch. Los resultados de la prueba se incluyen en la Tabla 5.4.15.

\begin{tabular}{|l|l|r|r|l|}
\hline \multicolumn{2}{|l|}{ Factor } & df & F & Sign. \\
\hline \multirow{2}{*}{ TV } & Entre Grupos & 2 & 21,316 & $6,845 \mathrm{e}-7$ \\
\cline { 2 - 5 } & Intra Grupos & 37,124 & \multicolumn{2}{|c}{} \\
\cline { 1 - 3 }
\end{tabular}

Tabla 5.4.15: Resultados del test ANOVA-Welch para TV y distancia al núcleo urbano.

Puesto que el valor de significación es inferior al error de la hipótesis nula, ésta se rechaza, por lo que no existe igualdad entre grupos. Al existir más de 2 grupos, a continuación se realizan las pruebas post-hoc BSD de Bonferroni, LSD de Fisher, Scheffé y HSD de Tukey, con el objetivo de determinar entre cuáles de ellos existen diferencias significativas. Los resultados de las pruebas son los que se incluyen en la Tabla 5.4.16. 
Estudio de influencia de variables sobre los resultados de TR y TV de los puntos limpios.

\begin{tabular}{|c|c|c|c|c|c|c|c|}
\hline \multirow{2}{*}{ TV } & & & \multirow{2}{*}{$\begin{array}{l}\text { Diferencia } \\
\text { de media }\end{array}$} & \multirow{2}{*}{$\begin{array}{c}\text { Error } \\
\text { Estándar }\end{array}$} & \multirow{2}{*}{ Sign. } & \multicolumn{2}{|c|}{$\begin{array}{c}\text { Intervalo de } \\
\text { confianza del } 95 \%\end{array}$} \\
\hline & & & & & & $\begin{array}{l}\text { Límite } \\
\text { inferior }\end{array}$ & $\begin{array}{l}\text { Límite } \\
\text { superior }\end{array}$ \\
\hline \multirow{6}{*}{ Bonferroni } & \multirow{2}{*}{$0-0,5 \mathrm{~km}$} & $0,5-1,5 \mathrm{~km}$ & 23,33 & 6,61 & 0,002 & 7,06 & 39,60 \\
\hline & & $1,5-5 \mathrm{~km}$ & 35,70 & 12,37 & 0,016 & 5,25 & 66,14 \\
\hline & \multirow{2}{*}{$0,5-1,5 \mathrm{~km}$} & $0-0,5 \mathrm{~km}$ & $-23,33$ & 6,61 & 0,002 & $-39,60$ & $-7,06$ \\
\hline & & $1,5-5 \mathrm{~km}$ & 12,37 & 12,37 & 0,964 & $-18,08$ & 42,81 \\
\hline & \multirow{2}{*}{$1,5-5 \mathrm{~km}$} & $0-0,5 \mathrm{~km}$ & $-35,70$ & 12,37 & 0,016 & $-66,14$ & $-5,25$ \\
\hline & & $0,5-1,5 \mathrm{~km}$ & $-12,37$ & 12,37 & 0,964 & $-42,81$ & 18,08 \\
\hline \multirow{6}{*}{$\begin{array}{l}\text { LSD } \\
\text { Fisher }\end{array}$} & \multirow{2}{*}{$0-0,5 \mathrm{~km}$} & $0,5-1,5 \mathrm{~km}$ & 23,33 & 6,61 & 0,001 & 10,11 & 36,55 \\
\hline & & $1,5-5 \mathrm{~km}$ & 35,70 & 12,37 & 0,005 & 10,96 & 60,43 \\
\hline & \multirow{2}{*}{$0,5-1,5 \mathrm{~km}$} & $0-0,5 \mathrm{~km}$ & $-23,33$ & 6,61 & 0,001 & $-36,55$ & $-10,11$ \\
\hline & & $1,5-5 \mathrm{~km}$ & 12,37 & 12,37 & 0,321 & $-12,37$ & 37,10 \\
\hline & \multirow{2}{*}{$1,5-5 \mathrm{~km}$} & $0-0,5 \mathrm{~km}$ & $-35,70$ & 12,37 & 0,005 & $-60,43$ & $-10,96$ \\
\hline & & $0,5-1,5 \mathrm{~km}$ & $-12,37$ & 12,37 & 0,321 & $-37,10$ & 12,37 \\
\hline \multirow{6}{*}{ Scheffé } & \multirow{2}{*}{$0-0,5 \mathrm{~km}$} & $0,5-1,5 \mathrm{~km}$ & 23,33 & 6,61 & 0,003 & 6,74 & 39,92 \\
\hline & & $1,5-5 \mathrm{~km}$ & 35,70 & 12,37 & 0,020 & 4,66 & 66,73 \\
\hline & \multirow{2}{*}{$0,5-1,5 \mathrm{~km}$} & $0-0,5 \mathrm{~km}$ & $-23,33$ & 6,61 & 0,003 & $-39,92$ & $-6,74$ \\
\hline & & $1,5-5 \mathrm{~km}$ & 12,37 & 12,37 & 0,609 & $-18,67$ & 43,40 \\
\hline & \multirow{2}{*}{$1,5-5 \mathrm{~km}$} & $0-0,5 \mathrm{~km}$ & $-35,70$ & 12,37 & 0,020 & $-66,73$ & $-4,66$ \\
\hline & & $0,5-1,5 \mathrm{~km}$ & $-12,37$ & 12,37 & 0,609 & $-43,40$ & 18,67 \\
\hline \multirow{6}{*}{$\begin{array}{l}\text { HSD } \\
\text { Tukey }\end{array}$} & \multirow{2}{*}{$0-0,5 \mathrm{~km}$} & $0,5-1,5 \mathrm{~km}$ & 23,33 & 6,61 & 0,002 & 7,45 & 39,21 \\
\hline & & $1,5-5 \mathrm{~km}$ & 35,70 & 12,37 & 0,015 & 5,99 & 65,41 \\
\hline & \multirow{2}{*}{$0,5-1,5 \mathrm{~km}$} & $0-0,5 \mathrm{~km}$ & $-23,33$ & 6,61 & 0,002 & $-39,21$ & $-7,45$ \\
\hline & & $1,5-5 \mathrm{~km}$ & 12,37 & 12,37 & 0,580 & $-17,34$ & 42,08 \\
\hline & \multirow{2}{*}{$1,5-5 \mathrm{~km}$} & $0-0,5 \mathrm{~km}$ & $-35,70$ & 12,37 & 0,015 & $-65,41$ & $-5,99$ \\
\hline & & $0,5-1,5 \mathrm{~km}$ & $-12,37$ & 12,37 & 0,580 & $-42,08$ & 17,34 \\
\hline
\end{tabular}

Tabla 5.4.16: Resultados de las pruebas post-hoc de significación de TV entre grupos de distancia a núcleo urbano.

Todas las pruebas reflejan resultados de significación equivalente. No obstante, en las comparaciones sin resultados de significación $(>0,05)$, los valores obtenidos son inferiores en la prueba LS de Ficher, similares en las pruebas de Scheffé y HSD de Tukey, y mayores en la prueba de Bonferroni, mientras que en las comparaciones en que se halla significación $(<0,05)$, los valores de las pruebas BSD de Bonferroni y HSD de Tukey son iguales, siendo algo inferiores en la LSD de Ficher y superiores en el test de Scheffé, por lo que se considera que la prueba posthoc más adecuada para esta comparación, dado el reducido número de comparaciones, es la BSD de Bonferroni.

Se observa que no existen diferencias significativas entre los grupos de puntos limpios situados a más de $0,5 \mathrm{~km}$ (de 0,5 a $1,5 \mathrm{~km}$ y de 1,5 a $5 \mathrm{~km}$ ), mientras que entre los situados a distancia inferior y los otros dos valores de la variable sí existen diferencias significativas, al obtenerse un resultado de significación inferior a 0,05.

Por tanto, la variable TV presenta diferencias significativas en función de la distancia del punto limpio al núcleo urbano; se observa que pueden considerarse que los resultados son similares 
para los puntos limpios situados a más de $0,5 \mathrm{~km}$ del núcleo urbano, siendo éstos distintos de los que presentan los puntos limpios situados a menos de $0,5 \mathrm{~km}$ del núcleo urbano.

\section{A5.4.3. Transporte público.}

Se analiza en este punto la influencia que pueda representar la disponibilidad o no de transporte público hasta el punto limpio, en la medida en que éste puede facilitar el acceso de los usuarios al mismo.

\section{A5.4.3.1. Análisis de TR considerando factor de comparación la disponibilidad de transporte público.}

Se dispone de información de valor del factor de comparación para todos los elementos de la muestra considerados válidos, excepto en un caso (Catarroja), por lo que el tamaño del grupo analizado es de 83 elementos. La distribución de los puntos limpios en los subgrupos segregados según el valor que toma la variable es la que se muestra en el Gráfico 5.4.7.

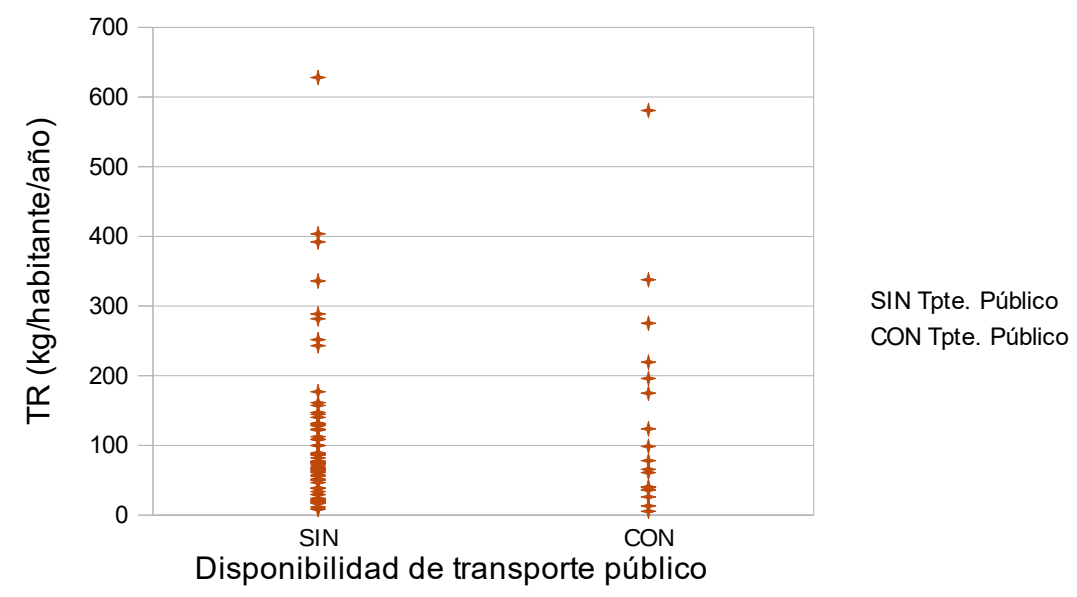

Gráfico 5.4.7: TR frente a disponibilidad de transporte público.

La media y desviación estándar de las distribuciones de TR en cada uno de los subgrupos en que se divide la muestra, así como de la totalidad de la muestra, se incluyen en la Tabla 5.4.17. 


\begin{tabular}{|c|c|c|c|c|c|c|c|c|c|}
\hline \multirow{2}{*}{\multicolumn{2}{|c|}{ Grupo }} & \multirow[t]{2}{*}{$\mathbf{N}$} & \multirow[t]{2}{*}{ Media } & \multirow{2}{*}{$\begin{array}{l}\text { Desviación } \\
\text { Estándar }\end{array}$} & \multirow[t]{2}{*}{$\begin{array}{c}\text { Error } \\
\text { Estándar }\end{array}$} & \multicolumn{2}{|c|}{$\begin{array}{c}\text { Intervalo de } \\
\text { Confianza } 95 \% \\
\text { para la Media }\end{array}$} & \multirow[t]{2}{*}{ Mínimo } & \multirow[t]{2}{*}{ Máximo } \\
\hline & & & & & & $\begin{array}{l}\text { Límite } \\
\text { Inferior }\end{array}$ & $\begin{array}{c}\text { Límite } \\
\text { Superior }\end{array}$ & & \\
\hline \multirow{3}{*}{ TR } & SIN tpte público & 66 & 110,95 & 107,70 & 13,26 & 84,47 & 137,42 & 8,42 & 628,02 \\
\hline & CON tpte público & 17 & 139,51 & 149,58 & 36,28 & 62,60 & 216,41 & 5,43 & 580,66 \\
\hline & Total & 83 & 116,80 & 117,03 & 12,85 & 91,24 & 142,35 & 5,43 & 628,02 \\
\hline
\end{tabular}

Tabla 5.4.17: Media, desviación estándar, error estándar e intervalo de confianza de TR para los grupos de disponibilidad de transporte público.

Aparentemente, los resultados de TR son superiores en aquellos puntos limpios que cuentan con transporte público en sus proximidades; no obstante, se observa que la desviación estándar es asimismo superior. Al ser TR una variable que no sigue una distribución normal, se comprueba la hipótesis de igualdad de grupos mediante aplicación de la prueba $\mathrm{H}$ de Kruskal-Wallis, cuyos resultados se muestran en las Tablas 5.4 .18 y 5.4.19.

\begin{tabular}{|c|l|r|r|}
\hline \multicolumn{1}{|c|}{ Variable } & \multicolumn{1}{|c|}{ Grupo } & \multicolumn{1}{c|}{ N } & \multicolumn{1}{c|}{ Rango medio } \\
\hline \multirow{4}{*}{ TR } & SIN Tpte Púb & 66 & 41,76 \\
\cline { 2 - 4 } & CON Tpte Púb & 17 & 42,94 \\
\cline { 2 - 4 } & Total & 83 & \\
\hline
\end{tabular}

Tabla 5.4.18: Kruskal-Wallis. № de elementos y rango medio de TR en cada grupo de disponibilidad de transporte público.

\begin{tabular}{|l|r|}
\hline & \multicolumn{2}{|c|}{ TR } \\
\hline Chi-cuadrado & 0,03 \\
\hline df & 2 \\
\hline Sign. Asint. & 0,857 \\
\hline
\end{tabular}

Tabla 5.4.19: Resultados de significación del test de Kruskal-Wallis de TR respecto de la disponibilidad de transporte público.

Puesto que el resultado de significación en superior a 0,05 , se valida la hipótesis nula de igualdad entre grupos. Por tanto, la variable disponibilidad de transporte público no resulta significativa sobre los resultados de TR del punto limpio. 


\section{A5.4.3.2. Análisis de TV considerando factor de comparación la disponibilidad de transporte público.}

Se estudia si la frecuencia de utilización del punto limpio varía en función de la disponibilidad o no de servicios de transporte público hasta las proximidades de las instalaciones. Como sucedía en el apartado anterior, el número de elementos a analizar se reduce en 1 con respecto a los que presentan datos de TV considerados válidos, puesto que no se dispone de información de la variable de análisis para el punto limpio de Catarroja, por lo que el número de casos considerados es de 64. La distribución de los elementos de cada subgrupo es la que se observa en el Gráfico 5.4.8.

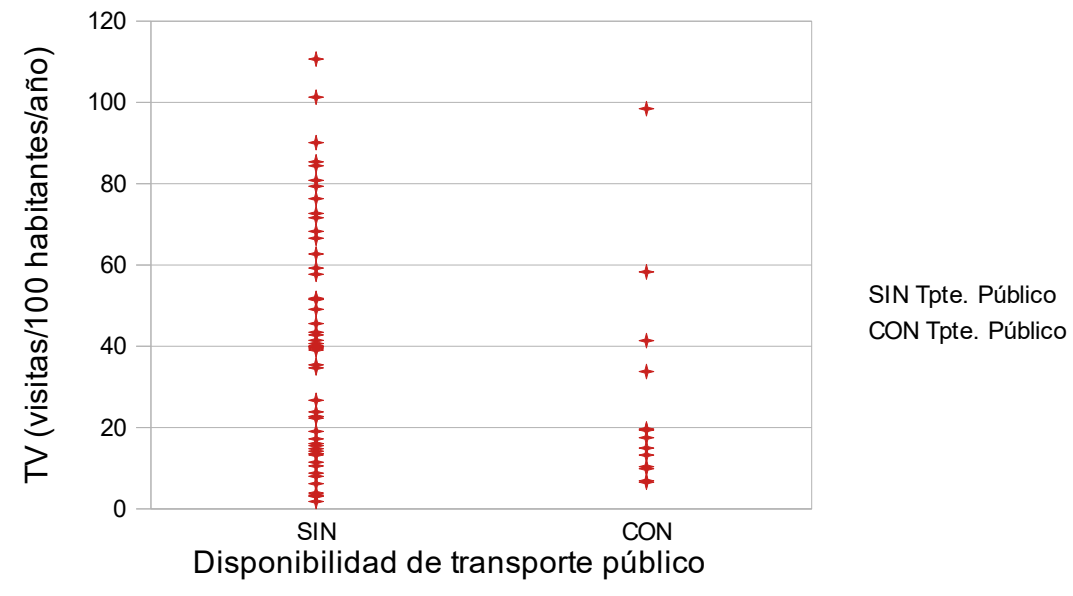

Gráfico 5.4.8: TV frente a disponibilidad de transporte público.

El análisis gráfico únicamente permite comprobar que es mayoritaria la existencia de puntos limpios sin disponibilidad de transporte público. La media y desviación estándar de TV en cada uno de los grupos en que se ha subdividido la muestra son los que se incluyen en la Tabla 5.4.20.

\begin{tabular}{|c|c|c|c|c|c|c|c|c|c|}
\hline & \multirow[t]{2}{*}{ Grupo } & \multirow[t]{2}{*}{$\mathbf{N}$} & \multirow[t]{2}{*}{ Media } & \multirow{2}{*}{$\begin{array}{l}\text { Desviación } \\
\text { Estándar }\end{array}$} & \multirow{2}{*}{$\begin{array}{c}\text { Error } \\
\text { Estándar }\end{array}$} & \multicolumn{2}{|c|}{$\begin{array}{c}\text { Intervalo de } \\
\text { Confianza } 95 \% \\
\text { para la Media }\end{array}$} & \multirow[t]{2}{*}{ Mínimo } & \multirow[t]{2}{*}{ Máximo } \\
\hline & & & & & & $\begin{array}{l}\text { Límite } \\
\text { Inferior }\end{array}$ & $\begin{array}{c}\text { Límite } \\
\text { Superior }\end{array}$ & & \\
\hline \multirow{3}{*}{ TV } & SIN Tpte Púb & 51 & 40,75 & 28,71 & 4,02 & 32,68 & 48,83 & 1,82 & 110,66 \\
\hline & CON Tpte Púb & 13 & 26,95 & 26,25 & 7,28 & 11,09 & 42,81 & 6,56 & 98,46 \\
\hline & Total & 64 & 37,95 & 28,58 & 3,57 & 30,81 & 45,09 & 1,82 & 110,66 \\
\hline
\end{tabular}

Tabla 5.4.20: Media, desviación estándar, error estándar e intervalo de confianza de TV para los grupos de disponibilidad de transporte público. 
La hipótesis de homogeneidad de varianzas entre los grupos se comprueba mediante aplicación del test de Levene, cuyos resultados se presentan en la Tabla 5.4.21.

\begin{tabular}{|c|r|r|r|r|}
\hline Variable & $\begin{array}{c}\text { Estadístico de } \\
\text { Levene }\end{array}$ & df1 & df2 & \multicolumn{1}{c|}{ Sign. } \\
\hline TV & 0,70 & 1 & 62 & 0,406 \\
\hline
\end{tabular}

Tabla 5.4.21: Resultados del test de Levene para TV y disponibilidad de transporte público.

Los resultados del test proporcionan un valor del estadístico de Levene de 0,70, inferior a 3,996, valor que toma la $\mathrm{F}$ de Snedecor para $\alpha=0,05$, y grados de libertad 1 y 62 , mientras que el valor de significación es superior a 0,05 , por lo que se cumple el supuesto de homocedasticidad; es decir, las distribuciones de los elementos de los subgrupos presentan varianzas homogéneas.

En cuanto a la comparación de igualdad de los grupos, mediante el análisis de varianza d emedias, a continuación se realiza el test ANOVA, cuyos resultados son los mostrados en la Tabla 5.4.22.

\begin{tabular}{|c|c|c|c|c|c|c|}
\hline \multicolumn{2}{|c|}{ Factor } & $\begin{array}{c}\text { Suma de } \\
\text { Cuadrados }\end{array}$ & df & $\begin{array}{c}\text { Cuadrado } \\
\text { medio }\end{array}$ & $\mathbf{F}$ & Sign. \\
\hline \multirow{3}{*}{ TV } & Entre Grupos & $1.973,95$ & 1 & $1.973,95$ & 2,47 & 0,121 \\
\hline & Intra Grupos & $49.476,52$ & 62 & 798,01 & & \\
\hline & Total & $51.450,47$ & 63 & & & \\
\hline
\end{tabular}

Tabla 5.4.22: Resultados test ANOVA para TV y disponibilidad de transporte público.

Resultando un valor de significación superior a 0,05 , por lo que la hipótesis nula se considera válida: el valor del criterio de segregación de la muestra no constituye un factor diferenciador en términos de resultados de TV.

En definitiva, los resultados de las variables TR y TV no se ven influenciados de manera significativa por el valor de la variable relativa a la disponibilidad de transporte público en las proximidades del punto limpio. 


\section{A5.4.4. Carril bici.}

En este punto se analiza la relevancia que pueda representar la existencia de carril bici hasta el punto limpio sobre los resultados de gestión de residuos de la instalación.

\section{A5.4.4.1. Análisis de TR considerando factor de comparación la existencia de carril bici.}

Los casos de que se dispone de información al respecto son los mismos que en el punto anterior, por lo que el número de elementos a analizar es de 83 . Estos puntos limpios se segregarán en 2 subgrupos, dependiendo de si cuentan con carril bici hasta la instalación o no. La representación gráfica de los datos de la muestra conforme a esta segregación es la que se observa en el Gráfico 5.4.9.

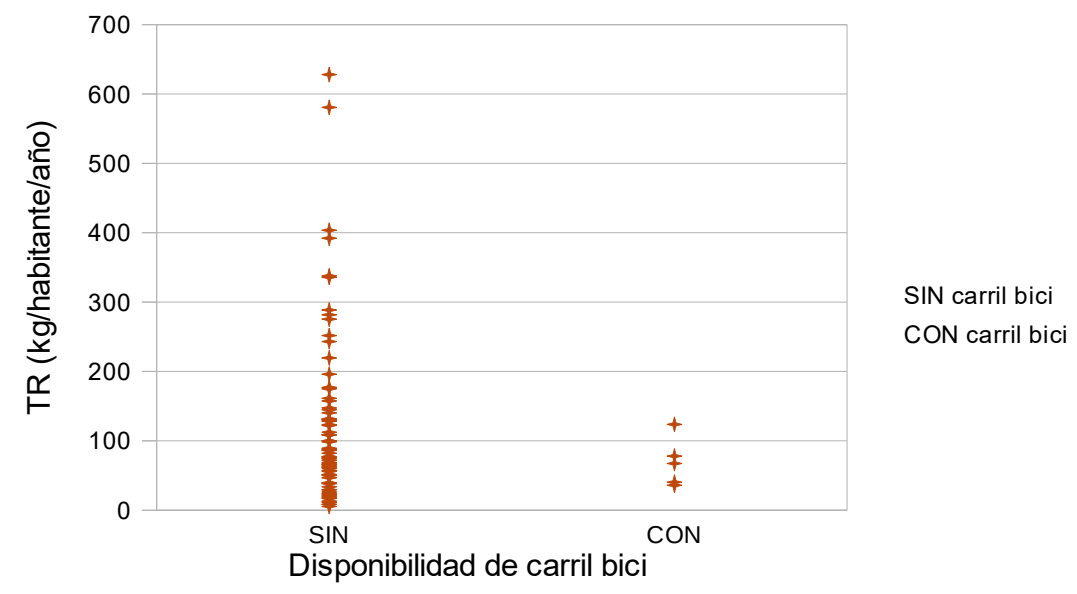

Gráfico 5.4.9: TR frente a disponibilidad de carril bici.

Se observa que representan una amplia mayoría los puntos limpios que no cuentan con carril bici. En la Tabla 5.4.23, en que se presentan los valores de media y desviación estándar de TR para los grupos en que se divide la muestra, se observa que únicamente 5 puntos lipios cuentan con carril bici. 
Estudio de influencia de variables sobre los resultados de TR y TV de los puntos limpios.

\begin{tabular}{|c|c|c|c|c|c|c|c|c|c|}
\hline & \multirow[t]{2}{*}{ Grupo } & \multirow[t]{2}{*}{$\mathbf{N}$} & \multirow[t]{2}{*}{ Media } & \multirow{2}{*}{$\begin{array}{l}\text { Desviación } \\
\text { Estándar }\end{array}$} & \multirow{2}{*}{$\begin{array}{c}\text { Error } \\
\text { Estándar }\end{array}$} & \multicolumn{2}{|c|}{$\begin{array}{c}\text { Intervalo de } \\
\text { Confianza } 95 \% \\
\text { para la Media }\end{array}$} & \multirow[t]{2}{*}{ Mínimo } & \multirow[t]{2}{*}{ Máximo } \\
\hline & & & & & & $\begin{array}{l}\text { Límite } \\
\text { Inferior }\end{array}$ & $\begin{array}{l}\text { Límite } \\
\text { Superior }\end{array}$ & & \\
\hline \multirow{3}{*}{ TR } & SIN carril bici & 78 & 119,86 & 119,84 & 13,57 & 92,84 & 146,88 & 5,43 & 628,02 \\
\hline & CON carril bici & 5 & 69,09 & 35,33 & 15,80 & 25,22 & 112,96 & 35,91 & 123,72 \\
\hline & Total & 83 & 116,80 & 117,03 & 12,85 & 91,24 & 142,35 & 5,43 & 628,02 \\
\hline
\end{tabular}

Tabla 5.4.23: Media, desviación estándar, error estándar e intervalo de confianza de TR para los grupos de disponibilidad de carril bici.

La media de TR es claramente superior para los puntos limpios sin disponibilidad de carril bici; no obstante, las diferencias existentes asimismo en el valor de la desviación estándar y el tamaño de los grupos no permiten determinar más conclusiones previas.

La hipótesis nula de igualdad de grupos para TR se comprueba mediante la prueba $\mathrm{H}$ de KruskalWallis, cuyos resultados se muestran en las Tablas 5.4 .24 y 5.4 .25 .

\begin{tabular}{|c|l|r|r|}
\hline \multicolumn{1}{|c|}{ Variable } & \multicolumn{1}{|c|}{ Grupo } & N & Rango medio \\
\hline \multirow{4}{*}{ TR } & SIN Carril bici & 78 & 42,49 \\
\cline { 2 - 4 } & CON Carril bici & 5 & 34,40 \\
\cline { 2 - 4 } & Total & 83 & \\
\hline
\end{tabular}

Tabla 5.4.24: Kruskal-Wallis. $N^{\circ}$ de elementos y rango medio de TR en cada grupo de disponibilidad de carril bici.

\begin{tabular}{|l|r|}
\hline & \multicolumn{2}{|c|}{ TR } \\
\hline Chi-cuadrado & 0,53 \\
\hline df & 1 \\
\hline Sign. Asint. & 0,467 \\
\hline
\end{tabular}

Tabla 5.4.25: Resultados de significación del test de Kruskal-Wallis de TR respecto de la disponibilidad de carril bici.

Al obtenerse un valor de significación de 0,467 , superior a 0,05 , se concluye que no existen diferencias entre los subgrupos de la muestra y, por tanto, las poblaciones son iguales, por lo que no existen significación estadística entre la disponibilidad de carril bici y los resultados de TR del punto limpio. Esta falta de influencia significativa puede ser debida al hecho de que, con carácter mayoritario, el tipo de residuos que se depositan en los puntos limpios presentan elevada masa y/o volumen, por lo que su transporte a bordo de un medio que haga uso del carril bici no resulta el idóneo. 


\section{A5.4.4.2. Análisis de TV considerando factor de comparación la existencia de carril bici.}

Los datos disponibles para este análisis son los mismos que los que se han tenido en cuenta en el punto A5.4.3.2., representando un $93,75 \%$ los puntos limpios que no cuentan con carril bici. La representación gráfica de TV para los grupos de la muestra en la que se observa en el Gráfico 5.4.10. En la Tabla 5.4.26 se observa que tanto la media como la desviación estándar de TV del grupo de puntos limpios sin carril bici son aproximadamente el doble de las del grupo con carril bici.

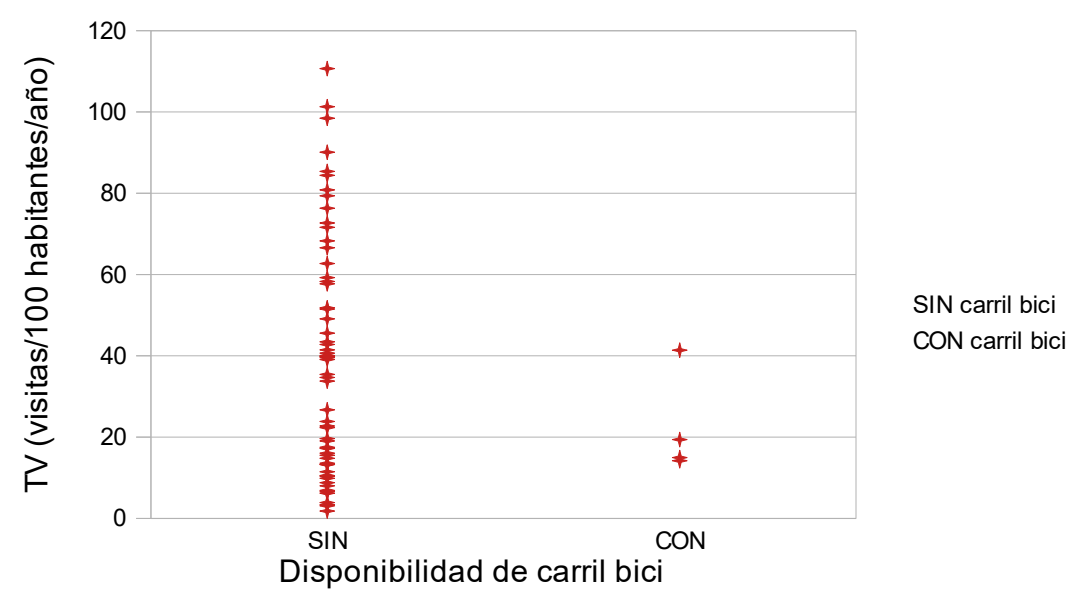

Gráfico 5.4.10: TV frente a disponibilidad de carril bici.

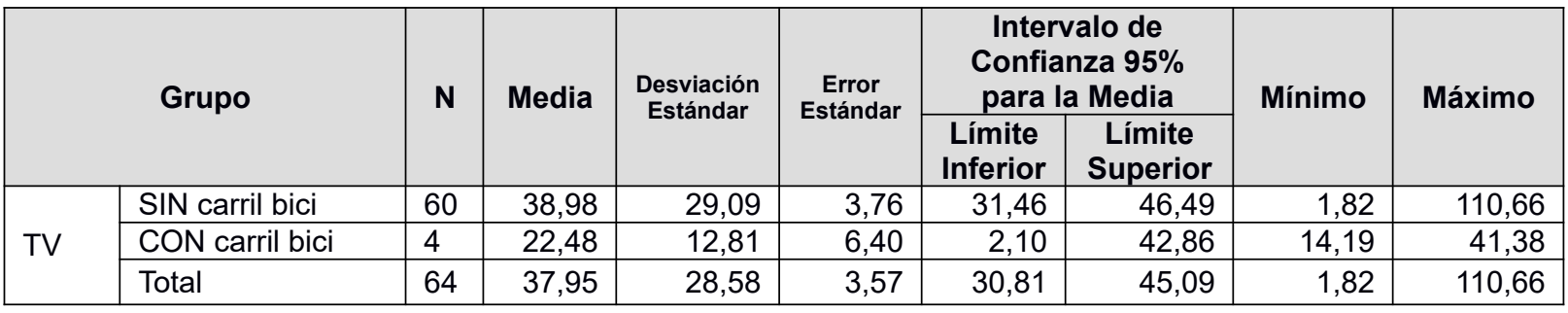

Tabla 5.4.26: Media, desviación estándar, error estándar e intervalo de confianza de TV para los grupos de disponibilidad de carril bici.

La comprobación de la hipótesis de homogeneidad de varianzas entre grupos se realiza mediante aplicación del test de Levene, cuyos resultados se muestran en la Tabla 5.4.27. El valor del estadístico de Levene es de 3,15, inferior al que toma la $F$ de Snedecor para $\alpha=0,05$ y grados de libertad 1 y 62, mientras que el valor de significación de la prueba es 0,081 , superior a 0,05 , por lo que puede afirmarse que se cumple la hipótesis nula de homocedasticidad. 


\begin{tabular}{|l|r|r|r|r|}
\hline Variable & $\begin{array}{c}\text { Estadístico de } \\
\text { Levene }\end{array}$ & df1 & df2 & \multicolumn{1}{c|}{ Sign. } \\
\hline TV & 3,15 & 1 & 62 & 0,081 \\
\hline
\end{tabular}

Tabla 5.4.27: Resultados del test de Levene para TV y disponibilidad de carril bici.

Para la comprobación de la igualdad de grupos se realiza el test ANOVA, cuyos resultados, que se presentan en la Tabla 5.4.28, muestran que no existen diferencias significativas entre ellos, con un valor de significación de 0,267 , superior al error de la hipótesis nula $(0,05)$ y, por tanto, la hipótesis nula queda validada.

\begin{tabular}{|c|c|c|c|c|c|c|}
\hline \multicolumn{2}{|c|}{ Factor } & $\begin{array}{l}\text { Suma de } \\
\text { Cuadrados }\end{array}$ & df & $\begin{array}{l}\text { Cuadrado } \\
\text { medio }\end{array}$ & $\mathbf{F}$ & Sign. \\
\hline \multirow{3}{*}{ TV } & Entre Grupos & $1.020,47$ & 1 & $1.020,47$ & 1,25 & 0,267 \\
\hline & Intra Grupos & $50.430,00$ & 62 & 813,39 & & \\
\hline & Total & $51.450,47$ & 63 & & & \\
\hline
\end{tabular}

Tabla 5.4.28: Resultados test ANOVA para TV y disponibilidad de carril bici.

Por tanto, se concluye que no existe relación estadísticamente significativa entre las variables TV y de disponibilidad de carril bici. Pese a que en el punto limpio pueden ser depositados residuos con un relativamente pequeño volumen (pequeños electrodomésticos, pilas), que podrían ser transportados por medios aptos para su circulación por carril bici, y que podrían incrementar el número de visitas recibidas en el punto limpio, esta solución no parece ser la más común; de hecho, la media de TV es inferior en aquellos casos que sí cuentan con carril bici.

En resumen, no existen relaciones significativas entre la disponibilidad de carril bici y las variables TR y TV de los puntos limpios.

\section{A5.4.5. Año de construcción del punto limpio.}

En este punto se analiza la influencia debida al año de construcción del punto limpio sobre las variables TR y TV. Resulta una forma de estudiar si la cantidad de tiempo que lleva en funcionamiento la instalación constituye un factor relevante en los resultados de explotación y gestión de residuos de la misma. 
Para el análisis de influencia de la antigüedad de la instalación, se va a subdividir la muestra en grupos, que aglutinen los puntos limpios construidos en diferentes periodos, con el objetivo de asegurar la viabilidad de los análisis: realizando la comparación por años, pueden existir grupos con un único elemento y, por tanto, sin posibilidad de determinar varianzas.

Como principales hitos para la segregación de la muestra en grupos se consideran los siguientes:

- 1996: en este año se funda Ecoembes, entidad sin ánimo de lucro para la gestión de residuos de envases y embalajes.

- 1998: Ecovidrio comienza a operar en toda España.

- 1998: se aprueba la Ley 10/1998, de Residuos; la legislación anteriormente existente está formada por: Ley 42/1975, sobre desechos y residuos sólidos urbanos, y la Ley 20/1986, básica de Residuos Tóxicos y Peligrosos

- 2011: se aprueba la Ley 22/2011, de residuos y suelos contaminados.

Por lo que puede considerarse que existen 2 años que pueden representar puntos de inflexión en cuanto a la gestión de residuos se refiere:

- 1998: aprobación de nueva legislación, e impulso de la separación de residuos en origen por parte de Ecovidrio y Ecoembes, ya constituidos.

- 2011: aprobación de cambio legislativo en materia de residuos.

Así, se decide subdividir la muestra en 3 grupos: puntos limpios construidos antes de 1998; los construidos entre 1998 y 2010, y los construidos a partir del año 2011.

\section{A5.4.5.1. Análisis de TR considerando factor de comparación el año de construcción.}

Para los elementos de la muestra de que se dispone de datos de TR considerados válidos $(2<$ TR $<1000$ ), existen 13 casos en que no se aporta la información relativa al año de construcción del punto limpio (Benicarló, Soneja, Aldaya y Alacuás, Algimia de Alfara, Estivella, Gilet, Quart de les Valls, Silla, Torrent -2 puntos limpios-, Tudela, Cabezas de San Juan y Utrera), por lo que el número de elementos se reduce a 71, cuya distribución es la mostrada en el Gráfico 5.4.11. 


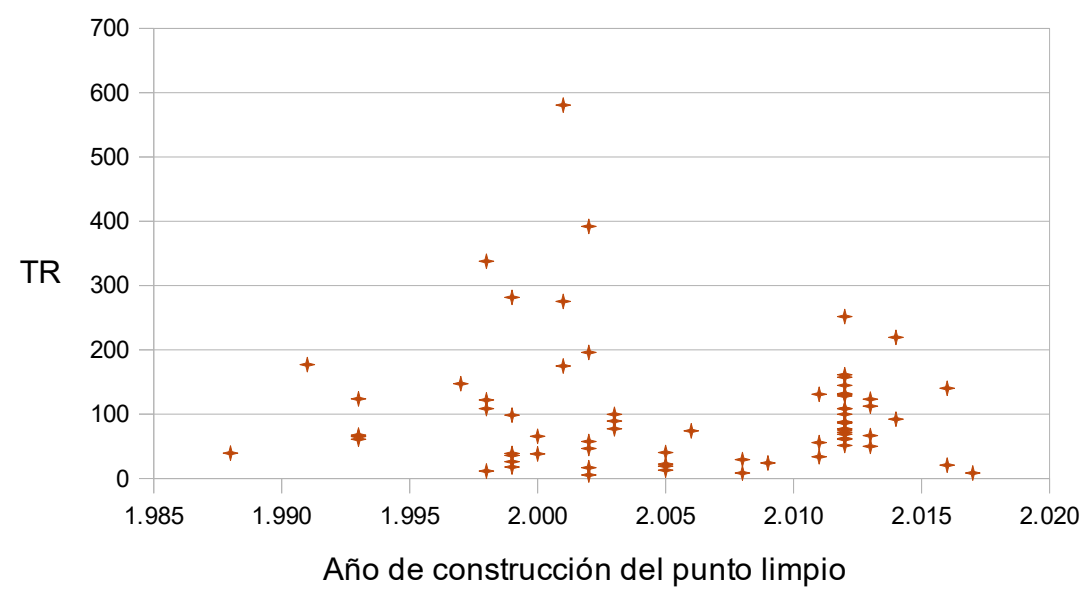

Gráfico 5.4.11: TR frente a año de construcción del punto limpio.

Teniendo en cuenta el criterio de agrupación de la muestra en función del año de construcción del punto limpio y los periodos indicados punto A5.4.5., la representación de la muestra es la mostrada en el Gráfico 5.4.12.

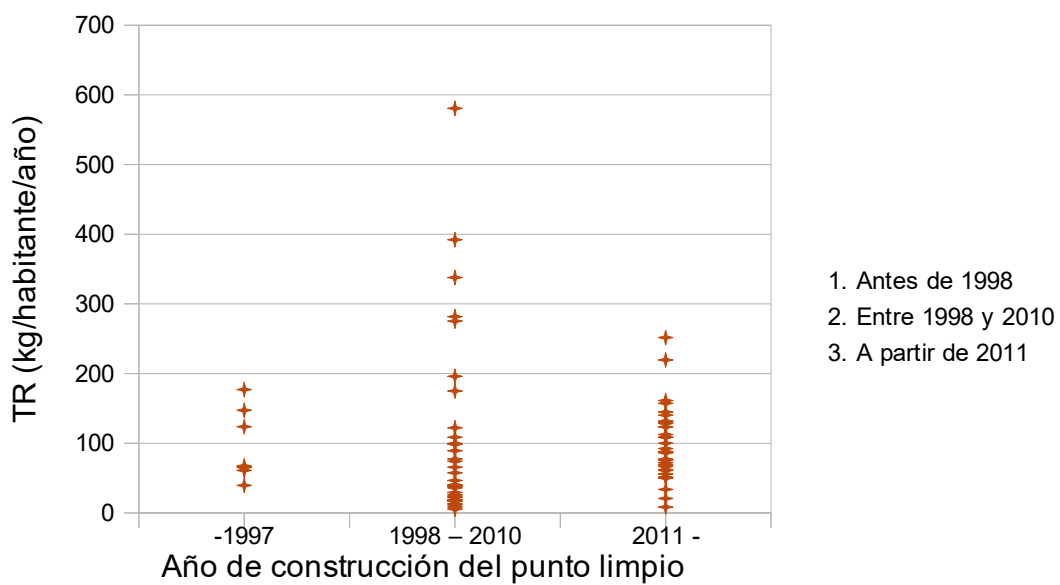

Gráfico 5.4.12: TR frente a antigüedad del punto limpio.

En la Tabla 5.4.29 se muestran la media y desviación estándar de TR en cada uno de los grupos en que se ha dividido la muestra, a los efectos de poder realizar el análisis de influencia de la variable. Se observa que tanto la media como la desviación estándar son superiores en el grupo de puntos limpios construidos entre 1998 y 2010, infraestructuras consolidadas tras la incorporación de sistemas de fomento de la recuperación de materiales mediante la separación en 
origen. Asimismo, los tamaños de los grupos que aglutinan a los puntos limpios más recientes son similares, con un número muy reducido de puntos limpios construidos antes de 1998.

\begin{tabular}{|c|c|c|c|c|c|c|c|c|c|}
\hline \multirow{2}{*}{\multicolumn{2}{|c|}{ Grupo }} & \multirow[t]{2}{*}{$\mathbf{N}$} & \multirow[t]{2}{*}{ Media } & \multirow{2}{*}{$\begin{array}{l}\text { Desviación } \\
\text { Estándar }\end{array}$} & \multirow{2}{*}{$\begin{array}{c}\text { Error } \\
\text { Estándar }\end{array}$} & \multicolumn{2}{|c|}{$\begin{array}{c}\text { Intervalo de } \\
\text { Confianza } 95 \% \\
\text { para la Media }\end{array}$} & \multirow[t]{2}{*}{ Mínimo } & \multirow[t]{2}{*}{ Máximo } \\
\hline & & & & & & $\begin{array}{l}\text { Límite } \\
\text { Inferior }\end{array}$ & $\begin{array}{l}\text { Límite } \\
\text { Superior }\end{array}$ & & \\
\hline \multirow{4}{*}{ TR } & Antes de 1998 & 7 & 97,31 & 51,88 & 19,61 & 49,33 & 145,29 & 39,48 & 177,02 \\
\hline & Entre 1998 y 2010 & 32 & 107,04 & 132,96 & 23,50 & 59,10 & 154,98 & 5,43 & 580,66 \\
\hline & A partir de 2011 & 32 & 100,19 & 52,65 & 9,31 & 81,21 & 119,18 & 8,44 & 251,74 \\
\hline & Total & 71 & 102,99 & 96,45 & 11,45 & 80,17 & 125,82 & 5,43 & 580,66 \\
\hline
\end{tabular}

Tabla 5.4.29: Media, desviación estándar, error estándar e intervalo de confianza de TR para los grupos de antigüedad de punto limpio.

Puesto que TR no sigue una distribución normal, la prueba de igualdad de los subgrupos se realiza mediante el test $\mathrm{H}$ de Kruskal-Wallis, cuyos resultados se muestran en las Tablas $5.4 .30 \mathrm{y}$ 5.4.31.

\begin{tabular}{|l|l|r|r|}
\hline \multicolumn{1}{|c|}{ Variable } & \multicolumn{1}{|c|}{ Grupo } & N & \multicolumn{1}{c|}{ Rango medio } \\
\hline \multirow{4}{*}{ TR } & Anterior a 1998 & 7 & 39,43 \\
\cline { 2 - 4 } & Entre 1998 y 2020 & 32 & 30,81 \\
\cline { 2 - 4 } & A partir de 2011 & 32 & 40,44 \\
\cline { 2 - 4 } & Total & 71 & \\
\hline
\end{tabular}

Tabla 5.4.30: Kruskal-Wallis. $N^{\circ}$ de elementos y rango medio de TR en cada grupo de antigüedad de punto limpio.

\begin{tabular}{|l|r|}
\hline & \multicolumn{2}{|c|}{ TR } \\
\hline Chi-cuadrado & 3,69 \\
\hline df & 2 \\
\hline Sign. Asint. & 0,158 \\
\hline
\end{tabular}

Tabla 5.4.31: Resultados de significación del test de Kruskal-Wallis de TR respecto de la antigüedad de punto limpio.

Puesto que el valor de significación de la prueba es superior a 0,158 , superior al error de la hipótesis nula $(0,05)$, se valida la misma, concluyendo que no existen diferencias entre los grupos en que se ha subdivido la muestra.

En términos estadísticos, no existe influencia significativa entre las variables asociadas a la antigüedad del punto limpio y TR. 


\section{A5.4.5.2. Análisis de TV considerando factor de comparación el año de construcción.}

En cuanto a los elementos de la muestra de que se dispone de datos de TV considerados válidos $(1<$ TV < 120), existen 9 casos en los que no se dispone del año de construcción del punto limpio (Benicarló, Soneja, Aldaya y Alacuás, Algimia de Alfara, Estivella, Gilet, Silla y Torrent -2 puntos limpios), por lo que el número de registros a analizar se reduce a 56, cuya distribución gráfica es la mostrada en el Gráfico 5.4.13.

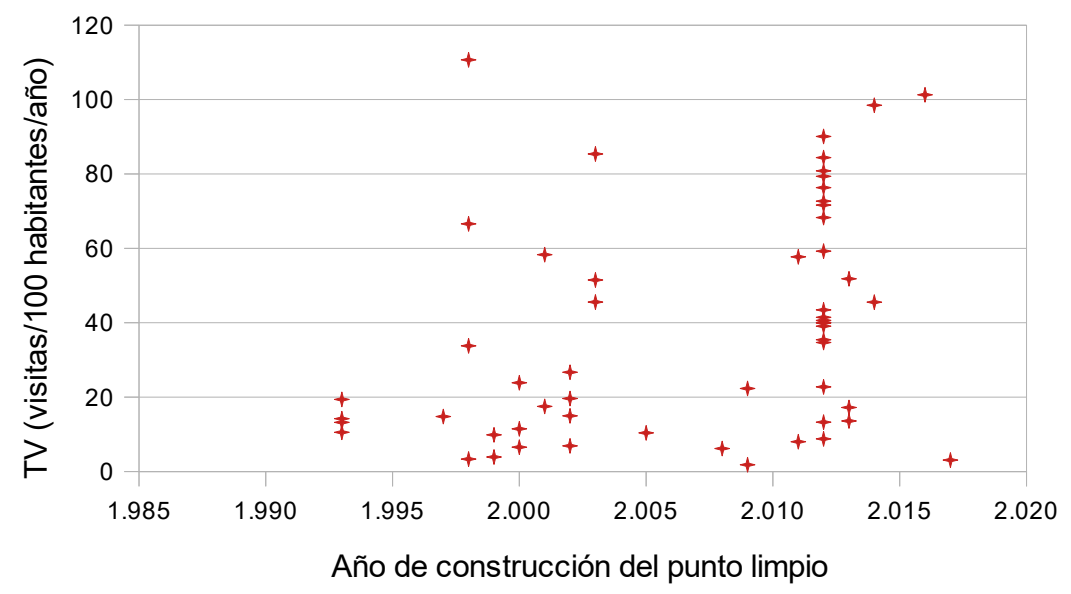

Gráfico 5.4.13: TV frente a año de construcción del punto limpio.

Realizando la segregación de estos elementos conforme a los mismos criterios que en el apartado de análisis de TR, se obtiene la distribución mostrada en el Gráfico 5.4.14, en el que se observa que es muy minoritaria la cantidad de puntos limpios anteriores a 1998. 


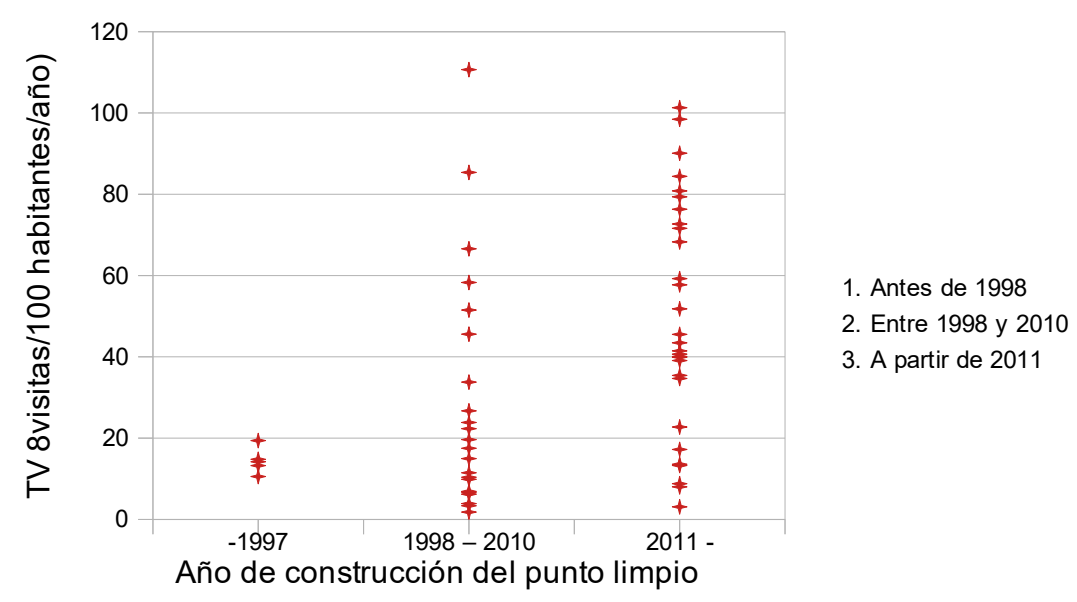

Gráfico 5.4.14: TV frente a antigüedad del punto limpio.

En la Tabla 5.4.32 se muestran los valores de media y desviación estándar de TV para cada grupo en que se ha dividido la muestra, con un aparente crecimiento de TV para los ecoparques más recientes.

\begin{tabular}{|c|c|c|c|c|c|c|c|c|c|}
\hline \multirow{2}{*}{\multicolumn{2}{|c|}{ Grupo }} & \multirow[t]{2}{*}{$\mathbf{N}$} & \multirow[t]{2}{*}{ Media } & \multirow[t]{2}{*}{$\begin{array}{l}\text { Desviación } \\
\text { Estándar }\end{array}$} & \multirow[t]{2}{*}{$\begin{array}{c}\text { Error } \\
\text { Estándar }\end{array}$} & \multicolumn{2}{|c|}{$\begin{array}{c}\text { Intervalo de } \\
\text { Confianza } 95 \% \\
\text { para la Media }\end{array}$} & \multirow[t]{2}{*}{ Mínimo } & \multirow[t]{2}{*}{ Máximo } \\
\hline & & & & & & $\begin{array}{l}\text { Límite } \\
\text { Inferior }\end{array}$ & $\begin{array}{c}\text { Límite } \\
\text { Superior }\end{array}$ & & \\
\hline \multirow{4}{*}{ TV } & Antes de 1998 & 5 & 14,43 & 3,22 & 1,44 & 10,43 & 18,42 & 10,54 & 19,39 \\
\hline & Entre 1998 y 2010 & 22 & 28,96 & 29,26 & 6,24 & 15,99 & 41,93 & 1,82 & 110,66 \\
\hline & A partir de 2011 & 29 & 49,62 & 28,59 & 5,31 & 38,75 & 60,49 & 3,08 & 101,28 \\
\hline & Total & 56 & 38,36 & 29,96 & 4,00 & 30,34 & 46,39 & 1,82 & 110,66 \\
\hline
\end{tabular}

Tabla 5.4.32: Media, desviación estándar, error estándar e intervalo de confianza de TV para los grupos de antigüedad de punto limpio.

La hipótesis de homogeneidad de varianzas se comprueba mediante aplicación del test de Levene, cuyos resultados se incluyen en la Tabla 5.4.33.

\begin{tabular}{|c|r|r|r|r|}
\hline Variable & $\begin{array}{c}\text { Estadístico de } \\
\text { Levene }\end{array}$ & df1 & df2 & \multicolumn{1}{c|}{ Sign. } \\
\hline TV & 4,24 & 2 & 53 & 0,020 \\
\hline
\end{tabular}

Tabla 5.4.33: Resultados del test de Levene para TV y antigüedad del punto limpio. 
Puesto que el valor del estadístico es 4,24 , superior a 3,172 , valor que toma la $\mathrm{F}$ de Snedecor para $\alpha=0,05$, y grados de libertad 2 y 53 , y el valor de significación es inferior a 0,05 , no puede afirmarse que se cumpla el supuesto de homocedasticidad, por lo que la prueba de varianza de medias debe realizarse mediante el test ANOVA-Welch. Los resultados de la prueba se incluyen en la Tabla 5.4.34.

\begin{tabular}{|l|l|r|r|l|}
\hline \multicolumn{2}{|l|}{ Factor } & df & F & Sign. \\
\hline \multirow{2}{*}{ TV } & Entre Grupos & 2 & 21,852 & $7,529 \mathrm{e}-7$ \\
\cline { 2 - 6 } & Intra Grupos & 34,365 & \multicolumn{2}{|c}{} \\
\cline { 1 - 3 } &
\end{tabular}

Tabla 5.4.34: Resultados del test ANOVA-Welch para TV y antigüedad del punto limpio.

Puesto que el valor de significación es inferior al error de la hipótesis nula, ésta se rechaza, por lo que no existe igualdad entre grupos. Al existir más de 2 grupos, a continuación se realizan las pruebas post-hoc BSD de Bonferroni, LSD de Fisher, Scheffé y HSD de Tukey, con el objetivo de determinar entre cuáles de ellos existen diferencias significativas. Los resultados de las pruebas son los que se incluyen en la Tabla 5.4.35.

\begin{tabular}{|c|c|c|c|c|c|c|c|}
\hline \multirow{2}{*}{ TV } & & & \multirow{2}{*}{$\begin{array}{l}\text { Diferencia } \\
\text { de media }\end{array}$} & \multirow{2}{*}{$\begin{array}{l}\text { Error } \\
\text { Estándar }\end{array}$} & \multirow{2}{*}{ Sign. } & \multicolumn{2}{|c|}{$\begin{array}{c}\text { Intervalo de } \\
\text { confianza del } 95 \%\end{array}$} \\
\hline & & & & & & $\begin{array}{l}\text { Límite } \\
\text { inferior }\end{array}$ & $\begin{array}{l}\text { Límite } \\
\text { superior }\end{array}$ \\
\hline \multirow{6}{*}{ Bonferroni } & \multirow{2}{*}{ Antes de 1998} & Entre 1998 y 2010 & $-14,53$ & 13,76 & 0,887 & $-48,56$ & 19,49 \\
\hline & & A partir de 2011 & $-35,19$ & 13,45 & 0,035 & $-68,45$ & $-1,94$ \\
\hline & \multirow{2}{*}{ Entre 1998 y 2010} & Antes de 1998 & 14,53 & 13,76 & 0,887 & $-19,49$ & 48,56 \\
\hline & & A partir de 2011 & $-20,66$ & 7,85 & 0,033 & $-40,08$ & $-1,24$ \\
\hline & \multirow{2}{*}{ A partir de 2011} & Antes de 1998 & 35,19 & 13,45 & 0,035 & 1,94 & 68,45 \\
\hline & & Entre 1998 y 2010 & 20,66 & 7,85 & 0,033 & 1,24 & 40,08 \\
\hline \multirow{6}{*}{$\begin{array}{l}\text { LSD } \\
\text { Fisher }\end{array}$} & \multirow{2}{*}{ Antes de 1998} & Entre 1998 y 2010 & $-14,53$ & 13,76 & 0,296 & $-42,14$ & 13,07 \\
\hline & & A partir de 2011 & $-35,19$ & 13,45 & 0,012 & $-62,17$ & $-8,21$ \\
\hline & \multirow{2}{*}{ Entre 1998 y 2010} & Antes de 1998 & 14,53 & 13,76 & 0,296 & $-13,07$ & 42,14 \\
\hline & & A partir de 2011 & $-20,66$ & 7,85 & 0,011 & $-36,41$ & $-4,91$ \\
\hline & \multirow{2}{*}{ A partir de 2011} & Antes de 1998 & 35,19 & 13,45 & 0,012 & 8,21 & 62,17 \\
\hline & & Entre 1998 y 2010 & 20,66 & 7,85 & 0,011 & 4,91 & 36,41 \\
\hline \multirow{6}{*}{ Scheffé } & \multirow{2}{*}{ Antes de 1998} & Entre 1998 y 2010 & $-14,53$ & 13,76 & 0,576 & $-49,20$ & 20,13 \\
\hline & & A partir de 2011 & $-35,19$ & 13,45 & 0,040 & $-69,07$ & $-1,32$ \\
\hline & \multirow{2}{*}{ Entre 1998 y 2010} & Antes de 1998 & 14,53 & 13,76 & 0,576 & $-20,13$ & 49,20 \\
\hline & & A partir de 2011 & $-20,66$ & 7,85 & 0,039 & $-40,44$ & $-0,88$ \\
\hline & \multirow{2}{*}{ A partir de 2011} & Antes de 1998 & 35,19 & 13,45 & 0,040 & 1,32 & 69,07 \\
\hline & & Entre 1998 y 2010 & 20,66 & 7,85 & 0,039 & 0,88 & 40,44 \\
\hline \multirow{6}{*}{$\begin{array}{l}\text { HSD } \\
\text { Tukey }\end{array}$} & \multirow{2}{*}{ Antes de 1998} & Entre 1998 y 2010 & $-14,53$ & 13,76 & 0,545 & $-47,72$ & 18,65 \\
\hline & & A patir de 2011 & $-35,19$ & 13,45 & 0,031 & $-67,63$ & $-2,76$ \\
\hline & \multirow{2}{*}{ Entre 1998 y 2010} & Antes de 1998 & 14,53 & 13,76 & 0,545 & $-18,65$ & 47,72 \\
\hline & & A patir de 2011 & $-20,66$ & 7,85 & 0,029 & $-39,60$ & $-1,72$ \\
\hline & \multirow{2}{*}{ A patir de 2011} & Antes de 1998 & 35,19 & 13,45 & 0,031 & 2,76 & 67,63 \\
\hline & & Entre 1998 y 2010 & 20,66 & 7,85 & 0,029 & 1,72 & 39,60 \\
\hline
\end{tabular}

Tabla 5.4.35: Resultados de las pruebas post-hoc de significación de TV entre grupos de antigüedad del punto limpio. 
Como en los casos anteriores, se comprueba que, pese a que los resultados de significación son equivalentes entre todas las pruebas, la LSD de Fisher y la HSD de Tukey tienden más a encontrar significación, con resultados inferiores en todas las comparaciones, mientras que la de Scheffé tiene mayor tendencia a buscar significación cuando ésta no existe $(>0,05)$, con valores de significación más bajos, que sin embargo son ligeramente más altos en las comparaciones en que sí se halla significación $(<0,05)$, mientras que la prueba BSD de Bonferroni presenta resultados de significación en las comparaciones con significación similares a los del test HSD de Tukey, y valores de significación en las comparaciones en que no se halla significación más elevados. Nuevamente, debido a estos resultados y al reducido número de comparaciones realizadas, se considera que la prueba idónea es la BSD de Bonferroni.

Se observa existen diferencias significativas de TV entre los puntos limpios construidos antes y después del año 2011, al obtenerse un valor de significación inferior a 0,05. Para los puntos limpios construidos previamente, independiente de si son o no anteriores 1998, no presentan diferencias significativas en los valores de TV, por lo que puede considerarse que ambos grupos son iguales.

Por tanto, la variable TV presenta diferencias significativas en función de la fecha de construcción del punto limpio. Se puede considerar que TV es similar para los puntos limpios anteriores a 1998 y los construidos entre 1998 y 2010, siendo los resultados de TV de todos estos puntos limpios distinto de los de la variable para las instalaciones construidas a partir de 2011.

\section{A5.4.6. Número de carriles de circulación por sentido.}

Este parámetro de diseño del punto limpio es una medida de los flujos de circulación y accesibilidad interna a los puntos de entrega de residuos. En la base de datos formada por los elementos de la muestra se observa que, mayoritariamente, los puntos limpios disponen de 1 único carril de circulación por sentido; no obstante, existen casos en que se dispone de 2 carriles, por lo que se estudia a continuación la relevancia de dicho aspecto sobre el grado de utilización de los puntos limpios, tanto en términos de cantidades depositadas como de frecuencia de utilización. 


\section{A5.4.6.1. Análisis de TR considerando factor de comparación el número de carriles de circulación.}

Del total de elementos de la muestra con valor de TR considerado válido para el estudio, existen 4 puntos limpios de los que no se dispone de información sobre este parámetro (Mancomunidad Sasieta, Tudela, Churriana de la Vega y Las Cabezas de San Juan), por lo que el estudio se realiza sobre un total de 80 puntos limpios, que se distribuyen conforme se muestra en el Gráfico 5.4.15.

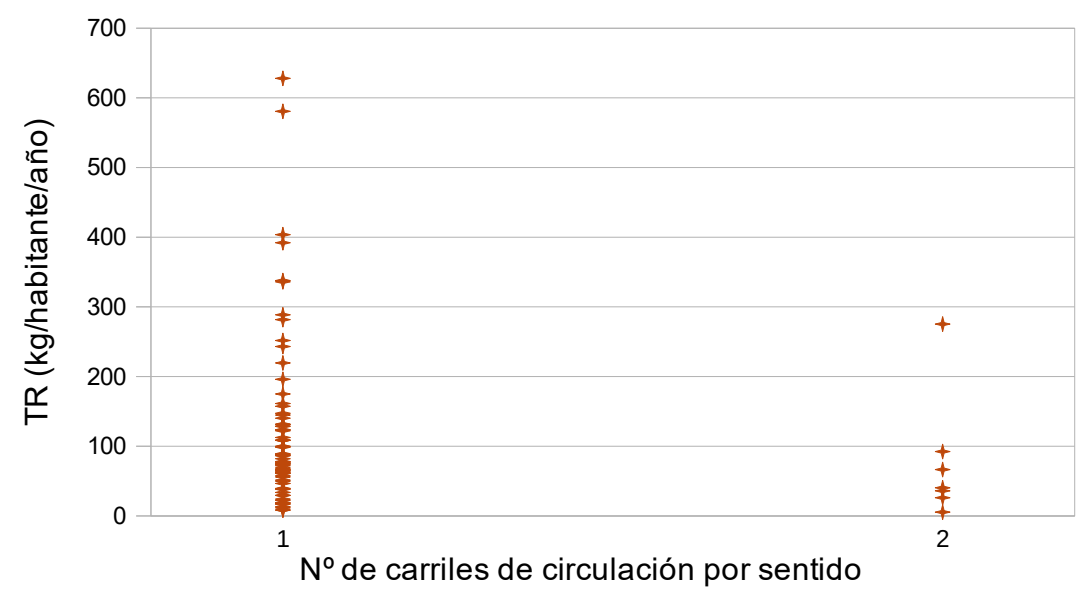

Gráfico 5.4.15: TR frente a número de carriles de circulación por sentido.

En la Tabla 5.4.36 se incluyen los valores que toman la media y la desviación estándar de cada uno de los grupos, así como de la totalidad de la muestra, observándose un aparente descenso en los valores de ambas para los puntos limpios con 2 carriles de circulación.

\begin{tabular}{|c|c|c|c|c|c|c|c|c|c|}
\hline & \multirow[t]{2}{*}{ Grupo } & \multirow[t]{2}{*}{$\mathbf{N}$} & \multirow[t]{2}{*}{ Media } & \multirow{2}{*}{$\begin{array}{l}\text { Desviación } \\
\text { Estándar }\end{array}$} & \multirow{2}{*}{$\begin{array}{c}\text { Error } \\
\text { Estándar }\end{array}$} & \multicolumn{2}{|c|}{$\begin{array}{c}\text { Intervalo de } \\
\text { Confianza } 95 \% \\
\text { para la Media }\end{array}$} & \multirow[t]{2}{*}{ Mínimo } & \multirow{2}{*}{ Máximo } \\
\hline & & & & & & $\begin{array}{l}\text { Límite } \\
\text { Inferior }\end{array}$ & $\begin{array}{c}\text { Límite } \\
\text { Superior }\end{array}$ & & \\
\hline \multirow{3}{*}{ TR } & 1 carril & 73 & 121,46 & 120,38 & 14,09 & 93,37 & 149,55 & 8,42 & 628,02 \\
\hline & 2 carriles & 7 & 77,42 & 91,69 & 34,66 & $-7,38$ & 162,22 & 5,43 & 275,38 \\
\hline & Total & 80 & 117,61 & 118,34 & 13,23 & 91,27 & 143,94 & 5,43 & 628,00 \\
\hline
\end{tabular}

Tabla 5.4.36: Media, desviación estándar, error estándar e intervalo de confianza de TR para los grupos de $n^{\circ}$ de carriles de circulación. 
Puesto que TR no sigue una distribución normal, se valida la hipótesis de igualdad de grupos de la muestra mediante la prueba $\mathrm{H}$ de Kruskal-Wallis, cuyos resultados se muestran en las Tablas 5.4 .37 y 5.4 .38 .

\begin{tabular}{|l|l|r|r|}
\hline \multicolumn{1}{|c|}{ Variable } & \multicolumn{1}{|c|}{ Grupo } & N & \multicolumn{1}{c|}{ Rango medio } \\
\hline \multirow{4}{*}{ TR } & 1 carril & 73 & 41,70 \\
\cline { 2 - 5 } & 2 carriles & 7 & 28,00 \\
\cline { 2 - 5 } & Total & 80 & \\
\hline
\end{tabular}

Tabla 5.4.37: Kruskal-Wallis. $N^{\circ}$ de elementos y rango medio de TR en cada grupo de $n^{\circ}$ de carriles de circulación.

\begin{tabular}{|l|r|}
\hline & \multicolumn{2}{|c|}{ TR } \\
\hline Chi-cuadrado & 2,22 \\
\hline df & 1 \\
\hline Sign. Asint. & 0,136 \\
\hline
\end{tabular}

Tabla 5.4.38: Resultados de significación del test de Kruskal-Wallis de TR respecto del nº de carriles de circulación.

Puesto que el valor de significación es superior a 0,05, no existen diferencias entre los subgrupos de la muestra y, por tanto, las poblaciones son iguales; es decir, el factor de comparación no resulta significativo para los resultados de TR del punto limpio.

En conclusión, el número de carriles de circulación por sentido con que cuenta el punto limpio no constituye un factor que influya significativamente en los resultados de TR.

\section{A5.4.6.2. Análisis de TV considerando factor de comparación el número de carriles de circulación.}

En el análisis de TV en función del número de carriles de circulación existentes por sentido, únicamente existe un punto limpio (Puerto de Santa María) sin información, por lo que la muestra válida consta de 64 elementos, cuya distribución en grupos en función del valor que toma dicha variable se muestra en el Gráfico 5.4.16. 


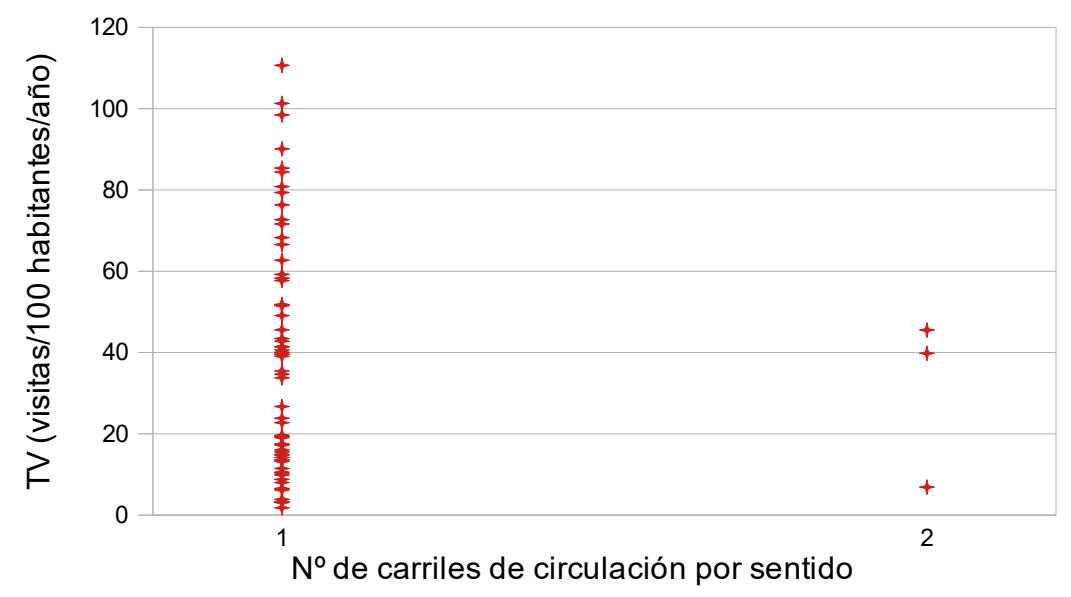

Gráfico 5.4.16: TV frente al número de carriles de circulación por sentido.

Se observa que todos los puntos limpios con TV > 45 cuentan con un único carril de circulación por sentido; sin embargo, el número de casos integrados en el grupo es muy reducido (3, inferior al $5 \%$ de los casos analizados), tal y como se detalla en la Tabla 5.4.39, en que se incluyen los valores de media y desviación estándar de TV de cada uno de los grupos.

\begin{tabular}{|c|c|c|c|c|c|c|c|c|c|}
\hline & \multirow[t]{2}{*}{ Grupo } & \multirow[t]{2}{*}{$\mathbf{N}$} & \multirow[t]{2}{*}{ Media } & \multirow[t]{2}{*}{$\begin{array}{l}\text { Desviación } \\
\text { Estándar }\end{array}$} & \multirow[t]{2}{*}{$\begin{array}{c}\text { Error } \\
\text { Estándar }\end{array}$} & \multicolumn{2}{|c|}{$\begin{array}{c}\text { Intervalo de } \\
\text { Confianza } 95 \% \\
\text { para la Media }\end{array}$} & \multirow[t]{2}{*}{ Mínimo } & \multirow[t]{2}{*}{ Máximo } \\
\hline & & & & & & $\begin{array}{l}\text { Límite } \\
\text { Inferior }\end{array}$ & $\begin{array}{c}\text { Límite } \\
\text { Superior }\end{array}$ & & \\
\hline \multirow{3}{*}{ TV } & 1 carril & 61 & 38,68 & 28,93 & 3,70 & 31,27 & 46,09 & 1,82 & 110,66 \\
\hline & 2 carriles & 3 & 30,74 & 20,86 & 12,04 & $-21,07$ & 82,55 & 6,89 & 45,53 \\
\hline & Total & 64 & 38,31 & 28,52 & 3,57 & 31,19 & 45,44 & 1,82 & 110,66 \\
\hline
\end{tabular}

Tabla 5.4.39: Media, desviación estándar, error estándar e intervalo de confianza de TV para los grupos de $n^{\circ}$ de carriles de circulación.

Los resultados del Test de Levene, de análisis de homogeneidad de varianzas, se incluyen en la Tabla 5.4.40.

\begin{tabular}{|c|r|r|r|r|}
\hline \multicolumn{1}{|c|}{ Variable } & $\begin{array}{c}\text { Estadístico de } \\
\text { Levene }\end{array}$ & df1 & df2 & \multicolumn{1}{c|}{ Sign. } \\
\hline TV & 0,74 & 1 & 62 & 0,393 \\
\hline
\end{tabular}

Tabla 5.4.40: Resultados del test de Levene para TV y nº de carriles de circulación.

En este caso, el valor del estadístico es 0,74 , inferior a 3,996, valor que toma la $\mathrm{F}$ de Snedecor para $\alpha=0,05$, y grados de libertad 1 y 62 , mientras que el valor de significación es superior a 0,05, 
por lo que se cumple el supuesto de homocedasticidad; es decir, las distribuciones de los elementos de los subgrupos presentan varianzas homogéneas.

En cuanto a la comparación de igualdad de los grupos, al presentar TV una distribución normal, se realiza a continuación el test ANOVA, cuyos resultados se muestran en la Tabla 5.4.41.

\begin{tabular}{|c|c|c|c|c|c|c|}
\hline \multicolumn{2}{|c|}{ Factor } & $\begin{array}{l}\text { Suma de } \\
\text { Cuadrados }\end{array}$ & df & $\begin{array}{l}\text { Cuadrado } \\
\text { medio }\end{array}$ & $\mathbf{F}$ & Sign. \\
\hline \multirow{3}{*}{ TV } & Entre Grupos & 180,30 & 1 & 180,30 & 0,22 & 0,642 \\
\hline & Intra Grupos & $51.074,78$ & 62 & 823,79 & & \\
\hline & Total & $51.255,09$ & 63 & & & \\
\hline
\end{tabular}

Tabla 5.4.41: Resultados test ANOVA para TV y $n^{\circ}$ de carriles de circulación.

Puesto que el valor de significación superior a 0,05, la hipótesis nula se considera válida y el criterio de comparación no constituye un factor diferenciador en términos de resultados de TV.

Por tanto, los resultados de la variable TV no se ven influenciados de manera significativa por el número de carriles de ciruclación por sentido con que cuenta el punto limpio.

\section{A5.4.7. Cotas de construcción.}

Los puntos limpios, como norma general, pueden ser construidos con todos los equipamientos y vías de circulación al mismo nivel (1 cota), o con los equipamientos accesibles al usuario a un nivel, y los necesarios para los vehículos del servicio de transporte, a un nivel inferior (2 cotas); en el primer caso, los costes de construcción son inferiores y, en el segundo, el diseño de los flujos de circulación interna resulta menos invasivo, quedando segregadas las áreas accesibles por los usuarios de las necesarias para la logística del servicio, posibilitando además la utilización de contenedores de alta capacidad con mejor accesibilidad para los usuarios, puesto que las entregas de residuos de gran volumen y/o masa no requieren ser realizadas mediante la elevación de los mismos a alturas por encima de la cintura.

En este punto se analiza la incidencia que presenta esta característica de diseño del punto limpio sobre los resultados de gestión de residuos de la instalación. 


\section{A5.4.7.1. Análisis de TR considerando factor de comparación el número de cotas constructivas.}

De los puntos limpios de la muestra con tasas de TR que se encuentran en valores considerados adecuados, existen 3 sobre los que no se dispone de información sobre esta variable (Mancomunidad Sasieta, Tudela y Las Cabezas de San Juan), por lo que se cuenta con 81 datos, que se distribuyen en función del valor del factor de comparación tal y como se muestra en el Gráfico 5.4.17, en el que se observa que el número de puntos limpios construidos a 2 cotas es superior al de construidos a 1 cota, con una aparente distribución de TR distinta.

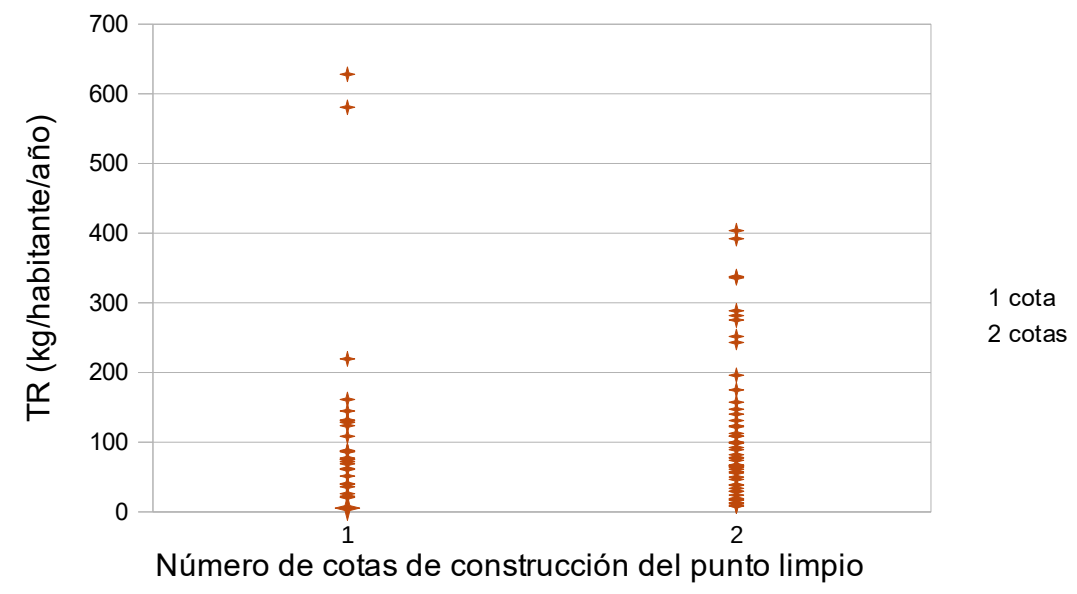

Gráfico 5.4.17: TR frente al número de cotas de construcción.

En la Tabla 5.4.42 se incluye el número de casos integrados en cada grupo, y la media y desviación estándar de TR en cada grupo y para la totalidad de la muesta. En ella se observa que los valores de media de TR son similares, no así la desviación estándar.

\begin{tabular}{|c|c|c|c|c|c|c|c|c|c|}
\hline & Grupo & $\mathbf{N}$ & Media & $\begin{array}{l}\text { Desviación } \\
\text { Estándar }\end{array}$ & $\begin{array}{c}\text { Error } \\
\text { Estándar }\end{array}$ & $\begin{array}{c}\text { Inte } \\
\text { Confi } \\
\text { para }\end{array}$ & $\begin{array}{l}\text { alo de } \\
\text { Iza 95\% } \\
\text { Media }\end{array}$ & Mínimo & Máximo \\
\hline & & & & & & $\begin{array}{l}\text { Límite } \\
\text { Inferior }\end{array}$ & $\begin{array}{l}\text { Límite } \\
\text { Superior }\end{array}$ & & \\
\hline & 1 cota & 28 & 119,69 & 145,27 & 27,45 & 63,36 & 176,02 & 5,43 & 628,02 \\
\hline TR & 2 cotas & 53 & 114,68 & 102,40 & 14,07 & 86,45 & 142,90 & 8,42 & 403,60 \\
\hline & Total & 81 & 116,41 & 118,09 & 13,12 & 90,30 & 142,52 & 5,43 & 628,02 \\
\hline
\end{tabular}

Tabla 5.4.42: Media, desviación estándar, error estándar e intervalo de confianza de TR para los grupos de $n^{\circ}$ de cotas de construcción. 
La comprobación de igualdad de los subgrupos se realiza mediante la prueba $\mathrm{H}$ de Kruskal-Wallis, cuyos resultados son los que se incluyen en las Tablas 5.4 .43 y 5.4.44.

\begin{tabular}{|c|l|r|r|}
\hline \multicolumn{1}{|c|}{ Variable } & \multicolumn{1}{|c|}{ Grupo } & N & \multicolumn{1}{c|}{ Rango medio } \\
\hline \multirow{4}{*}{ TR } & 1 cota & 28 & 40,75 \\
\cline { 2 - 4 } & 2 cotas & 53 & 41,13 \\
\cline { 2 - 4 } & Total & 81 & \\
\hline
\end{tabular}

Tabla 5.4.43: Kruskal-Wallis. $N^{\circ}$ de elementos y rango medio de TR en cada grupo de $n^{\circ}$ de cotas de construcción.

\begin{tabular}{|l|r|}
\hline & \multicolumn{2}{|c|}{ TR } \\
\hline Chi-cuadrado & 0,00 \\
\hline df & 1 \\
\hline Sign. Asint. & 0,945 \\
\hline
\end{tabular}

Tabla 5.4.44: Resultados de significación del test de Kruskal-Wallis de TR respecto del nº de cotas de construcción.

Al obtenerse un valor de significación superior a 0,05, se concluye que la hipótesis nula es cierta y, por tanto, no existen diferencias entre los subgrupos de la muestra.

Por tanto, el número de cotas constructivas del punto limpio no resulta estadísticamente significativo sobre los resultados de TR.

\section{A5.4.7.2. Análisis de TV considerando factor de comparación el número de cotas constructivas.}

Todos los puntos limpios de los que se dispone de datos relativos a TV informan del factor a analizar en este punto, por lo que el números de casos a estudiar es de 65 , cuya distribución en grupos es la mostrada en el Gráfico 5.4.18. 


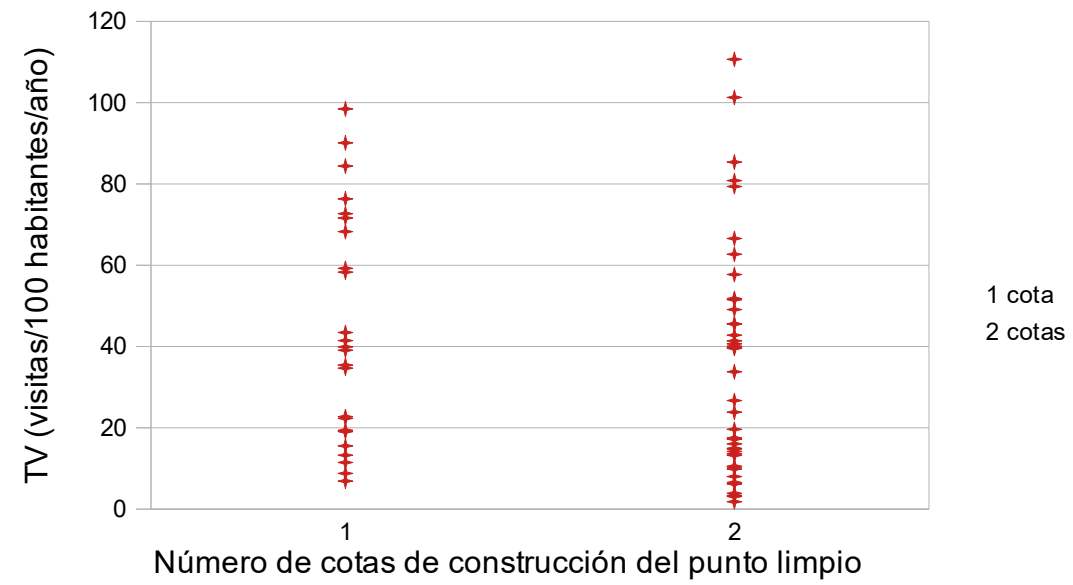

Gráfico 5.4.18: TV frente al número de cotas de construcción.

Como sucedía con TR, la mayor parte de los puntos limpios se encuentran construidos a 2 cotas, con máximos de TV similares. Los valores de media y desviación estándar de TV para cada grupo y la totalidad de la muestra se incluyen en la Tabla 5.4.45, en la que se observa un aparente descenso de TV en los puntos limpios construidos a 2 cotas, mientras que la desviación estándar es similar.

\begin{tabular}{|c|c|c|c|c|c|c|c|c|c|}
\hline & \multirow{2}{*}{ Grupo } & \multirow[t]{2}{*}{$\mathbf{N}$} & \multirow{2}{*}{ Media } & \multirow{2}{*}{$\begin{array}{l}\text { Desviación } \\
\text { Estándar }\end{array}$} & \multirow{2}{*}{$\begin{array}{c}\text { Error } \\
\text { Estándar }\end{array}$} & \multicolumn{2}{|c|}{$\begin{array}{c}\text { Intervalo de } \\
\text { Confianza } 95 \% \\
\text { para la Media }\end{array}$} & \multirow{2}{*}{ Mínimo } & \multirow{2}{*}{ Máximo } \\
\hline & & & & & & $\begin{array}{l}\text { Límite } \\
\text { Inferior }\end{array}$ & $\begin{array}{l}\text { Límite } \\
\text { Superior }\end{array}$ & & \\
\hline \multirow{3}{*}{ TV } & 1 cota & 24 & 43,87 & 28,10 & 5,74 & 32,00 & 55,73 & 6,89 & 98,46 \\
\hline & 2 cotas & 41 & 34,67 & 28,31 & 4,42 & 25,73 & 43,60 & 1,82 & 110,66 \\
\hline & Total & 65 & 38,06 & 28,37 & 3,52 & 31,04 & 45,09 & 1,82 & 110,66 \\
\hline
\end{tabular}

Tabla 5.4.45: Media, desviación estándar, error estándar e intervalo de confianza de TV para los grupos de $n^{\circ}$ de cotas de construcción.

Los resultados del Test de Levene, de análisis de homogeneidad de varianzas, se incluyen en la Tabla 5.4.46.

\begin{tabular}{|c|r|r|r|r|}
\hline Variable & $\begin{array}{c}\text { Estadístico de } \\
\text { Levene }\end{array}$ & df1 & df2 & \multicolumn{1}{c|}{ Sign. } \\
\hline TV & 0,02 & 1 & 63 & 0,877 \\
\hline
\end{tabular}

Tabla 5.4.46: Resultados del test de Levene para TV y nº de cotas de construcción. 
Se observa que el valor del estadístico es 0,02 , inferior a 3,993, valor que toma la $F$ de Snedecor para $\alpha=0,05$, y grados de libertad 1 y 63 , mientras que el valor de significación es muy superior a 0,05 , por lo que se cumple el supuesto de homocedasticidad; es decir, las distribuciones de los elementos de los subgrupos presentan varianzas homogéneas.

En cuanto a la comparación de igualdad de los grupos, mediante el análisis de varianza de las medias, se realiza a continuación el test ANOVA, cuyos resultados se muestran en la Tabla 5.4.47.

\begin{tabular}{|c|c|c|c|c|c|c|}
\hline \multicolumn{2}{|c|}{ Factor } & $\begin{array}{c}\text { Suma de } \\
\text { Cuadrados }\end{array}$ & df & $\begin{array}{l}\text { Cuadrado } \\
\text { medio }\end{array}$ & $\mathbf{F}$ & Sign. \\
\hline \multirow{3}{*}{ TV } & Entre Grupos & $1.280,62$ & 1 & $1.280,62$ & 1,61 & 0,210 \\
\hline & Intra Grupos & $50.226,43$ & 63 & 797,24 & & \\
\hline & Total & $51.507,05$ & 64 & & & \\
\hline
\end{tabular}

Tabla 5.4.47: Resultados test ANOVA para TV y nº de cotas de construcción.

Se obtiene un valor de significación superior a 0,05 , por lo que la hipótesis nula se considera válida y las distribuciones de TV son iguales entre los grupos en que se ha dividido la muestra atendiendo al valor del factor de comparación.

Por tanto, los resultados de la variable TV no se ven significativamente influidos por el número de cotas de construcción del punto limpio.

\section{A5.4.8. Número de contenedores caja abierta.}

Para un correcto funcionamiento del servicio, el número de contenedores debe estar dimensionado de manera que permita el almacenamiento temporal de las cantidades de materiales depositados en los mismos, con una gestión logística lo más homogénea posible y sin unos excesivos costes de inversión.

En términos de producción de residuos, las fracciones mayoritarias son las de:

- Residuos voluminosos y colchones (almacenamiento conjunto o segregado).

- Residuos de demolición.

- Residuos vegetales.

Que, generalmente, son almacenados en contenedores de tipo caja abierta, de capacidad variable; en función del tamaño del municipio, actividades económicas, condiciones de funcionamiento, etc, es frecuente que se instalen contenedores de este tipo para otras fracciones: 
- Residuos metálicos.

- Residuos de plástico distinto de envases.

- Papel y cartón voluminoso.

Puesto que número de contenedores caja abierta disponibles en el punto limpio puede tomar múltiples valores, el análisis directo de comportamiento de las variables TR y TV respecto del valor de la variable de comparación da lugar a un número elevado de situaciones, cuya comparación puede resultar ineficaz; por tanto, en primer lugar se debe establecer un criterio de agrupación de los casos de la muestra, que posibilite el análisis comparativo.

En el Gráfico 5.4.19 se muestra el elevado número de situaciones distintas que se dan en la muestra (14), así como la cantidad de casos correspondientes a cada una de ellas, independientemente de que hayan aportado información para el cálculo de TR y TV. En la mayoría de situaciones, este número es inferior a 10 , por lo que resulta evidente la necesidad de establecer criterios de agrupación.

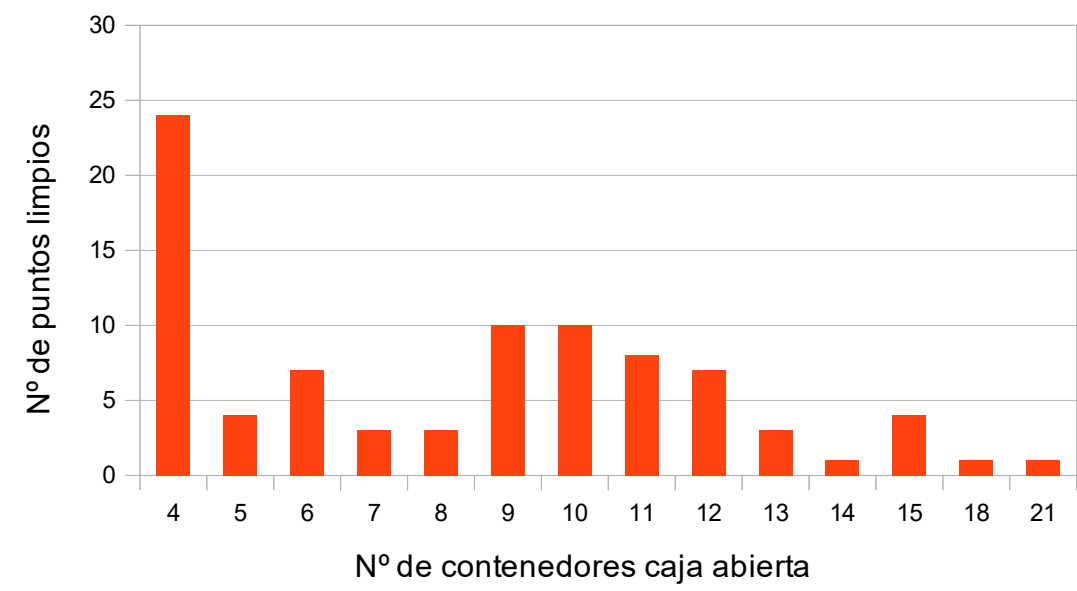

Gráfico 5.4.19: Número de puntos limpios por cantidad de contenedores caja abierta.

Además, para valores de TR (limitante en términos de capacidad) similares, es esperable que la generación total anual sea superior en áreas de influencia con mayor población adscrita, resultando, a priori, en un número de contenedores de este tipo superior. En el Gráfico 5.4 .20 se muestra el número de contenedores caja abierta en función de la población adscrita, teniendo en cuenta la clasificación establecida en el punto A5.4.1.. Se observa la tendencia creciente en la mayor dotación de contenedores en puntos limpios con mayor población adscrita. Por tanto, el 
análisis de significación de la variable se realizará previa segregación de la muestra atendiendo a la población adscrita, teniendo en cuenta la clasificación establecida en el punto A5.4.1.. Para cada grupo de puntos limpios según su población adscrita, se crearán subgrupos en función del número de contenedores tipo caja abierta con que cuenten. Este segundo nivel de segregación, que servirá para el análisis de significación de la variable correspondiente al número de contenedores, se realiza teniendo en cuenta la media de número de contenedores y los cuartiles primero y tercero del Gráfico 5.4.20, y que se resumen en la Tabla 5.4.48.

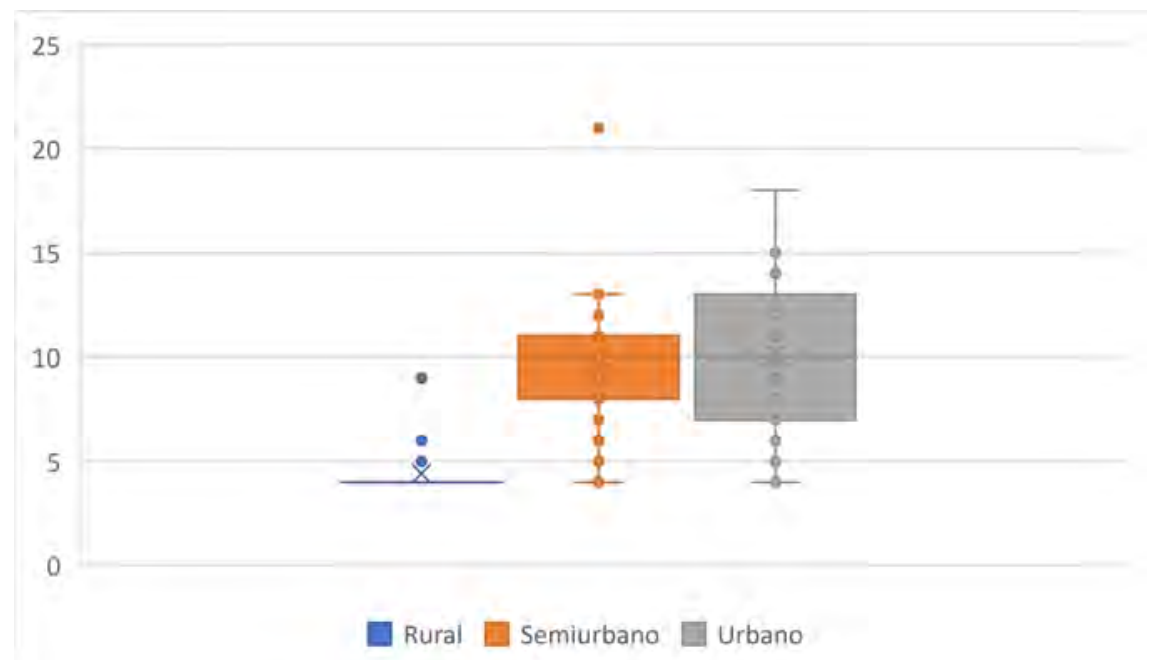

Gráfico 5.4.20: Número de contenedores caja abierta frente a tamaño de población adscrita.

\begin{tabular}{|l|c|c|c|c|}
\hline \multicolumn{1}{|c|}{ Tamaño } & Grupo 1 & Grupo 2 & Grupo 3 & Grupo 4 \\
\hline Rural & $<4$ & $=4$ & $=5$ & $>5$ \\
\hline Semiurbano & $<8$ & $8 \leq x \leq 10$ & $=11$ & $>11$ \\
\hline Urbano & $<7$ & $7 \leq x \leq 10$ & $10<x \leq 14$ & $>14$ \\
\hline
\end{tabular}

Tabla 5.4.48: Clasificación de puntos limpios por número de contenedores y tamaño de población adscrita.

\section{A5.4.8.1. Análisis de TR considerando factor de comparación el número de contenedores caja abierta.}

Se dispone de datos de TR y número de contenedores caja abierta de 81 puntos limpios (no aportan datos las instalaciones de Tudela, Mancomunidad de Sasieta y Las Cabezas de San Juan). En el Gráfico 5.4.21 se presentan los valores de TR de los puntos limpios de la muestra, en función del número de contenedores caja abierta con que cuentan. Se observa que los valores máximos de TR se obtienen en puntos limpios que cuentan con 6 y 9 contenedores de este tipo, 
sin que el incremento de dotación por encima de 15 unidades reporte valores de TR superiores. No obstante, como ya se ha indicado, el análisis de significación de esta variable sobre TR se va a llevar a cabo realizando una primera reagrupación de las instalaciones atendiendo a su población adscrita.

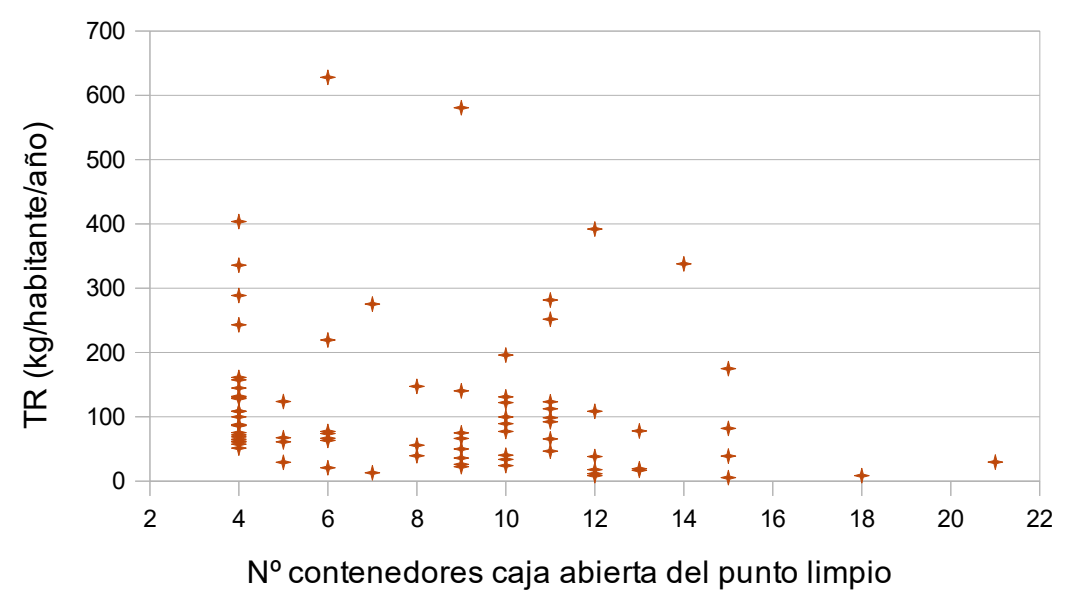

Gráfico 5.4.21: TR frente a número de contenedores caja abierta.

\section{Puntos limpios rurales:}

Para este análisis se cuenta con información relativa a 24 puntos limpios que, de acuerdo con el criterio establecido en la Tabla 5.4.48, se agrupan conforme se observa en la Tabla 5.4.49.

\begin{tabular}{|c|c|c|c|c|}
\hline & $<\mathbf{4}$ contenedores & $\mathbf{4}$ contenedores & $\mathbf{5}$ contenedores & $\mathbf{7} \mathbf{5}$ contenedores \\
\hline $\mathrm{N}^{\circ}$ puntos limpios & 0 & 20 & 1 & 3 \\
\hline
\end{tabular}

Tabla 5.4.49: Cantidad de puntos limpios rurales por número de contenedores caja abierta.

Por tanto, se realiza una reagrupación, en función de si los puntos limpios cuentan con 4 contenedores caja abierta o más, con el objetivo de poder realizar un análisis de significación. En la Tabla 5.4 .50 se muestran la media y desviación estándar de TR en cada grupo y para la totalidad de la muestra. Se observa que la media de TR es superior en el segundo grupo, aunque también se incrementa considerablemente la desviación estándar. 


\begin{tabular}{|c|c|c|c|c|c|c|c|c|c|}
\hline \multirow{2}{*}{\multicolumn{2}{|c|}{ Grupo }} & \multirow[t]{2}{*}{$\mathbf{N}$} & \multirow[t]{2}{*}{ Media } & \multirow{2}{*}{$\begin{array}{l}\text { Desviación } \\
\text { Estándar }\end{array}$} & \multirow{2}{*}{$\begin{array}{c}\text { Error } \\
\text { Estándar }\end{array}$} & \multicolumn{2}{|c|}{$\begin{array}{c}\text { Intervalo de } \\
\text { Confianza } 95 \% \text { para } \\
\text { la Media }\end{array}$} & \multirow[t]{2}{*}{ Mínimo } & \multirow[t]{2}{*}{ Máximo } \\
\hline & & & & & & $\begin{array}{l}\text { Límite } \\
\text { Inferior }\end{array}$ & $\begin{array}{c}\text { Límite } \\
\text { Superior }\end{array}$ & & \\
\hline \multirow{3}{*}{ TR } & 4 cont. C.Ab. & 20 & 147,35 & 96,64 & 21,61 & 102,12 & 192,58 & 51,35 & 403,60 \\
\hline & $>4$ cont. C.Ab. & 4 & 226,62 & 269,78 & 134,89 & $-202,66$ & 655,90 & 60,98 & 628,02 \\
\hline & Total & 24 & 160,56 & 134,61 & 27,48 & 103,72 & 217,40 & 51,35 & 328,02 \\
\hline
\end{tabular}

Tabla 5.4.50: Media, desviación estándar, error estándar e intervalo de confianza de TR para los grupos de $n^{\circ}$ de contenedores caja abierta para puntos limpios rurales.

La comprobación de igualdad de los subgrupos se realiza mediante la prueba $\mathrm{H}$ de Kruskal-Wallis, cuyos resultados son los que se incluyen en las Tablas 5.4.51 y 5.4.52.

\begin{tabular}{|l|l|r|r|}
\hline \multicolumn{1}{|c|}{ Variable } & \multicolumn{1}{c|}{ Grupo } & N & Rango medio \\
\hline \multirow{4}{*}{ TR } & 4 cont. C.Ab. & 20 & 12,55 \\
\cline { 2 - 4 } & $>4$ cont. C.Ab. & 4 & 12,25 \\
\cline { 2 - 4 } & Total & 24 & \\
\hline
\end{tabular}

Tabla 5.4.51: Kruskal-Wallis. $\mathrm{N}^{\circ}$ de elementos y rango medio de TR en cada grupo de $\mathrm{n}^{\circ}$ de contenedores caja abierta y puntos limpios rurales.

\begin{tabular}{|l|r|}
\hline & \multicolumn{1}{|c|}{ TR } \\
\hline Chi-cuadrado & 0,01 \\
\hline df & 1 \\
\hline Sign. Asint. & 0,938 \\
\hline
\end{tabular}

Tabla 5.4.52: Resultados de significación del test de Kruskal-Wallis de TR respecto del $\mathrm{n}^{\circ}$ de contenedores caja abierta para puntos limpios rurales.

$\mathrm{Si}$ el punto limpio que cuenta con 5 contenedores se integra en el grupo mayoritario (4 contenedores), los resultados de la prueba $\mathrm{H}$ de Kruskal-Wallis, son los que se incluyen en las Tablas 5.4 .53 y 5.4 .54 .

\begin{tabular}{|c|l|r|r|}
\hline \multicolumn{1}{|c|}{ Variable } & \multicolumn{1}{|c|}{ Grupo } & N & Rango medio \\
\hline \multirow{4}{*}{ TR } & $4-5$ cont. C.Ab. & 21 & 12,05 \\
\cline { 2 - 4 } & > 5 cont. C.Ab. & 3 & 15,67 \\
\cline { 2 - 4 } & Total & 24 & \\
\hline
\end{tabular}

Tabla 5.4.53: Kruskal-Wallis. $N^{\circ}$ de elementos y rango medio de TR en cada grupo de $\mathrm{n}^{\circ}$ de contenedores caja abierta y puntos limpios rurales. 


\begin{tabular}{|l|r|}
\hline & \multicolumn{2}{|c|}{ TR } \\
\hline Chi-cuadrado & 0,69 \\
\hline df & 1 \\
\hline Sign. Asint. & 0,407 \\
\hline
\end{tabular}

Tabla 5.4.54: Resultados de significación del test de Kruskal-Wallis de TR respecto del $\mathrm{n}^{\circ}$ de contenedores caja abierta para puntos limpios rurales.

En el Gráfico 5.4.22 puede observarse que la distribución de TR de los puntos limpios con población adscrita inferior a 5.000 habitantes y 4 contenedores caja abierta es similar a la de los puntos limpios con 4 y 5 contenedores, mientras que los valores de TR de los puntos limpios con más de 5 contenedores es muy dispersa, con valores de TR de 77,20, 140,29 (entre los cuartiles primero y tercero del resto de la muestra) y 628,02 , siendo además este registro superior en un $50 \%$ al máximo del resto de los casos del grupo analizado.

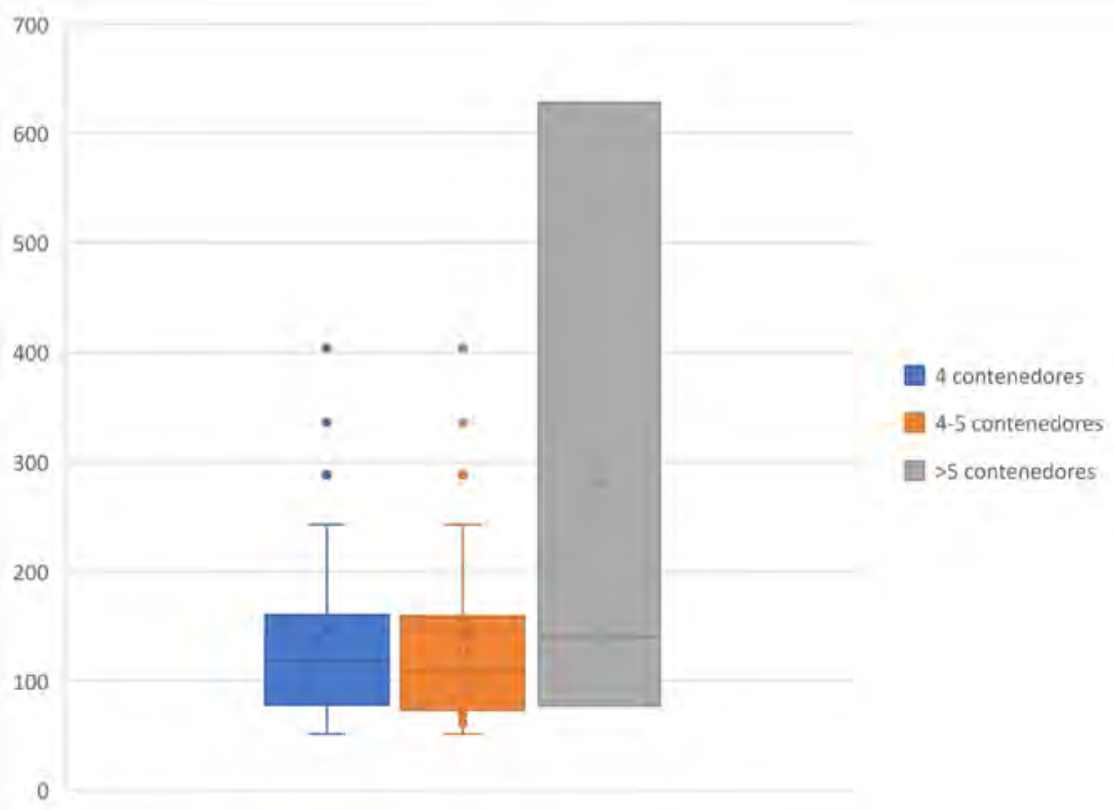

Gráfico 5.4.22: Distribución de TR en puntos limpios rurales frente a número de contenedores caja abierta.

Por tanto, se considera que el número adecuado de contenedores tipo caja abierta para este tipo de puntos limpios es de entre 4 y 5 unidades. 
Puntos limpios semiurbanos:

En este apartado se dispone de 35 casos. La distribución de puntos limpios en función del número de contenedores caja abierta, atendiendo al criterio de la Tabla 5.4.48, y los resultados de TR para cada subgrupo, son los que se observan en los Gráficos 5.4 .23 y 5.4 .24 , respectivamente. Los valores de media y desviación estándar de TR de cada grupo y la muestra total analizada se muestran en la Tabla 5.4.55.

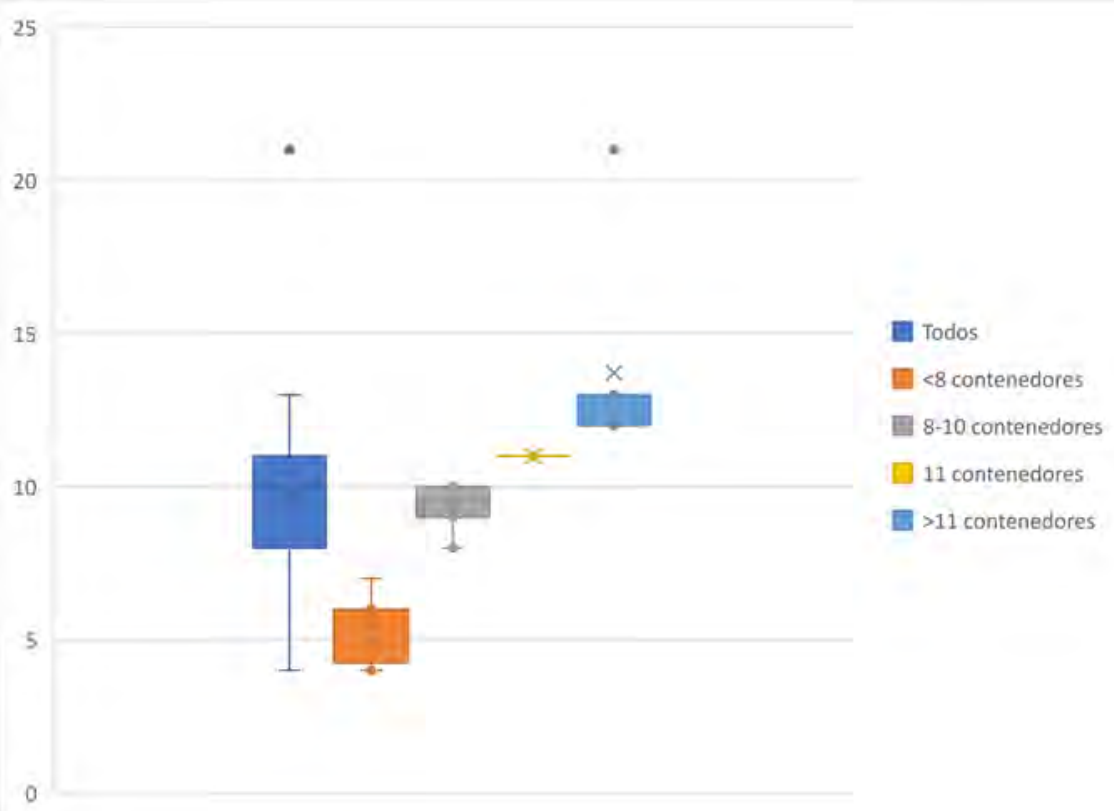

Gráfico 5.4.23: Número de contenedores caja abierta en puntos limpios semiurbanos. 


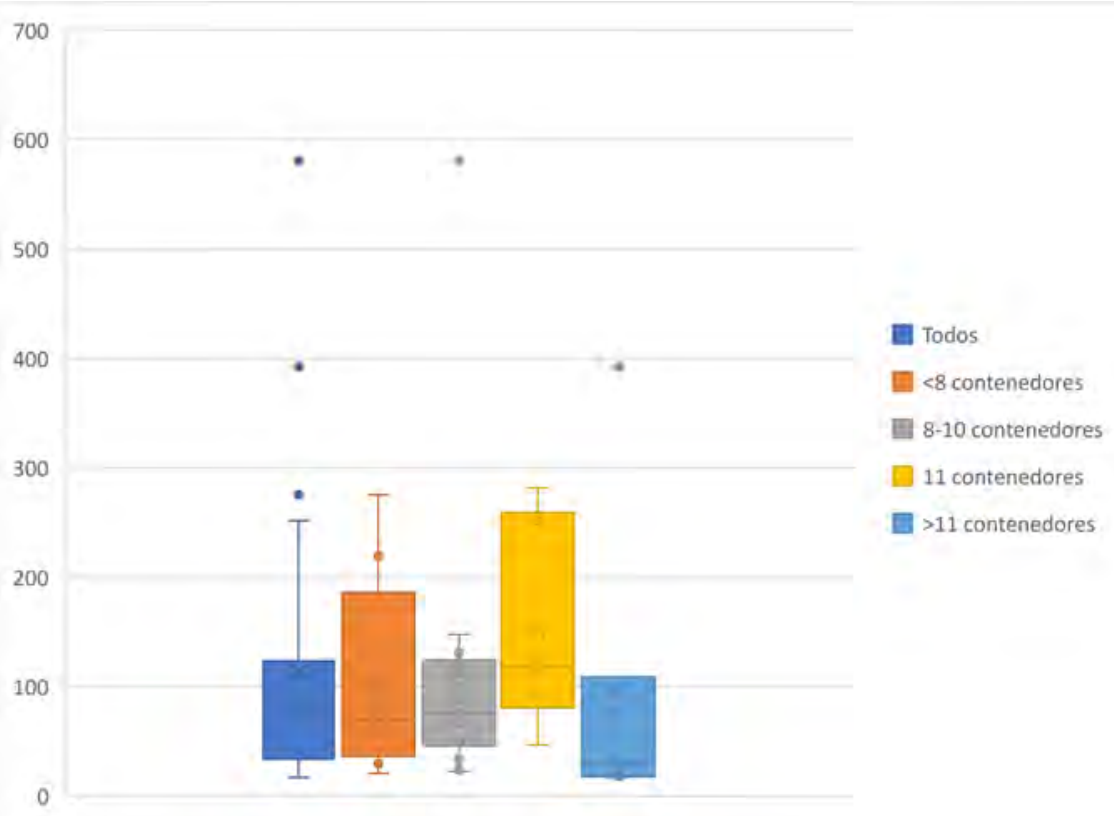

Gráfico 5.4.24: TR para grupos de $\mathrm{n}^{\circ}$ de contenedores caja abierta y puntos limpios semiurbanos.

\begin{tabular}{|c|c|c|c|c|c|c|c|c|c|}
\hline \multirow{2}{*}{\multicolumn{2}{|c|}{ Grupo }} & \multirow[t]{2}{*}{$\mathbf{N}$} & \multirow[t]{2}{*}{ Media } & \multirow{2}{*}{$\begin{array}{l}\text { Desviación } \\
\text { Estándar }\end{array}$} & \multirow{2}{*}{$\begin{array}{c}\text { Error } \\
\text { Estándar }\end{array}$} & \multicolumn{2}{|c|}{$\begin{array}{c}\text { Intervalo de } \\
\text { Confianza } 95 \% \text { para } \\
\text { la Media }\end{array}$} & \multirow[t]{2}{*}{ Mínimo } & \multirow[t]{2}{*}{ Máximo } \\
\hline & & & & & & $\begin{array}{l}\text { Límite } \\
\text { Inferior }\end{array}$ & $\begin{array}{l}\text { Límite } \\
\text { Superior }\end{array}$ & & \\
\hline \multirow{5}{*}{ TR } & $<8$ cont. C.Ab. & 8 & 103,64 & 92,59 & 32,73 & 26,24 & 181,05 & 20,70 & 275,38 \\
\hline & 8-10 cont. C.Ab. & 14 & 112,48 & 140,21 & 37,47 & 31,52 & 193,43 & 22,41 & 580,66 \\
\hline & 11 cont. C.Ab. & 6 & 151,35 & 93,62 & 38,22 & 53,10 & 249,59 & 46,58 & 281,66 \\
\hline & $>11$ cont. C.Ab. & 7 & 94,59 & 135,91 & 51,37 & $-31,10$ & 220,29 & 16,79 & 392,09 \\
\hline & Total & 35 & 113,54 & 119,08 & 20,13 & 72,64 & 154,45 & 16,79 & 580,66 \\
\hline
\end{tabular}

Tabla 5.4.55: Media, desviación estándar, error estándar e intervalo de confianza de TR para los grupos de $n^{\circ}$ de contenedores caja abierta para puntos limpios semiurbanos.

La comprobación de igualdad de los subgrupos se realiza mediante la prueba $\mathrm{H}$ de Kruskal-Wallis, cuyos resultados son los que se incluyen en las Tablas 5.4 .56 y 5.4 .57 .

\begin{tabular}{|c|l|r|r|}
\hline \multicolumn{1}{|c|}{ Variable } & \multicolumn{1}{|c|}{ Grupo } & N & \multicolumn{1}{c|}{ Rango medio } \\
\hline \multirow{4}{*}{ TR } & $<8$ cont. C.Ab. & 8 & 17,13 \\
\cline { 2 - 4 } & $8-10$ cont. C.Ab. & 14 & 18,14 \\
\cline { 2 - 5 } & 11 cont. C.Ab. & 6 & 24,67 \\
\cline { 2 - 5 } & $>11$ cont. C.Ab. & 7 & 13,00 \\
\cline { 2 - 5 } & Total & 35 & \\
\cline { 2 - 5 } & &
\end{tabular}

Tabla 5.4.56: Kruskal-Wallis. $\mathrm{N}^{\circ}$ de elementos y rango medio de TR en cada grupo de $\mathrm{n}^{\circ}$ de contenedores caja abierta y puntos limpios semiurbanos. 


\begin{tabular}{|l|r|}
\hline & \multicolumn{2}{|c|}{ TR } \\
\hline Chi-cuadrado & 4,27 \\
\hline df & 3 \\
\hline Sign. Asint. & 0,234 \\
\hline
\end{tabular}

Tabla 5.4.57: Resultados de significación del test de Kruskal-Wallis de TR respecto del $\mathrm{n}^{\circ}$ de contenedores caja abierta para puntos limpios semiurbanos.

Por tanto, no resulta significativo el número de contenedores sobre los resultados de TR de los puntos limpios semiurbanos. Por tanto, el incremento de dotación de contenedores, especialmente por encima de 11 unidades, no presenta los efectos deseados de incremento de TR.

En definitiva, se considera que el número adecuado de contenedores tipo caja abierta para los puntos limpios con población adscrita de entre 5.000 y 50.000 habitantes es de 4 a 11 unidades.

\section{Puntos limpios urbanos:}

Teniendo en cuenta el criterio de clasificación de la Tabla 5.4.48, la media y desviación estándar de TR de cada subgrupo en que se segregan los 22 casos disponibles son los que se incluyen en la Tabla 5.4.58. Por otro lado, en los Gráficos 5.4 .25 y 5.4 .26 se presentan las distribuciones correspondientes al número de contenedores caja abierta de cada subgrupo, así como de TR para dichos subgrupos.

\begin{tabular}{|c|c|c|c|c|c|c|c|c|c|}
\hline \multirow{2}{*}{\multicolumn{2}{|c|}{ Grupo }} & \multirow[t]{2}{*}{$\mathbf{N}$} & \multirow[t]{2}{*}{ Media } & \multirow{2}{*}{$\begin{array}{l}\text { Desviación } \\
\text { Estándar }\end{array}$} & \multirow{2}{*}{$\begin{array}{c}\text { Error } \\
\text { Estándar }\end{array}$} & \multicolumn{2}{|c|}{$\begin{array}{c}\text { Intervalo de } \\
\text { Confianza } 95 \% \text { para } \\
\text { la Media }\end{array}$} & \multirow[t]{2}{*}{ Mínimo } & \multirow[t]{2}{*}{ Máximo } \\
\hline & & & & & & $\begin{array}{l}\text { Límite } \\
\text { Inferior }\end{array}$ & $\begin{array}{l}\text { Límite } \\
\text { Superior }\end{array}$ & & \\
\hline \multirow{5}{*}{ TR } & $<7$ cont. C.Ab. & 5 & 76,13 & 26,71 & 11,94 & 42,96 & 109,29 & 60,98 & 123,72 \\
\hline & 7-10 cont. C.Ab. & 6 & 58,49 & 68,19 & 27,84 & $-13,07$ & 130,06 & 13,01 & 196,09 \\
\hline & 11-14 cont. C.Ab. & 6 & 93,36 & 124,49 & 50,82 & $-37,28$ & 224,00 & 8,42 & 337,77 \\
\hline & $>14$ cont. C.Ab. & 5 & 61,97 & 70,30 & 31,44 & $-25,32$ & 149,26 & 5,43 & 175,00 \\
\hline & Total & 22 & 72,80 & 78,00 & 16,63 & 38,22 & 107,38 & 5,43 & 337,77 \\
\hline
\end{tabular}

Tabla 5.4.58: Media, desviación estándar, error estándar e intervalo de confianza de TR para los grupos de $n^{\circ}$ de contenedores caja abierta para puntos limpios urbanos. 
Estudio de influencia de variables sobre los resultados de TR y TV de los puntos limpios.

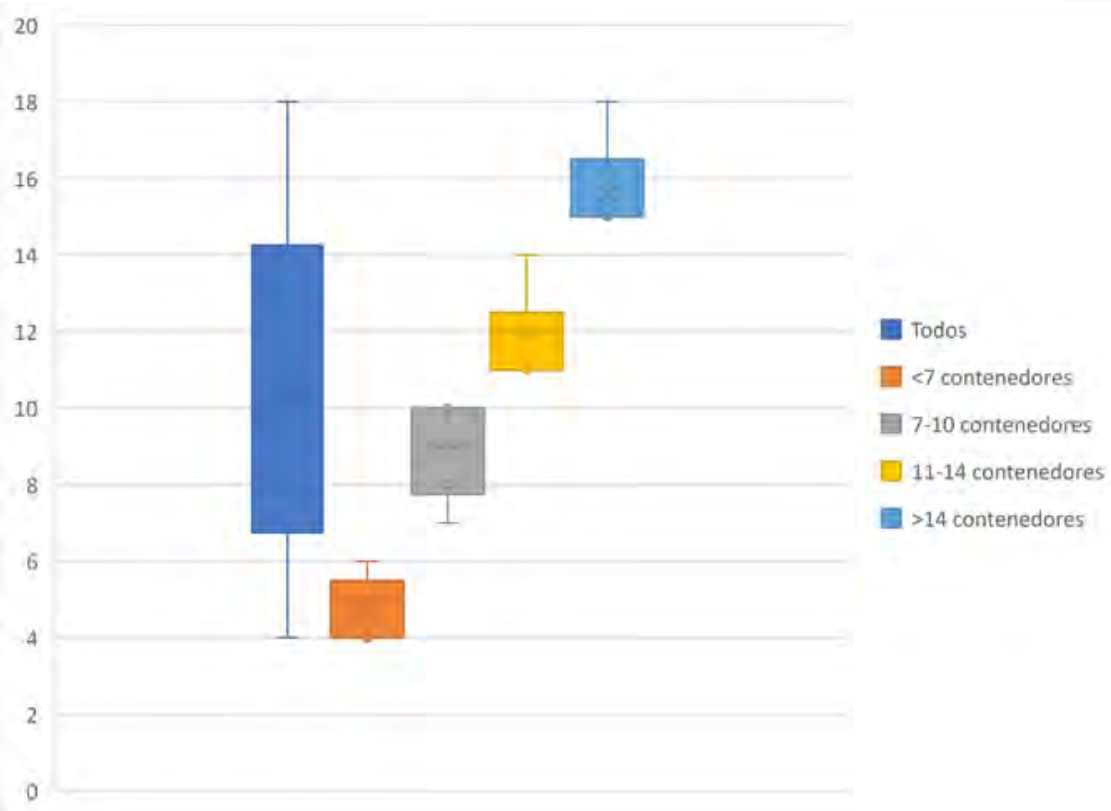

Gráfico 5.4.25: Número de contenedores caja abierta en puntos limpios urbanos.

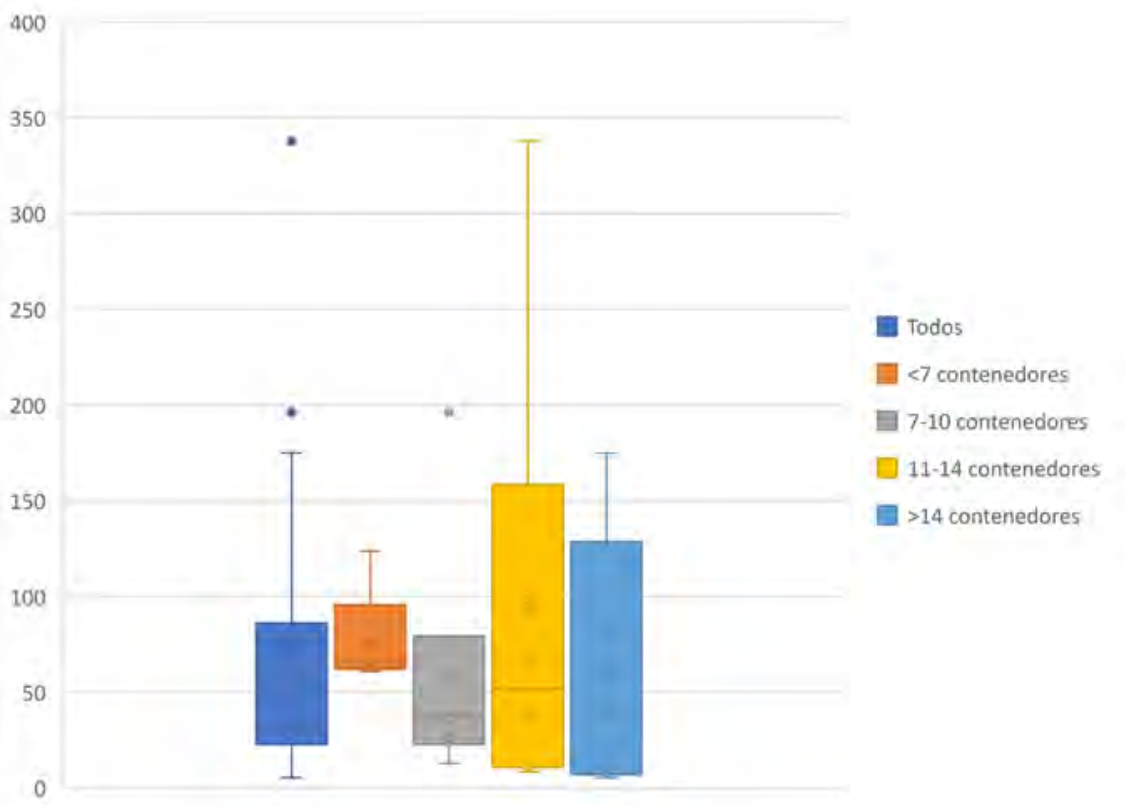

Gráfico 5.4.26: TR para grupos de $n^{\circ}$ de contenedores caja abierta y puntos limpios urbanos. 
La comprobación de igualdad de los subgrupos se realiza mediante la prueba $\mathrm{H}$ de Kruskal-Wallis, cuyos resultados son los que se incluyen en las Tablas 5.4 .59 y 5.4.60.

\begin{tabular}{|c|l|r|r|}
\hline \multicolumn{1}{|c|}{ Variable } & \multicolumn{1}{|c|}{ Grupo } & N & \multicolumn{1}{c|}{ Rango medio } \\
\hline \multirow{4}{*}{ TR } & $<7$ cont. C.Ab. & 5 & 14,80 \\
\cline { 2 - 4 } & $7-10$ cont. C.Ab. & 6 & 10,00 \\
\cline { 2 - 4 } & $11-14$ cont. C.Ab. & 6 & 11,50 \\
\cline { 2 - 4 } & $>14$ cont. C.Ab. & 5 & 10,00 \\
\cline { 2 - 4 } & Total & 22 & \\
\hline
\end{tabular}

Tabla 5.4.59: Kruskal-Wallis. $N^{\circ}$ de elementos y rango medio de TR en cada grupo de $\mathrm{n}^{\circ}$ de contenedores caja abierta y puntos limpios urbanos.

\begin{tabular}{|l|r|}
\hline & \multicolumn{2}{|c|}{ TR } \\
\hline Chi-cuadrado & 1,88 \\
\hline df & 3 \\
\hline Sign. Asint. & 0,598 \\
\hline
\end{tabular}

Tabla 5.4.60: Resultados de significación del test de Kruskal-Wallis de TR respecto del $n^{\circ}$ de contenedores caja abierta para puntos limpios urbanos.

Puesto que el valor de significación es superior a 0,05 , se valida la hipótesis de igualdad de grupos, por lo que el número de contenedores caja abierta no resulta estadísticamente significativo para los resultados de TR.

Como conclusión, para los puntos limpios con población adscrita superior a 50.000 habitantes, el incremento en dotación de contenedores por encima de 14 unidades no mejora los resultados de TR. En general, la variable no resulta significativa, aunque los valores de TR media máximos se consiguen con entre 11 y 14 contenedores tipo caja abierta.

\section{A5.4.8.2. Análisis de TV considerando factor de comparación el número de contenedores caja abierta.}

Todos los puntos limpios de los que se dispone de datos relativos a TV informan del número de contenedores tipo caja abierta con que cuenta la instalación, por lo que el número de casos a analizar es de 65. En el Gráfico 5.4.27 se muestran los valores de TV de los puntos limpios en función del número de contenedores caja abierta. 


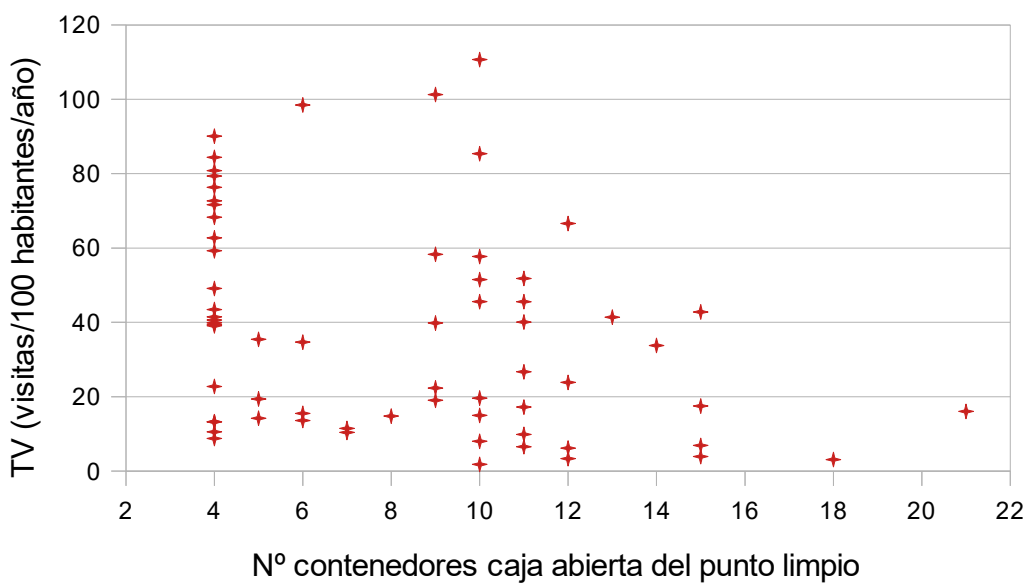

Gráfico 5.4.27: TV frente a número de contenedores caja abierta.

Se observa que los valores máximos de TV se registran en puntos limpios con entre 4 y 12 contenedores. No obstante, vista la influencia del factor demográfico (Gráfico 5.4.20), el estudio se realizará en función del tamaño de población adscrita y número de contenedores, agrupados según se indica en la Tabla 5.4.48.

\section{Puntos limpios rurales:}

Como sucedía con TR, los casos disponibles se dividen en puntos limpios con 4 contenedores e instalaciones con más unidades disponibles. Los valores de media y desviación estándar de TV para la muestra disponible, de 23 puntos limpios, y los 2 subgrupos en que se divide, en función del número de contenedores caja abierta, se incluyen en la Tabla 5.4.61.

\begin{tabular}{|c|c|c|c|c|c|c|c|c|c|}
\hline & \multirow[t]{2}{*}{ Grupo } & \multirow[t]{2}{*}{$\mathbf{N}$} & \multirow[t]{2}{*}{ Media } & \multirow{2}{*}{$\begin{array}{l}\text { Desviación } \\
\text { Estándar }\end{array}$} & \multirow{2}{*}{$\begin{array}{l}\text { Error } \\
\text { Estándar }\end{array}$} & \multicolumn{2}{|c|}{$\begin{array}{c}\text { Intervalo de } \\
\text { Confianza } 95 \% \\
\text { para la Media }\end{array}$} & \multirow[t]{2}{*}{ Mínimo } & \multirow[t]{2}{*}{ Máximo } \\
\hline & & & & & & $\begin{array}{l}\text { Límite } \\
\text { Inferior }\end{array}$ & $\begin{array}{c}\text { Límite } \\
\text { Superior }\end{array}$ & & \\
\hline \multirow{3}{*}{ TV } & 4 cont. C.Ab. & 19 & 56,33 & 22,45 & 5,15 & 45,50 & 67,15 & 8,77 & 90,09 \\
\hline & $>4$ cont. C.Ab. & 4 & 46,73 & 37,52 & 18,76 & $-12,97$ & 106,42 & 15,53 & 101,28 \\
\hline & Total & 23 & 54,66 & 24,86 & 5,18 & 43,90 & 65,41 & 8,77 & 101,28 \\
\hline
\end{tabular}

Tabla 5.4.61: Media, desviación estándar, error estándar e intervalo de confianza de TV para los grupos de $n^{\circ}$ de contenedores caja abierta para puntos limpios rurales. 
Los resultados del Test de Levene, de análisis de homogeneidad de varianzas, se incluyen en la Tabla 5.4.62.

\begin{tabular}{|c|r|r|r|r|}
\hline Variable & $\begin{array}{c}\text { Estadístico de } \\
\text { Levene }\end{array}$ & df1 & df2 & \multicolumn{1}{c|}{ Sign. } \\
\hline TV & 1,37 & 1 & 21 & 0,256 \\
\hline
\end{tabular}

Tabla 5.4.62: Resultados del test de Levene para TV y $n^{\circ}$ de contenedores caja abierta en puntos limpios rurales.

Se observa que el valor del estadístico es 1,37 , inferior a 4,325, valor que toma la $\mathrm{F}$ de Snedecor para $\alpha=0,05$, y grados de libertad 1 y 21 , mientras que el valor de significación es superior a 0,05, por lo que se valida la hipótesis de homogeneidad de varianzas.

En cuanto a la comparación de igualdad de los grupos, mediante el análisis de varianza de las medias, se realiza a continuación el test ANOVA, cuyos resultados se muestran en la Tabla 5.4.63.

\begin{tabular}{|c|c|c|c|c|c|c|}
\hline \multicolumn{2}{|c|}{ Factor } & $\begin{array}{c}\text { Suma de } \\
\text { Cuadrados }\end{array}$ & df & $\begin{array}{l}\text { Cuadrado } \\
\text { medio }\end{array}$ & $\mathbf{F}$ & Sign. \\
\hline \multirow{3}{*}{ TV } & Entre Grupos & 304,39 & 1 & 304,39 & 0,48 & 0,496 \\
\hline & Intra Grupos & $13.297,26$ & 2 & 633,20 & & \\
\hline & Total & $13.604,65$ & 21 & & & \\
\hline
\end{tabular}

Tabla 5.4.63: Resultados test ANOVA para TV y $n^{\circ}$ de contenedores caja abierta en puntos limpios rurales.

Puesto que el valor de significación es superior a 0,05 , se valida la hipótesis nula, por lo que el número de contenedores caja abierta disponibles no presenta significación sobre los resultados de TV. Por tanto, el incremento en el número de contenedores disponibles no incrementa los valores de TV.

Así, se considera que el número adecuado de contenedores tipo caja abierta para este tipo de puntos limpios es de 4 unidades.

\section{Puntos limpios semiurbanos:}

En los puntos limpios semiurbanos existe mayor variedad en cuanto al número de contenedores caja abierta instalados. El análisis gráfico de distribución de número de contenedores en los puntos limpios, en función de la clasificación definida en la Tabla 5.4.48, y los valores de TV para cada uno de los subgrupos en que se dividen los 23 puntos limpios disponibles, se muestran en 
los Gráficos 5.4 .28 y 5.4.29. En ellos se observa que ningún punto limpio dispone de menos de 4 contenedores, mientras que los puntos limpios con más de 11 contenedores cuentan con hasta 22 unidades.

En la Tabla 5.4.64 se muestran los valores de media y desviación estándar de TV para cada agrupación de puntos limpios, con resultados similares de media, no así de desviación estándar.

\begin{tabular}{|c|c|c|c|c|c|c|c|c|c|}
\hline & \multirow[t]{2}{*}{ Grupo } & \multirow[t]{2}{*}{$\mathbf{N}$} & \multirow[t]{2}{*}{ Media } & \multirow{2}{*}{$\begin{array}{c}\text { Desviación } \\
\text { Estándar }\end{array}$} & \multirow[t]{2}{*}{$\begin{array}{c}\text { Error } \\
\text { Estándar }\end{array}$} & \multicolumn{2}{|c|}{$\begin{array}{c}\text { Intervalo de } \\
\text { Confianza } 95 \% \\
\text { para la Media }\end{array}$} & \multirow[t]{2}{*}{ Mínimo } & \multirow[t]{2}{*}{ Máximo } \\
\hline & & & & & & $\begin{array}{l}\text { Límite } \\
\text { Inferior }\end{array}$ & $\begin{array}{c}\text { Límite } \\
\text { Superior }\end{array}$ & & \\
\hline \multirow{5}{*}{ TV } & $<8$ cont. C.Ab. & 3 & 41,77 & 49,10 & 28,35 & $-80,19$ & 163,73 & 13,27 & 98,46 \\
\hline & 8-10 cont. C.Ab. & 11 & 44,78 & 33,42 & 10,08 & 22,33 & 67,23 & 1,82 & 110,66 \\
\hline & 11 cont. C.Ab. & 5 & 36,78 & 14,11 & 6,31 & 18,75 & 53,78 & 17,22 & 51,80 \\
\hline & $>11$ cont. C.Ab. & 3 & 41,34 & 25,26 & 14,58 & $-21,41$ & 104,08 & 16,05 & 66,57 \\
\hline & Total & 22 & 41,97 & 29,53 & 6,30 & 28,87 & 55,06 & 1,82 & 110,66 \\
\hline
\end{tabular}

Tabla 5.4.64: Media, desviación estándar, error estándar e intervalo de confianza de TV para los grupos de $n^{\circ}$ de contenedores caja abierta para puntos limpios semiurbanos.

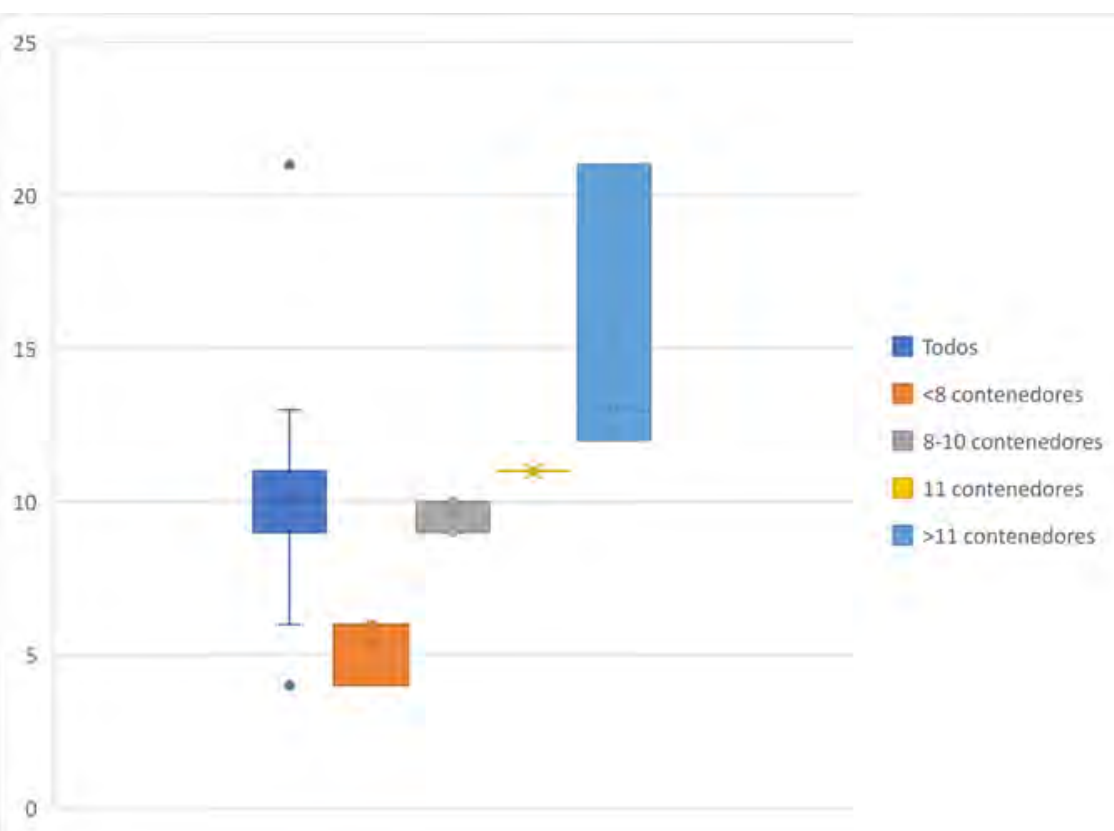

Gráfico 5.4.28: Número de contenedores caja abierta en puntos limpios semiurbanos. 


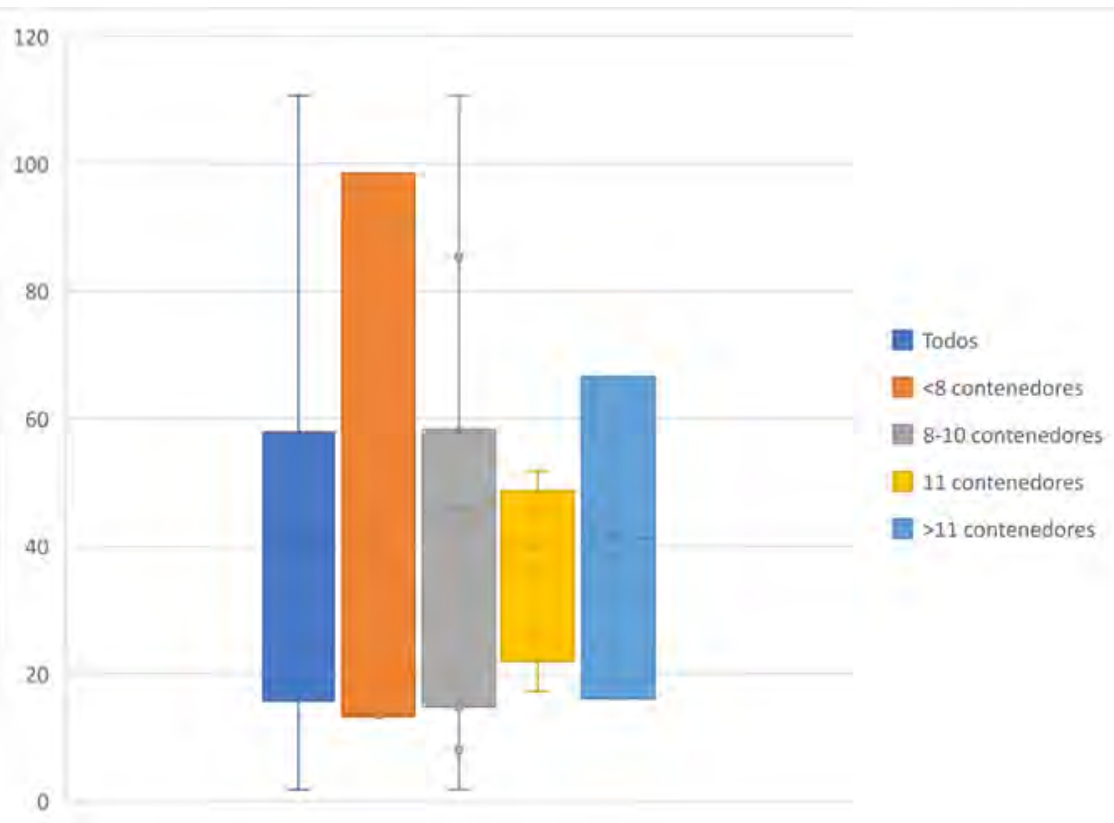

Gráfico 5.4.29: TV para grupos de $\mathrm{n}^{\circ}$ de contenedores caja abierta y puntos limpios semiurbanos.

La hipótesis de homogeneidad de varianzas se valida mediante aplicación del Test de Levene, cuyos resultados se incluyen en la Tabla 5.4.65.

\begin{tabular}{|r|r|r|r|r|}
\hline Variable & $\begin{array}{c}\text { Estadístico de } \\
\text { Levene }\end{array}$ & df1 & df2 & \multicolumn{1}{c|}{ Sign. } \\
\hline TV & 1,77 & 3 & 18 & 0,188 \\
\hline
\end{tabular}

Tabla 5.4.65: Resultados del test de Levene para TV y $\mathrm{n}^{\circ}$ de contenedores caja abierta en puntos limpios semiurbanos.

El valor del estadístico de Levene es 1,77 , inferior a 3,160, valor que toma la $\mathrm{F}$ de Snedecor para $\alpha=0,05$, y grados de libertad 3 y 18, mientas que el valor de significación es superior a 0,05, por lo que se cumple el supuesto de homocedasticidad.

A continuación se aplica el test ANOVA, de análisis de varianza de las medias, para comprobar si se cumple la hipótesis nula de igualdad de grupos. Los resultados se muestran en la Tabla 5.4.66. 


\begin{tabular}{|c|c|c|c|c|c|c|}
\hline \multicolumn{2}{|c|}{ Factor } & $\begin{array}{c}\text { Suma de } \\
\text { Cuadrados }\end{array}$ & df & $\begin{array}{l}\text { Cuadrado } \\
\text { medio }\end{array}$ & $\mathbf{F}$ & Sign. \\
\hline \multirow{3}{*}{ TV } & Entre Grupos & 250,81 & 3 & 83,60 & 0,08 & 0,968 \\
\hline & Intra Grupos & $18.062,04$ & 18 & $1.003,45$ & & \\
\hline & Total & $18.312,84$ & 21 & & & \\
\hline
\end{tabular}

Tabla 5.4.66: Resultados test ANOVA para TV y $n^{\circ}$ de contenedores caja abierta en puntos limpios semiurbanos.

Se observa que el valor de significación es muy superior a 0,05, error de la hipótesis nula, por lo ésta se considera válida y, por tanto, los grupos son iguales.

Así, el número de contenedores tipo caja abierta disponibles en el punto limpio no presenta significación estadística sobre los resultados de TV. No obstante, se observa que la media de TV es mayor en los puntos limpios con entre 8 y 10 contenedores caja abierta, presentando resultados muy parecidos entre sí los puntos limpios de la muestra con menos de 8 contenedores de este tipo, y los que cuentan con más de 11 unidades.

\section{Puntos limpios urbanos:}

A continuación se analiza la significación del número de contenedores caja abierta sobre TV. Para este análisis se dispone de datos de 20 puntos limpios. En los Gráficos 5.4 .30 y 5.4 .31 se muestra la variedad de dotación elegida y los valores de TV obtenidos, mediante la agrupación de las instalaciones atendiendo a los criterios de la Tabla 5.4.48. 


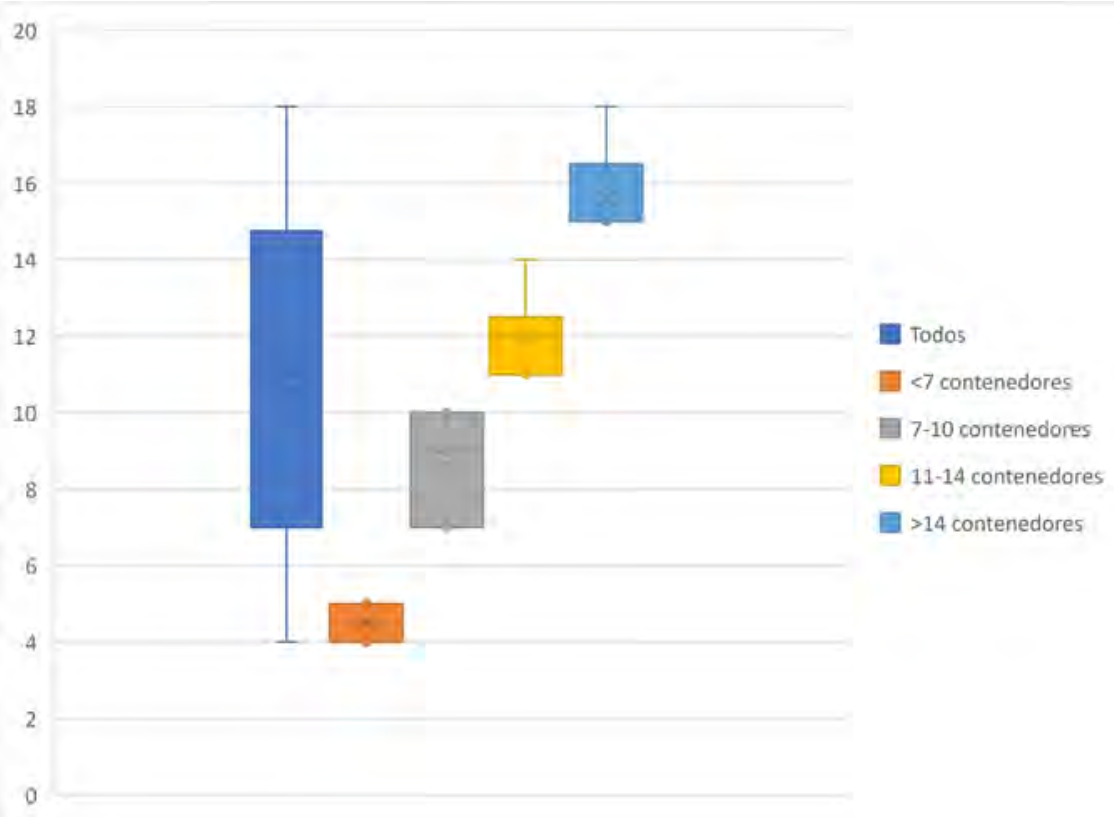

Gráfico 5.4.30: Número de contenedores caja abierta en puntos limpios urbanos.

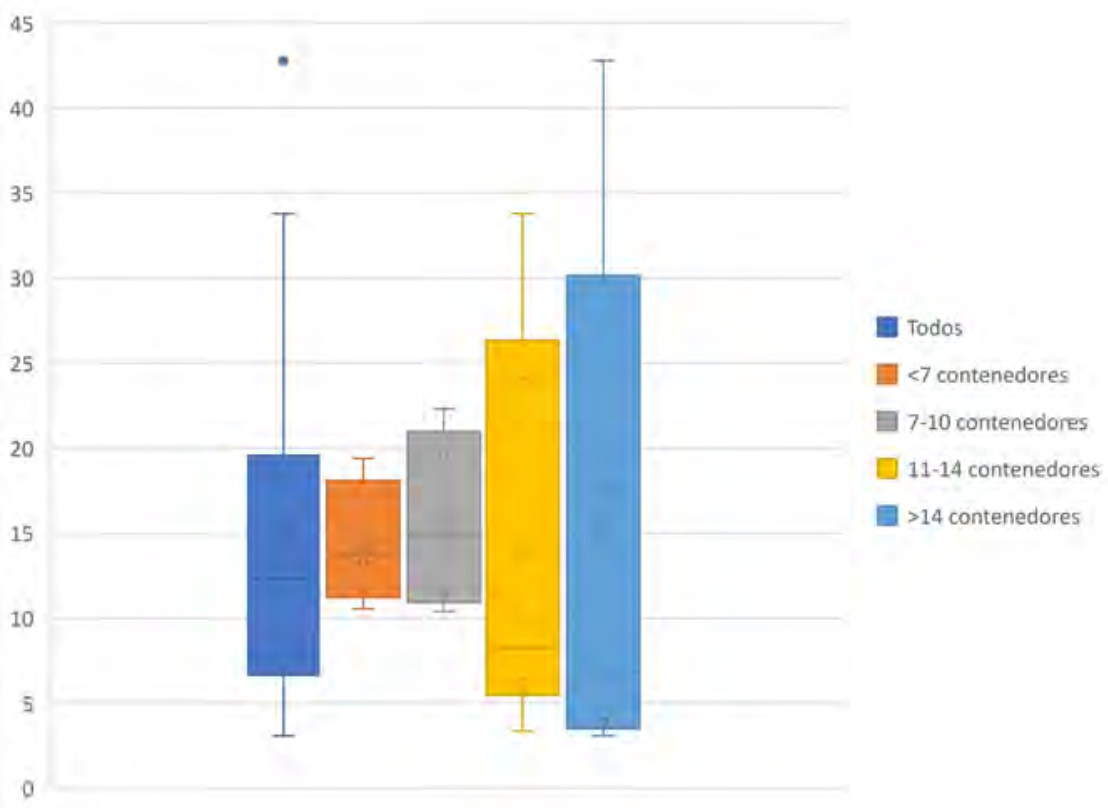

Gráfico 5.4.31: TV para grupos de $\mathrm{n}^{\circ}$ de contenedores caja abierta y puntos limpios urbanos.

En la Tabla 5.4.67 se muestran los valores de media y desviación estándar de TV para cada agrupación de puntos limpios, con resultados similares de media, aunque máximos para 
instalaciones con entre 7 y 10 contenedores caja abierta, y desviación estándar creciente a medida que aumenta la dotación de unidades disponibles.

\begin{tabular}{|c|c|c|c|c|c|c|c|c|c|}
\hline \multirow{2}{*}{\multicolumn{2}{|c|}{ Grupo }} & \multirow[t]{2}{*}{$\mathbf{N}$} & \multirow[t]{2}{*}{ Media } & \multirow{2}{*}{$\begin{array}{c}\text { Desviación } \\
\text { Estándar }\end{array}$} & \multirow{2}{*}{$\begin{array}{c}\text { Error } \\
\text { Estándar }\end{array}$} & \multicolumn{2}{|c|}{$\begin{array}{c}\text { Intervalo de } \\
\text { Confianza } 95 \% \\
\text { para la Media }\end{array}$} & \multirow[t]{2}{*}{ Mínimo } & \multirow[t]{2}{*}{ Máximo } \\
\hline & & & & & & $\begin{array}{l}\text { Límite } \\
\text { Inferior }\end{array}$ & $\begin{array}{c}\text { Límite } \\
\text { Superior }\end{array}$ & & \\
\hline \multirow{5}{*}{ TV } & $<7$ cont. C.Ab. & 4 & 14,34 & 3,71 & 1,85 & 8,44 & 20,24 & 10,54 & 19,39 \\
\hline & 7-10 cont. C.Ab. & 5 & 15,75 & 5,14 & 2,30 & 9,37 & 22,14 & 10,39 & 22,31 \\
\hline & 11-14 cont. C.Ab. & 6 & 13,93 & 12,13 & 4,95 & 1,21 & 26,66 & 3,35 & 33,78 \\
\hline & >14 cont. C.Ab. & 5 & 14,83 & 16,66 & 7,45 & $-5,85$ & 35,51 & 3,08 & 42,79 \\
\hline & Total & 20 & 14,69 & 10,26 & 2,30 & 9,39 & 19,50 & 3,08 & 42,79 \\
\hline
\end{tabular}

Tabla 5.4.67: Media, desviación estándar, error estándar e intervalo de confianza de TV para los grupos de $n^{\circ}$ de contenedores caja abierta para puntos limpios urbanos.

A continuación se aplica el test de Levene, para comprobar la validez de la hipótesis de homogeneidad de varianzas. Los resultados se incluyen en la Tabla 5.4.68.

\begin{tabular}{|l|r|r|r|r|}
\hline Variable & $\begin{array}{c}\text { Estadístico de } \\
\text { Levene }\end{array}$ & df1 & df2 & \multicolumn{1}{c|}{ Sign. } \\
\hline TV & 3,00 & 3 & 16 & 0,062 \\
\hline
\end{tabular}

Tabla 5.4.68: Resultados del test de Levene para TV y $n^{\circ}$ de contenedores caja abierta en puntos limpios urbanos.

El valor del estadístico de Levene es 3,00 , inferior a 3,239, valor que toma la $\mathrm{F}$ de Snedecor para $\alpha=0,05$, y grados de libertad 3 y 16 , mientas que el valor de significación es superior a 0,05 , por lo que se valida la hipótesis de homocedasticidad.

Los resultados del test ANOVA, para la validación de la hipótesis nula de igualdad de grupos, se muestran en la Tabla 5.4.69.

\begin{tabular}{|c|c|c|c|c|c|c|}
\hline \multicolumn{2}{|c|}{ Factor } & $\begin{array}{c}\text { Suma de } \\
\text { Cuadrados }\end{array}$ & df & $\begin{array}{l}\text { Cuadrado } \\
\text { medio }\end{array}$ & $\mathbf{F}$ & Sign. \\
\hline \multirow{3}{*}{ TV } & Entre Grupos & 9,72 & 3 & 3,24 & 0,03 & 0,994 \\
\hline & Intra Grupos & $1.991,80$ & 16 & 124,49 & & \\
\hline & Total & $2.001,52$ & 19 & & & \\
\hline
\end{tabular}

Tabla 5.4.69: Resultados test ANOVA para TV y $\mathrm{n}^{\circ}$ de contenedores caja abierta en puntos limpios urbanos.

Al obtenerse un resultado de significación superior a 0,05 , se concluye que los grupos son iguales. 
Por tanto, los grupos de número de contenedores caja abierta pueden considerarse iguales, por lo que esta variable no presenta significación estadística sobre los resultados de TV. No obstante, se observa que la media de TV es superior en los puntos limpios con entre 7 y 10 contenedores de caja abierta.

Finalmente, puede concluirse que el número de contenedores caja abierta no presenta significación estadística sobre los resultados de TR y TV, por lo que la mayor inversión en equipamiento y espacio disponible para su instalación no incrementa los resultados de gestión de los puntos limpios. Para cada rango de población adscrita, puede definirse que el número de contenedores caja abierta óptimos es de entre 4 y 5 para los puntos limpios rurales, hasta 11 en los semiurbanos y entre 7 y 14 en los urbanos.

\section{A5.4.9. Superficie del punto limpio.}

La superficie necesaria para la instalación del punto limpio será uno de los factores que condicione en mayor medida la determinación de la localización final, en función de la disponibilidad de suelo con que cuente la Administración competente; además, se encuentra íntimamente ligada al diseño y distribución interior, así como al equipamiento con que se dotará la instalación, por lo que constituye uno de los parámetros básicos de partida para el proyecto de un punto limpio. La superficie adopta múltiples valores, con un total de 55 instalaciones de la muestra, de las 85 que informan de la superficie disponible, que se presentan como casos únicos, tal y como se observa en el Gráfico 5.4.32, por lo que se hará necesario establecer un criterio de agrupación que permita realizar un análisis comparativo del funcionamiento de los puntos limpios en función de este parámetro que resulte eficaz. Por otra parte, puesto que las variables que se están analizando, TR y TV, están definidas como ratios por habitante, a igualdad de valores para distintas instalaciones, en la medida en que la población adscrita sea superior, mayor cantidad de residuos se gestionarán y mayor número de visitas recibirá el punto limpio y, por tanto, las necesidades de almacenamiento y de ordenación de los flujos internos de circulación, áreas de parada y estacionamiento, etc, serán asimismo superiores, por lo que parece claro que las agrupaciones para la comparación deban realizarse atendiendo a criterios demográficos. En el Gráfico 5.4 .33 se observa que la superficie ocupada por los puntos limpios de la muestra evoluciona de forma creciente con la población adscrita, con un importante salto cuantitativo entre los puntos limpios de menos de 5.000 habitantes y de entre 5.000 y 50.000 habitantes. 


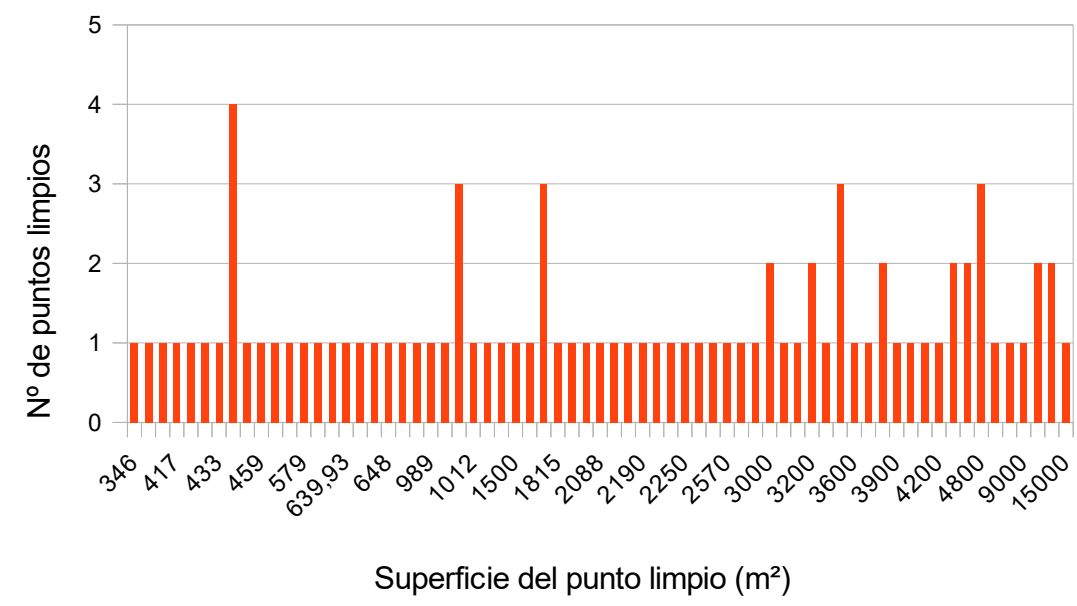

Gráfico 5.4.32: Número de puntos limpios por superficie ocupada.

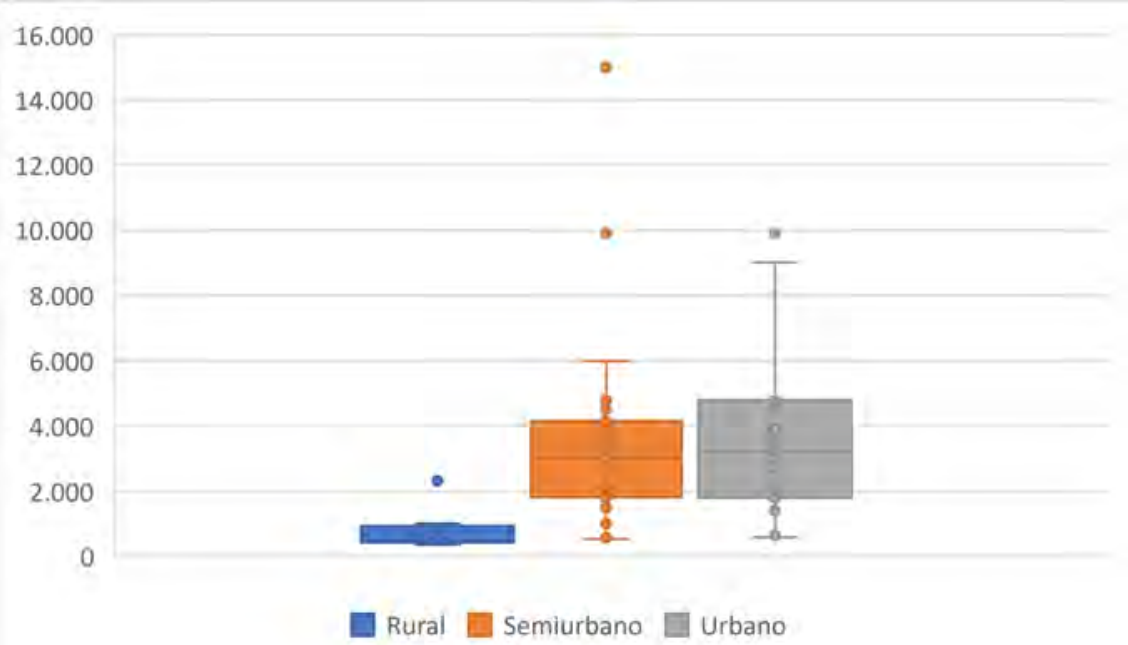

Gráfico 5.4.33: Superficie ocupada por el punto limpio frente a tamaño de población adscrita.

Teniendo en cuenta la superficie media disponible en cada uno de los grupos de puntos limpios, y los valores de los cuartiles primero y tercero de las representaciones del Gráfico 5.4 .34 se establecen los límites de cada uno de los grupos de subdivisión en cada caso, que se resumen en la Tabla 5.4.70. 


\begin{tabular}{|l|c|c|c|c|}
\hline \multicolumn{1}{|c|}{ Tamaño } & Grupo 1 & Grupo 2 & Grupo 3 & Grupo 4 \\
\hline Rural & $<450 \mathrm{~m}^{2}$ & $450 \mathrm{~m}^{2} \leq \mathrm{x} \leq 750 \mathrm{~m}^{2}$ & $750 \mathrm{~m}^{2}<\mathrm{x} \leq 900 \mathrm{~m}^{2}$ & $>900 \mathrm{~m}^{2}$ \\
\hline Semiurbano & $<1.800 \mathrm{~m}^{2}$ & $1.800 \mathrm{~m}^{2} \leq \mathrm{x} \leq 3.000 \mathrm{~m}^{2}$ & $3.000 \mathrm{~m}^{2}<\mathrm{x} \leq 4.100 \mathrm{~m}^{2}$ & $>4.100 \mathrm{~m}^{2}$ \\
\hline Urbano & $<1.800 \mathrm{~m}^{2}$ & $1.800 \mathrm{~m}^{2} \leq \mathrm{x} \leq 3.200 \mathrm{~m}^{2}$ & $3.200 \mathrm{~m}^{2}<\mathrm{x} \leq 4.500 \mathrm{~m}^{2}$ & $>4.500 \mathrm{~m}^{2}$ \\
\hline
\end{tabular}

Tabla 5.4.70: Clasificación de puntos limpios por superficie y tamaño de población adscrita.

\section{A5.4.9.1. Análisis de TR considerando factor de comparación la superficie del punto limpio.}

Para este estudio se dispone de información de 81 casos (no aportan datos los puntos limpios de Tudela, Mancomunidad de Sasieta y Tarragona). En el Gráfico 5.4 .34 se representan los valores que adopta TR para cada valor de superficie de punto limpio. Se observa que la mayoría de puntos limpios cuentan con entre 350 y $4.000 \mathrm{~m}^{2}$. Sin embargo, el comportamiento de TR no es lineal respecto de la superficie ocupada por la instalación. Por otro lado, se observa que únicamente 2 de los puntos limpios con superficie superior a $4.000 \mathrm{~m}^{2}$ presentan valores de TR superiores a $100 \mathrm{~kg} / \mathrm{habitante} / \mathrm{año}$.

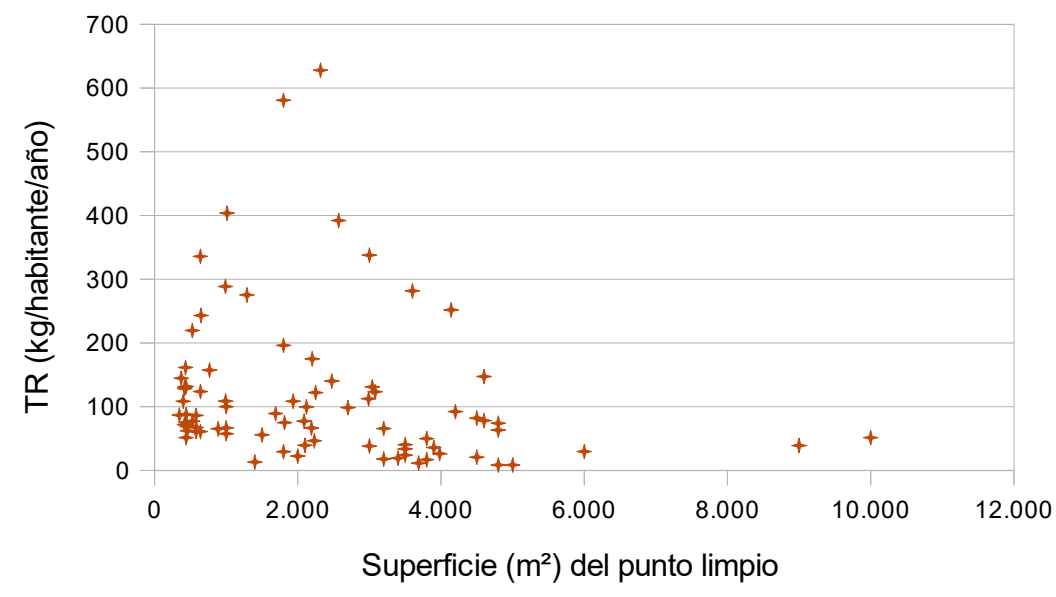

Gráfico 5.4.34: TR frente a superficie del punto limpio.

A continuación se realiza el estudio de significación de la variable superficie del punto limpio sobre $T R$, teniendo en cuenta que la muestra se va a dividir, en primer lugar, teniendo en cuenta el criterio de población adscrita y, a continuación, la variable superficie, atendiendo a los criterios de la Tabla 5.4.70. 


\section{Puntos limpios rurales:}

Existen 23 puntos limpios con población adscrita inferior a 5.000 habitantes que informan sobre la superficie de la instalación. La clasificación indicada en la Tabla 5.4 .70 se simplifica, puesto que sólo uno de los puntos limpios de la muestra se sitúa en el rango de superficies del grupo 3 (entre 750 y $900 \mathrm{~m}^{2}$ ), tal y como se observa en la Tabla 5.4.71, por lo que se realiza una reagrupación para los puntos limpios con superficie de entre 450 y $900 \mathrm{~m}^{2}$.

\begin{tabular}{|c|c|c|c|c|}
\hline & $<450 \mathrm{~m}^{2}$ & $450 \mathrm{~m}^{2} \leq x \leq 750 \mathrm{~m}^{2}$ & $750 \mathrm{~m}^{2}<x \leq 900 \mathrm{~m}^{2}$ & $>900 \mathrm{~m}^{2}$ \\
\hline $\mathrm{N}^{\circ}$ puntos limpios & 11 & 6 & 1 & 6 \\
\hline
\end{tabular}

Tabla 5.4.71: Cantidad de puntos limpios rurales por superficie.

En los Gráficos 5.4 .35 y 5.4 .36 se muestran, respectivamente, las distribuciones de superficie de los puntos limpios y de TR de cada uno de los grupos resultantes. En ellos se observa que la superficie de los puntos limpios más pequeños es de entre 350 y $450 \mathrm{~m}^{2}$; entre 450 y $900 \mathrm{~m}^{2}$, la distribución de superficie es bastante regular, mientras que por encima de $900 \mathrm{~m}^{2}$ hay mucha dispersión, con puntos limpios de hasta $2.500 \mathrm{~m}^{2}$. Los valores de TR también presentan cierta dispersión, mayor cuanto mayor es el rango de superficie del grupo. Los valores de media y desviación estándar de TR de cada grupo de puntos limpios se incluyen en la Tabla 5.4.72, en la que se observa que ambas son mayores para el grupo de puntos limpios con mayor superficie.

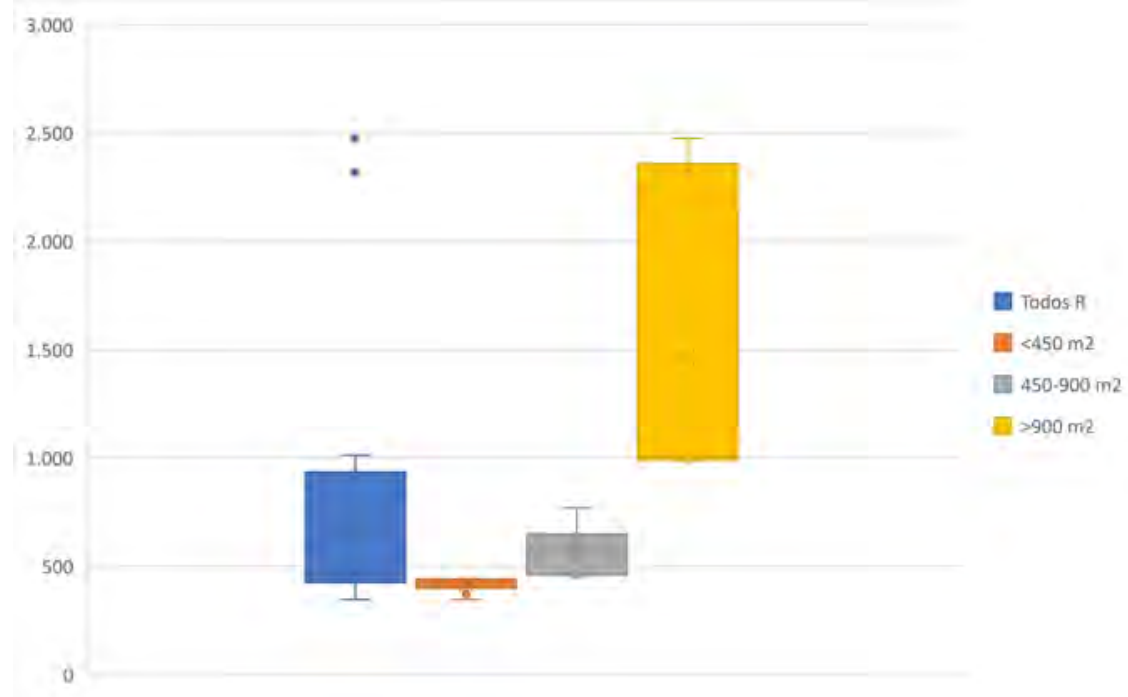

Gráfico 5.4.35: Superficie de punto limpio en puntos limpios rurales. 


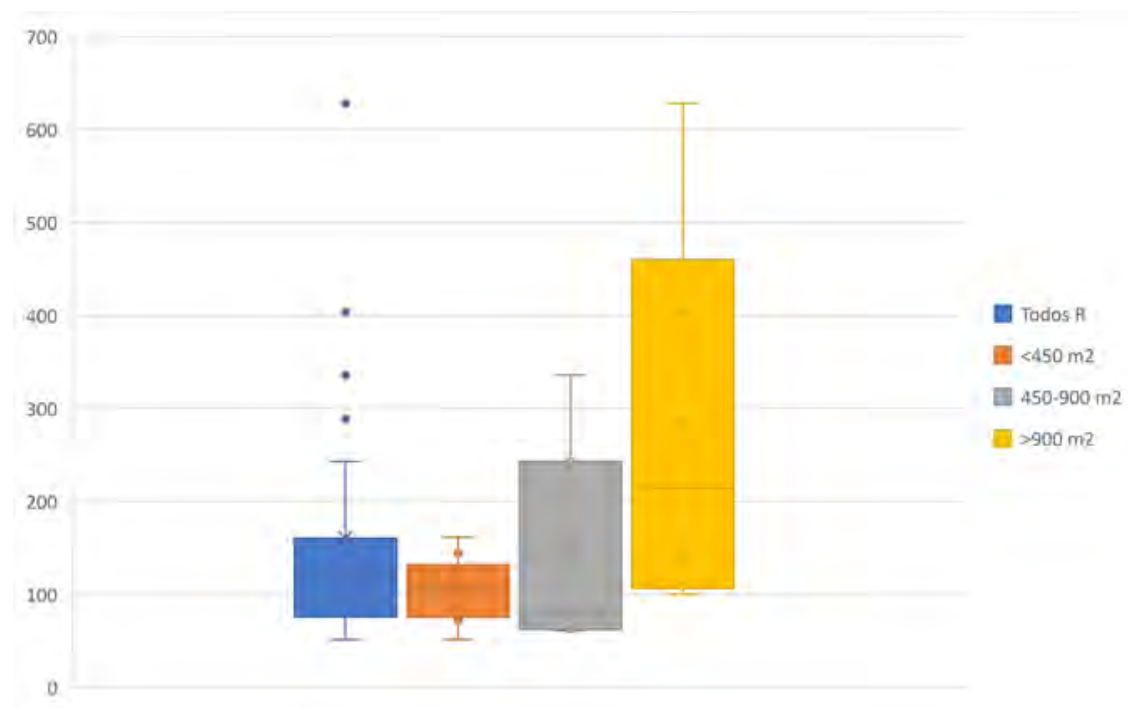

Gráfico 5.4.36: TR para grupos de superficie ocupada y puntos limpios rurales.

\begin{tabular}{|c|c|c|c|c|c|c|c|c|c|}
\hline \multirow{2}{*}{\multicolumn{2}{|c|}{ Grupo }} & \multirow[t]{2}{*}{$\mathbf{N}$} & \multirow[t]{2}{*}{ Media } & \multirow{2}{*}{$\begin{array}{l}\text { Desviación } \\
\text { Estándar }\end{array}$} & \multirow{2}{*}{$\begin{array}{c}\text { Error } \\
\text { Estándar }\end{array}$} & \multicolumn{2}{|c|}{$\begin{array}{c}\text { Intervalo de } \\
\text { Confianza } 95 \% \\
\text { para la Media }\end{array}$} & \multirow[t]{2}{*}{ Mínimo } & \multirow[t]{2}{*}{ Máximo } \\
\hline & & & & & & $\begin{array}{l}\text { Límite } \\
\text { Inferior }\end{array}$ & $\begin{array}{c}\text { Límite } \\
\text { Superior }\end{array}$ & & \\
\hline \multirow{4}{*}{ TR } & $<450 \mathrm{~m}^{2}$ & 11 & 107,16 & 34,78 & 10,49 & 83,79 & 130,53 & 51,35 & 161,34 \\
\hline & $450-900 \mathrm{~m}^{2}$ & 7 & 143,64 & 40,98 & 40,98 & 43,38 & 243,91 & 60,98 & 335,88 \\
\hline & $>900 \mathrm{~m}^{2}$ & 6 & 278,20 & 85,19 & 85,19 & 59,22 & 497,19 & 99,93 & 628,02 \\
\hline & Total & 24 & 160,56 & 134,61 & 27,48 & 103,72 & 217,40 & 51,35 & 628,02 \\
\hline
\end{tabular}

Tabla 5.4.72: Media, desviación estándar, error estándar e intervalo de confianza de TR para los grupos de superficie para puntos limpios rurales.

Para comprobar la validez de la hipótesis nula de igualdad entre grupos se realiza la prueba $\mathrm{H}$ de Kruskal-Wallis, cuyos resultados se muestran en las Tablas 5.4.73 y 5.4.74.

\begin{tabular}{|l|l|r|r|}
\hline \multicolumn{1}{|c|}{ Variable } & \multicolumn{1}{|c|}{ Grupo } & N & \multicolumn{1}{c|}{ Rango medio } \\
\hline \multirow{4}{*}{ TR } & $<450 \mathrm{~m}^{2}$ & 11 & 10,73 \\
\cline { 2 - 4 } & $450-900 \mathrm{~m}^{2}$ & 7 & 10,86 \\
\cline { 2 - 4 } & $>900 \mathrm{~m}^{2}$ & 6 & 17,67 \\
\cline { 2 - 4 } & Total & & \\
\hline
\end{tabular}

Tabla 5.4.73: Kruskal-Wallis. $N^{\circ}$ de elementos y rango medio de TR en cada grupo de superficie de puntos limpios rurales. 


\begin{tabular}{|l|r|}
\hline & \multicolumn{2}{|c|}{ TR } \\
\hline Chi-cuadrado & 4,27 \\
\hline df & 2 \\
\hline Sign. Asint. & 0,118 \\
\hline
\end{tabular}

Tabla 5.4.74: Resultados de significación del test de Kruskal-Wallis de TR respecto de la superficie para puntos limpios rurales.

Se observa que el valor de la prueba es superior a 0,05, por lo que se acepta la hipótesis nula de igualdad entre grupos y, por tanto, la mayor superficie disponible no mejora los resultados de TR del punto limpio. Por otro lado, del análisis de los casos se observa que únicamente 3 puntos limpios disponen de superficie superior a $1.000 \mathrm{~m}^{2}$, con una gran dispersión de valores de TR (de 140 a 628). En cuanto a los puntos limpios de menor tamaño, únicamente en 3 de los 11 puntos limpios de este grupo la superficie es inferior a $400 \mathrm{~m}^{2}$, siendo en 4 de ellos de $440 \mathrm{~m}^{2}$. Por otro lado, pese a que la media de TR de la muestra es de 160, únicamente uno de estos puntos limpios presenta valores de TR superiores a la media. Por lo que puede concluirse que la superficie más adecuada para estos puntos limpios es de $450 \mathrm{~m}^{2}$ ó más.

\section{Puntos limpios semiurbanos:}

En la muestra existen 36 puntos limpios semiurbanos que informan sobre la variable superficie. En la Tabla 5.4.75 se incluyen los valores de media y desviación estándar de TR de cada grupo de puntos limpios en que éstos se clasifican, atendiendo el criterio establecido en la Tabla 5.4.70.

En los Gráficos 5.4 .37 y 5.4 .38 se muestran, respectivamente, las distribuciones superficie y TR de cada grupo de puntos limpios. Se observa que la media de TR disminuye para los puntos limpios con mayor superficie disponible, obteniéndose los valores máximos de TR en el grupo de puntos limpios de entre 1.800 y $3.000 \mathrm{~m}^{2}$. Por otro lado, existe un punto limpio cuya superficie se desmarca el resto, con un valor de $10.000 \mathrm{~m}^{2}$. 


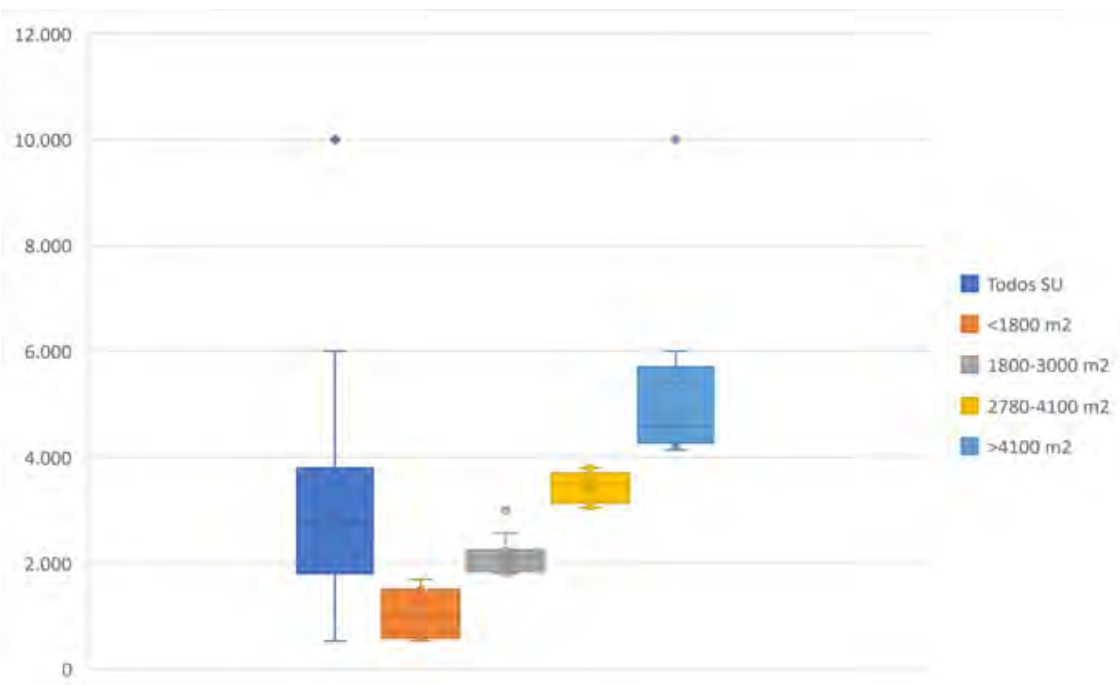

Gráfico 5.4.37: Superficie de punto limpio en puntos limpios semiurbanos.

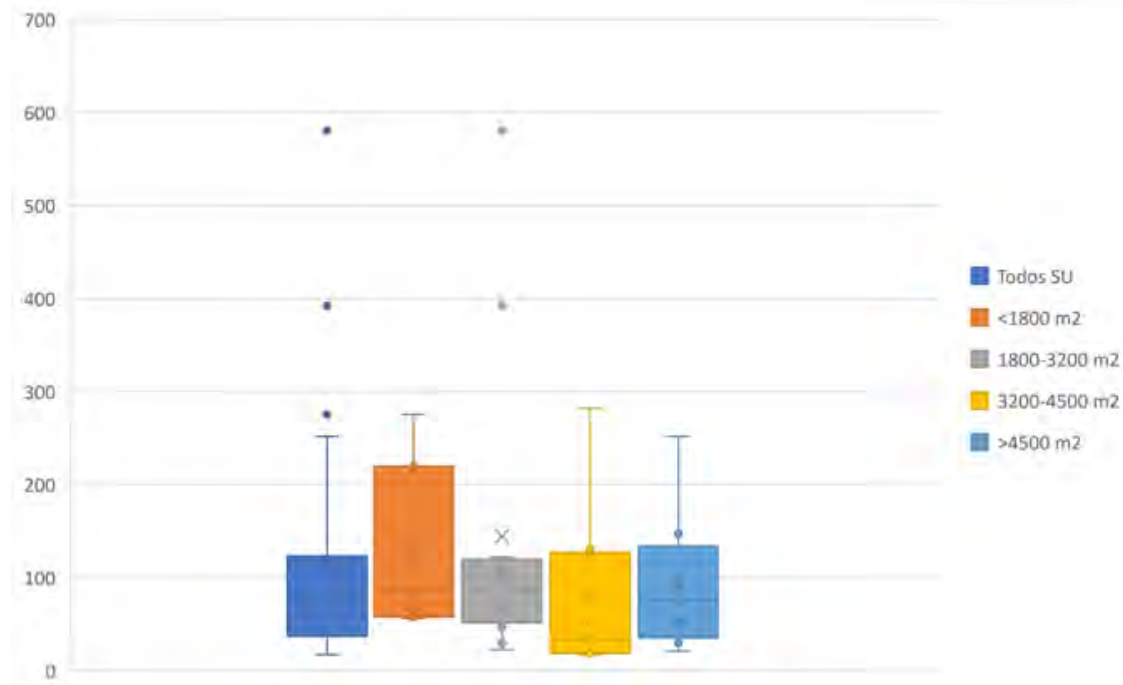

Gráfico 5.4.38: TR para grupos de superficie ocupada y puntos limpios semiurbanos.

\begin{tabular}{|c|c|c|c|c|c|c|c|c|c|}
\hline \multirow{2}{*}{\multicolumn{2}{|c|}{ Grupo }} & \multirow[t]{2}{*}{$\mathbf{N}$} & \multirow[t]{2}{*}{ Media } & \multirow{2}{*}{$\begin{array}{l}\text { Desviación } \\
\text { Estándar }\end{array}$} & \multirow{2}{*}{$\begin{array}{c}\text { Error } \\
\text { Estándar }\end{array}$} & \multicolumn{2}{|c|}{$\begin{array}{c}\text { Intervalo de } \\
\text { Confianza } 95 \% \\
\text { para la Media }\end{array}$} & \multirow[t]{2}{*}{ Mínimo } & \multirow[t]{2}{*}{ Máximo } \\
\hline & & & & & & $\begin{array}{c}\text { Límite } \\
\text { Inferior }\end{array}$ & $\begin{array}{c}\text { Límite } \\
\text { Superior }\end{array}$ & & \\
\hline \multirow{5}{*}{ TR } & $<1.800 \mathrm{~m}^{2}$ & 7 & 121,48 & 88,48 & 33,44 & 39,65 & 203,31 & 55,88 & 275,38 \\
\hline & $1.800-3.000 \mathrm{~m}^{2}$ & 12 & 144,37 & 167,77 & 48,43 & 37,78 & 250,97 & 22,41 & 580,66 \\
\hline & $3.000-4.100 \mathrm{~m}^{2}$ & 9 & 77,50 & 88,61 & 29,54 & 9,38 & 145,61 & 16,79 & 281,66 \\
\hline & $>4.100 \mathrm{~m}^{2}$ & 8 & 93,14 & 75,33 & 26,63 & 30,16 & 156,11 & 20,70 & 251,74 \\
\hline & Total & 36 & 111,82 & 117,82 & 19,64 & 71,95 & 151,68 & 16,79 & 580,66 \\
\hline
\end{tabular}

Tabla 5.4.75: Media, desviación estándar, error estándar e intervalo de confianza de TR para los grupos de superficie para puntos limpios semiurbanos. 
La comprobación de la hipótesis de igualdad entre grupos se realiza mediante la prueba $\mathrm{H}$ de Kruskal-Wallis, cuyos resultados se muestran en las Tablas 5.4.76 y 5.4.77.

\begin{tabular}{|l|l|r|r|}
\hline \multicolumn{1}{|c|}{ Variable } & \multicolumn{1}{|c|}{ Grupo } & N & \multicolumn{1}{c|}{ Rango medio } \\
\hline \multirow{4}{*}{ TR } & $<1.800 \mathrm{~m}^{2}$ & 7 & 21,43 \\
\cline { 2 - 4 } & $1.800-3.000 \mathrm{~m}^{2}$ & 12 & 20,58 \\
\cline { 2 - 4 } & $3.000-4.100 \mathrm{~m}^{2}$ & 9 & 13,67 \\
\cline { 2 - 5 } & $>4.100 \mathrm{~m}^{2}$ & 8 & 18,25 \\
\cline { 2 - 5 } & Total & 36 & \\
\hline
\end{tabular}

Tabla 5.4.76: Kruskal-Wallis. $N^{\circ}$ de elementos y rango medio de TR en cada grupo de superficie de puntos limpios semiurbanos.

\begin{tabular}{|l|r|}
\hline & \multicolumn{2}{|c|}{ TR } \\
\hline Chi-cuadrado & 2,91 \\
\hline df & 3 \\
\hline Sign. Asint. & 0,406 \\
\hline
\end{tabular}

Tabla 5.4.77: Resultados de significación del test de Kruskal-Wallis de TR respecto de la superficie para puntos limpios semiurbanos.

Puesto que el valor de significación de la prueba es 0,406 , superior a 0,05 , se acepta la hipótesis nula de igualdad entre grupos, por lo que un aumento en la superficie disponible no incrementa los resultados de TR. Por otro lado, se observa que los valores de TR superiores a la media se obtienen en los puntos limpios con superficie inferior a $3.000 \mathrm{~m}^{2}$, por lo que puede establecerse como superficie máxima recomendable para estos puntos limpios $3.000 \mathrm{~m}^{2}$.

\section{Puntos limpios urbanos:}

En la muestra se cuenta con 21 puntos limpios con población adscrita superior a 50.000 habitantes y que proporcionan el dato de superficie de la instalación. En el Gráfico 5.4.39 puede observarse que la superficie del punto limpio más pequeño es de aproximadamente $600 \mathrm{~m}^{2}$, mientras que existe una instalación que dispone de hasta $9.000 \mathrm{~m}^{2}$, lo que hace que la dispersión de superficies del grupo de puntos limpios más grandes sea muy alta. Por otro lado, en el Gráfico 5.4.40 se observa que la media de TR es superior para el grupo de puntos limpios con superficie de entre 1.800 y $3.200 \mathrm{~m}^{2}$ que, por otro lado, incluye el punto limpio que registra el valor máximo 
Anexo A5.4.

de TR. Además, la dispersión de la variable es muy alta en este grupo. En la Tabla 5.4.78 puede observarse el detalle de media y desviación estándar de TR en cada uno de los grupos.

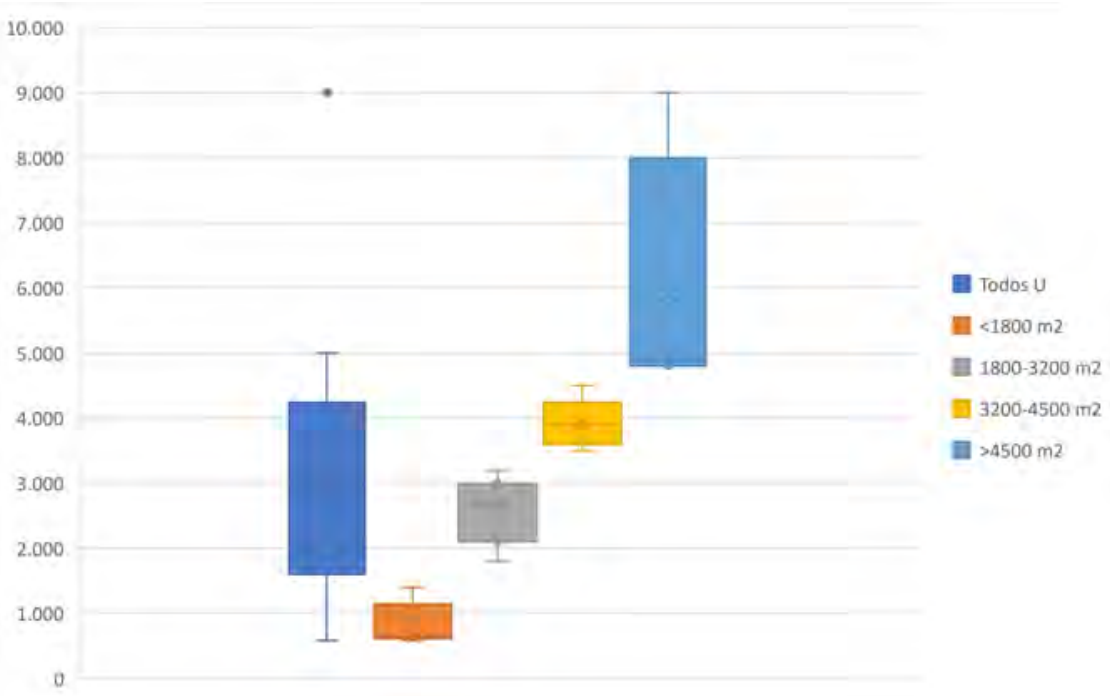

Gráfico 5.4.39: Superficie de punto limpio en puntos limpios urbanos.

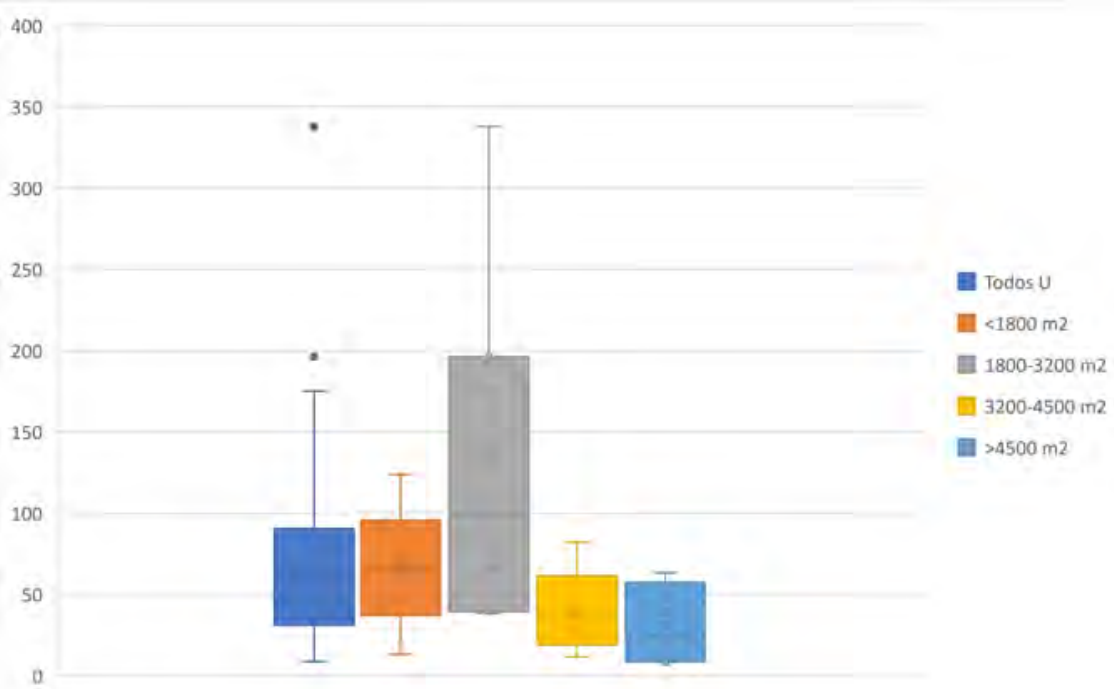

Gráfico 5.4.40: TR para grupos de superficie ocupada y puntos limpios urbanos. 
Estudio de influencia de variables sobre los resultados de TR y TV de los puntos limpios.

\begin{tabular}{|c|c|c|c|c|c|c|c|c|c|}
\hline \multirow{2}{*}{\multicolumn{2}{|c|}{ Grupo }} & \multirow[t]{2}{*}{$\mathbf{N}$} & \multirow[t]{2}{*}{ Media } & \multirow{2}{*}{$\begin{array}{l}\text { Desviación } \\
\text { Estándar }\end{array}$} & \multirow[t]{2}{*}{$\begin{array}{c}\text { Error } \\
\text { Estándar }\end{array}$} & \multicolumn{2}{|c|}{$\begin{array}{c}\text { Intervalo de } \\
\text { Confianza } 95 \% \\
\text { para la Media }\end{array}$} & \multirow[t]{2}{*}{ Mínimo } & \multirow[t]{2}{*}{ Máximo } \\
\hline & & & & & & $\begin{array}{l}\text { Límite } \\
\text { Inferior }\end{array}$ & $\begin{array}{c}\text { Límite } \\
\text { Superior }\end{array}$ & & \\
\hline \multirow{5}{*}{ TR } & $<1.800 \mathrm{~m}^{2}$ & 5 & 66,06 & 39,26 & 17,56 & 17,30 & 114,81 & 13,01 & 123,72 \\
\hline & $1.800-3.200 \mathrm{~m}^{2}$ & 7 & 135,83 & 108,83 & 41,13 & 35,17 & 236,48 & 38,27 & 337,77 \\
\hline & $3.200-4.500 \mathrm{~m}^{2}$ & 5 & 39,19 & 26,39 & 11,80 & 6,41 & 71,96 & 11,49 & 82,04 \\
\hline & $>4.500 \mathrm{~m}^{2}$ & 4 & 29,79 & 26,60 & 13,30 & $-12,53$ & 72,12 & 8,42 & 63,35 \\
\hline & Total & 21 & 76,01 & 78,42 & 17,11 & 40,31 & 111,71 & 8,42 & 337,77 \\
\hline
\end{tabular}

Tabla 5.4.78: Media, desviación estándar, error estándar e intervalo de confianza de TR para los grupos de superficie para puntos limpios urbanos.

La validación de la hipótesis de igualdad entre grupos se realiza mediante la prueba $\mathrm{H}$ de KruskalWallis. En las Tablas 5.4 .79 y 5.4 .80 se presentan los resultados, en los que se obtiene un valor de significación de 0,056, superior a 0,05, por lo que se acepta la hipótesis nula.

\begin{tabular}{|l|l|r|r|}
\hline \multicolumn{1}{|c|}{ Variable } & \multicolumn{1}{|c|}{ Grupo } & N & \multicolumn{1}{c|}{ Rango medio } \\
\hline \multirow{4}{*}{ TR } & $<1.800 \mathrm{~m}^{2}$ & 5 & 12,20 \\
\cline { 2 - 4 } & $1.800-3.200 \mathrm{~m}^{2}$ & 7 & 15,29 \\
\cline { 2 - 4 } & $3.200-4.500 \mathrm{~m}^{2}$ & 5 & 8,00 \\
\cline { 2 - 4 } & $>4.500 \mathrm{~m}^{2}$ & 4 & 5,75 \\
\cline { 2 - 4 } & Total & 21 & \\
\hline
\end{tabular}

Tabla 5.4.79: Kruskal-Wallis. $N^{\circ}$ de elementos y rango medio de TR en cada grupo de superficie de puntos limpios urbanos.

\begin{tabular}{|l|r|}
\hline & \multicolumn{2}{|c|}{ TR } \\
\hline Chi-cuadrado & 7,56 \\
\hline df & 3 \\
\hline Sign. Asint. & 0,056 \\
\hline
\end{tabular}

Tabla 5.4.80: Resultados de significación del test de Kruskal-Wallis de TR respecto de la superficie para puntos limpios urbanos.

Por tanto, la variable no presenta significación estadística respecto de la superficie de los puntos limpios de más de 50.00 habitantes. Por otro lado, se observa que los valores de TR superiores a la media únicamente se alcanzan en el grupo de puntos limpios con superficie de entre 1.800 y $3.200 \mathrm{~m}^{2}$, por lo que, unido a la no significación de la superficie sobre TR, permite concluir que estos puntos limpios disponen de una superficie adecuada para la población adscrita. 


\section{A5.4.9.2. Análisis de TV considerando factor de comparación la superficie del punto limpio.}

De los puntos limpios con valor de TV considerado apto para el análisis estadístico, existen 3 casos en que no se informa de la superficie de la instalación (Benidorm, Cornellà de Llobregat y Tarragona). En el Gráfico 5.4.41 se presentan los valores de TV de cada uno de ellos, en función de su superficie disponible. Se observa que ésta varía entre 350 y $10.000 \mathrm{~m}^{2}$, encontrándose la mayoría de ellos entre 350 y $4.000 \mathrm{~m}^{2}$. Para superficies superiores, únicamente 4 puntos limpios superan el valor de TV de 40 visitas/100 habitantes/año.

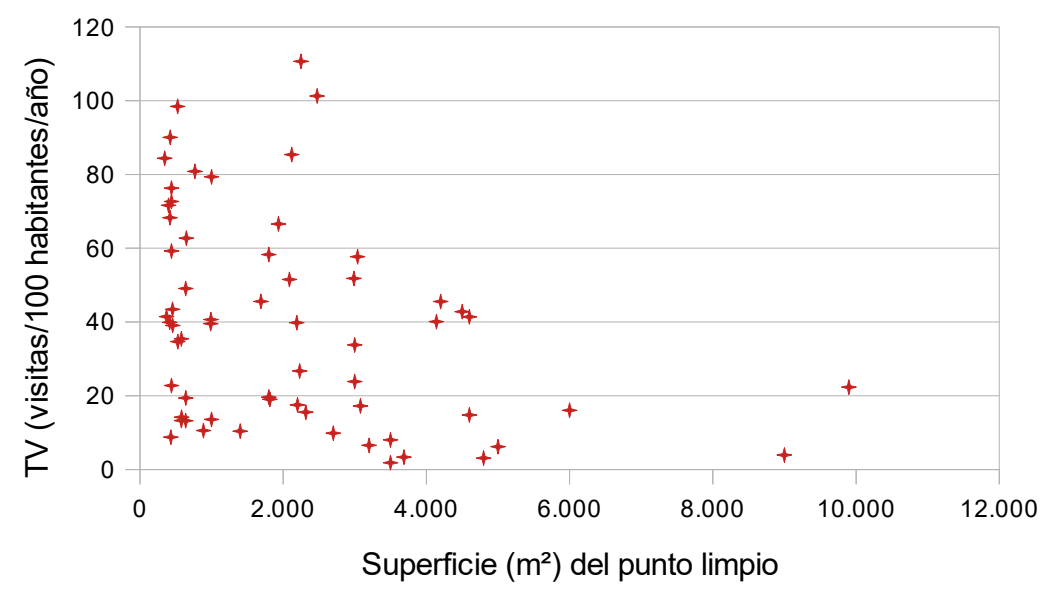

Gráfico 5.4.41: TV frente a superficie del punto limpio.

Como se ha indicado anteriormente, el análisis de significación de la variable superficie se va a realizar mediante la agrupación de puntos limpios, por rangos de superficie ocupada. Puesto que las necesidades de almacenamiento vienen condicionadas por la cantidad de residuos gestionada, y ésta se encuentra relacionada con la población adscrita, se realiza en primer lugar una segregación de la muestra atendiendo al criterio demográfico, y un segundo nivel de subdivisión en función de la superficie del punto limpio, de acuerdo con los parámetros de la Tabla 5.4.70. 
Puntos limpios rurales:

Se dispone de registros de superficie de 23 puntos limpios con población adscrita de hasta 5.000 habitantes. Estableciendo la agrupación de éstos siguiendo el mismo criterio que el llevado a cabo con TR, en los Gráficos 5.4 .42 y 5.4 .43 se muestran, respectivamente, las distribuciones de superficie de los puntos limpios y de TV de cada uno de los grupos resultantes. Se observa que la superficie de estos puntos limpios se encuentra entre 350 y $2.500 \mathrm{~m}^{2}$, lo que produce una gran dispersión en el grupo de puntos limpios más grandes. En cuanto a los valores de TV, en la Tabla 5.4.81 se observa que los valores de la media son similares en los tres grupos, mientras que el comportamiento de la desviación estándar es irregular.

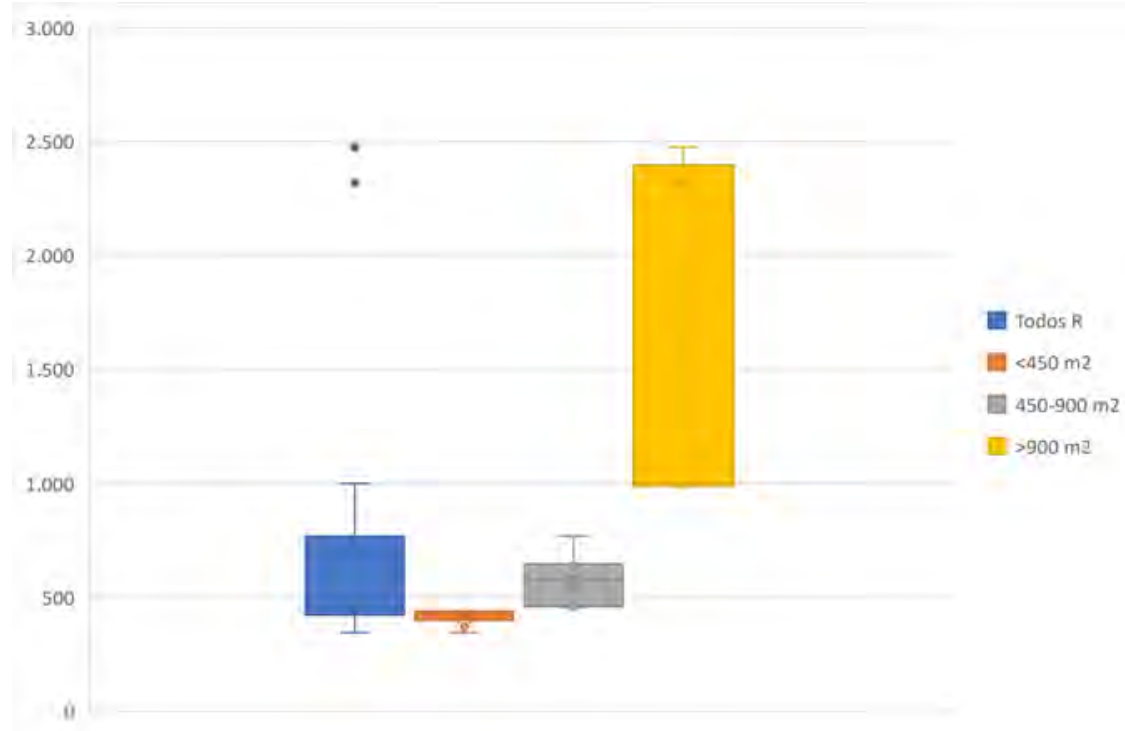

Gráfico 5.4.42: Superficie de punto limpio en puntos limpios rurales. 


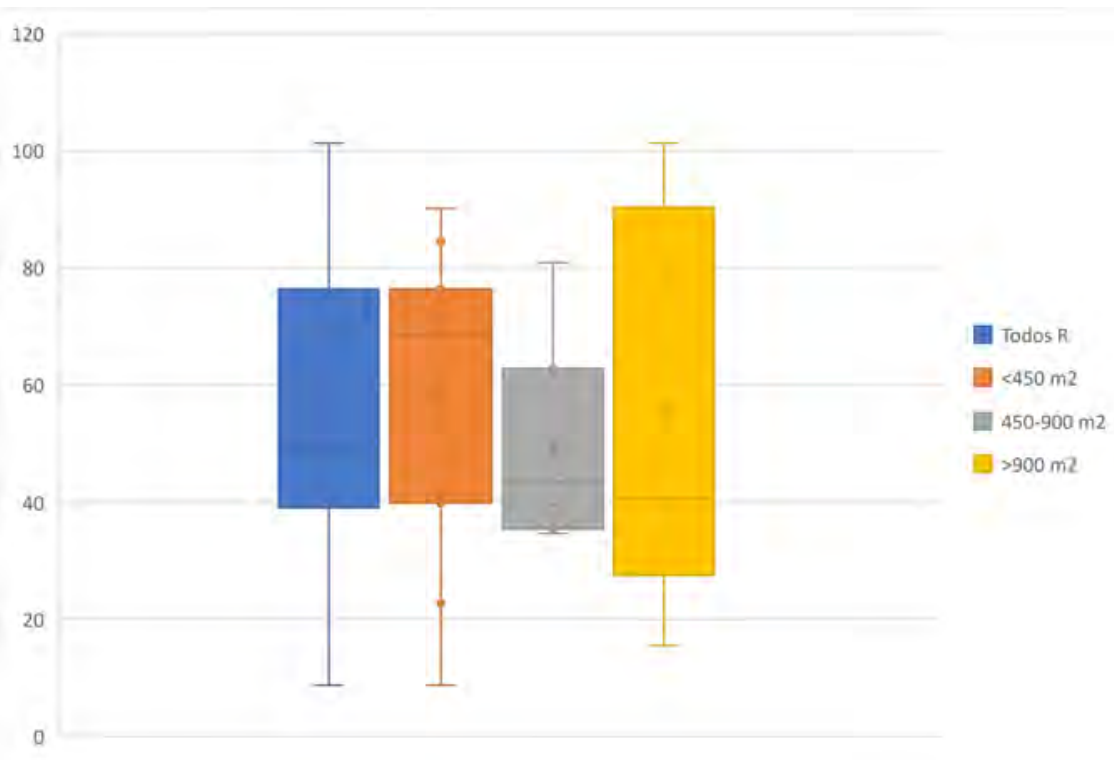

Gráfico 5.4.43: TV para grupos de superficie ocupada y puntos limpios rurales.

\begin{tabular}{|c|c|c|c|c|c|c|c|c|c|}
\hline \multirow{2}{*}{\multicolumn{2}{|c|}{ Grupo }} & \multirow[t]{2}{*}{$\mathbf{N}$} & \multirow[t]{2}{*}{ Media } & \multirow{2}{*}{$\begin{array}{l}\text { Desviación } \\
\text { Estándar }\end{array}$} & \multirow{2}{*}{$\begin{array}{c}\text { Error } \\
\text { Estándar }\end{array}$} & \multicolumn{2}{|c|}{$\begin{array}{c}\text { Intervalo de } \\
\text { Confianza } 95 \% \\
\text { para la Media }\end{array}$} & \multirow[t]{2}{*}{ Mínimo } & \multirow[t]{2}{*}{ Máximo } \\
\hline & & & & & & $\begin{array}{c}\text { Límite } \\
\text { Inferior }\end{array}$ & $\begin{array}{c}\text { Límite } \\
\text { Superior }\end{array}$ & & \\
\hline \multirow{4}{*}{ TV } & $<450 \mathrm{~m}^{2}$ & 11 & 57,77 & 26,15 & 7,88 & 40,21 & 75,34 & 8,77 & 90,09 \\
\hline & $450-900 \mathrm{~m}^{2}$ & 7 & 49,32 & 16,93 & 6,40 & 33,67 & 64,98 & 34,67 & 80,83 \\
\hline & $>900 \mathrm{~m}^{2}$ & 5 & 55,27 & 34,41 & 15,39 & 12,54 & 98,00 & 15,53 & 101,28 \\
\hline & Total & 23 & 54,66 & 24,86 & 5,18 & 43,90 & 65,41 & 8,77 & 101,28 \\
\hline
\end{tabular}

Tabla 5.4.81: Media, desviación estándar, error estándar e intervalo de confianza de TV para los grupos de superficie para puntos limpios rurales.

Para comprobar la hipótesis de igualdad de grupos, en primer lugar se realiza el test de Levene, que analiza la homogeneidad de varianzas entre grupos. Los resultados se incluyen en la Tabla 5.4.82.

\begin{tabular}{|c|r|r|r|r|}
\hline Variable & $\begin{array}{c}\text { Estadístico de } \\
\text { Levene }\end{array}$ & df1 & df2 & \multicolumn{1}{c|}{ Sign. } \\
\hline TV & 2,26 & 2 & 20 & 0,131 \\
\hline
\end{tabular}

Tabla 5.4.82: Resultados del test de Levene para TV y superficie en puntos limpios rurales.

El valor del estadístico de Levene es 2,26, inferior a 4,351, valor que toma la $\mathrm{F}$ de Snedecor para $\alpha=0,05$, y grados de libertad 1 y 20 , mientas que el valor de significación es superior a 0,05 , por lo que se acepta la hipótesis nula de homogeneidad de varianzas. 
A continuación se aplica el test ANOVA, cuyos resultados se muestran en la Tabla 5.4.83.

\begin{tabular}{|c|c|c|c|c|c|c|}
\hline \multicolumn{2}{|c|}{ Factor } & $\begin{array}{c}\text { Suma de } \\
\text { Cuadrados }\end{array}$ & df & $\begin{array}{l}\text { Cuadrado } \\
\text { medio }\end{array}$ & $\mathbf{F}$ & Sign. \\
\hline \multirow{3}{*}{ TV } & Entre Grupos & 307,94 & 2 & 153,97 & 0,23 & 0,795 \\
\hline & Intra Grupos & $13.293,71$ & 20 & 664,69 & & \\
\hline & Total & $13.601,65$ & 22 & & & \\
\hline
\end{tabular}

Tabla 5.4.83: Resultados test ANOVA para TV y superficie en puntos limpios rurales.

Puesto que el valor de significación de la prueba es 0,795 , superior al error de la hipótesis nula de igualdad de medias, ésta se acepta, concluyendo que las poblaciones son iguales.

Por tanto, la superficie del punto limpio no presenta significación estadística sobre los valores de TV. Pese a los resultados, se observa que la media de TV es superior en los puntos limpios con más de $900 \mathrm{~m}^{2}$ de superficie, aunque este hecho se debe al contar con el caso extremo superior de TV; descontado el efecto debido a dicho punto, 3 de los 4 puntos restantes presentan valores de TV en el rango del grupo con superficie de 450 a $900 \mathrm{~m}^{2}$, y el restante, con TV inferior. En este mismo grupo, únicamente 2 puntos limpios disponen de más de $1.000 \mathrm{~m}^{2}$, por lo que teniendo en cuenta que el grupo inmediatamente anterior cuenta con superficies de hasta $900 \mathrm{~m}^{2}$, se considera que este valor máximo es adecuado para este tipo de puntos limpios.

\section{Puntos limpios semiurbanos:}

La muestra contiene 22 puntos limpios cuya población adscrita se sitúa entre 5.000 y 50.000 habitantes y que informan de la superficie disponible. Teniendo en cuenta el criterio de segregación de éstos establecido en la Tabla 5.4.70, en la Tabla 5.4.84 se incluyen los valores de media y desviación estándar de cada uno de los grupos creados, en la que se observa que los puntos limpios con superficie de hasta $3.000 \mathrm{~m}^{2}$ presentan valores de TV superiores a la media total. Por otro lado, la desviación estándar disminuye a medida que aumenta la superficie disponible.

En los Gráficos 5.4 .44 y 5.4 .45 se muestran, respectivamente, las distribuciones de superficie de los puntos limpios y de TV de cada uno de los grupos resultantes. En el primero de ellos se observa que la superficie de estos puntos limpios se encuentra entre 500 y $6.000 \mathrm{~m}^{2}$, con únicamente 4 casos son superficie inferior a $1.000 \mathrm{~m}^{2}$, mientras que en el segundo se comprueba que los valores máximos de TV se obtienen para puntos limpios con entre 1.800 y $3.000 \mathrm{~m}^{2}$. 


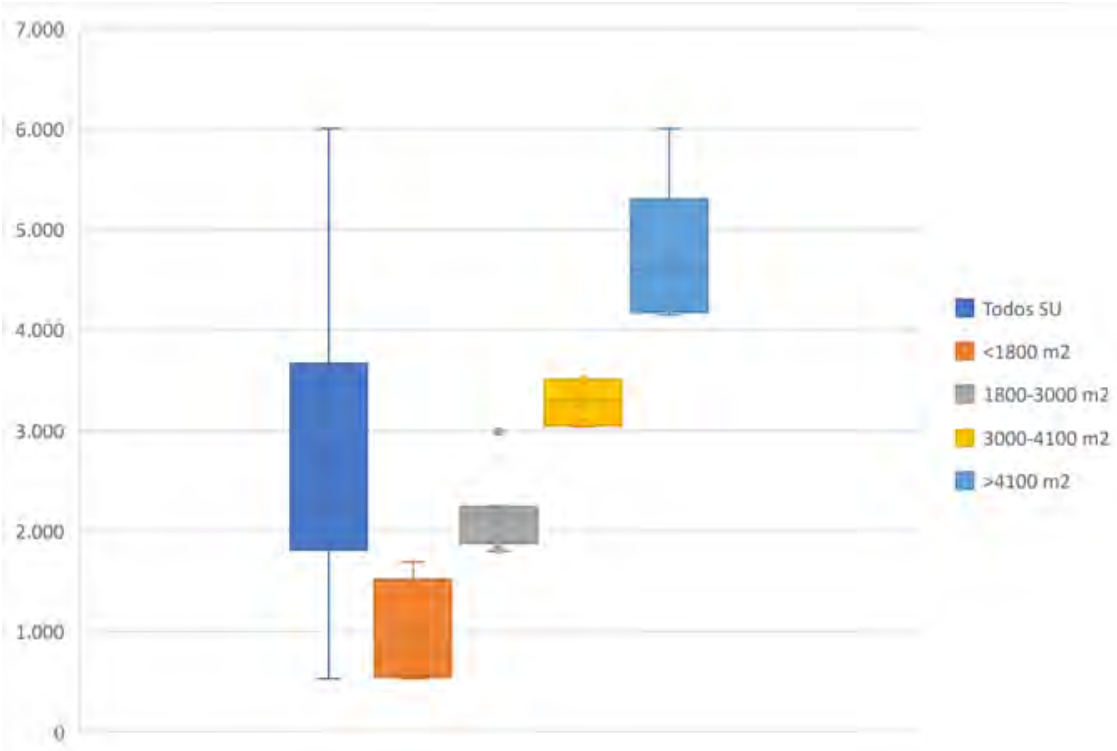

Gráfico 5.4.44: Superficie de punto limpio en puntos limpios semiurbanos.

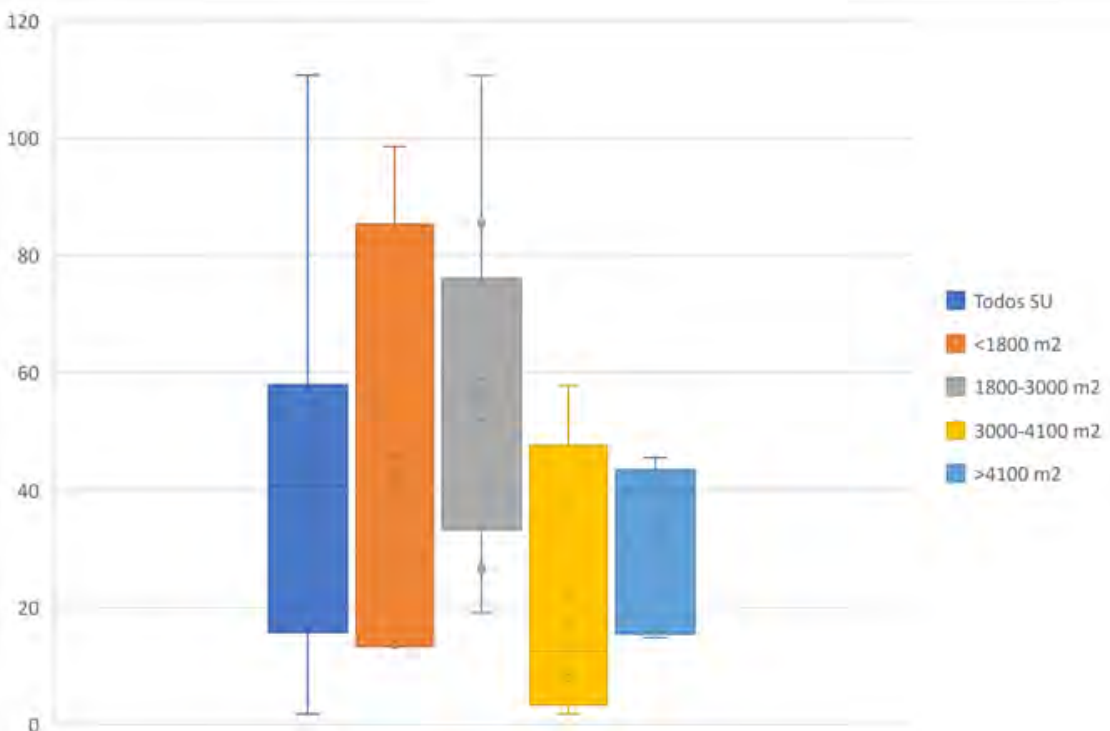

Gráfico 5.4.45: TV para grupos de superficie ocupada y puntos limpios semiurbanos. 
Estudio de influencia de variables sobre los resultados de TR y TV de los puntos limpios.

\begin{tabular}{|c|c|c|c|c|c|c|c|c|c|}
\hline \multirow{2}{*}{\multicolumn{2}{|c|}{ Grupo }} & \multirow[t]{2}{*}{$\mathbf{N}$} & \multirow[t]{2}{*}{ Media } & \multirow{2}{*}{$\begin{array}{l}\text { Desviación } \\
\text { Estándar }\end{array}$} & \multirow[t]{2}{*}{$\begin{array}{c}\text { Error } \\
\text { Estándar }\end{array}$} & \multicolumn{2}{|c|}{$\begin{array}{c}\text { Intervalo de } \\
\text { Confianza } 95 \% \\
\text { para la Media }\end{array}$} & \multirow[t]{2}{*}{ Mínimo } & \multirow[t]{2}{*}{ Máximo } \\
\hline & & & & & & $\begin{array}{l}\text { Límite } \\
\text { Inferior }\end{array}$ & $\begin{array}{c}\text { Límite } \\
\text { Superior }\end{array}$ & & \\
\hline \multirow{5}{*}{ TV } & $<1.800 \mathrm{~m}^{2}$ & 4 & 42,72 & 40,13 & 20,07 & $-21,14$ & 106,58 & 13,27 & 98,46 \\
\hline & $1.800-3.000 \mathrm{~m}^{2}$ & 9 & 56,64 & 28,48 & 9,49 & 34,75 & 78,53 & 19,05 & 110,66 \\
\hline & $3.000-4.100 \mathrm{~m}^{2}$ & 4 & 21,19 & 25,15 & 12,58 & $-18,84$ & 61,21 & 1,82 & 57,70 \\
\hline & $>4.100 \mathrm{~m}^{2}$ & 5 & 31,56 & 14,89 & 6,66 & 13,08 & 50,05 & 14,78 & 45,53 \\
\hline & Total & 22 & 41,96 & 29,53 & 6,30 & 28,87 & 55,06 & 1,82 & 110,66 \\
\hline
\end{tabular}

Tabla 5.4.84: Media, desviación estándar, error estándar e intervalo de confianza de TV para los grupos de superficie para puntos limpios semiurbanos.

Para comprobar la hipótesis de igualdad de grupos, en primer lugar se realiza el test de Levene, que analiza la homogeneidad de varianzas entre grupos. Los resultados se incluyen en la Tabla 5.4.85.

\begin{tabular}{|l|r|r|r|r|}
\hline Variable & $\begin{array}{c}\text { Estadístico de } \\
\text { Levene }\end{array}$ & df1 & df2 & \multicolumn{1}{c|}{ Sign. } \\
\hline TV & 0,81 & 3 & 18 & 0,503 \\
\hline
\end{tabular}

Tabla 5.4.85: Resultados del test de Levene para TV y superficie en puntos limpios semiurbanos.

El valor del estadístico de Levene es 2,26, inferior a 3,160, valor que toma la $\mathrm{F}$ de Snedecor para $\alpha=0,05$, y grados de libertad 3 y 18, mientas que el valor de significación es superior a 0,05, por lo que se acepta la hipótesis nula de homogeneidad de varianzas.

A continuación se aplica el test ANOVA, cuyos resultados se muestran en la Tabla 5.4.86.

\begin{tabular}{|c|c|c|c|c|c|c|}
\hline \multicolumn{2}{|c|}{ Factor } & Suma de & df & Cuadrado & $\mathbf{F}$ & Sign. \\
\hline \multirow{3}{*}{ TV } & Entre Grupos & $4.208,38$ & 3 & $1.402,79$ & 1,79 & 0,185 \\
\hline & Intra Grupos & $14.104,30$ & 18 & 783,575 & & \\
\hline & Total & $18.312,68$ & 21 & & & \\
\hline
\end{tabular}

Tabla 5.4.86: Resultados test ANOVA para TV y superficie en puntos limpios semiurbanos.

Puesto que el valor de significación de la prueba es 0,185 , superior al error de la hipótesis nula de igualdad de medias, ésta se acepta, concluyendo que las poblaciones son iguales.

Por tanto, pese a observarse que únicamente los puntos limpios con superficie inferior a $3.000 \mathrm{~m}^{2}$ presentan valores de TV superiores a la media, puede aceptarse la hipótesis de igualdad entre grupos. No obstante, puesto que existen grupos con un reducido número de casos disponibles 
para el estudio, a continuación se realiza una reagrupación de los mismos, en función de si la superficie del punto limpio es superior o inferior a $3.000 \mathrm{~m}^{2}$. Los resultados de la comparación se muestran en las Tabla 5.4.87.

\begin{tabular}{|c|c|c|c|c|c|c|c|c|c|}
\hline \multirow{2}{*}{\multicolumn{2}{|c|}{ Grupo }} & \multirow[t]{2}{*}{$\mathbf{N}$} & \multirow[t]{2}{*}{ Media } & \multirow[t]{2}{*}{$\begin{array}{c}\text { Desviación } \\
\text { Estándar }\end{array}$} & \multirow[t]{2}{*}{$\begin{array}{c}\text { Error } \\
\text { Estándar }\end{array}$} & \multicolumn{2}{|c|}{$\begin{array}{c}\text { Intervalo de } \\
\text { Confianza } 95 \% \\
\text { para la Media }\end{array}$} & \multirow[t]{2}{*}{ Mínimo } & \multirow[t]{2}{*}{ Máximo } \\
\hline & & & & & & $\begin{array}{l}\text { Límite } \\
\text { Inferior }\end{array}$ & $\begin{array}{c}\text { Límite } \\
\text { Superior }\end{array}$ & & \\
\hline \multirow{3}{*}{ TV } & $<3.000 \mathrm{~m}^{2}$ & 13 & 52,36 & 31,43 & 8,72 & 33,36 & 71,35 & 13,27 & 110,66 \\
\hline & $>3.000 \mathrm{~m}^{2}$ & 9 & 26,95 & 19,44 & 6,48 & 12,01 & 41,90 & 1,82 & 57,70 \\
\hline & Total & 22 & 41,96 & 29,53 & 6,30 & 28,87 & 55,06 & 1,82 & 110,66 \\
\hline
\end{tabular}

Tabla 5.4.87: Media, desviación estándar, error estándar e intervalo de confianza de TV para puntos limpios semiurbanos de superficie superior e inferior a $3.000 \mathrm{~m}^{2}$.

Los resultados del test de Levene, que se muestran en la Tabla 5.4.88, muestran que existe homogeneidad de varianzas entre grupos, al obtenerse un estadístico de Levene de 1,18, inferior a 4,351, valor que toma la $F$ de Snedecor para $\alpha=0,05$, y grados de libertad 1 y 20 , y un valor de significación superior a 0,05.

\begin{tabular}{|c|r|r|r|r|}
\hline Variable & $\begin{array}{c}\text { Estadístico de } \\
\text { Levene }\end{array}$ & df1 & df2 & Sign. \\
\hline TV & 1,18 & 1 & 20 & 0,290 \\
\hline
\end{tabular}

Tabla 5.4.88: Resultados del test de Levene para TV para puntos limpios semiurbanos de superficie superior e inferior a $3.000 \mathrm{~m}^{2}$.

En cuanto a la hipótesis de igualdad de medias, y por tanto entre grupos, en la Tabla 5.4 .89 se muestran los resultados del test ANOVA, obteniéndose un valor de significación inferior a 0,05, por lo que se rechaza la hipótesis nula.

\begin{tabular}{|c|c|c|c|c|c|c|}
\hline \multicolumn{2}{|c|}{ Factor } & $\begin{array}{c}\text { Suma de } \\
\text { Cuadrados }\end{array}$ & df & $\begin{array}{l}\text { Cuadrado } \\
\text { medio }\end{array}$ & $\mathbf{F}$ & Sign. \\
\hline \multirow{3}{*}{ TV } & Entre Grupos & $3.432,51$ & 1 & $3.432,51$ & 4,61 & 0,044 \\
\hline & Intra Grupos & $14.880,17$ & 20 & 744,01 & & \\
\hline & Total & $18.312,68$ & 21 & & & \\
\hline
\end{tabular}

Tabla 5.4.89: Resultados test ANOVA para TV y superficie en puntos limpios semiurbanos. 
Por tanto, se concluye que TV presenta significación respecto de la superficie en los puntos limpios con entre 5.000 y 50.000 habitantes de población adscrita, obteniéndose mejores resultados en los puntos limpios con superficie inferior a $3.000 \mathrm{~m}^{2}$. La superficie media de estos puntos limpios es de $1.800 \mathrm{~m}^{2}$.

Puntos limpios urbanos:

Para el estudio de significación de la variable superficie en puntos limpios con población adscrita superior a 50.000 habitantes se dispone de 17 casos en la muestra. Teniendo en cuenta el criterio de segregación de las instalaciones conforme a lo indicado en la Tabla 5.4.70, en la Tabla 5.4.90 se incluyen los valores de media y desviación estándar de cada uno de los grupos creados, así como el número de casos en cada grupo. Se observa que únicamente existen 2 puntos limpios con superficie entre 3.200 y $4.500 \mathrm{~m}^{2}$, con valores de TV extremos, lo que hace que este grupo presente los mayores valores de media y desviación estándar.

En los Gráficos 5.4 .46 y 5.4 .47 puede verse la representación gráfica de las superficies y valores de TV, respectivamente, de cada uno de los grupos.

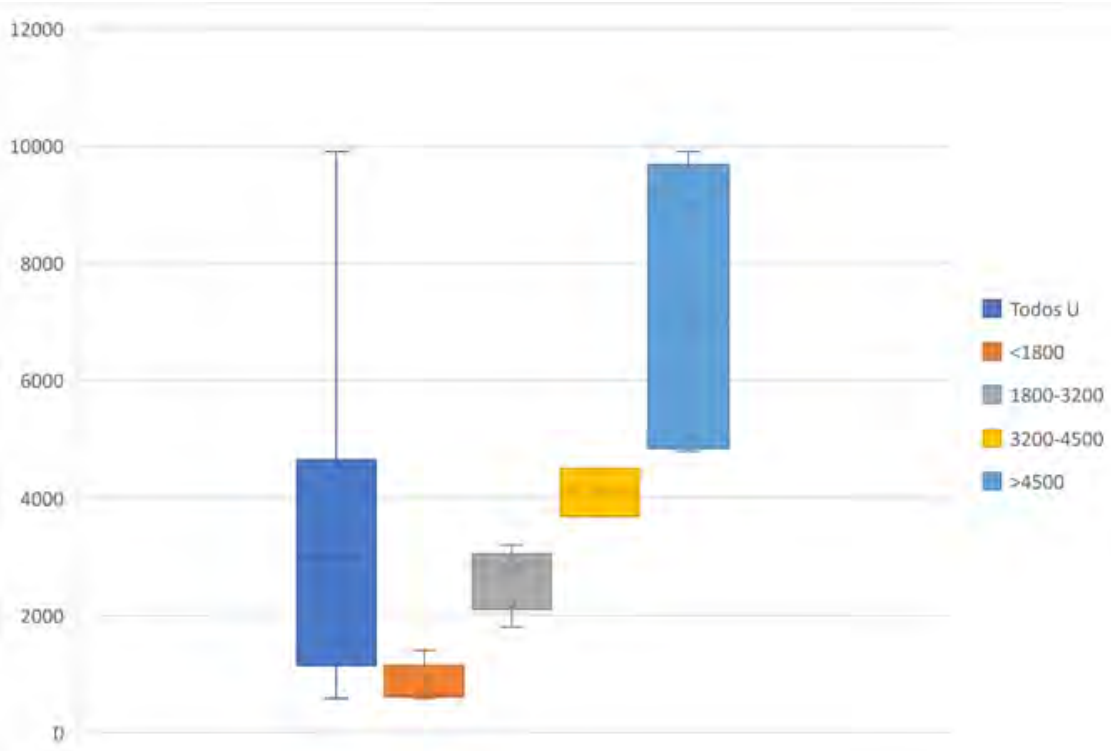

Gráfico 5.4.46: Superficie de punto limpio en puntos limpios urbanos. 


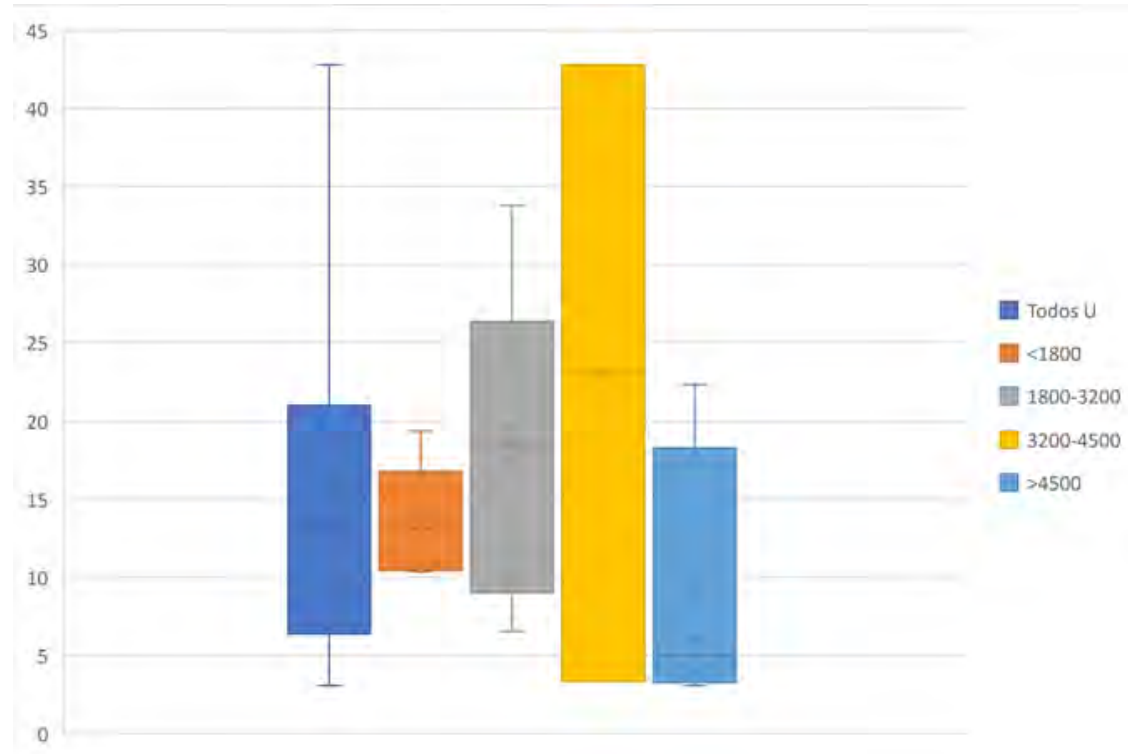

Gráfico 5.4.47: TV para grupos de superficie ocupada y puntos limpios urbanos.

\begin{tabular}{|c|c|c|c|c|c|c|c|c|c|}
\hline \multirow{2}{*}{\multicolumn{2}{|c|}{ Grupo }} & \multirow[t]{2}{*}{$\mathbf{N}$} & \multirow[t]{2}{*}{ Media } & \multirow[t]{2}{*}{$\begin{array}{l}\text { Desviación } \\
\text { Estándar }\end{array}$} & \multirow[t]{2}{*}{$\begin{array}{c}\text { Error } \\
\text { Estándar }\end{array}$} & \multicolumn{2}{|c|}{$\begin{array}{c}\text { Intervalo de } \\
\text { Confianza } 95 \% \\
\text { para la Media }\end{array}$} & \multirow[t]{2}{*}{ Mínimo } & \multirow[t]{2}{*}{ Máximo } \\
\hline & & & & & & $\begin{array}{l}\text { Límite } \\
\text { Inferior }\end{array}$ & $\begin{array}{l}\text { Límite } \\
\text { Superior }\end{array}$ & & \\
\hline \multirow{5}{*}{ TV } & $<1.800 \mathrm{~m}^{2}$ & 5 & 13,55 & 3,66 & 1,64 & 9,00 & 18,10 & 10,39 & 19,39 \\
\hline & $1.800-3.200 \mathrm{~m}^{2}$ & 6 & 18,53 & 9,81 & 4,01 & 8,23 & 28,83 & 6,56 & 33,78 \\
\hline & $3.200-4.500 \mathrm{~m}^{2}$ & 2 & 23,07 & 27,89 & 19,72 & $-227,48$ & 273,62 & 3,35 & 42,79 \\
\hline & $>4.500 \mathrm{~m}^{2}$ & 4 & 8,87 & 9,06 & 4,53 & $-5,55$ & 23,28 & 3,08 & 22,31 \\
\hline & Total & 17 & 15,33 & 10,96 & 2,66 & 9,69 & 20,96 & 3,08 & 42,79 \\
\hline
\end{tabular}

Tabla 5.4.90: Media, desviación estándar, error estándar e intervalo de confianza de TV para los grupos de superficie para puntos limpios urbanos.

Así, para realizar el análisis de significación de la variable superficie, los puntos limpios de más de $3.200 \mathrm{~m}^{2}$ se reagrupan. En la Tabla 5.4 .91 se incluyen los valores de los grupos así configurados.

\begin{tabular}{|c|c|c|c|c|c|c|c|c|c|}
\hline \multirow{2}{*}{\multicolumn{2}{|c|}{ Grupo }} & \multirow[t]{2}{*}{$\mathbf{N}$} & \multirow[t]{2}{*}{ Media } & \multirow{2}{*}{$\begin{array}{l}\text { Desviación } \\
\text { Estándar }\end{array}$} & \multirow{2}{*}{$\begin{array}{c}\text { Error } \\
\text { Estándar }\end{array}$} & \multicolumn{2}{|c|}{$\begin{array}{c}\text { Intervalo de } \\
\text { Confianza } 95 \% \\
\text { para la Media }\end{array}$} & \multirow[t]{2}{*}{ Mínimo } & \multirow[t]{2}{*}{ Máximo } \\
\hline & & & & & & $\begin{array}{l}\text { Límite } \\
\text { Inferior }\end{array}$ & $\begin{array}{c}\text { Límite } \\
\text { Superior }\end{array}$ & & \\
\hline \multirow{4}{*}{ TV } & $<1.800 \mathrm{~m}^{2}$ & 5 & 13,55 & 3,66 & 1,64 & 9,00 & 18,10 & 10,39 & 19,39 \\
\hline & $1.800-3.200 \mathrm{~m}^{2}$ & 6 & 18,53 & 9,81 & 4,01 & 8,23 & 28,83 & 6,56 & 33,78 \\
\hline & $>3.200 \mathrm{~m}^{2}$ & 6 & 13,60 & 16,08 & 6,56 & $-3,27$ & 30,48 & 3,08 & 42,79 \\
\hline & Total & 17 & 15,33 & 10,96 & 2,66 & 9,69 & 20,96 & 3,08 & 42,79 \\
\hline
\end{tabular}

Tabla 5.4.91: Media, desviación estándar, error estándar e intervalo de confianza de TV para los grupos de superficie para puntos limpios urbanos. 
A continuación se aplica el test de Levene, para comprobar la hipótesis de homogeneidad de varianzas entre grupos, que se acepta, al obtenerse un valor de significación de 0,051 y un valor del estadístico de 3,71, inferior a 3,739, valor que toma la $F$ de Snedecor para $\alpha=0,05$, y grados de libertad 2 y 14. Estos resultados pueden verse en la Tabla 5.4.92.

\begin{tabular}{|l|r|r|r|r|}
\hline Variable & $\begin{array}{c}\text { Estadístico de } \\
\text { Levene }\end{array}$ & df1 & df2 & \multicolumn{1}{c|}{ Sign. } \\
\hline TV & 3,71 & 2 & 14 & 0,051 \\
\hline
\end{tabular}

Tabla 5.4.92: Resultados del test de Levene para TV y superficie en puntos limpios urbanos.

Validado el supuesto de homocedasticidad, a continuación se comprueba la igualdad de media mediante el test ANOVA, cuyos resultados se muestran en la Tabla 5.4.93.

\begin{tabular}{|c|c|c|c|c|c|c|}
\hline \multicolumn{2}{|c|}{ Factor } & $\begin{array}{c}\text { Suma de } \\
\text { Cuadrados }\end{array}$ & df & $\begin{array}{l}\text { Cuadrado } \\
\text { medio }\end{array}$ & $\mathbf{F}$ & Sign. \\
\hline \multirow{3}{*}{ TV } & Entre Grupos & 95,22 & 2 & 47,61 & 0,36 & 0,701 \\
\hline & Intra Grupos & $1.828,13$ & 14 & 130,58 & & \\
\hline & Total & $1.923,35$ & 16 & & & \\
\hline
\end{tabular}

Tabla 5.4.93: Resultados test ANOVA para TV y superficie en puntos limpios urbanos.

Puesto que el valor de significación de la prueba es 0,701 , superior a 0,05 , se acepta la hipótesis de igualdad.

Por tanto, la superficie del punto limpio no presenta significación estadística sobre los resultados de TV. Por tanto, puede concluirse que las superficies de entre 1.800 y $3.200 \mathrm{~m}^{2}$ resultan adecuadas para los puntos limpios con población adscrita superior a 50.000 habitantes, puesto que superficies superiores no redundan en mayores valores de TV. 


\section{A5.4.10. Punto limpio móvil asociado.}

Los puntos limpios objeto de la encuesta han sido en todos los casos instalaciones fijas; en este punto se estudia si el hecho de que dichos puntos limpios cuenten con un servicio complementario de punto limpio móvil resulta significativo para el grado de utilización y cantidades de residuos depositadas en los puntos limpios fijos.

\section{A5.4.10.1. Análisis de TR considerando factor de comparación la presencia de punto limpio móvil asociado.}

El número de casos de la muestra de que se dispone de información y cuyos valores se consideran adecuados es de 82, puesto que los puntos limpios de Mancomunidad de Sasieta y Tudela no aportan información respecto de esta característica encuestada. En el Gráfico 5.4.48 se muestra la distribución de TR de cada uno de los subgrupos en que se divide la muestra, en función del valor de la variable analizada.

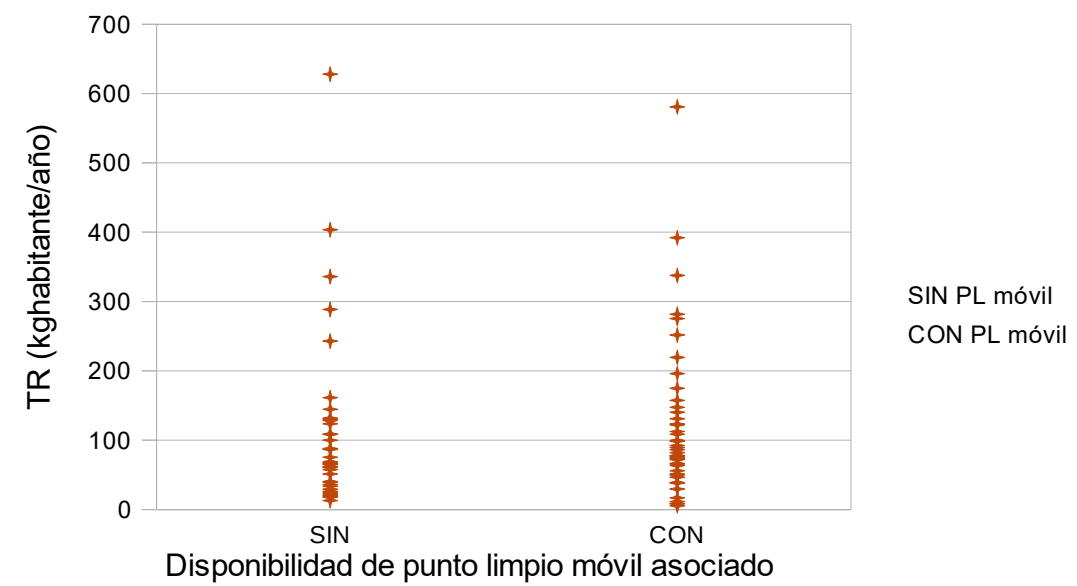

Gráfico 5.4.48: TR frente a disponibilidad de punto limpio móvil asociado.

Realizando una aproximación inicial partiendo del análisis gráfico, aparentemente las distribuciones son similares. En la Tabla 5.4.94 se observa que, aunque las características de las distribuciones son muy similares, existe un ligero incremento de la media y descenso de la desviación estándar de TR en los puntos limpios con punto limpio móvil asociado. 
Estudio de influencia de variables sobre los resultados de TR y TV de los puntos limpios.

\begin{tabular}{|c|c|c|c|c|c|c|c|c|c|}
\hline & \multirow[t]{2}{*}{ Grupo } & \multirow[t]{2}{*}{$\mathbf{N}$} & \multirow[t]{2}{*}{ Media } & \multirow{2}{*}{$\begin{array}{l}\text { Desviación } \\
\text { Estándar }\end{array}$} & \multirow{2}{*}{$\begin{array}{c}\text { Error } \\
\text { Estándar }\end{array}$} & \multicolumn{2}{|c|}{$\begin{array}{c}\text { Intervalo de } \\
\text { Confianza } 95 \% \\
\text { para la Media }\end{array}$} & \multirow[t]{2}{*}{ Mínimo } & \multirow[t]{2}{*}{ Máximo } \\
\hline & & & & & & $\begin{array}{l}\text { Límite } \\
\text { Inferior }\end{array}$ & $\begin{array}{l}\text { Límite } \\
\text { Superior }\end{array}$ & & \\
\hline \multirow{3}{*}{ TR } & SIN PL móvil & 38 & 109,74 & 123,83 & 20,09 & 69,04 & 150,44 & 13,01 & 628,02 \\
\hline & CON PL móvil & 44 & 120,69 & 113,09 & 17,05 & 86,31 & 155,07 & 5,43 & 580,66 \\
\hline & Total & 82 & 115,62 & 117,57 & 12,98 & 89,78 & 141,45 & 5,43 & 628,02 \\
\hline
\end{tabular}

Tabla 5.4.94: Media, desviación estándar, error estándar e intervalo de confianza de TR para los grupos de disponibilidad de punto limpio móvil asociado.

La validación de la hipótesis nula de igualdad de grupos se realiza mediante la prueba $\mathrm{H}$ de Kruskal-Wallis, cuyos resultados son los que se incluyen en las Tablas 5.4.95 y 5.4.96.

\begin{tabular}{|c|l|r|r|}
\hline \multicolumn{1}{c|}{ Variable } & \multicolumn{1}{|c|}{ Grupo } & N & \multicolumn{1}{c|}{ Rango medio } \\
\hline \multirow{4}{*}{ TR } & SIN PL móvil & 38 & 38,68 \\
\cline { 2 - 4 } & CON PL móvil & 44 & 43,93 \\
\cline { 2 - 4 } & Total & 82 & \\
\hline
\end{tabular}

Tabla 5.4.95: Kruskal-Wallis. № de elementos y rango medio de TR en cada grupo de disponibilidad de punto limpio móvil asociado.

\begin{tabular}{|l|r|}
\hline & \multicolumn{1}{|c|}{ TR } \\
\hline Chi-cuadrado & 0,99 \\
\hline df & 1 \\
\hline Sign. Asint. & 0,320 \\
\hline
\end{tabular}

Tabla 5.4.96: Resultados de significación del test de Kruskal-Wallis de TR respecto de la disponibilidad de punto limpio móvil asociado.

Puesto que el valor de significación es superior a 0,05, no existen diferencias entre los subgrupos de la muestra y, por tanto, las poblaciones son iguales; es decir, los resultados de TR no presentan diferencias significativas en términos estadísticos en función de la disponibilidad de punto limpio móvil asociado al punto limpio.

Por tanto, la existencia de un punto limpio móvil asociado al punto limpio fijo no presenta influencia significativa sobre las cantidades de residuos depositadas en este último. Cabría esperar que, si la presencia de puntos limpios móviles permite que las cantidades de residuos recolectadas en conjunto se incrementen, y los residuos entregados en el punto limpio móvil son a su vez depositados, para su posterior gestión conjunta, en el punto limpio fijo, los valores de TR fuesen superiores en los casos en que se cuenta con un punto limpio móvil. Sí se observa dicho 
comportamiento, sin resultados significativos en términos estadísticos; puesto que no existe información respecto a si los residuos recolectados a través del punto limpio móvil son gestionados de manera independiente, o se depositan en el punto limpio fijo, no es posible realizar un análisis en mayor profundidad, que permita establecer si esa pequeña variación observada en la media de TR se debe a la poca cantidad, en términos relativos, de residuos recogidos en los puntos limpios.

\section{A5.4.10.2. Análisis de TV considerando factor de comparación la presencia de punto limpio móvil asociado.}

De los puntos limpios de la muestra considerados válidos, existe 1 (Puerto de Santa María) que no aporta información sobre la disponibilidad de punto limpio móvil asociado, por lo que el número de casos que se tendrán en cuenta para el análisis de significación estadística sobre TV es de 64, que se agrupan según se observa en el Gráfico 5.4.49.

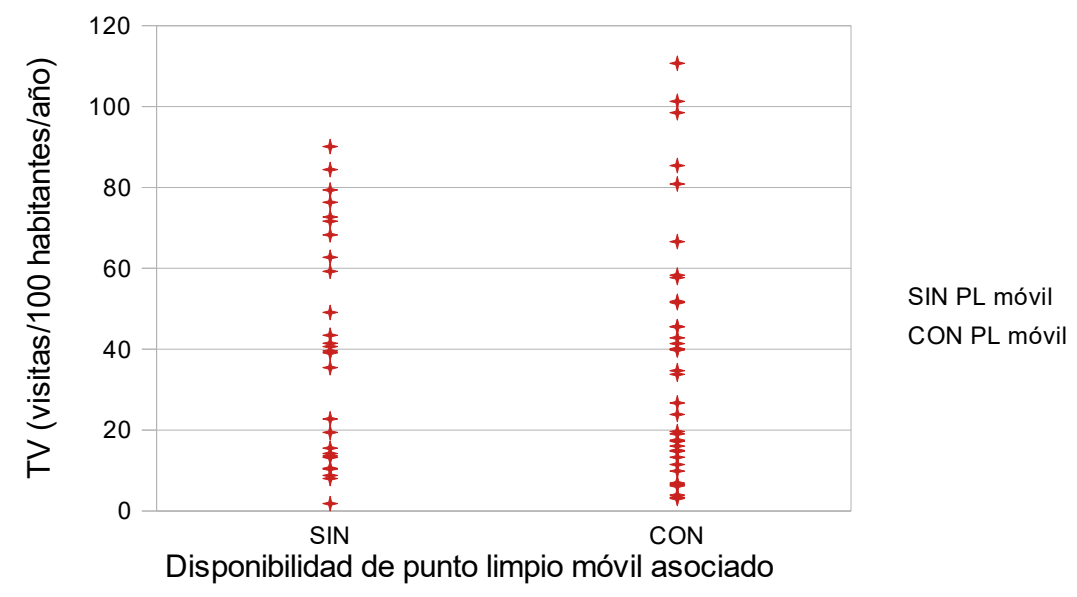

Gráfico 5.4.49: TV frente a disponibilidad de punto limpio móvil asociado.

Se observa que los valores máximos de TV se alcanzan en aquellos puntos limpios que disponen de punto limpio móvil asociado. Los valores de media y desviación estándar de TV se muestran en la Tabla 5.4.97, en que se observa que los valores que toma cada parámetro estadístico en cada distribución son muy similares entre la totalidad de la muestra y los subgrupos en que se ha segregado. 
Estudio de influencia de variables sobre los resultados de TR y TV de los puntos limpios.

\begin{tabular}{|c|c|c|c|c|c|c|c|c|c|}
\hline & \multirow[t]{2}{*}{ Grupo } & \multirow[t]{2}{*}{$\mathbf{N}$} & \multirow[t]{2}{*}{ Media } & \multirow{2}{*}{$\begin{array}{l}\text { Desviación } \\
\text { Estándar }\end{array}$} & \multirow{2}{*}{$\begin{array}{c}\text { Error } \\
\text { Estándar }\end{array}$} & \multicolumn{2}{|c|}{$\begin{array}{c}\text { Intervalo de } \\
\text { Confianza } 95 \% \\
\text { para la Media }\end{array}$} & \multirow[t]{2}{*}{ Mínimo } & \multirow[t]{2}{*}{ Máximo } \\
\hline & & & & & & $\begin{array}{l}\text { Límite } \\
\text { Inferior }\end{array}$ & $\begin{array}{l}\text { Límite } \\
\text { Superior }\end{array}$ & & \\
\hline \multirow{3}{*}{ TV } & SIN PL móvil & 27 & 40,43 & 27,61 & 5,31 & 29,51 & 51,35 & 1,82 & 90,09 \\
\hline & CON PL móvil & 37 & 36,77 & 29,45 & 4,84 & 26,95 & 46,59 & 3,08 & 110,66 \\
\hline & Total & 64 & 38,31 & 28,52 & 3,57 & 31,19 & 45,44 & 1,82 & 110,66 \\
\hline
\end{tabular}

Tabla 5.4.97: Media, desviación estándar, error estándar e intervalo de confianza de TV para los grupos de disponibilidad de punto limpio móvil asociado.

Los resultados del Test de Levene, para la validación del supuesto de homogeneidad de varianzas, se incluyen en la Tabla 5.4.98:

\begin{tabular}{|l|r|r|r|r|}
\hline Variable & $\begin{array}{c}\text { Estadístico de } \\
\text { Levene }\end{array}$ & df1 & df2 & \multicolumn{1}{c|}{ Sign. } \\
\hline TV & 0,00 & 1 & 62 & 0,973 \\
\hline
\end{tabular}

Tabla 5.4.98: Resultados del test de Levene para TV y disponibilidad de punto limpio móvil asociado.

El valor del estadístico es 0,00 , inferior a 3,996, valor que toma la $F$ de Snedecor para $\alpha=0,05$, y grados de libertad 1 y 62, mientras que el valor de significación es claramente superior a 0,05, por lo que se cumple el supuesto de homocedasticidad.

Respecto a la comparación de igualdad de los grupos, y puesto que TV presenta una distribución normal, se realiza a continuación el test ANOVA, cuyos resultados se muestran en la Tabla 5.4.99.

\begin{tabular}{|c|c|c|c|c|c|c|}
\hline \multicolumn{2}{|c|}{ Factor } & $\begin{array}{c}\text { Suma de } \\
\text { Cuadrados }\end{array}$ & df & $\begin{array}{c}\text { Cuadrado } \\
\text { medio }\end{array}$ & $\mathbf{F}$ & Sign. \\
\hline \multirow{3}{*}{ TV } & Entre Grupos & 209,35 & 1 & 209,35 & 0,25 & 0,616 \\
\hline & Intra Grupos & $51.045,73$ & 62 & 823,32 & & \\
\hline & Total & $51.255,09$ & 63 & & & \\
\hline
\end{tabular}

Tabla 5.4.99: Resultados test ANOVA para TV y disponibilidad de punto limpio móvil asociado.

Resultando un valor de significación superior a 0,05 , por lo que la hipótesis nula se considera válida.

Por tanto, no existe significación estadística entre la disponibilidad de punto limpio móvil asociado y los resultados de TV. 
Podría esperarse que, si se dispone de punto limpio móvil, en el que pueden depositarse pequeñas cantidades de residuos, principalmente de origen doméstico, más habituales (pilas, bombillas, pequeños electrodomésticos), el acceso al punto limpio móvil provoque una menor afluencia de usuarios al punto limpio fijo, puesto que los residuos que se depositan en el punto limpio móvil ya no van a ser transportados hasta el fijo.

Por otro lado, si se dispusiera de información relativa a las visitas a los puntos limpios móviles, podría tratar de analizarse la correlación existente entre visitas al punto limpio móvil equivalentes a visitas al punto limpio fijo, y la significación de este factor: si el punto limpio móvil se encuentra a menos distancia del origen de los residuos que el punto limpio fijo, es previsible que las visitas a éste último se espacien, y presenten un mayor peso por visita que las registradas en los puntos limpios móviles; no obstante, este análisis no es posible realizarlo con los datos de que se dispone.

En conclusión, la disponibilidad de punto limpio móvil no tiene significación estadística en términos de TR y TV; puesto que no se dispone de información suficiente referente a número de visitas a los puntos limpios móviles, cantidades depositadas en los mismos, y destino de los residuos recolectados a través de ellos, no es posible realizar un análisis más profundo.

\section{A5.4.11. Horario de apertura.}

Se analiza en este punto la significación sobre la frecuencia de uso del punto limpio y la cantidad de residuos depositados en el mismo, considerando como elemento diferenciador el horario de apertura. La información disponible permite realizar el estudio en función de los días de la semana en que la instalación se encuentra abierta, puesto que no se dispone de datos sobre franjas horarias. Así, el objetivo es tratar de determinar si existen patrones de frecuencia de uso en función del día de la semana que se trate, que maximizan la afluencia de usuarios y cantidades de residuos depositadas en los puntos limpios.

En primer lugar, se analizará la diferencia entre los tamaños de los grupos en que se segrega la muestra, en función de si el punto limpio permanece abierto o cerrado un día dado de la semana. Si el número de puntos limpios en cada uno de los grupos en suficiente para poder llevar a cabo el estudio de comparación (mínimo 7 casos), a continuación se procederá a estudiar el comportamiento de TR y TV para cada situación en que la variable correspondiente al día de la semana presente los valores abierto o cerrado. 


\section{A5.4.11.1. Análisis de TR considerando factor de comparación el horario de apertura.}

Se cuenta con información relativa a los días de la semana en que el punto limpio se encuentra abierto en todos los casos en que se dispone de valor de TR, por lo que el tamaño de la muestra a analizar es de 84. El Gráfico 5.4.50 muestra los valores de TR de los puntos limpios que permanecen abiertos cada uno de los días de la semana.

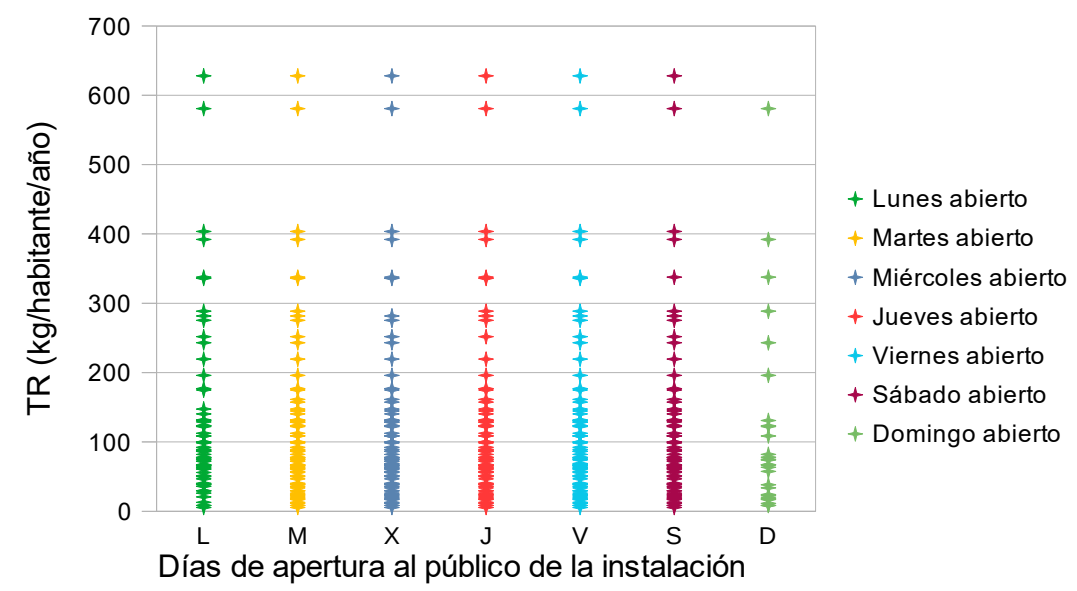

Gráfico 5.4.50: TR frente a días de apertura semanal de la instalación.

Se observa que el número de casos en los que la variable referida a la apertura en domingo presenta el valor correspondiente a cerrado es inferior al resto de días de la semana y, por tanto, el número de puntos representados es menor que en el resto de días de la semana.

Para evaluar la significación estadística sobre TR del horario de apertura de la instalación, en primer lugar se analiza la homogeneidad de respuestas, con el objetivo de establecer las situaciones cuyo análisis es viable en términos estadísticos. En la Tabla 5.4.100 se muestra el número de puntos limpios que se encuentran abiertos cada día de la semana.

\begin{tabular}{|l|r|r|r|r|r|r|r|}
\hline \multicolumn{1}{|c|}{ Apertura } & Lunes & Martes & Miércoles & Jueves & Viernes & Sábado & Domingo \\
\hline Abierto & 67 & 80 & 81 & 80 & 82 & 79 & 28 \\
Cerrado & 17 & 4 & 3 & 4 & 2 & 5 & 56 \\
& 84 & 84 & 84 & 84 & 84 & 84 & 84 \\
\hline
\end{tabular}

Tabla 5.4.100: TR. Número de puntos limpios abiertos y cerrados por día de la semana. 
Se observa que entre el $94 \%$ y el $98 \%$ de los puntos limpios se encuentran abiertos los martes, miércoles, jueves, viernes y sábado, al integrarse en los respectivos grupos que conforman la parte de la muestra correspondiente a los puntos limpios que se encuentran cerrados únicamente entre 2 y 5 casos, por lo que el estudio estadístico de significación para estos días no resulta viable. Por lo que se refiere a los lunes, es mayoritario el grupo de puntos limpios que se encuentran abiertos, mientras que los domingos se encuentran, en su mayoría, cerrados. Así pues, se analizará la significación sobre TR de la apertura del punto limpio en lunes y en domingo.

Significación de la variable correspondiente al estado de apertura en lunes:

En la Tabla 5.4.101 se muestra la media y desviación estándar de TR de los puntos limpios, según se encuentren abiertos o cerrados en lunes, en la que puede observarse que ambos valores son superiores para el grupo de instalaciones abiertas.

\begin{tabular}{|c|c|c|c|c|c|c|c|c|c|}
\hline & \multirow[t]{2}{*}{ Lunes } & \multirow[t]{2}{*}{$\mathbf{N}$} & \multirow[t]{2}{*}{ Media } & \multirow{2}{*}{$\begin{array}{l}\text { Desviación } \\
\text { Estándar }\end{array}$} & \multirow{2}{*}{$\begin{array}{c}\text { Error } \\
\text { Estándar }\end{array}$} & \multicolumn{2}{|c|}{$\begin{array}{c}\text { Intervalo de } \\
\text { Confianza } 95 \% \\
\text { para la Media }\end{array}$} & \multirow[t]{2}{*}{ Mínimo } & \multirow[t]{2}{*}{ Máximo } \\
\hline & & & & & & $\begin{array}{l}\text { Límite } \\
\text { Inferior }\end{array}$ & $\begin{array}{l}\text { Límite } \\
\text { Superior }\end{array}$ & & \\
\hline \multirow{3}{*}{ TR } & Cerrado & 17 & 71,56 & 54,73 & 13,27 & 43,42 & 99,70 & 11,49 & 161,34 \\
\hline & Abierto & 67 & 127,91 & 125,08 & 15,28 & 97,40 & 158,42 & 5,43 & 628,02 \\
\hline & Total & 84 & 116,51 & 116,35 & 12,69 & 91,26 & 141,76 & 5,43 & 628,02 \\
\hline
\end{tabular}

Tabla 5.4.101: Media, desviación estándar, error estándar e intervalo de confianza de TR para los grupos de apertura en lunes.

Para validar la hipótesis nula de igualdad de los subgrupos, se realiza la prueba $\mathrm{H}$ de KruskalWallis, cuyos resultados se muestran en las Tablas 5.4.102 y 5.4.103.

\begin{tabular}{|l|l|r|r|}
\hline \multicolumn{1}{|c|}{ Variable } & \multicolumn{1}{|c|}{ Grupo } & \multicolumn{1}{c|}{ N } & \multicolumn{1}{c|}{ Rango medio } \\
\hline \multirow{4}{*}{ TR } & Cerrado & 17 & 32,65 \\
\cline { 2 - 4 } & Abierto & 67 & 45,00 \\
\cline { 2 - 4 } & Total & 84 & \\
\hline
\end{tabular}

Tabla 5.4.102: Kruskal-Wallis. $N^{\circ}$ de elementos y rango medio de TR en cada grupo de apertura en lunes. 


\begin{tabular}{|l|r|}
\hline & \multicolumn{2}{|c|}{ TR } \\
\hline Chi-cuadrado & 3,48 \\
\hline df & 1 \\
\hline Sign. Asint. & 0,062 \\
\hline
\end{tabular}

Tabla 5.4.103: Resultados de significación del test de Kruskal-Wallis de TR respecto de la apertura en lunes.

Por lo que, en términos estadísticos, no resulta significativo sobre TR que el punto limpio se encuentre abierto o cerrado los lunes, aunque sí se observa una influencia próxima a la significación.

Significación de la variable correspondiente al estado de apertura en domingo:

En la Tabla 5.4.104 se muestra la media y desviación estándar de TR de los puntos limpios, según éstos se encuentren abiertos o cerrados en domingo. Se observa que los valores de media de TR son muy similares, mientras que la desviación estándar es superior para los puntos limpios que se encuentran abiertos.

\begin{tabular}{|c|c|c|c|c|c|c|c|c|c|}
\hline & \multirow[t]{2}{*}{ Domingo } & \multirow[t]{2}{*}{$\mathbf{N}$} & \multirow[t]{2}{*}{ Media } & \multirow{2}{*}{$\begin{array}{l}\text { Desviación } \\
\text { Estándar }\end{array}$} & \multirow{2}{*}{$\begin{array}{c}\text { Error } \\
\text { Estándar }\end{array}$} & \multicolumn{2}{|c|}{$\begin{array}{c}\text { Intervalo de } \\
\text { Confianza } 95 \% \\
\text { para la Media }\end{array}$} & \multirow[t]{2}{*}{ Mínimo } & \multirow[t]{2}{*}{ Máximo } \\
\hline & & & & & & $\begin{array}{l}\text { Límite } \\
\text { Inferior }\end{array}$ & $\begin{array}{c}\text { Límite } \\
\text { Superior }\end{array}$ & & \\
\hline \multirow{3}{*}{ TR } & Cerrado & 56 & 116,05 & 106,14 & 14,18 & 87,62 & 144,47 & 5,43 & 628,02 \\
\hline & Abierto & 28 & 117,42 & 136,62 & 25,82 & 64,44 & 170,40 & 8,42 & 580,66 \\
\hline & Total & 84 & 116,51 & 116,35 & 12,69 & 91,26 & 141,76 & 5,43 & 628,02 \\
\hline
\end{tabular}

Tabla 5.4.104: Media, desviación estándar, error estándar e intervalo de confianza de TR para los grupos de apertura en domingo.

Para validar la hipótesis nula de igualdad de los subgrupos, se realiza la prueba $\mathrm{H}$ de KruskalWallis, cuyos resultados se muestran en las Tablas 5.4.105 y 5.4.106.

\begin{tabular}{|l|l|r|r|}
\hline \multicolumn{1}{|c|}{ Variable } & \multicolumn{1}{c|}{ Grupo } & N & \multicolumn{1}{c|}{ Rango medio } \\
\hline \multirow{4}{*}{ TR } & Cerrado & 56 & 44,61 \\
\cline { 2 - 4 } & Abierto & 28 & 38,29 \\
\cline { 2 - 4 } & Total & 84 & \\
\hline
\end{tabular}

Tabla 5.4.105: Kruskal-Wallis. $N^{\circ}$ de elementos y rango medio de TR en cada grupo de apertura en domingo. 


\begin{tabular}{|l|r|}
\hline & \multicolumn{2}{|c|}{ TR } \\
\hline Chi-cuadrado & 1,25 \\
\hline df & 1 \\
\hline Sign. Asint. & 0,263 \\
\hline
\end{tabular}

Tabla 5.4.106: Resultados de significación del test de Kruskal-Wallis de TR respecto de la apertura en domingo.

El valor de significación es superior a 0,05 , por lo que no resulta significativo en términos estadísticos que el punto limpio se encuentre abierto o cerrado en domingo sobre los resultados de TR.

No ha sido posible estudiar la significación de la variable correspondiente a la apertura del punto limpio sobre TR entre martes y sábado, puesto que la mayoría de las instalaciones se encuentran abiertas. Para los lunes y los domingos, se concluye que no existe significación. No obstante, en el caso de los lunes, el resultado de significación se encuentra muy próximo al error de la hipótesis nula $(0,062>0,05)$, con valores tanto de media como de desviación estándar de TR muy superiores para los puntos limpios que se encuentran abiertos en lunes, mientras que los que se encuentran cerrados presentan una media de TR muy inferior tanto a la de los puntos limpios abiertos en dicho día como a la totalidad de la muestra. Por tanto, se puede concluir que la apertura en lunes constituye un factor de cierta relevancia sobre TR.

\section{A5.4.11.2. Análisis de TV considerando factor de comparación los días de apertura semanal.}

Al igual que sucedía con TR, se cuenta con información relativa a los días de la semana en que el punto limpio se encuentra abierto en todos los casos en que se dispone de valor de TV, por lo que el tamaño de la muestra a analizar es de 65. Los resultados de TV para las instalaciones que permanecen abiertas un día concreto de la semana son los mostrados en el Gráfico 5.4.51. 


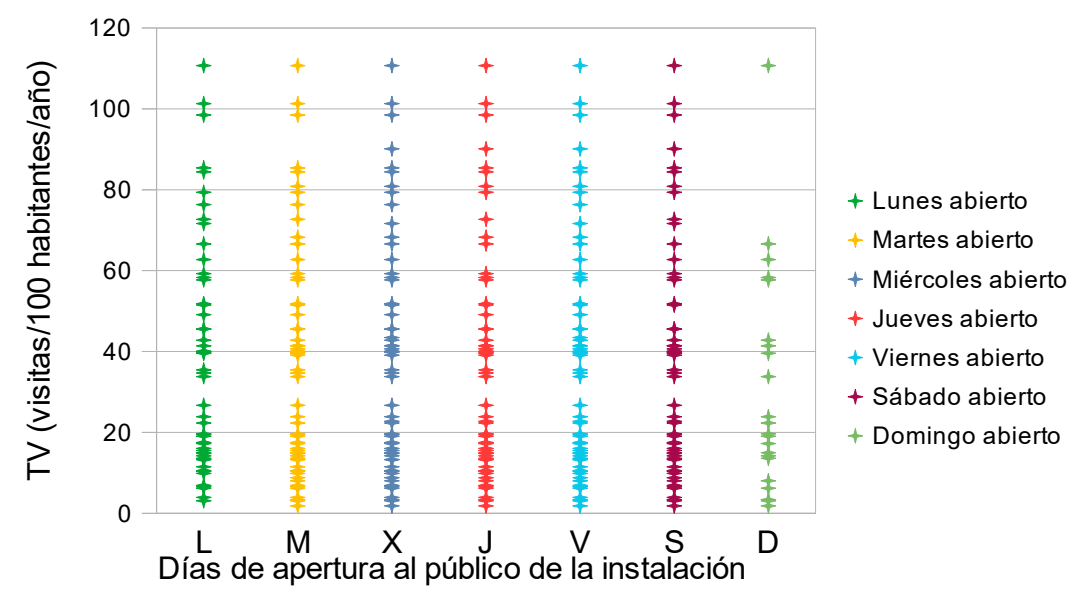

Gráfico 5.4.51: TV frente a días de apertura semanal de la instalación.

Como ocurría con TR, el número de casos en que el punto limpio se encuentra abierto en domingo es inferior al resto de días de la semana.

Por lo que respecta a la significación estadística sobre TV del horario de apertura de la instalación, en primer lugar se analiza la homogeneidad de respuestas, con el objetivo de establecer las situaciones cuyo análisis es viable en términos estadísticos. En la Tabla 5.4.107 se muestra el número de puntos limpios que disponen de valor considerado válido de TV y se encuentran abiertos cada día de la semana.

\begin{tabular}{|l|r|r|r|r|r|r|r|}
\hline \multicolumn{1}{|c|}{ Apertura } & Lunes & Martes & Mierrcoles & Jueves & Viernes & Sábado & Domingo \\
\hline Abierto & 53 & 61 & 62 & 61 & 63 & 60 & 22 \\
Cerrado & 12 & 4 & 3 & 4 & 2 & 5 & 43 \\
& 65 & 65 & 65 & 65 & 65 & 65 & 65 \\
\hline
\end{tabular}

Tabla 5.4.107: TV. Número de puntos limpios abiertos y cerrados por día de la semana.

Se observa que entre el $92 \%$ y el $97 \%$ de los puntos limpios se encuentran abiertos los martes, miércoles, jueves, viernes y sábado, permaneciendo cerrados entre 2 y 5 puntos limpios, por lo que el estudio de significación estadística para estos días no resulta viable. En cuanto a los lunes, es mayoritario el grupo de puntos limpios que se encuentran abiertos, mientras que los domingos se encuentran, en su mayoría, cerrados. Por tanto, se analizará la igualdad de grupos de la muestra, teniendo en cuenta la apertura del punto limpio en lunes y en domingo y los valores de TV. 
Significación de la variable correspondiente a la apertura en lunes:

En la Tabla 5.4.108 se muestra la media y desviación estándar de TV de los puntos limpios, según se encuentren abiertos o cerrados en lunes, en la que puede observarse que ambos valores son superiores para el grupo de instalaciones abiertas.

\begin{tabular}{|c|c|c|c|c|c|c|c|c|c|}
\hline & \multirow{2}{*}{ Lunes } & \multirow{2}{*}{$\mathbf{N}$} & \multirow{2}{*}{ Media } & \multirow{2}{*}{$\begin{array}{l}\text { Desviación } \\
\text { Estándar }\end{array}$} & \multirow{2}{*}{$\begin{array}{c}\text { Error } \\
\text { Estándar }\end{array}$} & \multicolumn{2}{|c|}{$\begin{array}{c}\text { Intervalo de } \\
\text { Confianza } 95 \% \\
\text { para la Media }\end{array}$} & \multirow{2}{*}{ Mínimo } & \multirow{2}{*}{ Máximo } \\
\hline & & & & & & $\begin{array}{l}\text { Límite } \\
\text { Inferior }\end{array}$ & $\begin{array}{c}\text { Límite } \\
\text { Superior }\end{array}$ & & \\
\hline \multirow{3}{*}{ TV } & Cerrado & 12 & 37,37 & 30,16 & 8,71 & 18,21 & 56,54 & 1,82 & 90,09 \\
\hline & Abierto & 53 & 38,22 & 28,25 & 3,88 & 30,43 & 46,01 & 3,08 & 110,66 \\
\hline & Total & 65 & 38,06 & 28,37 & 3,52 & 31,04 & 45,09 & 1,82 & 110,66 \\
\hline
\end{tabular}

Tabla 5.4.108: Media, desviación estándar, error estándar e intervalo de confianza de TV para los grupos de apertura en lunes.

Se observa que los valores de las tres distribuciones (muestra total puntos limpios abiertos en lunes y puntos limpios cerrados en lunes) son muy similares.

A continuación se analiza el supuesto de homocedasticidad, mediante aplicación del test de Levene, cuyos resultados se muestran en la Tabla 5.4.109.

\begin{tabular}{|c|r|r|r|r|}
\hline Variable & $\begin{array}{c}\text { Estadístico de } \\
\text { Levene }\end{array}$ & df1 & df2 & \multicolumn{1}{c|}{ Sign. } \\
\hline TV & 0,01 & 1 & 63 & 0,931 \\
\hline
\end{tabular}

Tabla 5.4.109: Resultados del test de Levene para TV y apertura en lunes.

El valor del estadístico es 0,01 , inferior a 3,993, valor que toma la $F$ de Snedecor para $\alpha=0,05, y$ grados de libertad 1 y 63, y el valor de significación es claramente superior a 0,05 , por lo que se cumple el supuesto de homocedasticidad.

Respecto a la comparación de igualdad de los grupos, se realiza a continuación el test ANOVA, cuyos resultados se muestran en la Tabla 5.4.110. 


\begin{tabular}{|c|c|c|c|c|c|c|}
\hline \multicolumn{2}{|c|}{ Factor } & $\begin{array}{c}\text { Suma de } \\
\text { Cuadrados }\end{array}$ & df & $\begin{array}{l}\text { Cuadrado } \\
\text { medio }\end{array}$ & $\mathbf{F}$ & Sign. \\
\hline \multirow{3}{*}{ TV } & Entre Grupos & 7,01 & 1 & 7,01 & 0,01 & 0,927 \\
\hline & Intra Grupos & $51.500,05$ & 63 & 817,46 & & \\
\hline & Total & $51.507,05$ & 64 & & & \\
\hline
\end{tabular}

Tabla 5.4.110: Resultados test ANOVA para TV y apertura en lunes.

Resultando un valor de significación muy superior a 0,05 , por lo que la hipótesis nula se considera válida y TV no presenta significación respecto de la apertura los lunes.

\section{Significación de la variable correspondiente a la apertura en domingo:}

Como sucedía con TR, el grupo de casos de la muestra que permanecen cerrados en domingo está formado por un mayor número de puntos limpios, al contrario de lo que sucede el resto de días de la semana. En la Tabla 5.4.111 se observa que la media de TV es superior para los puntos limpios que se encuentran cerrados en domingo, con un valor similar de desviación estándar al de puntos limpios abiertos.

\begin{tabular}{|c|c|c|c|c|c|c|c|c|c|}
\hline & mingo & $\mathbf{N}$ & Media & $\begin{array}{l}\text { Desviación } \\
\text { Estándar }\end{array}$ & $\begin{array}{c}\text { Error } \\
\text { Estándar }\end{array}$ & $\begin{array}{c}\text { Inter } \\
\text { Confia } \\
\text { para }\end{array}$ & $\begin{array}{l}\text { alo de } \\
\text { רza } 95 \% \\
\text { Media }\end{array}$ & Mínimo & Máximo \\
\hline & & & & & & $\begin{array}{c}\text { Límite } \\
\text { Inferior }\end{array}$ & $\begin{array}{l}\text { Límite } \\
\text { Superior }\end{array}$ & & \\
\hline & Cerrado & 43 & 41,71 & 28,64 & 4,37 & 32,90 & 50,52 & 3,90 & 101,28 \\
\hline TV & Abierto & 22 & 30,94 & 27,06 & 5,77 & 18,94 & 42,94 & 1,82 & 110,66 \\
\hline & Total & 65 & 38,06 & 28,37 & 3,52 & 31,04 & 45,09 & 1,82 & 110,66 \\
\hline
\end{tabular}

Tabla 5.4.111: Media, desviación estándar, error estándar e intervalo de confianza de TV para los grupos de apertura en domingo.

Para validar la hipótesis de homogeneidad de varianzas entre grupos, se realiza el test de Levene, cuyos resultados se muestran en la Tabla 5.4.112.

\begin{tabular}{|l|r|r|r|r|}
\hline Variable & $\begin{array}{c}\text { Estadístico de } \\
\text { Levene }\end{array}$ & df1 & df2 & \multicolumn{1}{c|}{ Sign. } \\
\hline TV & 0,25 & 1 & 63 & 0,621 \\
\hline
\end{tabular}

Tabla 5.4.112: Resultados del test de Levene para TV y apertura en domingo. 
El valor del estadístico es 0,25 , inferior a 3.993, valor que toma la $\mathrm{F}$ de Snedecor para $\alpha=0,05$, y grados de libertad 1 y 63 , y el valor de significación es superior a 0,05, por lo que se cumple el supuesto de homocedasticidad.

Para validar la hipótesis nula de igualdad de los grupos, se realiza a continuación el test de varianza de medias (ANOVA), cuyos resultados se muestran en la Tabla 5.4.113.

\begin{tabular}{|c|c|c|c|c|c|c|}
\hline \multicolumn{2}{|c|}{ Factor } & $\begin{array}{c}\text { Suma de } \\
\text { Cuadrados }\end{array}$ & df & $\begin{array}{c}\text { Cuadrado } \\
\text { medio }\end{array}$ & $\mathbf{F}$ & Sign. \\
\hline \multirow{3}{*}{ TV } & Entre Grupos & $1.688,11$ & 1 & $1.688,11$ & 2,13 & 0,149 \\
\hline & Intra Grupos & $49.818,94$ & 63 & 790,78 & & \\
\hline & Total & $51.507,05$ & 64 & & & \\
\hline
\end{tabular}

Tabla 5.4.113: Resultados test ANOVA para TV y apertura en domingo.

Puesto que el valor de significación superior a 0,05, superior al error de la hipótesis nula, ésta se admite, por lo que los grupos son iguales entre sí.

En conclusión, los resultados de TV no presentan significación estadística respecto de la apertura de los puntos limpios los lunes o los domingos. No ha sido posible realizar este análisis para el resto de días de la semana, puesto que existe un número de casos distintos suficiente para poder llevarlo a cabo. Sin embargo, sí se observa que, para la apertura en lunes, los resultados de TR se encuentran próximos a significación, con una media muy inferior para los puntos limpios que permanecen cerrados. En términos de TV, no se halla significación, con resultados muy similares. Para la apertura en domingo no se halla significación estadística sobre TR ni sobre TV, pese a que la media de TV es superior en los puntos limpios que se encuentran cerrados en domingo y con una desviación estándar similar al resto de la muestra, ni sobre TR, con valores muy similares.

\section{A5.4.12. Acceso a empresas.}

Como norma general, los puntos limpios son instalaciones concebidas para su uso únicamente por parte de particulares; sin embargo, existen entidades municipales y supramunicipales que permiten el depósito en los puntos limpios de residuos asimilables a domésticos por parte de empresas, facilitándoles la gestión de residuos producidos por sus actividades, y como medida tendente a evitar la gestión incorrecta de los mismos. 
En este apartado se estudia si aquellos casos en que se permite el uso de los puntos limpios a las empresas presentan signos significativamente diferenciadores de los casos en que no se permite su uso por parte de las empresas.

\section{A5.4.12.1. Análisis de TR considerando factor de comparación la autorización de acceso a empresas.}

Existen 9 puntos limpios de la muestra de los que se dispone de información sobre cantidades de residuos depositadas en los mismos (TR) que, en cambio, no aportan datos sobre si autorizan o no el uso de las instalaciones por parte de empresas (Mancomunidad de Sasieta, Tudela, Churriana de la Vega, Rincón de la Victoria, Las Cabezas de San Juan, Utrera, Puerto de Santa María, Málaga y Valverde del Camino). Puesto que los datos de 3 de estos puntos limpios ya han sido descartados anteriormente por presentar valores de TR considerados anormalmente bajos, se dispone de 78 casos para el análisis, que quedan subdivididos en 2 subgrupos, en función de si se autoriza o no a empresas el depósito de residuos en el punto limpio, según se muestra en el Gráfico 5.4.52, en el que se observa que la mayoría de los puntos limpios sí permiten el depósito de residuos a empresas.

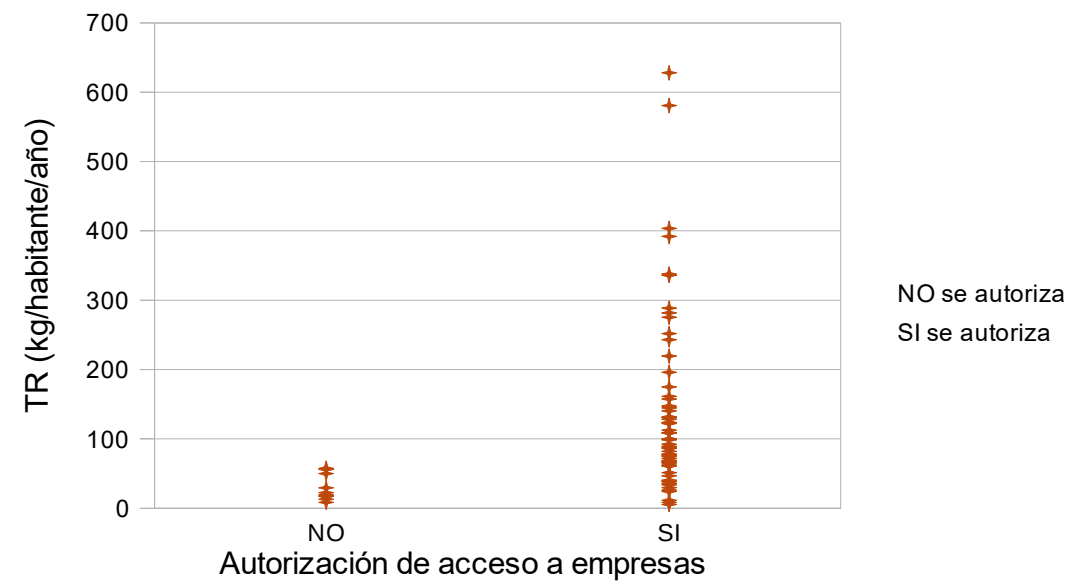

Gráfico 5.4.52: TR frente a autorización de acceso a empresas.

En la Tabla 5.4.114 se incluyen la media y la desviación estándar de TR de los puntos limpios, para la muestra total y los subgrupos en que ésta se segrega, en función de si se autoriza o no el 
acceso a las empresas. Se observa que tanto la media como la desviación estándar de TR son superiores en los puntos limpios en que se autoriza el acceso a empresas.

\begin{tabular}{|c|c|c|c|c|c|c|c|c|c|}
\hline \multirow{2}{*}{\multicolumn{2}{|c|}{ Grupo }} & \multirow[t]{2}{*}{$\mathbf{N}$} & \multirow[t]{2}{*}{ Media } & \multirow{2}{*}{$\begin{array}{c}\text { Desviación } \\
\text { Estándar }\end{array}$} & \multirow{2}{*}{$\begin{array}{c}\text { Error } \\
\text { Estándar }\end{array}$} & \multicolumn{2}{|c|}{$\begin{array}{c}\text { Intervalo de } \\
\text { Confianza } 95 \% \\
\text { para la Media }\end{array}$} & \multirow[t]{2}{*}{ Mínimo } & \multirow[t]{2}{*}{ Máximo } \\
\hline & & & & & & $\begin{array}{l}\text { Límite } \\
\text { Inferior }\end{array}$ & $\begin{array}{l}\text { Límite } \\
\text { Superior }\end{array}$ & & \\
\hline \multirow{3}{*}{ TR } & NO Acc. Empresas & 10 & 29,02 & 18,46 & 5,84 & 15,82 & 42,22 & 8,42 & 57,49 \\
\hline & SI Acc. Empresas & 68 & 132,07 & 122,51 & 14,86 & 102,42 & 161,73 & 5,43 & 628,02 \\
\hline & Total & 78 & 118,86 & 119,59 & 13,54 & 91,90 & 145,83 & 5,43 & 628,02 \\
\hline
\end{tabular}

Tabla 5.4.114: Media, desviación estándar, error estándar e intervalo de confianza de TR para los grupos de acceso a empresas.

Para la comprobación de validez de la hipótesis nula de igualdad de los subgrupos, se realiza la prueba $\mathrm{H}$ de Kruskal-Wallis, cuyos resultados se muestran en las Tablas 5.4.115 y 5.4.116.

\begin{tabular}{|c|l|r|r|}
\hline \multicolumn{1}{|c|}{ Variable } & \multicolumn{1}{c|}{ Grupo } & \multicolumn{1}{c|}{ N } & \multicolumn{1}{c|}{ Rango medio } \\
\hline \multirow{4}{*}{ TR } & NO Acc. Empresas & 10 & 11,70 \\
\cline { 2 - 4 } & SI Acc. Empresas & 68 & 43,59 \\
\cline { 2 - 4 } & Total & 78 & \\
\hline
\end{tabular}

Tabla 5.4.115: Kruskal-Wallis. $N^{\circ}$ de elementos y rango medio de TR en cada grupo de acceso a empresas.

\begin{tabular}{|l|r|}
\hline & \multicolumn{1}{|c|}{ TR } \\
\hline Chi-cuadrado & 17,26 \\
\hline df & 1 \\
\hline Sign. Asint. & 0,000 \\
\hline
\end{tabular}

Tabla 5.4.116: Resultados de significación del test de Kruskal-Wallis de TR respecto de acceso a empresas.

El resultado de significación de la prueba es 0,000 , por lo que los subgrupos son claramente distintos y, por tanto, pertenecen a poblaciones distintas.

En conclusión, si se autoriza el depósito de residuos en los puntos limpios a las empresas, las cantidades anuales gestionadas a través de los mismos van a ser diferentes de si no se autoriza el acceso de las empresas; el efecto es claramente de incremento de TR, con una media de 29,02 $\mathrm{kg} / \mathrm{habitante/año} \mathrm{para} \mathrm{la} \mathrm{parte} \mathrm{de} \mathrm{la} \mathrm{muestra} \mathrm{constituida} \mathrm{por} \mathrm{los} \mathrm{puntos} \mathrm{limpios} \mathrm{en} \mathrm{que} \mathrm{no} \mathrm{se}$ autoriza el depósito de residuos a las empresas, y de 132,07 kg/habitante/año en los casos en que sí se autoriza el acceso de las empresas. 


\section{A5.4.12.2. Análisis de TV considerando factor de comparación la autorización de acceso a empresas.}

De los elementos de la muestra considerados válidos, existe 1 (Puerto de Santa María) que no aporta información sobre la autorización de acceso a empresas, por lo que el número de casos que se tendrán en cuenta en el análisis es de 64. Los valores de TV, agrupados en función de si se autoriza o no el acceso a empresas al punto limpio, son los mostrados en el Gráfico 5.4.53, en el que se observa que representan una amplia mayoría los puntos limpios en que sí se autoriza el acceso de las empresas al servicio.

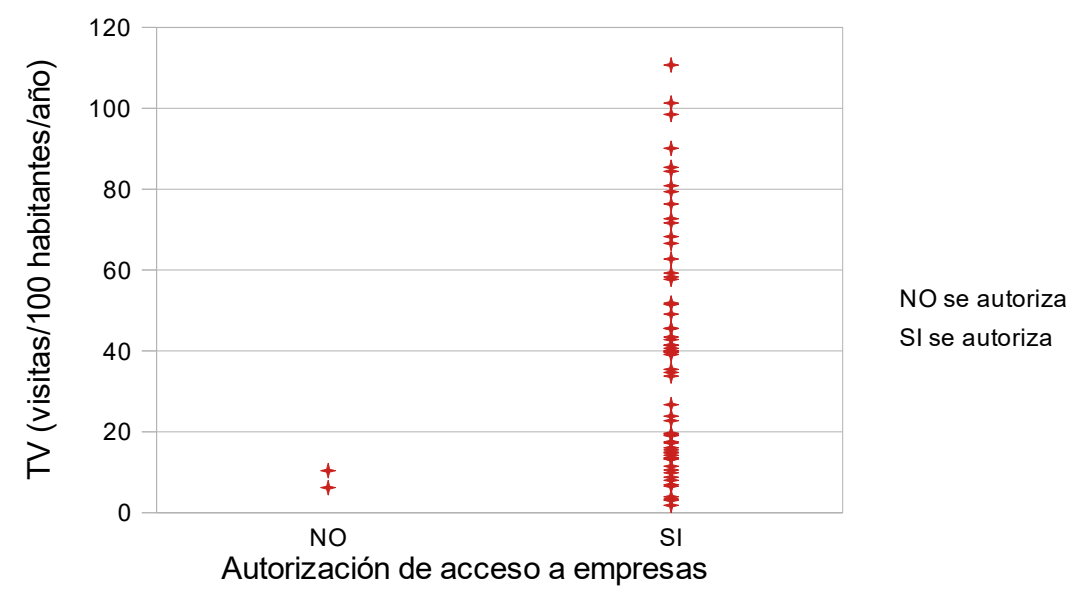

Gráfico 5.4.53: TV frente a autorización de acceso a empresas.

En la Tabla 5.4.117 se observa que tanto la media como la desviación estándar de TV es muy superior en los puntos limpios en que se autoriza el acceso a las empresas.

\begin{tabular}{|c|c|c|c|c|c|c|c|c|c|}
\hline \multirow{2}{*}{\multicolumn{2}{|c|}{ Grupo }} & \multirow[t]{2}{*}{$\mathbf{N}$} & \multirow[t]{2}{*}{ Media } & \multirow{2}{*}{$\begin{array}{l}\text { Desviación } \\
\text { Estándar }\end{array}$} & \multirow{2}{*}{$\begin{array}{c}\text { Error } \\
\text { Estándar }\end{array}$} & \multicolumn{2}{|c|}{$\begin{array}{c}\text { Intervalo de } \\
\text { Confianza } 95 \% \\
\text { para la Media }\end{array}$} & \multirow[t]{2}{*}{ Mínimo } & \multirow[t]{2}{*}{ Máximo } \\
\hline & & & & & & $\begin{array}{l}\text { Límite } \\
\text { Inferior }\end{array}$ & $\begin{array}{c}\text { Límite } \\
\text { Superior }\end{array}$ & & \\
\hline \multirow{3}{*}{ TV } & NO Acc. Empresas & 2 & 8,28 & 2,97 & 2,10 & $-18,44$ & 35,01 & 6,18 & 10,39 \\
\hline & SI Acc. Empresas & 62 & 39,28 & 28,45 & 3,61 & 32,05 & 46,50 & 1,82 & 110,66 \\
\hline & Total & 64 & 38,31 & 28,52 & 3,57 & 31,19 & 45,44 & 1,82 & 110,66 \\
\hline
\end{tabular}

Tabla 5.4.117: Media, desviación estándar, error estándar e intervalo de confianza de TV para los grupos de acceso a empresas. 
La validación de hipótesis de homocedasticidad entre grupos se realiza mediante el test de Levene, cuyos resultados se muestran en la Tabla 5.4.118.

\begin{tabular}{|c|r|r|r|r|}
\hline Variable & $\begin{array}{c}\text { Estadístico de } \\
\text { Levene }\end{array}$ & df1 & df2 & \multicolumn{1}{c|}{ Sign. } \\
\hline TV & 3,33 & 1 & 62 & 0,073 \\
\hline
\end{tabular}

Tabla 5.4.118: Resultados del test de Levene para TV y acceso a empresas.

El valor del estadístico es 3,33, inferior a 3,996, valor que toma la $F$ de Snedecor para $\alpha=0,05, y$ grados de libertad 1 y 62 , y el valor de significación es superior a 0,05 , por lo que se cumple el supuesto de homocedasticidad.

La hipótesis nula de igualdad de los grupos se comprueba mediante el test ANOVA, cuyos resultados se muestran en la Tabla 5.4.119.

\begin{tabular}{|c|c|c|c|c|c|c|}
\hline \multicolumn{2}{|c|}{ Factor } & $\begin{array}{c}\text { Suma de } \\
\text { Cuadrados }\end{array}$ & df & $\begin{array}{l}\text { Cuadrado } \\
\text { medio }\end{array}$ & $\mathbf{F}$ & Sign. \\
\hline \multirow{3}{*}{ TV } & Entre Grupos & $1.861,41$ & 1 & $1.861,41$ & 2,34 & 0,131 \\
\hline & Intra Grupos & $49.393,67$ & 62 & 796,67 & & \\
\hline & Total & $51.255,09$ & 63 & & & \\
\hline
\end{tabular}

Tabla 5.4.119: Resultados test ANOVA para TV y acceso a empresas.

Puesto que el valor de significación superior a 0,05, superior al error de la hipótesis nula, ésta se admite, y por tanto los grupos son iguales entre sí.

Por tanto, pese a las diferencias observadas en la Tabla 5.4.117, los resultados de la variable TV no se ven influenciados por la autorización de acceso a empresas para el depósito de residuos en el punto limpio. No obstante, los resultados de significación de esta prueba pueden no ser concluyentes, dado el reducido número de casos que conforman el grupo correspondiente a los puntos limpios en que no se autoriza el acceso a empresas.

Teniendo en cuenta los resultados del apartado anterior, puede concluirse que la diferencia es más significativa en términos de cantidades depositadas, que en número de visitas; el incremento de visitas que se produce en los puntos limpios en que se autoriza el acceso a las empresas no presenta un grado de significación determinante. Una lectura que puede realizarse es que las empresas que depositan residuos en los puntos limpios en que se les autoriza el acceso, entregan grandes cantidades de residuos por visita, mientras que los usuarios particulares realizan un 
elevado número de visitas con poco peso específico por visita, y por eso la variable sí resulta significativa para TR y no para TV.

\section{A5.4.13. Incentivos por utilización.}

Para la correcta gestión de los residuos, se han constituido diferentes SIG (Sistema Integrados de Gestión) o SCRAP (Sistema Colectivo de Responsabilidad Ampliada del Productor), que establecen tasas a la puesta en el mercado de productos que acabarán generando o convirtiéndose en residuos, con los que establecer bonificaciones económicas a aquellos actores que intervengan en su posterior recuperación: almacenamiento, transporte, clasificación, valorización. Siendo los puntos limpios uno de los eslabones en la recuperación de parte de estos residuos, en la medida en que realizan operaciones de almacenamiento, pueden ver bonificada su actividad mediante aportaciones económicas de los SCRAP que, a su vez, pueden decidir trasladar al usuario que realice aportaciones de residuos.

En este apartado se estudia si la existencia de bonificaciones por la utilización de los puntos limpios constituye un factor diferenciador en términos de frecuencia de uso y cantidades aportadas a los puntos limpios.

En la tabla del ANEXO A5.3 se observa que todos aquellos puntos limpios de la muestra para los que se han habilitado incentivos por el uso de los puntos limpios, existen asimismo tasas por el servicio, con excepción del Área Metropolitana de Valencia (se aplican tasas, pero no se bonifica la utilización del servicio).

\section{A5.4.13.1. Análisis de TR considerando factor de comparación la existencia de incentivos por utilización.}

Los casos de análisis de este factor son los mismos que los que se han considerado en el punto 5.4.10.1; por tanto, el tamaño de la muestra a estudiar es de 82 casos, con la distribución de la variable TR en función de si existen incentivos por el uso del punto limpio que se muestra en el Gráfico 5.4.54. 


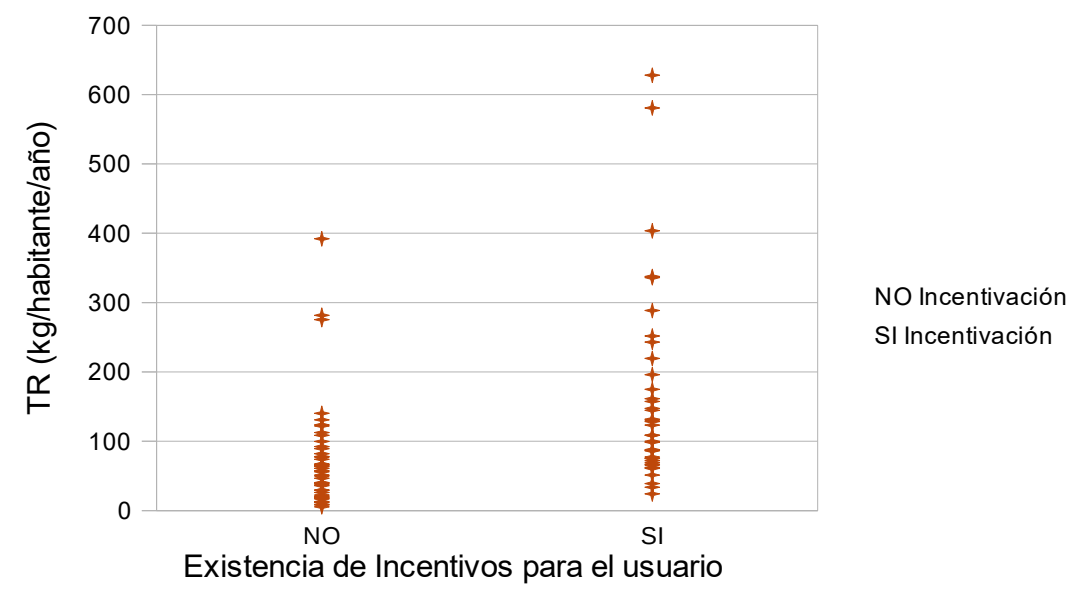

Gráfico 5.4.54: TR frente a incentivos por uso.

Se observa que se obtienen valores máximos de TR superiores en los puntos limpios en que sí existen incentivos por la utilización del servicio. Por otro lado, en la Tabla 5.4.120 se observa que tanto la media como la desviación estándar de TR son superiores para este mismo subgrupo de puntos limpios.

\begin{tabular}{|c|c|c|c|c|c|c|c|c|c|}
\hline \multirow{2}{*}{\multicolumn{2}{|c|}{ Grupo }} & \multirow[t]{2}{*}{$\mathbf{N}$} & \multirow[t]{2}{*}{ Media } & \multirow{2}{*}{$\begin{array}{l}\text { Desviación } \\
\text { Estándar }\end{array}$} & \multirow{2}{*}{$\begin{array}{l}\text { Error } \\
\text { Estándar }\end{array}$} & \multicolumn{2}{|c|}{$\begin{array}{c}\text { Intervalo de } \\
\text { Confianza } 95 \% \\
\text { para la Media }\end{array}$} & \multirow[t]{2}{*}{ Mínimo } & \multirow[t]{2}{*}{ Máximo } \\
\hline & & & & & & $\begin{array}{l}\text { Límite } \\
\text { Inferior }\end{array}$ & $\begin{array}{c}\text { Límite } \\
\text { Superior }\end{array}$ & & \\
\hline \multirow{3}{*}{ TR } & NO incentivación & 43 & 75,52 & 77,35 & 11,80 & 51,71 & 99,32 & 5,43 & 392,09 \\
\hline & SI incentivación & 39 & 159,83 & 137,94 & 22,09 & 115,11 & 204,54 & 24,07 & 628,02 \\
\hline & Total & 82 & 115,62 & 117,57 & 12,98 & 89,78 & 141,45 & 5,43 & 628,02 \\
\hline
\end{tabular}

Tabla 5.4.120: Media, desviación estándar, error estándar e intervalo de confianza de TR para los grupos de incentivos por uso.

La comprobación de validez de la hipótesis nula de igualdad de los subgrupos, se realiza mediante la prueba $\mathrm{H}$ de Kruskal-Wallis, cuyos resultados se muestran en las Tablas 5.4.121 y 5.4.122.

\begin{tabular}{|c|l|r|r|}
\hline \multicolumn{1}{|c|}{ Variable } & \multicolumn{1}{c|}{ Grupo } & \multicolumn{1}{c|}{ N } & \multicolumn{1}{c|}{ Rango medio } \\
\hline \multirow{4}{*}{ TR } & NO incentivación & 43 & 31,05 \\
\cline { 2 - 4 } & SI incentivación & 39 & 53,03 \\
\cline { 2 - 4 } & Total & 82 & \\
\hline
\end{tabular}

Tabla 5.4.121: Kruskal-Wallis. $N^{\circ}$ de elementos y rango medio de TR en cada grupo de incentivos por uso. 


\begin{tabular}{|l|r|}
\hline & \multicolumn{2}{|c|}{ TR } \\
\hline Chi-cuadrado & 17,42 \\
\hline df & 1 \\
\hline Sign. Asint. & 0,000 \\
\hline
\end{tabular}

Tabla 5.4.122: Resultados de significación del test de Kruskal-Wallis de TR respecto de incentivos por uso.

Al obtener un resultado de significación de la prueba de 0,000 , se rechaza la hipótesis nula, por lo que los grupos son distintos

En conclusión, la parte de la muestra compuesta por los puntos limpios en que se han habilitado incentivos por uso presenta valores de TR significativamente distintos a aquellos puntos limpios en que dichos incentivos no existen, con valores que duplican los obtenidos en éstos últimos. Es decir: las cantidades de residuos depositados en los puntos limpios se incrementan si el usuario que realiza la entrega obtiene algún incentivo a cambio de dicha gestión.

\section{A5.4.13.2. Análisis de TV considerando factor de comparación la existencia de incentivos por utilización.}

El número de casos que se van a tener en cuenta en este estudio es de 64 , puesto que los puntos limpios que informan sobre la existencia de incentivos por uso son los mismos que los analizados en el punto 5.4.12.2. Los valores de TV de los casos que componen cada subgrupo, en función de si se incentiva o no el uso del punto limpio, se muestran en el Gráfico 5.4.55, en el que se observa una aparente mayor dispersión en los puntos limpios sin incentivos que, por otro lado, alcanzan cotas máximas de TV superiores. 


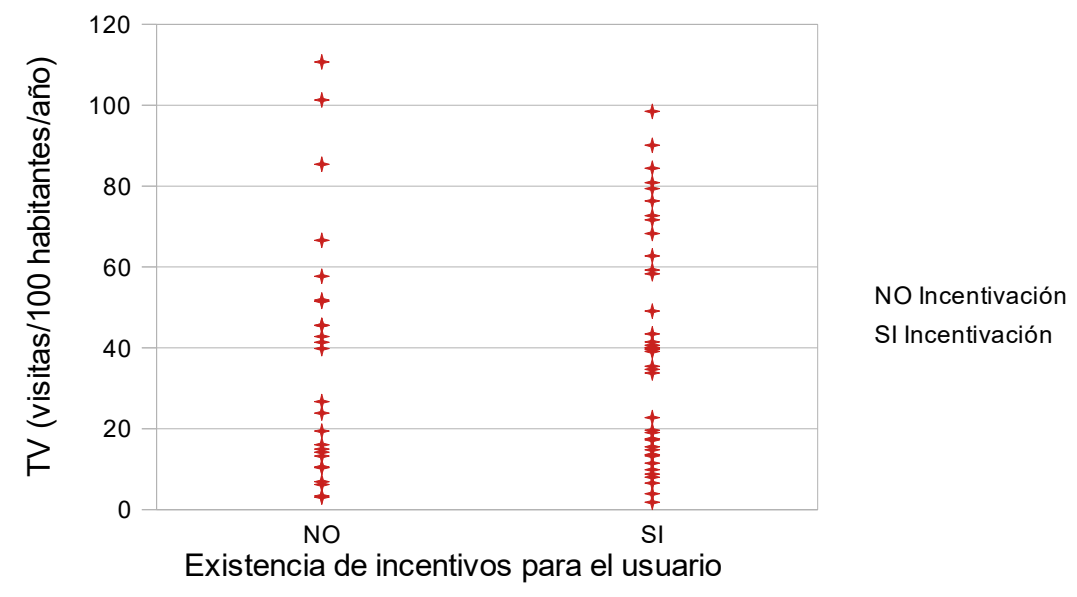

Gráfico 5.4.55: TV frente a incentivos por uso.

En la Tabla 5.4.123 se observa que el número de puntos limpios en que se incentiva su uso es mayoritario, con una media de TV superior y una desviación estándar inferior a las que presentan los puntos limpios sin incentivos por uso.

\begin{tabular}{|c|c|c|c|c|c|c|c|c|c|}
\hline \multirow{2}{*}{\multicolumn{2}{|c|}{ Grupo }} & \multirow[t]{2}{*}{$\mathbf{N}$} & \multirow[t]{2}{*}{ Media } & \multirow{2}{*}{$\begin{array}{l}\text { Desviación } \\
\text { Estándar }\end{array}$} & \multirow[t]{2}{*}{$\begin{array}{c}\text { Error } \\
\text { Estándar }\end{array}$} & \multicolumn{2}{|c|}{$\begin{array}{c}\text { Intervalo de } \\
\text { Confianza } 95 \% \\
\text { para la Media }\end{array}$} & \multirow[t]{2}{*}{ Mínimo } & \multirow[t]{2}{*}{ Máximo } \\
\hline & & & & & & $\begin{array}{l}\text { Límite } \\
\text { Inferior }\end{array}$ & $\begin{array}{c}\text { Límite } \\
\text { Superior }\end{array}$ & & \\
\hline \multirow{3}{*}{ TV } & NO incentivación & 25 & 36,35 & 30,26 & 6,05 & 23,86 & 48,84 & 3,08 & 110,66 \\
\hline & SI incentivación & 39 & 39,57 & 27,68 & 4,43 & 30,59 & 48,54 & 1,82 & 98,46 \\
\hline & Total & 64 & 38,31 & 28,52 & 3,57 & 31,19 & 45,44 & 1,82 & 110,66 \\
\hline
\end{tabular}

Tabla 5.4.123: Media, desviación estándar, error estándar e intervalo de confianza de TV para los grupos de incentivos por uso.

A continuación se aplica sobre la muestra el test de Levene, para validar el supuesto de homogenidad de varianzas entre grupos, cuyos resultados se presentan en la Tabla 5.4.124.

\begin{tabular}{|c|r|r|r|r|}
\hline \multicolumn{1}{|c|}{ Variable } & $\begin{array}{c}\text { Estadístico de } \\
\text { Levene }\end{array}$ & df1 & df2 & \multicolumn{1}{c|}{ Sign. } \\
\hline TV & 0,13 & 1 & 62 & 0,718 \\
\hline
\end{tabular}

Tabla 5.4.124: Resultados del test de Levene para TV e incentivos por uso. 
El valor del estadístico de Levene es 0,13 , inferior a 3,996, valor que toma la $\mathrm{F}$ de Snedecor para $\alpha=0,05$, y grados de libertad 1 y 62 , y el valor de significación es muy superior a 0,05 , por lo que puede afirmarse que se cumple el supuesto de homocedasticidad.

La hipótesis nula de igualdad de los grupos se comprueba mediante el test ANOVA, cuyos resultados se muestran en la Tabla 5.4.125.

\begin{tabular}{|c|c|c|c|c|c|c|}
\hline \multicolumn{2}{|c|}{ Factor } & $\begin{array}{c}\text { Suma de } \\
\text { Cuadrados }\end{array}$ & df & $\begin{array}{l}\text { Cuadrado } \\
\text { medio }\end{array}$ & $\mathbf{F}$ & Sign. \\
\hline \multirow{3}{*}{ TV } & Entre Grupos & 157,44 & 1 & 157,44 & 0,19 & 0,664 \\
\hline & Intra Grupos & $51.097,64$ & 62 & 824,16 & & \\
\hline & Total & $51.255,09$ & 63 & & & \\
\hline
\end{tabular}

Tabla 5.4.125: Resultados test ANOVA para TV e incentivos por uso.

Resultando un valor de significación superior a 0,05 , por lo que la hipótesis nula se considera válida y las poblaciones de ambos subgrupos son iguales. Por tanto, la variable TV no presenta significación estadística respecto de la incentivación de uso del punto limpio.

Finalmente, puede concluirse que el hecho de se habiliten incentivos para los usuarios de los puntos limpios no presenta incidencia significativa en el número de visitas que se realizan a la instalación para el depósito de residuos, pero sí lo hace sobre las cantidades depositadas, con valores de TR superiores los puntos limpios en que se incentiva su uso.

\section{A5.4.14. Límites de aportación.}

Con el objetivo de ordenar el funcionamiento de los puntos limpios, con los objetivos de evitar usos inadecuados, saturación de la gestión del servicio y costes asumidos por la Administración, en ocasiones se establecen límites, en $\mathrm{kg}$ o en volumen de residuos aportados, a los usuarios y por periodo, que puede ser diario, semanal, mensual o anual.

En este apartado se estudia si el establecimiento de estos límites constituye un elemento significativo sobre los resultados de gestión del punto limpio. 


\section{A5.4.14.1. Análisis de TR considerando factor de comparación la limitación de cantidades aportadas.}

Los elementos de la muestra de que se dispone de información y cuyos valores se consideran adecuados son los mismos que los analizados en el punto 5.4.12.1; es decir, se dispone de 78 registros válidos que, agrupados en función de si en las instalaciones existen límites de aportación, presentan los valores de TR que se muestran en el Gráfico 5.4.56.

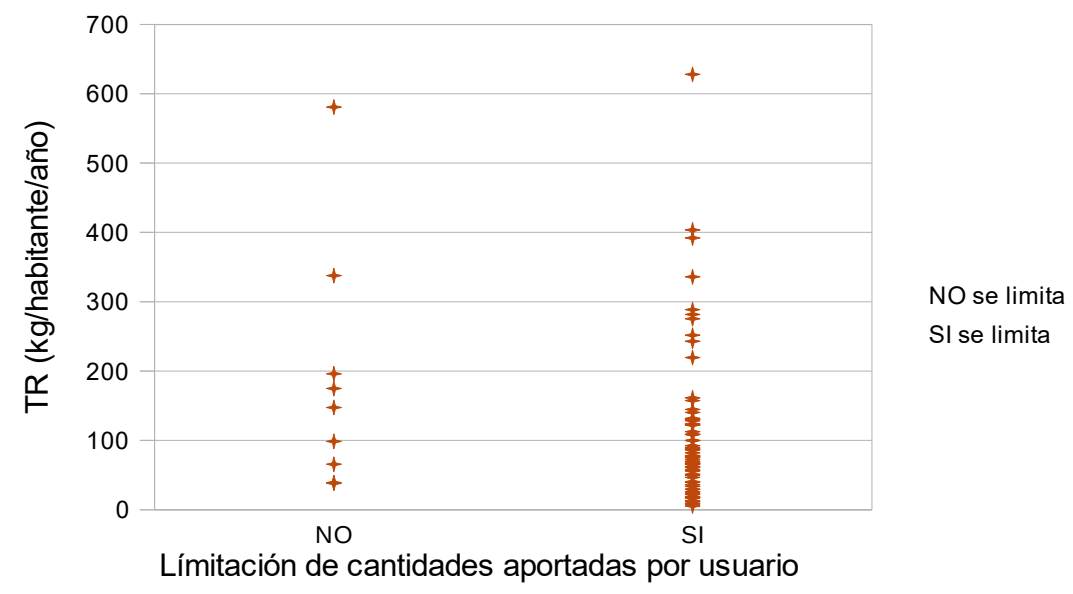

Gráfico 5.4.56: TR frente a límites de aportación.

Se observa que constituyen mayoría los casos en que sí existen límites a las aportaciones que realizan los usuarios a los puntos limpios, con valores máximos de TR superiores y una aparente menor dispersión de la variable que la que presenta el subgrupo de puntos limpios sin limitaciones a la aportación. En la Tabla 5.4.126 puede observarse que tanto la media como la desviación estándar de TR son superiores para los puntos limpios en que no se fijan límites de aportación.

\begin{tabular}{|c|c|c|c|c|c|c|c|c|c|}
\hline & \multirow[t]{2}{*}{ Grupo } & \multirow[t]{2}{*}{$\mathbf{N}$} & \multirow[t]{2}{*}{ Media } & \multirow{2}{*}{$\begin{array}{l}\text { Desviación } \\
\text { Estándar }\end{array}$} & \multirow{2}{*}{$\begin{array}{c}\text { Error } \\
\text { Estándar }\end{array}$} & \multicolumn{2}{|c|}{$\begin{array}{c}\text { Intervalo de } \\
\text { Confianza } 95 \% \\
\text { para la Media }\end{array}$} & \multirow[t]{2}{*}{ Mínimo } & \multirow[t]{2}{*}{ Máximo } \\
\hline & & & & & & $\begin{array}{l}\text { Límite } \\
\text { Inferior }\end{array}$ & $\begin{array}{l}\text { Límite } \\
\text { Superior }\end{array}$ & & \\
\hline \multirow{3}{*}{ TR } & NO se limita & 9 & 186,48 & 175,39 & 58,46 & 51,66 & 321,29 & 38,27 & 580,66 \\
\hline & SI se limita & 69 & 110,04 & 109,05 & 13,13 & 83,84 & 136,24 & 5,43 & 628,02 \\
\hline & Total & 78 & 118,86 & 119,59 & 13,54 & 91,90 & 145,83 & 5,43 & 628,02 \\
\hline
\end{tabular}

Tabla 5.4.126: Media, desviación estándar, error estándar e intervalo de confianza de TR para los grupos de límites de aportación. 
Mediante la prueba $\mathrm{H}$ de Kruskal-Wallis se comprueba la validez de la hipótesis nula de igualdad de los subgrupos. Los resultados de la prueba se muestran en las Tablas 5.4.127 y 5.4.128.

\begin{tabular}{|l|l|r|r|}
\hline \multicolumn{1}{|c|}{ Variable } & \multicolumn{1}{c|}{ Grupo } & N & \multicolumn{1}{c|}{ Rango medio } \\
\hline \multirow{4}{*}{ TR } & NO se limita & 9 & 50,22 \\
\cline { 2 - 4 } & SI se limita & 69 & 38,10 \\
\cline { 2 - 4 } & Total & 78 & \\
\hline
\end{tabular}

Tabla 5.4.127: Kruskal-Wallis. № de elementos y rango medio de TR en cada grupo de límites de aportación.

\begin{tabular}{|l|r|}
\hline & \multicolumn{2}{|r|}{ TR } \\
\hline Chi-cuadrado & 2,28 \\
\hline df & 1 \\
\hline Sign. Asint. & 0,131 \\
\hline
\end{tabular}

Tabla 5.4.128: Resultados de significación del test de Kruskal-Wallis de TR respecto de límites de aportación.

Puesto que el valor de significación es superior a 0,05 , no existen diferencias entre los subgrupos de la muestra y, por tanto, las poblaciones son iguales, no presentando significación estadística la variable TR respecto de la existencia de límites de aportación de residuos en el punto limpio. Pese a que la media de TR es superior en los puntos limpios en que no existen límites de aportación, la diferencia entre ambos subgrupos no es estadísticamente significativa.

\section{A5.4.14.2. Análisis de TV considerando factor de comparación la limitación de cantidades aportadas.}

Los casos con información relevante a efectos del estudio de significación de la variable representativa de la existencia de limitación a las aportaciones realizadas y TV son los mismos que los considerados en el punto 5.4.12.2, por lo que el tamaño de la muestra a analizar es de 64 puntos limpios, cuyos valores de TV, agrupados en función de si se han establecido límites de aportación por usuario, es la que se muestra en el Gráfico 5.4.57. 


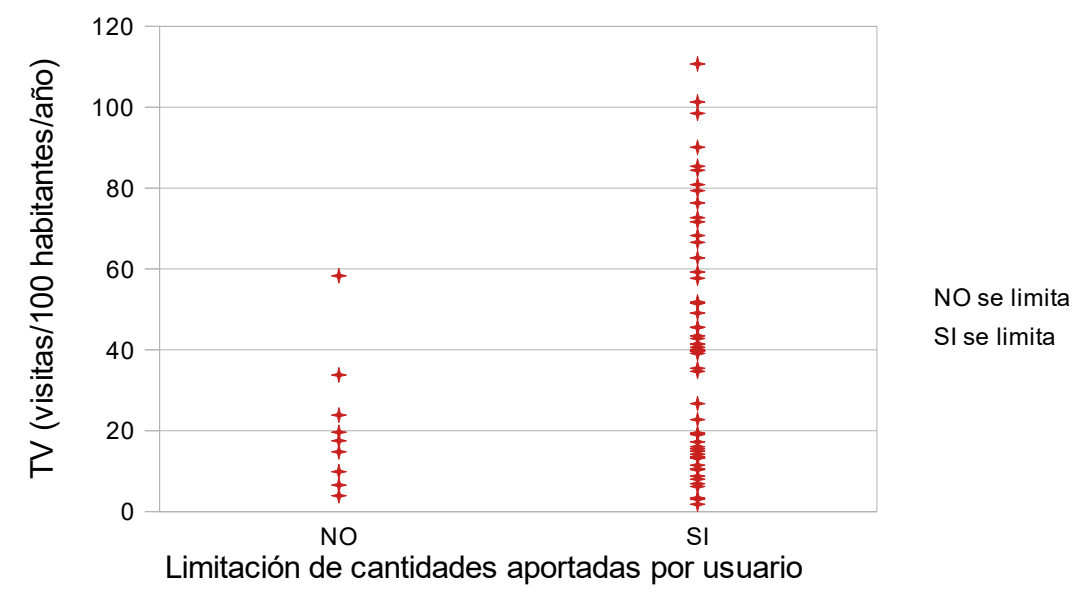

Gráfico 5.4.57: TV frente a límites de aportación.

Al igual que en el estudio de TR, se observa que la cantidad de puntos limpios en que se limitan las cantidades aportadas es superior a la de aquellos en que no se limita, alcanzando valores máximos de TV superiores si existen dichos límites.

En la Tabla 5.4.129 se comprueba la dispar cantidad de puntos limpios en que existen o no límites de aportación. Asimismo, se observa que los valores de media y desviación estándar de TV son superiores en los puntos limpios en que existen límites de aportación.

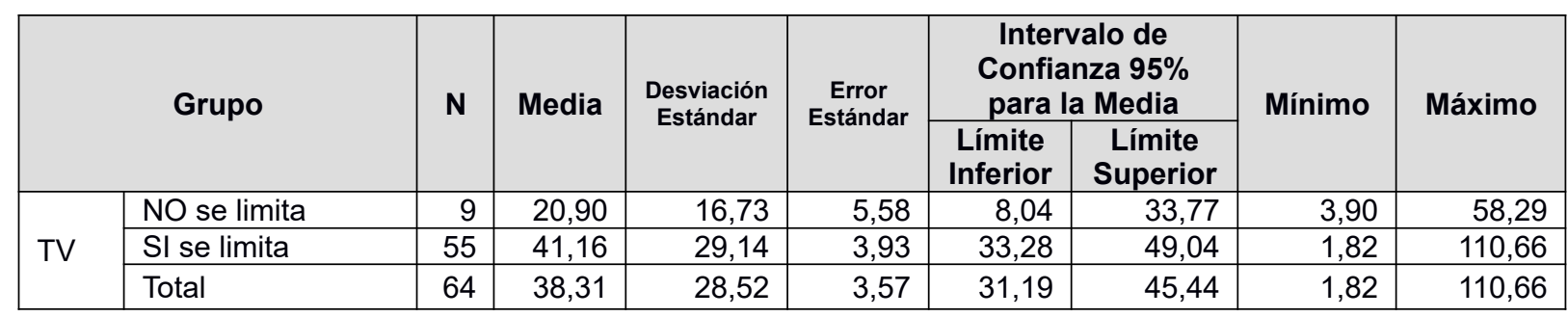

Tabla 5.4.129: Media, desviación estándar, error estándar e intervalo de confianza de TV para los grupos de límites de aportación.

La validación del supuesto de homocedasticidad se realiza mediante aplicación del test de Levene. Los resultados de la prueba se presentan en la Tabla 5.4.130.

\begin{tabular}{|c|r|r|r|r|}
\hline Variable & $\begin{array}{c}\text { Estadístico de } \\
\text { Levene }\end{array}$ & df1 & df2 & \multicolumn{1}{c|}{ Sign. } \\
\hline TV & 4,12 & 1 & 62 & 0,047 \\
\hline
\end{tabular}

Tabla 5.4.130: Resultados del test de Levene para TV y límites de aportación. 
El valor del estadístico de Levene es 4,12, superior a 3,996, valor que toma la $\mathrm{F}$ de Snedecor para $\alpha=0,05$, y grados de libertad 1 y 62 , mientras que el valor de significación es inferior a 0,05 , por lo que no puede afirmarse que exista homogeneidad de varianzas. Así, la prueba de igualdad de grupos, mediante el análisis de varianza de las medias entre grupos, deberá llevarse a cabo mediante el test ANOVA-Welch. Los resultados de la prueba se incluyen en la Tabla 5.4.131.

\begin{tabular}{|l|l|r|r|c|}
\hline \multicolumn{2}{|c|}{ Factor } & df & F & Sign. \\
\hline \multirow{2}{*}{ TV } & Entre Grupos & 1 & 8,814 & $8,497 e-3$ \\
\cline { 2 - 6 } & Intra Grupos & 17,278 & \multicolumn{2}{|c}{} \\
\cline { 1 - 6 } & &
\end{tabular}

Tabla 5.4.131: Resultados del test ANOVA-Welch para TV y límites de aportación.

El resultado de significación de la prueba es inferior a 0,05, por lo que se rechaza la hipótesis nula de igualdad entre grupos.

Por tanto, los resultados de la variable TV presentan diferencias significativas en virtud del valor de la variable asociada a la existencia de límites a las aportaciones de residuos por los usuarios. Se observa que los valores de TV son superiores en el grupo de casos de la muestra formado por los puntos limpios en que sí existen límites de aportación; es decir, el número de visitas se incrementa de manera significativa cuando existen límites a las cantidades aportadas, por lo que no puede concluirse que tenga un efecto disuasorio en términos de accesos; de hecho, podría incluso interpretarse que existe cierto segmento de usuarios que incrementa el número de accesos, con el efecto de repartir las cantidades a depositar en varias visitas.

En definitiva, la variable no presenta significación sobre TR (que, no obstante, es inferior en los puntos con limitación en la aportación de residuos), y sí sobre TV (incrementándose su valor medio en aquellos puntos con limitación en la aportación). Por tanto, la existencia de límites de aportación de residuos en los puntos limpios sí tiene cierto efecto, no significativo, de reducción de las cantidades depositadas, que posiblemente fomente la búsqueda de métodos de gestión de residuos alternativos (no por ello más adecuadas o con mayor coste para su poseedor, puesto que puede estar propiciando la aparición de puntos de vertido clandestino), y un claro efecto significativo de incremento en el número de visitas, presumiblemente con el fin de amortiguar la tasa diaria de aportación. La combinación de ambos efectos puede, a priori, tener como consecuencia una mejor planificación de la logística de almacenamiento y transporte de los residuos depositados. 


\section{A5.4.15. Tipo de gestión.}

La gestión de los puntos limpios puede realizarse, principalmente, a través de una de las siguientes opciones:

- Gestión directa por parte de la Administración competente

- Gestión indirecta mediante Concesión

En este apartado se analizará si la elección adoptada por la Administración para la gestión de la instalación resulta significativa sobre los resultados de gestión de residuos del punto limpio.

\section{A5.4.15.1. Análisis de TR considerando factor de comparación la gestión de la instalación.}

El número de casos de que se dispone de información es de 84, la totalidad de los considerados para el análisis de TR. Los valores de TR de cada uno de los grupos en que se segrega la muestra, en función del modelo elegido para la gestión de la instalación, se muestran en el Gráfico 5.4.58.

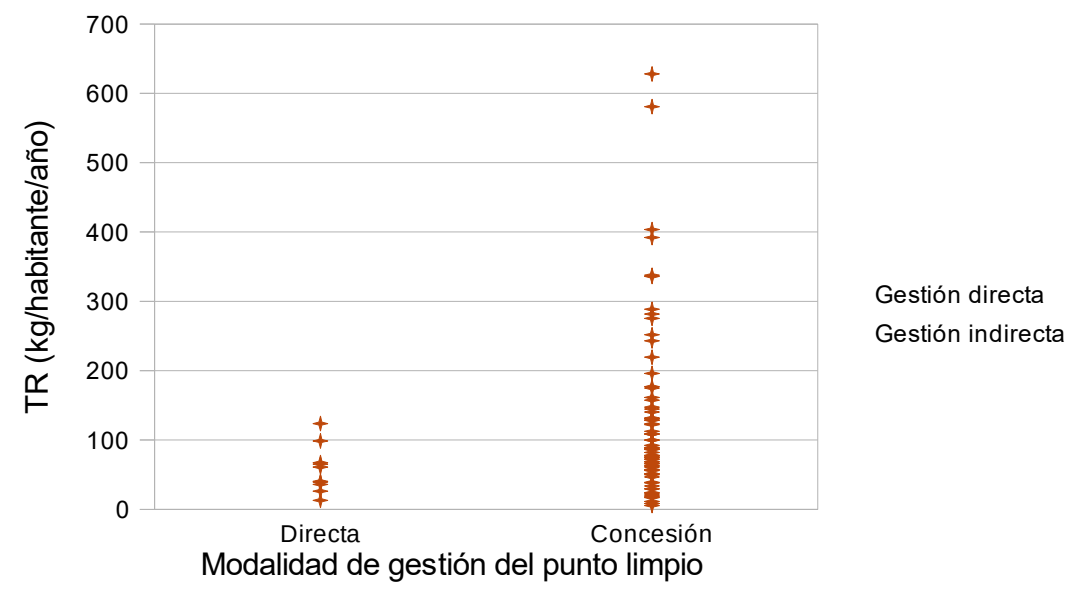

Gráfico 5.4.58: TR frente a tipo de gestión.

Se observa que en la mayoría de los casos, el $88 \%$, la gestión de los puntos limpios se lleva a cabo mediante la figura de un concesionario, alcanzando cotas máximas de TR claramente 
superiores al otro grupo de puntos limpios. En la Tabla 5.4.132 se muestran los valores de media y desviación estándar de TR en cada grupo y la muestra total, presentando valores superiores de ambas los puntos limpios gestionados mediante concesión.

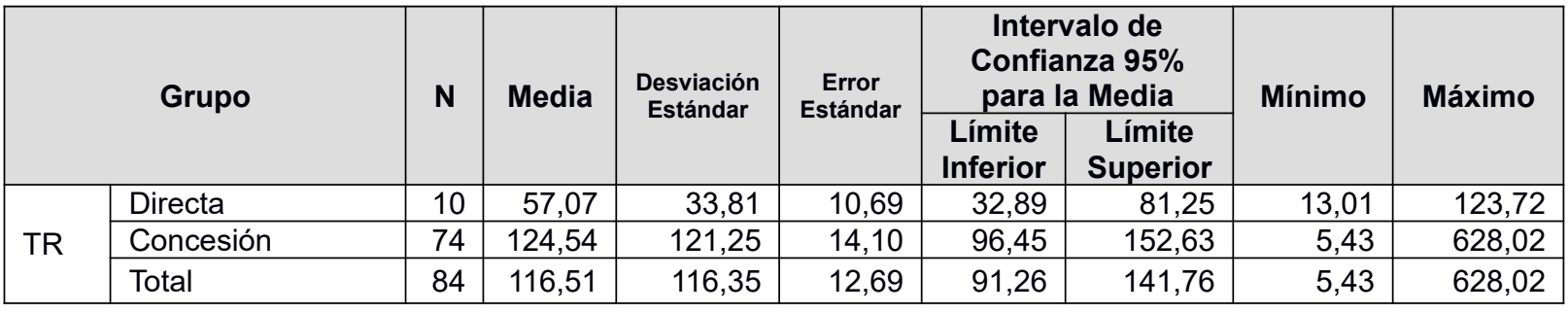

Tabla 5.4.132: Media, desviación estándar, error estándar e intervalo de confianza de TR para los grupos de tipo de gestión.

Para la validación de la hipótesis nula de igualdad entre grupos se aplica la prueba $\mathrm{H}$ de KruskalWallis, cuyos resultados se presentan en las Tablas 5.4.133 y 5.4.134.

\begin{tabular}{|l|l|r|r|}
\hline \multicolumn{1}{|c|}{ Variable } & \multicolumn{1}{|c|}{ Grupo } & \multicolumn{1}{c|}{ N } & \multicolumn{1}{c|}{ Rango medio } \\
\hline \multirow{4}{*}{ TR } & Directa & 10 & 27,40 \\
\cline { 2 - 4 } & Concesión & 74 & 44,54 \\
\cline { 2 - 4 } & Total & 84 & \\
\hline
\end{tabular}

Tabla 5.4.133: Kruskal-Wallis. $N^{\circ}$ de elementos y rango medio de TR en cada grupo de tipo de gestión.

\begin{tabular}{|l|r|}
\hline & \multicolumn{2}{|c|}{ TR } \\
\hline Chi-cuadrado & 4,35 \\
\hline df & 1 \\
\hline Sign. Asint. & 0,037 \\
\hline
\end{tabular}

Tabla 5.4.134: Resultados de significación del test de Kruskal-Wallis de TR respecto de tipo de gestión.

Al obtenerse un valor de significación como resultado de aplicación de la prueba inferior al error de la hipótesis nula $(0,05)$, se rechaza la hipótesis nula de igualdad de grupos, y por tanto se concluye que los casos integrados en los subgrupos creados pertenecen a poblaciones distintas.

No obstante, es habitual que las administraciones titulares de los servicios dirigidos a los ciudadanos, principalmente entidades locales, se inclinen más un modelo de gestión de los mismos en función de su tamaño de población, directamente relacionado con los presupuestos y, por tanto, con la disponibilidad económica para la administración de recursos, tanto personales 
(dimensionamiento de los servicios de prestación directa) como de contratación. A continuación se analiza si existen modelos de gestión mayoritarios en función del tamaño del municipio, y si dicha elección afecta a los resultados de análisis de la muestra en su conjunto, y la posible obtención de resultados distintos si se tiene en consideración el factor demográfico.

Del total de la muestra analizada, la segregación conforme a la combinación de criterios demográficos y de gestión del punto limpio es la que se muestra en la Tabla 5.4.135.

\begin{tabular}{|l|l|r|}
\hline Tamaño punto limpio & \multicolumn{1}{|c|}{ Gestión } & N. ${ }^{\circ}$ casos \\
\hline Rural & Concesión & 24 \\
\hline Semiurbano & Concesión & 37 \\
\hline \multirow{2}{*}{ Urbano } & Directa & 10 \\
\cline { 2 - 3 } & Concesión & 13 \\
\hline TOTAL & 81 \\
\hline
\end{tabular}

Tabla 5.4.135: TR. Número de casos por tamaño de población adscrita y tipo de gestión.

Por tanto, no procede el análisis de los casos de puntos limpios con población adscrita inferior a 50.000 habitantes (puntos limpios rurales y semiurbanos), puesto que en todos los casos la gestión se realiza mediante concesión.

En la Tabla 5.4.136 se muestran los valores de media y desviación estándar de TR de los puntos limpios urbanos, en función de si su gestión se realiza directamente por la Administración o mediante concesión, observándose que ambas son muy superiores en los segundos.

\begin{tabular}{|c|c|c|c|c|c|c|c|c|c|}
\hline \multirow{2}{*}{\multicolumn{2}{|c|}{ Grupo }} & \multirow[t]{2}{*}{$\mathbf{N}$} & \multirow{2}{*}{ Media } & \multirow{2}{*}{$\begin{array}{l}\text { Desviación } \\
\text { Estándar }\end{array}$} & \multirow{2}{*}{$\begin{array}{c}\text { Error } \\
\text { Estándar }\end{array}$} & \multicolumn{2}{|c|}{$\begin{array}{c}\text { Intervalo de } \\
\text { Confianza } 95 \% \\
\text { para la Media }\end{array}$} & \multirow{2}{*}{ Mínimo } & \multirow{2}{*}{ Máximo } \\
\hline & & & & & & $\begin{array}{l}\text { Límite } \\
\text { Inferior }\end{array}$ & $\begin{array}{c}\text { Límite } \\
\text { Superior }\end{array}$ & & \\
\hline \multirow{3}{*}{ TR } & Directa & 10 & 57,07 & 33,81 & 10,69 & 32,89 & 81,25 & 13,01 & 123,72 \\
\hline & Concesión & 13 & 92,92 & 100,25 & 27,80 & 32,34 & 153,50 & 5,43 & 337,77 \\
\hline & Total & 23 & 77,33 & 79,24 & 16,52 & 43,06 & 111,60 & 5,43 & 337,77 \\
\hline
\end{tabular}

Tabla 5.4.136: Media, desviación estándar, error estándar e intervalo de confianza de TR en puntos limpios urbanos para los grupos de tipo de gestión.

La hipótesis nula de igualdad entre grupos se comprueba mediante la la prueba $\mathrm{H}$ de KruskalWallis, cuyos resultados se presentan en las Tablas 5.4.137 y 5.4.138. 
Estudio de influencia de variables sobre los resultados de TR y TV de los puntos limpios.

\begin{tabular}{|l|l|r|r|}
\hline \multicolumn{1}{|c|}{ Variable } & \multicolumn{1}{c|}{ Grupo } & \multicolumn{1}{c|}{ N } & \multicolumn{1}{c|}{ Rango medio } \\
\hline \multirow{4}{*}{ TR } & Directa & 10 & 11,80 \\
\cline { 2 - 4 } & Concesión & 13 & 12,15 \\
\cline { 2 - 4 } & Total & 23 & \\
\hline
\end{tabular}

Tabla 5.4.137: Kruskal-Wallis. $N^{\circ}$ de elementos y rango medio de TR en cada grupo de tipo de gestión para puntos limpios urbanos.

\begin{tabular}{|l|r|}
\hline & \multicolumn{1}{|c|}{ TR } \\
\hline Chi-cuadrado & 0,02 \\
\hline df & 1 \\
\hline Sign. Asint. & 0,901 \\
\hline
\end{tabular}

Tabla 5.4.138: Resultados de significación del test de Kruskal-Wallis de TR respecto de tipo de gestión para puntos limpios urbanos.

Se obtiene un valor de significación superior a 0,05 y, por tanto, se valida la hipótesis nula y los grupos pertenecen a la misma población.

En conclusión, los resultados de TR resultan estadísticamente significativos respecto de la variable asociada al tipo de gestión del punto limpio, con valores de media de TR superiores si se lleva a cabo mediante concesión. Sin embargo, en la muestra únicamente se gestionan mediante concesión puntos limpios con población adscrita superior a 50.000 habitantes. Realizado el estudio de significación sobre este grupo, se observa que todos los elementos pertenecen a misma población y, por tanto, no existe significación estadística sobre TR relativa al tipo de gestión del punto limpio.

\section{A5.4.15.2. Análisis de TV considerando factor de comparación la gestión de la instalación.}

Todos los puntos limpios considerados válidos respecto de la variable TV informan del tipo de gestión de la instalación, por lo que el número de casos que se tendrán en cuenta para el análisis es de 65. En el Gráfico 5.4.59 se observa que los valores máximos de TV se obtienen en los puntos limpios gestionados mediante concesión que, además, representan la situación mayoritaria. En la Tabla 5.4.139 se comprueba que constituyen el $91 \%$ de la muestra, con valores de media y desviación estándar de TV muy superiores a los de los puntos limpios de gestión directa. 


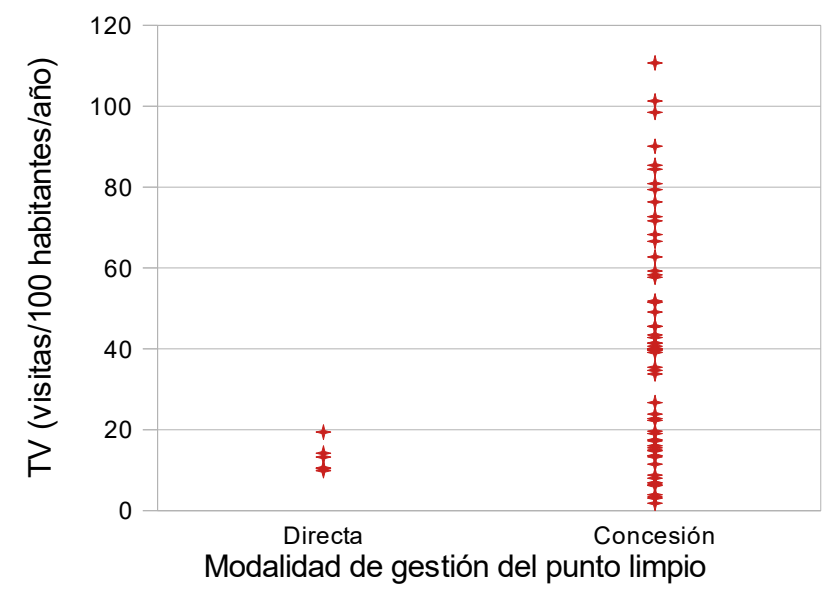

Gráfico 5.4.59: TV frente a tipo de gestión.

\begin{tabular}{|c|c|c|c|c|c|c|c|c|c|}
\hline \multirow{2}{*}{\multicolumn{2}{|c|}{ Grupo }} & \multirow[t]{2}{*}{$\mathbf{N}$} & \multirow[t]{2}{*}{ Media } & \multirow[t]{2}{*}{$\begin{array}{l}\text { Desviación } \\
\text { Estándar }\end{array}$} & \multirow[t]{2}{*}{$\begin{array}{c}\text { Error } \\
\text { Estándar }\end{array}$} & \multicolumn{2}{|c|}{$\begin{array}{c}\text { Intervalo de } \\
\text { Confianza } 95 \% \\
\text { para la Media }\end{array}$} & \multirow[t]{2}{*}{ Mínimo } & \multirow[t]{2}{*}{ Máximo } \\
\hline & & & & & & $\begin{array}{l}\text { Límite } \\
\text { Inferior }\end{array}$ & $\begin{array}{c}\text { Límite } \\
\text { Superior }\end{array}$ & & \\
\hline \multirow{3}{*}{ TV } & Directa & 6 & 12,93 & 3,61 & 1,47 & 9,15 & 16,72 & 9,86 & 19,39 \\
\hline & Concesión & 59 & 40,62 & 28,55 & 3,72 & 33,18 & 48,06 & 1,82 & 110,66 \\
\hline & Total & 65 & 38,06 & 28,37 & 3,52 & 31,04 & 45,09 & 1,82 & 110,66 \\
\hline
\end{tabular}

Tabla 5.4.139: Media, desviación estándar, error estándar e intervalo de confianza de TV para los grupos de tipo de gestión.

A continuación se aplica sobre la muestra el test de Levene, para la comprobación del supuesto de homogenidad de varianzas entre grupos, cuyos resultados se presentan en la Tabla 5.4.140.

\begin{tabular}{|l|r|r|r|r|}
\hline Variable & $\begin{array}{c}\text { Estadístico de } \\
\text { Levene }\end{array}$ & df1 & df2 & \multicolumn{1}{c|}{ Sign. } \\
\hline TV & 8,97 & 1 & 63 & 0,004 \\
\hline
\end{tabular}

Tabla 5.4.140: Resultados del test de Levene para TV y tipo de gestión.

El valor del estadístico de Levene es 8,97, superior a 3,993, valor que toma la $\mathrm{F}$ de Snedecor para $\alpha=0,05$, y grados de libertad 1 y 63 , y el valor de significación es inferior a 0,05 , por lo que se rechaza la hipótesis nula de homogeneidad de varianzas.

Al no cumplirse el supuesto de homocedasticidad, la hipótesis nula de igualdad de grupos debe comprobarse mediante el test ANOVA-Welch. Los resultados de la prueba se incluyen en la Tabla 
5.4.141, que muestran que sí existen significativas en los valores de TV, al obtenerse un valor de significación inferior a 0,05.

\begin{tabular}{|l|l|r|r|c|}
\hline \multicolumn{2}{|c|}{ Factor } & df & F & Sign. \\
\hline \multirow{2}{*}{ TV } & Entre Grupos & 1 & 47,969 & $3,251 \mathrm{e}-9$ \\
\cline { 2 - 6 } & Intra Grupos & 60,380 & \multicolumn{2}{|c}{} \\
\cline { 1 - 3 } &
\end{tabular}

Tabla 5.4.141: Resultados del test ANOVA-Welch para TV y tipo de gestión.

Por otro lado, realizando el mismo análisis que en el punto anterior, en función del tamaño del punto limpio basándose en la población adscrita, la muestra únicamente incluye puntos limpios con gestión directa para instalaciones con población adscrita superior a 50.000 habitantes, como puede observarse en la Tabla 5.4.142.

\begin{tabular}{|l|l|r|}
\hline Tamaño punto limpio & \multicolumn{1}{|c|}{ Gestión } & N. ${ }^{\circ}$ casos \\
\hline Rural & Concesión & 23 \\
\hline Semiurbano & Concesión & 22 \\
\hline \multirow{2}{*}{ Urbano } & Directa & 6 \\
\cline { 2 - 3 } & Concesión & 65 \\
\hline TOTAL & & 62 \\
\hline
\end{tabular}

Tabla 5.4.142: TV. Número de casos por tamaño de población adscrita y tipo de gestión.

Por lo que, nuevamente, únicamente puede realizarse el análisis diferenciado para los puntos limpios con población adscrita superior a 50.000 habitantes. En la Tabla 5.4 .143 se observa que la media de TV es algo superior en los puntos limpios gestionados mediante concesión, con una elevada desviación estándar respecto al grupo de puntos limpios de gestión directa.

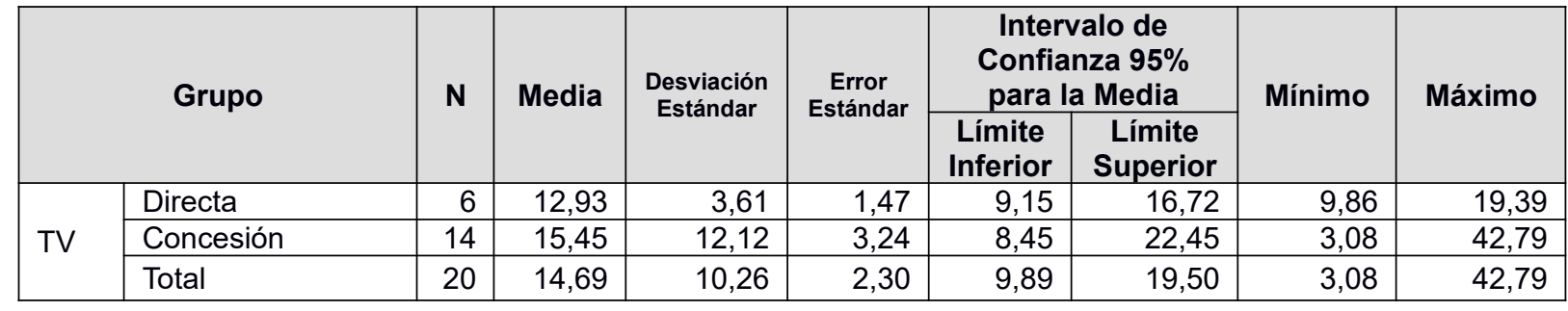

Tabla 5.4.143: Media, desviación estándar, error estándar e intervalo de confianza de TV en puntos limpios urbanos para los grupos de tipo de gestión. 
A continuación se aplica sobre la muestra el test de Levene, para la comprobación del supuesto de homogenidad de varianzas entre grupos, cuyos resultados se presentan en la Tabla 5.4.144.

\begin{tabular}{|c|r|r|r|r|}
\hline Variable & $\begin{array}{c}\text { Estadístico de } \\
\text { Levene }\end{array}$ & df1 & df2 & \multicolumn{1}{c|}{ Sign. } \\
\hline TV & 5,64 & 1 & 18 & 0,029 \\
\hline
\end{tabular}

Tabla 5.4.144: Resultados del test de Levene para TV y tipo de gestión para puntos limpios urbanos.

El valor del estadístico de Levene es 5,64 , superior a 4,414 , valor que toma la $F$ de Snedecor para $\alpha=0,05$, y grados de libertad 1 y 18 , y el valor de significación es inferior a 0,05 , por lo que se rechaza la hipótesis nula de homogeneidad de varianzas.

Puesto que no se cumple el requisito de homocedasticidad para la realización del test ANOVA, la hipótesis nula de igualdad de grupos debe comprobarse mediante el test ANOVA-Welch. Los resultados de la prueba se incluyen en la Tabla 5.4.145.

\begin{tabular}{|l|l|r|r|r|}
\hline \multicolumn{2}{|c|}{ Factor } & df & F & Sign. \\
\hline \multirow{2}{*}{ TV } & Entre Grupos & 1 & 0,49936 & 0,4893 \\
\cline { 2 - 6 } & Intra Grupos & 17,036 & \multicolumn{2}{|c}{} \\
\cline { 1 - 3 }
\end{tabular}

Tabla 5.4.145: Resultados del test ANOVA-Welch para TV y tipo de gestión para puntos limpios urbanos.

Al obtenerse un valor de significación de la prueba superior a 0,05, se acepta la hipótesis nula de igualdad entre grupos y, por tanto, el tipo de gestión del punto limpio no presenta significación estadística sobre TV para los puntos limpios urbanos.

Por tanto, pese a haberse detectado significación sobre TV en función del tipo de gestión del punto limpio, tras realizarse este análisis únicamente sobre los puntos limpios con población adscrita superior a 50.000 habitantes, puesto que el resto de puntos limpios de la muestra se gestionan todos mediante concesión, se concluye que, para dicho grupo de puntos limpios, el tipo de gestión no presenta significación sobre los resultados de TV.

En definitiva, se ha observado que los puntos limpios gestionados mediante concesión obtienen mejores resultados tanto en número de visitas de los usuarios como en cuanto a las cantidades de residuos depositadas en el punto limpio. Puesto que se ha observado que todos los puntos limpios con población adscrita inferior a 50.000 habitantes se realiza mediante concesión, se ha estudiado la significación específicamente sobre el grupo de puntos limpios cuya población adscrita es 
superior a 50.000 habitantes, con un resultado de no significación de la variable sobre TR ni sobre TV, por lo que, para puntos limpios con población adscrita superior a 50.000 habitantes, el tipo de gestión elegido no presenta significación estadística sobre TR ni sobre TV.

\section{A5.4.16. Admisión de fracción resto.}

En general, los puntos limpios disponen de contenedores para el depósito de residuos de las fracciones de recogida selectiva presentes en la vía pública. En la muestra sobre la que se ha realizado la encuesta, en 1 caso no se informa al respecto, y en 3 de ellos la instalación no cuenta con contenedores específicos para estas fracciones, por lo que en el $96 \%$ de los casos los puntos limpios cuentan con contenedores para la recogida selectiva de envases ligeros, papel y cartón y vidrio; no obstante, en cuanto a la fracción resto, la situación es más dispar, por lo que se considera conveniente analizar la relevancia de dicha decisión sobre los resultados de utilización de los puntos limpios.

\section{A5.4.16.1. Análisis de TR considerando factor de comparación la disponibilidad de contenedores de resto.}

De los 84 casos considerados para el estudio de TR, uno de ellos (Catarroja) no aporta datos sobre la admisión de fracción resto, por lo que se dispone de 83 casos para realizar el análisis. En el Gráfico 5.4.60 se representan los valores de TR de los puntos limpios, segregando aquéllos que cuentan con contenedores para el depósito de fracción resto de los que no. En el $61 \%$ de los casos se admite el depósito de residuos de fracción resto, observándose asimismo que los registros máximos de TR son superiores en los puntos limpios en que dicha fracción es admitida. Por otro lado, en la Tabla 5.4 .146 se observa que la media y desviación estándar de TR es superior en los puntos limpios en que se admite fracción resto. 


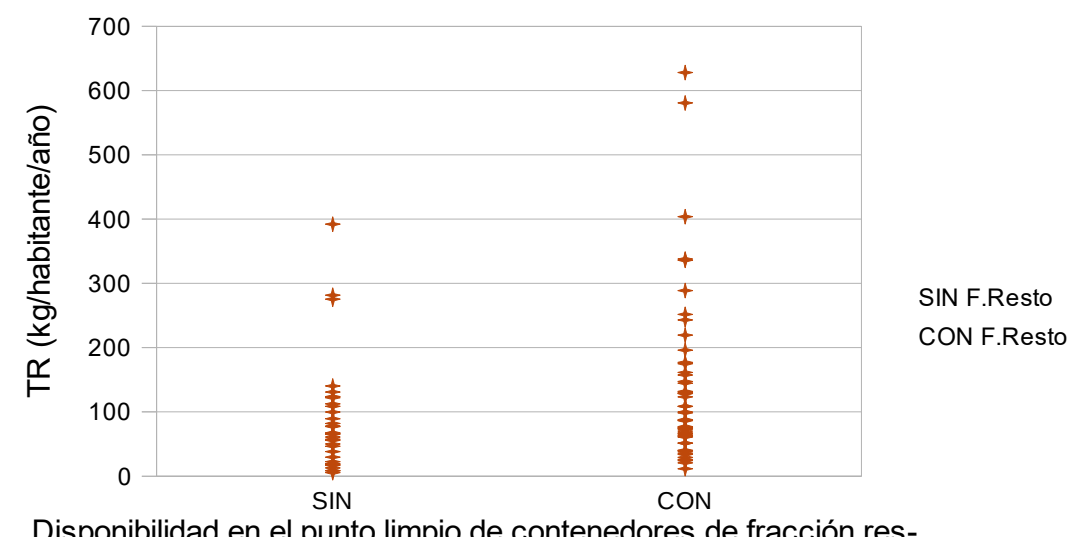

Disponibilidad en el punto limpio de contenedores de fracción res-

to

Gráfico 5.4.60: TR frente a admisión de fracción resto.

\begin{tabular}{|c|c|c|c|c|c|c|c|c|c|}
\hline \multirow{2}{*}{\multicolumn{2}{|c|}{ Grupo }} & \multirow[t]{2}{*}{$\mathbf{N}$} & \multirow[t]{2}{*}{ Media } & \multirow{2}{*}{$\begin{array}{l}\text { Desviación } \\
\text { Estándar }\end{array}$} & \multirow{2}{*}{$\begin{array}{c}\text { Error } \\
\text { Estándar }\end{array}$} & \multicolumn{2}{|c|}{$\begin{array}{c}\text { Intervalo de } \\
\text { Confianza } 95 \% \\
\text { para la Media }\end{array}$} & \multirow[t]{2}{*}{ Mínimo } & \multirow{2}{*}{ Máximo } \\
\hline & & & & & & $\begin{array}{c}\text { Límite } \\
\text { Inferior }\end{array}$ & $\begin{array}{c}\text { Límite } \\
\text { Superior }\end{array}$ & & \\
\hline \multirow{3}{*}{ TR } & SIN F. Resto & 32 & 86,34 & 86,27 & 15,25 & 55,24 & 117,44 & 5,43 & 392,09 \\
\hline & CON F. Resto & 51 & 135,91 & 129,92 & 18,19 & 99,37 & 172,45 & 11,49 & 628,02 \\
\hline & Total & 83 & 116,80 & 117,03 & 12,85 & 91,24 & 142,35 & 5,43 & 628,02 \\
\hline
\end{tabular}

Tabla 5.4.146: Media, desviación estándar, error estándar e intervalo de confianza de TR para los grupos de admisión de fracción resto.

Para la validación de la hipótesis nula de igualdad entre grupos se aplica la prueba $\mathrm{H}$ de KruskalWallis, cuyos resultados se presentan en las Tablas 5.4.147 y 5.4.148.

\begin{tabular}{|l|l|r|r|}
\hline \multicolumn{1}{|c|}{ Variable } & \multicolumn{1}{|c|}{ Grupo } & \multicolumn{1}{c|}{ N } & \multicolumn{1}{c|}{ Rango medio } \\
\hline \multirow{4}{*}{ TR } & SIN F. Resto & 32 & 34,34 \\
\cline { 2 - 4 } & CON F. Resto & 51 & 46,80 \\
\cline { 2 - 4 } & Total & 83 & \\
\hline
\end{tabular}

Tabla 5.4.147: Kruskal-Wallis. $N^{\circ}$ de elementos y rango medio de TR en cada grupo de admisión de fracción resto.

\begin{tabular}{|l|r|}
\hline & \multicolumn{2}{|c|}{ TR } \\
\hline Chi-cuadrado & 5,25 \\
\hline df & 1 \\
\hline Sign. Asint. & 0,022 \\
\hline
\end{tabular}

Tabla 5.4.148: Resultados de significación del test de Kruskal-Wallis de TR respecto de admisión de fracción resto. 
Puesto que el valor de significación es inferior a 0,05, existe significación estadística entre la admisión de fracción resto y TR, por lo que no se cumple la hipótesis nula y los subgrupos pertenecen a poblaciones distintas.

Dado que en la encuesta se informaba tanto de las cantidades anuales de residuos depositadas en los puntos limpios, como de las cantidades correspondientes a la fracción resto, puede realizarse el análisis de significación sobre la variable TR, excluyendo de la misma las cantidades debidas a la fracción resto (TR_noR). Así, en la Tabla 5.4.149 se muestran la media y desviación estándar de esta variable, para los grupos de puntos limpios en que se segrega la muestra en función de la admisión de fracción resto.

Se excluyen, con respecto al análisis anterior, los casos en que, habiéndose indicado que se admite fracción resto, no se ha informado de las cantidades de gestionadas a través del punto limpio (El Prat de Llobregat) o las cantidades totales coinciden con las de fracción resto (Esplugues de Llobregat - Sant Joan Despí, Hospitalet de Llobregat, Molins de Rei, Sant Andreu de la Barca, Sant Boi de Llobregat, Santa Coloma de Gramenet y Viladecans), así como aquéllos en que, habiéndose indicado que no se admite fracción resto, se indican cantidades gestionadas de la misma (los 4 puntos limpios de Bilbao). En la Tabla 5.4 .149 se observa que tanto la media como la desviación estándar de TR_noR son superiores en los casos en que se admite fracción resto en el punto limpio.

\begin{tabular}{|c|c|c|c|c|c|c|c|c|c|}
\hline & \multirow[t]{2}{*}{ Grupo } & \multirow[t]{2}{*}{$\mathbf{N}$} & \multirow[t]{2}{*}{ Media } & \multirow{2}{*}{$\begin{array}{l}\text { Desviación } \\
\text { Estándar }\end{array}$} & \multirow{2}{*}{$\begin{array}{c}\text { Error } \\
\text { Estándar }\end{array}$} & \multicolumn{2}{|c|}{$\begin{array}{c}\text { Intervalo de } \\
\text { Confianza } 95 \% \\
\text { para la Media }\end{array}$} & \multirow[t]{2}{*}{ Mínimo } & \multirow{2}{*}{ Máximo } \\
\hline & & & & & & $\begin{array}{l}\text { Límite } \\
\text { Inferior }\end{array}$ & $\begin{array}{l}\text { Límite } \\
\text { Superior }\end{array}$ & & \\
\hline \multirow{3}{*}{ TR_noR } & SIN F. Resto & 28 & 87,34 & 91,86 & 17,36 & 51,72 & 122,96 & 5,43 & 392,09 \\
\hline & CON F. Resto & 43 & 123,05 & 117,24 & 17,88 & 86,97 & 159,13 & 11,59 & 628,02 \\
\hline & Total & 71 & 108,97 & 108,68 & 12,90 & 83,25 & 134,69 & 5,43 & 628,02 \\
\hline
\end{tabular}

Tabla 5.4.149: Media, desviación estándar, error estándar e intervalo de confianza de TR_noR para los grupos de admisión de fracción resto.

La comprobación de la hipótesis nula de igualdad entre grupos se realiza mediante la prueba $\mathrm{H}$ de Kruskal-Wallis, cuyos resultados se presentan en las Tablas 5.4.150 y 5.4.151.

\begin{tabular}{|c|l|r|r|}
\hline Variable & Grupo & N & Rango medio \\
\hline TR_noR & SIN F. Resto & 28 & 30,39 \\
\hline
\end{tabular}




\begin{tabular}{|l|l|r|r|}
\hline Variable & \multicolumn{1}{|c|}{ Grupo } & \multicolumn{1}{c|}{ N } & \multicolumn{1}{c|}{ Rango medio } \\
\hline & CON F. Resto & 43 & 39,65 \\
\cline { 2 - 4 } & Total & 71 & \\
\hline
\end{tabular}

Tabla 5.4.150: Kruskal-Wallis. Nº de elementos y rango medio de TR_noR en cada grupo de admisión de fracción resto.

\begin{tabular}{|l|r|}
\hline & \multicolumn{2}{|c|}{ TR } \\
\hline Chi-cuadrado & 3,41 \\
\hline df & 1 \\
\hline Sign. Asint. & 0,065 \\
\hline
\end{tabular}

Tabla 5.4.151: Resultados de significación del test de Kruskal-Wallis de TR_noR respecto de admisión de fracción resto.

El valor de significación de la prueba es superior a 0,05 , por lo que los grupos en que se ha dividido la muestra pertenecen a la misma población y la variable TR, calculada como cantidades de residuos depositados distintos de la fracción resto, no presenta resultados estadísticamente significativos respecto de la admisión de dicha fracción.

Por tanto, se concluye que las cantidades de residuos depositadas en los puntos limpios son significativamente superiores en los casos en que se admite el depósito de fracción resto a aquéllos en que esta fracción no se admite. No obstante, excluido el efecto debido a las cantidades de fracción resto depositadas en el punto limpio, en aquellos casos en que dicho valor ha sido informado, puede afirmarse que los valores de TR no son significativamente distintos en función de la admisión de fracción resto.

\section{A5.4.16.2. Análisis de TV considerando factor de comparación la disponibilidad de contenedores de resto.}

El número de elementos de la muestra con datos relevantes para el análisis es de 64; es decir, los considerados válidos tras descartar valores de TV considerados anormalmente elevados o bajos, con la excepción de Catarroja, que no aporta información al respecto. En el Gráfico 5.4.61 se muestran los valores de TV de los puntos limpios, diferenciando aquellos que sí admiten fracción resto de los que no, observándose valores máximos de TV superiores en el segundo grupo. 


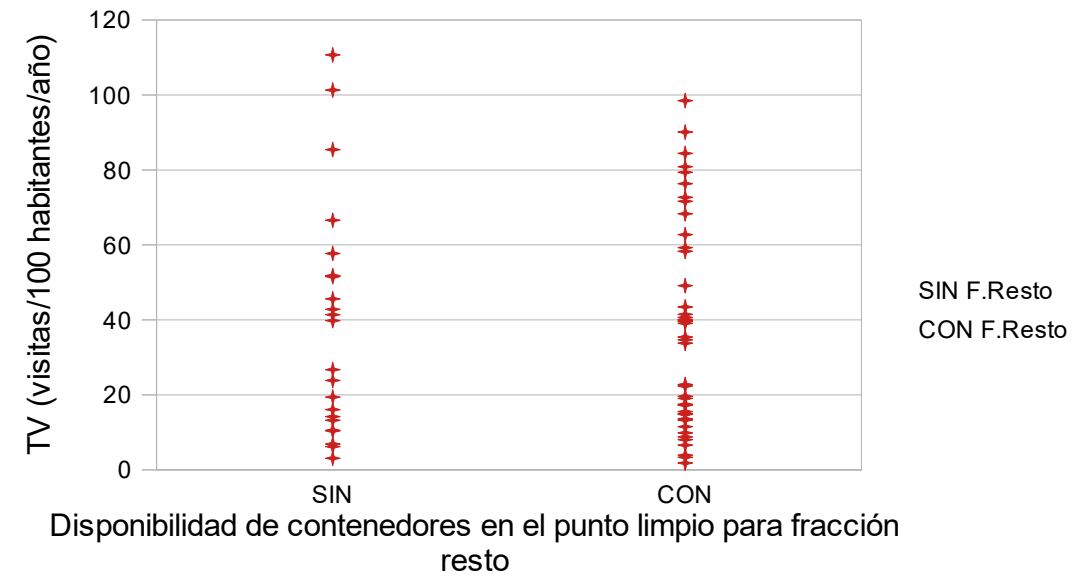

Gráfico 5.4.61: TV frente a admisión de fracción resto.

En cuanto a los valores de media y desviación estándar de TV, presentan valores similares en ambos grupos, tal y como se observa en la Tabla 5.4.152.

\begin{tabular}{|c|c|c|c|c|c|c|c|c|c|}
\hline \multirow{2}{*}{\multicolumn{2}{|c|}{ Grupo }} & \multirow{2}{*}{$\mathbf{N}$} & \multirow{2}{*}{ Media } & \multirow{2}{*}{$\begin{array}{l}\text { Desviación } \\
\text { Estándar }\end{array}$} & \multirow{2}{*}{$\begin{array}{c}\text { Error } \\
\text { Estándar }\end{array}$} & \multicolumn{2}{|c|}{$\begin{array}{c}\text { Intervalo de } \\
\text { Confianza } 95 \% \\
\text { para la Media }\end{array}$} & \multirow{2}{*}{ Mínimo } & \multirow{2}{*}{ Máximo } \\
\hline & & & & & & $\begin{array}{l}\text { Límite } \\
\text { Inferior }\end{array}$ & $\begin{array}{l}\text { Límite } \\
\text { Superior }\end{array}$ & & \\
\hline \multirow{3}{*}{ TV } & SIN F. Resto & 22 & 38,41 & 31,05 & 6,62 & 24,64 & 52,18 & 3,07 & 110,66 \\
\hline & CON F. Resto & 42 & 37,71 & 27,58 & 4,26 & 29,11 & 46,30 & 1,82 & 98,46 \\
\hline & Total & 64 & 37,95 & 28,58 & 3,57 & 30,81 & 45,09 & 1,82 & 110,46 \\
\hline
\end{tabular}

Tabla 5.4.152: Media, desviación estándar, error estándar e intervalo de confianza de TV para los grupos de admisión de fracción resto.

A continuación se aplica sobre la muestra el test de Levene, para validar el supuesto de homogenidad de varianzas entre grupos, cuyos resultados se presentan en la Tabla 5.4.153.

\begin{tabular}{|l|r|r|r|r|}
\hline Variable & $\begin{array}{c}\text { Estadístico de } \\
\text { Levene }\end{array}$ & df1 & df2 & \multicolumn{1}{c|}{ Sign. } \\
\hline TV & 0,18 & 1 & 62 & 0,670 \\
\hline
\end{tabular}

Tabla 5.4.153: Resultados del test de Levene para TV y admisión de fracción resto. 
El valor del estadístico de Levene es 0,18 , inferior a 3,996, valor que toma la $\mathrm{F}$ de Snedecor para $\alpha=0,05$, y grados de libertad 1 y 62 , y el valor de significación es superior a 0,05 , por lo que puede afirmarse que se cumple el supuesto de homocedasticidad.

La hipótesis nula de igualdad de los grupos se comprueba mediante el test ANOVA, cuyos resultados se muestran en la Tabla 5.4.154.

\begin{tabular}{|c|c|c|c|c|c|c|}
\hline \multicolumn{2}{|c|}{ Factor } & $\begin{array}{c}\text { Suma de } \\
\text { Cuadrados }\end{array}$ & df & $\begin{array}{c}\text { Cuadrado } \\
\text { medio }\end{array}$ & $\mathbf{F}$ & Sign. \\
\hline \multirow{3}{*}{ TV } & Entre Grupos & 7,05 & 1 & 7,05 & 0,01 & 0,927 \\
\hline & Intra Grupos & $51.443,42$ & 62 & 829,73 & & \\
\hline & Total & $51.450,47$ & 63 & & & \\
\hline
\end{tabular}

Tabla 5.4.154: Resultados test ANOVA para TV y admisión de fracción resto.

Resultando un valor de significación muy superior a 0,05 , por lo que la hipótesis nula se considera válida y los grupos son iguales, sin que exista significación estadística de la admisión de fracción resto sobre los valores de TV.

Puesto que no puede cuantificarse el número de visitas debidos únicamente al deposito de residuos de fracción Resto, no cabe análisis posterior similar el del punto anterior.

Por tanto, los resultados de la TV no se ven influenciados por la admisión o no de residuos de fracción resto en el punto limpio y, por tanto, que el punto limpio acepte el depósito de residuos de fracción resto no incrementa el número de visitas de usuarios, que puedan aprovechar dichas visitas para realizar entregas de otros materiales.

En conclusión, que un punto limpio disponga de contenedores para el depósito de residuos de la fracción resto no fomenta el uso del servicio en términos de visitas, durante las cuales los usuarios puedan realizar aportaciones, aunque pequeñas, de otros residuos; en cambio, sí que incrementa de manera significativa las cantidades de residuos depositadas en el punto limpio, pero únicamente debido a la aportación de dicha fracción, puesto que la variable TR_noR, calculada sin como aportación por habitante de residuos distinto a la fracción resto, no presenta significación respecto de la admisión de dicha fracción. 


\section{A5.4.17. Depósito de RAEE.}

Resulta cada vez más habitual que los puntos limpios cuenten áreas específicas para el almacenamiento específico de Residuos de Aparatos Eléctricos y Electrónicos (RAEE), que pueden, a su vez, segregarse en depósitos diferenciados en función de sus características: tamaño y tipo aparato eléctrico o electrónico original. En este apartado se analiza si el hecho de que los puntos limpios dispongan de una zona específica para el almacenamiento de RAEE, con dispositivos antiderrame (para la recogida de posibles vertidos de líquidos contenidos en los mismos) representa un factor diferenciador para los resultados de gestión de residuos a través del punto limpio.

\section{A5.4.17.1. Análisis de TR considerando factor de comparación la zona de almacenamiento de RAEE.}

El número de casos a analizar es de 69 , debido a que no se dispone de información sobre el factor en los puntos limpios de El Prat de Llobregat, Esplugues de Llobregat/Sant Joan Despí, Hospitalet de Llobregat, Molins de Rei, Sant Andreu de la Barca, Sant Boi de Llobregat, Santa Coloma de Gramenet, Viladecans, Mancomunidad de Sasieta, Tudela, Churriana de la Vega, Guadix, Rincón de la Victoria, Las Cabezas de San Juan y Utrera.

Los puntos limpios se segregan en 2 grupos, en función de la disponibilidad de zona acondicionada para el almacenamiento de RAEE, cuyos valores de TR se muestran en el Gráfico 5.4.62. En él se observa que presenta valores máximos de TR el grupo de puntos limpios con zona específicamente acondicionada para el almacenamiento de RAEE, siendo además este grupo más mayoritario. En la Tabla 5.4 .155 se observa que este grupo representa el $75 \%$ de los casos analizados, mientras que los valores de la media y desviación estándar de TR son similares en la muestra total y entre los subgrupos. 


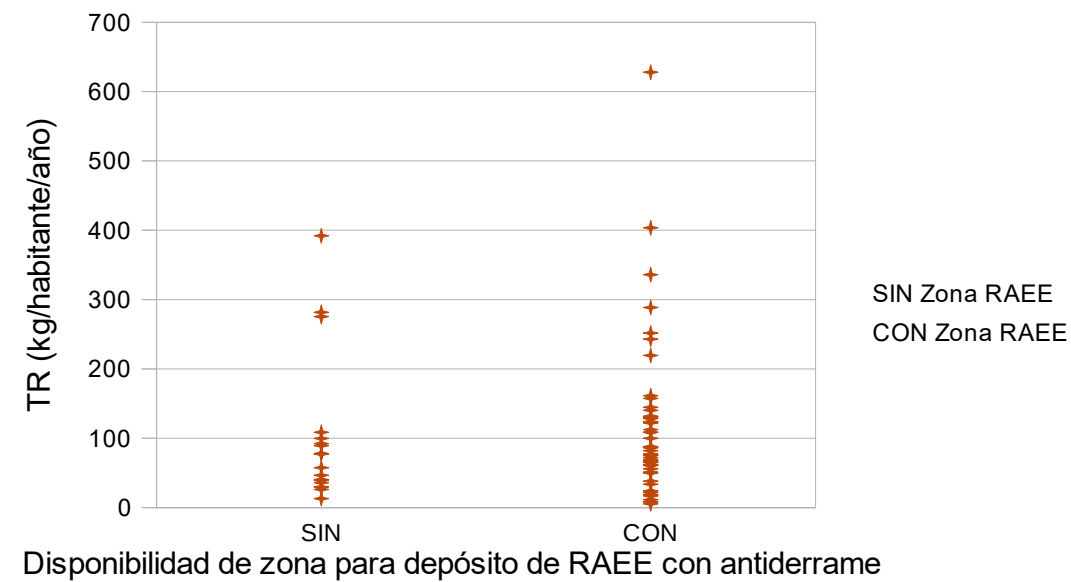

Gráfico 5.4.62: TR frente a disponibilidad de zona para RAEE.

\begin{tabular}{|c|c|c|c|c|c|c|c|c|c|}
\hline \multirow{2}{*}{\multicolumn{2}{|c|}{ Grupo }} & \multirow{2}{*}{$\mathbf{N}$} & \multirow{2}{*}{ Media } & \multirow{2}{*}{$\begin{array}{l}\text { Desviación } \\
\text { Estándar }\end{array}$} & \multirow{2}{*}{$\begin{array}{c}\text { Error } \\
\text { Estándar }\end{array}$} & \multicolumn{2}{|c|}{$\begin{array}{c}\text { Intervalo de } \\
\text { Confianza } 95 \% \\
\text { para la Media }\end{array}$} & \multirow{2}{*}{ Mínimo } & \multirow{2}{*}{ Máximo } \\
\hline & & & & & & $\begin{array}{l}\text { Límite } \\
\text { Inferior }\end{array}$ & $\begin{array}{l}\text { Límite } \\
\text { Superior }\end{array}$ & & \\
\hline \multirow{3}{*}{ TR } & SIN zona_RAEE & 17 & 104,87 & 107,21 & 26,00 & 49,75 & 159,99 & 13,01 & 392,09 \\
\hline & CON zona_RAEE & 52 & 111,90 & 110,51 & 15,32 & 81,14 & 142,67 & 5,43 & 628,02 \\
\hline & Total & 69 & 110,17 & 108,96 & 13,12 & 84,00 & 136,35 & 5,43 & 628,02 \\
\hline
\end{tabular}

Tabla 5.4.155: Media, desviación estándar, error estándar e intervalo de confianza de TR para los grupos de disponibilidad de zona para RAEE.

La validación de la hipótesis nula de igualdad entre grupos se realiza mediante la aplicación de la prueba $\mathrm{H}$ de Kruskal-Wallis, cuyos resultados se presentan en las Tablas 5.4.156 y 5.4.157.

\begin{tabular}{|c|l|r|r|}
\hline \multicolumn{1}{|c|}{ Variable } & \multicolumn{1}{|c|}{ Grupo } & \multicolumn{1}{c|}{ N } & \multicolumn{1}{c|}{ Rango medio } \\
\hline \multirow{4}{*}{ TR } & SIN zona_RAEE & 17 & 32,47 \\
\cline { 2 - 4 } & CON zona_RAEE & 52 & 35,83 \\
\cline { 2 - 4 } & Total & 69 & \\
\hline
\end{tabular}

Tabla 5.4.156: Kruskal-Wallis. $N^{\circ}$ de elementos y rango medio de TR en cada grupo de disponibilidad de zona para RAEE.

\begin{tabular}{|l|r|}
\hline & TR \\
\hline Chi-cuadrado & 0,36 \\
\hline df & 1 \\
\hline Sign. Asint. & 0,549 \\
\hline
\end{tabular}

Tabla 5.4.157: Resultados de significación del test de Kruskal-Wallis de TR respecto de disponibilidad de zona para RAEE. 
Puesto que el valor de significación es superior a 0,05 , se cumple la hipótesis nula y los grupos pertenecen a la misma población.

Por tanto, la habilitación de una zona específica, con características constructivas especialmente diseñadas al efecto, para el almacenamiento de RAEE, no resulta significativa en términos de TR. Podría interpretarse que el usuario no se siente más concienciado y mejora sus hábitos de gestión de RAEE si el punto limpio dispone de unas condiciones mejoradas para su almacenamiento.

\section{A5.4.17.2. Análisis de TV considerando factor de comparación la zona de almacenamiento de RAEE.}

Para este análisis se dispone de datos considerados válidos de 56 puntos limpios, al no contar con información sobre la disponibilidad de zona acondicionada para el almacenamiento de RAEE de los puntos limpios de El Prat de Llobregat, Esplugues de Llobregat - Sant Joan Despí, Hospitalet de Llobregat, Molins de Rei, Sant Andreu de la Barca, Sant Boi de Llobregat, Santa Coloma de Gramenet, Viladecans y Puerto de Santa María.

Nuevamente representan una mayoría los puntos limpios que afirman disponer de una zona especialmente adaptada para el almacenamiento de RAEE, presentando estos puntos limpios valores de TR máximos superiores a los puntos limpios que no disponen de dicha zona. Este comportamiento puede ser observado en el Gráfico 5.4.63.

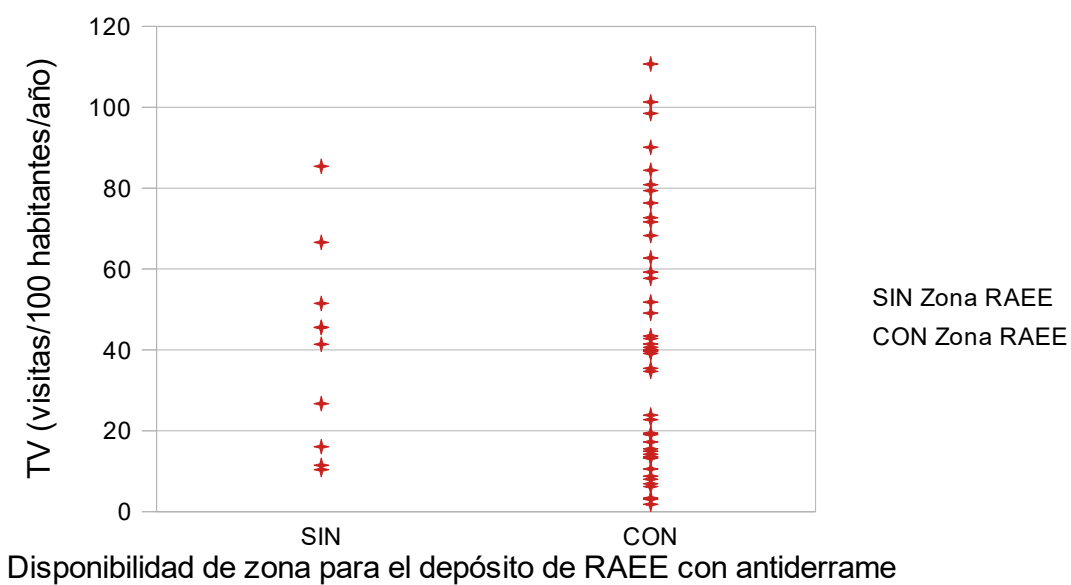

Gráfico 5.4.63: TV frente a disponibilidad de zona para RAEE. 
Como puede observarse en la Tabla 5.4.158, tanto la media como la desviación estándar de TV son ligeramente superiores en los puntos limpios que disponen de zona con antiderrame para el depósito de RAEE, que representan el $82 \%$ de los casos analizados.

\begin{tabular}{|c|c|c|c|c|c|c|c|c|c|}
\hline \multirow{2}{*}{\multicolumn{2}{|c|}{ Grupo }} & \multirow[t]{2}{*}{$\mathbf{N}$} & \multirow[t]{2}{*}{ Media } & \multirow{2}{*}{$\begin{array}{l}\text { Desviación } \\
\text { Estándar }\end{array}$} & \multirow[t]{2}{*}{$\begin{array}{c}\text { Error } \\
\text { Estándar }\end{array}$} & \multicolumn{2}{|c|}{$\begin{array}{c}\text { Intervalo de } \\
\text { Confianza } 95 \% \\
\text { para la Media }\end{array}$} & \multirow[t]{2}{*}{ Mínimo } & \multirow[t]{2}{*}{ Máximo } \\
\hline & & & & & & $\begin{array}{l}\text { Límite } \\
\text { Inferior }\end{array}$ & $\begin{array}{l}\text { Límite } \\
\text { Superior }\end{array}$ & & \\
\hline \multirow{3}{*}{ TV } & SIN zona_RAEE & 10 & 40,06 & 24,50 & 7,75 & 22,53 & 57,58 & 10,39 & 85,38 \\
\hline & CON zona_RAEE & 46 & 41,02 & 30,08 & 4,44 & 32,09 & 49,96 & 1,82 & 110,66 \\
\hline & Total & 56 & 40,85 & 28,96 & 3,87 & 33,09 & 48,61 & 1,82 & 110,66 \\
\hline
\end{tabular}

Tabla 5.4.158: Media, desviación estándar, error estándar e intervalo de confianza de TV para los grupos de disponibilidad de zona para RAEE.

Los resultados del test Levene, para la validación del supuesto de homocedasticidad de la muestra, son los que se incluyen en la Tabla 5.4.159.

\begin{tabular}{|c|r|r|r|r|}
\hline \multicolumn{1}{|c|}{ Variable } & \multicolumn{1}{|c|}{$\begin{array}{c}\text { Estadístico de } \\
\text { Levene }\end{array}$} & df1 & df2 & \multicolumn{2}{c|}{ Sign. } \\
\hline TV & 0,85 & 1 & 54 & 0,361 \\
\hline
\end{tabular}

Tabla 5.4.159: Resultados del test de Levene para TV y disponibilidad de zona para RAEE.

El valor del estadístico de Levene es 0,85 , inferior a 4,020 , valor que toma la $\mathrm{F}$ de Snedecor para $\alpha=0,05$, y grados de libertad 1 y 54 , y el valor de significación es superior a 0,05 , por lo que puede afirmarse que se cumple el supuesto de homocedasticidad.

La hipótesis de igualdad de los grupos se comprueba a través del test ANOVA, cuyos resultados se muestran en la Tabla 5.4.160.

\begin{tabular}{|c|c|c|c|c|c|c|}
\hline \multicolumn{2}{|c|}{ Factor } & $\begin{array}{c}\text { Suma de } \\
\text { Cuadrados }\end{array}$ & df & $\begin{array}{l}\text { Cuadrado } \\
\text { medio }\end{array}$ & $\mathbf{F}$ & Sign. \\
\hline \multirow{3}{*}{ TV } & Entre Grupos & 7,69 & 1 & 7,69 & 0,01 & 0,925 \\
\hline & Intra Grupos & $46.128,92$ & 54 & 854,24 & & \\
\hline & Total & $46.136,61$ & 55 & & & \\
\hline
\end{tabular}

Tabla 5.4.160: Resultados test ANOVA para TV y disponibilidad de zona para RAEE. 
Puesto que resulta un valor de significación muy superior a 0,05, se considera válida la hipótesis nula y los grupos pertenecen a la misma población.

Por tanto, que el punto limpio cuente con un área especialmente acondicionada para el depósito y almacenamiento de RAEE no presenta significación estadística para los resultados de TV.

En conclusión, que un punto limpio cuente con un área diseñada y acondicionada para el almacenamiento de RAEE, con dispositivos de contención de posibles derrames, no resulta relevante para el usuario, que realiza el mismo tipo de uso, en términos generales, del punto limpio. 

Anexo A7.1. Presupuesto DESGLOSADO DE CONSTRUCCIÓN DE NUEVO PUNTO LIMPIO EN CASTELLÓ. 



\section{CAPITULO C1 Movimiento de tierras}

D02EF 201

m2 Explanación terreno a máquina

Explanación y nivelación de terrenos por medios mecánicos.

Parcela

$$
14.262,00
$$

\section{$4.262,00$}

$4.262,00$

D02TK051 m2 Compactado tierras sin aporte

Compactación de tierras propias, con apisonadora vibrante de $6 \mathrm{Tm}$., en una tongada de hasta $30 \mathrm{~cm}$. de espesor máximo, regado de las mismas y p.p. de costes indirectos.

$$
14.262,00
$$

\begin{tabular}{llll}
$4.262,00$ & & & \\
\hline $4.262,00$ & 2,45 & $10.441,90$
\end{tabular}

ECOMASD02AA60m2 Retirada tierra vegetal

Desbroce y limpieza del terreno por medios mecánicos con retirada de la capa de tierra vegetal de $20 \mathrm{~cm}$ de espesor, sin carga ni transporte.

Parcela $1 \quad 4.262,00$

$4.262,00$

$4.262,00 \quad 0,28 \quad 1.193,36$

D02TF 151

m3 Relleno y compactación mecánica s/aportación

Relleno, extendido y compactacion de tierras procedentes de la excavacion, por medios mecanicos, en tongadas de espesor maximo $30 \mathrm{~cm}$. hasta $95 \% \mathrm{PN}$, i/regado de las mismas.

$$
1960,01
$$

960,01

960,01 $1.209,61$

ECOMASD02VK 45m 3 Trans. Int. Tierras $<\mathrm{km}$. Car. Mec

Transporte de tierras procedentes de excavación dentro de la obra, incluso carga y descarga.

$$
1960,01
$$

$$
960,01
$$

960,01

$2.553,63$

C_D02VF001 M3 TRANSPORTE TIERRAS $<10 \mathrm{~km}$

M3. Transporte de tierras procedentes de excavación a vertedero, con un recorrido total menor de 10 km., con camión volquete de $10 \mathrm{Tm}$., i/p.p. de costes indirectos.Se incluye carga sobre el transporte y canon de vertido.

$$
20,00
$$

20,00

20,00

CR_01001ROT M3 RELLENO Y COMPAC. MECÁN. C/APORT.

M3. Relleno, extendido y compactado de tierras con características de "suelo seleccionado" con un CBR may or de 10, procedente de prestamos, incluso extendido, humectación y compacto hasta el $100 \%$ P.N. utilizando rodillo vibratorio.

$$
12.990,00
$$

$2.990,00$

$2.990,00 \quad 19,41$

$58.035,90$

TOTAL CAPÍTULO C1 Movimiento de tierras 


CÓDIGO RESUMEN UDS LONGITUD ANCHURA ALTURA PARCIALES CANTIDAD $\quad$ PRECIO

\section{CAPITULO C2 Muros de contención}

ECOMASD02EP05m3 Excav. Mecánica terreno flojo

Excavación en desmonte en todo tipo de terrenos excepto roca por medios mecánicos para formación de explanada, incluso carga, transporte de tierras dentro de la obra y descarga.

\begin{tabular}{|c|c|c|c|c|c|c|}
\hline Muro Rampa salida & 1 & 18,87 & 1,50 & 0,60 & 16,98 & \\
\hline Muro Rampa entrada & 1 & 15,00 & 1,50 & 0,60 & 13,50 & \\
\hline Muelles nuevos, Muros rectos & 1 & 10,50 & 1,50 & 0,60 & 9,45 & \\
\hline Muelles nuevos, Zig-Zag & 1 & 23,00 & 1,50 & 0,60 & 20,70 & \\
\hline
\end{tabular}

C_D04EF061 m3 Hormigón en masa HL-150/B/20 limpieza

Hormigón en masa HL-150/B/20 N/mm2, con tamaño máximo del árido de $20 \mathrm{~mm}$. elaborado en central para relleno y nivelado de fondos de cimentación, incluso vertido por medios manuales, vibrado y colocación según EHE.

CIMENTACIÓN

Muro Rampa salida

Muro Rampa entrada

Muelles nuevos, Muros rectos

Muelles nuevos, Zig-Zag

$\begin{array}{llll}18,87 & 1,50 & 0,10 & 2,83 \\ 15,00 & 1,50 & 0,10 & 2,25 \\ 10,50 & 1,50 & 0,10 & 1,58 \\ 23,00 & 1,50 & 0,10 & 3,45\end{array}$

C_D38EC640 m3 Hormigón HA-25/B/40/lla cimientos

Hormigón HA-25/B/20/lla en zapatas, riostras, cimentaciones de muros y superficies horizontales en general, incluso vertido, vibrado y curado según prescripciones de la instrucción EHE.

CIMENTACIÓN

Muro Rampa salida

$18,87 \quad 1,50 \quad 0,50 \quad 14,15$

Muro Rampa entrada

Muelles nuevos, Muros rectos

Muelles nuevos, Zig-Zag

$\begin{array}{rrrr}15,00 & 1,50 & 0,50 & 11,25 \\ 10,50 & 1,50 & 0,50 & 7,88\end{array}$

$23,00 \quad 1,50 \quad 0,50 \quad 17,25$

$50,53 \quad 93,34 \quad 4.716,47$

C_D38EC660 m3 Hormigón HA-25/B/20/lla alzados

Hormigón HA-25/B/20/lla en alzados, puesto en obra, vibrado y curado.

Muro Rampa salida

Muro Rampa entrada

Muelles nuevos, Muros rectos

Muelles nuevos, Zig-Zag

$\begin{array}{rrrr}18,87 & 0,25 & 1,95 & 9,20 \\ 15,00 & 0,25 & 1,95 & 7,31 \\ 10,50 & 0,25 & 2,70 & 7,09 \\ 23,00 & 0,25 & 2,50 & 14,38\end{array}$

D38EJ 015A m2 Encofrado plano visto, en param. verticales a dos caras

Encofrado plano en muros medido a dos caras así como las superficies horizontales, en paramentos vistos incluso suministro, elementos auxiliares, colocación con ayuda de camión grúa, utilizacion de desencofrante, desencofrado y posterior apilado de paneles para posteriores puestas.

$\begin{array}{llllr}\text { Muro Rampa salida } & 2 & 18,87 & 1,95 & 73,59 \\ \text { Muro Rampa entrada } & 2 & 15,00 & 1,95 & 58,50 \\ \text { Muelles nuevos, Muros rectos } & 2 & 10,50 & 2,70 & 56,70 \\ \text { Muelles nuevos, Zig-Zag } & 2 & 23,00 & 2,70 & 124,20\end{array}$

Muelles nuevos, Zig-Zag

312,99

48,00

$15.023,52$

ECOMAD04AA201Kg Acero corrugado B500S

Acero corrugado B $500 \mathrm{~S}$ incluso cortado, doblado, armado y colocado en obra, i/p.p. de mermas y despuntes.Cimentaciones muros $40 \mathrm{~kg} / \mathrm{m} 3$. Alzados muros $80 \mathrm{~kg} / \mathrm{m} 3$.

$\begin{array}{rrrr}24,00 & 1,90 & 0,89 & 40,58 \\ 62,00 & 1,90 & 0,89 & 104,84 \\ 32,00 & 1,90 & 0,89 & 54,11 \\ 48,00 & 1,90 & 0,89 & 81,17 \\ 28,00 & 1,90 & 0,89 & 47,35 \\ 44,00 & 1,90 & 0,89 & 74,40 \\ 104,00 & 1,90 & 0,89 & 175,86 \\ 152,00 & 1,90 & 0,89 & 257,03 \\ 16,00 & 2,67 & 0,89 & 38,02 \\ 16,00 & 6,53 & 0,89 & 92,99 \\ 16,00 & 3,46 & 0,89 & 49,27\end{array}$




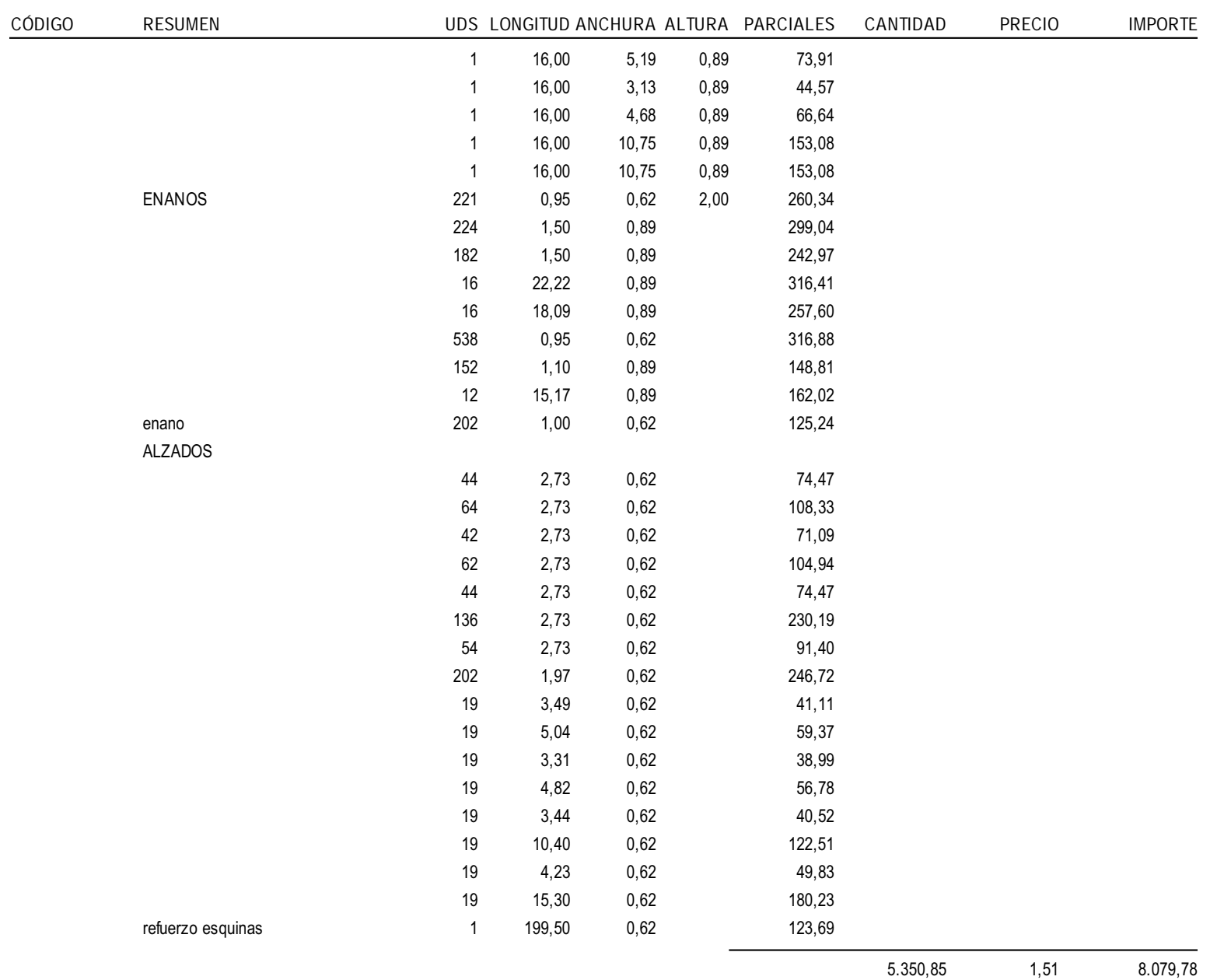

C_N_DEMOL m3 Demolicion muro de hormigón armado

M3. Demolición muro de hormigón armado con martillo compresor de 2000 l/min., i/retirada de escombros a pie de carga, maquinaria auxiliar de obra y p.p. de costes indirectos, según NTE/ADD-16.Incluido el corte del muro mediante fresadora/radial con peón especializado.

Muro existente

0,575

8,50

0,25

1,00

1,22

C_CARGA

m3 Carga y transporte de escombros incluso canon de vertido

$\begin{array}{llllll}\begin{array}{l}\text { Tramo muro de contención } \\ \text { existente(fondo parcela)con }\end{array} & 0,5 & 8,50 & 0,25 & 1,20 & 1,28 \\ \text { esponjamien } & & & & & \end{array}$

esponjamien

1,28

7,50

9,60

TOTAL CAPÍTULO C2 Muros de contención.

$32.835,43$ 
CAPITULO C3 Firmes, pavimentación y urbanización

D36CE008 MI Bordillo de hormigón recto $14 \times 20 \mathrm{~cm}$

MI. Bordillo prefabricado de hormigón de 14x20 cm., sobre solera de hormigón HNL15 N/mm2. Tmáx. 40 de $10 \mathrm{~cm}$. de espesor, incluso excavación necesaria, colocado.

\begin{tabular}{lrrrr} 
Vial perimetral & 1 & 250,00 & 250,00 & \\
Junto a casetas & 1 & 55,00 & 55,00 & \\
Jardines tóxicos & 1 & 40,00 & 40,00 & \\
\cline { 2 - 5 } & & & & $345,00 \quad 8,05 \quad 2.777,25$
\end{tabular}

UPCR.laa ud Riego imprimación $100 \mathrm{~m} 2$ emulsión aniónica

Riego de imprimación sobre subbase de calzada y caminos de servicio, para una superficie de 100 $\mathrm{m}^{2}$, con emulsión aniónica rápida tipo EAR-0 a razón de $0.9 \mathrm{l} / \mathrm{m}^{2}$ y cubrición con $4 \mathrm{l} / \mathrm{m}^{2}$ de árido calizo, incluso extendido y apisonado.

Zona asfalto (viales)

0,01

756,92 7,57

m2 J ardín tipo

Ejecución de jardin tipo incluyendo las siguientes actuaciones:

- laboreo mecánico del terreno hasta una profundidad de $20 \mathrm{~cm}$.

- suministros y extendido a mano de abono organico bien fermentado (0,03 m3 por m2)

-suministro y apertura de hoyo, plantacion y primer riego de especies arboreas como coniferas $(42 \%)$, frondosas $(53 \%$ ) y olivos $(5 \%)$ con una densidad de 1 planta cada $400 \mathrm{~m} 2$.

- suministro y apertura de zanja, plantación y primer riego de Cupressus sempervirens (cipres) de

1,2 a $1,5 \mathrm{~m}$. de altura con cepellon en container, $(3 \mathrm{ud} / \mathrm{m})$ a plantar como barrera vegetal en zonas adecuadas.

- suministro y apertura de hoyo, plantacion y primer riego de Jaras, Lavandas, romero, salvia,santo-

lina, uña de gato y tomillo (en identica, proporción) de 0.2 a $0.3 \mathrm{~m}$. de altura con cepellón en maceta con una densidad de 1 planta cada 1,5 m2.

$\begin{array}{llll}\text { jardinera perimetral , junto rampa y } & 1 & 924,04 & 924,04\end{array}$

caseta toxicos

Jardinera junto caseta control

149,30

49,30

D03DA004 Ud ARQUETA REGISTRO 51X51X80 CM.

Ud Arqueta de registro de $51 \times 51 \times 80 \mathrm{~cm}$. realizada con fabrica de ladrillo macizo de $1 / 2$ de espesor recibido con mortero de cemento M5 según UNE-EN-998-2, enfoscada y bruñida en su interior, i/solera de hormigón HM-20 N/mm2 y tapa de hormigón armado, según CTE/DB-HS 5.

5,00

\begin{tabular}{llll}
5,00 & & & \\
\hline 5,00 & 88,99 & 444,95
\end{tabular}

C_PT_D360G525 MI TUBERIA POLIETILENO AD 63/10 ATM.

MI. Tuberia de polietileno alta densidad de $D=63 \mathrm{~mm}$. apta para uso alimentario, para presion de trabajo de 10 atmosferas, incluso p.p. de piezas especiales, junta, excavacion, cama de arena de 20 $\mathrm{cm}$. rasanteo de la misma, colocacion de la tuberia, relleno de arena de $15 \mathrm{~cm}$. y terminacion de relleno con tierra procedente de excav acion, totalmente colocada.

$1 \quad 18,28$
18,28

$18,28 \quad 210,22$

C_PT_D360G010 MI TUBERIA POLIETILENO AD 32/4 ATM.

MI. Tuberia de polietileno alta densidad de $\mathrm{D}=32 \mathrm{~mm}$. apta para uso alimentario, para presion de trabajo de 4 atmosferas, incluso p.p. de piezas especiales, junta, excavacion, cama de arena de 20 $\mathrm{cm}$. rasanteo de la misma, colocacion de la tuberia, relleno de arena de $15 \mathrm{~cm}$. y terminacion de relleno con tierra procedente de excavacion, totalmente colocada.

1308,59

308,59

C_D 16 MI TUBERIA POLIETILENO AD 16/4 ATM.

MI. Tuberia de polietileno con gotero integrado a una equidistancia de $60 \mathrm{~cm}$. de $D=16 \mathrm{~mm}$. , incluso p.p. de piezas especiales, junta, colocacion de la tuberia, totalmente colocada.

$1 \quad 1.486,18$

$1.486,18$

$\begin{array}{lll}1.486,18 & 5,02 & 7.460,62\end{array}$


C_IV_ARQAVAL Ud Arqueta alojamiento de valvulas.

Ud. Arqueta para ubicación de valvulas, ventosa, y sistema reductor de presion de dimensiones 100x $100 \times 100 \mathrm{~cm}$. de dimensiones interiores, realizada con fabrica de ladrillo macizo de $1 / 2$ de espesor, recibido con mortero de cemento $1 / 2$ enfoscada y bruñida en su interior, i/ solera de hormigón HM-20 y tapa de hormigón armado, incluso desagüe formado por tubo de PVC $110 \mathrm{~mm}$. en pozo de grava de $1 \mathrm{~m}$. de profundidad y $50 \mathrm{~cm}$. de diametro. Todo ello completamente terminado, instalado, probado y en perfecto funcionamiento.

\begin{tabular}{llll}
1,00 & & & \\
\hline & 1,00 & 218,34 & 218,34
\end{tabular}

C_IV_TOMABALDUd Toma de Baldeo Racor Tipo Barcelona

Ud. Toma de baldeo con recubrimiento anticorrosivo y resistente al agua y cierre mediante asiento elastico totalmente estanco de $40 \mathrm{~mm}$. de seccion nominal , con marcado AENOR. Totalmente instalada.

\begin{tabular}{llll}
1,00 & & & \\
\hline 1,00 & 408,53 & 408,53
\end{tabular}

C_PROGPILAS4S Ud Programador de riego a pilas 4 sectores.

Ud. Programador de riego a pilas para cuatro sectores de riego sin soporte, sello AENOR. Totalmente instalado, programado y comprobado.

$$
1
$$

\begin{tabular}{llll}
1,00 & & & \\
\hline & 1,00 & 328,42 & 328,42
\end{tabular}

C_MALLAANTIHIM2 Malla antihierba

M2 Malla antihierba de polipropileno con una densidad de $150 \mathrm{gr} / \mathrm{m} 2$ : Totalmente instalada.

$$
1492,70
$$

492,70

\begin{tabular}{lll}
492,70 & & \\
\hline 492,70 & 1,93 & 950,91
\end{tabular}

C_GRAVA M2 Grava decorativa

M2 Grava decorativa para colocar encima de la malla antihierba con un espesor maximo de $6 \mathrm{~cm}$. totalmente estendida y colocada.

\begin{tabular}{llllll}
492,78 & & & & \\
\cline { 2 - 5 } & 492,78 & 492,78 & 9,00 & $4.435,02$
\end{tabular}

D38IA010 m Premarcaje

Premarcaje a cinta corrida.

$\begin{array}{llll}\text { Carril vehículos } & 1 & 115,00 & 115,00\end{array}$

$\begin{array}{llll}\text { Stops, Paso cebra, flechas } & 1 & 95,00 & 95,00\end{array}$

D38IA040 m Marca vial $15 \mathrm{~cm}$

MI. Marca vial reflexiva de $15 \mathrm{~cm}$, con pintura reflectante y microesferas de vídrio, con máquina autopropulsada.

Carril vehículos

Stops, Paso cebra, flechas

$\begin{array}{rr}1 & 115,00 \\ 1 & 95,00\end{array}$

\begin{tabular}{rrrr}
115,00 & & & \\
95,00 & & & \\
\hline 210,00 & 0,50 & 105,00
\end{tabular}

D38IM030

m Barrera de seguridad doble onda

MI. Barrera de seguridad doble onda, i/p.p. poste, captafaros, separadoor y colocación.

Vial perimetral

1234,50

234,50

CR_D36DC005 m2 Baldosa hidráulica

$\begin{array}{lll}234,50 & \\ 234,50 & 32,19 & 7.548,56\end{array}$

M2. Acera de loseta hidráulica de $20 \times 20 \mathrm{~cm}$.(4 pastillas), sobre solera de hormigón HNL-15 $\mathrm{N} / \mathrm{mm} 2$. Tmáx. $40 \mathrm{~mm}$. y $10 \mathrm{~cm}$. de espesor, iljunta de dilatación.

$\begin{array}{llrr}\text { Aceras } & 1 & 9,00 & 9,00\end{array}$

Perimetral tóxicos $\quad 1 \quad 11,00$

11,00

$20,00 \quad 454,60$


Anexo A7.1.

CÓDIGO

C_D04PM210R m2 Solera ligera 1

M2. Solera de $20 \mathrm{~cm}$. de espesor, realizada con hormigón $H A-25 / B / 20 / l l a ~ N / m m 2$., tamaño máximo del árido $20 \mathrm{~mm}$. elaborado en central, i/vertido, colocación y armado con mallazo electrosoldado \#150*150*10 mm + \#150*150*5 mm +lámina plástico., incluso p.p. de juntas, aserrado de las mismas y fratasado. Según EHE-08.

Zona soleras:

$1 \quad 1.665,30$

$1.665,30$

\begin{tabular}{llll}
$1.665,30$ & & & \\
\hline $1.665,30$ & 34,45 & $57.369,59$
\end{tabular}

MASD38GA115 m3 Zahorra artificial

Zahorra artificial, de acuerdo a lo señalado en el PG3 incluso ex tendido, refinado, riego y compactacion en capas de $30 \mathrm{~cm}$. Como máximo, para formación de base granular.

Zona soleras:

toxicos

$1.665,30$

71,97

10,96

aceras

caseta control

asfalto

$1 \quad 3,31$

$1 \quad 5,03$

120,45

1756,92

D36GD305

M2 Pavimento m.B.C. Tipo AC22 surf D (D-20) $5 \mathrm{~cm}$.

M2. Pavimento M.B.C. tipo AC22 surf D (D-20) con espesor de $5 \mathrm{~cm}$.

Zona asfalto (viales)

1756,92

$\begin{array}{lr}0,25 & 416,33 \\ 0,25 & 17,99 \\ 0,25 & 2,74 \\ 0,25 & 0,83 \\ 0,25 & 1,26 \\ 0,25 & 5,11 \\ 0,25 & 189,23\end{array}$

633,49

20,98

$13.290,62$

TOTAL CAPÍTULO C3 Firmes, pavimentación y urbanización...

756,92

756,92

5,22

$3.951,12$

$112.457,49$ 


\begin{tabular}{llllll} 
CÓDIGO & RESUMEN & UDS LONGITUD ANCHURA ALTURA PARCIALES & CANTIDAD & PRECIO & IMPORTE \\
\hline CAPITULO C4 Red saneamiento &
\end{tabular}

\section{C_D03AG256 m Tuberia pvc sanecor $315 \mathrm{~s} /$ arena}

Tubería de PVC SANECOR, de $315 \mathrm{~mm}$. de diámetro, compuesta por dos paredes extruidas y soldadas simultaneamente con una altura del nervio de las paredes de $4,1 \mathrm{~mm}$, la interior lisa para mejorar el comportamiento hidráulico y la exterior corrugada para aumentar la resistencia mecánica en uso enterrado, unión por enchufe con junta elástica de cierre, color teja, en tubos de longitud de $6 \mathrm{~m}$., colocada sobre cama de arena de río lavada y posterior relleno de al menos $5 \mathrm{~cm}$ con arena seleccionada exenta de piedras mayores a $10 \mathrm{~mm}$., con una pendiente mínima del $2 \%$, i/pp. de piezas especiales.

Red de saneamiento pluviales

$1 \quad 148,53$

148,53

\section{D03AG254 MI Tubería pvc sanecor 200 s/arena}

MI. Tubería de PVC SANECOR, de $200 \mathrm{~mm}$. de diámetro, compuesta por dos paredes extruidas y soldadas simultaneamente con una altura del nervio de las paredes de $7,4 \mathrm{~mm}$, la interior lisa para mejorar el comportamiento hidráulico y la exterior corrugada para aumentar la resistencia mecánica en uso enterrado, unión por enchufe con junta elástica de cierre, color teja, en tubos de longitud de 6 $\mathrm{m}$., colocada sobre cama de arena de río lavada y posterior relleno de al menos $5 \mathrm{~cm}$ con arena seleccionada exenta de piedras mayores a $10 \mathrm{~mm}$., con una pendiente mínima del $2 \%$, i/pp. de piezas especiales, instalación de acuerdo al Pliego de prescripciones Tecnicas Generales para tuberías de saneamiento de poblaciones (MOPU), según UNE EN 1329 y CTE/DB-HS 5.

16,00

6,00

C_D03AG253 MI Tuberia pvc sanecor 160 s/arena

MI. Tubería de PVC SANECOR, de $160 \mathrm{~mm}$. de diámetro, compuesta por dos paredes extruidas y soldadas simultaneamente con una altura del nervio de las paredes de $5,8 \mathrm{~mm}$, la interior lisa para mejorar el comportamiento hidráulico y la exterior corrugada para aumentar la resistencia mecánica en uso enterrado, unión por enchufe con junta elástica de cierre, color teja, en tubos de longitud de 6 $\mathrm{m}$., colocada sobre cama de arena de río lavada y posterior relleno de al menos $5 \mathrm{~cm}$ con arena seleccionada exenta de piedras may ores a $10 \mathrm{~mm}$., con una pendiente mínima del $2 \%$, i/pp. de piezas especiales, instalación de acuerdo al Pliego de prescripciones Tecnicas Generales para tuberías de saneamiento de poblaciones (MOPU), según UNE EN 1329 y CTE/DB-HS 5.

Red saneamiento fecales

143,05

43,05

\section{C_D03AG254 MI Tuberia pvc sanecor 110 s/arena}

MI. Tubería de PVC SANECOR, de $110 \mathrm{~mm}$. de diámetro, compuesta por dos paredes extruidas y soldadas simultaneamente con una altura del nervio de las paredes de $5,8 \mathrm{~mm}$, la interior lisa para mejorar el comportamiento hidráulico y la exterior corrugada para aumentar la resistencia mecánica en uso enterrado, unión por enchufe con junta elástica de cierre, color teja, en tubos de longitud de 6 $\mathrm{m}$., colocada sobre cama de arena de río lavada y posterior relleno de al menos $5 \mathrm{~cm}$ con arena seleccionada exenta de piedras mayores a $10 \mathrm{~mm}$., con una pendiente mínima del $2 \%$, i/pp. de piezas especiales, instalación de acuerdo al Pliego de prescripciones Tecnicas Generales para tuberías de saneamiento de poblaciones (MOPU), según UNE EN 1329 y CTE/DB-HS 5.

Interior caseta

16,00

6,00

\section{C_D03AG254- MI Tuberia pvc sanecor 250 s/arena}

MI. Tubería de PVC SANECOR, de $250 \mathrm{~mm}$. de diámetro, compuesta por dos paredes extruidas y soldadas simultaneamente con una altura del nervio de las paredes de $5,8 \mathrm{~mm}$, la interior lisa para mejorar el comportamiento hidráulico y la exterior corrugada para aumentar la resistencia mecánica en uso enterrado, unión por enchufe con junta elástica de cierre, color teja, en tubos de longitud de 6 $\mathrm{m}$., colocada sobre cama de arena de río lavada y posterior relleno de al menos $5 \mathrm{~cm}$ con arena seleccionada exenta de piedras mayores a $10 \mathrm{~mm}$., con una pendiente mínima del $2 \%$, i/pp. de piezas especiales, instalación de acuerdo al Pliego de prescripciones Tecnicas Generales para tuberías de saneamiento de poblaciones (MOPU), según UNE EN 1329 y CTE/DB-HS 5.

Marquesina 1

Marquesina 2

24,00

24,00

$\begin{array}{lll} & 1 & 20,00\end{array}$

20,00

$\begin{array}{lll}44,00 & 35,02 & 1.540,88\end{array}$




\begin{tabular}{|c|c|c|c|c|c|c|c|}
\hline \multirow{5}{*}{$\frac{\text { CÓDIGO }}{\text { D03DG005 }}$} & RESUMEN & \multicolumn{2}{|c|}{ UDS LONGITUD ANCHURA ALTURA } & PARCIALES & CANTIDAD & PRECIO & IMPORTE \\
\hline & \multirow{2}{*}{\multicolumn{7}{|c|}{$\begin{array}{l}\text { ud Imbornal sifonico } 60 \times 30 \times 50 \mathrm{~cm} \\
\text { Imbormal sif́nico de } 60 \times 30 \times 50 \mathrm{~cm} \text {. de hormigón prefabricado, sobre solera de hormigón } \\
\text { HNE- } 20 / B / 20 \text { de } 10 \mathrm{~cm} \text {. de espesor y recibido com mortero de cemento y arena de rio } 1 / 6 \text {, total- } \\
\text { mente instalado. }\end{array}$}} \\
\hline & & & & & & & \\
\hline & \multirow[t]{2}{*}{ Recogida pluviales } & 1 & 7,00 & 7,00 & & & \\
\hline & & & & & 7,00 & 172,79 & $1.209,53$ \\
\hline \multirow[t]{5}{*}{ C_U03101 } & \multicolumn{7}{|c|}{ m Imbornal lineal fundición de $0,15 \times 0,135 \mathrm{~m}$} \\
\hline & \multicolumn{7}{|c|}{$\begin{array}{l}\text { Características técnicas: } \\
\text { Canal de drenaje lineal tipo V100 para instalación enterrada de hormigón polímero con bastidor de } \\
\text { acero galvanizado, con sección transversal en "V" con efecto autolimpiante y sistema de fijación rá- } \\
\text { pida de rejas sin tornillo. Premarca para salida tubo vertical DN100. } \\
\text { Rejillas de cobertura tipo pasarela de acero galvanizado, inoxidable y fundición, tipo entramada gal- } \\
\text { vanizada, inoxidable y fundición, clases de carga A15-D400, según EN1433. } \\
\text { Certificados homologación CE y cumplimiento integro de toda la normativa EN1433. } \\
\text { ACCESORIOS DEL SISTEMA: tapa para inicio y final de canal,tapa con manguito incorporado, } \\
\text { sumideros, clavija,calza de empalme, clavija de seguridad } \\
\text { Según plano de detalle. }\end{array}$} \\
\hline & Rampas entrada & 1 & 4,70 & 4,70 & & & \\
\hline & \multirow[t]{2}{*}{ Rampas salida } & 1 & 5,00 & 5,00 & & & \\
\hline & & & & & 9,70 & 117,73 & $1.141,98$ \\
\hline \multirow[t]{5}{*}{ CR_D36VL050X } & \multicolumn{7}{|c|}{ P.AJConexión a la red de saneamiento } \\
\hline & \multicolumn{7}{|c|}{$\begin{array}{l}\text { Acometida de saneamiento a la red general de la urbanización, hasta una longitud de } 15 \text { metros, en } \\
\text { cualquier clase de terreno, incluso demoliciones, excavación mecánica, relleno y apisonado de zan- } \\
\text { ja con tierra procedente de la excavación, limpieza y transporte de tierras sobrantes a vertedero, re- } \\
\text { posición de frmes, tubo de acometida de hasta } 400 \mathrm{~mm} \text {. y conexión a pozo existente. Se incluyen } \\
\text { los cruces con otros servicios afectados, la conexión al pozo existente. }\end{array}$} \\
\hline & Fecales & \multicolumn{2}{|l|}{1} & 1,00 & & & \\
\hline & \multirow[t]{2}{*}{ Pluviales } & \multirow{2}{*}{\multicolumn{2}{|c|}{1}} & 1,00 & & & \\
\hline & & & & & 2,00 & $2.536,08$ & \\
\hline
\end{tabular}

CR_C090112 UD POZO REGISTRO D $=100 \mathrm{H}=1,5 \mathrm{~m}$

Ud. Pozo de registro con anillos prefabricados de hormigón en masa con un diámetro interior de 100 $\mathrm{cm}$ y una altura total de pozo hasta $1,5 \mathrm{~m}$, incluso solera de hormigón en masa HNL-15 de $20 \mathrm{~cm}$ de espesor, pates de polipropileno de $25 \times 31.5 \mathrm{~cm}$, cada $30 \mathrm{~cm}$, marco y tapa de fundición de $80 \mathrm{~cm}$ clase D400 s/ EN-1443, totalmente terminado, incluso T interior de PVC para sifón (caso de pozos sifónicos).

\begin{tabular}{llllll}
1 Pluviales +1 fecales & 2 & \multicolumn{2}{l}{2,00} & & \\
toma muestras & 1 & \multicolumn{1}{l}{1,00} & & & \\
\cline { 2 - 6 } & & & 3,00 & 422,02 & $1.266,06$
\end{tabular}

C_Arqueta1 ud Arqueta ciega pluviales

Arqueta de obra para recogida de pluviales, construida con fábrica de ladrillo macizo tosco de 1/2 pie de espesor,

recibido con mortero de cemento, incluso accesorios de conexión, tapa de fundicion y montaje, instalada, comprobada.

Altura total de hasta 1,5 m, incluso solera de hormigón HNL-15 de $20 \mathrm{~cm}$ de espesor, totalmente terminada.

Conexion canal lineal a red pluviales $\quad 2$

\begin{tabular}{llll}
2,00 & & & \\
\hline 2,00 & 534,87 & $1.069,74$
\end{tabular}

C_Arqueta2 ud Arqueta pluviales

Arqueta de obra para recogida de pluviales, con tapa (rejilla) de fundición, construida con fábrica de ladrillo macizo tosco de $1 / 2$ pie de espesor,

recibido con mortero de cemento, incluso accesorios de conexión y montaje, instalada, comprobada. Altura total de hasta $1 \mathrm{~m}$, incluso solera de hormigón HNL-15 de $20 \mathrm{~cm}$ de espesor, totalmente terminada.

Arqueta pluviales recogida rampas $\quad 2$

2,00

$2,00 \quad 415,53 \quad 831,06$

ECOMASD02EP05m3 Excav. Mecánica terreno flojo

Excavación en desmonte en todo tipo de terrenos excepto roca por medios mecánicos para formación de explanada, incluso carga, transporte de terras dentro de la obra y descarga. 
Red pluviales

$\begin{array}{lrrrrr}\text { D400 } & 1 & 10,70 & 0,60 & 0,80 & 5,14 \\ \text { D315 } & 1 & 148,53 & 0,60 & 0,60 & 53,47 \\ \text { D200 } & 1 & 6,00 & 0,60 & 0,50 & 1,80 \\ \text { Marquesina 1 } & 1 & 24,00 & 0,60 & 0,50 & 7,20 \\ \text { Marquesina 2 } & 1 & 20,00 & 0,60 & 0,50 & 6,00 \\ \text { Red fecales: } & & & & & \\ & 1 & 43,05 & 0,60 & 0,50 & 12,92\end{array}$

D02TF151 m3 Relleno y compactación mecánica s/aportación

Relleno, extendido y compactacion de tierras procedentes de la excavacion, por medios mecanicos, en tongadas de espesor maximo $30 \mathrm{~cm}$. hasta $95 \%$ PN, i/regado de las mismas.

Red pluviales

$\begin{array}{llllll}\text { D315 } & 1 & 148,53 & 0,60 & 0,60 & 53,47\end{array}$

$\begin{array}{llllll}\text { D200 } & 1 & 6,00 & 0,60 & 0,50 & 1,80\end{array}$

$\begin{array}{llllll}\text { Marquesina } 1 & 1 & 24,00 & 0,60 & 0,50 & 7,20\end{array}$

$\begin{array}{llllll}\text { Marquesina } 2 & 1 & 20,00 & 0,60 & 0,50 & 6,00\end{array}$

$\begin{array}{llllll}\text { Red fecales: } & 1 & 43,05 & 0,60 & 0,50 & 12,92\end{array}$

C_D04EF061 m3 Hormigón en masa HL-150/B/20 limpieza

Hormigón en masa HL-150/B/20 N/mm2, con tamaño máximo del árido de $20 \mathrm{~mm}$. elaborado en central para relleno y nivelado de fondos de cimentación, incluso vertido por medios manuales, vibrado y colocación según EHE.

$\begin{array}{llllll}\text { Cuneta perimetral } & 1 & 250,00 & 0,92 & 0,10 & 23,00\end{array}$

$\begin{array}{llllll}\text { Desaguaderos } & 1 & 33,10 & 0,60 & 0,10 & 1,99\end{array}$

C_D38CC015 $\mathrm{ml}$ Bajante prefabricada de aguas pluviales, en horm. HA-20/P/40/lla

$24,99 \quad 112,55 \quad 2.812,62$

Bajante prefabricada de aguas pluviales (sección libre mínima: $2 \times 0,5 \times 25 \times 25 \mathrm{~cm}$ ), en hormigón HA-20/P/40/Ila, i/colocación

Desaguaderos

33,10

33,10

C_CUNETA $\mathrm{ml}$ Cuneta triangular de hormigón en masa e $=10 \mathrm{~cm}$ y $0,5 \times 0,25 \mathrm{~m}$ libres

Cuneta triangular perimetral formada por base de hormigón con mallazo. Totalmente ejecutada.

$\begin{array}{lll}\text { Cuneta perimetral } & 1 & 250,00\end{array}$

250,00

$250,00 \quad 5.252,50$

C_D38CV010 MI TUBO DREN. PVC 110 MM. MAT. FILTRO

MI. Tubería drenaje PVC D=110 mm de diámetro incluso colocación y material filtro.

\begin{tabular}{|c|c|c|c|c|}
\hline \multirow[t]{2}{*}{ Fachada lataral } & 104,00 & \multicolumn{3}{|l|}{104,00} \\
\hline & & 104,00 & 19,37 & $2.014,48$ \\
\hline
\end{tabular}




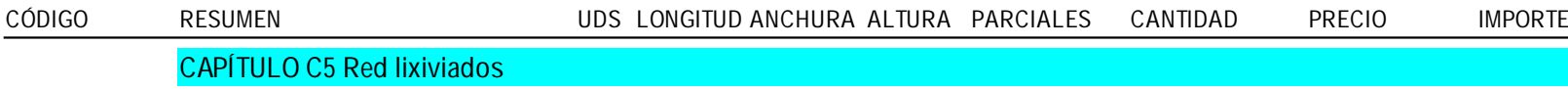

ECOMASD02EP05m3 Excav. Mecánica terreno flojo

Excavación en desmonte en todo tipo de terrenos excepto roca por medios mecánicos para formación de explanada, incluso carga, transporte de tierras dentro de la obra y descarga.

\begin{tabular}{llllllll} 
& 1 & 17,96 & 0,60 & 0,80 & 8,62 & & \\
\cline { 4 - 7 } & & & & & 8,62 & 2,76
\end{tabular}

D02TF151 m3 Relleno y compactación mecánica s/aportación

Relleno, extendido y compactacion de tierras procedentes de la excavacion, por medios mecanicos, en tongadas de espesor maximo $30 \mathrm{~cm}$. hasta $95 \% \mathrm{PN}$, i/regado de las mismas.

Red de lixiviados

$17,96 \quad 0,60 \quad 0,80$

8,62

$8,62 \quad 1,26 \quad 10,86$

D03DG005 ud Imbornal sifonico $60 \times 30 \times 50 \mathrm{~cm}$

Imbornal sifónico de $60 \times 30 \times 50 \mathrm{~cm}$. de hormigón prefabricado, sobre solera de hormigón $\mathrm{HNE}-20 / \mathrm{B} / 20$ de $10 \mathrm{~cm}$. de espesor y recibido com mortero de cemento y arena de rio $1 / 6$, totalmente instalado.

Caseta tóxicos

3,00

D03AH011 m Tuberia PEAD DN=250 mm. PN=16 atm

Tubería enterrada, realizado con tubo para saneamiento de polietileno de alta densidad (PEAD) de diámetro exterior $250 \mathrm{~mm}$, con incremento del precio del tubo del $30 \%$ en concepto de uniones, accesorios y piezas especiales, colocado en zanja sobre lecho de arena / grava , sin incluir excavación, relleno de la zanja ni compactación final.

Tubo para saneamiento de polietileno de alta densidad (PE-AD), para canallización enterrada, de diámetro exterior $250 \mathrm{~mm}$ e interior $210 \mathrm{~mm}$, de doble pared, exterior corrugada negra con resistencia al aplastamiento $\mathrm{SN}>=8$ e interior lisa de color blanco, resistente a la abrasión, según Proyecto Norma europeo pr-EN-13476-1, suministrado en tramos de $6 \mathrm{~m}$, con unión mediante junta elástica incluida y montada en cada tubo, con incremento del precio del tubo del 30\% en concepto de uniones, accesorios y piezas especiales.

A depósito lixiviados

$1 \quad 17,96$

17,96

DEPHOR ud Deposito prefabricado hormigón 1000 l.

Déposito de hormigón prefabricado de 1000 I de capacidad, con marco y tapa de fundición, impermeabilizado, sellado y demás actuaciones necesarias, excavación y ciementación. Completamente terminado

1

$1,00 \quad 920,00 \quad 920,00$

TOTAL CAPÍTULO C5 Red lixiviados 


\section{CAPITULO C 6 Electricidad, Alumbrado, Telefonía}

ud. Cuadro general de protección del alumbrado público formado por:

- Armario IP528 poliestireno, con rigidizador trasero formador por perfil 50×60×0,4 mm galvanizado

sujeto a cuadros y empotrado al suelo, incluso rigidizador lateral galvanizado.

- Apoyo sobre peana de homigón $\mathrm{H}-150$.

- Bases de protección fusible y fusibles de $3 \times 80 \mathrm{~A}+\mathrm{N}$ en paquete seccionador

- Protección general compuesta por interriptor magnetotérmico 4x80A

10kA, interruptor diferencial $4 \times 80 \mathrm{~A}$ sensibilidad regulable hasta $10 \mathrm{~mA}$.

- Contactor tetrapolar 63A

- Bases de protección de fusibles y fusibles de 16A en protección de cada circuito.

- Interruptor posicionamiento manual-automático.

- Equipo de compensación de energía reactiva automático 12,5 KVAr 400V escalonada.

- Pequeño material e interconexión.

Totalmente terminado y en condiciones de prestar servicio.

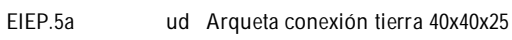

Arqueta de conexión de puesta a tierra de 40×40×25 cm., formada por muro aparejado de ladrillo macizo de $12 \mathrm{~cm}$. de espesor, con juntas de mortero M-40a (1:6) de $1 \mathrm{~cm}$. de espesor enfoscado interior con

mortero de cemento M-160a (1:3), solera de hormigón en masa HNL-15 y tapa de hormigón armado HA 25/B/20/lla, con parrilla formada por redondos de diámetro $8 \mathrm{~mm}$. cada $10 \mathrm{~cm}$. y refuerzo perimetral formado por perfil de acero laminado $L 60.6$, soldado a la malla con

cerco de perfil $L 70.7$ y patillas de anclaje en cada uno de sus ángulos, tubo de fibrocemento ligero de diámetro $60 \mathrm{~mm}$. y punto de puesta a tierra,

incluso conexiones, sin incluir excavación, relleno y transporte de tierras sobrantes a vertedero, según NTE/IEP-6.

Casetas

Muros marquesina existente

\begin{tabular}{llll}
2,00 & & & \\
2,00 & & & \\
\hline 4,00 & 98,52 & 394,08
\end{tabular}

m Linea principal de tierra

Linea principal de puesta a tierra con conductor unipolar de $16 \mathrm{~mm}^{2}$ con aislamiento de polietileno reticulado $0,6 / 1 \mathrm{kV}$, instalado bajo tubo, apto para tensión de servicio de 1.000 voltios y tensión de prueba de 4.000 voltios, incluso portes e instalación

$\begin{array}{llll}\text { Caseta } & 1 & 10,00 & 10,00\end{array}$

$\begin{array}{llll}\text { Caseta tóxicos } & 1 & 10,00 & 10,00\end{array}$

$\begin{array}{llll}\text { Marquesina y muros } & 5 & 5,00 & 25,00\end{array}$

EIEP.1a ud Piqueta pt $200 \mathrm{~cm} ø 14 \mathrm{~mm}$

Piqueta de cobre de puesta a tierra formada por electrodo de acero recubierto de cobre de diámetro $14 \mathrm{~mm}$. y longitud $200 \mathrm{~cm}$., incluso hincado y conexiones, según NTE/IEP-5.

Caseta control $\quad 1 \quad 1,00$

Caseta lixiviados $\quad 2 \quad 2,00$

$\begin{array}{lll}\text { Marquesina grande } & 2 & 2,00\end{array}$

$\begin{array}{lll}\text { Marquesina pequeña } & 1 & 1,00\end{array}$

C0.8 ud Farola solar +luminaria de led's

$6,00 \quad 21,35 \quad 128,10$

Farola o luminaria solar con cuerpo de poliéster reforzado con fibra de vidreo, en el que, en su parte superior se encuentra una placa solar.

Empotrada en la parte inferior saliente va insertada una luminaria de led's. Potencia sistema led's 30 W.

C_CO.8A

ud Farola solar +luminaria de led's sobre marquesina 


\begin{tabular}{|c|c|c|c|c|c|c|}
\hline CÓDIGO & RESUMEN & LONGITUD ANCHURA ALTURA & PARCIALES & CANTIDAD & PRECIO & IMPORTE \\
\hline \multirow[t]{4}{*}{$\mathrm{C}_{-} \mathrm{AH}$} & \multicolumn{6}{|l|}{ P.A.Conexión a hornacina de parcela } \\
\hline & \multicolumn{6}{|c|}{$\begin{array}{l}\text { Conexión a la hornacina de parcela bajo condiciones estandar que marque la compañía suministra- } \\
\text { dora en su momento, incluidas las solicitudes a la compañía distribuidora. } \\
\text { Partida Alzada a justicar tras ejecución. }\end{array}$} \\
\hline & \multirow{2}{*}{\multicolumn{2}{|c|}{1}} & 1,00 & & & \\
\hline & & & & 1,00 & 398,93 & 398,93 \\
\hline
\end{tabular}

\section{EIEL.2bbea $\quad m \quad$ Lin trif $5 \times 10$ tb flx PVC}

Línea de cobre cero halógenos trifásica con aislamiento de tensión nominal $0.6 / 1 \mathrm{kV}$ formada por 3 fases+neutro+tierra de $10 \mathrm{~mm} 2$ de sección, colocada bajo tubo flexible de PVC de $63 \mathrm{~mm}$ de diámetro, según Reglamento Electrotécnico de Baja Tensión, incluso parte proporcional de pequeño material y piezas especiales, totalmente instalada, conectada y en correcto estado de funcionamiento.

Acometida

134,88

34,88

34,88

26,76

933,39

C_EIEL.2abaa $m$ Lin monof $3 \times 1.5$ tb flx PVC

Línea de cobre cero halógenos monofásica con aislamiento de tensión nominal $0.6 / 1 \mathrm{kV}$ formada por fase +neutro+tierra de $1.5 \mathrm{~mm} 2$ de sección, colocada bajo tubo flexible de PVC diámetro nominal $25 \mathrm{~mm}$, según Reglamento Electrotécnico de Baja Tensión, incluso parte proporcional de pequeño material y piezas especiales, totalmente instalada, conectada y en correcto estado de funcionamiento.

De caseta a caseta tóxicos

10,00

10,00

$10,00 \quad 5,55 \quad 55,50$

C_EIEM21b u Conector RJ 45 p/alojar en caj mec

Conector RJ45 para alojar en caja de mecanismos, según Reglamento Electrotécnico de Baja Tensión 2002, totalmente instalada, conectada y en correcto estado de funcionamiento

Caseta control

2

2,00

2,00

24,88

C_EIAD.4bba $\quad \mathrm{m} \quad$ Cbl pares red dt UTP ctg 6 libre

Instalación de cable de pares UTP para red de datos de categoría 6 y cubierta libre de halógenos, las características de los cables, la asignación de colores a los pares y demás detalles acerca de la instalación y conexionado se encuentran recogidos en la categoría 6 y la especificación de clase $E$ de las normas ISO/IEC 11801 y EIA/TIA $568 \mathrm{~B}$, totalmente instalado, comprobado y en correcto estado de funcionamiento.

Caseta control

140,00

40,00

$40,00 \quad 1,45 \quad 58,00$

D02TF 151 m3 Relleno y compactación mecánica s/aportación

Relleno, extendido y compactacion de tierras procedentes de la excavacion, por medios mecanicos, en tongadas de espesor maximo $30 \mathrm{~cm}$. hasta $95 \%$ PN, i/regado de las mismas.

Tierras casetas (arqueta)

$2 \quad 0,40 \quad 0,40 \quad 0,20$

\begin{tabular}{llll}
0,06 & & & \\
\hline 0,06 & 1,26 & 0,08
\end{tabular}

C_D0001TF1 m3 Relleno y compactacion mecanica con arena

Relleno, extendido y compactacion de arena, por medios mecanicos, en tongadas de espesor maximo $30 \mathrm{~cm}$. , i/regado de las mismas.

$\begin{array}{llllll}\text { Acometida } & 1 & 34,88 & 0,40 & 0,80 & 11,16\end{array}$

$\begin{array}{llllll}\text { De caseta control a caseta tóxicos } & 1 & 10,00 & 0,40 & 0,80 & 3,20\end{array}$

C_TELEF pa Acometida de telefonía desde valla parcela

pa Partida alzada a justificar de telefonía desde el punto de la valla de cerramiento parcela que determine la compañia hasta la caseta de control siguiendo las instrucciones de la compañia correspondiente.

\begin{tabular}{llll}
1,00 & & & \\
\hline 1,00 & 658,00 & 658,00
\end{tabular}

ECOMASD02EP05m3 Excav. Mecánica terreno flojo

Excavación en desmonte en todo tipo de terrenos excepto roca por medios mecánicos para formación de explanada, incluso carga, transporte de tierras dentro de la obra y descarga.

$\begin{array}{lllllr}\text { Acometida } & 1 & 34,88 & 0,40 & 0,80 & 11,16 \\ \text { De caseta control a caseta tóxicos } & 1 & 10,00 & 0,40 & 0,80 & 3,20\end{array}$


Presupuesto y mediciones.

\begin{tabular}{|c|c|c|c|c|c|c|c|c|c|}
\hline CÓDIGO & RESUMEN & UDS & LONGITUD & ANCHURA & ALTURA & PARCIALES & CANTIDAD & PRECIO & IMPORTE \\
\hline & Tierras casetas (arqueta) & 2 & 0,40 & 0,40 & 0,20 & 0,06 & & & \\
\hline & & & & & & & 14,42 & 2,76 & 39,80 \\
\hline
\end{tabular}




\section{CAPITULO C7 Casetas y cubierta de contenedores}

EIFA.1a $\quad$ U Acometida agua $\emptyset 50$ PE

Acometida de agua desde la red general de diámetro $<50 \mathrm{~mm}$., a una distancia máxima de $5 \mathrm{~m}$., con tubo de polietileno de $32 \mathrm{~mm}$ y llave de compuerta manual en arqueta de 40x40 cm., con tapa de fundición, incluso accesorios de conexión y montaje, instalada, comprobada, según NTE-IFA-1/2.

Acomerida

1,00

$1,00 \quad 305,66 \quad 305,66$

AM11002 m2 Marquesina de cubrición de contenedores

Marquesina de estructura metálica en acero s 275 y cubierta completa realizada con chapa de acero galvanizado de $0.6 \mathrm{~mm}$. de espesor con perfil laminado tipo 40/250 de Aceralia ó similar, fjado a la estructura con ganchos o tornillos autorroscantes, dos manos de imprimación con pintura de minio de plomo totalmente montado, según CTE/ DB-SE-A; i/ejecución de cumbreras y limas, apertura y rematado de huecos y p.p. de costes indirectos.

\begin{tabular}{|c|c|c|c|c|c|c|}
\hline \multirow{2}{*}{$\begin{array}{l}\text { Marquesina } 1 \\
\text { Marquesina } 2\end{array}$} & 1 & 61,90 & 6,70 & 414,73 & & \\
\hline & 1 & 13,50 & 6,70 & 90,45 & & \\
\hline
\end{tabular}

C EEAS.2aac u PI anclaje S275] R ejecutada en taller

Placa de anclaje de soporte metálico (CAJEADA sobre el muro de hormigón), de acero S275JR, ejecutada en taller de $10 \mathrm{~mm}$ de espesor. Anclaje estadar de rosca extrema -Acero ø20: M20 -. Hilti o similar. Incluso taladros, roscados, tuercas, limpieza y pintura.

Dimensiones detalladas en los planos (forrando el muro sobre el que asienta hasta una profundidad de $0,5 \mathrm{mts}$.

D38Y002_C P.AlCaseta de control 20,47 $\mathrm{m}^{2}$

Ejecución de Caseta prefabricada con una superficie de 20,47 m², para información y control, con sanitario incluido y de características:

- revestimiento de gres en suelo, con rodapié.

- cuatro ventanas de aluminio tipo guillotina y dimensiones $1,20 \times 1,90$

$\mathrm{m}$, dos de ellas con mostrador de atención al público.

- dos puertas de acceso de dimensiones 0,82 x 2,00 m.

- instalación eléctrica de baja tensión compuesta por una regleta de 1

$\mathrm{x} 40 \mathrm{w}$, dos tomas de corriente, interruptor estándar, cuadro de protección

con diferencial y magnetotérmico, según normativa REBT. Incluye

alumbrado mediante pantallas fluorescentes de $2 \times 58 \mathrm{~W}$

- Instalación de protección contra incendios con extintor de polvo seco ABCE de $25 \mathrm{~kg}$

- servicios sanitarios.

Se incluye la demolición de la caseta existente, la gestión y transporte a vertedero de los residuos generados y la ejecución total de la nueva caseta.

Demolición y ejecución total

1

1,00

$1,00 \quad 16.800,00 \quad 16.800,00$

C Mobiliario P.AJMobiliario caseta

Mobiliario caseta: Aseos, espejos, toallas, mesa oficina 2 sillas, sillón, perchero, fax, fotocopiadora, estantería.

Partida Alzada a justificar. 
CASETRES_D P.AICaseta residuos mercuriales y RAEE's de $77 \mathrm{~m}^{2}$

Caseta prefabricada con una superficie de $77 \mathrm{~m}^{2}$,techada y cerrada mediante mediante muro de bloque para los residuos mercuriales y RAEE's, presenta las siguientes características:

- cubierta de chapa galvanizada 0,6 mm PL-40/250 (añadiendo un voladizo de 1,5 mts para evitar la entrada de lluvias)

- estructura metálica autoportante.

- solera de hormigón impermeabilizada.

- instalación eléctrica de baja tensión compuesta por una regleta de 1

$\mathrm{x} 40 \mathrm{w}$, dos tomas de corriente, interruptor estándar, cuadro de protección

con diferencial y magnetotérmico, según normativa REBT. Incluye

alumbrado mediante pantallas fluorescentes de $2 \times 58 \mathrm{~W}$

- Instalación de protección contra incendios con extintor de polvo seco

ABCE de $25 \mathrm{~kg}$

RAEE

1,00

C_EIFC.8bcdb m Tubería agua potable $32 \mathrm{~mm}$

Canalización oculta realizada con tubo de polietileno de media densidad (PE80), color negro con bandas azules, de $16 \mathrm{~atm}$ de presión de trabajo, de $32 \mathrm{~mm}$ de diámetro interior y espesor de pared $3.60 \mathrm{~mm}$, suministrado en rollo de $100 \mathrm{~m}$ de longitud, incluso garras de sujeción y con un incremento del precio del tubo del $30 \%$ en concepto de uniones, accesorios y piezas especiales, totalmente instalada y comprobada.

Red agua potable a caseta $\quad 1 \quad 36,00$

Red agua potable a caseta tóxicos $\quad 1 \quad 12,00$

$48,00 \quad 13,42 \quad 644,16$

ECOMASD02EP05m3 Excav. Mecánica terreno flojo

Excavación en desmonte en todo tipo de terrenos excepto roca por medios mecánicos para formación de explanada, incluso carga, transporte de tierras dentro de la obra y descarga.

$\begin{array}{llllll}\text { Red agua potable a caseta } & 1 & 36,00 & 0,40 & 0,40 & 5,76\end{array}$

$\begin{array}{llllll}\text { Red agua potable a caseta lix iviados } & 1 & 11,00 & 0,40 & 0,40 & 1,76\end{array}$

$7,52 \quad 276$

D02TF151 m3 Relleno y compactación mecánica s/aportación

Relleno, extendido y compactacion de tierras procedentes de la excavacion, por medios mecanicos, en tongadas de espesor maximo $30 \mathrm{~cm}$. hasta $95 \% \mathrm{PN}$, i/regado de las mismas.

$\begin{array}{llllll}\text { Red agua potable a caseta } & 1 & 36,00 & 0,40 & 0,40 & 5,76\end{array}$

$\begin{array}{llllll}\text { Red agua potable a caseta lixiviados } & 1 & 11,00 & 0,40 & 0,40 & 1,76\end{array}$

C_D01CE020 m2 Demolición de paramentos de bloques de hormigón

M2. Demolición fábrica de bloques prefabricados de hormigón, con sus senos macizados, de hasta $35 \mathrm{~cm}$. de espesor, con martillo compresor de $2000 \mathrm{l} / \mathrm{min}$., i/retirada de escombros a pie de carga, maquinaria auxiliar de obra y p.p. de costes indirectos, según NTE/ADD-13.

Demolición cerramientos caseta

$1 \quad 12,00$

$3,00 \quad 36,00$ existente(sin uso)

C_DEMOL

m3 Demolición muro de hormigón armado

Demolición solera caseta ex istente(sin

1 uso)

C_CARGA m3 Carga y transporte de escombros incluso canon de vertido

Demolición caseta existente(sin uso)

12,00

1,15

3,00

41,40

TOTAL CAPÍTULO C 7 Casetas y cubierta de contenedores

41,40 7,50 310,50 
cóDIGO

\section{CAPÍTULO C8 Cerramientos y señalización}

C_D04EF061 m3 Hormigón en masa HL-150/B/20 limpieza

Hormigón en masa HL-150/B/20 N/mm2, con tamaño máximo del árido de $20 \mathrm{~mm}$. elaborado en central para relleno y nivelado de fondos de cimentación, incluso vertido por medios manuales, vibrado y colocación según EHE.

$\begin{array}{llllllll}\text { Vallas lateral entrada } & 1 & 21,00 & 0,70 & 0,10 & 1,47 & & \\ \text { Valla inferior 1 (bloques) } & 1 & 65,19 & 0,70 & 0,10 & 4,56 & & \\ \text { Valla inferior 2 (hormigón) } & 1 & 40,50 & 1,50 & 0,10 & 6,08 & & 1,82 \\ \text { Protección palmera } & 1 & 16,50 & 1,10 & 0,10 & 1,2,55 & 13,93 & 1.567,82\end{array}$

D38IE010 m2 Señal informativa de chapa de hierro.

Señal informativa reflexiva en chapa de hierro, i/ p.p. poste galvanizado, tornillería, cimentación y anclaje, totalmente colocada

Carteles por planta

$1 \quad 9,73$

9,73

$9,73 \quad 279,81 \quad 2.722,55$

CR_D07AG015 m2 Muro de bloque de hormigón armado 40×20×20 cm

M2. Muro de bloque huecos FACOSA de hormigón gris de 40×20×20, incluso armadura vertical formada por 4 redondos de $D=12 \mathrm{~mm}$. por cada ml., y armadura horizontal formada por dos redondos de $D=6 \mathrm{~mm}$. por cada fila de bloques, rellenado con hormigón $H A-25 / B / 20 / I$ y recibido con mortero de cemento y arena de rio M 5 según UNE-EN 998-2, vertido, colocado, vibrado y rejuntado, según CTE/ DB-SE-F.

Valla inferior

$65,19 \quad 1,30$

84,75

D07AA201 m2 Fábrica bloques hormigón gris 40×20×20 cm coronado con rígola

$84,75 \quad 39,74$

Fábrica de bloques de hormigón color gris cara vista de medidas 40×20×20 cm., para terminación posterior, i/relleno de hormigón HNE-15 y armadura en zona según normativa y recibido con mortero de cemento y arena de río $1 / 6$, i/p.p. de piezas especiales, roturas, aplomados, nivelados y limpieza todo ello según NTE-FFB-6, coronada con rígola de hormigón.

Vallas laterales de entrada

$121,00 \quad 1,00$

21,00

C_D23KJ 015X m2 Valla tipo FAX

Valla de malla electrosoldada de 50x50/5 de Teminsa ó similar, tipo FAX, postes intermedios cada 2 $\mathrm{m}$. de tubo de $60 \times 60 \times 1,5 \mathrm{~mm}$., con arranque desde muro de fábrica u HA, totalmente montada, i/recibido con mortero de cemento y arena de río $1 / 4$, y accesorios.

\begin{tabular}{lllllll}
$\begin{array}{l}\text { Valla lateral sur-oeste (fachada } \\
\text { entrada) }\end{array}$ & 1 & 21,00 & 1,00 & & 21,00 \\
\cline { 3 - 5 }
\end{tabular}

D23KE105 MI MALLA GALV. ST 50/14 DE 1,00 M.

MI. Cercado con enrejado metálico galvanizado en caliente de malla simple torsión, trama 50/14 de $1,00 \mathrm{~m}$. de altura y postes de tubo de acero galvanizado por inmersión, de $48 \mathrm{~mm}$. de diámetro y tornapuntas de tubo de acero galvanizado de $32 \mathrm{~mm}$. de diámetro, totalmente montada, i/recibido con mortero de cemento y arena de río $1 / 4$, tensores, grupillas y accesorios.

$\begin{array}{lrrrr}\text { Valla inferior } & 1 & 105,82 & 1,00 & 105,82 \\ \text { Valla superior } & 1 & 106,24 & 1,00 & 106,24 \\ \text { Valla lateral nor-oeste } & 1 & 40,51 & 1,00 & 40,51\end{array}$

D23AN315 m2 Puerta cancela corredera cuarteron

$252,57 \quad 10,96 \quad 2.768,17$

Puerta cancela metálica para acceso de vehjculos, en hoja de corredera, fabricada a base de perfiles rectangulares en cerco, cuarterones de chapa metálica a dos caras y zócalo de chapa grecada, incluso p.p. de guía inferior formada por PNU 100, ruedas para deslizamiento de $200 \mathrm{~mm}$. con rodamiento de engrase permanente, cerrojo para enclavamiento manual y elementos de sustentación necesarios para su perfecto funcionamiento.

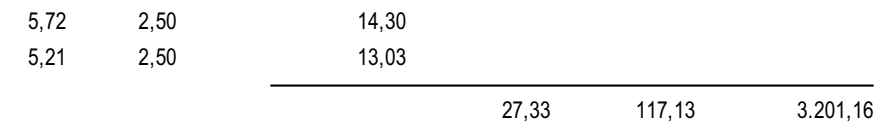


D02HF001 m3 Excavación mecánica zanjas t. terrenos s/roca

Excavación, con retroexcavadora, en terrenos de transito, en apertura de zanjas, con extracción de tierras a los bordes, incluido el refinado del fondo y paredes de la excavación.

Vallas lateral entrada

Valla inferior 1 (bloques)

Valla inferior 2 (hormigón)

Protección Palmera

\begin{tabular}{rrrrrrr}
21,00 & 0,70 & 0,45 & 6,62 & & & \\
65,19 & 0,70 & 0,45 & 20,53 & & & \\
40,50 & 1,50 & 0,60 & 36,45 & & & \\
16,50 & 1,10 & 0,40 & 7,26 & & & \\
\cline { 3 - 6 } & & & & 70,86 & 4,63 & 328,08
\end{tabular}

C_D38EC640 m3 Hormigón HA-25/B/40/lla cimientos

Hormigón HA-25/B/20/lla en zapatas, riostras, cimentaciones de muros y superficies horizontales en general, incluso vertido, vibrado y curado según prescripciones de la instrucción EHE.

$\begin{array}{lllllr}\text { Vallas lateral entrada } & 1 & 21,00 & 0,70 & 0,35 & 5,15 \\ \text { Valla inferior 1 (bloques) } & 1 & 65,19 & 0,70 & 0,35 & 15,97 \\ \text { Valla inferior 2 (hormigón) } & 1 & 40,50 & 1,50 & 0,50 & 30,38 \\ \text { Protección palmera } & 1 & 16,50 & 1,10 & 0,30 & 5,45\end{array}$

ECOMAD04AA201Kg Acero corrugado B500S

Acero corrugado B $500 \mathrm{~S}$ incluso cortado, doblado, armado y colocado en obra, i/p.p. de mermas y despuntes.Cimentaciones muros $40 \mathrm{~kg} / \mathrm{m3}$. Alzados muros $80 \mathrm{~kg} / \mathrm{m3}$.

Cimientos

MURO TIPO 2

enano

PALMERA

enano

Alzados

MURO TIPO 2

PALMERA

refuerzo esquinas

VALLADO

enanos

enanos

recrecido muro

$\begin{array}{rrrr}224,00 & 1,50 & 0,89 & 299,04 \\ 182,00 & 1,50 & 0,89 & 242,97 \\ 16,00 & 22,22 & 0,89 & 316,41 \\ 16,00 & 18,09 & 0,89 & 257,60 \\ 538,00 & 0,95 & 0,62 & 316,88 \\ 152,00 & 1,10 & 0,89 & 148,81 \\ 12,00 & 15,17 & 0,89 & 162,02 \\ 202,00 & 1,00 & 0,62 & 125,24\end{array}$

$\begin{array}{lll}56,95 & 93,34 & 5.315,71\end{array}$

$\begin{array}{rrrrr}1 & 298,00 & 2,73 & 0,62 & 504,39 \\ 1 & 242,00 & 1,97 & 0,62 & 295,58 \\ 1 & 19,00 & 22,50 & 0,62 & 265,05 \\ 1 & 14,00 & 22,50 & 0,62 & 195,30\end{array}$

$\begin{array}{lllll}1 & 10,00 & 15,17 & 0,62 & 94,05\end{array}$

$\begin{array}{lllll}1 & 15,00 & 3,00 & 0,62 & 27,90\end{array}$

112,00

$\begin{array}{rrrr}6,00 & 15,18 & 0,89 & 81,06\end{array}$

$\begin{array}{llll}122,00 & 1,00 & 0,89 & 108,58\end{array}$

$\begin{array}{llll}122,00 & 1,69 & 0,89 & 183,50\end{array}$

$6,00 \quad 65,29 \quad 0,89 \quad 348,65$

$262,00 \quad 1,00 \quad 0,89 \quad 466,36$

$262,00 \quad 1,69 \quad 0,89 \quad 394,07$

C_D38EC660 m3 Hormigón HA-25/B/20/lla alzados

Hormigón HA-25/B/20/lla en alzados, puesto en obra, vibrado y curado.

Muro ex terior inferior

Muro ex terior inferior

Protección palmera (muros)

Recrecido muro trasero

$\begin{array}{llll}1 & 22,22 & 0,25 & 2,80 \\ 1 & 18,28 & 0,25 & 2,0 \\ 1 & 16,50 & 0,20 & 1,50 \\ 1 & 11,30 & 0,20 & 0,50\end{array}$

D38EJ 015A

m2 Encofrado plano visto, en param. verticales a dos caras

Encofrado plano en muros medido a dos caras asi como las superficies horizontales, en paramentos vistos incluso suministro, elementos auxiliares, colocación con ayuda de camión grúa, utilizacion de desencofrante, desencofrado y posterior apilado de paneles para posteriores puestas. 
Anexo A7.1.

\begin{tabular}{|c|c|c|c|c|c|c|c|c|c|}
\hline CÓDIGO & RESUMEN & UDS & LONGITUD A & ANCHURA & ALTURA & PARCIALES & CANTIDAD & PRECIO & IMPORTE \\
\hline & Muro exterior inferior & 2 & 22,22 & & 2,80 & 124,43 & & & \\
\hline & Muro exterior inferior & 2 & 18,28 & & 2,05 & 74,95 & & & \\
\hline & Protección palmera & 2 & 16,50 & 1,50 & & 49,50 & & & \\
\hline & Recrecido muro trasero & 2 & 11,30 & & 0,50 & 11,30 & & & \\
\hline
\end{tabular}

PNTW43a u Perno $12 \mathrm{~mm}$

Perno roscado de diámetro SAmm de precisión antivibratoria atornillable, con espárrago. Se incluye el taladrado del mismo al muro existente.

Unión recrecido muro trasero con

existente

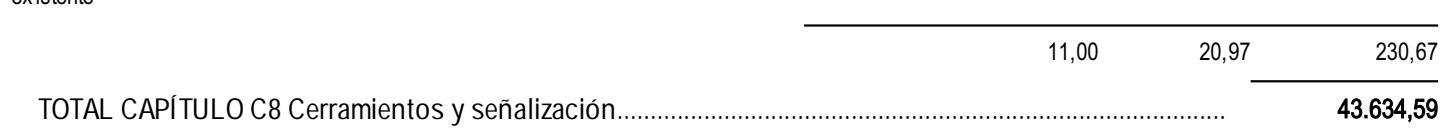




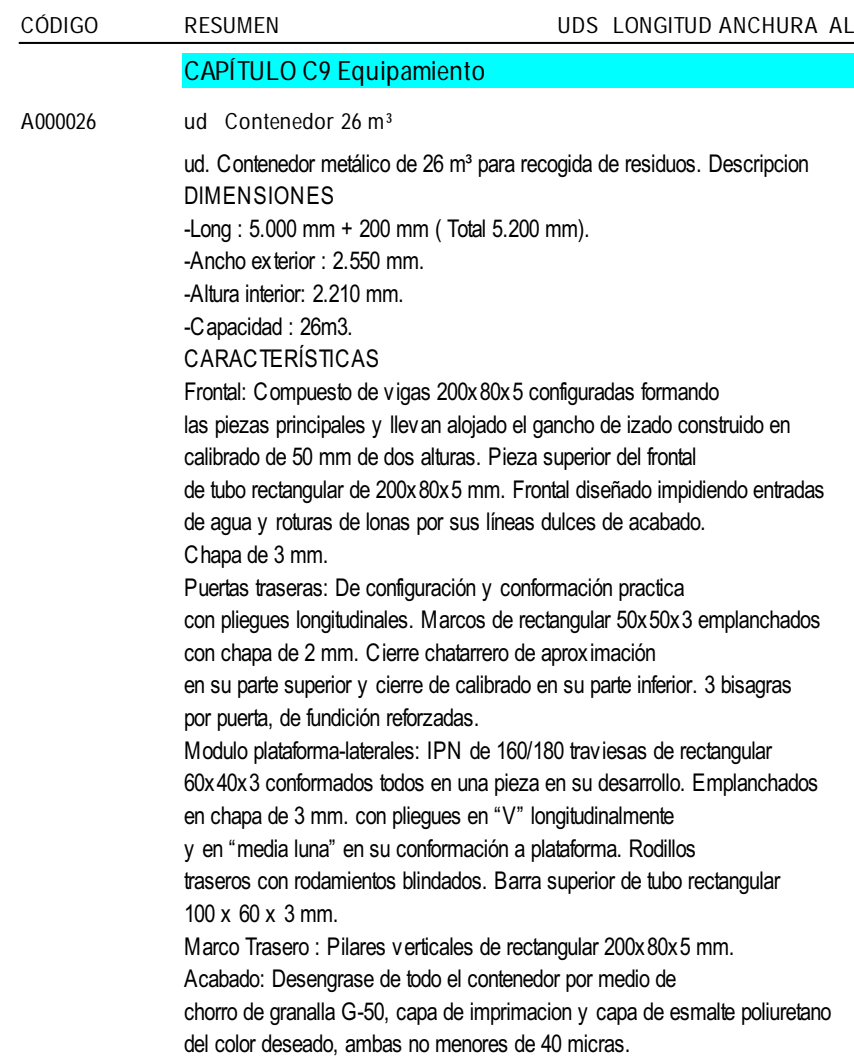

En uso $\quad 10$

Reserva 1

$11,00 \quad 3.458,00 \quad 38.038,00$

C_A 000027 ud Contenedor $26 \mathrm{~m}^{3}$ Chatarra con tapa y sistema hidráulico

Para Chatarra

1

1,00

$1,00 \quad 7.200,00 \quad 7.200,00$

OFERTA ud Chapa rotulada

Chapa rotulada con logo del consorcio colocada en lateral contenedores metálicos.

Sobre contenedor

14,00

$14,00 \quad 300,00 \quad 4.200,00$

C_CHAPAS m2 Chapas de acero bajo contenedores

Chapas de acero bajo contenedores de 6,5 $\mathrm{m}$ de longitud, $0,5 \mathrm{~m}$ de ancho y $15 \mathrm{~mm}$ de espesor fijadas en solera, incluso garrotas para fijación.

Chapas bajo contenedores

26

6,50

0,50

84,50

C_EILS.1bfa u Lum autn emer 160 Imn nor

$84,50 \quad 166,96 \quad 14.108,12$

Luminaria autónoma para alumbrado de emergencia normal de calidad media, material de la envolvente autoextinguible, con dos leds de alta luminosidad para garantizar alumbrado de señalización permanente, con lámpara fluorescente de tubo lineal de $6 \mathrm{~W}, 160$ lúmenes, superficie cubierta de $32 \mathrm{~m} 2$ y 1 hora de autonomía, alimentación de $220 \mathrm{~V}$ y conexión para mando a distancia, totalmente instalada, comprobada y en correcto funcionamiento según DB SUA-4 del CTE y el Reglamento Electrotécnico de Baja Tensión 2002.

Total cantidades alzadas

2,00

$2,00 \quad 70,42 \quad 140,84$

C_EllS.1bbaa- u Señ PVC $210 \times 297 \mathrm{~mm}$ ftlumi c/txt 


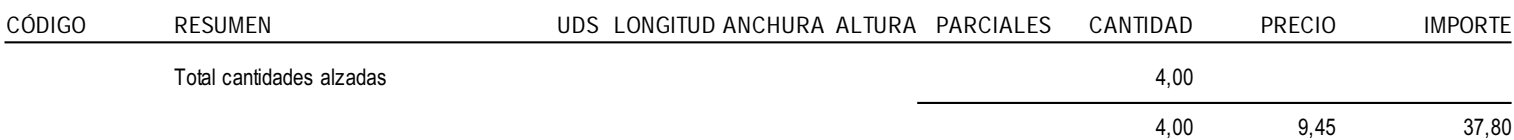

C_EllE.2a u Exti aut polv ABC $6 \mathrm{~kg}-21 \mathrm{~A}$

Extintor por disparo automático con válvula sprinkler accionado a temperatura de $68^{\circ} \mathrm{C}$, con agente extintor polvo polivalente $A B C$ y $6 \mathrm{~kg}$ de capacidad con marcado $C E$, para la extinción de fuegos de tipo $A, B$ y $C$, fabricado en acero y protegido exteriormente con pintura epoxi de color rojo, agente impulsor N2, manómetro extraíble y válvula de comprobación de presión interna, conforme a las especificaciones dispuestas en el Reglamento de Instalaciones de Protección contra Incendios, incluso cadena y accesorios de montaje, totalmente instalado comprobado y en correcto funcionamiento según DB SI-4 del CTE.

Por planta

2,00

A00206

ud Papelera metálica

\begin{tabular}{llll}
2,00 & & & \\
\hline 2,00 & 80,73 & 161,46
\end{tabular}

ud. Papelera metálica de $35 \mathrm{~cm}$ de diámetro y $90 \mathrm{~cm}$ de altura, i. cimentación de hormigón con excavación, totalmente instalada.

Planta

2

\begin{tabular}{llll}
2,00 & & & \\
\hline 2,00 & 88,65 & 177,30
\end{tabular}

A00209

ud Cajón para recogida de baterías, móviles y radiografías

Cubo para recogida de baterías, móviles y radiografias de PHD. 650 I de capacidad, según especificaciones técnicas, i. trasnporte y colocación, con colocación de papel indicativo del vertido en su superficie.

2,00

\begin{tabular}{llll}
2,00 & & & \\
\hline 2,00 & 324,36 & 648,72
\end{tabular}

A00210 ud Cubo de ABS para recogida de pilas botón

Cubo de ABS para recogida de pilas botón, de 10 I de capacidad, según especificaciones técnicas,

i. colocación de papel indicativo del vertido en su superficie, transporte y colocación.

1,00

\begin{tabular}{llll}
1,00 & & & \\
\hline 1,00 & 24,67 & 24,67
\end{tabular}

A00211 ud Módulo chapa madera para recogida tubos fluorescentes

Módulo de chapa de madera para recogida de tubos fluorescentes, 200 uds. de capacidad, según especificaciones técnicas. Incluso transporte y colocación.

1,00

\begin{tabular}{llll}
1,00 & & & \\
\hline 1,00 & 400,80 & 400,80
\end{tabular}

A0023 ud Cubo de ABS para recogida de pilas alcalinas

Cubo de ABS para recogida de pilas alcalinas, de 10 I de capacidad, según especificaciones técnicas, i. colocación de papel indicativo del vertido en su superficie, transporte y colocación.

A000018 ud Contenedor $18 \mathrm{~m}^{3}$

ud. Contenedor metálico de $18 \mathrm{~m}^{3}$ para recogida de residuos. Dimensiones

-Long : $5.000 \mathrm{~mm}+200 \mathrm{~mm}$, gancho. ( Total $5.200 \mathrm{~mm}$ ).

-Ancho exterior : $2.550 \mathrm{~mm}$

-Altura interior: $1.500 \mathrm{~mm}$

-Capacidad : $18 \mathrm{~m} 3$

\begin{tabular}{llll}
2,00 & & & \\
\hline 2,00 & $3.381,00$ & $6.762,00$
\end{tabular}

ud Tanque recogida aceite doméstico

Bidón de recogida de aceites domésticos de $1200 \mathrm{I}$.

\begin{tabular}{llll}
2,00 & & & \\
\hline 2,00 & 24,67 & 49,34
\end{tabular}


Presupuesto y mediciones.

\begin{tabular}{llcrrrr} 
CÓDIGO & RESUMEN & UDS LONGITUD ANCHURA ALTURA PARCIALES & CANTIDAD & PRECIO & IMPORTE \\
\hline \cline { 4 - 5 } & & 1,00 & $1.350,00$ & $1.350,00$
\end{tabular}

A000057 ud Tanque recogida aceite mineral

Bidón de recogida de aceites minerales de 1200

ud Saca para envases de fertilizantes

Saca para envases de fertilizantes.

\begin{tabular}{llll}
1,00 & & & \\
\hline 1,00 & $1.350,00$ & $1.350,00$
\end{tabular}

A 000032 2

A000012 ud Saca para envases de plásticos y metálicos peligrosos Bidones de 200 I para envases metálicos y plásticos peligrosos.

2

ud Jaula para RAEE's

Jaula para RAEE's de categorías 2,3, 4, 6, 7, 8 y 9. Dimensiones: 810x680x $1700 \mathrm{~mm}$.

4

\begin{tabular}{rrr}
4,00 & & \\
\hline 4,00 & 248,88 & 995,52 \\
\cline { 2 - 2 } & & $75.984,57$
\end{tabular}


Anexo A7.1.

CÓDIGO RESUMEN UDS LONGITUD ANCHURA ALTURA PARCIALES

CAPÍTULO C10 Protección caída muelle

Z_ECOBAR1 m Baranda de protección ext. Perfiles (\#80x40×2)

Barandilla de protección ex terior sobre propio terreno o pequeñas alturas, de un metro, realizada con

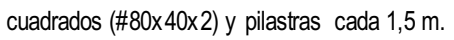

Muelle existente

Nuev o muelle

Enlace entre muelles

$\begin{array}{ll}1 & 84,31 \\ 1 & 18,77\end{array}$

84,31

121,00

18,77

21,00

TOTAL CAPÍTULO C 10 Protección caída muelle.

124,08

58,29

$7.232,62$

$7.232,62$ 
CAPÍTULO C11 Vigilancia y control

C11.1

ud Vigilancia y control

3 camaras ccd tipo bullet funcion dia/noche color optica varifocal 3,6-bmm , i p67 Aumentacion 12

volt.

- 1 videograbador digital 4 entradas, funcion triplex, disco duro 260gb, caudad 100

Ips, conexión tcp/ip, saudas usb para ex portar directamente grabaciones, Aumentacion 220v olt.

- 1 monitor de 19" color

Instalación anti intrusión

1 central alarma microprocesada híbrida maguellan

1 teclado alfanumerico de conexión/desconexion

1 bateria de $12 v$. Paraaumentación auxilar

3 detectores barreras de exterior pararecinto

2 detectores deray os infrarrojos para oficinas

1 sirena interior exponencial de 120db.

1 sirena exterior con flash lanzadestellos

1 kit de carteles disuasorios

Parcela 
Anexo A7.1

CÓDIGO

\section{CAPITUL O C12 S eguridad y salud}

SEGYSALD1 ud SyS

Según el Estudio de seguridad y Salud anexo a la memoria del proyecto.

Total cantidades alzadas

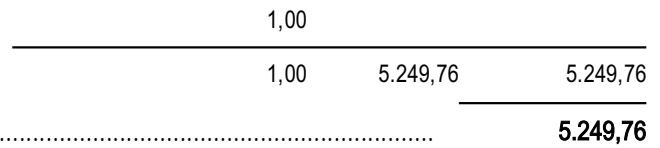

TOTAL CAPÍTULO C12 S eguridad y salud 
C13.1 P.A.Control de calidad

Material para terraplenes

Por cada $3.000 \mathrm{~m} 3$ de material de la misma procedencia:

- 1 Ensayo Proctor Normal, s/NLT-104.

- 1 Determinación de los Límites de Atterberg, s/NLT-105 y NLT-106.

Por lo tanto y dado que hay $>$ de $3000 \mathrm{~m} 3$ propongo hacer dos ensay os

Hormigones

Propongo 2 lotes Zapatas y Muros. De cada lote haría 2 ensayos en dos amasadas diferentes con dos probetas cada una. Se determinará la consistencia del cono de Abrams y de la resistencia a compresión.

Acero

2 ensayos en los que se muestre

- Sección media equivalente, en dos probetas (NORMA UNE 36068 o 36099).

- Caracteristicas geométricas del corrugado en dos probetas (NORMA UNE 36068 o 36099).

- Doblado y desdoblado en dos probetas (NORMA UNE 36068 o 36099).

3 ensay os (uno para cada diámetro)

- Ensayo de tracción, límite elástico, carga y alargamiento de rotura. (NORMA UNE 7474).

Explanada resultante

Se tomarán muestras superficiales, de al menos $50 \mathrm{~cm}$, para efectuar los siguientes ensay os:

Por cada $1.000 \mathrm{~m} 2$ de base de asiento con las mismas caracteristicas:

- 1 Análisis granulométrico NLT-104.

- 1 Determinación de los límites de Atterberg NLT-105 y NLT-106.

- 1 Equivalente de arena NLT-113.

- 1 Contenido de materia orgánica NLT- 117

- 1 Proctor Normal NLT- 107.

Realizaría 5 ensay os definiendo los parámetros anteriores

Por cada $3.000 \mathrm{~m} 2$ de base de asiento con las mismas características:

-1 CBR de laboratorio NLT-111.

Realizaría 2 ensay os definiendo los parámetros anteriores

Por cada $2.000 \mathrm{~m} 2$ de base de asiento, de un material de un mismo tipo:

- 5 determinaciones de humedad in situ NLT-109

Realizaría 10 determinaciones definiendo los parámetros anteriores

Control de compactación

LOTE Material que entra en $3.000 \mathrm{~m} 3$ de tongada o fracción.

MUESTRA Conjunto de 5 unidades, tomadas de forma aleatoria de la superficie definida como LO-

TE.

En cada una de estas unidades se realizarán ensayos de: Humedad, s/NLT-109. Densidad, s/NLT-109.

Zahorras

LOTE Material que entra en $3.000 \mathrm{~m} 3$ de tongada o fracción.

MUESTRA Conjunto de 5 unidades, tomadas de forma aleatoria de la superficie definida como LOTE.

En cada una de estas unidades se realizarán ensayos de: Humedad, s/NLT-109. Densidad, s/NLT-109.

Composición granulométrica

Se realizarán 5 ensay os

Geotextiles y geomembranas

Por cada lote de $3.000 \mathrm{~m} 2$ se harán los siguientes ensay os:

- 1 Ensayo de perforación dinámica por caída de cono (UNE EN 918)

- 1 Ensayo de punzonamiento estático (geotextil + geomembrana, ASTM 5494).

- 1 Ensay o de espesor a distintas presiones (UNE EN 964-1)

- 1 Ensayo de masa por unidad de supericie (UNE EN 965)

- 1 Ensayo de resistencia a la tracción y alargamiento en rotura (UNE EN ISO 10319)

Se realizará 1 ensayo.

Ensayo de permeabilidad

Procedimiento

Se realizarán ensay os in situ de medida de permeabilidad:

Por cada $10.000 \mathrm{~m} 3$ de material puesto en obra

- 1 Ensayo de permeabilidad in situ (ensayo Lefranc de carga variable) sobre sondeo de $80 \mathrm{~cm}$ de profundidad.

Se realizará un ensayo

Pruebas de estanqueidad encubiertas

Una vez tapados todos los desagües, se verterá agua hasta un nivel de $5 \mathrm{~cm}$. por debajo del punto más alto de la entrega, sin superar los $15 \mathrm{~cm}$. en ningún punto, durante 24 horas. Si no es posible la inundación, riego continuo durante 48 horas. 


\begin{tabular}{|c|c|c|c|c|c|}
\hline CÓDIGO & UDS LONGITUD ANCHURA ALTURA & PARCIALES & CANTIDAD & PRECIO & IMPORTE \\
\hline & \multicolumn{5}{|c|}{$\begin{array}{l}\text { Se realizará } 2 \text { ensayos. } \\
\text { Tubería y piezas de polietileno } \\
\quad \text { Sobre el material del tubo: } \\
\text { - } 1 \text { - Densidad (UNE-53020/73). } \\
\text { - } 1 \text { - Coeficiente de dilatación lineal (UNE-53126/79). } \\
\text { - } 1 \text { - Temperatura de reblandecimiento (UNE-53118/78). } \\
\text { - } 1 \text { - Índice de fluidez (UNE-53200/83). } \\
\text { - } 1 \text { - Resistencia a tracción simple y alargamiento a la rotura (UNE53133/82). } \\
\quad \text { Sobre los tubos: } \\
\text { - } 1 \text { - E. comportamiento al calor (UNE-53133/82). } \\
\text { - } 1 \text { - E. presión hidráulica interior en función del tiempo (UNE-53133/82). } \\
\text { - } 1 \text { - E. flexión transversal (UNE-53323/84). } \\
\text { - } 1 \text { - E. estanqueidad (UNE-53114/80 p. II) } \\
\text { Prueba de estanqueidad: } 1 \text { prueba } \\
\text { Prueba de presión: } 1 \text { prueba } \\
\text { Bloque de Hormigón } \\
\text { - Bloque de hormigón exterior, por cada } 5.000 \text { unidades o fracción, ABSORCIÓN DE AGUA } \\
\text { (UNE } 41170) . \\
\text { Se realizará un análisis. }\end{array}$} \\
\hline & \multirow[t]{2}{*}{ Total cantidades alzadas } & & 1,00 & & \\
\hline & & & 1,00 & $3.817,90$ & $3.817,90$ \\
\hline & 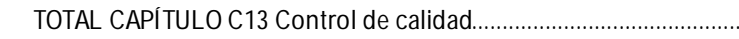 & $\ldots$ & & & $3.817,90$ \\
\hline & TOTAL & & & & $61.673,55$ \\
\hline
\end{tabular}

